\title{
Diversity or polarisation? The growth in work-rich and work- poor individuals, families and communities between 1986 and 1996
}

Paul Callister

A thesis submitted for the degree of Doctor of Philosophy at Victoria University of Wellington, New Zealand 



\section{Abstract}

Despite a period of dramatic job loss from the mid 1980s to the mid 1990s, long-term employment data do not support the view that paid work has been disappearing from the New Zealand economy. However, the distribution of work for people aged 25-59 has been changing. In particular, between 1986 and 1996 there was a strong decline in fulltime employment of prime-aged men, along with a decline in full-time employment amongst young people. In 1986, just over a tenth of prime-aged men were either not in paid work or worked part time. By 1996, this had increased to a quarter. While most of the changes in male employment were driven by shifts in labour demand, a small group of men actively chose to reduce their hours of work or to have breaks from paid work.

In the decade 1986 to 1996 , formal educational qualifications became a more powerful predictor of a person's employment status. In particular, by the early 1990s, prime-aged men and women without a formal educational qualification faced major disadvantages in the labour market. In contrast, the variable of gender, while still very important, weakened as a predictor of employment status.

Employment data also show that there was some shift away from "standard" weekly hours of paid work for prime-aged people between 1986 and 1996. For both men and women, there was some growth in the proportion who worked very short hours as well as an increase in the proportion working 50 or more hours per week. Some of this appears to have taken place by choice, but some due to changing demands by employers.

Employment status also has some association with living arrangement for prime-aged men. However, while employed men were far more likely to live in a couple than men not in work at both the beginning and end of the main period studied, this relationship weakened. In 1986, education had little predictive power regarding male living arrangements. However, by 1996, its importance had increased. 
Assortative mating patterns mean that couples tend to be education-rich or educationpoor. However, the concentration of education within particular couples changed little over the decade.

There was a shift within prime-aged couples and households to either work-poor or workrich status between 1986 and 1996. In 1996, just under a fifth of prime-aged households were work-poor. The significant growth in the proportion of work-poor couples and households took place in the period of job loss between 1986 and 1991. While the strong employment growth in the economy in the next five years increased the proportion of work-rich households it only marginally reduced the proportion of work-poor households.

In the 1990s, education-poor couples were over-represented amongst prime-aged workpoor couples. Yet, the New Zealand data suggest that a wide range of other factors influence the growth of this family type. This includes health issues and barriers to employment amongst well-qualified immigrants.

The reasons behind the growth of work-rich couples are also complex. They include push factors such as well-educated women increasingly wanting to have a long-term attachment to the labour force, through to pull factors of women obtaining work to supplement family income in the face of declining male income.

On a geographic area basis, the data does show that in the 1990s there were extremes of work-rich and work-poor residential areas. In addition, using various measures, the proportion of work-poor areas increased between 1986 and 1996. There was also a small, but important, group of area units that remained work-poor for the ten years studied. A significant proportion of long-term work-poor areas were also classified as "deprived".

Finally, the rapid rise in educational attainment over the last decade was unevenly spread on a geographic basis. While there remain many communities where there is a wide mixture of education levels amongst the residents, the spatial clustering of similarly qualified (or unqualified) people is important in New Zealand. 


\section{Acknowledgements}

Many people deserve thanks for their part in supporting this thesis. I am particularly indebted to Judith Davey as my primary supervisor and Gary Hawke as my secondary supervisor. Both Judith's and Gary's support goes back to the mid 1980s when Judith was the Deputy Director of the New Zealand Planning Council (NZPC), Gary Hawke the Chairperson and I was employed as a economist studying labour market change. I have particularly valued the way Judith and Gary allowed me, both in my previous work and in this doctoral research, to explore my own ideas, yet provide me with useful comment and guidance when needed.

It was at during my time at the NZPC that I first started thinking about whether there were connections between the very rapid changes taking place in the labour market and the changes in families that were also occurring. It was also during this time that I developed an interest in the links between education and employment. Another NZPC colleague, Dennis Rose, fostered much of this interest. In recent years I have lived in the same coastal village, Paekakariki, as Dennis and we have continued our discussions about employment and other related issues on our weekly beach walks. Dennis has also commented on some aspects of my doctoral research.

After the NZPC was closed in the early 1990s, I was over the next six years awarded three grants from the Foundation for Research. Science and Technology. They allowed me to continue to explore aspects of labour market change and to begin my exploration of how this might be linked to parallel changes taking place in families and households. In this research, I was particularly interested in changes occurring in families with young children. In part through having my own child in this period, as well as working part time and from home for five years, I also became very interested in the changes taking place in the lives of men in New Zealand in relation to both work and family. I became even more interested in work and family change when my partner, Judith Galtry, commenced her 
own doctoral thesis on breastfeeding, paid work and feminism. It was Judith who first suggested that I commence a doctorate. When I did, in the official statistics we were plunged into a work-poor couple status for the next three years. Having a young child and two doctoral theses being worked on in the same household created its moments of stress but also generated some useful debates and discussions. I would therefore like to thank both Judith and our daughter, Hester, for their support.

Funding has of course been an extremely important aspect of this project. Victoria University made it possible for Judith and myself to undertake our work by awarding us doctoral scholarships and other research grants. The research grants supported travel, data purchase and general research expenses. Special thanks are owed to Maureen Penning of the Scholarships Office for her helpfulness in this respect. In addition, my research was also made possible by the generosity of Statistics New Zealand in allowing me free access to their census data through their datalab. In Statistics New Zealand many people provided assistance, but I would like to particularly thank Len Cook, Ian Ewing, Mike Brookes, Denise Brown, Chris Toohey, Steve Kendall, and Trish Morant. Finally, I wish to thank Bryan Perry at the Ministry of Social Policy for arranging a small amount of further funding to allow me to purchase specialist datasets.

Various people provided specialist advice. In terms of statistical analysis of my marriage market material Fraser Jackson, Max Wigbout, Peter Smith and Hongsheng Gao all gave me useful advice. Philip Morrison shared his considerable expertise on the spatial aspects of labour market change. Allan Levett supplied me with many useful articles on work and family change and gave me advice on sociological approaches to research. Harvey Franklin, originally in the 1970 s and then twenty years later, influenced my thinking. Kay Goodger provided helpful comments on my sex-ratio data and influenced my thinking about the links between changes in male employment and family form and function. Simon Chapple and Sylvia Dixon helped me by supplying some labour market data. Stuart Birks challenged my thinking about family change and also provided a way through his Directorship of the Centre for Public Policy Evaluation at Massey University to publish some of the emerging research material. 
I would also like to thank Gary Hawke in his role as director of the Institute of Policy Studies, and subsequently the new director, Arthur Grimes. I was able to present some of my early findings at seminars at the Institute and obtain some useful feedback.

As I was dealing with a contemporary topic, I felt it was important to publish aspects of my research as it proceeded. I would therefore like to thank the journal editors, referees and reviewers who have been very helpful. In particular, I would like to thank Marlene Levine, editor of the New Zealand Social Policy Journal, and Dharma Dharmalingam, editor of the New Zealand Population Review. I would also like to thank the Ministry of Social Policy for allowing flexibility in copyright so I could utilize some material in my doctoral thesis for reports I have prepared for that organisation.

Audrey Griffiths, of the Sociology and Sociology Department, provided much practical assistance in terms of access to printing, photocopying and other such support. From the reference section at VUW Library, I would particularly like to thank Justin Cargill.

Finally, as well as those people I have named there are numerous other people who have provided advice, information or support at different stages of the project and to whom I am also grateful. 


\section{Contents}

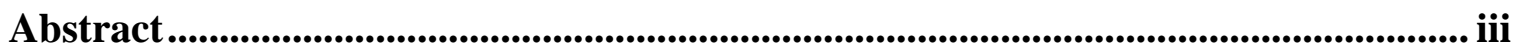

Acknowledgements.................................................................................................................................v

Chapter 1 ............................................................................................................................15

Introduction ...........................................................................................................................15

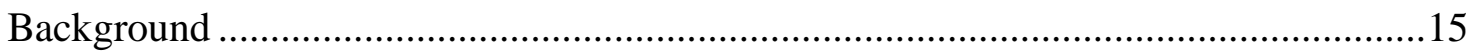

Polarisation in work and living arrangements (and polarisation in thinking)...............21

Polarisation and mobility .........................................................................................25

An alternative tale - The increasing diversity of experience in post-modern society ...26

Research questions in a New Zealand context ............................................................2

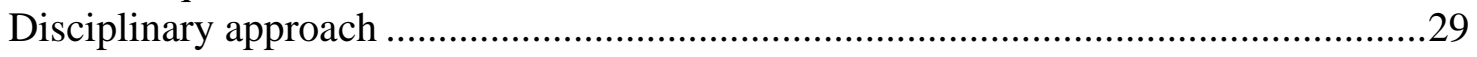

The strengths (and weaknesses) of a multi-disciplinary approach..................................30

Theories about how people make choices and my own views ......................................34

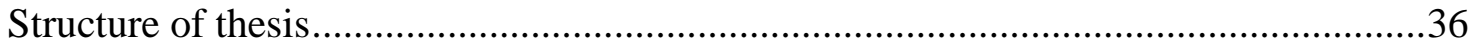

Part one ........................................................................................................................................39

Methodological issues in analysing work, education, families, households and

geographic communities .......................................................................................................39

Chapter 2 .....................................................................................................................41

Work and education: Concepts, definitions and measures...................................................41

Defining and measuring paid work ...........................................................................4

Defining whether individuals are work rich or work poor..........................................4

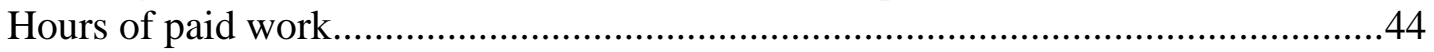

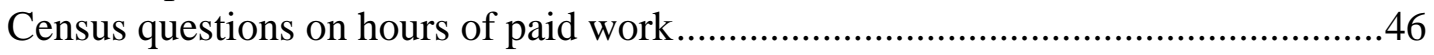

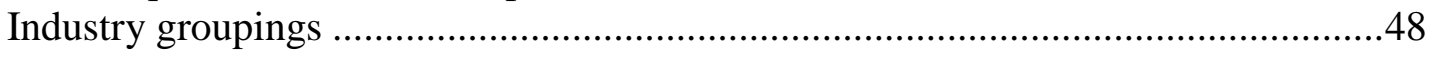

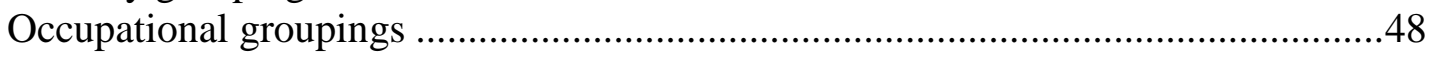

Other work classification systems........................................................................51

Job security and non-standard work................................................................56

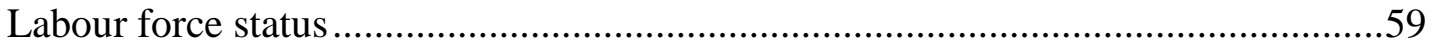

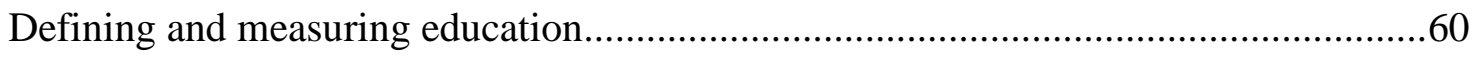

Census questions on highest level of education .......................................................66

Chapter 3 ............................................................................................................................69

Prime-aged people, families, households and geographic communities: Concepts, definitions and measures ..............................................................................................69

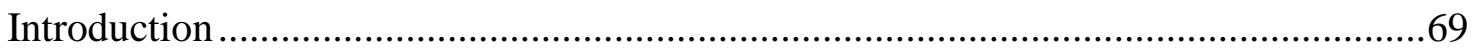

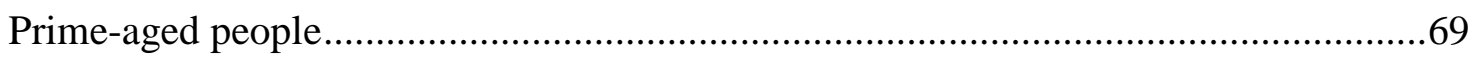

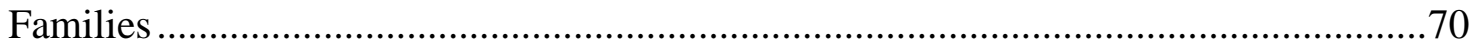

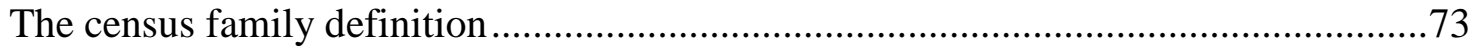

The impact of choosing various measures of living arrangement..................................79

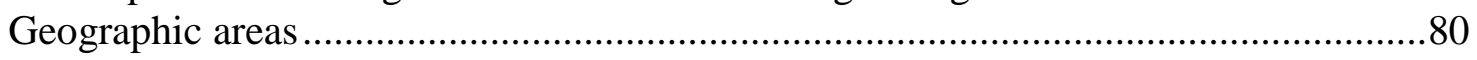

Chapter 4 ..........................................................................................................................................85

Using census data and other technical issues...........................................................................85 


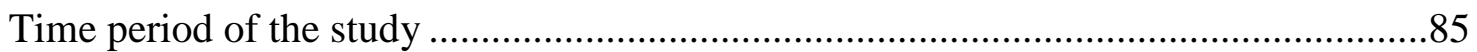

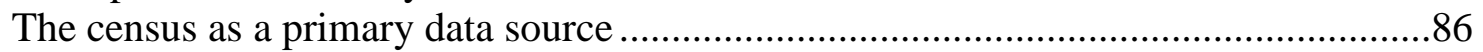

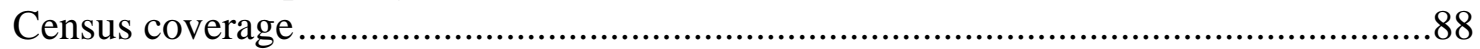

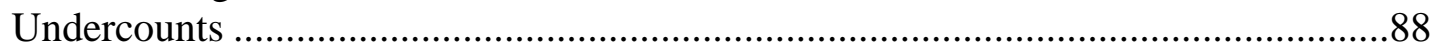

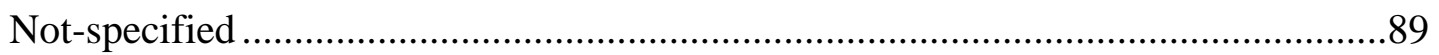

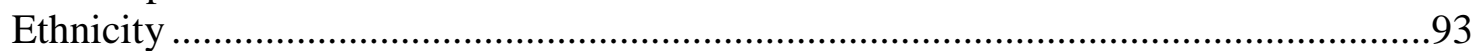

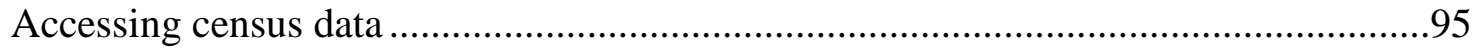

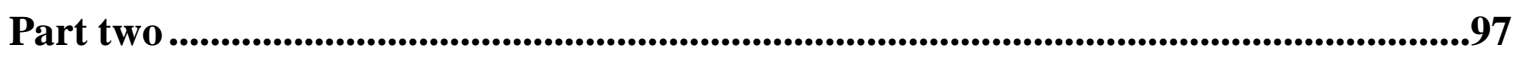

Changes in work, education, families, households and geographic communities: The

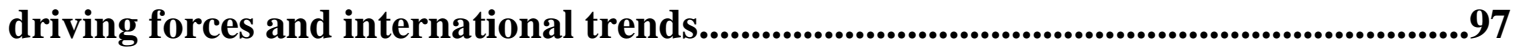

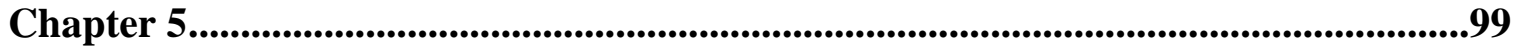

Nature versus nurture - Why this debate is still important .......................................99

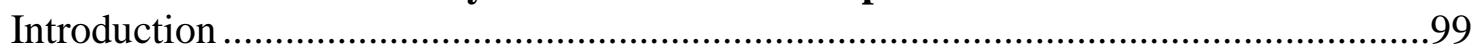

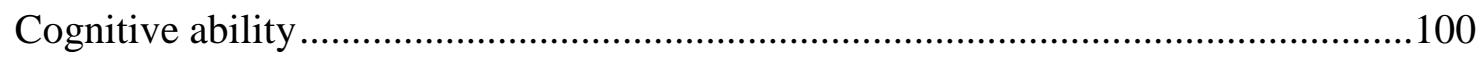

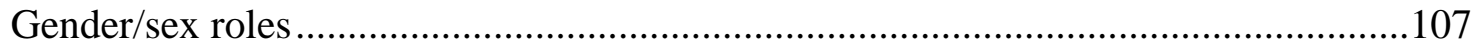

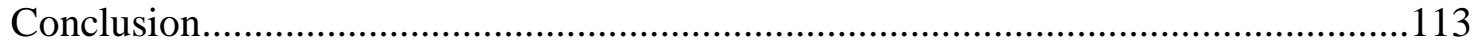

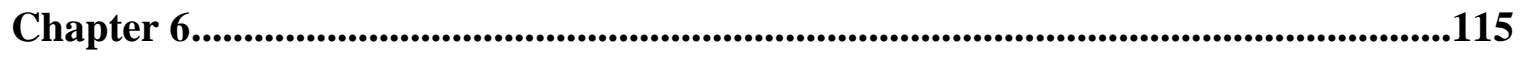

Why are patterns of paid work changing? .........................................................115

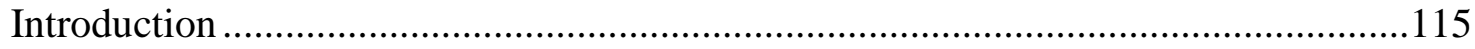

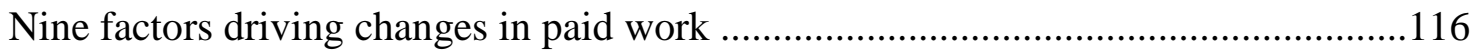

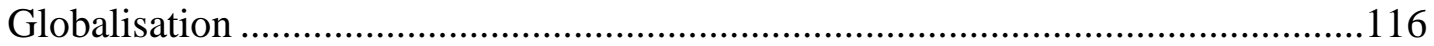

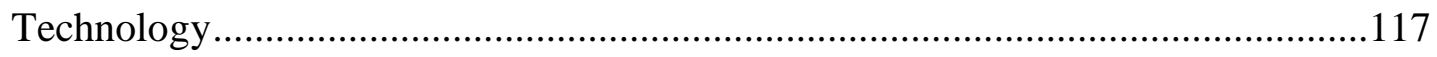

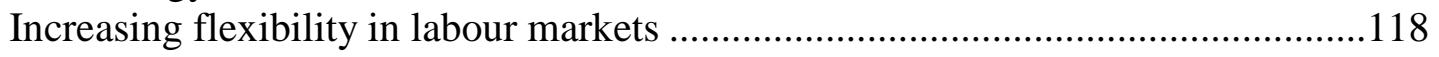

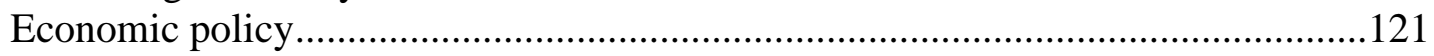

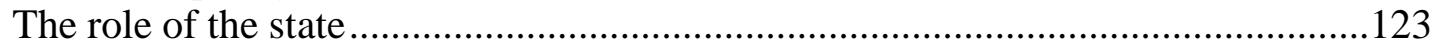

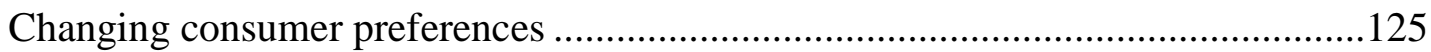

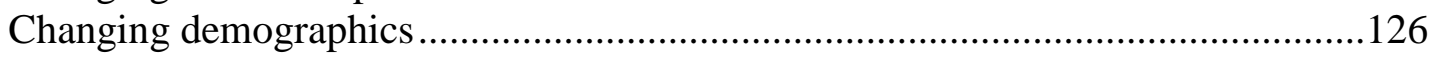

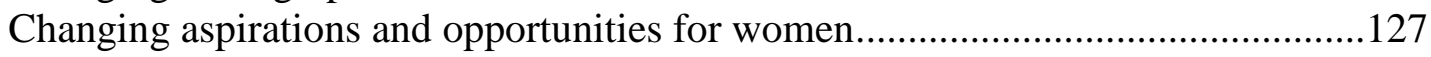

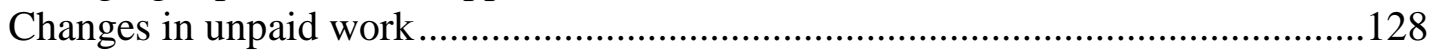

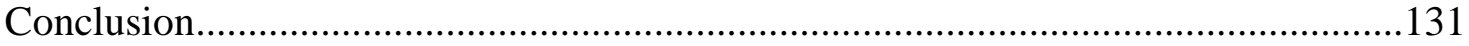

Chapter 7......................................................................................................................................133

The upskilling/deskilling debate: An overview of the literature...............................133

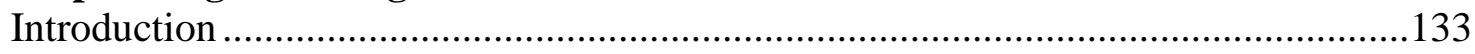

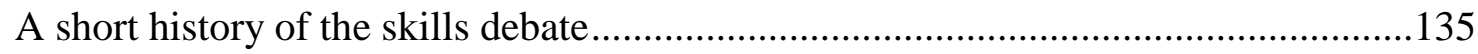

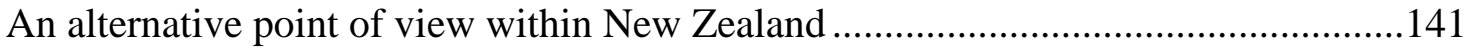

A polarisation in the demand for skills? .......................................................... 142

Is a base level of skill required for participation in paid work? ...............................144

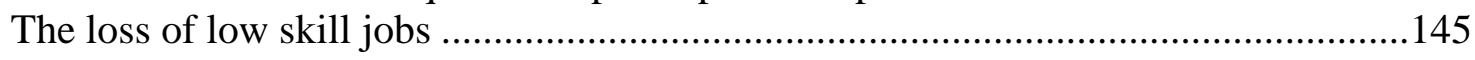

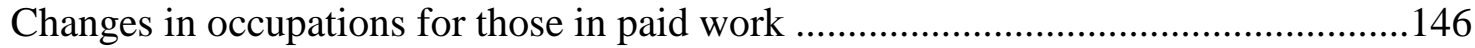

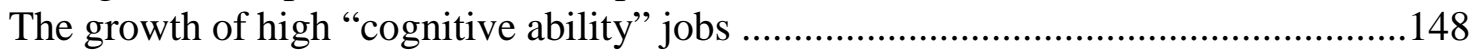

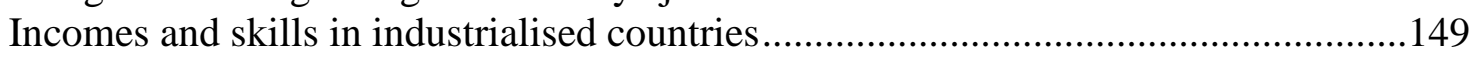

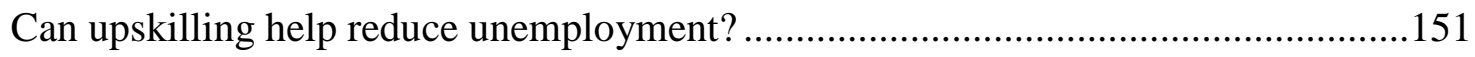

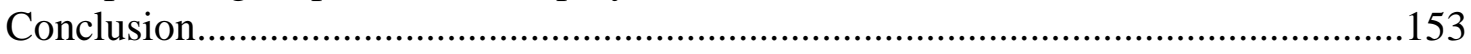

Chapter 8..............................................................................................................................157

Changes in paid work-time patterns ..............................................................................157 


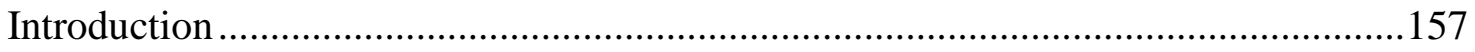

Casual work, temporary work and work tenure .......................................................159

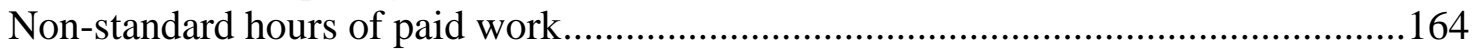

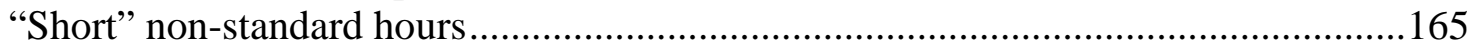

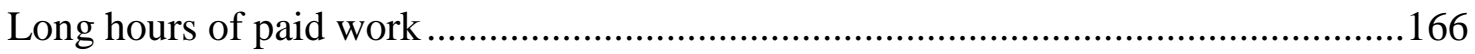

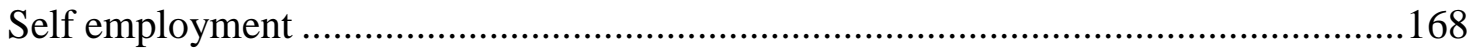

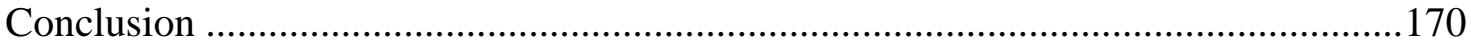

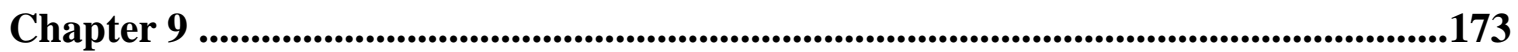

Why have prime-aged men been exiting full-time paid work? ......................................173

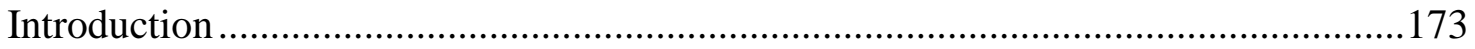

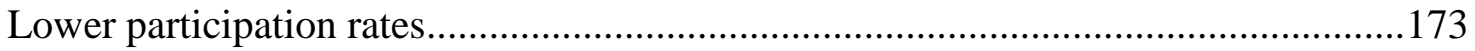

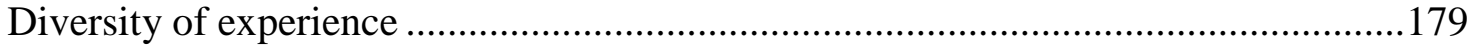

Some potentially positive reasons for non-labour force participation ...........................181

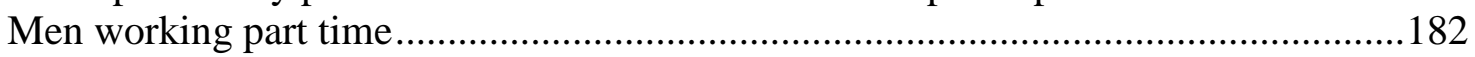

Are work-poor prime-aged men part of an emerging underclass? ...............................183

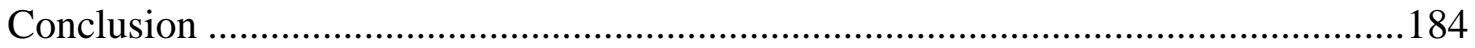

Chapter 10 ................................................................................................................................187

Changes in work: Have they been driving changes in family and household type? 187

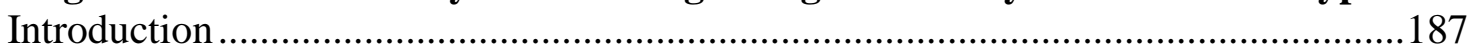

Theories about family and household formation ....................................................18

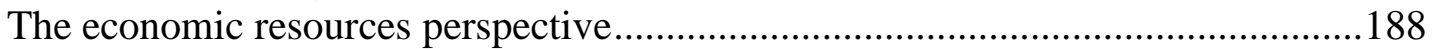

An absolute shortage of potential partners? ...........................................................

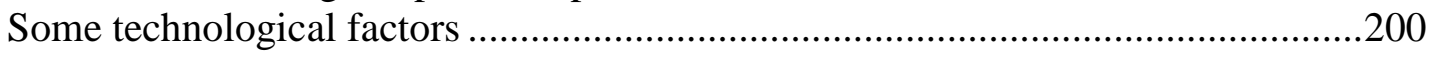

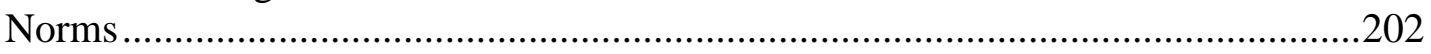

Government social and economic policies.........................................................204

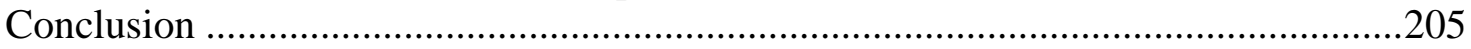

Chapter 11 .................................................................................................................................209

The "meet" market: The marriage market and concentration of education in

couples ..................................................................................................................................209

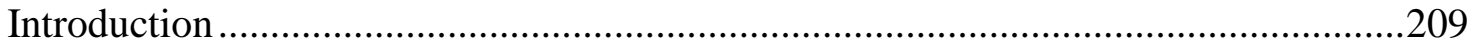

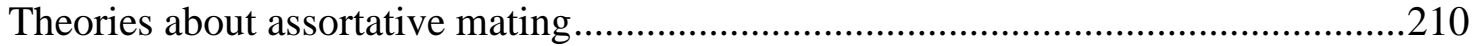

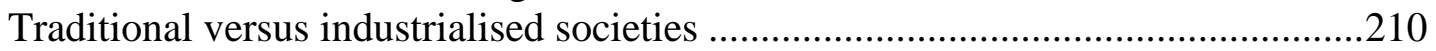

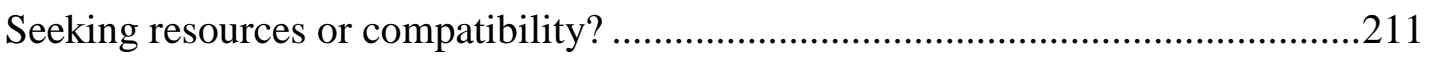

Why information is important in seeking a partner ................................................212

Cohabitation versus legal marriage in marriage market literature .............................213

Education and the marriage market.................................................................2.

The workplace and marriage markets …………………......................................2.

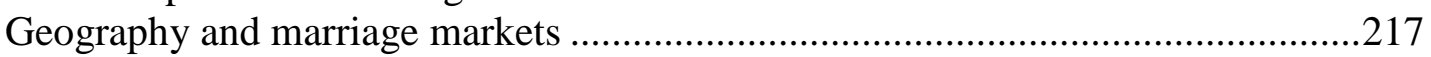

Gender roles and changing levels of competition in the marriage market................218

Further ideas about separate marriage markets ......................................................221

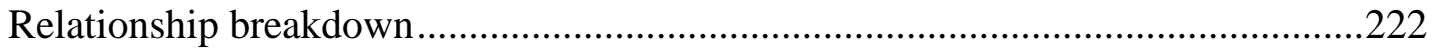

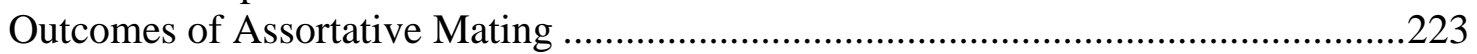

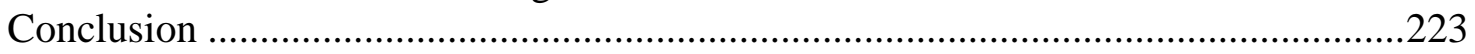

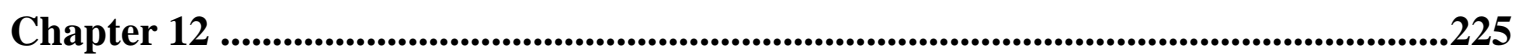

Changes in work within families and households and some reasons for the growth of work-rich and work-poor couples ............................................................................................225 


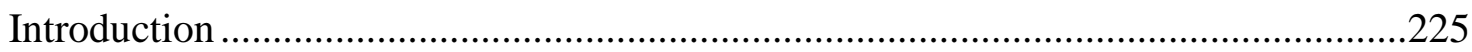

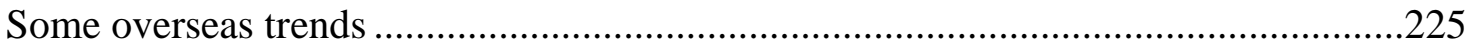

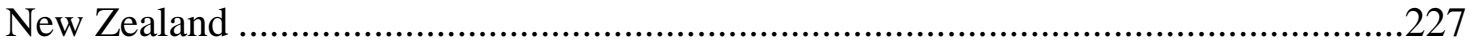

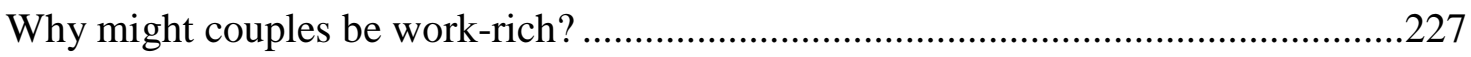

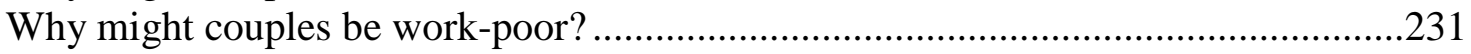

Do work-poor couples stay work-poor long term? ...............................................234

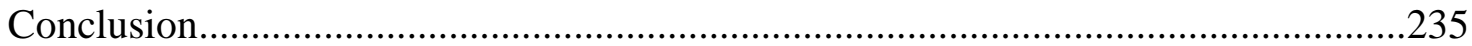

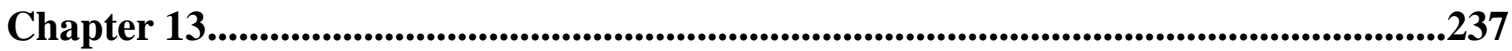

A spatial dimension to changes in work, education and living arrangements .........237

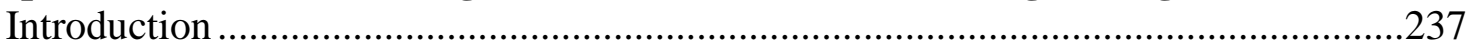

Theories about the clustering of people with similar characteristics .........................238

Clustering of the economically and socially disadvantaged .........................................240

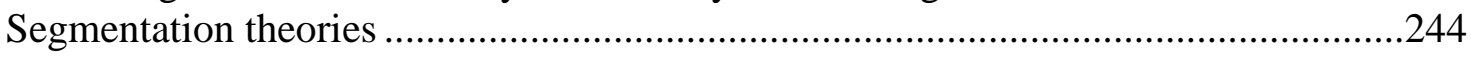

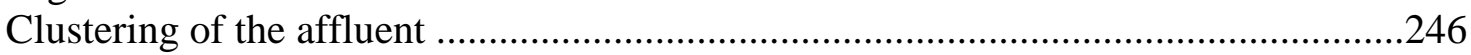

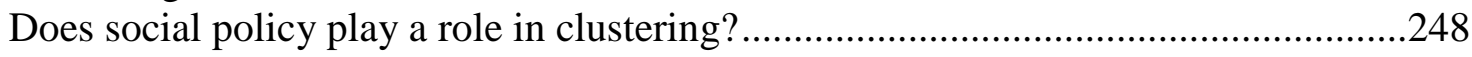

Some challenges to the polarisation hypothesis ........................................................250

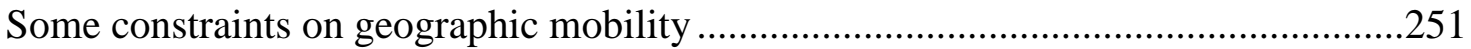

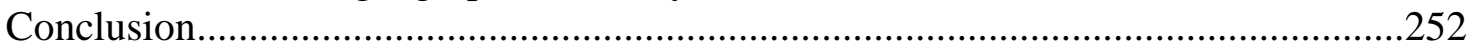

Part three ......................................................................................................................................253

Changes in work, education, families, households and geographic communities in

New Zealand 1986 to 1996 ..............................................................................................253

Chapter 14........................................................................................................................................255

Changes in the economy, population and government transfer payments................255

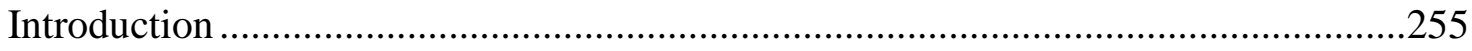

Economic Growth and Employment Growth....................................................255

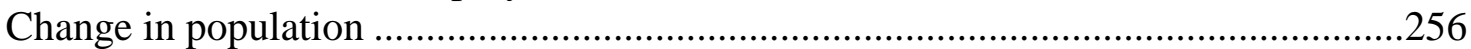

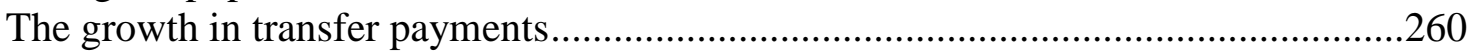

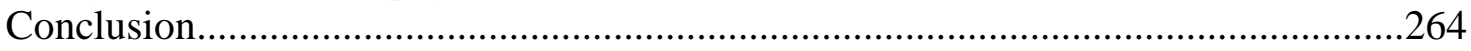

Chapter 15...........................................................................................................................267

Changes in educational participation and attainment......................................................267

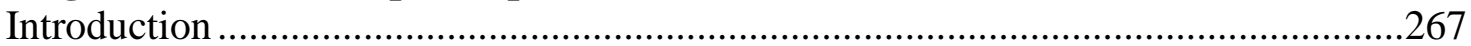

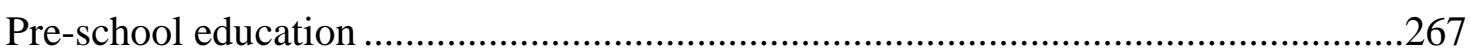

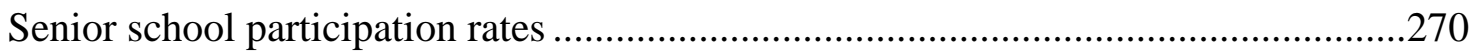

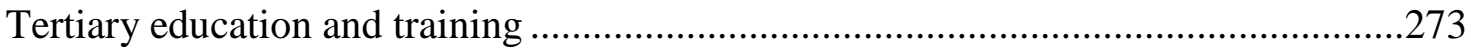

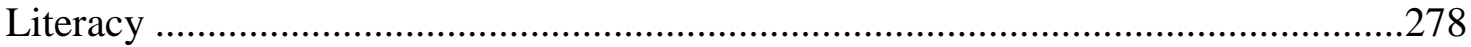

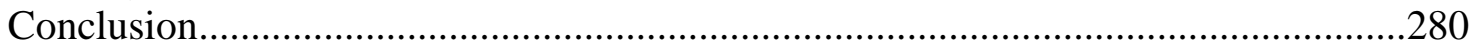

Chapter 16.........................................................................................................................283

Broad changes in employment and skill use ......................................................................283

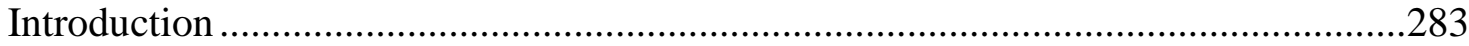

Changes in employment for the working age population, 1950s to the 1990s ............284

Was paid work disappearing between the 1950s and the late 1990s?.........................286

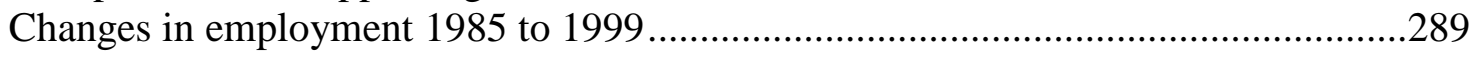

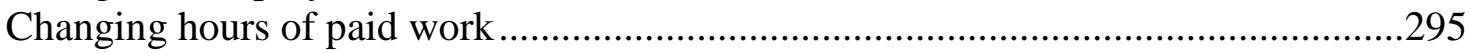

Prime-aged workers as a percentage of those in paid work ...........................................301

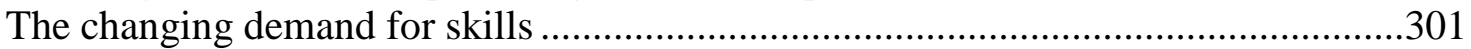




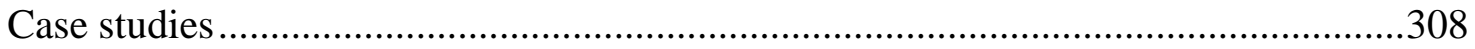

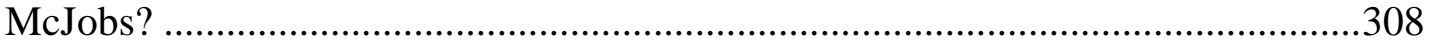

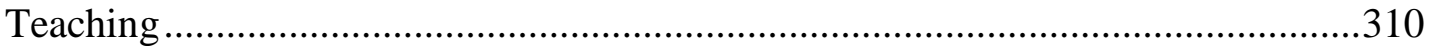

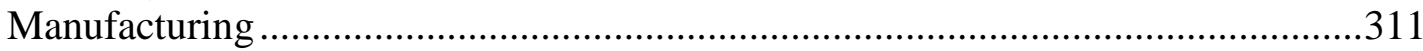

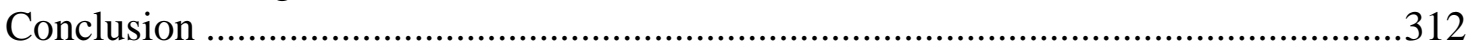

Chapter 17 ......................................................................................................................317

The changing distribution of paid work for prime-aged people.....................................317

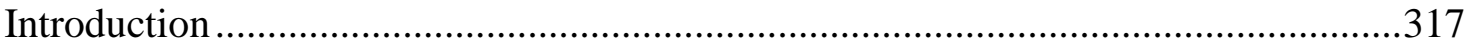

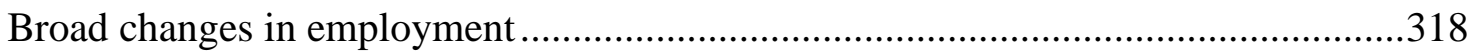

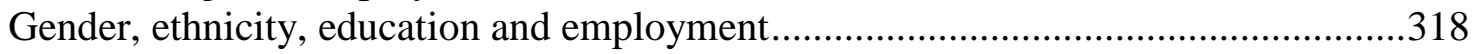

Hours of paid work for prime-aged people ..............................................................323

Education and changing hours of paid work for prime aged people............................328

Change in the types of jobs held by prime-aged people ................................................333

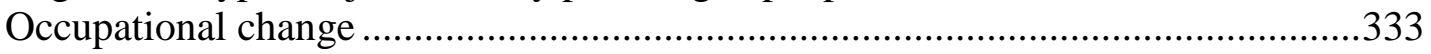

A Growth in Symbolic-analytical jobs?..............................................................336

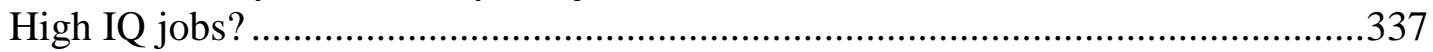

Were female occupations growing faster than male occupations for prime-aged

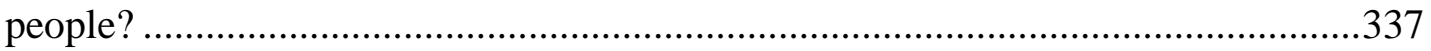

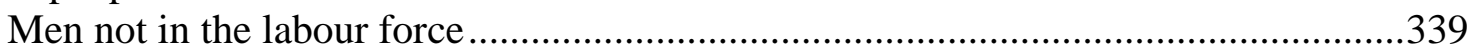

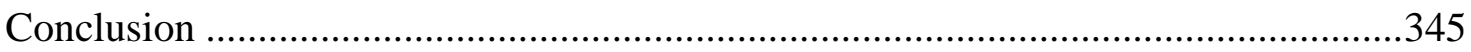

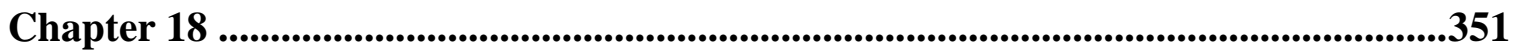

Some associations between education, paid work and living arrangements for primeaged people.....................................................................................................................................351

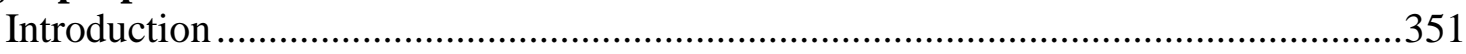

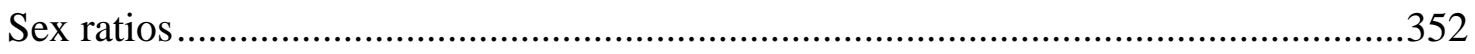

Some trends in living arrangements amongst prime-aged people ...............................354

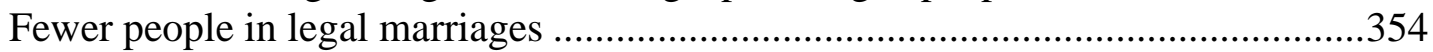

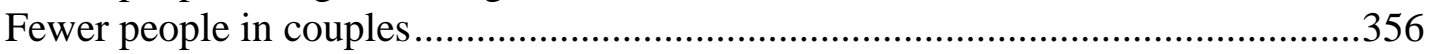

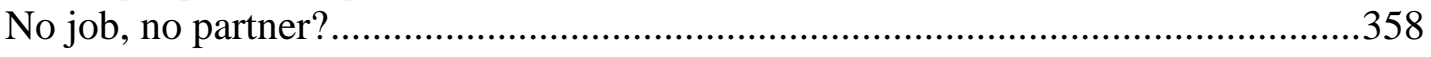

Men, employment and childrearing couples …………………………………......364

Some associations between education and living arrangements for men .................366

Non-couple living arrangements for men ..............................................................369

Some associations between employment, education and living arrangements for

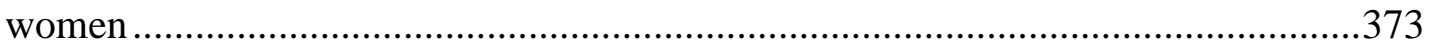

Were part-time jobs held by prime-aged people mainly filled by women in couples?376

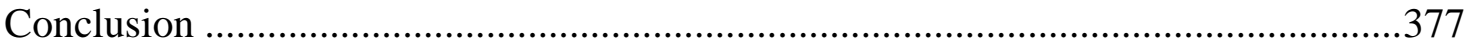

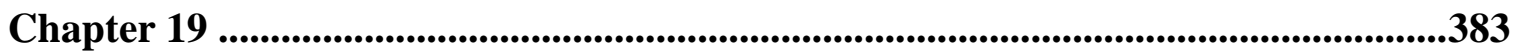

A polarisation into education-rich and education-poor households and couples? ..383

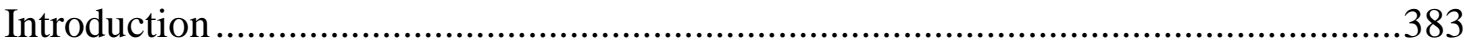

The concentration of education in particular households ............................................384

Assortative mating outcomes for couples aged 25-59 ...........................................385

Assortative mating outcomes in couples aged 25-34 ..............................................38

Other associations in the marriage market outcomes for couples aged 25-34 ..........392

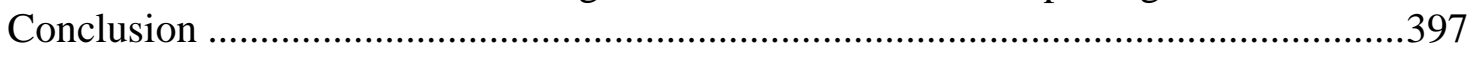

Chapter 20 ........................................................................................................................399

A polarisation into work-rich and work-poor couples and households?....................399 


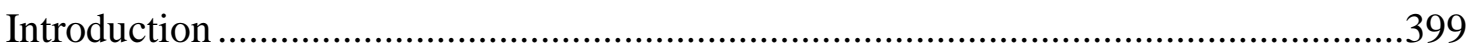

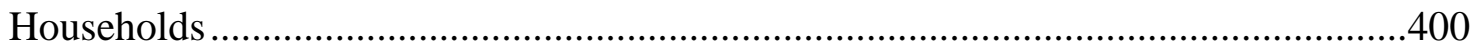

Changes in patterns of paid work within prime-age couples ......................................405

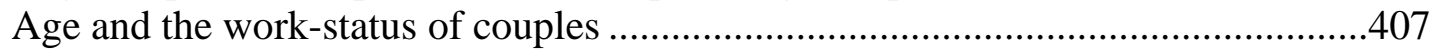

Male income and the employment status of women ..............................................408

Self-employment and couples .............................................................................410

Was male employment seeking behaviour associated with the labour force status of their partner? ................................................................................................ 412

Some characteristics of prime-aged work-rich and work-poor couples........................413

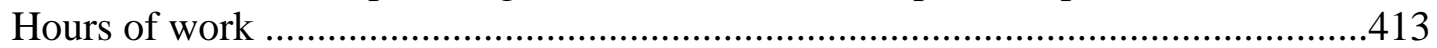

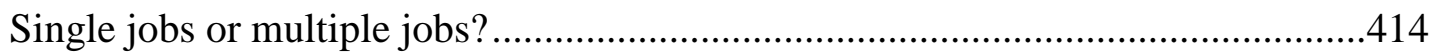

Educational qualifications ............................................................................415

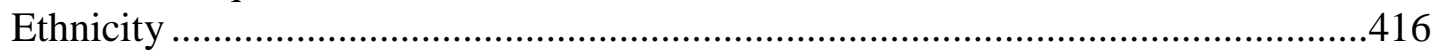

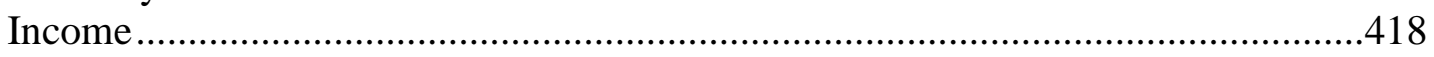

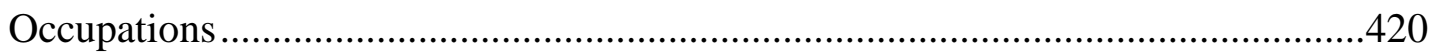

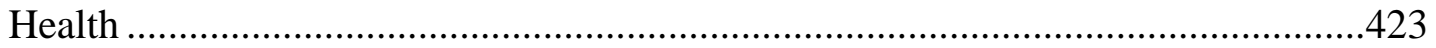

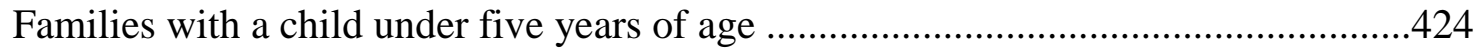

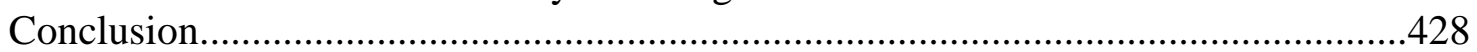

Chapter 21.............................................................................................................................431

A polarisation into work-rich and work-poor geographic areas? .................................431

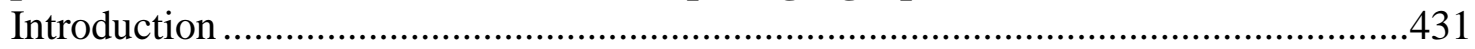

The growth of work-rich and work-poor area units .................................................432

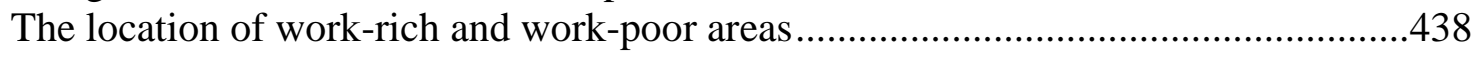

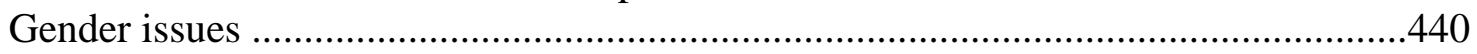

Were work-poor residential areas actually work-poor? ...............................................443

Do work-poor couples live in work-poor areas? .........................................................443

Some reasons for residents in particular area units being work-rich or work-poor .....445

Were there education-rich and education-poor area units? ..........................................449

Changes in the prime-aged population in area units .................................................454

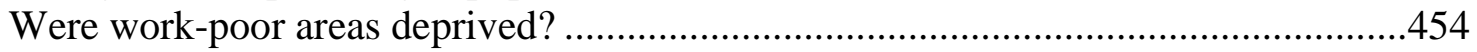

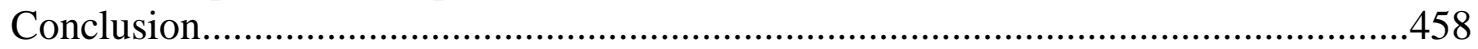

Chapter 22 ...............................................................................................................................4461

Conclusion.....................................................................................................................461

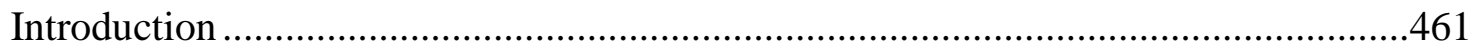

Summary answers to the eight major research questions...........................................462

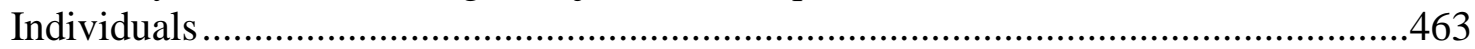

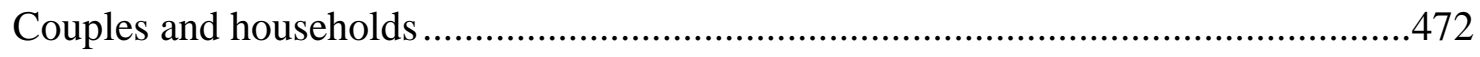

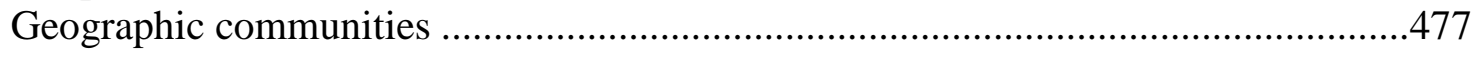

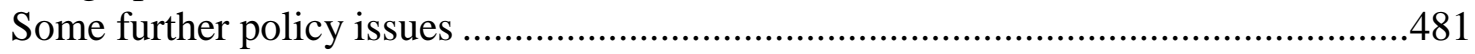

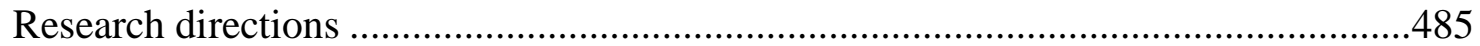

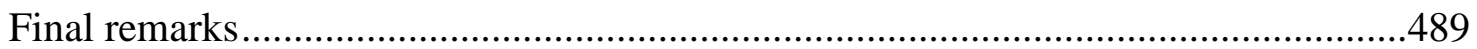

References .................................................................................................................................491

Appendix ............................................................................................................................................523 


\section{Chapter 1}

\section{Introduction}

In this introductory chapter, I set out the broad research areas in which I have an interest and the research questions that emerge from this interest. I then go on to discuss my overall approach to the research. This includes a guide to the main disciplines that I draw upon. Next, I develop a rationale for undertaking a multi-disciplinary style of research, particularly when undertaking research in the area of social policy. After that, partly as an example of the variety of thinking in a range of disciplines, I specifically look at some theories about how people make choices. This is followed by an assertion of my own view as to how people endeavour to make decisions. Identifying factors, including social policy, that enhance, or alternatively constrain, wise decision-making is an important aspect of this research. Finally, I provide an outline of the structure of the thesis.

\section{Background}

The 1980s and 1990s were very eventful periods in New Zealand's history. They were a time in which there were major economic, political and social transformations. Some of the changes that occurred were simply the extension of long term shifts in behaviour, some were deliberately brought about by new approaches in economic and social policy, while others came about in reaction to external forces. Given the extent of the change, it is not surprising that there remains intense debate about the causes and outcomes of the events that took place in this time. Amongst the many issues which are still of concern to 
New Zealanders, two are of particular relevance to this research. The first concerns the inability of the economy to deliver sustainable high-income, full employment. ${ }^{1}$

New Zealand is not unique in its concern about the loss of full employment. Throughout the OECD, with perhaps the exception of the U.S., there are major worries about unemployment. In particular, there is currently a concern about the growth of a core group of long-term, prime-working age, unemployed people, many of whom are no longer actively looking for work.

The second, and interconnected problem, facing New Zealand and other OECD countries is the inability of governments to significantly reduce the number of people who are receiving income support from the state as well as to reduce the total cost of welfare transfers. While some people who are not in the labour force will be supported by families or by other private support systems, many have become dependent on various types of state welfare payments. This, in part, reflects a change in living arrangements, such as the growth of non-employed sole parent families. A concern about "dependency" on welfare is heightened by worries about the impact of the growth in the proportion of retired people in most industrialised countries.

However, at the same time there is attention given to whether some groups in industrialised societies may now be "over-employed". At times, in some policy debates, underemployment and overemployment are linked, with an argument put forward that there is enough paid work for everyone if work was shared more equally. That is, it is not necessarily a lack of work that is the key problem, it is the uneven distribution of that work.

\footnotetext{
${ }^{1}$ Rose (1990: 1) defines full employment as "paid work for all those who seek it." However, of relevance to this research, Rose goes on to note that "[f]ull employment will not mean 40 hours a week for 40 years in the same job - either for men, or for the increasing proportion of women in paid employment. Career changes, time-out for retraining or child-rearing, self-employment and part-time work will be more common." In addition, while high wages would be an important part of a high-income economy other income streams, such as from self-employment, from overseas investments or from intellectual property would also be important.
} 
All these issues of unemployment, overemployment, supporting and caring for the young, the elderly and the sick as well supporting a group of able bodied prime-aged people who are not in work generate complex debates about the distribution of both work and income amongst individuals, the distribution within families and the distribution within households. While an analysis of the distribution of income, including the redistribution of market income by governments, is a critical social policy issue, measuring changes in income is not a central part of this research. ${ }^{2}$ Instead, the primary focus of this research is an analysis of changes in the total amount of paid employment undertaken in New Zealand between 1986 and 1996 and changes in the distribution of this work.

The amount of paid work carried out in a society and its distribution is important for a number of reasons. These include (in no particular order of importance):

- in market economies a person's paid work status, including the hours worked and hourly rates of pay, is usually a critical factor in determining their total individual income as well as family and household income (Statistics New Zealand 1999) ${ }^{3}$

- for women, participation in paid work, and especially working the same hours for the same pay as men in similar occupations, has been seen as a critical factor in gaining economic independence and as a crucial step towards achieving equality with men (Bergmann 1986)

- a changing distribution of paid work has the potential to have an impact on the amount and type of unpaid caring community work carried out in a society, and thus the development of social capital (Putnam 1993)

\footnotetext{
${ }^{2}$ There are many reasons for this. One is that the main data source used for the research is not ideal for measuring income derived from paid work. A further, and a more important reason, is that measuring income changes is a very specialised field and worthy of specialist doctoral research itself. Finally, and connected to this latter reason, is that there are already many competent researchers who are active in this field (e.g. Podder and Chatterjee 1998, Statistics New Zealand 1999, Stephens et al 1995) In contrast, far less attention has been given to the changing distribution of paid work in New Zealand, particularly using family, household and wider spatial units.

${ }^{3}$ Costa (2000) demonstrates that amongst prime-aged workers in the U.S. in the 1880s the most highly paid workers worked shorter hours than the lowest paid, but by the 1990s this relationship had reversed. In New Zealand, for prime-aged men, Dixon (1998) has demonstrated a strong relationship between hours worked and income with this relationship strengthening between 1984 and 1997. Costa argues that hours of work should be an important variable in studies of income inequality.
} 
- changes in the distribution of paid work potentially impact on couple formation and childrearing patterns (Wilson 1987)

- changes in patterns of paid work, such as mothers with young children being in paid work, have been seen as potentially having an impact on children's wellbeing (Haveman and Wolfe 1995)

- a person's paid work status is strongly associated with health status (Statistics New Zealand 1993a)

- paid work status is closely linked with a person's social status (Kalmijn 1994)

Overall, Sen (1999: 21) argues that a lack of paid work leads to deprivations that are not shown up in income distribution data, particularly in countries where social security can make up for some of the income loss.

...unemployment is not merely a deficiency of income that can be made up through transfers by the State (at heavy fiscal cost that can itself be a serious burden); it is also a source of far-reaching debilitating effects on individual freedom, initiative, and skills. Among its manifold effects, unemployment contributes to "social exclusion" of some groups, and it leads to losses of selfreliance, self-confidence and psychological and physical health.

In the debates about a lack of work there are those who approach the problem primarily from a labour demand perspective and, alternatively, those who focus on issues of labour supply. For instance, in discussions about poverty in the U.S., Mead (1997: 1) takes a labour supply viewpoint suggesting that low wages or lack of jobs are not the main causes of poverty. He argues that “[o]verwhelmingly, today's working-age poor are needy, at least in the first instance, because the adults in these families do not work normal hours".

In this research, I have a particular interest in the changing distribution of paid work amongst people who could be considered in their prime working ages. I define this as being in the 25-59 age group. ${ }^{4}$ Within this overall group, special regard is given to changes in the paid work patterns of prime-aged men. In the 1950s and 1960s, almost all

\footnotetext{
${ }^{4}$ The reasons for choosing this age group are set out in Chapter three.
} 
prime-aged men were in long-term, full-time paid work. The main groups of men not in paid work were those in prison, in psychiatric institutions or hospitalised through other forms of illness. In the late 1990s, there are now a significant number of prime-aged men who, for either long or short periods, have withdrawn from paid work, are recipients of welfare benefits or are financially supported by other family or household members. This is in contrast to their traditional role generating the income to support families and the welfare system.

When analysing the changes in paid work it is recognised that individuals generally do not live, or function, as isolated individuals. They usually group together, sometimes in couples or other family and household arrangements. Often these groupings are based on kinship arrangements. These households then usually cluster together in villages, towns and larger urban areas. Many individuals, in a variety of living arrangements, are also raising children. As will be explored, there are a wide variety of factors influencing living arrangements. For instance, as will be shown there is a body of literature which suggests that changes in paid (and unpaid) work can influence living arrangements and that, conversely, changes in living arrangements can have an influence on patterns of work. In addition, changes in both work and family arrangements do have an impact on the welfare system. For example, a breakdown of the extended family may lessen the chances that unemployed, or retired, family members will be financially supported by a wider family network. The growth of "no-job" households, that is where no working age person is in paid work, means that the members of those households will generally turn to the state for support.

In the discussions about changing patterns of both work and family types, some groups have expressed concern about the decline in the "traditional" family (Morgan 1999). This traditional family has usually been seen as a heterosexual, legally married, childrearing couple living in one household, and where the male has been in full-time work and was the primary income earner for the family and the main contributor to the tax base. This type of family was an important element of the "Wage Earners Welfare State" (Shirley 1999). Some of the literature that expresses concern about the decline of this family type 
focuses primarily on the decline in legal marriage rates. This view is particularly expressed in U.S. literature. For instance, children born outside of marriage, even if in long-term defacto relationships, are still often described as being born out of wedlock. This is a term rarely used in New Zealand. A decline in marriage rates, or long-term couple arrangements, is sometimes seen as part of a "social pathology" which occurs alongside, or may even be linked to, a rise in crime and substance abuse (Akerlof 1998). Single men, especially if also unemployed, are seen as creating major problems in society. One of the concepts behind some of these views is that marriage "tames" single men, makes them socially and financially more responsible and, linked to this, ties them to the raising of the next generation. For example, in the U.S., there has been concern expressed by some researchers and policy makers about the growth of "fatherless" families and its impact on children. This debate has flowed through into the policy arena with, for example, a Bill introduced into the Senate in late 1999 to support poor fathers to strengthen their links to both work and family life. ${ }^{5}$ This is based on the view that government policy can influence both employment and living arrangements for men, an assumption that will be explored in this research.

Major changes in both work and living arrangements raise questions as to whether the shifts benefit or harm particular groups in society, or society as whole. These include questions as to whether established gender roles are being undermined, maintained, intensified or expanded, questions about the ability or desirability of people to be economically independent of the State or other household members, issues of who is responsible for looking after and investing resources in children, and questions as to whether there is an increasing polarisation of experience, incomes and well-being of individuals, families, households and geographic communities. All of these questions have moral, cultural and political dimensions.

\footnotetext{
${ }^{5}$ The Senators introducing the Bill argued that welfare reform in the U.S. had been very successful in helping poor mothers obtain jobs and improve their economic circumstances. They suggested the next step in reforming welfare was to help poor fathers raise their standard of living and participate directly in the rearing of their children.
} 


\section{Polarisation in work and living arrangements (and polarisation in thinking)}

Lilla (1998), in A Tale of Two Reactions, outlines a polarisation in concern about the changes in work and living arrangements that have taken place in the U.S. He argues that the political left is generally concerned about the apparent excesses of capitalism, such as the increasing gap between the rich and the poor and the growth of low paid, insecure work. However, he suggests the left is generally supportive of the moral, family and social changes that have occurred since the 1960s. In contrast, Lilla claims that the political right is uncritical of capitalism. The unequal distribution of paid work, or income, is not a major concern. However the political right is concerned with what they see as an increasing moral permissiveness. This permissiveness is indicated by some of the trends already discussed, such as the breakdown of the two-parent family. He also suggests that the analysis of social and economic policy is polarised in the U.S. He illustrated this by discussing books that are available in bookshops in the U.S.:

There one will find a long shelf of conservative books documenting the horrific consequences of the cultural revolution, but none that also probes the quite real sense of insecurity many Americans are feeling in the whirlwind of our new economy's creative destruction. There is another shelf, not quite as long as it used to be, purporting to show how the corporate-media-military complex keeps the Reagan revolution going, but again with no sober account from the left of the very real, very troubling side effects of the sixties cultural revolution (pp. 6-7)

On the shelf of the "left" are many books critical of the emerging economic environment in industrialised countries. A common theme in these books, and associated articles, is the view that connected with "globalisation" the number of "core" jobs in the economy is declining, the "contingent" workforce is rapidly increasing, and through "downsizing" there is potential for growth in unemployment or underemployment even amongst the middle classes (e.g. Aronowitz and DiFazio 1994, Head 1996, Sherman 1995). Amongst the more pessimistic writers, the view is put forward that work is disappearing. This view about work disappearing, particularly for older people, has also been presented in New Zealand by some researchers (Thomson 1999). 
On the shelf filled with literature from the "right" is a book that, not surprisingly, focuses more on the social breakdown apparently occurring in society. However, it is a publication that does see a link between the changing economy and changing work and living arrangements. The Bell Curve talks about a dividing society, but has been heavily criticised by liberals. This criticism has particularly focussed on the assertion that Blacks have, on average, lower IQ's than whites in America. It is, nevertheless, a book that makes some important predictions about American life that are worth exploring in a New Zealand context. These include the observation that:

In one segment, life gets better in many ways. The people in this group are welcomed at the best colleges, then at the best graduate and professional schools, regardless of their parents' wealth. After they complete their education, they enter fulfilling and prestigious careers. Their incomes continue to rise even when income growth stagnates for everyone else. By their maturity, these fortunate ones commonly have six-figure incomes. Technology works in their behalf, expanding their options and their freedom, putting unprecedented resources at their command, enhancing their ability to do what they enjoy doing. And as these good things happen to them, they gravitate to one another, increasingly enabled by their affluence and by technology to work together and live in one another's company - and in isolation from everybody else.

In the other group, life gets worse, and its members collect at the bottom of society. Poverty is severe, drugs and crime are rampant, and the traditional family all but disappears. Economic growth passes them by. Technology is not a partner in their lives but an electronic opiate. They live together in urban centers or scattered in rural backwaters, but their presence hovers over the other parts of town and countryside as well, creating fear and resentment in the rest of society that is seldom openly expressed but festers nonetheless.

(Herrnstein and Murray 1996: xxi-xxii)

Herrnstein and Murray see a polarisation occurring at a number of levels, each of which individually or collectively, could affect a significant proportion of the population. First, there is a polarisation of paid work experiences in terms of both participation and income earned. Herrnstein and Murray see inherited cognitive ability as a key factor in this work polarisation although, as will be discussed in following chapters, this view is highly contested. Then, there is a polarisation of living arrangement. Couples and two parent 
families are more common amongst those who are in paid work, while single parenthood is common amongst the poor. Again cognitive ability is seen by Herrnstein and Murray to be an important factor in living arrangements. For example, people with low cognitive ability are less likely to live in couples, and when couples do form the cognitive elite are likely to intermarry. This advantage and disadvantage amongst individuals and households is then reinforced by an increasing polarisation in areas of residence. The well educated, and generally employed, live in separate communities from those work-poor people who have little education. "Good" and "bad" communities develop, which creates "norms" which further entrench particular behaviours and attitudes. In turn, family type and type of community are both seen as having an impact on the life chances of the next generation. In this type of analysis, ethnicity, or what tends to be described as race in the U.S., is a critical element of discussions.

This type of polarisation is illustrated in Table 1. It shows some of the characteristics associated with being at both extremes of the social and economic spectrum.

Table 1 - The potential polarisation of life experiences within industrialised societies in the late 1990s

\begin{tabular}{|c|c|c|}
\hline & Life is getting better & Life is getting worse \\
\hline Education & $\begin{array}{l}\text { university degree or advanced } \\
\text { qualification }\end{array}$ & $\begin{array}{c}\text { low levels of literacy, school } \\
\text { dropout }\end{array}$ \\
\hline Paid work & high income, secure, full time & $\begin{array}{c}\text { no work, or low paid, insecure, part } \\
\text { time }\end{array}$ \\
\hline Living arrangement & $\begin{array}{c}\text { owning a home, living in married } \\
\text { couples, two-parent families, } \\
\text { choosing to live alone, delayed } \\
\text { childbearing }\end{array}$ & $\begin{array}{l}\text { being homeless or living in } \\
\text { boarding houses, prison, } \\
\text { overcrowded multi-family } \\
\text { households, teenage pregnancy }\end{array}$ \\
\hline Neighbourhood & $\begin{array}{l}\text { neighbourhood of "choice" } 6 \text {, good } \\
\text { schools, safe environment, positive } \\
\text { social norms }\end{array}$ & $\begin{array}{c}\text { neighbourhood of "fate", poor } \\
\text { schools, high crime levels, negative } \\
\text { social norms }\end{array}$ \\
\hline
\end{tabular}

Herrnstein and Murray are not alone in their views about polarisation, although other researchers often have quite different ideas about the causes of changes. For instance, in Britain work-poor households and work-rich households have emerged in the last two decades, as have the terms work rich and work poor (Gregg and Wadsworth 1994). ${ }^{7}$ In the

\footnotetext{
${ }^{6}$ The terms neighbourhood of choice and fate are borrowed from Jordan (1996).

${ }^{7}$ These terms are defined in Chapter two.
} 
U.S. there has been much concern about the plight of people living in inner city ghettos (Wilson 1987). Closer to home, research in Australia suggests that particular communities within large metropolitan areas have, since the 1970s, become work-rich and work-poor (Gregory and Hunter 1995). Living in the work-poor communities are "marginal men" (Sydney Morning Herald 1998). Many of these men are seen as part of a growing underclass of males who are "excluded from family life, from settled relationships and marriage" and "whose lack of economic resources is sentencing them to life as outsiders."

However, some writers add more complexity to the concept of polarisation by discussing the notion of segmentation. While the two extremes represent polarisation, in the middle there is also a diversity of experience. For instance, Marcuse (1996: 207) makes some predictions about the changing workforce. In doing so, he then suggests that not only will the highly skilled be concentrated in industrial nations, but they will also cluster together in particular areas within these countries. He suggests the following trends:

- for the owners of wealth and wielders of power, increases in wealth and power;

- for professionals, technicians, managers, the owners of productive equities, the winners in the process of economic change, a large increase in numbers, and often in income and privilege, but accompanied by some insecurity as to status;

- for the old middle class, civil servants, skilled workers, semi-professionals, a decline in numbers and a loss of status and security;

- and, most important ..., for the excluded and the marginalized, the victims of economic change, the very poor, squeezed more and more out of the mainstream of economic activity, presumptively no longer needed even as a 'reserve army of the unemployed', no perceptible long-term prospects of improvements through normal economic channels.

Some researchers see this last group as a new "underclass" who are socially and economically excluded (Buckingham 1999). 


\section{Polarisation and mobility}

A further major dimension to the polarisation debate is the question of mobility. If people are part of an underclass, do they remain in this state for long periods and, perhaps even more importantly, is there an intergenerational dimension to the polarisation? Can people only become upwardly mobile if they shift out of geographic areas where local norms reinforce failure? Perhaps, in a period of major adjustment, there may sometimes be a "lost generation", but with the next generation better adapted to the changed economy. High levels of polarisation and mobility can potentially co-exist and may mean that advantage and disadvantage are not fixed states. For example, while income distribution at a particular point in time might be extreme, people may not remain poor (or rich) for long periods. Equally, in the spatial dimension people may not live for long periods in poor neighbourhoods. In addition, a polarisation in one area of life may actually help reduce a polarisation in another. For example, there is much debate in OECD countries as to whether an increased flexibility in the setting of wages, and therefore the chance that there will be increased income inequality, might eventually lead to a more equal distribution of paid work. A nation may have to have a period of being "work-poor" due to restructuring to ensure its population is "work-rich" in the long term. This type of social policy trade-off is illustrated by Esping-Andersen (1996: 25-26).

More generally, if a return to full employment will have to rely on greater earnings inequalities and a profusion of 'lousy' service jobs, active social investment policies should diminish the chance that certain groups become chronic losers. 'Lousy' jobs will constitute only a marginal welfare problem (and may even be beneficial) if they are merely stop-gap, or easy first entry, jobs for school leavers or immigrant workers. They are a major problem if they become life cycle traps. We know that education and skills offer the best odds for people to move on to better jobs. Hence, a low-wage-based employment strategy can be reconciled with equality if there exist guarantees of mobility and improvement. 


\section{An alternative tale - The increasing diversity of experience in post- modern society}

In contrast to themes of polarisation and, at times, connected with the ideas of mobility are themes of increasing diversity for individuals. This diversity of experience, including shifting identities, is at the forefront of much post-modernist writing. The diversity can actually be a shift away from old styles of polarisation, particularly polarisation along gender lines. While there have always been exceptions, in the 1950s, examples of the old styles of polarisation included:

- almost all men were in full-time paid work while relatively few childrearing women were in paid work

- young people were in full-time education while the middle-aged were either in the workforce or looking after children

- only men were cabinet ministers while only women were nurses

There are also themes of diversity in family and household type in some research literature. Once, women in their mid 30's would have been in three main groups, legally married wife, spinster, or widow. Now the options are much wider and include being in a de-facto heterosexual couple, single motherhood, being a partner in a same-sex couple with or without children, or living in a blended heterosexual family. There are also often transitions between various living arrangements. One result of changes in both work and family type is that in terms of women's and men's participation in paid work in countries such as the U.K there appears to be increasing differences between families and households, rather than within families or households (Himmelweit 1995).

There are also some challenges to the idea that polarised geographic communities are forming. Forrest and Kennett (1997) argue that there is actually much variation of people's characteristics within seemingly homogeneous neighbourhoods, especially middle class ones. They suggest that increasingly people's life cycle decisions are being made individually. Therefore, individuals, families and households might appear similar on some standard social indicators, such as income level or education. However, there 
may be quite major differences when wider indicators are used. For example, levels of debt may be quite different, as may be differences in wider social resources, lifestyles, and future paid work prospects. Forrest and Kennett argue that private safeguards against poor health, loss of employment and other risks create a wider range of potential longterm outcomes. People may have quite different superannuation schemes, access to private health care, or redundancy agreements. For the middle class, they suggest that even home ownership can now be a risk and potential liability. There is the risk of loss of future income streams, or lack of inflation to reduce loans when people have bought in the wrong part of the housing cycle. Even middle class suburbs are no longer places where there are stable careers and stable family lives.

\section{Research questions in a New Zealand context}

In this thesis, I first intend to gain an understanding of broad changes in work, shifts in educational qualifications and changes in living arrangements, including some spatial aspects of these altering patterns. This includes identifying driving forces behind changes, as well as developing an understanding of possible links between changing work patterns and living arrangements.

In order to undertake this analysis, the first section of the research involves bringing together a wide range of theory and published research in a form of "meta-analysis". Included in this literature are studies based on overseas longitudinal databases so as to gain a better idea of dynamics. This is important given that my main data source, the census, is cross-sectional and that there is little New Zealand longitudinal data. While this meta-analysis is not an attempt to identify one grand unified theory that explains all the change, such a review helps set a theoretical and evidence-based background to my main research questions. This meta-analysis also allows the development of a further cluster of related research questions. The third section of the thesis then tries to answer these questions using mainly New Zealand census data. In this data testing section, some new methodologies are explored. Therefore, this thesis is a mixture of meta-analysis and primary research. It also uses a multi-disciplinary approach. 
There are eight main research questions in this research. These questions do not emerge from the development of new theoretical perspectives but are drawn from existing theory. The first over-riding question is whether, in New Zealand, paid work is disappearing. If there is strong evidence that it is disappearing then this change may be potentially far more significant than any distributional change.

The five further questions that then lead on from this initial question are:

- in New Zealand, did the employment loss and subsequent employment growth between 1986 and 1996 lead to an increasing polarisation in paid work participation and hours worked for prime-aged individuals? ${ }^{8}$

- in this time period, was there also an increasing concentration of paid work, in terms of both participation and total hours worked, within particular families and households?

- was there a change in the concentration of hours of paid work by prime-aged people within geographic areas?

- was formal education a critical factor in any polarisation taking place in the distribution of paid work?, and

- have changes in paid work had a major influence on any of the changes in living arrangements, which may have occurred over the time period studied?

In addition, based on the assumption that participation in the labour market by individuals is very closely related to level of education, two further main questions are explored:

- did human capital, as measured by formal education, became more concentrated within particular families between 1986 and 1996 ?

- did formal education also become more concentrated within particular geographic areas in the period studied?

\footnotetext{
${ }^{8}$ While, ideally, I would have liked to analyse changes in a longer time period for the reasons set out in Chapter three I have concentrated on the decade between 1986 and 1996.
} 
For individuals, age and gender are key variables in the analysis. ${ }^{9}$ Ethnicity is considered in the research but, for reasons that are fully laid out in Chapter four, it is not a key variable in any time series analysis. While a variety of family and household types are considered, there is a particular focus on heterosexual couple families. This family type is of interest as it provides a site of potential conflict, bargaining and adaptation over changing roles and expectations in paid and unpaid work of men and women. The spatial area considered in this analysis is an "area unit", a term which is defined in Chapter three. While these are the main research questions, further related questions emerged as the meta-analysis developed.

Finally, some of the possible implications of any polarisation in paid work on society are explored. These are not only in terms of the impact on the current generation of primeaged people, but also on the impact on the next generation.

\section{Disciplinary approach}

While this research is located within a social policy department, I take a multidisciplinary approach. The strengths and weaknesses of such an approach are explored more fully in the following section. However, in order to keep a multi-disciplinary approach manageable some limits need to be placed on the disciplines drawn upon. In this research there is a particular emphasis on theories and research emerging from within economics, sociology, geography, and social policy. An attraction of economics is that financial factors are considered to be of great importance in influencing people's behaviour. However, a further appeal of economics is that it has a strong interest in the workings of the whole economy as well as a focus on statistical analysis and predictive models. The key elements of sociology that are attractive are the extensive, and often indepth, research within that discipline on families, gender, changes in work and the idea that social norms impact on behaviour. Geography is of value to this research mainly because of its strong focus on a spatial dimension of societal change. Finally, the discipline of social policy itself has an attraction for two main reasons. First, it

\footnotetext{
${ }^{9}$ Although in much of the analysis of prime-aged people I use a broad age band of 25-59.
} 
encourages the exploration of links between societal trends and policy formulation (and visa versa). Second, social policy is not discipline bound. It recognises that real life policy formulation is usually problem oriented and, generally, involves drawing on research from many disciplines.

Particular pieces of research and theories are also drawn upon from within other disciplines, including demography, psychology, women's studies and education. For instance, demography has influenced me to include an age cohort factor in some of my analysis. ${ }^{10}$ From psychology, I draw upon the on-going debates about nature versus nurture determining a person's life chances. Some of the fundamental assumptions underlying this research, such as the notion that human relationships are characterised by multiplicity, plurality and difference, are also in accord with some aspects of postmodernist thinking. Also in accord with postmodernist thinking is an acceptance of the idea that much policy debate focuses around "discourse" rather than an analysis of "facts". However, while acknowledging the power of discourse, that post-industrial society is becoming more complex and that no single coherent grand theory is sufficient to guide us in understanding society or making good social policy, I nevertheless assume that some discernible patterns emerge out of the chaos. I suggest that policy discussions benefit from an identification and discussion of these patterns. Therefore, I do not formally draw on postmodernist theory.

\section{The strengths (and weaknesses) of a multi-disciplinary approach}

Human activity is complex and is difficult to explain. One approach to dealing with complexity is to develop simplified and specialised models. The specialisation may be either in a subject area or be based around a specific set of assumptions or theories. In a time of very rapid expansion of knowledge, such specialisation allows an in-depth expertise to be developed. It is also easier to work with an abstraction that removes many variables. Once a person has a good understanding of this area of specialised knowledge,

\footnotetext{
${ }^{10}$ As I am using cross-sectional data I do not follow actual cohorts.
} 
the boundaries of knowledge in a narrow area of interest can then be expanded incrementally.

This specialisation is essential in trying to understand particular problems but often a "bigger picture" is needed. This will require either people from two or more disciplines working together, one person having a good understanding of a range of disciplines or, alternatively a wider discipline emerging. In addition, some problems are so large, or the time frame required to solve them is so short, that people with a variety of narrow expertise are required to solve them. Constructing complex buildings, undertaking advanced surgery, or developing social policy are examples.

However, like all classification systems, research disciplines themselves are not unchanging. Some of the change comes from internal debates. For example, within each major discipline there are often many possible approaches. However, often one approach will dominate overall thinking for a particular period or, alternatively, will dominate thinking within particular countries or universities. For example, within economics, the neoclassical approach currently holds centre stage, but there are many complementary/alternative approaches. These include institutional economics, a neoKeynesian approach, political economy and feminist economics. Often people attracted to these approaches have their own set of journals, each with its own specialised literature.

The outer boundaries of disciplines also do not remain fixed. For example, Collins (1998) notes "[d]iscoveries do not respect administrative boundary lines. Major advances in research or theory pull followers after them, who institutionalise themselves in turn for a while in some organizational form, if only until the next big round of discovery" (p. 2). He also argues that "hybrid" communities form on the borders of disciplines. These communities in their formation stages may exhibit signs of "hybrid vigour" as they bring new insights into research questions and may eventually institutionalise into new disciplines or schools of thought within an existing one. Alternatively, they may fail to develop a critical mass and wither away. Smelser and Swedberg (1994) provide examples of hybrid communities. This includes attempts by economists to bring sociological 
perspectives into economics, which led to the development of New Institutional Economics. There are many examples of sociologists bringing economics into their work, some of which are included in this research and a sub-discipline of economic sociology has also developed.

In contemporary research, various researchers have promoted the idea of moving beyond narrow disciplinary approaches in undertaking research, particularly in the areas of work and families. For instance, Becker (1996) notes "[b]ut with a few exceptions, economists and political scientists typically pay little attention to the structure of preferences, while sociologists and anthropologists do not embed their analyses of social forces and culture in a powerful analytical framework"(p. 1). In New Zealand, Shirley (1998) stresses a need for more of a collegial and collective response to examining social issues, which he suggests needs to goes beyond individual disciplines and even interdisciplinary traditions. As a further specific example, when looking at risks of becoming unemployed Caspi et al (1998: 443) state "[e]conomists, sociologists, and psychologists have tended to focus on different individual-level predictors of unemployment. As a result, each discipline's "error term" has been the others' substantive concern." The researchers go on to suggest:

[t]he problem of unemployment - its prediction, explanation, and possibly its resolution - requires interdisciplinary collaboration. Economic, sociological and psychological perspectives yield complementary rather than competing accounts of how individual-level characteristics give rise to and shape different life-course trajectories (p.445).

This is a "whole-life" approach, rather than an oversimplified abstraction. Some writers also see this type of research as an "ecological" approach (Bronfenbrenner 1979).

In terms of family research, Katz (1997), an economist by training, argues that many research perspectives need to be drawn upon when theorising and analysing empirical data on decision making within families. Similarly, Weiss (1997: 120), in a primarily economics-based review of family formation and dissolution, notes gains in understanding can only be made "...by the interweaving of social economic and demographic consideration." He goes on to note that "...no single discipline seems 
capable of providing such as synthesis." In addition, while not moving as far as a postmodernist stance, Hahn (1991) argues that, in the future, economics will not be so focussed on creating "grand unifying theory", but will need to take into account history, sociology and biology.

There are some dangers associated with individuals trying to undertake a multidisciplinary approach. A major one is that, with a rapidly expanding and increasingly unmanageable amount of theory and data being available, a researcher could easily end up being swamped by the information or could become a "jack of all trades and master of none". This is particularly the situation if some boundaries are not set as to which major disciplinary areas will be drawn upon. There is also the danger that without an in-depth understanding of the literature and debates within a particular field it will not be clear which theories or studies have been discredited or, just as importantly, new advances may be overlooked. There is, therefore, the potential for no new insights to be developed and a partially understood or misunderstood research literature to be simply summarised rather than expanded.

Finally, there are also practical, although in some cases relatively minor, barriers to multidisciplinary research. The first is a discipline-specific jargon. This, at times, can be a major barrier. Second, although computer software has been developed to help overcome this problem, there are discipline specific (and often journal specific) referencing systems when publishing. ${ }^{11}$ There is also research literature that suggests that there are some particular difficulties identified in doctoral research that crosses disciplinary lines (Parry et al 1997). The two main problems are that, first, even if the research is undertaken in a multidisciplinary environment, external examiners often have a narrow disciplinary background and, second, that in a multidisciplinary setting both candidates and supervisors may be working in isolation from specialist expertise in any particular field. They may therefore not be able to seek useful advice.

\footnotetext{
${ }^{11}$ In terms of my own referencing system I have decided to adopt the referencing style of the Social Policy Journal of New Zealand.
} 


\section{Theories about how people make choices and my own views}

Deciding how people make choices is an important and a much-debated issue in social science. ${ }^{12}$ Determining the processes is particularly important if social policy makers wish to try and alter the choices people are making. For instance, if it is social norms which mainly impact on whether people seek tertiary education, then campaigns to increase participation rates are useful, but if people are undertaking detailed cost/benefit analyses then it will be an assessment of likely future earning steams which will be a critical factor. In the latter scenario, it may be more important to publish data on occupations and incomes. If people simply decide whether to move into paid work by comparing the earnings from a welfare benefit versus available market income then the incentive effects of setting benefit levels is extremely important, but if a "work ethic" is a powerful influencing force then social norms need to be considered in work choices. If men are biologically driven to be primary income earners and will only be positive parents if they have a full-time paid job, then the creation of full-time jobs for men will be a critical part of strengthening families. But if social norms influence commitment to parenting, then ways of changing norms amongst unemployed men need to be examined.

In mainstream neo-classical economics it often assumed that people make rational decisions, and that preferences or tastes are primarily determined endogenously. Within this school of thought, the process of selecting a job or a marriage partner involves rational decision-making where the costs and benefits of such a decision are carefully weighed up. If biologically determined love and/or lust are the chief determinants in choosing a future marriage partner then different choices may be made.

Alternatively, in mainstream sociology, it is generally assumed that exogenous factors such as social norms, culture, tradition, social class, as well as factors such as gender, age and ethnicity have a major influence on decision-making. Within much of sociology, there is the view that many of these factors heavily constrain the decisions an individual

\footnotetext{
${ }^{12}$ It is also a very practical topic much debated in the business world, particularly in areas such as advertising.
} 
can make. There are of course challenges within each discipline to these approaches. In sociology, for example, there is the rational action theory school of thought (e.g. Goldthorpe 1998). In mainstream economics, Becker (1996: 2) argues that while individuals behave to maximise utility, individual preferences need to be extended to include "...personal habits and addictions, peer pressure, parental influences on the tastes of children, advertising, love and sympathy, and other neglected behavior." Also within economics, a challenge to rational decision-making comes from within institutional economics and, its more recent form, new institutional economics. In undertaking this research, I have an attraction to elements of institutional economics.

In a summary of characteristics of (old) institutional economics, Hodgson (1994: 69), suggests that key characteristics are:

- Instead of the rational, calculating agent of neoclassical theory, institutionalism sees human behavior as normally driven by habit and routine, but occasionally punctuated by acts of creativity and novelty.

- Instead of an exclusive focus on individuals as units of analysis, institutionalism regards self-reinforcing institutions as additional or even alternative analytical units.

- Institutionalism sees individuals as situated in and moulded by an evolving social culture, so that their preference functions are not given and fixed but in a process of continuous adaptation and change.

- There is a pervasive concern with the role and significance of power and of the conflict between both individuals and institutions in socioeconomic life.

So, in this form of economics, exogenous influences are seen as very important. However, new institutional economics (NIE) goes on to develop the idea of "bounded rationality". This is an assumption that human cognitive capacities are limited and there are constraints on the ability to gather, store, process, and communicate information (Rae 1999). The limits on gathering information could be time limits, the size of the problem could be too large to consider all options, and choices about the future are constrained by 
lack of information about future events. Information can also be costly. However, even when information can be easily acquired, it takes time to process and analyse. It also requires a minimum level of cognitive ability, with decision making generally enhanced as cognitive ability improves.

Given that rationality is "bounded", then established habits, tradition, and cultural and social norms provide individuals with decision-making shortcuts. Folbre (1994: 20), drawing on a NIE framework, suggests that people should be seen as "imperfectly rational somewhat economic persons". She sees that people are endeavouring to make "purposeful choices" rather than "rational choices". Folbre argues that these new terms

encourage an investigation of how people define and pursue their desires, but avoids any implicit dichotomy between rational and irrational decision-making.

While change in cultural norms is possible, there is the concept of a "cultural lag". This idea of a cultural lag will be referred to a number of times in this research.

Overall, I am assuming that people are making "purposeful" decisions and that most decisions are "rational". However, this rationality is bounded by factors such as social norms, a lack of information, lack of cognitive ability or, at times, biological factors.

\section{Structure of thesis}

The thesis is divided into three sections. The first section is concerned with definitions and methodological issues. Definitions of many of the units of analysis focussed on, such as families and households, are complex and highly contested. This section also discusses issues such as the quality of the census data I use for my primary analysis and the methods used to access it. In section two, the "meta-analysis" of relevant international literature is used to build a picture of the broad changes in education, work and living arrangements as well as the possible linkages between them. Some of the studies referred to are based on complex multivariate analysis and longitudinal databases. The metaanalysis begins with a discussion of debates about nature and nurture in determining cognitive ability and gender roles. Assumptions about the impact of nature and nurture 
are important when trying to understand changes in work and living arrangements for individuals. Chapter six then focuses on the broad forces that are altering patterns of paid work. This discussion then leads onto the next two chapters. The first canvasses views about upskilling and deskilling and changes in work, the next about changes in work time patterns. The three chapters on work provide a backdrop to a discussion as to why a particular group of men have been exiting paid work or are working part time.

Chapter ten then focuses on the idea that changes in paid work might be linked to changes in living arrangements and, in particular, the formation of couple families. Theories and research discussed in this chapter then provide the background for a discussion of theories of assortative mating. A key question in Chapter eleven is if couples do form, do people with similar levels of education tend to cohabit? The idea of a concentration of education within particular households is seen as a factor in the growth of work-rich and work-poor households. However, the changes in work pattern discussed in earlier chapters are also seen as having some influence on changes in work patterns within households. Chapter twelve examines some of these ideas. Finally, the last chapter in this section brings a spatial dimension into the discussion. In particular, there is an interest in theories and evidence about the idea that work-rich and work-poor people are becoming geographically separated.

The third section of the thesis focuses on trying to answer the research questions that have been developed in the first two sections. However, it needs to be acknowledged that relatively few of the wider issues canvassed in sections one and two are actually explored using empirical data. This is mainly due to deficiencies in the data. This disjuncture between theory and measurement is quite common in the area of economic and social policy.

Chapter fourteen first provides an overview of the changing economy, changing demographics and the changes in welfare use. The changes in welfare use are included in order to provide an initial idea of whether changes in work only have an impact on financial transfers within families or households or whether they impact on wider society. 
Chapter fifteen analyses changes in educational participation and attainment. The next chapter looks at broad changes in paid work. This includes an analysis of changes in skill, as able to be measured by using census data. Chapter seventeen then focuses more narrowly on changes in paid work for prime-aged people. The next chapter focuses on associations between education, paid work, and living arrangements for prime-aged men. In this chapter, a key issue to be explored is whether prime-aged men with little formal education are not only more likely to be out of the workforce but also to be isolated from family life. Chapter nineteen moves onto an analysis of marriage market outcomes by considering the education status of both partners in couples. Chapter twenty examines trends in the numbers of work-rich and work-poor families and households between 1986 and 1996. This analysis flows into Chapter twenty-one where a geographic dimension is brought into the analysis of changing work patterns. The final chapter draws together broad conclusions of the research.

Finally, in undertaking this doctoral research, I considered it important that I utilised my data quickly in order to engage in public debate. Therefore, from early on in the research process I published aspects of it. I note where I draw on this published research 


\section{Part one}

\section{Methodological issues in analysing work, education, families, households and geographic communities}




\section{Chapter 2}

\section{Work and education: Concepts, definitions and measures}

This chapter explores conceptual, definitional and measurement issues regarding paid work and education. In particular, an emphasis is placed on definitions used in the type of surveys that provide both the primary and secondary data used in this research. Chapter four covers some specific methodological issues encountered when using census data to measure changes in work and education.

\section{Defining and measuring paid work}

Work $n . \& v .1$. the application of mental or physical effort to a purpose; the use of energy

Concise Oxford Dictionary (1990: 1412)

For most people, daily life involves some "work". Work can take a variety of forms, but as the above definition suggests work is often divided into physical or mental effort. The most common forms in industrialised economies are employment in the market economy; unpaid work within a family or household, and unpaid community work. A primary aim of this research is to analyse changes in time spent in paid work in New Zealand at the level of the individual, family and community. This requires some understanding of changes in paid work at a national and international level. It also requires some understanding of changes in unpaid work. However, despite its importance, unpaid work is not a primary focus of the research. Therefore definitions of unpaid work are not explored in this chapter. Definitions of work, the type of data collected, the time period 
used and how the data are subsequently categorised and analysed all have a major impact on the ability of researchers to determine how paid work is changing.

Language is always important in research and policy making. For example, Steve Maharey, the Minister of Social Services and Employment in the newly elected Labour government in 1999, argues that it important to talk about employment rather than work. He suggests that the term employment signals "real jobs with real wages attached" (The Jobs Letter 1999: 3). However, in this research I have chosen to use the term paid work rather than others such as simply "work", "employment", "market work", or "gainful employment". These latter terms are often used when referring to work that is generally paid.

The main reason for not using the term "work" is the recognition that unpaid work is also an important part of the total work carried out in a society. The term "gainfully employed" is also as problematic in that it implies that unpaid work has no "gain". In this research "paid work" includes any time spent undertaking activities that someone else pays for and, as such, matches the Statistics New Zealand category "gainfully employed". Pay can be in the form of wages, other forms of income (such as non-wage benefits) and profits. For example, unpaid workers in a family business are included in the Statistics New Zealand group "gainfully employed". The treatment of unpaid work in family businesses has had a major impact on long-term time series for women's participation in "work". If "unpaid" farmers' wives are actually seen to be in paid work then the strong rise in the participation of partnered women in paid work since WWII simply takes women back to a workpattern last seen in most industrialised countries in the late $1800 \mathrm{~s}$ (e.g. Ohlander 1994). The treatment of unpaid work in a family business also has a major impact on whether families and communities are seen as being work rich.

Non-wage income is particularly relevant to the self-employed who, generally for short periods, may be working for no pay or in a loss situation, but with the expectation of future income. In industrialised economies, paid work will normally take place in an outof-home setting, although there are people who undertake their work from their homes. 
Work such as paid cleaning, cooking or plumbing can also take place within private households. People in paid work, and those not in paid work but actively seeking it, are seen to be part of a wider grouping, that of the labour force. However, as will be discussed subsequently, there are various definitions of "unemployed and seeking work".

There are many boundary problems between paid, unpaid work and, at times, leisure. Becker (1965) developed a simple work-leisure model but did discuss the difficulties of distinguishing "work" from "non-work". There are also, at times, overlaps between work and leisure. Some people may be undertaking both paid and unpaid work simultaneously. Examples are craftwork in the home, which may be sold, or in the school holidays a courier van driver who may be looking after a child while undertaking deliveries. In addition, an activity that for one group is leisure, such as playing tennis, can for others be paid work. There is also the question of whether for some people work has become a new type of leisure. For some people in particular jobs, especially those in managerial and professional occupations, but also in areas such as artists or writers, work can be enjoyable and provide considerable satisfaction. In the latter occupations work can often be undertaken at very low (or no) rates of pay. ${ }^{13}$ As will be subsequently explored, it is possible that if the amount of enjoyable work is increasing in society this might affect hours worked.

There are a number of dimensions of paid work that could be measured, but two common ones are quantity and price (which could be seen to be a measure of quality). This research has quantity as its main focus although price usually affects quantity and vice versa. Quantity can be measured in a number of ways, hours per day or week, weeks worked per year, and years of paid work over a lifetime. In this research, due primarily to data limitations, the main focus is on hours per week.

\footnotetext{
13 Although in some of these occupations the people may rely substantially on other forms of income support, including welfare benefits.
} 


\section{Defining whether individuals are work rich or work poor}

As part of the focus on quantity of paid work, the terms work-rich and work-poor are used both in my research title and in the actual research. These terms need defining. Gregg and Wadsworth (1994), from whom I have borrowed the concept, used them in relation to households rather than individuals or communities. They were also only used in relation to paid work. According to these researchers, a work-poor couple was one in which neither partner was in paid work, while in a work-rich couple both were in paid work. In this latter situation, actual hours of paid work were not a critical part of the research. In couple families, a situation where one partner was in paid work, but the other not in work, has been described by Gregg and Wadsworth as mixed work.

\section{Hours of paid work}

At the level of the individual there are specific problems in measuring hours of paid work. Gershuny et al (1994) note one particular problem with time diaries. Time at paid work is often not broken down so rest breaks cannot be identified. The researchers argue that people in unpaid work tend to record such breaks. Therefore time-use data will tend to over-estimate paid work hours. In addition, Becker (1965) and, more recently, Ironmonger (1996) raise questions about time use such as travel to and from paid work. Self-education also does not easily fit easily into either the paid or unpaid work classification system, although in early writings on time use it was seen as part of "productive" non-market activities (Hawrylyshyn 1977). However, in recent times there has been more of a focus on education and training which is connected to paid work, such as in-house training or work sponsored education.

There are further problems in measuring hours of paid work in official surveys. In a study of respondents to the official US labour force survey, Robinson and Bostrom (1994) found that there was an over-estimation of hours worked each week. They compared responses to the surveys with data recorded in time use diaries by the same respondents. The researchers found a mean difference of around five hours a week. The relative size of the difference was positively correlated with hours worked. This means that those 
working the longest hours also inflated their hours the most. Robinson and Bostrom also found that the size of discrepancy between survey estimates and hours recorded in time diaries was increasing over time. ${ }^{14}$ New Zealand census data provides some indications that the recorded hours of those working very short periods each week may be more accurate than those working long hours. In recent censuses, while respondents are asked to put actual hours in recent censuses, for both men and women there was considerable clustering around the categories 40, 50 and 60 hours of paid work, and to a lesser degree $30,70,80$, and 90 hours. It may that people do tend to work set blocks of time, but it is more likely that people simply estimate work time on such a basis. This clustering is not so evident under 20 hours, perhaps because when people work relatively short hours they are much clearer about the actual time worked. An alternative way of measuring hours is to use employers' records, but these records, even if available, generally do not allow an analysis of an employee's family, household or community situations.

In measuring hours of paid work there is also an issue of "intensity" of the work carried out in a particular time. Fleisher and Kniesner (1984) argue that intensity of work is generally not reported in official statistics, but is naturally not unnoticed by employers. They suggest that given the very long-term trend of work hours falling per a year, that it is likely that work carried out in the shorter hours has increased in intensity. In a slightly different context Floro (1995) discusses intensity, with a focus on women with multiple tasks such as selling in a market and looking after children. In paid work, intensity, or productivity, should be somewhat linked to pay rates. In unpaid work there is no direct or indirect measure of intensity.

A further problem in measuring paid work is that some people, for a variety of reasons, may be reluctant to record their hours or involvement in work in official surveys. Whatman (1995) outlines “non-standard” work in New Zealand including 'homework' and work undertaken in the 'black' economy. Both types of work may include illegal activities, or types of work that are not illegal but are not being recorded for tax or other

\footnotetext{
${ }^{14}$ This type of bias has also been found in other measurements of time in paid work. Paull (1996) notes that if employment tenure data is based on recall then there is likely to be an upward bias the longer the period of recall.
} 
regulatory related reasons. Some seemingly work-poor people might in fact be quite busy with money-making ventures, such as drug dealing.

When measuring quantity, in some surveys actual hours of work are measured. However, there are issues as to whether these are hours worked in a particular reference period (often the previous week) or perhaps alternatively "usual" hours. Even defining "usual" hours can be difficult for some types of workers. Examples include seasonal workers who have major peaks and troughs in paid work, or a "casual" worker, and crew of fishing boats or oilrigs who may work six weeks intensely and then have six weeks off. Knowing paid work patterns over a whole year, or even a longer period, is an important factor in

thinking about whether individuals are work-rich or work-poor. There is also the issue of whether any overtime is included in any measure, and whether paid work undertaken in any secondary jobs is included.

In many surveys respondents state their hours in broad groupings, or alternatively the data collected is then aggregated by broad groupings. The most common grouping is that of part time and full time. Yet there are compatibility problems. For instance, in New Zealand the current official definition of part-time work is under 30 hours per week, whereas in the U.S. and Sweden it is under 35 hours. In New Zealand prior to the 1986 census part time was defined as less than 20 hours of paid work. However, in more common use, part-time work can be seen simply as working less than a particular norm. For example, in discussions of the hours of paid work of some lawyers in the U.S. parttime work is seen as working about 40 hours per week (Loveman 1994).

\section{Census questions on hours of paid work}

While industry, occupation and employment status have long been a key feature of the New Zealand census, hours of paid work have only been collected since 1945 .

In 1986, the starting point for this research, the census form asked "how many hours did you work last week?" In 1986 the question sets a specific reference point of the previous week. However, the question goes on to state "if on holiday, sick or absent for other 
reasons, state usual hours". The hours in the main job and hours in other jobs were asked separately, with the respondent being asked to enter 0 in the other job category if there was no other job. In accompanying notes it was stated that overtime hours were to be included and that unpaid household and voluntary work was not to be included.

In 1991 the question was again "how many hours did you work last week?" The question then asked "if you were absent from work last week, please enter your usual hours." Again hours in main job and other jobs were asked separately.

As a further guide in accompanying notes it was again stated overtime hours were to be included and that unpaid work other than that in a family business was not to be included. They also stated that if the person changed jobs in the previous week the current job was to be used.

In 1996 the question was changed and definitions were laid out in more detail. The question was "How many hours, to the nearest hour, do you usually work each week". Again hours for a main job and other jobs were recorded separately.

In the accompanying notes it stated: "if you work different hours from one week to the next, print your average hours per week over the last 4 weeks. Again the same rules as in 1991 applied to overtime and unpaid work in a family business.

While in each of the censuses covered it is likely a person on holiday or sick would have put their usual hours, in relation to the specific absences from paid work it is difficult to be sure how people would respond. It may be that most would put their usual hours. An example is parental leave. The issue of parental leave was partly tested using 1991 data (Callister 1995). This suggested that a high proportion of mothers of new babies were, in fact, on parental leave.

It is difficult to judge how the minor changes in questions affects the analysis of trends of hours worked. At least the census has been consistent in asking for usual hours worked if 
the person was absent in the reference week. I am assuming that the changes will not have had a significant impact. However, it is worth noting that major differences in questions, as well as survey coverage, do create some "gaps" between data collections in New Zealand. For example, the Household Labour Force Survey (HLFS) aggregate actual weekly hours worked in March 1996 were $57.8 \mathrm{~m}$. This is actual worked hours not the usual hours and only private dwellings were covered in the survey. In comparison the census, also in March, showed a total of $69.6 \mathrm{~m}$ hours work. This figure was for usual hours and includes non-private dwellings.

\section{Industry groupings}

While hours of paid work is an important measurement, and the primary variable focussed on in this research, other important characteristics of the work are useful when trying to understand changing patterns of labour demand and supply. Both industry and occupational classifications are commonly used when analysing labour market behaviour. Industry classification systems are based on the output of good and services. They are useful in that links can be relatively easily made to production data, such as exports or imports. It is relatively simple to make links to spatial issues, such as production plants in the meat industry being relatively easily located.

A question about a person's industry has been included in the New Zealand census since the census began in 1851 (Statistics New Zealand 1993b). As well, since 1945 the name of a person's employer has been asked, and since 1971 the address of the respondent's workplace has been asked for.

In this research, there will be some analysis of changes in employment by industry, but generally this will be carried in conjunction with occupation groupings.

\section{Occupational groupings}

Occupation involves defining the type of work undertaken by a person. Occupations, and occupational shifts, have the potential to yield very useful information about changes in 
paid work. With some occupations, such as a doctor or a teacher, it is relatively easy to understand what is involved in the job. But for some occupations the type of work carried out in different industries can vary significantly. A labourer on a construction site is likely to have different characteristics from a labourer in a dairy factory in terms of skills used and work practices. Increasingly, occupational classification systems have embedded in them some measure of the underlying skills used in a job. Because of this, analysing occupational change will be a key part of this research

In the New Zealand census, occupation has been included since 1851. From 1986 the question has been divided into two parts. The first asks for the person's occupation, the second asks about the tasks the person spends most time on.

In terms of the links between skill use and occupation, in 1987 the International Labour Office provided a new International Standard Classification of Occupations (ISCO-88). This was developed as the previous version adopted in 1968 was "being overtaken by technological advances and the increasing demand for skills-based occupation classifications around the world" (Statistics New Zealand 1995a: 9). The New Zealand Standard Classification of Occupations (NZSCO95) used the new classification system as a base for categorising paid work in terms of occupation, and Statistics New Zealand used it for the 1991 census and again for the 1996 census. The adoption of this new system, however, makes direct comparisons with censuses prior to 1991 difficult.

The NZSCO95 classifies occupations into nine major groups:

- Legislators, administrators and managers

- Professionals

- Technicians and associate professionals

- Clerks

- Service and sales workers

- Agriculture and fishery workers

- Trades workers 
- Plant and machine operators and assemblers

- Elementary occupations

While most of the grouping names provide an idea of what occupations are within them, the elementary occupational is rather diverse. It includes cleaners, building caretakers, messengers and doorkeepers, packers and freight handlers and labourers.

There are many problems with such occupational groupings. For instance, childcare teachers in the institutions of kindergarten and Kohanga Reo are seen as professionals while workers in creches are placed in sales and services. In addition, the sales and service classification contains both relatively unskilled and skilled jobs. Examples of skilled jobs include detective, funeral director, national park ranger, outdoor recreation guide. Relatively low skilled occupations include waiter/waitress and cloakroom attendant.

"Professionals" represent an unusual occupational group as education not only provides the skills needed to undertake the job, but is also generally the way membership of the group can be secured. Tilly and Tilly (1998: 29) note:

Professions consist of those exceptional labor markets in which workers, collaborating with governmental authorities, exercise collective control not only over employment but also over dispensation and consumption of a whole class of goods and services. Governments permit only licensed practitioners - persons who have received collective approval by existing members of the profession - to purvey the relevant goods and services.

Usually the key criterion for joining a particular profession is the holding of a formal qualification. Higher-level professionals will almost all have a university qualification, while associate professionals usually require either a university or other formal tertiary qualification.

The category managers can also be problematic. Generally people working in owneroperated businesses are assigned to their occupation speciality, for example 
retailing/farming. However, in bigger companies as the jobs become more specialised they then get assigned to specialist manager positions. This means that the growth in selfemployment will tend to understate people using "managerial skills". In addition, Gordon (1996) from a 1991 survey of the American workforce found that 80 percent of managers reported managerial or supervisory responsibilities. However, 29 percent of professionals, 16 percent of clerical and sales workers, 12 percent of skilled workers and 2 percent of unskilled workers also reported carrying out managerial or supervisory activities.

Despite all these problems occupational classifications still provide some guide to the changing nature of paid work. However, the change in occupational classification means that in using the new classification system in this research changes between 1991 and 1996 will be primarily focussed on.

\section{Other work classification systems}

Some labour market analysts have used either industry and occupational classification systems, or both, as the basis of further work classifications. Examples are the systems based on a "mental/manual", or "brains/brawn" dichotomy. These include the manual/ non-manual categorisation used by Morrison (1989), the extension of this to a manual/non-manual/primary and manufacturing/services breakdown by Haines (1989), and a three way split into manual/non-manual/physical work by Snooks (1994). Snooks gives examples of jobs which require physical strength where young strong males are at a premium such as physical contact sports, heavy construction, forestry and mining.

Overall, non-manual work is generally seen as requiring the most "skills" but this assertion has led to the "mental/manual" classification being criticised. Marxists have criticised it because such a split is then used by employers to deskill a group of workers. According to this view, the working class is not given knowledge about production processes and so can be more easily controlled by those who hold such knowledge, that is the managers and owners of capital. This issue is discussed more fully in the review of upskilling/deskilling in chapter seven. Some feminists also do not like the polarisation of mental/manual skills. For example, Jaggar (1988) argues that men are given the thinking 
jobs and women the manual work. Her category of manual work for women includes looking after young children in the home, in childcare centres, and primary schools, but she argues that as work becomes more mental (i.e. teaching in secondary schools and tertiary institutions) men take over these jobs.

Manual/mental classification systems have been used to try and assess whether "upskilling" is taking place in society. However, like most classification systems there are important boundary problems. For example, based on main tasks involved, is hip replacement surgery primarily a manual occupation? In addition, as will be discussed in subsequent chapters, some researchers argue that even traditional manual occupations, such as self-employed carpentry, now require more cognitive ability in areas such as financial management of the business

Other classification systems have been linked to a hierarchy of earnings, or control and/or education. New Zealand developed examples are managers/experts/workers (Franklin 1969) and employers and self employed/ "white collar" workers broken down into higher professionals, lower professionals, administrators and managers, clerical workers, sales, forepersons and supervisors/ all "blue collar" (Smith 1981). All these classification systems have been the subject of debate.

Reich (1993) has also developed a classification that tries to encompass the issue of skill but also includes other important characteristics. Reich suggests there are three main types of jobs that make up three quarters of employment in the U.S. These are routine production, in-person services, and symbolic analytic occupations. The remaining jobs in the economy comprise farmers, miners and "other extractors of natural resources" (p.180). However, in this remaining group he also includes government employees, including teachers, and employees in regulated industries such as utilities. ${ }^{15}$ This system also attempts to provide a framework for thinking about job creation (and destruction) in a global context.

\footnotetext{
${ }^{15}$ Perhaps reflecting his own professional background, Reich places university teachers within the symbolic analytical group but school teachers outside of this group.
} 
The routine production services entail repetitive tasks. Although often seen as mainly blue collar jobs, “ ...they also include routine supervisory jobs performed by low-and mid-level managers - foremen, line managers, clerical supervisors, and section chiefs involving repetitive checks on subordinates' work, and the enforcement of standard operating procedures (p.174)." They can be found in traditional manufacturing industries, in high technology industries such as manufacturing circuit boards, and they can include data entry and manipulation work. Reich suggests "[r]outine producers usually must be able to read and to perform simple computations." But their main virtues are "reliability, loyalty and the capacity to take direction (p.175)". They therefore do not require a high level of education. Their wages are based on the amount of time they put in. Reich suggests that in the U.S. in 1990 routine production jobs formed about a quarter of the workforce.

The in-person services work can also entail repetitive and simple tasks. They generally do not require a high level of education, but will often require some vocational training. Inperson servers "are supposed to be as punctual, reliable, and tractable as routine production workers", but they must also "smile and exude confidence, and good cheer, even when they feel morose (p.176)." Reich goes on to note that "[a]bove all, they must make others feel happy and at ease". Reich argues that it should be no surprise that most in person services workers are women. These latter qualities are sometimes described as "emotional" labour (Hochschild 1983). Unlike the routine jobs, many in-person services cannot be transferred to low wage nations. Exceptions include occupations such as "call centre" operators, who are delivering services from home banking to sex-lines. In addition, consumers can move between nations in the form of tourists exerting some further international pressures on wages and service standards. In addition many of these jobs are part of the infrastructure supporting the internationally competitive parts of the economy so there is an additional pressure for them to be competitive. Ultimately the wages of the in-person service workers depend on the incomes of the customers they serve, whether they are tourists or locals, and the productivity of their industries and 
occupations. Reich argues that in the U.S. in 1990 in-person service workers made up about 30 percent of the workforce.

Reich's last category, that of symbolic-analytic services, involves trade in the manipulation of data, words, oral and visual representations. They include all the problem solving, problem identifying, and "strategic brokering" activities within an economy. According to Reich (p. 178):

Symbolic analysts solve, identify, and broker problems by manipulating symbols. They simplify reality into abstract images that can be rearranged, juggled, experimented with, communicated to other specialists, and then, eventually, transformed back into reality. These manipulations are done with analytic tools, sharpened by experience. The tools may be mathematical algorithms, legal arguments, financial gimmicks, scientific principles, psychological insights about how to persuade or to amuse, systems of induction or deduction, or any other set of techniques for doing conceptual puzzles.

Reich argues that symbolic analysts all require a high level of skill. They require an education that develops innovative thought rather than learning a vast array of facts. He argues that their work uses four basic skills: abstraction, system thinking, experimentation, and collaboration.

Reich notes that symbolic analysts are often not in standard jobs. For example, many are found as self-employed or partners in firms. He also argues that while professional and symbolic analysts overlap considerably not all symbolic analysts are professionals and vice versa. There can be routine professional jobs such as lawyers making wills. There is also the question of where many managers fit in this classification system.

While Reich suggests that only about 20 percent of Americans are symbolic analysts, he goes on to say that symbolic analytical jobs are the economic drivers in an advanced economy with many other jobs depending on them directly or indirectly. These are the people from whom economic gains are often seen to "trickle down".

Reich also argues that simply undertaking symbolic-analytic work means that skills are continually built up, because learning is an integral part of the job. This suggestion 
potentially raises some problems in measuring skills by formal credentials. People in these occupations often are relatively mobile internationally and employers can seek out such labour internationally.

Reich's analysis can be summarised in Table 2.

Table 2 - Some characteristics of Reich's work classifications

\begin{tabular}{|l|l|l|l|}
\hline & Routine Production & In-Person Services & Symbolic-analytic \\
\hline Mobility of operation & $\begin{array}{l}\text { Most manufacturing } \\
\text { internationally mobile }\end{array}$ & $\begin{array}{l}\text { Generally not } \\
\text { internationally mobile, } \\
\text { except in terms of tourism } \\
\text { where the consumer is } \\
\text { mobile }\end{array}$ & $\begin{array}{l}\text { Highly mobile, but } \\
\text { question of whether it } \\
\text { needs to be attached to } \\
\text { some geographic } \\
\text { cluster }\end{array}$ \\
\hline $\begin{array}{l}\text { Mobility of labour in } \\
\text { these industries }\end{array}$ & $\begin{array}{l}\text { Generally immigration } \\
\text { laws limit mobility }\end{array}$ & $\begin{array}{l}\text { Some parts mobile, e.g. } \\
\text { domestic workers to Arab } \\
\text { countries }\end{array}$ & Highly mobile \\
\hline How earnings are set & In global marketplace & $\begin{array}{l}\text { By internal economy, } \\
\text { including minimum wage } \\
\text { legislation }\end{array}$ & In global marketplace \\
\hline Relative earnings & Low & $\begin{array}{l}\text { Low if economy is in poor } \\
\text { shape, high if economy is } \\
\text { strong and tight migration } \\
\text { laws exist }\end{array}$ & Potentially high \\
\hline $\begin{array}{l}\text { Level of education } \\
\text { required }\end{array}$ & Basic formal education & Mix of basic and high skill & High skill \\
\hline Types of occupations & $\begin{array}{l}\text { Factory process worker, } \\
\text { data entry operator }\end{array}$ & $\begin{array}{l}\text { Waiter, bank teller, bus } \\
\text { driver }\end{array}$ & $\begin{array}{l}\text { Designer, engineer, } \\
\text { sociologist, economist }\end{array}$ \\
\hline $\begin{array}{l}\text { Types of industries } \\
\text { hroduction }\end{array}$ & hotels & $\begin{array}{l}\text { Advertising, Research } \\
\text { Institutes, computer } \\
\text { programming }\end{array}$ \\
\hline
\end{tabular}

Source: Callister and Rose (1996: 104)

While presenting major problems in actually assigning jobs to each category, this classification system will be referred to in the research. However, a further group is added to the Reich classification system. I call this new group "technical-analysts". ${ }^{16}$ This will cover people in the technical and associated professional occupations and trades workers. People in agricultural and fisheries occupations are kept as a separate group in subsequent chapters. Finally, unlike Reich I allocate government workers to the various occupational groups rather than place them in the "other" group.

${ }^{16}$ In general, the education and training needed for technical-analytical jobs will have traditionally been supplied by polytechnics or through work based apprenticeships, while the education and training needed for symbolic-analytical jobs will have been supplied by universities. However, this boundary is rapidly being blurred. 


\section{Job security and non-standard work}

As will be outlined in Chapter eight, one important part of discussions around the changing nature of paid work is whether work is being "casualised", or that jobs are "temporary" or perhaps "non-standard". There is also much interest in the actual contracting process, such as whether contractual arrangements are explicit or implicit or, in the language of New Institutional Economics, complete contracts or incomplete. In addition, work time over a lifetime is a concern. Many of these discussions, and particularly those in the popular media, use terms that are only loosely defined. Trends about security and tenure of paid work are important in work-rich and work-poor discussions. For example, Gregg and Wadsworth (1996a) suggest that if entry-level jobs are insecure and low paid the only people who can take them on are those with other steady income earners in the household. In addition, unstable work might mean that a person over a long time period has relatively low hours of paid work.

Whatman (1995: 356) outlines "non-standard" work in New Zealand. He includes the following categories of paid work:

- Part time

- Casual

- Irregular hours or on-call

- Seasonal, temporary or fixed term contracts

- Self employment

- Undertaken as 'homework'

- Undertaken in the 'black' economy

- Any combination of the above

The "any combination" category is likely to be a large one as much of the international literature indicates strong links between the various forms of "non-standard" work (Callister 1997). 
Whatman and, earlier, Rose (1992) note that there are few data in New Zealand on "nonstandard" work. Providing data on the "informal" or "black" economy can be particularly difficult. In this sector, there will be barter, various forms of "self-employment", some work will be casual and some long term. Remuneration could include "drugs, drinks, food, stolen property, jobs, legal favors, sexual services, and housing as well as a wide variety of monetary payments" (Tilly and Tilly 1998: 32). There could be work-rich and work-poor people in this sector.

The most comprehensive data on non-standard work in New Zealand only covers parttime work and formal self-employment. Due to this restraint some researchers use parttime work as an indicator of casualisation (e.g. Shirley 1996).

The New Zealand census provides no information on security or tenure of job, although some employment status data is gathered. This is whether a person is working for wages or salary, is self-employed or an employer, or is working without direct pay in a family business. However, other employment surveys in both New Zealand and overseas, have attempted to specifically study security and tenure of work, as well as whether work is "non-standard". Some of these will be drawn upon in this research. In New Zealand and overseas, statistical, legal and common use definitions of permanent, temporary and casual work are evolving (Callister 1997).

Discussions of changes in patterns of paid work also sometime bring in more controversial categorisations, such as the idea that some work may be seen as a job and some as a career, as well as ideas of primary/secondary and/or "core"/ "periphery" labour markets (e.g. Cain 1976, Doeringer and Piore 1971, Reich et al 1973, Vietorisz and Harrison 1973).

Various writers have since reviewed the theories including Taubman and Wachter (1986) in the U.S. and, in New Zealand, Bowie (1983), Dixon (1995), and Harris (1995). These reviews indicate the evidence is conflicting as to whether separate labour markets operate. In addition, there is increasing evidence that a large group of the people who might be 
considered on the periphery of the labour market are not living in households that would be considered on the periphery of economic life (OECD 1998). Examples include primeage female part-time workers who tend to have partners with relatively high incomes, or children of middle-income families working in so-called "Macjobs".

In the mid 1980s, in the United Kingdom, Atkinson (1985) developed a theory of dual labour markets at the firm level. This put forward the idea that firms would increasingly move toward retaining a small "core" staff of permanent full-time workers, and around its "periphery" the firm would have various less secure, and more flexible, contractual arrangements with workers. This would include part-time work, self-employment, and casual work.

Explorations of dual or segmented labour markets have, in recent times, had a spatial dimension (e.g. Peck 1996). This exploration parallels discussions about location of industries, which in a global context, go beyond national boundaries (Krugman and Venables 1995). In the international context some areas can be seen as being core, and often metropolitan, labour markets, and others as "peripheral" areas. Some spatial aspects of changes in work are explored in this research.

A further categorisation, which is applied to both individuals and couples is that of careers versus jobs. For example, Hertz (1986) suggests careers provide some realistic expectation of upward occupational and financial mobility. In addition, careers most commonly begin within the salaried ranks of an organisation and provide a path for advancement from lower to higher levels of responsibility, authority, and reward. In contrast, jobs offer limited opportunities for advancement, responsibility, and authority, are paid by the hour, and provide little significant increase in financial reward for achievement or for longevity of employment.

In these discussions of dual labour markets, segmented markets, core/periphery markets, and careers versus jobs it would appear that generally those at the core of the labour 
market have the potential to be work rich, while many of those on the periphery either of the labour market or in peripheral geographic areas have the potential to be work poor.

\section{Labour force status}

While in much of this research I use the two categories in paid work and not in paid work, at times I break those not in paid work into those who are unemployed and seeking work and those who are not in the labour force. Again, there are definitional problems around these two categories and treating them separately can be problematic.

The 1986 census definition of "unemployed and looking for work" included all persons who specified they looked for work regardless of methods. However, by 1991 persons who only looked in newspapers were not considered to be actively seeking work.

In 1991, the census question asked whether the respondent looked for paid work in the last four weeks? There were three choices: No; Yes - looked for full-time work; and Yeslooked for part-time work. The next question then asked about methods of looking for paid work. The tick box choices were:

- Looked at job advertisements in newspapers

- Contacted the Department of Labour's New Zealand Employment Service

- Wrote, phoned or applied in person to an employer

- Contacted friends or relatives for help in finding a job

- Other methods (such as contacted a private employment agency, took steps to set up own business)

A final question on job seeking was "if a job had been available, would you have started last week?"

In 1996 there were some slight changes to these questions. The first asked again if the respondent looked for paid work in the previous four weeks.

- Looked at job advertisements in the newspapers

- Wrote, phoned or applied in person to an employer 
- Contacted the Department of Labour's NZ Employment Service to look for a job

- Contacted friends or relatives for help in finding a job

- Contacted career advisers or vocational guidance officers

- Other method(s), for instance: contacted other employment agency; placed an ad about a job; took steps to set up own business

Again there was a final question on job seeking, but with the word "paid" added:

If a paid job had been available, would you have started last week?

In 1996, if the person had looked for work and was available to start a job then they are classified as seeking work. In my research, I use the 1996 definition of unemployed and seeking work. Finally, the question of whether unemployed people were looking for parttime or full-time work was dropped in 1996

If a person is not seen to be actively looking for a job, then they are classified as being not in the labour force. However, as Dixon (1999) notes the classification assigned to individuals in a range of official surveys depends on whether or not they report any 'active' job search activities in the reference period. This may be a rather arbitrary matter, depending on respondents' ability to recall their search activities, as well as on small distinctions in job search methods. This is primarily why I generally combine those unemployed and those not in the labour force.

\section{Defining and measuring education}

Defining and measuring education, and more importantly the actual skills and abilities that the education might represent, is even more problematic than dealing with work. Underlying many of the discussions about education are assumptions about how abilities are transferred from one generation to the next. In particular there is the issue of whether education is a sorting mechanism, with abilities based primarily on genetics, or whether education is actually adding new skills. This nature versus nurture argument is discussed in more detail in Chapter five. 
Amongst economists in particular, the use of the term "human capital" has become common. It is assumed that human capital can be developed in a number of ways, and can take a variety of forms. Human capital investment includes looking after one's health, investments in formal education, and geographic mobility. More recently Becker has divided human capital into two types, personal capital and social capital. He sees personal capital as "...the relevant past consumption and other personal experiences that affect current and future utilities" and social capital " ...incorporates the influence of past actions by peers and others in an individual's social network and control system" (1996: 4). Other researchers have some slight variations on these definitions that can cause misunderstandings. For instance, Caspi et al (1998) suggest that human capital include factors such as occupational status of parents, educational credentials, reading ability, and IQ. They see reading ability as an important separate factor affecting people's lives. For social capital they include factors such as family type, conflict in home, weak attachment to parents, and involvement in school activities. Finally, personal capital can cover issues such as a person's involvement in antisocial behaviour, symptoms of mental illness, and poor physical health. Most of these variables are not measured in official surveys such as the census.

Assuming that nurture is important, parents generally undertake early investments in human capital. This can include providing optimal nutrition, exposing children to a wide range of positive experiences, or investing in their formal education. However, in general human capital has been associated with skills acquired through education, which are then of prime use in paid work and ultimately in maximising "wealth" (e.g. Fleisher and Kniesner 1984). Firms can invest in a person's human capital, such as through on-the-job training, in order to increase an employees' productivity. Some of this latter human capital may be job or employer specific rather than transferable skills. Some researchers take an even wider view of what human capital is, but usually linking it to productivity issues. 
Like physical capital, human capital is seen by most people as something that can be increased or reduced. Sociologists England and Farkas (1986) describe people having achieved and changeable characteristics, whereas ascribed characteristics such as race, gender, social class of parents are difficult to alter. Becker (1996) sees these ascribed characteristics as being part of a person's "culture", which is in turn part of a person's "social capital". But he does note that over time people's behaviour can slowly alter parts of seemingly fixed "culture".

Formal education, within pre-schools, schools or tertiary institutions is an important component of human capital. There is now, however, increasing interest in skills gathered while in a job, either formally or informally. Both types of training can provide general skills or firm-specific skills. Although some industry-based training is already recognised in formal qualifications such as apprenticeships often it is not "credentialised".

There are many definitional and measurement problems with any sort of education or skill. However, Herrnstein and Murray (1996) suggest that there are good measures of cognitive ability available. They note (pp. 22-23):

- there is such a thing as general factor of cognitive ability on which humans differ.

- all standardised tests of academic aptitude or achievement measure this general factor to some degree, but IQ tests expressly designed for the purpose measure it most accurately.

- IQ scores match, to a first degree, whatever it is that people mean when they use the word intelligent or smart in ordinary language.

- IQ scores are stable, although not perfectly so, over much of a persons' life.

- properly administered IQ tests are not demonstrably biased against social, economic, ethnic, or racial groups.

While Herrnstein and Murray see a direct link between IQ and cognitive ability, Caspi et al (1998) argue that IQ can influence further education in an indirect way. They suggest that less able children can find school stressful and fail to form a bond with the institution 
and then not utilise education. The question of what IQ actually measures has been the subject of much debate.

Livingstone (1994) suggests that there are three main measures of educational performance. These are participation, achievement and attitudinal effects. Participation can measure the proportion of a population involved in education, the average school leaving age, the number of people who attended secondary school, the proportion who reached a senior level at school, or the proportion of a population who have attended a tertiary education institution. Age specific attendance rates are commonly used in international comparisons of educational performance (e.g. OECD 1992). Using such measures can be useful if there is an undeveloped system of formal credentials. Their use also reflects a view that education is part of a linear life cycle, with formal education completed early in one's life.

Achievement is seen as a measure of the knowledge and skills people have. The measure is commonly some credential or paper qualification, which certifies that a person has passed an examination or test of skills. This is often seen as a relatively "objective" measure. Achievement could also potentially be based on some secondary measure such as occupation or possibly income.

According to Livingstone, attitudinal effects of education can be seen as the "attitudes and values acquired by individual students and displayed in later life" (p. 3). He suggests these include factors such as motivation, self-discipline, reliability, willingness to accept responsibility and, increasingly, entrepreneurial flair. He goes on to note that these traits are commonly looked for by potential employers, but for a variety of reasons are rarely recorded in a systematic way. Some writers have suggested that employers often use formal credentials as a signal of attitudes rather than actual skills. For example, Peck (1996: 33) provides a summary of a school of thought that suggests "those willing to conform to educational authority may also be amenable to workplace authority." 
Some attitudes can be seen as part of "cultural capital". The concept of cultural capital was developed by Bourdieu and Passerson (1977). There has been much interest amongst educationalists in the links between cultural capital, class, ethnicity, educational outcomes and inequality (e.g. Nash and Harker 1992). Kalmijn notes that cultural status or resources can cover a wide range of values and behaviours, "such as child-rearing values, political attitudes, cultural literacy, taste in art and music, and styles of speech" (Kalmijn 1994: 426). Nash and Harker (1992: 6) also discuss "preferences for textual and broadcast media" as an important aspect of cultural capital. Kalmijn argues that cultural resources can be gained in the home, in educational institutions and from peer groups. Although cultural capital can be absorbed from a wide variety of sources, Kalmijn has argued that formal education provides an effective signal of cultural capital. A number of researchers (e.g. DiMaggio and Mohr 1985, Nash and Harker 1992) argue that "cultural capital" itself has a major influence on educational outcomes. DiMaggio and Mohr argue that if a person is well endowed with cultural capital they will have more opportunities for special help from teachers and "other gatekeepers" as well as better access to situations in which education is valued and where information about educational opportunities is available. They go on to argue that cultural capital is important in building social networks that will be helpful for educational, marital and occupational opportunities. Although researchers have developed measures of cultural capital, these require specialist surveys. The concept of "cultural capital", as well as "human capital", is revisited in Chapter eleven.

Linked to the concept of "networking" Bullard et al (1995) suggest that there are both 'hard' and 'soft' skills. Hard skills are "observable psychomotor and cognitive skills". These are the skills that tend to be measured by formal education. The researchers suggest that soft skills are "those process, cognitive and affective skills that are becoming more important in the new paradigm"(p. 14). Hard skills involve technical knowledge while soft skills "are the process skills which enable people to cope with and adapt to change uncertainty and working in teams and networks".

Increasingly, there is interest in literacy as an objective, but non-credentialised, measure of basic underlying skills. In New Zealand, there has been a particular interest recently in 
measuring the level of literacy amongst adults (Ministry of Education 1997). The Ministry define literacy as (p. 1):

Using printed and written information to function in society, to achieve one's goals and to develop one's knowledge and potential.

There is clearly a strong, but not perfect, relationship between formal education and literacy. This relationship is explored in more detail in chapter seven. Reading and writing skills can be important in finding a job, even if the particular job is low skilled. For example, Caspi et al (1998) note that without basic reading skills finding a job is very difficult through not being able to read job advertisements or filling out applications. Of direct relevance to this research, the actual census collection process is a form of literacy test.

This research uses formal educational credentials obtained from census data as a proxy for skills. Practical problems in using this data source are discussed in various chapters. There are, however, wider problems when using formal education as a measure of skills. First, it is often not clear whether the person continues, over time, to retain the skills the credential is signalling. Related to this, newly acquired qualifications may signal a very different set of skills than qualifications obtained many years ago. This problem is likely to be reduced if a person has participated in formal or informal industry based training since obtaining their qualification. Second, a qualification can be very broad and cover a wide range of skills, which may or may not be in demand. For example, a university degree may be in law, science, arts or perhaps architecture, and even within specific degrees particular subjects may be in greater or lesser demand. Third, the qualifications gained from one set of institutions may be seen by employers as being of superior quality to those gained in another set. Fourth, skills obtained on the job are often not counted in these formal qualifications. Fifth, there have been ideas put forward that some skills, both formal and informal, are unrecognised or undervalued by society. For example, Rose et al (1994) argue that feminist researchers have brought this to the fore, both for skills developed undertaking unpaid work and skills utilised in traditionally female occupations such as nursing, However, they suggest that it is not only an issue facing women. The 
researchers review studies that indicate that work that was skilled in terms of job content was not perceived, graded or rewarded as skilled work. This potential "undervaluation" of skill has been the foundation of pay equity arguments. The terms "social construction" or "cultural construction" of skills have also been used when discussing issues of comparable worth and undervaluation of skills (Steinberg 1990).

However, this view of unrecognising or undervaluation of skills is disputed by neoclassical economists. They argue that in a perfectly operating labour market, the price of labour would provide a clear indicator of skill. People are theoretically paid the value of their marginal labour productivity. This, in turn, relates to the skills they bring to a job. However, even if this was correct, the primary data source for this research, the census, does not provide an adequate measure of earnings from paid work. In addition, if a person was not in paid work then it would not be possible to assess his/her skill level.

A final problem with using census education data is that due to the dramatically changing participation rates in senior school and tertiary education over time there are strong cohort effects in educational qualifications. This will tend to disguise the actual distribution of particular skills in society. For example, there will be many people in the older age groups, and in particular women, who have no formal qualifications. However, through some combination of natural ability and learning through life experiences some of these people are more skilled in many aspects of work and life than younger people who do have formal qualifications.

\section{Census questions on highest level of education}

Using the New Zealand census to measure formal education is not without its own particular set of problems.

A question on educational qualifications was first included in the 1966 census. It was repeated in 1971 but not in 1976 (Statistics New Zealand 1993b). Questions were reintroduced in 1981, but there have been a number of changes in the question/s in the census between 1981 and 1996. In part, the changes in questions have been prompted by 
a rapidly changing education and qualifications system. These changes make detailed comparisons of educational attainment over time very difficult.

The changes in questions mean that for this research qualifications could potentially be amalgamated into four groups. The measure is for highest qualification attained, and are:

- no formal qualifications/still at school

- school qualification

- other tertiary

- university qualification

While the group "still at school" is included it is generally of little relevance to the primeage group who are the main subject of this research. Other tertiary covers a wide range of polytechnic, college of education and apprenticeship type training including Technicians Certificate/New Zealand Certificate or Diploma, Teachers/Nurses Certificate/Diploma, and Trade or Advanced Trade Certificate. University covers Post Graduates Degree, Bachelors Degree, and Under Graduate Certificate/Diploma. However, even the difference between polytechnic and university qualifications is blurring.

However, given the blurring between polytechnics and universities, in much of the research I use the grouping

- no formal qualifications/still at school

- school qualification

- other tertiary

- degree or higher qualifications

While the four suggested categories appear to allow comparisons over time, in fact, the data in the group "other tertiary" was problematic in 1991. In 1991, the "other tertiary" category suddenly became a very large grouping. It appears that during coding of census data in this particular year the category became a repository for short access courses, two- 
week computer skills courses and other short formal and informal qualifications. Therefore, when time comparisons are made two methods are used. The first way is to simply compare data between 1986 and 1996. The other way is to combine the other tertiary and school qualifications in all three censuses. 


\section{Chapter 3}

\section{Prime-aged people, families, households and geographic communities: Concepts, definitions and measures}

\section{Introduction}

In this chapter I define prime-age and explore definitions and measures of families, households and geographic communities.

\section{Prime-aged people}

Age is a key variable in many types of social science analysis, including those looking at work patterns. However, in order to simplify the analysis most researchers use broad age groups.

The idea of a "prime age" for participation in paid work is not a static measure with many factors driving change. These include an extended period of education for most people in their early years, longer life expectancy, changes in types of work that allow a longer "working life", and changes in government and employers policies towards support in retirement.

The Department of Statistics (1993) note that in the 30 years to 1981 men aged 25-54 years had the highest participation rates in paid work. However, it is problematic choosing a lower and upper boundary for a prime working age simply from paid work 
participation rates in official statistics. Such statistics may reflect demand patterns in the labour market, rather than supply. For instance, it may be that one group want to be actively involved in paid work, but as a group face barriers. For example, although the participation rates for men 55-59 age group are lower than those in the previous 5-year age grouping, a significant proportion of these men may want to be in paid work but are unable to find it.

Given the long term trend to longer life expectancy and the rising age at which government superannuation will be paid, as well as the relatively high paid work participation rates in the 55-59 age groups, I decided to have the upper limit for the prime age working group set at 59. The bottom age limit was set at 25 primarily based on education participation rates, paid work participation rates, and because the average age of marriage for both men and women was above 24 (Davey 1998a).

\section{Families}

In this research the changing work patterns of families, and in particular heterosexual couple families, is of prime interest. However defining families is problematic. Perhaps the broadest definition of family could be of one generation nurturing the next generation. In a New Zealand context, Hyman (1995: 120) argues that an "appreciation (worship?) of the family is confined in government philosophy to the nuclear, two parents and children, family." Yet, while most New Zealand researchers are conscious of the diversity among families and family arrangements certain types of families, such as same-sex couples, are often "invisible" in policy analysis and in public debates. Cairns (1991) has suggested that members of extended families are also often overlooked, and there have also been criticisms that Maori concepts of family, such as whanau and hapu have tended to be ignored when discussing families.

According to Maxwell (1989), the family has often been thought of as a biological unit in which kinship is important. An important aspect of kinship is that it is not spatially constrained. Family members can be spread across various households, or even countries 
yet still be part of a family. However, Maxwell suggests that the family is increasingly becoming a social construction. As part of this change there is now debate about whether fatherhood should be primarily defined biologically or socially (Sarre 1996).

The family has also often been defined as a religious or legal institution. In Western society legal marriage has been seen, and is often still seen, as the key base unit of the family. One view of marriage is that it is an institution that ties men to children. However, there are other views about the role of legal marriage, including that it is a primarily a patriarchal institution, with a prime aim of keeping women economically and socially dependent on men.

In some countries there is still much focus on legal marriage. In particular, in the U.S. research tends to focus only on legally married couples. This is in contrast to the Nordic countries where de facto relationships are seen as a key group within couple relationships.

Language is also important when discussing families where there is only one childrearing parent present. This type of discussion is often based on ideology with strong feelings about family change. For example, the term "fatherless families" has been used recently by some groups when promoting the idea of shifting back to living in traditional families (e.g. Blankenhorn 1996). With a more sympathetic view towards differing family types, Duncan and Edwards (1997: 30) use the term "lone mothers" for "all mothers bringing up children without a resident partner. However, while accepting the concept of various family types, actually defining them for the purposes of analysis presents major difficulties. This includes, at times, the need for new terms. Carmichael (1995:1), in a review of the rise in consensual partnering, notes there is a variety of definitions and terminology regarding non-married couples. These include "cohabitation, "unmarried cohabitation", "nonmarital cohabitation", "living together" and "living in a de facto relationship". He notes "definitions abound" but "most have at their core the notion of a heterosexual couple who are not formally married to one another living in a sexually intimate domestic relationship under the same roof". In this particular definition, and other discussions about families, a physical dwelling element, that of a household, is seen 
as important. However, a couple may be in a long-term sexual relationship but not living together. Examples include young people who each live with their own parents, and older single people who retain their own houses despite forming a couple.

While a sexual relationship is seen as a key part of a definition of couples (although for various reasons is virtually never a question in official surveys), another key part is some notion of a "time" commitment. Someone living for one night with another person is generally not seen as a couple. This is especially relevant to defacto relationships where there may be no public or formally recorded commitment to each other. In a discussion about married couples, Farkas and England explicitly raise the question of "time" (1986). They argue that the formation of such families involves an expectation of a long-term contract, even if there is the possibility that the couple will separate. Within this, they suggest that families are units in which ongoing bargaining takes place about various of aspects of life including roles in paid and unpaid work.

If marriage were a spot market, one would simply leave the minute one was displeased and could attract a more promising partner. Thus there would be only limited occasions for bargaining. On the other hand, if marriage were a contingent-claims contract, almost all bargaining would occur "up front", when the contract was first negotiated. Later negotiations would concentrate on issues of interpretation and enforcement. However, because marriage is an implicit contract, bargaining and negotiation is a constant feature, typically conducted with a combination of exhortation and offers of exchange (p. 51).

They go onto to note (P. 70):

The term "implicit contract" refers to a relationship in which there is no formal contract, but in which partners stay together because of the informal incentives provided by such things as the desire to benefit from relationship-specific investments made early in the relationship.

There are contemporary examples of couples where pre-nuptial contracts are signed either before a formal marriage or on setting up a defacto relationship.

Bargaining is sometimes not successful. If people are able to dissolve a relationship, such as through divorce, and particularly if the couple have children, then new definitions of 
families are needed. Concepts such as blended families, non-custodial parenting, step mothers and step fathers and even step grandparents all become part of wider family definitions. In the past, terms such as widowhood also reflected a previous living arrangement.

Financial transfers and support (including emotional support) for other members of a group are also seen as an important aspect of defining families. However, there is the potential for people to be living together as a family but with no explicit financial or emotional transfers, or family members could be living apart and there is a high level of such transfers. At times, social policy assumptions are made about transfers within families that might not reflect a universal reality. An example is the government policy in the area of student allowances where, until the age of 25, income is assessed on the basis of parental income even if the students do not live with their parent(s). Such definitions are difficult to operationalise, partly because questions about money transfers are intrusive while measuring emotional transfers poses major methodological problems.

Finally, official definitions of families and methodologies for collecting data do change. For example, in the U.S. the concept of "head of household" was changed after much debate, and in New Zealand, in 1996, gay families could be identified for the first time.

\section{The census family definition}

Statistics New Zealand (1995b: 9) use the term "family nucleus" which they see as being more specific than the term "family". They note "a family nucleus consists of two or more persons who are members of the same household, and who comprise either a couple, at least one parent role/child relationship, or both."

Concepts of families are restricted to those actually or usually resident in the same households for practical data collection and analysis reasons. This rules out identifying families such as joint custody couples where children may spend alternative weeks with each parent. 
A parent/child relationship is a key factor in defining some family types. Being a dependent child depends on a number of factors (ibid):

All persons in a household under the age of 18 who are not employed full-time are classified as a child in a family nucleus in that household, except when they have a partner or child (or children) of their own in the household or do not usually reside with the members of that household.

Statistics New Zealand have two further important definitions, that of extended families and economic families. They note that:

An extended family is a group of related persons who usually reside together and consist of:

- a family nucleus and one or more related persons; or

- two or more related family nuclei, with or without other related persons (p. 10).

Groups of siblings do not form family nuclei and are therefore not included in the family type classification. Working out who is related is also potentially problematic. Statistics New Zealand state that (p. 11):

Related means that persons have a familial relationship. In the classifications, "related persons" and "other persons who are related" are persons who have a familial relationship to each other or to the family nucleus or extended family in the household, depending on the category. In a twofamily household, families are "related" if at least one person in one family has a familial relationship to at least one person in the other family. Otherwise the families are "unrelated."

They go on to note "[a] familial relationship is a relationship by blood, marriage (registered or de facto) or adoption." It is possible some people are included in this who are not actually related, such as where a person is well known to the family and called an "aunt" or an "uncle".

Of particular interest in this research is the definition of couples. There are two ways of defining couples in the census. The first is via the marital status question. People can define themselves as being in a couple, either married or, since 1986, as being in a defacto relationship. They can be living in either private or non-private dwellings and 
these people do not have to be living with their partner. Some may even claim to be in a couple relationship when their potential partner would dispute this.

Statistics New Zealand note (pp. 23-24) that:

Marital status is a person's reported status with respect to the marriage laws or customs of the country. There are two types of marital status: legal marital status and social marital status.

Legal marital status is a person's reported status with respect to registered marriage. A person's legal marital status can be legally married for the first time, remarried, separated, divorced, widowed, or never married.

Social marital status is a person's reported status with respect to partnership. A person's social marital status can be partnered or non-partnered.

While some data from the marital status question is presented, this data source is not the main one used in this research. Instead, the following derived definition is used (p. 11):

A couple consists of two persons who usually reside together and are legally married, or two persons who are in a consensual union. There are three types of couples: opposite-sex, male and female.

Statistics New Zealand staff derives this type of couple, using both the personal questionnaire and the household form. 1996 was the first year that same-sex couples could be identified in census output. Within this definition is the concept of usual residence. On census night some people are not located in the home they normally live in. Examples are salespeople staying in motels, workers on fishing boats, and people who are temporarily in hospital. For couples, or even some wider family groupings, it is possible for all family members to be absent from the dwelling on census night. These families are unlikely to be derived by Statistics New Zealand. In addition, as shown in the following set of definitions, there are some boundary problems in areas such as children living in separated families (pg 12): 
A person's usual residence is the address of the dwelling or place where the person considers himself or herself to live except in the specific cases listed below:

1. A person from another country who has lived, or intends to live, in New Zealand for 12 months or more usually resides at his or her address in New Zealand (as in external migration).

2. People who board at another residence to attend primary or secondary school, and return to their parent's (s') or guardian's (s') homes for holidays, usually reside at the address of their parent(s) or guardian(s). Post-secondary students usually reside at the address where they live while studying.

3. People who are in a rest home, hospital, prison or other institution, usually reside where they consider themselves to live.

4. A person whose home is on any ship, boat or vessel permanently located in any harbour shall be deemed to usually reside at the wharf or landing place (or main wharf or landing place) of the harbour.

5. People who spend time residing at more than one residence usually reside where they consider themselves to live. Children in joint custody usually reside at the place where they spend more nights, or, if they spend equal amounts of time at each residence, they usually reside at the place where they are at the time of the survey.

Statistics New Zealand also note that those with no fixed abode have no usual residence. Finally, if a person spends an equal amount of time at many places, or does not fit the guidelines, they are seen as residing at the survey address. In this research, where possible those people temporarily absent from their dwelling on census night have been coded back into family settings. However, in doing so there are limits on being able to analyse the characteristics of the absent people as only limited data is collected on absent family members. In addition, Statistics New Zealand staff cannot adequately derive families living in some types of non-private dwelling.

Table 3 indicates that in the 1996 census people tended not to record persons absent from the dwelling on census night. Theoretically, the number of absentees and those living elsewhere should be the same. 
Table 3 - Numbers of temporary absentees and those living elsewhere in New Zealand on census night, 1996

\begin{tabular}{lc}
\hline & Number \\
\hline Absentees & 105,448 \\
Living elsewhere in NZ & 136,826 \\
\hline \multicolumn{2}{l}{ Source: Derived from the Census of Population and Dwellings, Statistics New Zealand. }
\end{tabular}

Finally, definitions such as age and ethnicity becomes more complex when dealing with a unit of two or more people. While ethnicity is at times brought into the analysis of families in this research, for reasons that are explored in more depth in the following chapter, ethnicity is not a key variable in the time series aspects of this research.

Age is a key variable in selecting suitable families to analyse. As already discussed, in this research I am focussing on people aged 25-59. One approach would be to have one target person in a family in this age group. For people living alone, or for sole parent families this approach is suitable as only one adult is counted. However, for couples the other partner could be outside this age group. At times within this research, couples with one partner outside the target age range are analysed. However another approach, and the one mainly used in this research, is that in couples both partners need to be within the target age group. A similar approach is used when analysing households.

\section{Households}

There is considerable overlap between households and families. However, using only the family definition does disguise some important relationships and excludes some groups. For instance, while many Maori children are living in sole parent families, a significant proportion are living in dwellings containing other related adults (Davey 1998b). As a further example, the Statistics New Zealand definition of families excludes flatting situations of unrelated people and people living alone. While families are of key interest in this research, in some chapters attention is also given to various other non-family household types. 
The Statistics New Zealand (1995) definition of a household is (p. 9):

A household is either one person who usually resides alone or two or more persons who usually reside together and share facilities (such as eating facilities, cooking facilities, bathroom and toilet facilities, a living area).

\section{Private and non-private dwellings}

Dwellings are divided into private and non-private. A private dwelling accommodates a person or a group of people, but is not available to the public. Included are houses, flats, and apartments; residences attached to a business or institution; baches, cribs and huts; garages; caravans, cabins and tents; vehicles; vessels; or any dwelling under construction. Non-private dwellings include hotels and motels, guest houses and boarding houses; hostels; public and private hospitals; homes for the elderly; educational, welfare, religious and charitable institutions; prisons and penal institutions; defence establishments; work camps, staff quarters; motor camps; and other communal dwellings.

In New Zealand and overseas it is common for researchers and collectors of official Statistics to exclude non-private private dwellings from any data collection and analysis. For example, in New Zealand the HLFS does not include people in non-private dwellings so official measures of unemployment do not cover people who are in prison. Jencks (1993) argues that there is a need to go beyond private dwellings to see the extent of a lack of paid work. With particular reference to the U.S., Jencks states that many of the people in prison would be unemployed or not in the labour force if they were set free. However, in some non-private dwellings such as hospitals and prisons specialist official data collections are developed. The census of population and dwellings does include nonprivate dwellings, although inevitably some people living in some informal non-private dwellings, such as park benches, will be missed from this collection.

However, as already discussed in the section on usual residence, most people in short term hospital stays or in prison will record their usual residence as some other dwelling. This other dwelling could still be another non-private dwelling, such as a boarding house. 


\section{The impact of choosing various measures of living arrangement}

If simply studying the behaviour of individuals without any regard to status of other family or household members then researchers can use marital status data. Generally published data using marital status covers people whether they are living in a public or private dwelling. In addition, in the situation of couples defined by marital status, people could be in a couple, and even legally married, but not usually living in the same household. There are also households with absent members on a short-term basis, such as a partner of a couple who was travelling on census night. But there are longer-term examples. These include couples where one partner is in prison, a young person living at home with their parents but in a long-term couple relationship, or older couples who mostly live in their own dwellings. It is possible to have different total of men and women in couples when using marital status. In contrast, the total of men and women living in couples in the same households as derived by Statistics New Zealand has to be same.

An issue when analysing derived couples living in the same household is whether to include those absent on census night. Table 4 shows that the level of absence changes by living arrangements, but for couples, in particular, men were more likely to be absent.

Table 4 - Percentage of prime-aged men and women who were absent on census night by living arrangement, 1996

\begin{tabular}{lrr}
\hline & Men & Women \\
\hline Couple in Couple Only & 3.0 & 1.9 \\
Parent in Couple Family & 3.8 & 1.7 \\
Sole Parent & 2.6 & 1.3 \\
Adult Child in Family & 7.6 & 8.5 \\
Other Family Relationship & 8.1 & 6.7 \\
Living with Family or Families, not Related & 7.1 & 8.0 \\
Living Alone & 0.2 & 0.3 \\
Living in a Non-Family Household & 5.8 & 5.2 \\
N= & 29,907 & 17,532 \\
\hline Source: Derived from the Census of Population and Dwellings, Statistics New Zealand.
\end{tabular}

The following provides examples of percentages of prime-aged men living in couples in 1996 using a range of measures. This includes the issue of how to treat those people who did not answer a particular question. This non-response issue is discussed in more detail 
in the following chapter. The example shows that, depending on the purposes the statistics were being used for, different stories could be told.

1. 75 percent of prime-aged men were in a couple in 1996 if the marital status data is used and the denominator is usually resident population specifying marital status (that is excluding the not specified group from the denominator). These couples are not necessarily cohabiting with their partner.

2. This reduces to 70 percent if the not specified group are included in the denominator.

3. This further declines to 68 percent if cohabiting married or defacto couple households, excluding absent partners, are used and the not specified group are excluded from the denominator. These data automatically exclude non-private dwellings.

4. If absent partners are then included, the percentage in point three rises to 70 .

5. When this is further recalculated to include the not specified group in the denominator the percentage declines to 66 .

Each definition has its strengths and weaknesses. However, except where specifically noted I exclude the non-specified group from any calculations. In addition, I primarily focus on household data rather than marital status data.

\section{Geographic areas}

For geographers "space" has always mattered in research. In social policy discussions a geographic dimension is now often considered to be of importance such as when considering the distribution of paid work, income, health and overall wellbeing (e.g. Crampton et al 1997).

In parallel, in policy debates there is an interest in "communities" (e.g. Department of Internal Affairs 1997). Various types of "communities" and geographic areas sometimes overlap, and while I am primarily interested in geographic areas some of the other types are important. 
As an example, Internal Affairs discuss "social enclaves". These include retirement villages, religious communities, and gangs. Some of these types of enclaves, and potential social policy issues associated with them are discussed further in chapter thirteen.

In this research, while I am interested in hours of paid work undertaken by prime-aged people, my focus is on where people usually live rather than where they work, or their often much larger community of interest. In the geographic analysis, I continue to use data for usual residence rather than a person's census night location. However, once a decision has been made to analyse residential areas a further decision needs to be made as to the size and nature of the areas studied. Some recent overseas research has argued that a geographic analysis should focus down onto individual streets (Grannis 1998). For example, he argues that racial segregation by streets is more important than a wider spatial analysis.

In New Zealand, the smallest geographic area used by Statistics New Zealand is the meshblock. A New Zealand wide system of meshblocks was established in 1976, although Statistics New Zealand note the term was used in the 1916 census (Department of Statistics 1992). According to the Department, in the early days the meshblocks followed physical boundaries, such as road patterns, rivers and other geographical features. While this still occurs meshblocks are increasingly aligned to legally defined cadastral boundaries. This helped linking to administrative boundaries such as electoral districts.

While there are some advantages in using meshblocks in a geographic analysis there are also some disadvantages. First, the small number of people in each meshblock can present confidentiality problems, thereby limiting the analysis. Second, as meshblocks often represent only a couple of streets they may be too small to create "neighbourhood effects". However, most importantly, meshblocks have coded names that are not generally recognisable. 
The first aggregation of meshblocks are unit areas. There were 1,775 area units in 1996, and the 1986 and 1991 censuses were recoded to the 1996 boundaries. A key feature of unit areas is that they can easily be identified, as each area unit must be a single geographic entity with a unique name referring to a geographical feature. Having recognisable names assists policy makers and the general public locate and consider the characteristics of an area.

Area units must either define, or aggregate to define, territorial local authorities, urban areas and statistical areas. In some of these aggregations, a sense of "community" is sought with, for example, minor urban areas needing to provide five out of eight possible services such as a school or community centre (Department of Statistics 1992). In addition, area units of main or secondary urban areas generally coincide with suburbs or parts of suburbs that, for some people, will have some sense of "community", perhaps centred on a church or shopping centre. Unit areas can be further aggregated in a variety of ways, for example electoral districts and Social Welfare districts.

According to Statistics New Zealand while the maximum total population of an area unit is about 5,000 people area units vary in physical size and population. In 1992 the largest land area was Fiordland (8,400 sq kilometres) and the smallest Taitville in Wellington City (14.8 hectares). In terms of population the largest was Kawerau while some small areas (e.g. Dog Island) had no people living in them. The very small population size of some area units meant that an analysis of these units would provide some distorted results. Therefore, the very small units were amalgamated into a category "other".

The following criteria were used for placing small geographic areas in the "other" category. 1991 was used as a low point in overall employment. In this year, if there were less than 10 women or 10 men in the 25-59 age group who were gainfully employed in each area then the area unit was placed in an "other" group. The 1991 grouping was then applied to 1986 and 1996 data. However, in these years, if an area unit included in 1991 had less than 6 women or 6 men gainfully employed in the 25-59 age group, then, this 
area was also moved to the "other" category. This left a total of 1,636 area units that were analysed.

Finally, in my research I am interested in whether unit areas were work-rich or workpoor. In doing so I focus on the amount of paid work undertaken by the people living in a particular area. I do not analyse the amount of work carried out in businesses in that area. Many people live in one area and work in another. As will be discussed in subsequent chapters, it is actually possible for an area to be work-rich on one measure and work-poor on another.

There are various possible measures for determining the residential workstatus of a geographic area. One measure of employment in an area unit might be the percentage of prime-age people who are unemployed and seeking work. As discussed in Chapter two, using an "unemployed and seeking work" classification is problematic because this can be defined narrowly through setting strict criteria for determining how much a person has actively looked for a job. In addition, even with a wide definition of ways of seeking work this measure will still remove those "discouraged" job seekers not in the labour force who, in some communities, represent a significant group. For example, Morrison (1997a) found that in the Wellington metropolitan area there was not only a widening gap in inequality between 1981 and 1991 when rates of unemployment were used, but the inequality increased when those not in the labour force were included in the analysis. However, there are also some problems of including people who are not in the labour force. For example, an area unit may contain a large educational institution where many prime-age people are studying, and who may, therefore, not be in the labour force. This type of work-poor geographic area will be quite different to one where people are not in the labour force because they are discouraged job seekers. This particular issue is explored in the data analysis section.

In this study a new approach was taken. First, the hours of paid work were added together for every prime-age person in each unit area. This measure of total hours of paid work in 
each unit was then divided by the total population, whether in paid work or not, in the target age group in each area. ${ }^{17}$

This gave an average of hours of involvement in paid work per person per week across the total prime-age population. This calculation was carried out using data from the 1986, 1991 and 1996 censuses to provide a time series. This type of measure controls for differences in population in each area unit, although there are still some problems with a potentially changing age distribution within the prime-age group within each area. In choosing this average hours measure, the relationship between the percentage of the prime-age population in each area not in paid work and the calculated average hours in paid work was explored. In 1986, a regression analysis had an $r^{2}$ of 0.58 , but by 1996 the $\mathrm{r}^{2}$ had increased to 0.80 .

In undertaking this calculation, the nature of the work carried out in an area and the timing of the survey may have an impact on some area units. For example, long hours are worked in many agricultural, fisheries and tourism occupations over the period the census is carried out and people in agricultural and tourism occupations will tend to be concentrated in particular geographic areas. At other times of the year the hours may be considerably lower.

\footnotetext{
${ }^{17}$ This total population includes those who did not specify their hours. Unfortunately, when I gathered the initial data I did not realise the full implications of non-response rates in the 1996 census. I discuss this issue further in the following chapter.
} 


\section{Chapter 4}

\section{Using census data and other technical issues}

\section{Time period of the study}

While the primary focus of the research is on the 1980s and 1990s, ideally I would have liked this research to cover a relatively long time period, such as from the first World War through to the late 1990s. This would have provided long-term trends over periods of major social and economic change, including times of recession and strong economic growth. This would allow a better judgement to be made as to whether any recent trends identified are simply part of longer-term cycles, or whether "paradigm shifts" have truly occurred.

All research is constrained by the amount of research time available, as well as the cost and availability of suitable data. In research that uses time series, both the research time involvement and cost are heavily influenced by the availability of comparable data series for the key variables. Some of the data I was interested in were not available over a long time period. For example, reliable data on defacto couples are not available prior to 1986. While estimates can sometimes be made of the data which are unavailable, usually based on secondary data sources, this process is often very time consuming.

Of equal importance, at the time I gathered the data, the electronic, and unit record based, SUPERCROSS census databases on which I base most of this research were only available for 1986, 1991 and 1996. In my original proposal, I had wanted to include 1981 data as this was a census before the major period of restructuring in New Zealand. 
However, I had to adapt the research once I found that this was not possible. ${ }^{18}$ While some of the data prior to 1986 could have been accessed by purchasing special datasets from Statistics New Zealand, the cost would have been prohibitive. However, some of the long-term series I required, such as overall employment trends, have been published and I accessed these when needed.

\section{The census as a primary data source}

There is no ideal data source for research into changes in work, families, households and communities While the census of population and dwellings has many strengths when undertaking such research there are also major weaknesses. A key strength is that the census, as its name would suggest, is designed to have a full coverage of the population. However, in reality it is a survey with a very high level of response. The high level of coverage is due to a range of factors, including a statutory obligation to complete the census. The wide coverage provides an ability to analyse small sub-populations nationally, as well sub-populations even at a level of small geographic areas. Second, the personal questionnaire has a considerable level of detail on people's lives and, through having a dwelling questionnaire, these personal data can be aggregated to a family and household level. A further strength is that it is a survey that is regularly repeated (five yearly), enabling time series to be built up. However, changing questions or definitions are a major limiting factor. Other strengths are that researchers can replicate (and potentially challenge) any analysis as well as carry out further analysis using the same data source. A final strength is that, depending on access arrangements, the cost of the data is relatively low.

However, there are problems in using census data for this type of research. A first one is that like all written surveys there are problems with people who have limited literacy. This is despite Statistics New Zealand enumerators being available to assist people in filling out the forms. Potentially excluding people with low literacy, and generally low

\footnotetext{
${ }^{18}$ In fact, my original agreement with Statistics New Zealand was for access to unit record data from the 1981 census and it was only when I commenced my data processing in the datalab that it became clear that 1981 data would not be available.
} 
levels of education, is particularly problematic when the effects of education on people's lives is a core part of the research. A second problem is that although the survey is regularly repeated, in times of rapid economic and social change major changes can occur in short periods. Where the census occurs within an economic and employment cycle is discussed in subsequent chapters. There are also specific problems with particular questions. An example is that income data (gathered on a yearly basis and covering all forms of income) is not directly linked to paid work (based on the previous week). Of direct relevance to my research, the time of the year a census takes place can also influence results. In New Zealand the census takes place during March. This is a time of high employment, and long hours of paid work, for many seasonal workers in areas such as agriculture and summer based tourism.

Further problems with the census, which are common to most large scale quantitative surveys, are that: most of the questions are of the yes/no or limited choice type allowing little in-depth analysis; people are steered down particular routes when filling out the questionnaires (for example only people not in paid work are asked if they are seeking work whereas employed people who are perhaps working shorter hours may also be actively seeking other work); and that, as already discussed, narrow definitions of units of analysis, such as families do not always accurately reflect the actual way people live their lives.

A further major weakness of census data is that it is cross-sectional. In recent years, there has been much criticism of cross-sectional data and an emphasis on the findings from longitudinal datasets. Some of this longitudinal research indicates a relatively high level of mobility between various states of work, income and living arrangements. However, other research does indicate that particular time periods in a person's life cycle may be important, such as when children are very young, so large scale cross-sectional data can be valuable in assessing the characteristics of people at this stage. For example, if parents 
are in poverty while they have young children this might have a long-term impact on the children even if the parents then become upwardly mobile. ${ }^{19}$

Recognising the strengths of longitudinal data and research based on such data, in the meta-analysis I draw on such research. The studies I draw on are primarily based on U.S. and, to a lesser degree, U.K. longitudinal datasets. However, there are always some problems in applying the results of studies in one country to another. In addition, longitudinal studies are not without their faults.

Key problems with longitudinal datasets are that they are often relatively small and so present problems when dealing with sub-populations, they usually have a significant respondent dropout rate (although often not emphasised by the researchers using them) and they may deal with an unusual cohort and an unusual time period. For example, while the Christchurch Health and Development study has provided some very useful insights into New Zealand society, it does not have a representative sample of Maori and Pacific Island groups and the children were born into the "baby boom" families who were a quite unusual group in New Zealand's history. Other cohorts in different time periods (and economic cycles) may make quite different decisions.

\section{Census coverage}

\section{Undercounts}

Statistics New Zealand endeavours to collect information on all people in New Zealand on census night. This includes tourists from overseas countries. However, in this research I only analyse New Zealand residents.

A post-enumeration survey carried out by Statistics New Zealand following the 1996 census showed that, over all age groups, males may have been undercounted by 1.4 percent and females by 1.0 percent. This is a small undercount, but it could be that a

\footnotetext{
${ }^{19}$ Naturally, a longitudinal study is needed to find this out.
} 
particularly important group of people are undercounted. If a particular group are consistently undercounted in each census this may not alter trends (although we then have little knowledge about this group). But, if for some reason, one group suddenly declines to fill in the census this might distort trends. For instance, if people receiving welfare transfers come to believe that the data may be being matched with social welfare files this is likely to discourage some of them from completing their form, or alternatively putting in incorrect information. ${ }^{20}$

\section{Not-specified}

Even if people are counted in the census their actual responses can still be inadequate. For example, in many of the actual census responses the "not specified" category is an important one. This was particularly the situation in 1996. The reasons for the high notspecified rates in the 1996 census are not entirely clear but a crowded census form seems to have been one contributing factor. There was a tendency for the not-specified category to increase towards the end of the questionnaire.

Table 5 focuses on labour force status data to show the impact of the not-specified category in both 1991 and 1996. It shows that the not-specified group was significantly larger in 1996. For example, in 1996 over three percent of males in most age groups did not specify their labour force status. Given both the size of this group in 1996, and that it has grown considerably since 1991 this presents researchers with a problem as to how to calculate time series.

\footnotetext{
${ }^{20}$ It is generally difficult to judge if any census information is incorrect. For instance, a 15 year olds putting $\$ 100,000$ or more as their income category is likely in most cases to be putting incorrect information, but it is possible that some do exist. It is less likely that people noting down Martian as their nationality are putting their correct birthplace.
} 
Table 5 - Percentage of people not specifying labour force status, 1991 and 1996

\begin{tabular}{lrrrr}
\hline & Male & \multicolumn{3}{c}{ Female } \\
\hline & 1991 & 1996 & 1991 & 1996 \\
$15-17$ & 0.5 & 3.5 & 0.4 & 3.0 \\
$18-19$ & 0.7 & 3.8 & 0.7 & 3.4 \\
$20-24$ & 0.8 & 3.8 & 0.7 & 3.3 \\
$25-29$ & 0.9 & 3.7 & 0.6 & 3.0 \\
$30-34$ & 0.9 & 3.6 & 0.7 & 2.8 \\
$35-39$ & 0.8 & 3.4 & 0.7 & 2.9 \\
$40-44$ & 0.8 & 3.0 & 0.8 & 2.7 \\
$45-49$ & 0.8 & 2.9 & 0.7 & 2.5 \\
$50-54$ & 0.8 & 3.1 & 0.7 & 2.6 \\
$55-59$ & 0.8 & 3.0 & 0.6 & 2.6 \\
$60+$ & 0.4 & 3.1 & 0.1 & 2.6 \\
Total & 0.7 & 3.3 & 0.6 & 2.8 \\
\hline Source: Table derived from the census, Statistics New Zealand.
\end{tabular}

Source: Table derived from the census, Statistics New Zealand.

If the not specified category is left in the total population and the percentage of people in paid work is being calculated, then it is being assumed that those who did not specify were not in paid work. The impact of this assumption is illustrated in Table 6. The data in the table relates to a study carried out in New Zealand and which was widely reported in the media (Thomson 1999).

Amongst the many findings of the study by Thomson was that the long-term growth in full-time employment for women ( 20 or more hours in his study) had not only come to a halt between 1991 and 1996 but that there were some significant declines in some age groups. In his calculations Thomson included the not specified in his population denominator. ${ }^{21}$ Table 6 shows the effect of including and excluding the not-specified groups. In two age groups, 20-24 and 45-49 the apparent decline in overall employment rates turns into a gain. In some other age groups a strong decline in employment is substantially lessened.

\footnotetext{
${ }^{21}$ In 1996, the number of people who did not specify their hours of work was slightly higher than those who simply did not note their employment status.
} 
Table 6 - Percentage of women working full time (20 or more hours per week), 1991 and 1996

\begin{tabular}{lrrrrrr}
\hline & Excluding not specified & \multicolumn{5}{c}{ Including not-specified } \\
\hline & 1991 & 1996 & Change & 1991 & 1996 & Change \\
$15-19$ & 22.5 & 19.8 & -2.7 & 22.4 & 18.4 & -4.0 \\
$20-24$ & 52.6 & 53.3 & 0.7 & 52.3 & 49.7 & -2.6 \\
$25-29$ & 47.4 & 53.8 & 6.4 & 47.1 & 50.4 & 3.3 \\
$30-34$ & 42.2 & 46.2 & 4.0 & 41.9 & 43.5 & 1.6 \\
$35-39$ & 51.3 & 50.3 & -1.0 & 50.9 & 47.1 & -3.8 \\
$40-44$ & 60.9 & 60.0 & -0.9 & 60.5 & 56.3 & -4.2 \\
$45-49$ & 60.8 & 63.3 & 2.5 & 60.4 & 59.6 & -0.8 \\
$50-54$ & 51.9 & 56.7 & 4.8 & 51.5 & 53.3 & 1.8 \\
$55-59$ & 34.0 & 40.6 & 6.6 & 33.9 & 38.2 & 4.3 \\
$60-64$ & 11.0 & 16.3 & 5.3 & 11.0 & 15.3 & 4.3 \\
$65-69$ & 3.4 & 3.7 & 0.3 & 3.4 & 3.6 & 0.2 \\
\hline Source: Table derived from census data, Statistics New Zealand. & \multicolumn{7}{c}{}
\end{tabular}

To further assess the impact of the not specified category, the Table 7 shows the percentage of men and women who did not specify marital status in 1986 and 1996. It shows that the percentage increased substantially between 1986 and 1996, and that younger people were slightly less likely to specify their marital status.

Table 7 - Percentage of men and women who did not specify marital status, 1986 and 1996

\begin{tabular}{lrrrr}
\hline & Men & \multicolumn{3}{c}{ Women } \\
\hline & 1986 & 1996 & 1986 & 1996 \\
$25-29$ & 1.3 & 8.3 & 1.1 & 6.9 \\
$30-34$ & 1.3 & 6.9 & 1.1 & 6.0 \\
$35-39$ & 1.2 & 6.4 & 1.1 & 5.7 \\
$40-44$ & 1.3 & 5.9 & 1.1 & 5.6 \\
$45-49$ & 1.4 & 5.7 & 1.2 & 5.4 \\
$50-54$ & 1.5 & 6.0 & 1.3 & 5.6 \\
$55-59$ & 1.4 & 6.2 & 1.4 & 5.8 \\
\hline \multicolumn{4}{l}{ Source: Table derived from census data, Statistics New Zealand. }
\end{tabular}

Finally, Table 8 shows the effect of including and excluding the not specified category from a calculation of total averaged hours worked per person (whether employed or not) in New Zealand in 1996. It shows that not only is the average higher if the not specified group is excluded but an apparent decline in average hours between 1986 and 1996 turns into a gain. Given that I include the not specified group in my geographic analysis, my data for 1996 is likely to slightly understate the amount of work undertaken in communities in 1996. 
Table 8 - Total averaged hours of paid work for people 15 and older, 1986-1996

\begin{tabular}{lllr}
\hline \multicolumn{4}{c}{ Averaged hours per person } \\
\hline 1986 & 1991 & 1996 & $1996^{*}$ \\
25.7 & 21.8 & 25.0 & 26.5 \\
Source: Table derived from census data, Statistics New Zealand. \\
*excluding not specified in denominator
\end{tabular}

In examining unit record data in 1996, I also found that a non-response in the education question seemed to be associated with a non-response in other questions. In addition, it also appears that people who stated that they had no formal qualifications were overrepresented in the "not specified" responses in many other questions. ${ }^{22}$ Therefore, a first possible difference between those who are well qualified and those who are poorly qualified is that it is likely we know less about the lives of the latter group. This may be due to differences in attitude to surveys or may simply reflect the fact that well-educated people have the necessary skills to fill in a complex written questionnaire. It may also be that for well-qualified people, with satisfying jobs, and possibly good relationships, filling a census form is a positive experience. Filling in this form is likely to be a depressing experience for people who are economically and socially excluded. This is likely to affect both the quality and quantity of responses. Finally, people with low levels of education may tend to lead "non-standard" lives, which are difficult to categorise on a census form. This would suggest that there is an undercount of those people who are socially and economically disadvantaged.

However, while there did seem to be a propensity for some people to have a not specified response in many questions, non-responses were not always clustered. Therefore, when analysing a number of variables at the same time this increases the total of potential nonresponses to at least one question.

Except in the geographic analysis, in this research I normally exclude the not specified category from any calculations. This is also the standard practice of Statistics New Zealand when they publish data series. Where this was not the method used, this is noted.

\footnotetext{
${ }^{22}$ No formal statistical testing was undertaken of these observed relationships.
} 
Clearly, the relatively high rate of not specified means that some caution needs to be taken when reporting any minor changes in time series data. An apparent small change in direction of a trend may not reflect reality but may simply reflect poor questionnaire design. This is partly why I have tried to draw on a wide range of research in my metaanalysis section to see if the trends I identify are supported by other research.

\section{Ethnicity}

Ethnicity is a key question in the census. According to Statistics New Zealand (1993b: 20) identifying Maori is important for electoral reasons, in defining Iwi, identifying Maori communities, and in terms of Treaty of Waitangi obligations. They go on to state that there is a need to ask "people whether they identify as Maori, the Iwi they belong to and, for electoral purposes, whether they are descendants of Maori."

While ethnicity is an important variable when studying changes in work, families and households, there are major definitional problems when using census data. This problem particularly affects the group Maori, but this has a flow-on effect to other ethnic counts. These definitional problems not only affect counts at a particular census, but also create particular difficulties in making time comparisons. In recent censuses there have been larger than expected changes in the number of Maori in the population. The changes are complex and are the subject of on-going investigation (e.g. Maori Statistics Forum 1997). A key change between 1991 and 1996 was that the number of people identifying themselves as belonging only to the Maori ethnic group fell by 50,000, or 16 percent, while the number identifying themselves as Maori as well as one or more ethnic groups rose by 88,000 or 20 percent. This was a period where the non-Maori population only increased by 5 percent. The differences in these numbers suggest that comparisons of ethnic data over the period studied will be subject to a high level of error.

For individuals, New Zealand research shows that there are some major differences between the characteristics of those who define themselves as being solely from the Maori ethnic group and those who have more than one ethnic affiliation (Chapple and 
Rea 1998, Chapple 2000). Chapple shows that there are significant differences between sole Maori and mixed Maori in terms of employment, with sole Maori considerably more disadvantaged than mixed Maori. There are also major issues within some ethnic groups in relation to where a person was born. For instance, there are differences between the overall characteristics of New Zealand born Pacific Island people and those who are immigrants (Fletcher 1995).

In this research, I have not attempted to develop ethnic based time series for individuals. Instead, where I consider ethnicity for individuals I only use 1996 data. In light of the research by Chapple and Rea, where I do refer to ethnicity and where I have the necessary data, I use the following categories, sole Maori, mixed Maori group, Pacific Island ethnic group, Asian ethnic group and a residual, "other". The mixed Maori group are those Maori who state that they have two or more ethnic affiliations, the Pacific Island group includes a wide range of communities, including those for Fijian, Samoan and Tongan groups, and the Asian ethnic group includes a wide range of people including those from the Chinese, Korean and Thai ethnic groups. The "other" group are primarily from European backgrounds.

As already discussed in Chapter three, researchers analysing census data are well aware of the problems associated with defining families, but a further complication arises when adding ethnicity into the equation. This is particularly problematic with couples and extended families. In the example of couples, it is recognised that both partners may not be from the same ethnic group, and this may also be so for their children. This is even more problematic with households, which can contain many and often unrelated members. However, in order to reduce the complexity of analysis it is still common for researchers to define the ethnicity of the family or household by the ethnicity of one family member or household member.

In parallel as to how individuals are treated, Statistics New Zealand has historically classified families and households through prioritising ethnic groups, giving priority to non-Pakeha/European family members and special priority to Maori and Pacific Islands 
people. For example, where one partner is Maori and the other New Zealand European the family is classified as Maori. Similarly, where one partner is Maori and the other from a Pacific Islands group the family is classified as Maori. Other researchers, however, have defined the ethnicity of the family by the ethnicity of the male partner (Johnstone and Pool 1995). Jackson and Pool (1996) also note that defining the ethnicity of families with only one parent can also be problematic, particularly in families where the children identify with the ethnic group of the absent parent.

I have not attempted to define the ethnicity of families or households. Where I discuss ethnicity within couples, I consider the ethnicity of both partners separately. In this I do not consider sole Maori and mixed Maori as separate groups.

\section{Accessing census data}

This research was made possible through the generosity of Statistics New Zealand. Access to the data through conventional means would have been difficult and the cost would have been prohibitive. Statistics New Zealand therefore agreed to appoint me as a research affiliate and provide me with access to their newly developed data laboratory facility. There was no charge for the use of the data laboratory nor for access to census data for the years sought. However, normal charging applied for tabulations prepared by Statistics New Zealand.

There were a number of confidentiality provisions in place. This included signing an agreement on the 6th June, 1997, to abide by sections 37 and 37C of the Statistics Act 1975 and, in addition, signing a declaration of secrecy specified in Section 21 of the Act. During the actual data collection all output was checked by Statistics New Zealand staff.

In terms of actually accessing the data I used the program SUPERCROSS, a data extraction program developed specifically for Statistics New Zealand. The data was then transferred into excel spreadsheets which, once they were checked for any breaches of confidentiality by Statistics New Zealand staff, were transferred onto my own computer. 
In addition, I purchased three sets of specialist tables from Statistics New Zealand. All three requests involved complex definitional issues and cross-tabulations involving household, age, gender, education, and employment variables. 


\section{Part two}

\section{Changes in work, education, families, households and geographic communities: The driving forces and international trends}




\section{Chapter 5}

\section{Nature versus nurture - Why this debate is still important}

\section{Introduction}

Assumptions about the development of cognitive ability are important in this research. In addition, how gender-roles in paid work and family life are determined is also of importance. For example, making the assumption that intelligence and work roles are primarily genetically determined leads to the conclusion that a person's position in life is little affected by factors such as the type of family they live in, the type of neighbourhood, the quality of and access to education and training, and what social norms sanction. It then follows on that views about nature and nurture have implications for social policy. For instance, Herrnstein and Murray (1996) suggest that there are major limitations in the ability of policy makers to increase the intelligence of people with low levels of inherited ability. In addition, they propose that there are important genetic differences by race that can help explain relative economic and social advantage or disadvantage.

Fukuyama (1997) provides an example of the possible implications of genetically determined sex-roles. He suggests that men are not genetically predisposed to be faithful or to look after their children. From this basis, he then goes on to argue that, in times of high male unemployment, policies should be developed to "protect" men in paid work in order to support the traditional family unit so mothers can nurture the children.

In addition, assumptions about behaviour, such as selfishness and cooperative behaviour also form foundations of many theoretical approaches to studying and predicting 
behaviour. An example can be found in economics. If there are significant genetic differences between women and men, neoclassical economics might be helpful in understanding the generally "selfish" behaviour of men, but new institutional economics or feminist economics may be more suited for understanding women's more "altruistic" behaviour.

This chapter very briefly examines some of the arguments on nature versus nurture in relation to cognitive ability and, to a lesser degree, gender roles. From this I develop my own set of assumptions that will guide the subsequent research. ${ }^{23}$

\section{Cognitive ability}

Herrnstein and Murray (1996) are near one extreme of the nature/nurture debate. Their contribution to the debate is particularly important as their book, The Bell Curve, was a best seller in the U.S. Herrnstein and Murray suggest that cognitive ability is substantially heritable, with "apparently no less than 40 percent and no more than 80 percent" of such ability inherited (p. 65). More recently, psychologists such as Chabris (1998) suggest that there are strong arguments for genetic effects on intelligence. Molecular-biologists and other scientists are also busy hunting for an "IQ gene" and in the late 1990s appear to be meeting with some limited success in animal experiments (Lemonick 1999). While such work has the potential to significantly alter the nature versus nurture debates in the future, it is certainly already clear that "nature" has the potential to create a small group of children who have moderate to severe intellectual impediments whom, if they survive to become adults, are likely to be work poor. ${ }^{24}$ It is also appears to have the potential to provide some children with extremely high capabilities, particularly in areas such as

\footnotetext{
${ }^{23}$ While this chapter focuses on debates about nature and nurture in cognitive ability and gender roles, there is a research interest in the impact of genes on a wide range of behaviours such as disposition to alcoholism, incidence of depression, sexual orientation and chances of developing a wide range of diseases. Genetics may be also be affecting other behaviours. For example, an American study has suggested that genetics may play a role in the timing of first sexual activity amongst young people (Rodgers et al 1999).

${ }^{24}$ Improved medical technology and changing views about infanticide have meant that this group is now more likely to survive once born. However, at the same time improved foetus screening technology and liberal attitudes towards abortion reduces the number of severely disabled children who are born.
} 
music and mathematics. However, the debates about nature and nurture focus more on the general population.

Herrnstein and Murray, using an analysis of an American longitudinal dataset, argue that a low level of cognitive ability is a powerful predictor for a range of negative outcomes in a person's life, such as involvement in crime, sole parenthood, and an increased level of accidents. They also argue that, for a variety of reasons, people with similar levels of cognitive ability tend to mate and this further reinforces differences in the next generation. $^{25}$

Based on this assumption about the genetic transmission of cognitive ability, Herrnstein and Murray then argue that this limits the choices made by society, parents and children. In particular, they suggest that the government has few ways of dramatically improving the cognitive ability of its population. This means they are not optimistic about the role of increased schooling, including pre-school, in improving cognitive ability in industrialised countries. The changes in environmental factors, which they suggest may assist in improving cognitive ability, tend to be based within the family. As Herrnstein and Murray bring a strong biological perspective into debates, it is not surprising that they suggest that improving nutrition may be one way of raising intelligence. They also suggest that adoption at birth of children from a "bad" family environment into a "good" family environment can assist children's cognitive ability. Underlying this latter view is the idea that sole parent families, for a variety of reasons, have a negative impact on children.

Herrnstein and Murray add a much more controversial element to their discussion of genetics and cognitive ability. They suggest that there are important ethnic differences in inherited cognitive ability. Yet, at the same time, they suggest there will be a "bell curve" distribution of intelligence within each racial or gender group. It would, therefore, be expected that some people in each group would be very poorly endowed with intelligence while other will have very high abilities. These differences within particular groups, in an

\footnotetext{
${ }^{25}$ This issue of people with similar abilities forming relationships is revisited in chapter eleven.
} 
environment which rewards and "sorts" primarily by intelligence, will then result in increasing inequality within each group.

Many of the type of views expressed by Herrnstein and Murray, but particularly the genetically based ethnic differences in cognitive ability, have long been highly contested in the U.S. and elsewhere. Fischer et al (1996) and Currie and Thomas (1999) have reworked the original longitudinal data of Herrnstein and Murray and argue that it shows that socio-economic background is a critical factor in children's future lives. Levine and Painter (1999), using alternative longitudinal data, also reject the idea that family background is less important than a child's early IQ test scores. The criticisms of nature theories and IQ tests have also come from New Zealand. Flynn (Scientific America 1999) has developed what has become known as the "Flynn effect". Flynn reworked historical IQ test data from a range of industrialised countries and found that the average scores from the same tests over time have been rising. Flynn does not have a clear theory as to why this might be occurring but suggests reasons might include better nutrition, better parenting, extended schooling, as well as potentially the new visual and spatial demands of television and video games.

Haveman and Wolfe (1995) take a broad view about nature and nurture. In a review of determinants of children's outcomes in life, Haveman and Wolfe suggest that there are many factors at work. In their article, they initially review economic perspectives. In doing this, they draw on the work of Leibowitz (1974) and note that genetic endowments and "home investments" will both impact on children. Haveman and Wolfe, themselves, form no strong opinion about the extent of genetics in determining cognitive ability. Instead they suggest that genetic factors will be greater than zero but less than one. Home investments will be affected by parental education and parental ability. Naturally, parental education and ability may, in turn, be determined by genetics. According to Haveman and Wolfe, parental education and ability will impact on the quantity of time inputs, quality of time inputs, quality of goods inputs, and quantity of goods input. Parents will be making many decisions which will affect these factors including fertility, their hours of paid 
work, where they live, the number of times they move, which schools children are sent to, and bequests to children. These later inputs are all aspects of nurture.

The review then goes on to briefly discuss "attainment" perspectives from other research disciplines. While again these primarily relate to influences on children many are of relevance to adult learning. They divide these theories into broad groups:

- Socialisation/role model perspectives

- "Life course" or "ecological systems" perspectives

- Stress theory and coping strategies

- "Working mother" perspective

- "Economic deprivation" perspective

All of these have some relevance to the development of cognitive ability. Within the socialisation model parents, peers, television, schools, and neighbourhoods are all seen as having an important impact on children's aspirations and actual learning. While this is primarily a nurture perspective, as will be subsequently explored, people of similar cognitive ability, as measured by formal education, tend to cluster together in couples and in neighbourhoods. The ecological approach argues that life involves a continuous adjustment and adaptation to changing outside forces, and the impact of these forces needs to be assessed within complex models.

The ecological approach also has some similarities with the approach of institutional economics, in that it suggests that reductionist models (such as econometric modelling) cannot capture the full complexities needed to understand human behaviour.

The stress theories are primarily emphasising the influence of nurture. One line of thought suggests that particularly stressful events during a childhood can have a major impact on life chances. These events could include unexpected parental unemployment or divorce, a 
stressful geographic move, or moving schools. ${ }^{26}$ Underlying these theories is that stability matters for children's learning. It may be better for a child to be in a stable poor home, than an unstable wealthy home. This line of thinking has particularly relevance if it appears that both work and family life is becoming less secure.

The "working mother" theory is based on two main potential impacts. The first is that an absence of mothers during the working day might have a negative impact on learning opportunities for children. The second is that working mothers provide economic resources and new role models, which have a positive impact in terms of learning for children. There has been much writing, particularly in the popular media, which argues the advantages of the working mother (e.g. Crosby 1991). However, a recent popular book goes further and stresses that the main influence of parents on a child's development is a genetic one, but that at the same time peer groups have a major influence on child development (Harris 1998). Her book, The Nurture Assumption: Why Children Turn Out the Way They Do, implies that parental quantity or even quality time is not of great importance, but sending a child to the "right" school or living in the "right" neighbourhood is critical. ${ }^{27}$ Ecological approaches have also taken to the question of the working mother (Podmore 1994). For example, in much of the recent childcare literature attention is given to the quality, rather than just quantity, of non-family childcare in terms of its potential impact on children's learning. ${ }^{28}$

Finally, Haveman and Wolfe report on the "economic deprivation perspective". They argue that this perspective suggests that poverty itself, rather than the other factors related to low family income, has an impact on children's learning. They also suggest that this school of thought is linked to the idea that "welfare dependency" has a negative impact on families and children. This includes the view that the work ethic is undermined when people become dependent on welfare.

\footnotetext{
${ }^{26}$ Often these three events will occur simultaneously.

27 The issue of "neighbourhood effects" on the behaviour of children and adults is discussed in Chapter thirteen.

${ }^{28}$ Although this ecologically based childcare literature does not normally focus on the effect of peer groups on children.
} 
Mayer (1997) makes the point that, in studying the link between family income and children's outcomes, many researchers base their findings on simplistic regression analysis. She suggests that there is the on-going question of whether low-income parents may differ from middle or high-income parents in "social adjustment, skills, enthusiasm, dependability and hard work". These might be the differences that count not income, but income is one result of such characteristics. Other researchers lend some support to this view that attitudes and "soft skills" are of critical importance in determining outcomes for children. For example, Hobcroft (1998), using British longitudinal data, found that parental "interest" in schooling is a powerful predictor of educational success. In the U.S., the work of Plotnick and Hoffman (1999) suggests that the unobserved family characteristics, such as those listed by Mayer, are very important on child outcomes.

Other researchers have provided further review articles focussing on the link between family poverty and child development (e.g. Boggess and Corcoran 1999). In summarising this type of research (as well as that of Haveman and Wolfe), Duncan et al (1998: 407) suggest that a consensus emerges.

- The effects of parental income vary from one outcome to another;

- for achievement-related outcomes such as completed schooling and early-adult labor market success the estimated effects of parental income are usually statistically significant, but there is little consensus regarding the size of these effects;

- by not attending to the confounding parental and neighborhood characteristics, even the mostly modest estimates of the effects of parental income may be upwardly biased.

In their own research they suggest "timing" of poverty is a very important factor. In particular they suggest that low family income in early childhood can have a particularly negative effect on children's long-term attainment. This supports the idea that while studies of income dynamics are important, and that many people may move in and out of poverty, a static analysis which can be provided by data sources such as the census, remains important if it identifies poverty at certain stages of peoples lives. It suggests that focussing on the life experiences of children aged under five is of particular importance in 
research on changing families and work. ${ }^{29}$ Changing patterns of paid work of parents with pre-schoolers are analysed in chapter twenty.

While most of individual theories within each perspective are based on the impact of environmental factors rather than genetics, at times it is still difficult to determine whether it is actually nature or nurture that is creating the impact. For example, it may be that it is genetics that primarily determine whether a mother succeeds in paid work, and these genetic characteristics are then passed onto the children. In addition, the environmental "working mother" theories have, paradoxically, within them major, biologically based, assumptions about the roles of men and women. Until recently little has been said about the possible impact of "working fathers", or alternatively "nonworking" fathers, in two parent and sole-father families.

In addition, changes in family type, structure, and patterns of paid and unpaid work within families are all intertwined. For example, sole parent families are more likely to be poor, and mothers in two parent families more likely to be "working mothers". As another example, the impact on children of sole parenthood may be through a lack of parental time to invest in the child. The time that a child itself can invest in homework and other educational activities can also be undermined in sole parent families. For example, Goldscheider and Waite (1991) argue that with U.S. sole mothers being under considerable pressure to undertake paid work, children in these families are under more pressure to undertake both paid work and housework. ${ }^{30}$

Overall, Haveman and Wolfe suggest that a wider framework is needed when thinking about influences on children's attainment. They argue three perspectives are needed.

- The choices made by society (social investment)

\footnotetext{
${ }^{29}$ This is partly why I focus on families with a child under five in Chapter twenty.

${ }^{30}$ Goldscheider and Waite (1991) also note that children from highly educated couple families undertook much less unpaid work than that carried out by children in poorly educated families. This may reflect a higher level of professionalisation of housework in the well educated, and generally higher earning, families.
} 
- The choices made by parents

- The choices made by the children themselves

While the government can make direct investments in children, it also sets the economic environment in which parents and children make their own choices. The choices made by parents include family type and structure. How actual choices are made by each group, the impact of each choice, and constraints to choice are still the subject of much debate, but some of the influences are discussed in this research.

Overall, it would seem that genetics do have some impact on people's cognitive abilities and their general life chances. But it also seems that there are many other important, but complex, nurture factors at work.

Finally, Jencks (1993: 13) makes an important point in the debate over nature versus nurture, that ways need to be found to reduce disadvantage caused by both nature and nurture and adds that "[t]here is no evidence that genetically based learning problems are harder to treat than environmental based problems. The opposite could equally be true." The need to overcome such disadvantage becomes more critical if it is found that an increasing level of cognitive ability is needed to fully function in the labour market and society in general.

\section{Gender/sex roles}

Historically, the sex of a person has had a major impact on their life chances, including whether they were work rich or work poor in either paid or unpaid work. There still remains considerable debate about differences and similarities between women and men. In the popular media differences are often emphasised, such as in best selling books like Men are from Mars, Women from Venus (Gray 1992). In this "difference" literature men and women have been associated with particular activities, even if there is actually much variation within groups of men and within groups of women. 
Changes in patterns of paid work are a key part of this research. It is clear that there are still some major differences in the overall patterns of paid and unpaid (particularly childcare) work for men and women, and that responsibility for undertaking unpaid caring work has been a major reason for women's lower participation and earnings in employment. Are these differences the result of nature or nurture?

Language has been an important part of this debate with the terms sex and gender key elements. Jaggar (1988: 112) notes:

As it is conceived ordinarily, sex is thought of as a set of fixed biological characteristics, whereas gender is construed as a set of variable social norms about the proper behavior of sexed individuals. If, however, we acknowledge human biology, including sexual biology, as created partly by society, and if we acknowledge human society as responding to human biology, we lose the clarity of the distinctions between sex and gender. We see that sex does not uniquely determine gender but that it is not irrelevant to it either; moreover, we see that sex itself is partly created by gender.

By using the term sex-roles there is an assumption that differences in men's and women's lives are primarily based on biological factors, while using the term gender-roles implies a high level of cultural construction of roles. In this research I have chosen to generally use the term gender-roles. However, the following section illustrates some variety of thinking about the choices, or the lack of them, available to men and women. This section draws heavily on the work of Nussbaum (1985).

Firstly, there is a biologically deterministic set of arguments. For example, male hormones might reduce "nurturing" characteristics (e.g. Tiger and Shepher 1975). It has been suggested that evolution has assisted this genetic programming (Barash 1982, Wilson 1978). Other researchers, such as Rossi (1977), have argued that genetics interact with societal conditions and tend to perpetuate the traditional divisions of labour. Biological explanations generally assume that behaviours in areas such as physical work and childcare are inherited. Therefore change in the traditional patterns of such work is 
almost impossible to change. This might mean that "gaps", such as the pay gap, can never be closed.

There are many views within the nurture perspective. For instance, Skinner (1953) focussed on the reinforcement of appropriate behaviours. Other people, such as Chodorow (1978) argue that patterns of parenting provide models to follow. Chodorow argued that because women generally raise both boys and girls, it would be girls who then develop the psychological tendencies that allow them to form intimate relations with children. These socialisation theories share with the biological schools the assumption that change in some areas of work, such as nurturing work, is difficult. However, they disagree as to the source of those behaviours.

Another set of theories takes an historical perspective (e.g. Gough 1971). They say that because almost all of human history has been lived under conditions that have suited assigning particular roles to men and women, then these roles persist even when these conditions change. For example in hunting, the hunters could not be looking after children and only women could feed infants. Today's division of labour represents a “cultural lag" (Ogburn 1964). Again, this idea is reflected in current debates (Gershuny et al 1997).

A number of researchers have reviewed sociobiological studies of primate behaviour and refute ideas of universal male dominance and fixed behaviour patterns on a gender basis. Blau and Ferber (1986) suggest that the change in perceptions in this area of study occurred at the same time as thinking about roles in human society was changing and was also influenced by the entry of women into the field of primate studies. The suggestion is that research can reflect the beliefs of the people undertaking the research. The idea that women should study women has been put forward in many forums in New Zealand (e.g. Glamuzina 1992). Organisations such as the New Zealand Women's Studies Association 
promote such a concept. This is also reflected in social policy formation with organisations such as the Ministry of Women's Affairs only hiring women on their staff. ${ }^{31}$

In the popular media, psychologists such as Gilligan (1982) have put forward arguments that women are more capable of affiliation than men. However, other psychologists such as Crosby (1991: 121) note:

\begin{abstract}
The new sexism seems as potentially crippling as the old sexism. If we accept the view that men and women differ in their need to attach themselves to others and in their skill at relationships, we have only a tiny distance to go before we decide that mothers make the best parents. We would see mothers as more involved with their children than are fathers. And, after all, who do we want raising our children - someone who is detached and uncaring or someone who is tuned-in, emotionally available, and sensitive.
\end{abstract}

There is on-going debate about whether men and women exhibit different behaviours in many areas of life, such as the way they communicate or whether one group is more cooperative. For example, based on experiments with students, Seguino et al (1996) argue that a key factor affecting cooperative behaviour was gender.

An example of the potential impact of nurture (or lack of), there is much discussion internationally about the possible impact of "fatherless" families on children (e.g. Biddulph 1995, Blankenhorn 1994). Blankenhorn, in a simplistic approach, associates the rise in the proportion of "fatherless" families with major social problems, such as crime, teenage pregnancy and child sexual abuse.

In much of this literature, fatherhood is seen as inherently different to motherhood and that a father, and usually the biological father, is essential to bring up well adjusted children. There is a particular concern about the raising of boys. In one strand of this literature fathers are seen as needed to provide positive role models of masculinity (e.g. Biddulph 1995). In the absence of fathers in families, male role models, or mentors, are

\footnotetext{
31 The question of who should study "marginal men" is now starting to emerge as a methodological debate (e.g. Callister 1999a).
} 
needed in areas such as childcare and schooling. For instance, male teachers might allow some boys to be more active learners instead of them being classified as having attention deficits. It is argued by supporters of this model that in a "feminised" pre-school and school education system if boys are particularly "boisterous" they will be sanctioned and this will lead to difficulties in their learning. This concern is linked to the idea that a group of boys are now failing at school and will have little future in a rapidly changing labour market. The use of "calming" drugs, such as Ritalin, has also been linked to children living in sole-mother families or families lacking a positive male presence (Gliksman 1998).

Researchers such as Amato and Rivera (1999) take a more cautious view of the role of fathers. However, they do note that although data sources are problematic paternal involvement does seem to have a positive effect on children's behaviour. Other researchers take even more of a cautious approach to the nurture impact of fathers and "fatherless" families on children. For instance, in New Zealand, Fergusson (1998: 170) argues that an absence of a father in itself is not the key factor behind children being at more risk when raised in sole mother families. He suggests that this risk does not reflect the number of parents "but rather a series of social and contextual features that are more common in single-parent families." This issue of male, or female, role models in parenting is the subject of on-going, and intense, debate in social policy and academic circles (e.g. Birks and Callister 1999a\&b).

The nurture school of thought suggests that social norms are important in sanctioning certain behaviour. Researchers within anthropology, psychology, sociology and women's studies have been particularly interested in the way that norms are developed, reinforced, but also challenged. Feminism, in its various forms, has been a major influence in changing work expectations for women, particularly in the last twenty years. The growth of feminism, and in more recent time a "men's movement" has also, at times, endeavoured to challenge paid and unpaid work 'norms' for men. ${ }^{32}$

\footnotetext{
32 However, one strand of the men's movement appears to be reinforcing some traditional "masculine" characteristics (e.g. Biddulph 1995).
} 
While many factors will influence norms education appears to be an important factor. There are many examples of where well-educated people have been the early adopters of new ideas and lifestyles. For example, a number of researchers have suggested that well educated people are more accepting of changes in traditional gender roles for men and women (e.g. Sandqvist 1987). But other research shows that better-educated people are also more likely to uphold "traditional" values in some areas of life. An example is entering a formal legal marriage. However, education is not "neutral" and there has been much debate about curriculum content, how it is delivered (e.g. whether boys or girls are advantaged in some subjects), where it is delivered (e.g. such as whether schools are sex segregated) and who delivers it.

There also remains the question that biology may have an important impact on some areas of ability and very little on others. For instance, Jencks (1993: 23) argues that "[i]nstead of debating nature versus nurture, we should try to understand how a particular gene or set of genes influences some specific form of behavior". Given the strong occupational differences in some areas of work, both paid and unpaid, it may be that there are some specific abilities that men or women still have a genetic advantage, and yet other areas where there is little difference.

"Fixed" gender roles, whether fixed through nature or nurture, may not only have a significant impact on the creation of work-rich and work-poor individuals, but the creation of work-rich and work-poor families. In work-poor couples, it may be that some women are reluctant to become primary income earners if their partners are facing difficulties in the labour market. This may be through their own choice, because they face pressure not to take on this role, or that following the nature line of thought because they are not biologically programmed for the role. Pressure not to take on the role may come from their partner but potentially from other groups as well. Men in these families may also be reluctant to specialise or even assist in non-market work. Again this may be their own decision, it may be that they are biologically unsuited to the role, or it may be as a reaction to outside pressures/attitudes. In these families, for a variety of reasons, there 
may also be reluctance by men to take on jobs in "women's areas" of paid work, such in many of the service industries of retailing, restaurants, cleaning, nursing and in paid childcare. There may also be reluctance by employers to take men on in some of these female "dominated" jobs. However, if roles are fixed by nurture then they can be "unfixed" by new role models, equal opportunities legislation or education.

Again, like the nature and nurture argument over the development of cognitive ability, I am taking the view that some element of nature is influencing behaviour. Some of this is clear, such as pregnancy, childbirth and breastfeeding, but much of it very difficult to identify. ${ }^{33}$ It is difficult, for example, to see why women would have a genetic propensity to be main toilet cleaners within heterosexual couple households or why women would be genetically less able than men at running large and complex organisations. Yet, if there are important characteristics which are difficult to change through nurture then some "gender gaps" will not close, even if the "cognitive gap" becomes more dominant in determining life chances. ${ }^{34}$

\section{Conclusion}

The potential impact of cognitive ability and gender on life chances, and in particular on paid work opportunities, are critical elements of this research. Based on a very brief review of the vast literature in both fields, this project assumes that nature has some impact on both cognitive ability and the roles assumed by women and men in paid work and family life.

At the very low end of cognitive ability, nature, through birth defects, has a considerable impact on the lives of particular individuals. While nurture can help lift the cognitive ability of this group, it is likely that at least in the short term, there will continue to be a group of intellectually disabled people who find it difficult to learn the skills that will enable them to fully participate in the labour market. But for the vast majority of the

\footnotetext{
33 Technology, through the development of formula, has provided an alternative to breastfeeding, and technology may well eventually provide alternatives to women bearing children.

${ }^{34}$ These "gaps" do not always favour men. For example, the life expectancy "gap" favours women.
} 
population the research literature suggest that currently nurture is a powerful force in determining a person's cognitive ability. This situation, of course, could change very rapidly in the future if an intelligence gene is discovered and can somehow be inserted into people.

In terms of pregnancy, childbirth, breastfeeding, and general body strength, nature creates differences between women and men. There may also be other genetically determined differences which are harder to detect or more difficult to prove. However, it appears that nurture also has a major influence on determining options in both paid and unpaid work for women and men.

But nurture itself is an extremely complex mix of factors including family type and resources, quality and quantity of parenting, quality and quantity of schooling, type of neighbourhood, investment in social services by government, and "norms" determined by the media.

While both nature and the various influences of nurture will be having an impact on the cognitive abilities and gender roles assumed by both children and adults, due to data constraints in this research it is only factors that might influence nurture that are focussed on. Within this already narrow model, the focus is further restricted. It is primarily changes within family / household type, structure and roles within them, the changing investment by government and individuals in formal education and some aspects of neighbourhood change, along with possible causes of such change, which are analysed in detail. So while an "ecological" model is suggested, as in most research for practical reasons a narrower, more reductionist, approach is taken. 


\section{Chapter 6}

\section{Why are patterns of paid work changing?}

\section{Introduction}

There is a substantial and diverse literature examining historical, current and predicted changes in patterns of paid work within industrialised countries. This literature focuses both on the forces driving changes and the actual changes in work. In the following section some of the key themes in this literature are briefly examined. In doing so, particular attention is given to demand factors that lead to changes in participation in paid work. However, some supply side issues are also addressed. In addition, while some longer-term trends will be analysed, the main focus of the discussion is on the period from the early 1980s to the mid 1990s. ${ }^{35}$

In this chapter nine broad, and interconnected, drivers of changes in paid work are briefly explored. These are:

1. globalisation

2. technology

3. flexibility in labour markets

4. economic policy

5. changes in the role of the state

6. changing consumer preferences

7. changing demographics

8. changing aspirations and opportunities for women, and linked to this last point,

9. changes in unpaid work.

\footnotetext{
${ }^{35}$ Parts of this chapter were drawn on for a paper prepared for the Super2000 Taskforce (Callister and Rose 2000).
} 
This is not an exhaustive list and there are additional factors which impact on patterns of paid work. Building on the possible driving forces, this chapter leads onto two further interconnected chapters. The first provides a more detailed review as to whether industrialised economies are "upskilling" or "deskilling". This discussion is important in terms of identifying the role of education in determining people's experiences in the labour market as well as the role of education in job creation. In a following chapter there is a discussion of specific factors that might be influencing changes in working time, both hours worked per day or week, and the time worked over a lifetime.

\section{Nine factors driving changes in paid work}

\section{Globalisation}

From the time of European settlement international trade has been very important to New Zealand, but in recent years the international process of globalisation has been having a major impact on trade. As a small country New Zealand has, and always will be, highly affected by trends occurring outside of its physical boundaries.

Throughout the OECD there has been a widespread, although certainly not universal, acceptance amongst governments of the argument that a relatively free movement of goods and services, including investment, is beneficial for countries. Although forms of trade restrictions and industry support are still widespread, in most countries there have been policy changes that assist freer trade. One example is the deregulation of financial market transactions. There has also been increased interest in promoting free trade agreements between countries, although there is still considerable resistance by some groups. There are particular concerns in areas such as loss of sovereignty, the effect on indigenous peoples and the loss of jobs for low skilled people. However, technological changes, particularly in the area of communications and travel are making it difficult for any government, and particularly the governments of small countries such as New Zealand, to resist many aspects of globalisation. There has, however, been more ambivalence, and even resistance, for freeing up the flow of people between countries, particularly long-term migrants. Overall, the processes of globalisation have resulted in 
increased international flows of money, goods and services and, to a lesser degree, of people.

There is still much debate about the impact of globalisation. As an example, Wood (1994) analysed the impact of trade on employment and inequality between 1960 and 1990 in the U.S. Wood suggests that skilled workers in industrialised countries benefited from the increase in world trade for two reasons. First, the increase in trade led to higher economic growth. Second, the new international division of labour gave their firms, and ultimately themselves, a comparative advantage in the high value end of the market. But low skilled workers, in routine production type jobs, lost work overseas, and overall demand for low skilled workers significantly reduced in industrialised countries.

While the spatial impact of globalisation between countries has attracted much attention, there is also an increasing focus on the impact with nations, within regions and within cities. For example, Van Kempen and Marcuse (1997) discuss how globalisation has created a work-rich elite within society that is far larger than their local neighbourhood. ${ }^{36}$ They suggest that increasingly these people work for global enterprises, they seek out international educational opportunities for themselves and their children, and for recreation they seek out international destinations. In contrast, for the work-poor, their neighbourhoods are bypassed by the mainstream global economy. These spatial issues are discussed in more detail in Chapter thirteen.

\section{Technology}

A wide range of commentators have suggested that changes in technology have been a key factor in driving changes in work patterns, and overall patterns and standards of living. Throughout history technological advances, such as the ability to refine and work metals, the domestication of wild plants and animals, the introduction of the printing press, and the technological advances of the industrial revolution have had major impacts on work. Some commentators view the introduction and rapid improvement of computer

\footnotetext{
${ }^{36}$ This is assisted by reductions in the costs of travel and communications.
} 
technology (including the internet), along with other recent advances in science and medicine, as potentially having an impact as great as the industrial revolution. They suggest we are now moving into a "post-industrial" era (e.g. Block 1990). In turn, Castells (1996) argues that is not appropriate to talk about post-industrial economy, but a move to "informationalism" which can be applied to agriculture, manufacturing and services. European economists, such as Freeman (1991) and Antonelli (1992), bring in the idea of "networks", and suggest that the development of information-based networks have been a key factor behind a shift from the "age of machines" to an "era of information".

There is a considerable amount of discussion around the actual and potential impact of technological change on work. There is the question whether technology leads to upskilling or deskilling, a topic discussed in more detail in the following chapter. Linked to this is whether technology creates jobs or whether it destroys them. In this latter debate the one extreme envisages workplaces full of high technology and well paid, occupations. This is the world presented by writers such as Naisbitt and Aburdene (1990) and, to a lesser degree, Toffler (1990). The other extreme is a pessimistic view, emphasising manufacturing moving to third world countries and technology steadily replacing jobs (e.g. Aronowitz and DiFazio 1994). ${ }^{37}$ This latter view provides a work-poor future for many in society.

\section{Increasing flexibility in labour markets}

Globalisation and changes in technology have created a more intense level of competition for enterprises both in their domestic markets and internationally. In order for enterprises to be competitive direct and indirect labour costs often need to be reduced. This reduction can come about by lowering wages/other labour overheads and/or increasing productivity through more flexible workpractices. There is, therefore, much focus on increasing flexibility in the labour market. There is much debate in the international literature about

\footnotetext{
37 The optimism or pessimism of books tends to reflect the economic cycle. For instance, Aronowitz and William DiFazio focus on the US economy in the early 1990s, a time of recession.
} 
the possible impact of various types of flexibility in the labour market on employment (e.g. Nickell 1997, Siebert 1997). At one extreme is the view that unemployment is primarily a result of wage rigidity. If wages at the bottom end of the job market were reduced a highly elastic labour market would expand.

In most industrialised countries there has been a major push by governments, employers and, in some situations, employees towards developing more flexible labour markets. The aim of both employers and governments is to improve productivity and, for governments in particular, to ultimately create jobs. In many nations there have been changes in labour market legislation to assist this process and, in parallel, a decline in the coverage of unions. However, flexibility has potentially different meanings for employers and employees

In broad terms the OECD suggests there are two areas of labour market flexibility internal and external (Working Party on Industrial Relations 1989). External flexibility concentrates on issues such as wage rates across a whole economy relative to other nations, geographic mobility (changing residence), job mobility (involving a change of employer), and occupational mobility (involving a change of skill undertaken outside the employing organisation). A number of these types of flexibility, if promoted or inhibited, have an impact on the development of work-rich or work-poor individuals, families, households and communities. For example, if there is little geographic mobility, perhaps through a lack of flexibility in the housing market, and some areas suffer job losses then these communities can become long-term work-poor.

In addition, according to the OECD, there are five main areas of internal labour market flexibility. 
1. externalisation or "distancing" (putting work out, on site subcontracting, conversion of dependent employees to self-employed status, etc)

2. functional flexibility (multi-skilled workforce, job mobility, semi-autonomous groups, rotation, etc)

3. wage flexibility (setting wages individually and linking part of earnings to performance)

4. external numerical flexibility (more flexible redundancy procedure, temporary work, fixed-term contracts or short-term contracts, etc)

5. internal numerical flexibility (variation of working hours, increase in shift work, weekend shifts, etc).

Again, many of these types of flexibility could have an impact on whether individuals became work rich or work poor.

The OECD (1994) have argued that less rigid arrangements for daily, weekly, annual and life-time working hours can meet both enterprise requirements and workers' aspirations. This permits firms to better use their productive capacities by matching production more closely to shifts in demand. But the OECD also suggested workers and their families gain from new working time arrangements tailored to their individual preferences or family circumstances. The OECD go on to argue that having more flexible working time arrangements can facilitate greater lifetime participation in paid work by women. In other studies increased flexibility is similarly promoted as a way for some people, particularly parents of young children, to find a balance between paid work and family life (Callister et al 1995). In relation to creating flexible work policies that assist balancing work and family obligations, there is now an increasing interest in "family-friendly" policies. These often embody flexible work arrangements (Callister 1996a).

A number of factors influence flexibility in labour markets. One is the level of union coverage. Union coverage is influenced by a number of factors including the proportion 
of people self employed, the size of workplaces, whether jobs are being created in the service sector and labour market legislation. In New Zealand, as in other industrialised countries, there has been a dramatic decline in union membership in the last decade. In a period similar to that studied in this research, unions went from covering just over 40 percent of workers in 1985 to just under a quarter of the workforce in 1995 (Harbridge et al 1995).

In recent years a major step in labour market deregulation in New Zealand was the passing of the State Sector Act in 1988 that provided more flexibility in employment relationships in the public service. The passing of the Employment Contracts Act in 1991

followed this. ${ }^{38}$ The prime aim of this act was to decentralise industrial bargaining, to either the enterprise level or to the individual. The aim was to improve productivity and this would, in theory, lead to an improved economic performance. An important aspect of this performance was job creation. The passing of the Act in 1991, after the 1991 census, means that measuring changes in employment between 1991 and 1996 is of particular interest.

However, in New Zealand there still remains a minimum employment code. This code includes minimum wages, statutory holidays and parental leave regulations. The effect of such regulations on employment is still the subject of much debate (e.g. Maloney 1998).

\section{Economic policy}

Within policy-making debates there is much attention given to the impact of economic policy on changing patterns of labour demand and supply. This applies to both macro and micro-economic policies although, historically, there has been much more focus on the possible impact of macro-economic policies on job creation or loss. In particular, Keynesian style macro-economic policies had been seen as an important factor in supporting employment and making the economy work-rich.

\footnotetext{
${ }^{38}$ At the time of submitting this thesis this Act was being repealed.
} 
In New Zealand, there has been much debate about the impact of monetary policy on employment. For example, there is a group of economists who argue that the exchange rate has been overvalued for much of the period between 1986 and 1996 (e.g. Easton 1997). In addition, it is argued that high interest rates in this period inhibited growth.

Within macro-economic policy, tax policy can also affect employment. The type of effects discussed include the possible "deadweight" of taxes on an economy, compliance costs impacts on small businesses, and the incentive effects on individuals to work harder (or less) or move from being on a benefit to participating in paid work. Tax policies can be designed to lift the cost of labour (e.g. payroll taxes), or perhaps tax consumption (e.g. GST). They can encourage research and development or the introduction of new technology. Tax policies can also boost the wages of low-income workers through tax credits or other tax incentives. This may encourage more people to move into paid work. Tax policy can also influence the mix of paid and unpaid work in an economy.

There is also debate about the impact of various micro-economic policies on the economy, and specifically employment. These include increasing the level of competition in various markets, including financial and labour markets. This has included reducing and removing protection of particular industries, such as through the reduction and removal of tariffs. Overall, a theme of the policy changes in New Zealand and in most industrialised countries has been a move by governments to try and withdraw from actively managing the operation of the economy. Instead, they are generally trying to set a regulatory framework that encourages, through competition, the most efficient allocation of resources, including labour. ${ }^{39}$ How much competition actually exists in many markets, such as telecommunications or even the labour market, is still unclear.

While recognising their importance in the potential creation of work-rich and work-poor individuals, families and communities, a review of these wider economic debates is

\footnotetext{
${ }^{39}$ However, there is evidence in even highly competitive marketplaces such as the U.S. of a significant level of "hidden" subsidies to particular businesses. In the U.S. these subsidies are often provided by individual states eager to attract or retain businesses in their geographic area (Time Magazine 1998).
} 
beyond this research. How much of the growth in the New Zealand economy in the early 1990s could be attributed to particular economic reforms, whether in fact some of the reforms process actually slowed long term growth and, alternatively, whether the growth would have been faster had further reforms been carried out, is still the subject of much discussion (e.g. Dalziel and Lattimore 1996, Kasper 1996). In addition, in an increasingly

global economy there is also concern that the control individual governments, and especially governments in small countries such as New Zealand, have over a variety of economic policies has diminished.

\section{The role of the state}

In most OECD countries there has been an objective of reducing the role of the state in the economy (Esping-Andersen 1996). Although still challenged by some groups on the political left, there is now widespread acceptance that private rather than public ownership and control of resources provides the optimal way of producing many of the goods and services demanded in industrialised countries. Areas where there remains considerable doubt include natural monopolies and services such as education and health care. There is, however, less consensus as to whether this policy of privatisation will assist to bring economies back to full-employment or, in fact, lead to higher levels of joblessness. There is also much debate about the impact of capitalism on income distribution. The reduction in the role of the state follows a period of major growth since World War II.

In the last century in most industrialised countries the state increased its involvement in the economy. Often this was linked to the promotion, or at least protection, of employment. This included protection of particular industries, often import substituting manufacturing industries; direct investment in infrastructure projects such as power supply, telephone provision, and in New Zealand in the late 1980s the "think big" projects; assistance to particular industries often using low cost loans; subsidising research and technology transfer; investment in social services such as education and health, and finally welfare transfer. 
Certain types of government assistance can create manual jobs in manufacturing or primary industries, but investment in areas such as infrastructure projects and social services tends to create many professional and technical jobs such as teachers, engineers, and legislators. In addition, the specific type of industry/service the government supports can have a major impact on the type of job created. For example, supporting the development of the car industry created many manual jobs, both skilled and unskilled, which historically had been held by prime age men, and in New Zealand, often Maori and Pacific Islands men. Alternatively, support of the textile industries has traditionally created a higher proportion of jobs for women. Traditionally, investing in early childhood services will tend to create jobs filled by women, while investing in tertiary education has tended to create a higher proportion of jobs filled by men.

Laws can also promote employment for some groups, or alternatively keep certain groups out of paid work. For example, in the U.S. tough criminal laws across a range of areas ensures a high prison population. This not only lowers the number of people officially unemployed but also creates a significant number of jobs, mainly filled by men, in areas such a policing and prison officers. Laws that can keep some groups out of paid work include those covering age restrictions or the sex of the worker. For example, in the past in many industrialised countries there were laws keeping women out of areas such as night work. Another example, are laws that try and prevent certain enterprises operating, such as the growing and selling of marijuana. Such laws also mean that people engaging in these activities are unlikely to be recorded in official employment Statistics.

A reduction in state involvement in an economy can come from removing rules and regulations that impede free trade or production, or by reducing the direct involvement in the economy. In New Zealand, in the 1980s there was a major program of reducing support for many areas of the private sector. These include the removal of export subsidies and import licensing, and a major reduction in tariff protection (Economic Monitoring Group 1989). These supports and barriers had been mainly targeted at the primary and manufacturing sectors. 
In New Zealand, since the 1930s the state had become a major employer. Jacoby and Sharma (1992) argue that the growth of large-scale bureaucracies, including those operated by the state, helped develop a stable, core labour market. One key part of reducing direct employment has been the privatisation of "non-core" assets, and in more recent times of parts of what might have been considered the "core" public service. A first step was the creation of State Owned Enterprises (SOE) in the late 1980s. This process involved major job loss. Subsequently, and a process which continues, many of these SOEs were privatised. In some of them, such as railways and the telecommunication branch of the Post Office, job loss occurred at both stages. In areas such as the railways, forestry and telecommunications the impact of lob loss was particularly major on Maori prime-aged men. As will be shown in later chapters, the loss of jobs also had a major impact on many smaller population centres.

As will be discussed in subsequent parts of the research, the provision or withdrawal of particular government services can have a major impact whether families are work-rich or work-poor. For example, if government provides subsidised or free childcare, or care for the elderly or the sick this takes the work outside of the home and generally assists women into paid work. Childcare policies can particularly impact on the labour market participation rates of sole parents.

While the government is withdrawing from many areas of the economy in most industrialised countries it is also becoming more interested in the operation of families. This includes an interest in reducing family violence, increasing parenting skills, and the state taking positions on custody and financial support issues in relation to separating families. As will be discussed in later chapters, this may have some impact on household form and function, including whether households are work-rich or work-poor.

\section{Changing consumer preferences}

A range of factors related to consumer preferences will have an impact on labour demand. For example, if people are placing more emphasis on saving rather than spending this 
may reduce employment in the short term. In addition, the weight a society places on spiritual well-being rather than material well-being will also impact on labour demand. ${ }^{40}$

Franklin (1997) argues that increasingly it is consumers rather than producers who actually determine the range and type of goods and services that are produced and consumed. Therefore, changing consumer preferences will have a major impact on labour demand. Linked to the globalisation of trade, Franklin (p. 80) argues that "[e]xercising today one's freedom to consume is as likely as not to put a fellow citizen out of work tomorrow, especially if one happens to choose the imported and probably cheaper article". In relation to one of New Zealand's traditional largest export industries, Franklin notes how New Zealand lamb could only be purchased by high income people in Britain at the end of the nineteenth century, but by the 1930s a rising standard of living had widened this demand to the working classes. This had a positive impact on the New Zealand meat industry, and demand for labour in the industry. However, in recent times, in industrialised countries, there has been a move away from red meat, particularly by people in higher socio-economic groups, which has had a negative impact on the New Zealand meat industry. Yet, a switch by many consumers from meat to fish has assisted the growth in New Zealand's fishing industry.

Finally, changing consumer preferences can also reverse seemly strong historical trends. For example, the trend to manufacturing clothes in low wage countries, can be challenged if consumers demand "original", non mass produced, clothing and, in addition, do not accept a delay between ordering and delivery.

\section{Changing demographics}

Changing consumer demands affect employment, but changing demographics also alter the composition of consumers in a society and the makeup of the workforce. Population growth, the size of the population and its geographic distribution all has an impact on the economy and, ultimately, patterns of employment. For example, the very small size of our

\footnotetext{
${ }^{40}$ Although, spiritual wellbeing can, itself, be a major industry.
} 
population relative to large industrialised countries makes external trade more vital as some goods and services, such as aircraft, could never be economically produced in New Zealand. Demographic change is influenced by shifts in fertility, changes in survivorship and migration. For example, in New Zealand as in other industrialised countries fertility rates are now below replacement levels.

Demographic change impacts on paid work patterns in a variety of ways. For example, the aging of the population increases demand for particular types of healthcare. This occurs both at the high end of skill requirements, such as people undertaking hip replacement operations, and at the lower end, such as nurse aides in retirement homes.

How the age structure of the New Zealand population is changing is discussed in Chapter fourteen.

\section{Changing aspirations and opportunities for women}

Closely linked into demographic change has been changing aspirations and opportunities for women. This impacts on patterns of paid (and unpaid) work.

The move into paid work by women since the 1950s has occurred in all industrialised countries. However, while the overall trends are similar between various countries there are some important country specific differences. For example, in the U.S. there has been a particularly strong movement of women into full-time paid work, while in Britain there is a much higher proportion of part-time work amongst women (Callister et al 1995). The differences in women's labour market patterns often are closely linked to attitudes and supports in childrearing. For example in the U.S. many women are now moving back to full-time paid work very rapidly after having children. In contrast, in Sweden a high proportion of women take a year of parental leave, and then work part time, yet overall women in Sweden have a higher participation rate than women in the U.S.

In many industrialised countries a small, but significant, group of women now have few long-term interruptions to their participation in full-time paid work. Esping-Andersen 
(1996) argues that women's economic independence is a critical feature of post-industrial society. But how to best deal with economic independence gained through paid work, with conflicting issues of pregnancy, childbearing, breastfeeding and the potentially less sex specific activity of rearing of children are still the subject of much debate (Galtry and Callister 1995).

There are many inter-related reasons for the strong movement of women into paid work. While the second wave of feminism is likely to have had an impact on attitudes other, more important, factors were also at work. These included a very rapid expansion of paid work in the 1960s and 1970s, demographic changes such as lower fertility rates, a shift to older parenting particularly amongst well-educated women and an increase in availability of childcare. A major "push" factor has been the increasing participation in tertiary education by women. While "market" driven factors have a major influence on women's participation in paid work, social policies including taxation regimes, childcare policies, parental leave, and welfare support can all have some impact on participation rates. International evidence also suggests that government policies appear to have a particular influence on employment rates of sole mothers (Duncan and Edwards 1997).

As will be discussed in this research, women's participation in paid work has an influence on issues such as couple formation, on whether families and households become workrich or work-poor, as well as influencing patterns of paid work within geographic communities.

\section{Changes in unpaid work}

Women's and men's patterns of paid work have, and continue to be, closely tied to patterns of household and community work. Unpaid household work can reduce, or increase, through a variety of means. These include new technology, declining fertility, "professionalisation" of household work, changing attitudes towards standards of 
household work; and possibly deskilling of unpaid work. ${ }^{41}$ A reduction in unpaid work can provide more time for leisure or for paid work. In addition, the professionalisation, or marketisation, of household work directly creates paid work. Finally, changing attitudes and expectations have an impact on the relative amount of unpaid work carried out by men and women. However, overall there is evidence that total household work has declined in industrialised countries since the 1960s (Gershuny and Robinson 1988).

Decreasing fertility reduces the number of children in a family, and this in turn reduces the amount of time needed for direct care of children and for undertaking the extra housework they create. However, while this reduces the total amount of childcare work more time might be spent with each child. As discussed in Chapter five, the time spent by parents with a child can have implications for the development of human capital.

The growth of many service industries can be traced to such switching of unpaid work to paid work. Some of this shift has created new occupations in which women are currently highly over-represented, such as childcare and domestic cleaning. In the longer term much of manufacturing growth also represents a shift from unpaid to paid work. Examples include clothing and footwear manufacturing and, more recently, the production of convenience foods. In the situation of clothing manufacture and footwear, the first step of outsourcing from the home was often to a local manufacturer. This "outsourcing" is now becoming globalised with now much of the work not only carried out outside of households but outside of the country in which the clothes or footwear are purchased.

"Outsourcing" of unpaid work can be a key element in determining whether a person or family with dependent children is work-rich. For example, the creation of work-rich childrearing couples, who work the same shifts, only generally becomes possible when

${ }^{41}$ Skill levels of unpaid work can change over time. For instance, Collins discusses the concept of deskilling of unpaid work (1998: 5). He argues that "[t]he Taylorized factory of the early twentieth century, with its efficiency oriented speed-up, has invaded the home just at the time that modern participative management techniques have made middle-class workplaces more emotionally friendly". He argues this makes people want to spend more time in paid work and less time in unpaid work within the home. 
childcare becomes marketised. An individualised childcare option, such as a "nanny" gives parents the most flexibility and is most likely used when long hours or non-standard hours are worked. The individualised option requires a large income gap between those hiring the labour and those working in childcare for the relationship to be commercially viable. This option would be expected to expand as income inequality increased. However, any childcare option could be subsidised, or even fully funded, by the state.

There is much debate about the limits, and impact, of professionalisation of unpaid work. For example, Hochschild (1983) discusses the "commercialisation of human feelings" in areas such as retailing. Hochschild suggests that workers, and mainly female workers, are required to sell their "emotional labour". This results in a sense of subservience, which is not associated with other jobs. In more controversial territory, Radin (1996) and Arrow (1997) discuss issues such as the commercialisation of sex through prostitution, the sale of children, and the sale of body parts.

Aside from ethical, moral and emotional issues there may be other factors that limit professionalisation. Ironmonger (1996) argues that a main reason why household production still continues is that the final products are superior in terms of quality, time and location of delivery of output. Weiss (1997) also notes that household production continues because of lowering costs of search (for goods and services), transaction costs and monitoring of the production and quality of goods and services.

Irongmonger, using Australian data, notes that despite professionalisation of unpaid work there is still more unpaid work carried out than paid work in industrialised economies. Secondly, he notes the importance of gender participation both in overall paid and unpaid work, and in specific tasks undertaken within each type of work. However, overall, he notes that the total amount of work carried out by men and women is similar. This suggests that unless unpaid work continues to be professionalised if more women are to increase their paid work, men, on average, need to reduce their hours of paid work. This reinforces the idea that work and family issues are difficult to separate. 


\section{Conclusion}

This brief review suggests that there is no one single cause of changes in paid work, including whether a nation is work-rich or work-poor. Some of the driving forces are primarily of an economic or technological nature, some due to social change while others are a mix of economic and social change. Some of the changes in paid work can potentially be traced back to policies developed and implemented by New Zealand governments, but many of the changes are being influenced by international factors. The power of governments, and particularly governments of small countries such as New Zealand, to directly influence employment levels appears to be now severely limited. In addition, most of the forces driving changes in paid work are interlinked. The causes are complex and often can have contradictory affects. In particular, technology has the ability to both destroy and create jobs.

While it is difficult to develop a simple model to explain, and potentially forecast, changes in work some initial broad theories can be postulated:

- globalisation means that labour demand is increasingly determined on an international basis rather than a local basis.

- linked to this, changes in technology and globalisation mean that low-skill routine production jobs will continue to be moved to low wage countries.

- the ability of a nation (or even a local region within a country) to hold, or attract, the higher skilled symbolic analytical and technical analytical jobs will depend on many factors. However, the quality and output of the education system will be a prime factor.

- an increasingly flexible labour market is likely to lead to a reduction in the proportion of people working "standard" hours. Some will become work-rich working long hours and some work-poor, with either (or both) short hours or intermittent work.

- women, and particularly well-qualified women, have continued and are likely to continue increasing their participation in paid work. 
- a higher proportion of goods and services, and jobs, are being provided by the private sector than a decade ago.

- unpaid work will continue to be "professionalised" thus creating new, and generally in-person service, paid jobs

- demographic changes and changing consumer tastes have a significant impact on demand for labour and the type of labour required and on labour supply.

- economic policies developed by a small country such as New Zealand have only a limited impact on patterns of employment. External factors have a much greater impact.

Not all these concepts can be tested using census data. However, where possible in this research there will be an exploration of these trends.

Finally, this chapter sets the scene for the next two chapters. The first develops a view as to whether industrialised economies are "upskilling" or "deskilling". In the following chapter there is a more detailed discussion of specific factors that might be influencing changes in working time. 


\title{
Chapter 7
}

\section{The upskilling/deskilling debate: An overview of the literature}

\begin{abstract}
The skills an individual needs to get a steady job, understand a tax form, or put together a "partially assembled" item from a mail-order catalogue are not fixed for all time. Nor do they depend on some impersonal technological imperative. They depend on the skills that other members of the society have. When most people are illiterate, society organizes itself on that assumption. Work is arranged so that very few workers have to read instructions, taxes are levied on the assumption that ordinary citizens cannot be expected to fill out forms, and Sears does not sell items that only a Swiss watchmaker can put together. When most people can read relatively complicated material, society reorganizes itself to take advantage of this fact, and those who cannot read such material are left behind.
\end{abstract}

It follows that if most citizens improve their reading and math skills a lot, while the least adept improve only a little, the least adept may become more of an underclass, even if they are more skilful than their counterparts were a generation earlier.

(Jencks 1993: 180)

\section{Introduction}

In this brief review I address three broad issues. The first is how do skills relate to employability? Secondly, can increases in skills contribute to lower employment? The third is the question of whether the economy is overall upskilling or deskilling.

A major underlying hypothesis in my research is that within advanced industrialised countries education and, more importantly the skills that education can develop, is a critical factor in determining a person's opportunities in the labour market as well as 
wider life chances. This is an assumption that is currently part of mainstream discourse in most industrialised countries.

In order to test this assumption a range of the arguments and research findings drawn from New Zealand and internationally are considered. In bringing together this literature it is clear that changes in the pattern of demand for skills and changes in supply of skills lead to both price and quantity changes in the labour market. For example, increasing demand for skilled people in an economy may lead to higher earnings for those high skill, high productivity people who are in short supply. Equally, price changes, for example induced by the removal of a minimum wage, may lead to the growth of low skill, low paid jobs that may not have been undertaken at a higher price.

Most researchers acknowledge there are major methodological problems in studying changes in demand for skills, and such problems can be found in all the studies cited. Some of the key methodological challenges relate to the fundamental issues raised at the start of this review such as how to define upskilling. Others relate to when the study was undertaken, and what was happening at the time in the wider social and economic context. For example, a study undertaken in the middle of an economic expansion where low skill people are being brought back into the labour market may come to different conclusions to a study undertaken in the height of a recession. A study undertaken in a period of a high level of domestic economic protection may come to a different conclusion about technological change to that undertaken in an open technologically driven economy. A high level of migration into, or out, of an economy by either highly or lowly skilled people may change a researcher's perspective on skill changes. In addition, the type of methodology used can influence the results of research. For example, whilst in depth case studies provide much useful data on the complex changes occurring at particular workplaces and in regards to particular skills, they are inevitably based on small, and possibly unrepresentative, samples. Alternatively, wider empirical studies can provide an idea of economy-wide changes, but usually rely on relatively crude measures of skill such as formal credentials or broad occupational changes. 
Finally, the outcome of theoretical upskilling/deskilling debates can itself affect trends in a society. If, for example, the upskilling philosophy is generally accepted by the state and by individuals then the concept of upskilling will, in part, be a self full-filling prophecy. For example, there will be an increase in teaching jobs that will be an important part of newly created "high skill" jobs.

\section{A short history of the skills debate}

Much of the debate around upskilling or deskilling has revolved around the impact of the introduction of new technology. In a review of the impact of technology on employment, innovation and the organisation of work, Adler (1992) argues that research on the employment impact of technological innovations have gone through four generations since the second World War. This review also indicates how much research on manufacturing had dominated thinking in this area.

Adler suggests that the first generation (1950s-1960s) was dominated by authors who saw the possibility of broadening jobs and upgrading skills, particularly in relation to repetitive and simple assembly line jobs.

The next group of researchers were to have a greater impact on thinking. Key researchers included Braverman (1974) who is often quoted in support of a deskilling thesis. However, according to Attewell (1992) this deskilling thesis had its original roots in the early decades of British industrialisation. In particular, Karl Marx is seen as greatly influencing thinking. Attewell suggests that this thinking reappeared in the U.S. at the end of the 19th century with the replacement of manual labour with machines. Attewell argues that the advent of computers again revived the debates in the 1970s.

Attewell also argues that theorists of deskilling often looked for proof of managers initiating deskilling and pointed to the use of "taylorism" or "scientific management" philosophies and practices, introduced early in the century. 
Overall, Adler suggests that this second generation of research was based primarily around the idea that "capitalist societies tend to de-skill work in their constant search for lower production costs and greater control over a potentially recalcitrant workforce" (p. 7). While the key researchers suggested that there would be a long run average decline in skills, and work would be organised around assembly lines, there would also be a small number of highly skilled jobs created. According to Adler this group of researchers generally used case studies to show:

- a frequent gap between worker's capabilities and job requirement

- instances in which profitability did seem to call for de-skilling

- other instances in which managerial ideologies and political concerns led to deskilling at the expense of technical efficiency.

It should be no surprise that a search for lower production costs will tend to undermine the position of established workers and established work practices. Expensive skills are a constant prompt for obsolescence. But this cannot establish a presumption of deskilling. For example, as Attewell (1987) notes, the most frequently automated tasks are often those that already utilise a low level of skill. In addition, any case study that focuses on existing enterprises cannot provide an adequate sample, because some of the new skills growth will be occurring in enterprises that fall outside the study frame. For example, a study in a "rust belt" will provide an inadequate picture of what is happening in the economy as a whole. Adler goes on to argue that while case studies were used to suggest widespread deskilling none of the larger scale statistical studies undertaken in this period supported the concept of economy-wide deskilling.

Adler suggests that the third generation of research (late 1970s-early 1980s) moved away from large-scale generalisations, and focussed instead on the "micro-dynamics of changes in technology and work" (p. 7). Within this generation of research it was also argued that skills could be "socially constructed", and that many factors such as political power, union organisation, and market conditions could moderate the direct effect of technology. At the limit, this would imply that a purely socially constructed skill has a zero 
technological base. In this extreme situation the holder of such "skills" depends entirely on her or his political power. This is potentially an exposed position as shown by the restructuring of the waterfront. However, it also clear from the "pay equity" literature which started to emerge in the 1970s that there have been, and no doubt still are, situations where men and women have been differentially rewarded for similar skill sets (e.g. Hyman 1994).

Despite a recognition of the complexity of deskilling / upskilling arguments, Adler argues that there is now a new generation of research providing evidence of a net upgrading of skill requirements in industrialised countries. However, this new generation does acknowledge that within this overall trend there will be pockets of deskilling as well as some continuing creation of low skill jobs. He suggests that the new research shows while class conflicts and local conditions are important they do not stop an overall shift to higher skills brought on by competitive pressures to bring in and use new technology more effectively. He notes (p. 8):

In the new paradigm, competition forces firms to seek out more productive combinations of machine and human capacities. In this process the outcome is, more often than not, an upgrading of skill requirements. Firms, regions, and countries that ignore this relationship suffer a critical competitive handicap.

This new generation of research is represented by writers in a collected of studies edited by Adler (1992). As an example, in a chapter in this book, Senker argues that in Britain while there are many situations where evidence cannot be found of upskilling in particular industries this can simply be that the industry has not recognised the need to change to remain competitive. He argues that in U.K. there are major managerial, organisational and social barriers to bringing in "best practice" use of technology.

Overall, Adler argues that two themes emerge as significant factors in competitive performance based on new technology, that of competence and continuous learning ( $\mathrm{p}$. 13). 
The effective use of new technologies will require a workforce with both higher skills and broader roles, and hence the theme of competence;

The effective use of new technologies also requires that the business firm be substantially reconfigured to support a process of continuous learning.

Adler (1992) argues that effective use of new technologies requires that enterprises be substantially reconfigured to support a process of continuous learning. The concept of "learning workplaces" is increasingly common in the upskilling/deskilling literature, with the idea that much of the learning involves "soft skills.

In New Zealand, Bullard (1996: 103) has also reviewed the literature on skills and expertise. He argues that the traditional literature is based on the following assumptions:

expertise is universal and homogenous. Its technical features exist independently of any cultural or historical context.

Expertise consists of the individual mastery of tasks, and once gained is consistent and largely invariable.

Expertise is gained through repeated experience and practice.

Bullard suggests that this model only holds in a period of stability and certainty. $\mathrm{He}$ argues that under conditions of rapid technological and social change there is a move away from traditional "hard skills" and a shift to an emphasis on "soft skills". Hard skills involve technical knowledge while soft skills are process skills that enable people to cope with and adapt to change, uncertainty and working in teams and networks. Given uncertainty there is a need for constant upskilling, or at least reskilling, and this is supported by their case studies. Much of this upskilling will not be recognised in formal credentials. Corcoran and Boggess (1995: 47), in a review of the intergenerational transmission of poverty and inequality also place much emphasis on "soft skills". They argue that a potentially important link between parental and child poverty is that it is possible that "economically unsuccessful parents fail to teach their children the non- 
cognitive or "soft" skills necessary to find and keep jobs." These type of "soft skills" can also be learnt from peers in a neighbourhood. For example, Wilson (1998) suggests that children in poor American neighbourhoods are taught not to make eye contact with strangers and to act tough. These are not seen as good characteristics in the job market.

Other recent international research support a trend to upskilling or just as importantly, if it is not occurring, the need to upskill. In a British study of manufacturing Haskel (1996) showed that by the mid 1990s the ratio of wages of non-manual manufacturing workers to manual workers was at the highest since the late 1940s. He suggested that it is new technology, such as computerisation, that has boosted demand for skilled workers.

In America, Gottschalk and Smeeding (1997) also focus closely on the role of technology in creating highly skilled, well paid jobs. In a review article, they note that U.S. data shows that over the 1980s there was an increase in the premium paid to skilled workers, at a time when the supply of such workers was increasing rapidly. They come to the conclusion that a major shift in labour demand must have occurred. In turn, they suggest that there may have been three reasons for this shift; "deindustrialization", increased international competition, and skill based technological change.

Based primarily on the review of Freeman (1995), Gottschalk and Smeeding suggest that, in the U.S., increased trade provides for only about 20 percent of the shift in the demand for skills. They do, however, note the work of Wood (1994) who argues that 50 percent of the decreased demand for less skilled workers came from increased international trade. But, Gottschalk and Smeeding contend that this does not explain the rise in skill demand in the non-traded section of economy.

Overall, as a result of their review of the literature, they conclude: (p. 650):

Technological change remains one of the only factors that will result in a ubiquitous increase in the proportion of college educated workers employers are willing to hire in spite of the large increase in the college premium. Deindustralization, increases in international trade, and declines in unionization and the real minimum wage are all consistent with the decline in the relative wages of less skilled workers but all these theories predict that firms would choose less skill intensive 
production methods, not more skill intensive methods, as we in fact observe. Only technological change is consistent with rising skill intensity in the face of rising prices.

However, again viewing these changes from a different perspective, another explanation could be put forward. Well-educated workers are destined to become part of a managerial elite and employers could be treating their credentials as a sign of similar attitudes and belief systems rather than the credentials signalling superior technical skills.

Castells (1996) discusses a range of case studies of particular industries that try and establish the direction of skill changes. In most of the case studies firms were eliminating routine jobs. As an example, he refers to a study of the clothing industry in U.S. undertaken by Parsons (1987). In this study direct production of clothing was being phased out, with the U.S. part of the operation becoming the design and dispatching centre. In these centres there were jobs for high skilled designers and marketeers (as well as mailing clerks). The low paid, low skilled workers were generally either offshore or, in line with concepts of core and periphery labour markets, in illegal, domestic "sweatshops".

Much of the work on skill changes focuses on manufacturing which in employment terms is now only a relatively small part of total employment in industrialised countries. Zuboff (1988) ventured further than manufacturing, and using U.S. manufacturing and service industries, found examples of both upskilling and deskilling. However, overall she argued that new technologies often require workers to use "intellective" skills. Workers no longer simply manipulated tools and other tangible objects, but also had to respond to abstract, electronically presented information. Zuboff suggested that computer technology has the potential to move beyond Taylorism, and instead create more skilled and rewarding jobs, and workplaces where learning is encouraged and rewarded. 


\section{An alternative point of view within New Zealand}

As discussed writers such as Braverman (1974) have put forward a deskilling thesis. In New Zealand, education commentators such as Snook (1989) have supported this view. While not arguing specifically a deskilling point of view, Higgins (1993) provides the most detailed, and well researched, alternative set of views about upskilling and deskilling available in New Zealand.

Higgins argues that the "official" view of skill changes is heavily influenced by ideology. For example, she argues there were incorrect assumptions made in sociological writings in the 1970s such as "white collar" employment in the service sector being seen as skilled. An assumption that it was skilled, but without detailed research to test of this was true, would then lead to the incorrect conclusion that a move to service industries led to upskilling. In reviewing a wide range of studies Higgins states:

\footnotetext{
...the changing composition of employment resulting from service sector growth is not a simple phenomenon involving a wholesale upskilling of the labour force. Not only must the nature of the sector and sub-sector growth be considered, but also the heterogeneity of the labour force and the positions of various groups within the occupational structure of both service and non-service sectors (p. 55).
}

Higgins draws heavily on a Marxist framework and is particularly critical of the view of many upskilling proponents about a move to more worker participation in the production process. She argues that many upskilling theorists ignore important social relations in firms, in particular that capital and labour are ultimately in conflict. This conflict will have a major impact on the effects of adopting and using new technology.

Higgins actual empirical research showed a complex set of trends that potentially support the view that there is a polarisation in the demand for skills 


\section{A polarisation in the demand for skills?}

In an overview of changes in skills, Castells (1996) argues that in advanced economies production is now increasingly concentrated on an educated section of the population aged between 25-40. He also argues that these economies could potentially operate without a significant proportion of the working age population, but suggests that this will not necessarily lead to mass unemployment. Instead, in order to keep participation rates high more "contingent" jobs will be created. These will not only be insecure jobs and lowly paid but will require few skills. Yet, at the same time he also argues that the new economy would increase the importance of occupations with a high information and knowledge content in their activity. Managerial, professional, and technical occupations would grow faster than any other occupational position. This will result in a highly segmented social structure.

There have been suggestions by other analysts that there will be both growth in "information-rich" occupations and in low-skilled jobs in the service sector (e.g. Sayer and Walker 1992, Bluestone and Harrison 1988).

The concept of a polarisation of skills comes up in other studies. In a New Zealand review of "upskilling/deskilling" Couchman et al (1988) argue, mainly on the basis of case studies, that technological change reduces the demand for middle skilled and low skilled workers and is likely to polarise the skill requirements of the workforce. A small proportion of jobs will become more skilled and a much larger proportion will become less skilled.

As discussed in Chapter two, Reich (1993) also sees the potential for polarisation. The symbolic-analytical" occupations will tend to be high skill and part of the international economy, while within "in-person services" there will be many low skill jobs. However, unlike low skill "routine production" work which can be carried out anywhere in the world, these low skill in-person service jobs usually remain within an economy. 
A case study showing polarisation is Milkman (1991), who studied an upgraded General Motors plant in the U.S. She argues that after plant modernisation, the skilled workers enjoyed skill upgrading and gained higher levels of responsibility. They also formed 11.5 percent of the workforce after upgrading, up from 5 percent. However this was due to a quarter of the production staff losing their jobs. For those remaining production workers, whose jobs were already extremely routinised, they typically experienced further deskilling and found themselves subordinated to and controlled by the new technology to an even greater extent.

This type of finding reinforces the idea that a specialisation of occupation brought about by an increasing division of labour can lead to a higher level of skills or a lower level depending upon the job and the setting it is carried out in. In professions, for example, specialisation is often connected to upskilling, such as a doctor becoming a specialist in a particular field. In assembly line work such as in car factory just described, specialisation often means simplifying tasks. In contrast, again in an assembly line type of job, team working and multi-skilling, particularly if linked into programmes such as "total quality management", are often associated with upskilling.

In the U.K., Gallie (1994) discusses the idea of skill polarisation. Based on extensive survey work he suggests that at first sight there appears to be little support for the "downskilling" scenario. However, instead he argues that there has been a polarisation of skill experiences between social classes. Those who already have high levels of skill have seen an increase in their skill levels, while those with low levels have seen their skills stagnate. Gallie suggests the growth of service industries has been a particularly important factor behind this trend. The expansion of private sector services has been associated with the growth of a large and low skilled area of manual work. He also suggests that technology is important in this process. Those in a position to use advanced technology have seen skills increase, whereas others may see skill stagnation. Overall, he argues men have benefited most, whereas women have been less likely to see their skills increase. Gallie suggests that this is linked to women being in part-time work, where skills are already low and there is little opportunity for upgrading. This supports the 
often-stated idea that "on-the-job" learning is an important part of the upskilling process, and makes issues such as whether people are in a "core" labour market increasingly important.

In support of this idea, Gobbi (1998), using New Zealand data, found that those most likely to receive employer support for education and training were those with relatively high formal education, while those least likely to receive support include those working part time and those people who were in casual jobs or temporary employment.

As another example of polaralisation, and again using British data, Elias (1997) argues that in the period 1990-95 there was an increase in senior managerial and professional occupations but a decline in lower level occupations (clerical, secretarial, personal services, operators). In between these occupations sit junior managers, associate professionals, technical and craft jobs. He suggests that craft jobs, many of which were relatively well paid, continued to be reduced over the period studied. The workers from these craft job found if difficult to find new work, or if they did it tended to be at lower wages. Elias makes the point that for these workers retraining does not offset negative impacts of redundancy.

Finally, a further issue in polarisation is whether there is a group in society who, for a variety of reasons, lack basic core skills on which to build more job specific skills. For example, in the U.K. Finegold and Soskice (1988) argue that many workers lack the basic skills needed for further on-going training.

\section{Is a base level of skill required for participation in paid work?}

The idea that a minimum, but rising, base level of skills is needed to participate in the economy and in society in general emerges in some studies of employment (e.g. Jencks 1993). As noted in the quote at the beginning of this chapter, Jencks suggests that as the majority of society moves to have a reasonably high base level of literacy, numeracy and perhaps social skills, then anyone lacking these skills has the potential to become economically and socially excluded. 
Such a view also emerges in specific studies of literacy. For example, in a New Zealand survey of prose literacy, document literacy and quantitative literacy amongst adults a bottom level of literacy was seen as where "[p]eople at this level have very poor skills, and could be expected to experience considerable difficulties in using many of the printed materials that may be encountered in daily life" (Ministry of Education 1997: 2). This group of people will find difficulty in even filling very low skilled jobs. In the New Zealand study about 1 in 5 people fell into this bottom group. Given that there was found to be a strong relationship between formal education and literacy it is not surprising that seventy five percent of those who had not gone beyond primary school were in the lowest level of prose literacy, with similar results for document and quantitative literacy. The researchers note that there is a need for a focus on adult literacy in New Zealand as a key part of any "upskilling" strategy.

Even if there is a base level of skills required, this base could rise or fall according to the business cycle. Those on the margins of skills will potentially be brought in to the labour market during strong economic growth. These marginal people will then tend to be the first people laid off in an economic decline. In addition, there will always be a small group of people through severe impairments who will never find a position in the labour market.

\section{The loss of low skill jobs}

The concept of a base level of skills is connected to the idea low skill jobs are disappearing from industrialised economies. There is a considerable amount of New Zealand and overseas literature that shows that the loss of jobs has particularly fallen on those with low levels of formal qualifications (e.g. OECD 1994, Herzog 1996). However age, gender, ethnicity, health status and other factors such as geographic location are also important factors when analysing loss of jobs or difficulty in finding paid work. Some of these variables are associated with the level of formal qualifications held. 
As already discussed, low skill "routine-production" type jobs will tend to be lost from high-income industrialised countries (Reich 1993). Many of these jobs have been found in manufacturing industries, and have tended to be filled by men.

\section{Changes in occupations for those in paid work}

Much of the literature arguing for a need to upskill has been based around actual or predicted growth in occupations that appear to require an advanced level of skills. This research has tended to be based on either broad groupings of occupations such as managerial and professional groupings, or focussing on specific occupations that require formal tertiary education such as accountants or economists.

This type of research generally indicates a shift to occupations that require higher levels of formal education. As discussed in Chapter two, there is much debate about how well broad groupings of occupations signal the use of particular skills. This is despite recent attempts by statistical agencies throughout the world to more closely align occupations with skills.

Castells (1996) provides an analysis of occupational growth at a broad level in the G-7 nations. Based on this type of international comparison he argues that across the economies studied there has been a trend towards the most "informational" occupations of managers, professionals and technicians. He also notes that the data does not suggest a strong move to a low skill "hamburger society" despite some growth in this area. He shows that in the U.S. in 1991 employment in "eating and drinking" places was 4.9 percent of total employment (up from 3.2 percent in 1970)

Drawing on these data, as well as other data sources, Castells argues that the evidence shows a common set of characteristics in G-7 countries, although with some variations around the development of services and manufacturing (pp. 228-229)

- the phasing out of agricultural employment

- $\quad$ the steady decline of traditional manufacturing employment 
- the rise of both producer services and social services, with the emphasis on business services in the first category, and health services in the second group

- the increasing diversification of service activities as sources of jobs

- the rapid rise of managerial, professional, and technical jobs

- the formation of a "white-collar" proletariat, made up of clerical and sales workers

- the relative stability of a substantial share of employment in retail trade

- the simultaneous increase of the upper and lower levels of the occupational structure

- the relative upgrading of the occupational structure over time, with an increasing share of those occupations that require higher skills and advanced education proportionally higher than the increase of lower-level categories

All these trends can be measured to some degree using official data sources. Many of them are therefore explored in Chapters sixteen and seventeen using New Zealand census data.

However, some researchers argue that there is a need to analyse industry and occupational changes simultaneously. Attewell looked at occupational change within manufacturing, suggesting that while the industry group was declining as an overall employer the occupational structure was changing. He analysed changes in manufacturing in the U.S. from 1976 to 1990 using Bureau of Labor Statistics' establishment surveys. From these data he shows a process of skill upgrading through occupational redistribution. Higher skilled occupations grew relative to lower-skill ones both in direct production areas and in non-production areas. This included a rising ratio of craft workers to machinery operators. He suggests that part of this may be to do with low skill "routine production" jobs moving offshore, but also may reflect a change in nature of work in manufacturing.

Attewell also notes that in manufacturing in the U.S. the proportion of non-production labour increased from around 18 percent in 1920 to around 32 percent in early 1990s. However, within this trend there was a large decrease in clerical and administrative employment since the early 1980s. 
Wright and Singelmann (1982) also analysed both industrial and occupational changes in the U.S. They suggested that much of the upgrading of skills was caused by the growth of particular industries, and occurred in parallel with de-skilling occurring in other industries. They suggested that the growth of high-skill jobs between 1960 and 1970 was due to the growth of sectors such as health and education, but in areas such as manufacturing deskilling was occurring. They suggested that if the growth of high skill areas, including many that were driven by increased government spending were to slow, then an overall pattern of deskilling might emerge.

Singelmann and Tienda (1985) then undertook further analysis in this area using data from 1960 to 1980. They found that while the growth of high-skill sectors had slowed, there were shifts in other industries towards managerial, professional and technical occupations.

While some of the occupational changes in large countries are of interest, occupational shifts could be somewhat different in a very small, but globalised, economy if there was a strong specialisation in particular industrial areas. For example, in New Zealand a much higher proportion of the population could be in farming or fishing occupations, or potentially in the computer programming industry, than would be possible in a large country such as the U.S. This specialisation could even be in areas such as management, design and research. For example, in manufacturing the managerial, design and marketing expertise is often concentrated in one nation, while the actual manufacturing workforce live in another. In contrast, in the past the number of managerial and professional jobs was somewhat more closely tied to the number of more elementary occupations directly supporting them within one country, and often within one city.

\section{The growth of high "cognitive ability" jobs}

Herrnstein and Murray (1996) argue that, historically, there were not many jobs that required a high level of cognitive ability. They argue that certain groups, such as high IQ women, were also excluded from particular areas of paid work. This meant that many 
high cognitive ability people were in jobs, which they suggest, could not use this ability, such as farmers, housewives, and shopkeepers. ${ }^{42}$

Herrnstein and Murray go on to argue that there has been rapid growth in high IQ occupations in the last century. As evidence they discuss a number of such professions taken from the 1900 census. These are accountants, architects, chemists, college teachers, dentists, engineers, lawyers, and physicians. They also added in some recent groups: computer scientists, mathematicians, natural scientists and social scientists. Using these data they argue that in 1900 the "high-IQ professions" employed 1 in 20 of the top decile of intelligence (all people not just those in labour force), but by 1990 one in four. Recent New Zealand trends for prime-aged people in the "high cognitive ability" jobs identified by Herrnstein and Murray are explored in Chapter seventeen.

Herrnstein and Murray also suggest that managerial occupations are increasingly being filled by people with high cognitive ability. Again limiting their analysis to the U.S., they contend that the recruiting of a chief executive officer now taps into a much wider pool of talent. They suggest that in the past this pool was limited to men born into an affluent family who were not only generally white anglo-saxon Protestants (WASP), but also Episcopalian WASPs. Historically, there was also a high rate of sons becoming the CEO of a family firm. Herrnstein and Murray argue in the past many people reached high positions "because they did not have to compete against more able people who were excluded from the competition for lack of the right religion, skin color, national origin, or family connections" (p. 58). Finally, they suggest that increasingly top people in companies are recruited from fields of study such as finance and law that, they suggest, already have a high level of screening for intelligence.

\section{Incomes and skills in industrialised countries}

Even in situations where low skill workers have kept their jobs their wages have been under pressure. For example, in the U.S. a range of writers have shown that the wages for

\footnotetext{
42 In New Zealand farmers generally continue to have a low level of formal qualifications. This is perhaps because family based inheritance in this type of enterprise can reduce the incentive to formally upskill.
} 
less skilled male workers had fallen steadily in the period prior to the current economic boom (e.g. Berman et al 1994, Katz and Murphy 1992, Juhn 1992, Levy and Murnane 1992, Topel 1993).

In the U.K., Haskel (1996) showed that the gap between the highest and lowest paid manual workers in British manufacturing enterprises was the greatest for over a 100 years. He links these changes in income to changing skill requirements. He suggests that since the 1940s the workforce has become more skilled, but until the 1970s this increase reduced the wage premium such workers could earn. Since then the demand for skilled workers has risen faster than supply. Also in Britain, researchers such as Gosling et al (1996) and Gregg and Machin (1994) have demonstrated increasing returns to education and experience. In addition, Gosling et al had investigated whether women moving into paid work in the U.K. had driven down wages for men. However, they found that the major increase in participation in paid work by women had come from skilled women.

In New Zealand, Maani (1995) has shown that income levels rise as formal qualifications increase. Maani found also that between 1981 and 1991 the rates of return to most educational qualifications, and especially returns to tertiary education increased for both men and women. Those with the highest incomes held postgraduate qualifications, and the lowest had no qualifications. Statistics New Zealand (1999) also shows this pattern in the 1996 census. This view has been supported by the work of Gibson (1998). Gibson studied twins and found that for each extra year of education there was an economic rate of return of 5 percent. However, Dixon (1996a) shows that in New Zealand between 1984 and 1994 the premium for those with university qualifications reduced. Dixon hypothesises that the supply of such people may have increased faster than demand in this period. At a more basic level in New Zealand, the 1996 Ministry of Education (1997) adult literacy survey showed that there was a strong link between literacy skills and income.

Finally, and linked at times to the globalisation of work, there can also be much polarisation of income within particular skill groups, credentials and occupations. For 
example, the most successful lawyer within commercial law is likely to be paid considerably more than the least successful. In addition, a commercial lawyer will generally be paid more than a family lawyer. In a more extreme example, a talented singer in a local cafe will be paid far less than a singer who may have similar talent but who has a world audience through electronic means and effective marketing. ${ }^{43}$ Finally, the polarisation of opportunities can be clearly seen in the area of physical skills. The demand for the strength and stamina needed in jobs such as mining or tree felling has diminished considerably. However, amongst an elite of sports people such skills are now highly rewarded.

\section{Can upskilling help reduce unemployment?}

This is perhaps the most important question in the skills debate. There are two levels to this question. Firstly, can upskilling reduce unemployment for individuals and particular groups of people? Secondly, can upskilling across the whole economy contribute to increases in employment?

With regards to the first proposition, as already discussed there is a considerable body of New Zealand research suggesting that education is a critical factor for determining labour market outcomes for individuals (for a summary see Morrison 1997b). Within this literature there is also some evidence that education can help reduce the impact of other variables associated with disadvantage. For example, Winkelmann and Winkelmann (1997) using 1981, 1986 and 1991 census data show that education is substantially more important in determining labour market outcomes for Maori than non-Maori. However, they add that the downside of this finding is that a lack of education imposes a major penalty on Maori.

As an example relevant to the New Zealand debate, Caspi et al (1998) used data from the Dunedin Multidisciplinary Health and Development Study to test hypotheses about

\footnotetext{
${ }^{43}$ Although new technology, such as illegally downloading music off the internet, may change this relationship.
} 
predictors of youth unemployment. They did this by using data on individual's human capital, social capital and personal capital (see chapter two). They found that there was a relationship between these factors and employment but in the area of human capital a lack of high-school qualifications, poor reading skills, low IQ scores, and limited parental resources significantly increased the risk of unemployment. They argue that basic reading skills are important in employment prospects. As an example, they suggest that a lack of reading skills make finding a job difficult through not being able to read job advertisements or filling out applications.

As a further New Zealand example, the 1996 New Zealand adult literacy survey showed that there was a strong link between literacy skills and labour force status (Ministry of Education 1997). They found that almost half the unemployed group had very low levels of prose, document and quantitative literacy. In addition, in a study of New Zealand long term unemployed a significant proportion of respondents stated that they had a lack of literacy, work experience and qualifications (Parker 1997). Pacific Island people were over-represented amongst those stating that they had literacy or numeracy problems.

This type of literature suggests that if an individual or a particular group can increase their level of skills versus another within the economy then their relative position is likely to improve.

The literature is, however, far less clear on whether the upgrading of skills across an economy will help lower unemployment. In part, this is because the skill base of people in other countries will not be static. But there are also theories that suggest that even if the people at the bottom end of the labour market upgrade their skills this will simply result in displacement not job creation. Those with basic literacy skills will replace those who currently have jobs but are illiterate (Solow 1998). Based in U.S. data, Solow goes on to suggest that even with some basic upskilling there would need to be a substantial reduction in wages at the bottom end of the labour market to increase aggregate demand enough to absorb low skilled people. 
The "new growth theories" (e.g. Denison 1985, Romer 1989) represent one approach to the possible link between education and overall job creation. They suggest that investment in human capital is an important factor in innovation, economic growth and, ultimately, job creation. However, they also suggest that the linkages are complex and depend on a wide range of factors including the openness of an economy to trade and information flows and the level of market competition. It would, for example, be difficult to have a period of strong job growth in a small country such as New Zealand during a period of world recession.

In a New Zealand review of innovation, Frater et al (1995) drew on the "new growth theories" but also discuss a range of factors that may lead to economic growth. In this study technology was ultimately seen, in the long term, as a job creator rather than a destroyer. With this type of view in mind Schultz (1975) and Gill (1988) indicate that higher levels of education give workers the skills to adopt new technology.

However, the route to job creation could also vary considerably. For example, Herrnstein and Murray (1996) argue that any attempts to improve education should focus on improving the opportunities for the "cognitive elite". They argue that it is this group who will provide the scientific research and entrepreneurial ability in an economy in order to create competitive industries. In contrast, researchers such as Fischer et al (1996) argue that more effort should placed on improving educational opportunities for disadvantaged groups.

\section{Conclusion}

As discussed at the beginning of this review a major underlying assumption in this research is that education and, more importantly the skills that education can develop, is increasingly a critical factor in determining a person's opportunities in the labour market as well as many other areas of life. On balance, I argue that the literature reviewed supports this broad conclusion for individuals. In particular, having a basic level of literacy, numeracy and social skills appears to a key in determining whether a person can participate in the labour market. 
At the economy wide level, the evidence suggests that labour demand in advanced industrialised economies has been shifting towards occupations that require higher levels of cognitive skill. In particular, there has been strong growth in skilled symbolicanalytical type managerial and professional occupations across most industries. At the same time, there has been a major loss of manual skilled and unskilled routine-production type jobs in industrial economies. In addition, in industrialised economies there has been significant growth in "in-person service" occupations. These can be either skilled or relatively unskilled occupations and are found predominantly in the retailing, hospitality, business and financial services, and community and personal services sections of the service sector. Many of the less skilled jobs in these industries are also part time. Moreover, these part-time occupations are often low paid with little opportunity for career advancement. So the research literature does lend support to the concept of a polarisation of skill demand. A critical question in this polarisation is whether people filling the low skill jobs are trapped for long periods in these occupations. A second critical question is whether people in low skill, low wage, areas of work generally live in low-income households. These two questions are partly explored in subsequent chapters.

Even more problematic is whether a group of people in industrialised countries now have insufficient skills, either through lack of natural ability or poor education, to even enter the labour market or to function adequately in many areas of an increasingly complex world. The research literature does lend support to the idea that in modern economies a small, but significant, group of people cannot, without considerable support from the community, participate in the market economy.

Finally, whether increasing the supply of skills across an economy will ultimately increase employment is less clear. This depends on the types of skills being developed, whether similar sets of skills are being developed in competing countries, as well as a complex set of additional factors such as the openness of an economy to trade and information flows, the level of natural resources, distance from markets, the level of market competition and, particularly for small countries such as New Zealand, the state of the world economy. In 
my view, a strategy of upskilling the population is likely to lead to higher employment levels than had this upskilling not occurred but a "full-employment" outcome is certainly not guaranteed. Taking a view that upskilling cannot improve the economic prospects of a nation seems an extremely risky strategy. If you are correct in this view, then a considerable amount of resources will have gone into education without lifting employment levels. However, this education is still highly likely to be able to improve a person's life through assisting them in coping in an adverse economy. But if a nation has under-invested in education then the loss is likely to be even greater. In a period of uncertainty, a commitment to upskilling does seem to have the greatest possible benefits and least risk despite the costs involved.

Many of the issues raised in this review cannot be tested using census data. Therefore, this research will focus on four "skill" hypotheses. These are:

- that in New Zealand formal education is an increasingly critical factor in determining whether a person participates in the labour market

- that the strongest growth in jobs in the 1986 to 1996 period has been in the skilled symbolic-analytical and technical analytical occupations

- that, supporting the concept of polarisation of the demand for skills, there has also been growth in low skill in-person services jobs

- that there was a loss of routine-production jobs over the whole period 1986 to 1996, with the loss continuing even in the employment growth period of 1991 to 1996. 


\section{Chapter 8}

\section{Changes in paid work-time patterns}

\section{Introduction}

While hourly rates of pay are clearly important, time spent in paid work will also generally directly impact on a person's income, and ultimately their standard of living. The time spent over a person's lifecycle in paid work is usually also important in terms of total earnings. When work is carried out can also be important. For example, parents undertaking Monday to Friday in daylight hours may find it easier to obtain low-cost childcare than those working "non-standard" hours. Parents who can work standard hours may therefore be more likely to be work rich.

Many of the forces discussed in Chapter six influence work-time patterns. There are also other factors that will influence the time spent in paid work by individuals. These include:

- unions - in the past unions were particularly important in reducing working weeks, but in recent times have been critical of part-time work

- laws - these can be related to safety issues, such as the amount of time a truck driver can work, or wider issues such as shop trading hours

- "gender contracts" negotiated within couples and households about paid and unpaid work

- a person's lifespan and their health within it

- the availability of parental leave and non-parental childcare

- the availability of income support and the eligibility criteria

- the satisfaction gained from paid work

- the level of earnings 
- whether a person is self employed, a wage earner or on a salary

Industrial changes can also affect work time patterns. For example, in an agricultural based economy paid work may need to be carried out 7 days a week, although usually during daylight hours, with an added intensity of work during peak periods such as harvests. In some forms of manufacturing, work may be able to be organised around a "standard" daylight hours working week. In contrast, a service-based economy may need to operate 7 days a week, 24 hours per day.

Work time, and thus whether people may be work rich or work poor, can be measured in terms of hours per day, weeks per year, or years per lifetime. Often "standard" employment is seen as working in a wage or salary type job 40-hour week, Monday to Friday in daylight hours, and around 48 weeks per year and long-term employment in one main job. While there is much interest in "non-standard" work patterns in New Zealand, very little empirical research has been carried out in this area. This primarily reflects a lack of suitable data.

Despite the lack of New Zealand data on the wider aspects of working time, Brosnan and Walsh (1996a) note:

The last three decades have seen a major challenge to traditional forms of work organisation. Until the 1960s, employment was offered predominantly as forty hours a week for 52 weeks of the year, performed in daylight hours, and with the possibility of continuous employment until retirement. This suited male workers who comprised the overwhelming majority of the paid labour force up to that time. By the 1990s, this model of "typical" employment had ceased to be the norm. (p. 78).

A "standard" work pattern has often been seen as a foundation for building heterosexual nuclear families upon. An expectation of having a standard work pattern can encourage people to take on long term financial commitments, such as borrowing for housing or having children. 
In the following sections, some international theory and evidence on three areas of nonstandard work time are discussed. These are casual and temporary work, and related to this type of work arrangement, work tenure. There is then a discussion of shifts towards shorter or longer hours than those that are seen as "standard". Finally, self-employment is discussed. Self-employment is often seen as being a "non-standard" type of work. With self-employment, there is also generally more scope for non-standard hours to be worked. In this review, as throughout all of the research, the role of education in the various changing work-time patterns is also discussed.

\section{Casual work, temporary work and work tenure}

As discussed in Chapter two, there are major definitional problems when dealing with temporary work, casual work, and tenure of paid work. There are also major data collection problems. In New Zealand, in particular, there is little data on casual and temporary work, and no reliable data on job tenure. This severely limits any analysis of the links between the provision of casual or short-term work contracts and the growth of work-poor and work-rich individuals and households as has been carried out in the U.K. The international literature, however, can provide a guide to what is likely to be happening in New Zealand.

While not solving the data definition and collection problems the OECD reviewed data on temporary work within OECD countries in 1993 and again in $1996 .{ }^{44}$ In their 1993 study the OECD found some evidence that previously unemployed people are over-represented in temporary work. They suggest this could mean that such work opens up opportunities for employment. However, they also suggest it might mean that a high proportion of new employment is through temporary contracts, so most of the unemployed would also end up on these contracts. Secondly, they suggest there may be continual turnover among temporary workers so they move back and forward between the states of unemployment and temporary work. This raises issues about ways of moving individuals from a state of being long-term work poor to long-term work rich.

\footnotetext{
44 Most of the studies discussed in this section on non-standard work are discussed in more detail in Callister (1997).
} 
In 1996, the OECD found in all countries that employed teenagers were generally far more likely to be in temporary work than older workers. There had been a strong increase in temporary work amongst youth in almost all countries. In part, this may reflect students increasingly working part time to support their studies, particularly when a private contribution is required for tertiary education. But in all countries women were also more likely than men to be in temporary work arrangements.

In this updated review the OECD again noted that while unemployed people who gain jobs are most likely to move into a permanent job, a higher than expected proportion flow from unemployment into temporary work. Teenagers are more likely to go from unemployment to temporary work than adults. The OECD also noted that there is some evidence from longitudinal studies that people in permanent work are likely to move to other permanent work, while a high proportion of temporary workers have come from other temporary work. Subsequent research in Britain by the Employment Policy Institute (1996), using both HLF data and official unemployment statistics, showed a link between temporary jobs, unemployment and ultimately benefit use. Three quarters of the people making new claims for unemployment benefits in 1996 had made at least one previous claim. In addition 52 percent of all people making new claims had been off a benefit for less than a year. The data indicated that people with short periods of unemployment tend to go to permanent jobs while those with long periods of unemployment end up in temporary jobs. This type of finding lends some support to the concept of dual, or possibly segmented, labour markets.

In New Zealand Anderson, Brosnan, and Walsh (1992) carried out a survey of enterprises to gauge changes in employment arrangements between 1985 and 1991. In analysing the findings the authors note:

The survey responses indicate some movement to a more flexible workforce as a means of reducing relative labour costs. This was achieved primarily by moving work outside the workplace or by the use of non-employees (externalisation) rather than increasing the use of casual and 
temporary employees (casualisation). The data do not support an overall conclusion that casualisation has been a widespread response to the recession of the late 1980s (p. 96).

In a follow-up, Brosnan and Walsh (1996a\&b) were involved in a postal survey in Australia, New Zealand and South Africa.

Brosnan and Walsh (1996b) note that in the mid 1990s the great majority of New Zealand workers were employed as permanent full-time employees, with little change in composition between 1991 and 1995. While the largest form of "non-standard" work in both years was permanent part-time work, the two forms to show the greatest change were fixed term and casual employment. According to their data casual work declined as a percentage of the workforce from 8.4 percent to 5.4 percent between 1991 and 1995 , whereas fixed term employment grew from 1.1 percent to 3 percent of the workforce. Brosnan and Walsh note that most of the decline in casual work was accounted for by a fall in part-time casual work, whereas full-time casual work as a percentage of the workforce only fell slightly. Most of the increase in temporary work was in part-time temporary work, which just about doubled in the period analysed. The researchers also state that in 1991 fixed term employment was almost totally within the public sector but by 1995 had risen to 2 percent of the private sector workforce and had doubled in the public sector.

Brosnan and Walsh give two possible reasons for the decline in casual work. The first is that the economic cycle is the main determinant of labour force composition and that in early stages of a recovery employers move away from casual employment. The second is that under the Employment Contracts Act it became cheaper to employ full-time permanent workers for longer hours and this was preferable to the employment of a casual workforce.

Overall, the authors argue that in New Zealand the suggestion "...that a pronounced shift to non-standard employment has taken place must be viewed with some scepticism"(p. 165). However, this does not rule out one small group in New Zealand society having 
insecure work, or the potential for many work-poor people to be moving in and out of insecure work.

In the U.K., Gregg and Wadsworth (1996a), using data from the General Household Survey and the LFS, studied entry-level jobs. They defined these as belonging to those who were in a job with 12 months or less tenure and who were out of paid work a year earlier. They conclude that the stock of jobs available to the non-employed worker is different in the 1990s from that of the 1970s. They state that the "full-time job is in secular decline and is being replaced with either part time, self-employed and latterly temporary working opportunities"(p.16). They also note the wages in these entry jobs had fallen in the period studied.

Job tenure is another potential measure of how "temporary" a job is. There are various measures of tenure. One is time spent with a particular employer. Another is time spent within a particular occupation. This part of the review only looks at tenure with a particular employer. Again, there is no reliable information on tenure in New Zealand. Research in the U.S. provides the most important source of information on changes in employer based tenure in industrialised countries. In the U.S. surveys go back to the 1970s. On the basis of a range of studies, using a variety of analytical approaches, it appears that there has been very little decline in average job tenure in the last couple of decades (e.g. Diebold et al 1994, 1996, Farber 1995, Swinnerton and Wial 1995, 1996). However, the distribution of long-term jobs across the population has changed in two ways, again demonstrating important links between education and employment. First, one group, particularly men with little formal education, are substantially less likely to be in long term jobs. Second, women with at least a high school education are substantially more likely to be in long-term jobs than they were twenty years ago. Despite these changes, men on average still have longer spells of job tenure than women.

In contrast, researchers in the U.K. found that over a twenty-year period from 1975 to 1995 median job tenure declined, with the distribution of job tenures shifting towards shorter-term jobs (Gregg and Wadsworth 1996b). Twenty percent of the workforce in 
1995 had been in a job for less than one year, compared with 15 percent in 1975 . However, they state that most of these changes occurred prior to 1985. In the twenty year period studied there had been a significant increase in average tenure for women. There were also group variations, with the most dramatic decline amongst men aged 50 and above. As in the U.S., average tenure for women was still significantly less than for men.

Closely related to tenure, Gregg and Wadsworth suggest that labour turnover has risen markedly for older workers and less-skilled men. For the former group this was primarily through increased exit from the employed labour force. They note that this is also a major factor in the reduction in overall job tenure.

Education and having dependent children are the key variables affecting tenure for women. Having young children tends to work towards removing women from the workforce, while education is a key factor in keeping women in it. For example, in the U.S. Klerman (1993) found that high school graduates were more likely than other women to have worked full time before the birth, more likely to return to same employer, and more likely to return to full-time work. According to Klerman in the early 1990s nearly 90 percent of women who worked full time both before and after childbirth continued to work for the same employer. In a more recent study, Angrist and Evans (1998) using U.S. census data from 1970 through to 1990 found that the effects of children on labour supply of college-educated women and women whose husbands had high wages was by 1990 very low and, they suggest, possibly even absent. ${ }^{45}$ In contrast their research showed that the labour market consequences of having children for poor and less educated women were far more substantial.

Other U.S. data indicates that two labour markets may be operating, with some women, particularly those well educated, in long duration full-time jobs, while another group have high turnover, "peripheral" jobs, and/or have long spells out of the labour force. In a review article (of primarily quantitative data from longitudinal surveys and census data)

\footnotetext{
45 As will be shown in other chapters the wives of high-income men will tend to be well educated so these variables are not independent.
} 
Nakamura and Shaw (1994) argue that in the U.S. most women are either persistent workers or non-workers, and the period surrounding the birth of a first child provides crucial information on this heterogeneity. Women who return to work shortly after the birth of a first child are considerably more likely to be workers throughout much of their adult lives. Klerman and Leibowitz (1993) provide estimates of job transitions over an eighteen-month period in 1990. For women in full-time work just over 55 percent would still be in full-time work with the same employer. Only 10 percent would not be in paid work. But if they were not in paid work at the start of the period then nearly 60 percent would not be in work at the end, with only 25 percent in full-time paid work. Amongst this latter group are women on welfare, who not only have difficulties moving into paid work but also if they do are more likely to enter low paid jobs with short tenure (Harris 1996).

However, in terms of tenure for women, and linked to this earnings, hours of work and occupational status, many writers have suggested that social policies, particularly policies which help integrate family and work life have a major impact for women. For example, Waldfogel (1998) argues that parental leave is a key factor in assisting women retain long-term links to paid work.

Finally, while the 1990s might look quite different to the 1970s, Jacoby and Sharma (1992) also make the observation that perceptions of job security change over time,

noting that at the turn of the century commentators thought a job that lasted a year was long term. In addition, and a point not noted by some commentators discussing changes in job security is that while in recent times there might be less stability in the labour market marking a returning to situation of earlier years, there is now far more income stability through the welfare system and, at times, from private insurance.

\section{Non-standard hours of paid work}

Over the last century in industrialised countries average hours of work have reduced significantly (Rose 1990). In New Zealand (Department of Statistics 1993) census data indicates that there has been a gradual decline in the average hours worked per week 
between 1961 and 1991. The reduction was 4.7 hours per week, from 45 hours in 1961 to 40.3 in 1991. In this period the average part-time week fell by 3.1 hours, while the fulltime week only decreased by 0.8 hours. Again, the overall decline was heavily influenced by the growth in part-time work over this period.

In studying hours of paid work there is a literature that focuses on hours that are shorter than "standard" hours, and another small, but growing one, on hours which are longer. Often a 40-hour week is seen as standard, but this is not the usual cut-off point for parttime work. ${ }^{46}$

\section{"Short" non-standard hours}

There has been much written about part-time work, particularly in relationship to women's patterns of work. As discussed in Chapter two, due to differing definitions, international comparisons of part-time work are difficult. Changing definitions also complicate changes even within individual countries over time. Trends in part-time work are of importance for a range of reasons, including when analysing whether individuals, families, households or communities are becoming work rich or work poor. Under some definitions of work rich, an increase in part-time work might lead towards a family becoming work rich.

Shirley (1996) shows the level of part-time work has increased slowly in OECD countries since the WWII. Most of the early growth was associated with women moving into the paid workforce. However, while in all OECD countries women were still far more likely than men to work part time, an increasing number of men are also working part time.

A wide range of both "push" and "pull" factors have been identified as leading to the growth in part-time work, initially for women and more recently for men. These include the growth of service industries where there are short periods of intensive work related to customer needs, a need to combine work and family commitments, people making a

\footnotetext{
${ }^{46}$ In many countries, including the U.S. and Sweden the cut-off point for full-time work is 35 hours or more rather than the 30 or more hours in New Zealand.
} 
transition into retirement, and in New Zealand a growth of user pays in tertiary education stimulating part-time work amongst students.

Part-time work is often been seen as being part of a "peripheral" labour market. Yet, other researchers acknowledge that part-time workers "are a heterogeneous lot, working less than full time for a great variety of reasons" (Warme et al 1992: 3). Also of major significance, part-time workers are not necessarily living in low-income households (OECD 1998). ${ }^{47}$

The reasons why a greater proportion of prime-aged men might be working part time are discussed more fully in Chapter nine. Actual changes in patterns of part-time work in New Zealand are examined in Chapters sixteen and seventeen.

\section{Long hours of paid work}

At the other end of the paid work-hours spectrum are those working extra long hours. This is in the realm of the fifty or more hours per week. There are less clear New Zealand data on this, but a mid 1990s study did indicate that the hours of some workers appeared to be increasing (Dixon 1996a).

In the U.S., Schor (1991) has identified a trend of increasing hours of paid work for many workers, and particularly those in management. She has also put forward some ideas as to why this might be occurring. First, Schor argues that capitalism has created strong incentives for employers to keep hours long. Schor suggests that in the early stages of capitalism payment took the form of a fixed daily wage so employers had an incentive to demand long hours of work for a fixed price. She argues that this has reappeared as a fixed annual salary. Schor suggests that although employees might be nominally employed for a 40-hour week if employers can in fact get 60 hours of work then it is in their interests to set up norms of long hours of work.

\footnotetext{
${ }^{47}$ However, there remains the question of how resources are shared in these households.
} 
Second, Schor suggests that often employers' want to keep machines, or other plant, operating continuously so this can encourage long hours. Third, Schor notes that in the U.S. fringe benefits are often paid on a "person" basis, so again discouraging short hours of work. Finally, Schor also argues that in America the long hours of paid work are often reinforced because performance bonuses are paid in terms of extra earnings rather than additional time off.

Other researchers provide various suggestions as to why hours of paid work for some may increase. Warme et al (1992) suggest that long hours act as a "signal" to employers of an employee's loyalty and commitment. Supporting this view, Booth and Francesconi (1997), using British Household Panel Study from 1991 to 1995, found that a major factor in promotion was working long hours of overtime.

The Economist (Workaholics Anonymous 1994) also tries to explain why Americans work long hours compared with Europeans. They suggest one reason was the fall in real earnings of many Americans in the period studied. But they also argue that many highly skilled workers, who have had big wage increases, had also been working harder. They suggest a fall in marginal tax rates since the 1970s made it more profitable to work longer. In addition, they suggest that the widening of wage differentials strengthened the incentives to work longer and harder by making promotion more rewarding.

Based primarily on case studies, Hochschild (1997) argues the one major reason why average working time per household is seen to be rising is the attraction of the workplace and better working conditions relative to household work. As discussed in Chapter two, for some people paid work can be enjoyable and provide considerable satisfaction. Even as recently as the 1960s most paid work in New Zealand may have been seen as an unpleasant, but necessary, interruption to the activities most people wanted to undertake in the weekends. With the change in industries and occupations a greater proportion of the population may have satisfying jobs. Many may therefore willingly work long hours.

However, the idea of the "overworked" American is challenged by some research. Robinson and Bostrom (1994) argue some people, and particularly those who say they 
work long hours, overestimate time in paid work in surveys. Second, in a different study Robinson (1996) suggests that in 18-64 age group, on average, most Americans now have more free time than 20 years ago. He notes the one exception is sole parents. Whether prime-aged New Zealanders appear to be working longer hours is discussed in Chapter seventeen.

A further final measure of work time is annual hours. ILO data show that U.S. workers work the longest hours per year in industrialized nations (ILO 1999). In 1997 they worked on average nearly 2,000 hours, almost two weeks more than their counterparts in Japan, where hours worked per year have been gradually declining since $1980 .{ }^{48}$ The ILO show that the U.S. pattern of increasing annual hours worked per person (which totalled 1,966 in 1997 versus 1,883 in 1980, an increase of nearly 4 percent) is contrary to a worldwide trend in industrialized countries that has seen hours at work remaining steady or declining in recent years. The long working hours of U.S. (and Japanese workers) contrasts strongly with Europe, where workers work progressively fewer hours. In particular, Scandinavian countries such as Norway and Sweden have much shorter hours. In 1997 annual hours worked in these countries were, respectively 1,399 and 1,552. It is not possible to estimate annual hours in New Zealand.

\section{Self employment}

Self-employment generally offers more scope for working non-standard hours. Growth in self-employment in New Zealand has been identified by a number of researchers. However, it is worth noting that while there have been major increases in self employment over the last two decades in New Zealand, using census data from 1926 to 1986 Haines and Callister (1989) showed that the 1970s represented a low point in self employment. This longer-term pattern also shows up in most OECD countries (OECD 1994). As a further example, Tilly and Tilly (1998) demonstrate that in the late 1700s in the U.S. around 80 percent of workers were self-employed. In part, this is due to the reduction of the importance of farming.

\footnotetext{
${ }^{48}$ Although the Japanese hours may be misleading because of many salary workers working unrecorded hours.
} 
In common with all types of employment, there are both "push" and "pull" factors driving the growth in self employment (Bollard 1988) and a wide range of income earning potential from such jobs (Bururu et al 1998). However, Bururu suggests that in New Zealand it has been "pull" factors rather than workers being unwillingly "pushed" out of being employees that has been the main contributor to growth. In addition, as selfemployment is more common amongst older workers, aging of the population tends to raise levels of self-employment. In the U.S. Farber (1996) found that self-employment, particularly amongst older better-educated workers, appears to be an important response to members of this group losing jobs. Self-employment has seen to at times to represent for women a chance to sidestep the "glass ceiling" or to enable more control over balancing work and family issues. Bollard argues that for some people, and particularly in risk-rewarding cultures such as the U.S., self-employment offers an opportunity for high profits (and more risk of losses as well).

Of direct relevance to the creation of work rich or work poor individuals some researchers have linked a growth in part-time work to self-employment and the level of security of work. For example, Casey (1991) in the U.K. found that between 1981 and 1984 half of the growth in self-employment could be linked to the growth in part-time work. Casey raises the question of whether some self-employed are part time because of "underemployment". Another example, on a household basis, comes from the U.K. Using data from the 1991 British Household Panel Study, Dex and Taylor (1994) found that couples who worked more than 80 hours per week were more likely to be in their twenties and also more likely to be self employed. International literature indicates that "nonstandard" hours of paid work are more common amongst the self-employed than amongst wage and salary earners. Therefore a growth in self-employment is likely to be associated with increasing diversity of hours worked.

Some shifts in self-employment in New Zealand are discussed in my data section. 


\section{Conclusion}

In recent years, in most industrialised countries, there has been much discussion in the popular media about changing work time patterns. In particular, there appears to be a widespread public perception that not only has unemployment increased, but also there are fewer long-term jobs and the "standard" 40 hour, Monday to Friday, daylight hours job is disappearing. It has also been suggested that perceptions of job insecurity come not only from information on issues such as tenure and turnover, but from changing dismissal protection, and from the actual and perceived costs of losing a job.

There is little New Zealand research available which test the theories about whether work has been casualised and that tenure has decreased. What little evidence is available does not provide strong evidence of a significant overall growth in "casual" work, where people are employed on an insecure, "on-call" basis. However, a significant number of people do appear to work on the basis of relatively insecure, short-term contracts. Yet, these people are not a homogenous group. Based on overseas evidence, within the group will be work-poor people with few formal qualifications who move out of unemployment to work in a short term, and low paid jobs, and then back into a state of unemployment. There is also some overseas evidence that entry-level jobs are more likely to be offered on a short-term basis. These entry level jobs may increasingly not only be the entry point to the labour market for young people, but also may represent a re-entry point for people having lost jobs in declining industries and occupations. However, for young people job turnover has always been high in entry level jobs as both employers and employees determine whether both parties are well matched, or simply as employees use these jobs to support education. At the other end of the labour market, some people with short-term contracts will be highly skilled, work-rich specialist professionals or managers, who have an ongoing series of well-paid contracts. Education appears to be a critical factor in determining whether short-term work is "bad" for employees. However, gender appears also to an important variable with a higher proportion of women than men working in temporary and casual work. 
In the related area of tenure, international evidence also suggests there has been very little overall decline in average job tenure in the last couple of decades. However, the distribution of long-term jobs across the population appears to have changed in two ways. First, some people, particularly men with little formal education, are substantially less likely to be in long-term jobs. Secondly, women with at least a high school education are substantially more likely to be in long-term jobs than they were twenty years ago. However, on average, men generally still have longer periods of tenure than women. These overall trends are likely to be also occurring in New Zealand.

International evidence also suggests that there are an increasing proportion of people working either shorter or longer than "standard" hours. Until recently much of the research has been on part-time work but there is also now much interest in people working long hours. There are many potential factors driving the changes in hours worked per week. The role of education in work hours appears to be complex. For example, despite a shift to full-time work there are still many well-educated women working part time while their children are young, and poorly educated people often work long hours. While its importance appears to be decreasing, gender remains very important in hours of paid work, with more women than men working part-time and men overall being over-represented amongst those working long hours.

Finally, self-employment has also grown in importance in industrialised countries since the 1970s. However, again, the self-employed are not a homogeneous group. There are examples of work-rich, low-income people, working as self-employed people in areas such as retailing. But there are also voluntarily work-poor people undertaking selfemployed consultancy work as part of an early retirement. Overall, self-employment is more likely to involve non-standard work hours than wage and salary work.

Despite some gloomy media predictions of the widespread loss of secure "standard" work-time jobs, overall, for a significant proportion of the population in industrialised countries paid work appears to remain relatively secure and hours worked are neither very long or very short. Yet "non-standard" work, such as any combination of part-time, self- 
employed, or temporary work does appear to be increasing in most OECD countries. It does appear that there is a group of people for whom work has become more insecure, and more likely to involve non-standard hours. In particular, for a significant number of prime-aged low skill men work has become more insecure. This contrasts with the trend for a significant number of well-educated prime-aged women to have more security in paid work, with a greater proportion in "standard" work time patterns. This suggests that not only is education a key variable in determining whether someone holds a job, but education will also be an important variable in relation to work-time patterns in New Zealand.

Many of the questions raised about changes in work-time patterns cannot be examined using New Zealand census date. However, some questions that will be explored in this research are:

- that an increasing proportion of prime-aged people are not working a "standard" 35-40 hour week

- that education is a critical variable in hours of work

- that while gender, and associated with this traditional childrearing responsibilities, is a critical issue in hours worked, the importance of gender is diminishing

- that age is also an important variable in hours worked, and that increasingly entrylevel jobs and jobs for semi-retired people tend to be part time. 


\section{Chapter 9}

\section{Why have prime-aged men been exiting full-time paid work?}

\section{Introduction}

The previous three chapters have touched on some of the reasons why prime-aged men might have been exiting full-time paid work. This chapter focuses in more closely on demand and supply factors which might have been influencing this behaviour. ${ }^{49}$

There are three main dimensions to prime-aged men's involvement in paid work. First, why have an increasingly number of prime-aged men become unemployed, often for considerable periods of time? Second, why has a group of men exited the labour force and do not appear to be actively seeking paid work? Third, what are the reasons behind the increase in the proportion of prime-aged men working part time?

Finally, there is a brief discussion of whether work-poor men are part of an emerging "underclass".

\section{Lower participation rates}

In New Zealand, Dixon (1996b) provides a brief review of relevant international literature, as well as an analysis of New Zealand data, to try and explain the reducing labour market participation of prime-aged men. ${ }^{50}$ Dixon uses a variety of official data labour market data sources, but primarily the HLFS for recent trends.

\footnotetext{
${ }^{49}$ Major parts of this chapter have been presented as seminar papers or published (Callister 2000a\&b).

${ }^{50}$ In Dixon's analysis of HLFS data, she uses an age group of 25-55. In her discussion of participation rates those unemployed and seeking work are included as is standard practice.
} 
Dixon notes that while male participation rates have moved in a pro-cyclical manner, falling during the economic downturn of 1986 to 1992, and rising from 1993 to 1996 in response to the economic recovery, the growth after 1993 was very weak. In contrast, while there was a decline in female employment and participation rates in the recession, post 1993 both employment and participation rates climbed strongly to reach significantly higher levels than in the previous decade.

Exploring the link to formal education, Dixon notes that while labour force participation rates fell for men at all levels of educational qualifications, the biggest fall was amongst men with no formal qualifications. However, a variety of factors were associated with a lower rate of participation. In particular, Maori and Pacific Islands men were overrepresented amongst those not in the labour force. However, it was also found that participation rates were lower for men not married or not in de facto relationships. While educational differences provide part of the explanation for the differences in participation by ethnicity, Herzog (1996), controlling for various factors including qualifications, age, and industry performance, found that Maori and Pacific Islands workers were still overrepresented amongst those who had lost their jobs in the restructuring process.

Based on both her research and the overseas literature, Dixon puts forward a number of reasons why labour force participation of prime-aged males might have declined:

- increases in the enrolment rates of people aged 25 and over in full-time tertiary education and training

- supply side adjustments to changes in demand patterns (wages and skills)

- supply side adjustments to type of job (an increase in part-time work, type of occupation)

- the long term unemployed may have permanently exited the labour force

- changes in the incidence of particular types of illness or disability

- changes in employer or employee responses to ill health and disability

- increases in the level or availability of non-wage sources of income, such as the income of other family members or government income maintenance transfers 
- increases in the level or availability of income from non-market or black market economic activities.

Work which may not be attractive to prime-age men includes occupations which are traditionally female dominated, such as nursing, childcare, primary teaching, clerical and secretarial work. Some of these are low paid which may, in fact, be the main barrier to participation of men (Lloyd 1999). But in some of these occupations, it may also be that employers, other employees, and also at times clients, might discriminate against men. An example is childcare work where many groups have reservations about male childcare workers. There is, therefore, the question of whether there are "women's" jobs and "men's" jobs, particularly in the lower skilled areas of work. This question, and the issues of whether "women's jobs" have been expanding faster than "men's jobs" is briefly explored in Chapters sixteen and seventeen. These questions, also link back to questions of "nature" and "nurture" discussed in Chapter five.

Dixon (1996b) raised the question as to whether poor health is affecting the employment patterns of prime-aged men. There will always be a small group who, through severe physical or mental handicap, will be out of the workforce for much of their lives. However, given increasing life expectancy, it is difficult to see why men, in general, would be less healthy than in the past. Also given reduced length of stays in hospital employable men will generally be out of the labour force for shorter periods. Yet in the late 1990s, particular sub-populations may have poorer health. Some may be self-induced, such as through drug and alcohol dependency. But such dependency may also be encouraged by increased unemployment. It may also be that non-employment and other types of poor health are linked in a vicious cycle where loss of employment causes poor health. For example, a lower income might mean a move to poorer overcrowded housing resulting in poorer health. Dixon (1999) shows the take-up of Sickness and Invalids' Benefits by men in the prime-age groups did increase during the late 1980s and the first half of the 1990s, but the reasons why this occurred are not clear. 
There is some overseas literature that explores whether the decline in male participation can be explained more by the demand side of the labour market or through supply aspects. For example, in the U.S., Juhn and Kim (1995) analysed the effects of rising female labour supply on male wages. They argue that demand shifts, rather than supply shifts, underlie the declining opportunities for less skilled men in the 1980s. They also found little evidence for the idea that many of the women moving into paid work were substitutes for lowly skilled men. In the U.S., the strongest growth of women's participation has been amongst skilled occupations.

Again in the U.S., Jencks (1993: 158) explored the decline in the proportion of primeaged men in paid work. Based on a period prior to the long economic boom, but of relevance to New Zealand, he notes a range of arguments around jobs and skills including:

- liberals arguing that there are not enough jobs or not enough low skilled ones available

- conservatives suggesting that there are low-wage jobs available but men will not take them

- that while men want work, they want only good jobs, but are not qualified for them. There is a belief that prime-aged men should not have to take "McJobs".

Jencks makes the point that there is little research on the type of jobs long-term unemployed men would be willing to take. He goes on to explore some possible reasons why men may not take certain jobs. He suggests that a change in income distribution could change men's reservation wage. If unskilled men have a reservation wage which relates to what an average man earns, an increase in inequality of wages will mean that fewer men can find work that meets this target wage. While in New Zealand, Statistics New Zealand (1999) data shows that there was an increase in inequality of incomes for men aged 15-64 over the period 1986 to 1996 it is not clear whether this would have had an impact on men's reservation wage. 
A second reason relates specifically to the U.S. but could have some parallels in New Zealand. Jencks suggests that civil-rights laws have made employers pay blacks the same rates as whites in similar jobs, but employers may still not believe that blacks are worth as much as whites. He also suggests that the civil rights movement may have made black men less willing to accept low wage menial jobs, which are the only ones open to low skilled men.

Jencks also explores whether the growth of the illegal economy provides employment that is not noted in official statistics. He argues that involvement in this type of activity can reduce a person's chances of being in the legal economy in the long term. This may be through obtaining a criminal record, or perhaps that heavy use of drugs will impair cognitive ability.

Based on these types of arguments Jencks puts forward tentative hypotheses about why long-term joblessness had increased among prime-age men in the U.S. in the period he analysed.

- Good jobs (steady jobs that paid enough to support a family) became scarcer after 1970.

- Firms increasingly reserved these jobs for the educated and for men with good work histories.

- Young men without higher education therefore found it harder to get good jobs. They responded by postponing marriage and by taking poorly paid short-term jobs.

- The substitution of short-term jobs for steady jobs drove up the percentage of young men who were not in paid work in a typical week but has little effect on the percentage who were out of work for long periods.

- As young men get older, they become increasingly reluctant to take poorly paid short-term jobs. Some find steady jobs. Others completely exit the labour market. 
In a follow-up to her 1996 study, Dixon (1999) analysed New Zealand men aged 25-55 who were not in the labour force in 1997. Her main data source was the June 1997 Income Survey. She found the following characteristics had a positive and statistically significant association with non-participation:

- age (older men were more likely to not be in the labour force)

- low qualifications

- Maori ethnicity

- being an immigrant from the Asian or Pacific regions

- being single, rather than living in a couple relationship

- sole parenthood and

- living in the Northland or Waikato regions

However, Dixon notes that these characteristics do not necessarily cause nonparticipation. Instead she suggests they are correlated with other unobserved factors that influence employment outcomes more directly. Building on her earlier list, these include disability, ill health, limited job skills, limited knowledge of the labour market, and residence in isolated, job-poor rural locations.

Dixon also tried to identify differences (and similarities) between men classified as unemployed and those not in the labour force. She shows that the incidence of unemployment declines with age whereas non-labour force participation increases with age. Other characteristics lead Dixon to suggest it is likely that non-participation and unemployment are overlapping rather than completely distinct states. She suggests that there is a sub-population of non-employed men who may be classified in labour force surveys as either non-participants or unemployed. She also notes it is possible that there is a sub-population of prime-aged males who are at higher risk of both unemployment and non-participation than the male population in general. Dixon notes that this subpopulation could be characterised as less-skilled, less-educated, and non-Pakeha men. 
Finally, there is the issue of duration of non-labour force participation or unemployment. For some men, unemployment or not being in the labour force will be only for a shortterm. Dixon's work does show that the length some men had been spending outside the labour force had been increasing. She shows that in 199225 percent of men aged 25-54 had spent 6 or more years not in the labour force, but by 1996 this has risen to 39 percent. ${ }^{51}$ In addition, some of men who had shorter durations could have moved in and out of work a number of times.

\section{Diversity of experience}

Both the research of Dixon and Jencks suggest that men not in paid work are not a homogenous group. For example, Jencks argues that long-term joblessness among white men is generally not an outcome of weak labour markets but more related to supply side issues. Jencks also suggests that research on men who are not in paid work should take into account the prison population and those in long term care in psychiatric institutions, as these people are likely to be work poor if and when they return to the community. This implies that research on work-poor men needs to count people living in non-private dwellings. Particularly in the U.S., it is recognised that surveys such as the census undercount people who are "homeless" and in New Zealand the HLFS covers only private dwellings.

As an example of the long-term unemployed not being a homogenous group, Levett (1995: 382) draws on the Dutch research of Engbersen et al (1993). They argue that there are various types of unemployed in terms of their expectations and behaviour. Unemployed people included people who made only proper use of social security system and continued to strive to find paid employment even though prospects of work were slight, through to people, some of whom were well educated, who attached little importance to goals of work and consumption.

\footnotetext{
${ }^{51}$ Her original figures include those who did not specify the time since they last worked. However, I have recalculated this to exclude this group. The differences were insignificant.
} 
This research suggested that there were some well-educated prime-aged men who, mainly due to labour supply side reasons, were long-term unemployed. Many of these men were no longer actively seeking paid work.

In the U.S., a behavioural approach to unemployment has been particularly popular amongst some researchers (for a review of this approach see Buckingham 1999). A group of men, and especially young black men, exit paid work because they are seen to have a weak work ethic. These are seen to be "work-shy" males, who through weak moral ethics also have little attraction to forming long-term childrearing partnerships. Buckingham examined this approach in the U.K. using longitudinal data. Supporting the idea of diversity, he found that while the "underclass" generally lacked ability and skills, a significant minority were relatively intelligent. Even when controlling for skills he found that men in underclass generally had a low commitment to paid work. However, he adds that this may have been a result of past experiences in the labour market.

Using British data, Morris (1987) focuses on changing demand patterns, but is also aware of the impact of labour market supply decisions on men's patterns of paid work. She makes the point that the impact, experience, and length of unemployment and non-labour force participation depend on a range of factors. These include the social and kinship setting, spatial concentrations, previous labour market experience, attitudes to work, and future prospects. She gives various examples of why men might not be in paid work long term. One example is men in their late fifties from heavy industries being made redundant or taking early retirement. Although still considered to be in the prime-aged group such men may be happy, particularly if there is a redundancy payment, to take early retirement from a physically hard job. Yet a middle age man with dependent children, with few savings or redundancy pay, will find it a very different experience if he is made redundant. In contrast, a young person who has never been firmly in the labour market, and surrounded by similar peers, may be "more likely to develop an alternative view of work and society, to generate their own activities, and to construct a counter to mainstream values" (p. 344). 


\section{Some potentially positive reasons for non-labour force participation}

The concept of diversity of experience suggests that a small group of prime-aged men may be making an active, and positive, choice not to be in paid work either for short or long periods. As already discussed, one of these choices could be gaining further education. A small group of high earning prime-aged men could be taking early retirement once a target level of savings had been reached. A third might be staying home to look after children or other dependents. This could be as part of a two-parent family, or through being a sole father.

New Zealand research using census data has already indicated that the reasons for men to not be in paid work, and not actively seeking it, are often quite different to those for women (Callister and Davey 1995). A high proportion of women who are not in the labour force are caring for relatives, particularly their own children. However, there is also international evidence that a small, but increasing, number of men are also not in the labour force due to childcare responsibilities (Callister 1994). The reasons for fathers taking up the full-time role of primary caregiver appear to consist of a complex combination of factors, including those specific to the culture in which the study was carried out (ibid 1994).

Restricting the analysis to men aged 25-54, Dixon (1999) found that 17 percent of nonlabour force participants were at home looking after children, and nearly 10 percent reported receipt of DPB payments. However, it was not clear whether the men looking after children full time made an active choice to take on this new role or whether it was forced on them through unemployment. This issue of men and childcare is further explored in Chapter seventeen. 


\section{Men working part time}

Some of the general reasons why more prime-aged men might be working part time have already been explored in Chapter eight. As with men exiting the workforce, the reasons for prime-aged men working part time are varied.

One potential reason for men to work part time, based on prime-aged women's patterns of work, is to look after children. Just as women work part time when their children are young some men are also taking up this pattern. In the U.S., Friedan has argued that as people have children at older ages, as well as fewer children, in couple families both parents are often more able to work out flexible parental leaves which will not damage their careers (Friedan 1982). Taylor cites studies in the U.S., which indicate that men are beginning to want the same kind of flexibility women have often wanted.

In Europe, while only small numbers of men work part time there are some indications that for many men this represents an ideal. One European study indicated that a significant proportion of both men and women would work part time if they were given a completely free choice. About 80 percent of women and 40 percent of men stated they would prefer not to work full time when their children were under school age (Kiernan 1992).

In contrast, and although not directly comparable with the overseas research, a small scale New Zealand study of unemployed job seekers that found that part-time work was a relatively unpopular option amongst married men and men aged over 24 years (Stewart et al 1998).

Also in New Zealand, in a study of the growth of part-time employment amongst men in the period 1986 to 1991, Callister (1993) found that although a high proportion of men working part time were in the 15-19 and 60 and over age groups, much of the growth in the period studied had been in the 20-59 age group. The study found part-time work for women could be explained, in general, by a need, or wish, to organise paid work around childcare arrangements. However, the growth amongst men was not generally linked to 
an increasing involvement in childcare, but instead to weak demand in the labour market and employer led labour market flexibility strategies. Maori men, men in low-income occupations, and linked to this men with few formal qualifications, were over represented amongst those working part time. Burgess et al (1995) suggest that in New Zealand the public sector had been leading the way in "flexible" arrangements including part-time work.

Callister also found that part-time work was more common amongst men who were not living in family type households. If prime-aged men are separated from family life, either through choice or changed family circumstances, this may also remove from them the traditional responsibilities of being a primary income earner. ${ }^{52}$ For some of these men part-time work may be more preferable than full-time work.

\section{Are work-poor prime-aged men part of an emerging underclass?}

The fact that there is some diversity amongst work-poor prime-aged men would suggest that they are not all part of an underclass. Jencks argues that a number of characteristics need to be considered when defining an underclass and suggests four possible variables:

- Income

- Income sources

- Cultural skills (cultural capital)

- Moral norms (such as irresponsible fatherhood)

In particular, he suggests that prime-aged males need to lack a job and have a low income if they are to be seen as part of an underclass (and therefore be generally dependent on the state). In addition, information is needed on the living arrangements of prime-aged men who seem to be excluded from the labour market and have low personal incomes. If they are not in paid work, have no formal qualification, are divorced, and living alone in a non-private dwelling, say a boarding house, they are likely to be economically and

\footnotetext{
${ }^{52}$ However, some men living on their own will still provide payments to a previous family.
} 
socially excluded (and dependent on the state for income). If they are not in paid work, but legally married, well qualified, and living in a middle-income family with dependent children, it is highly unlikely they are socially excluded (or dependent on the state for income).

Buckingham (1999: 55) also develops a set of criteria. The first variable requires some historical information. Such data are currently not available in New Zealand.

- the person has a weak attachment to paid work. Buckingham defined this as having spent more than 15 percent of the time since reaching working age not in paid work. This measure excludes periods of study

- the person relies on income from state

- if he has a cohabiting partner this partner also relies on income from state

- he does not own domestic housing assets

The third criteria is a primarily a measure of whether the couple, if they are living in a couple, is work-poor. The fourth measure is an attempt to estimate financial resources. Using these four measures he estimates that just over 5 percent of British men could be defined as part of an underclass.

\section{Conclusion}

This chapter reinforces the finding of previous chapters by suggesting there is an increasing diversity in the lives of prime-aged men in terms of paid work participation. There are many reasons why prime-aged men might be exiting paid work completely or reducing their hours. Yet, while the literature suggests that both demand and supply factors are having an impact on prime-aged men's patterns of paid work, for the majority of men the changes appear to have been forced on them as a result of changes in labour demand. 
In both New Zealand and overseas, over-represented in the group of men who are not in paid work are those with few formal qualifications. In New Zealand, Maori and Pacific Islands men are over-represented in this group. International research also suggests there is a small group of men who are taking advantage of changing economic and social conditions to diverge from traditional patterns of paid work for prime-age men. For men who are not earning their own income this implies a dependency on either other family or household members or on the state.

Simply measuring the changes in paid work participation, or the hours worked, for primeaged men does not provide enough information as to whether they are part of an emerging "underclass" and are socially and economically excluded. Other information such as level of savings, education, their income, their family circumstances, the income of the family they might be part of, and their age all help determine the impact of prime-aged men exiting from paid work.

While this chapter reinforces the view that no one simple theory can fully explain the declining hours of paid work for many prime-aged men, some hypotheses emerge which can be tested using census data over the period 1986 to 1996. These are:

- "women's" jobs had been increasing faster than "men's" jobs.

- most new jobs were part time and in in-person service type occupations

- the unskilled routine-production type jobs traditionally held by prime-aged men had been declining

- part-time work and non-labour force participation had been increasing amongst prime-aged men in childrearing couples to balance women's increasing participation in paid work

- there was a significant increase in the proportion of prime-aged men undertaking full-time or part-time tertiary study

- there was an increase in the proportion of prime-aged men looking after children full time 


\section{Chapter 10}

\section{Changes in work: Have they been driving changes in family and household type?}

\section{Introduction}

Families and households take many forms. While these forms are not static, in particular periods of time and cultural settings, certain family and household types have tended to be dominant. Therefore, as part of analysing whether a polarisation of paid work is taking place within, and between, families and households it is also helpful to try and understand how and why families and households themselves are changing.

There are many forces influencing the formation, structure, and function of families and households. In this chapter, some theories and evidence of possible linkages between changing work and changing family/household patterns are explored. These linkages can work both ways. Changes in both paid and unpaid work may influence family/household patterns, while changes in family/household patterns may influence patterns of work. However, attention is also drawn to some alternative theories about the cause of change in family and household structures. Although some historical perspective is provided, in exploring theories and evidence the primary focus is on the factors relevant to family formation, structure and function in contemporary industrialised societies. In addition, there is a particular emphasis on issues affecting the formation or breakdown of heterosexual couple relationships. As in all chapters there is a particular emphasis on changing lives of men. Where possible the theories discussed in this chapter are then explored in subsequent chapters using New Zealand census data. 
The chapter begins by briefly canvassing a variety of social science perspectives on why family or multi-adult household units might form, rather than individuals living separately. This includes a discussion of how ratios of men to women might influence couple formation. This section also examines literature which suggests that for primeaged men a low level of education is not only associated with lower labour market participation but is also associated with a higher level of exclusion from the marriage market. Chapter eleven looks specifically at the role of education in mate selection within couples.

\section{Theories about family and household formation}

Families have always existed in many forms (although sometimes unofficially). These include nuclear families, sole-parent families, extended families, same-sex couples, polyandry and polygamy, group marriage, and adults living alone. There is much discussion with both the academic and popular media about changes in family types and their internal workings. While there are many frameworks for thinking about family formation, structure and function, an economic resource perspective is considered by many theorists to be of primary importance.

\section{The economic resources perspective}

In a history of love, sex and marriage Murstein (1974) downplays the role of love and lust in family formation. He argues that these emotions have only recently influenced decisions. In relation to the couple formation in traditional societies he focuses on issues such as bride exchange, bride purchase and dowries. Couple formation was primarily an economic transaction. The economic considerations were seen as being particularly important amongst those people with significant power or assets, although in this group love could co-exist with business arrangements.

It is often suggested that the industrial revolution, and associated with this a revolution in farming methods, helped reduce the economic importance of the family unit. For

example, Ogburn (1938) argues that compared with America's colonial families there 
were decreasing functions for families in the early 20th century. The decreasing functions were seen to be not only economic, but also in education-socialisation and religious instruction.

While, in the 1960s and 1970s, many researchers within other disciplines were stating that economic considerations were becoming less important in determining family formation and structure, the economics discipline itself started developing ideas around family formation in which rational, "business" arrangements were considered to be of much importance. Within economics many of the ideas of relevance to family formation came from neo-classical "new home economics". Given that the dominant form of family in this era was still the nuclear family, the theories tended to focus on heterosexual couple formation. The early developers of key conceptual frameworks were Becker (1974, 1981), Becker et al (1977), Lancaster (1966) and Mincer (1962). In more recent times, and drawing particularly on the work of Becker, Grossbard-Shechtman (1993) has written extensively in this area. All these economists have a strong focus on individual utility maximisation and processes of rational decision-making. For example, Becker (1974: 302) uses language previously more common in describing business transactions "[e]ach marriage can be considered a two person firm with either member the 'entrepreneur' who hires the other..." This language shows up in his subsequent book (Becker 1981: 66) with him arguing:

...an efficient marriage market assigns imputed incomes or "prices" to all participants that attract them to suitable polygamous or monogamous marriages. Imputed prices are also used to match men and women of different qualities: some participants, we have seen, choose to be matched with "inferior" persons because they feel "superior" persons are too expensive.

He goes on to note (p. 66):

...an efficient marriage market usually has positive assortative mating, where high-quality men are matched with high-quality women and low-quality men with low-quality women, although negative assortative mating is sometimes important. 
Grossbard-Shechtman notes that "[g]enerally, marriage-related market mechanisms create a mutual dependence between men and women who want to work, buy, or reproduce"(p. 25). Based on these concepts potential marriage partners search for a suitable match who they can "trade" with to complement or substitute for their own particular set of assets. These assets may be physical attractiveness, earning potential, or childrearing potential. ${ }^{53}$ While Becker (1996: 234) suggests in recent times in most industrialised countries "love" is an important factor in this sorting process most women and men think about issues such as children, wealth, social status and other "goods". ${ }^{54}$

In a modern society, Weiss (1997: 82-83) argues that the production and rearing of children is still seen as one of the key roles of family. However, other economic reasons for couple formation might be:

- Division of labor to exploit comparative advantage or increasing returns. For instance, one partner works at home and the other works in the market.

- Extending credit and coordination of investment activities. For example, one partner works when the other is in school.

- Sharing of collective (nonrival) goods. For instance, both partners enjoy the same child and share the same home or the same information.

- Risk pooling. For example, one partner works while the other is sick or unemployed.

Examples of non-rival goods can be children or housing. Economic factors would tend to predict that low-income people would live together to save housing, heating and childcare costs.

Linking to some of issues discussed in Chapter four, Weiss contends that as unpaid work becomes professionalised then there is less of a need to form couples or other cooperating multi-adult households. For example, medical insurance or unemployment

\footnotetext{
${ }^{53}$ Liabilities are also likely to be considered. For example in New Zealand many young people may have a relatively high level of student debt when entering the marriage market.

${ }^{54}$ Becker argues that the issue of having children is one of the key reasons why "marriage" is so common throughout all cultures in the world. He suggests that people have a desire to have and raise one's own children.
} 
insurance reduce the need for families to form. In addition, he notes that sex can be obtained in the marketplace, and increasingly even children can be obtained in the marketplace through surrogacy and new medical technologies. Conversely, Weiss also argues that the weaker the marketplace, the more useful is the extended family. For example, the extended family can be critical for childcare, but there is less family need if professional childcare services are available.

The extended family still provides a form of welfare support and risk sharing in some industrialised countries. For example, Gregg and Wadsworth (1996c) studied patterns of unemployment or non-employment across a selection of OECD countries and found that they were only weakly correlated with the extent of workless households in a country. They found that while Spain had nearly three times the rate of unemployment in 1994 as the U.K. it only had a workless household rate of 20.1 percent compared with 18.9 percent for the U.K. As a further example, they found that U.S. had the same incidence of workless households as Portugal but a significantly higher level of employment. Gregg and Wadsworth note (p. 2) "[c]learly the structure of families and the distribution of work across families takes much of the strain of low employment in the Southern European countries and a smaller burden is placed on the state."

Like Weiss, Snooks (1994: 65) discusses professionalisation of unpaid work, such as food and clothing production, and the impact on both family formation and size of household. He suggests that historically the optimal family size was around five persons, with technology not allowing it to go under this size. Most families also needed to be work rich simply to survive. Snooks notes that in England between 1574 and 1821 the mean household size was around 4.75, but the size would have been bigger in elite households. ${ }^{55}$ Snooks notes that the break-up of the traditional Australian extended family, of three generations living in the same household, occurred in the period 1900 to 1930. He suggests that this had important implications for the living standards of both young families and elderly couples, who became separated from the more affluent

\footnotetext{
${ }^{55}$ Herlihy (1997: 54) also notes that in Europe in the Middle Ages household size increased with land size.
} 
middle-aged group. The separation meant that work-poor households could emerge even though the wider kinship group would not be classified as work-poor.

The professionalisation model, given the concept of traditional roles in unpaid work, has a particular potential to free well-paid men from needing to become part of a couple family. It is now possible to live alone and purchase the household services a wife or de facto partner might have provided in the past.

Changes in technology and professionalisation of household work now make it possible for many adults to survive, and potentially prosper, in a single person household. Yet, couples and wider family and household groupings do still form. Again from an economic point of view, Weiss notes that household production continues because such production reduces the costs of search, transactions costs and monitoring of many activities. However, he also notes that to fully exploit these advantages there needs to be durable relationships.

Snooks (1994) argues that specialisation and economies of scale provide pressure to, in fact, increase the size of production units. But he explores why this does not occur in families in industrialised societies. Drawing on the work of Becker, Snooks suggests that specialisation and economies of scale are outweighed by diseconomies such as shirking, and cheating owing to conflicted loyalties in an extended family, from costs associated with the invasion of privacy whenever an attempt is made to supervise family production, and because firms are more capital intensive than households. While there is much sociological literature discussing why larger units such as communes do not operate well, the Snooks view provides a basic economic rationale.

Franklin (1997), again drawing on ideas of rational economic choice, argues family formation and the role of the family in industrialised societies can be quite different amongst various socio-economic groups. In particular, he argues that, as in the past, those who control much wealth and have significant holdings of "positional" goods (such as land and art works) retain strong traditional family ties. Linked to this, Becker (1981: 
241-242) suggests that traditionally families have been important organisations for running businesses and providing “on-job” training:

Uncles, aunts, nieces and nephews, cousins, and other kin meet often to transfer gifts, plan family strategy, teach younger members, and inspect and monitor one another's performance and behavior.

But there are some negative features of family and business activities being connected. Becker notes that in the "successful" families the privacy of individuals is invaded because the behaviour of each individual affects the well-being of other members. He goes on to note that while people in poor or "unsuccessful" families often have little physical privacy, they usually have greater autonomy in many other choices. This includes choosing partners in the "marriage market" as the family has little to lose from whatever choice is made. They also have little to lose, in terms of property and other financial assets if a relationship does not work so face few disincentives to separation.

It is clear that in New Zealand some types of family and household structures are linked to business activity. A prime example is the family farm. However, describing the U.S. Herrnstein and Murray (1996) suggest that the traditional model of a son, and mainly the oldest son, becoming the head of the family firm is breaking down.

While writers such as Becker have been criticised for having a fixed view of men's and women's roles in society with too much emphasis women's perceived comparative advantage in unpaid work (e.g. Bergmann 1995), the economic perspective usually does involve discussions of the changing lives of women. ${ }^{56}$ For example, back in the 1970s Becker et al (1977) argued that increased schooling gives both men and women a comparative advantage in the marriage market. Lichter et al (1992) suggest that education and the earning potential associated with education allow women to search longer for a suitable partner. Employment not only subsidises the marital search process but it potentially reduces the economic need to marry. Well-educated women are particularly

\footnotetext{
${ }^{56}$ However, Becker contends that it takes only a very small difference between women and men, whether based on biology or discrimination, to make such specialisation advantageous (Becker 1996).
} 
likely to seek a higher "reservation quality partner" (p. 784), that is, to set higher standards for partner selection. But increasing economic security, along with social change, open up other potential living arrangements. These include living alone and same-sex couples. In addition, increasingly aided by new medical technology, as well as professionalisation of household work, some well educated single women can choose to be both economically independent and still have children. Overall, Snooks proposes that growing financial security for women, combined with declining family responsibilities of both females and males has reduced the need and desire for formal contracts of marriage. It has also reduced the reluctance to terminate marriages. A higher level of financial security for women will potentially lead to more well-educated prime-aged women living alone. As a result it may also lead to more prime-age men living alone. This of course does not rule out many of them having either casual or long-term friendships and sexual relationships with people outside their household.

However, many other women do not have the education required, the ability, or the opportunity to be economically independent. Bringing in the idea of social norms, other women may have traditional views about roles and not seek to be financially independent. For these women the loss of jobs by men may have had a major impact on family formation. Theories about job loss by men, and particularly black men in the U.S., have been popularised by Wilson (1987). ${ }^{57}$ Wilson has argued that black women, especially young black women, have been facing a shrinking pool of "marriageable" men. As part of his research, Wilson developed a "male marriageable pool index", which indicates the ratio of employed men to total women in the same broad age group and within the same racial grouping. The issue of whether crossing of racial boundaries in assortative mating is a more important issue in New Zealand is discussed in Chapter eleven. Under a theory of "marrying up", also to be discussed in Chapter eleven, the pool of marriageable men also declines if the earnings of a significant group of men decline substantially. Lichter et al (1992) argue that much of the debate on marriage formation in the U.S. in the early

\footnotetext{
${ }^{57}$ The idea that men with a low level of financial resources will delay marriage or perhaps not marry if they cannot find such resources is not new. For instance, Herlihy (1997) shows that in the Middle Ages in Europe men normally had to wait until they received a paternal inheritance or had earned sufficient resources themselves before they could marry.
} 
1990s was around men's changing employment patterns, particularly the rise in unemployment. A decline in the "marriageability" of men who have poor labour market prospects may lead to a significant proportion of them living alone or in some other form of non-family arrangement. The non-family arrangements include boarding house type living or even prison. However, some of these men may still be involved in casual, or even sometimes long term, relationships with people outside their households, and this may include having children which they neither live with nor support financially.

There are some U.S. studies that seem to support the Wilson hypothesis (e.g. Attewell 1999, Goldscheider and Waite 1991, Lichter et al 1991, 1992, South and Lloyd 1992). Of particular relevance to New Zealand, both in terms of type of economy and data source, is a recent Australian study (Birrell and Rapson 1998). This study used data from the 1986 and 1996 censuses and appears to lend some support to the Wilson hypothesis. While the researchers found that in all five yearly groups from 20-49 the proportion of men in couples (married or defacto) had declined between 1986 and 1996 the men least likely to be in couples were those not in the labour force, followed closely by men who were unemployed. In addition, the study found that men who had high incomes or were in high status occupations were more likely to be in couples.

Taken to an extreme, the Wilson type hypothesis would suggest that work-poor, or at least long-term work-poor, couples would not exist. Under this scenario, if men cannot find paid work, then they would not be in a couple, either through one not forming or an existing one separating.

However, there are challenges to the Wilson view. For example, in the U.S. Wood (1995) argues that there is little correlation between job loss and a person's chance of entering a marriage. His estimates suggest that the decline in the number of well earning, young black men explains only 3 to 4 percent of the decline in black marriage rates in the 1970s. In New Zealand, Goodger (1998) shows that the growth in sole parenthood began ahead of the growth in male unemployment. The growth in sole parenthood started in the early 1970s while the rapid increase in male unemployment occurred firstly in the late 1970s / 
early 1980s, with a further increase in the late 1980s. In addition, other studies suggest linkages between low male earnings and separation rates of existing relationships are complex. For example, Ono (1998) using U.S. longitudinal data suggests that when a wife has no earnings, low husband earnings lead to a higher rate of separation. But when a wife has earnings and there are low earnings by the husband there is no impact on separation rates.

In addition, even if there do seem to be associations between paid work status and living arrangements, it is always difficult to determine if there is any actual causation and, if there is, which way the causation might work. For example, some studies have suggested that once men marry they work more and earn more than when they were single (Akerlof 1998, Korenman and Neumark 1991). In addition, Akerlof suggests that there may be selection bias at work in this type of result, that is, men who are in couples and men who are single could have quite different physiological characteristics. Finally, it is not enough to examine current employment patterns as a predictor of living arrangement. Future expectations of work status and earnings are important. As discussed in previous chapters, education is one powerful predictor of future employment status and earnings for men.

Other researchers have focussed on the lack of paid work for women rather than men as a factor in the growth in one alternative to couple families, that is sole motherhood. For example, Olsen and Farkas (1990) suggest that increased economic opportunity discourages non-marital childbearing. This is seen as primarily due to the increasing opportunity cost of pregnancy and childbirth faced by young women, which discourages fertility. ${ }^{58}$ In addition, it may be that the reasons for the growth in sole parenthood change over time. For example, in the early growth of sole parenthood in New Zealand the increased ability to dissolve long-term, but unhappy, "shotgun" marriages was an important factor in the growth.

\footnotetext{
${ }^{58}$ How the theories of Wilson or Olsen and Farkas explain the simultaneous small, but significant, growth in sole fatherhood is unclear.
} 
Finally, a key feature of the economic perspective on family and household formation and function is that people are trying to make rational decisions that often have long-term consequences. However, as already discussed this rationality will be "bounded" due to lack of information, particularly about the future. For example, if the labour market appears to becoming less secure for men, then many women may have the expectation that men cannot be relied on in the future to be the primary, or even a major, income earner. This in fact may not be true as, for unexpected reasons, there may be further radical changes in labour market conditions. Not surprisingly, economic cycles have often been identified as a key factor in the timing of marriage, with people delaying couple formation in times of economic hardship. But these decisions are based on current conditions. People feeling optimistic about forming couples in times of economic expansion may, within a short time, be living in a period of economic recession.

Overall, the economic perspective of family formation and function is important as it suggests that people are trying to make some rational decisions regarding their short and long-term living arrangements. Within such a perspective is the suggestion that these decisions will be heavily influenced by wider systems of production, including patterns of paid work. The economic perspective suggests that changes in the economy have made it possible for many people to live alone rather than in groups, while other theories within it, such as the loss of jobs for men, or the increasing economic independence of women, would also seem to point to a potential reduction in the formation of couples or the length of time they remain together.

\section{An absolute shortage of potential partners?}

Changing demographics can have an influence on family and household forms in a variety of ways. For example, in New Zealand an aging population has led to a decline in the proportion of childrearing families, and an increase in single person households (Davey 1998a). However, another way is through the ratio of men to women in a particular population. 
While there are an increasing variety of family types, many people still wish to form heterosexual couples. These couples may form a household, or could live in separate households. Issues of age, social norms, economic issues, and geography are all drawn into discussions of sex-ratios.

Age is seen as an important variable in the process of couple formation although, on average, males in couples tend to be slightly older than females. In a review article, Bergstrom (1997) cites data from a wide range of countries that show that, during the period from 1950 to 1980, women, on average, married older men. However, he notes that the age differential tends to be larger in traditional societies but has diminished over time.

If couples form at a very young age, often due to an accidental pregnancy, then if the male is older he is more likely to have finished formal schooling. But his younger partner is likely not to have finished her formal school education. A difference in age also usually means a difference in one element of education, or human capital, not specifically focussed on in this research, that of work experience and any associated on-job training. The older partner will generally have more of this form of human capital, and this may influence decision making about paid and unpaid work roles.

However, with only a small age gap in most industrialised countries, most couples are to be found in similar age cohorts. Jensen (1978) provides early evidence that age is the characteristic with the strongest positive correlation in mating, with schooling second. In addition, Epstein and Guttman (1984), in a review article, also note a positive correlation of spouses' ages.

This broad age matching has led to "sex-ratios" being seen to be of some relevance to assortative mating by predicting the level of competition for a partner. Sex-ratios have traditionally been defined as the number of men to women in a particular age cohort. ${ }^{59}$

\footnotetext{
${ }^{59}$ Historically, sex-ratios have often been calculated using the number of "available", that is single, men and women. However, in a time of more fluidity of marriage and defacto relationships it has to be assumed that most people have the potential to enter, or re-enter, the marriage market.
} 
There will be cycles where men outnumber women in a particular age cohort and other times when women outnumber men. For example, wars have traditionally reduced the number of men relative to women and in the early colonisation of New Zealand men Pakeha men vastly outnumbered Pakeha women (Arnold 1982). In modern society, due to longer life expectancy women outnumber men in the latter years of their lives. If, for example, women outnumber men then there will be more competition for eligible men.

Sex-ratios have always had some impact on family formation, but in some societies have also had an impact on family type. Differences in numbers of men and women have been associated with the practice of polygamy and, less commonly, polyandry in some societies (Murstein 1974).

In contemporary industrialised societies, the concept of sex-ratios has been discussed in the economics literature (e.g. Grossbard-Shechtman 1993), in the sociological assortative mating literature (e.g. Fossett and Kiecolt 1991), and in the demography literature (e.g. Goldman et al 1984). Grossbard-Shechtman argues that sex ratios affect both couple formation and, more contentiously, women's patterns of paid work. GrossbardShechtman suggests that in the U.S. since the 1960s the growth of feminism, women's increasing labour force participation, the lower popularity of marriage, a later marriage age, and higher divorce rates can be linked to a marriage "squeeze" for women (that is, there were more women than men). She argues that this started when baby-boomers reached adulthood around 1965. A marriage squeeze for men started in the 1980s when post-baby-boom generation entered labour and marriage markets (p. 101).

Guttentag and Secord (1983), based on a potentially outdated concept of traditional sex/gender-roles, suggest that women and men will react differently to a shortage or an excess of potential partners. Discussing only legal marriage, they argue that women are more likely to marry when there is an excess of men because women depend more on marriage for financial support. In contrast, they suggest men may be less likely to marry when there are more women than men because they believe men can obtain many of the benefits of marriage, such as companionship and sex, outside marriage. 
Finally, an imbalance in sex-ratios will lead to more of the group in excess supply living alone or in other family and non-family arrangements. This can include same-sex couples. However, if it is women who are in excess supply then there is a potential for sole motherhood to increase.

\section{Some technological factors}

Although technology is a key part of economic change, particular technological changes have had an identifiable affect on family and household formation. As already discussed in earlier chapters, technological change can alter patterns of paid and unpaid work and these changes can then impact on family formation. But technology impacts in other, often more direct, ways as well. A key technological development is that of reliable contraception. Changes in current, and as importantly, expected childbearing (and childrearing) decisions have an impact on family formation and type. For example, Akerlof (1998:288) describes the relatively common "shotgun" marriages of young people in the 1960s. He notes that this often meant that "immature men married equally immature women, both ill prepared for life and each other." With divorce also more difficult in this period many men and women spent little time as single people. With effective contraception, sex becomes separated from procreation and for many people become recreational. Akerlof argues that this means that for many couples if a pregnancy does accidentally occur "because sexual relations are now occurring very early in relations, partners have so little acquaintance with one another that marriage in the event of pregnancy hardly seems practicable" (p. 288).

Effective contraception has been a key factor in a significant decline in fertility in all industrialised countries in recent decades (McDonald 1996). This means that most women can expect to spend considerably more time in the labour market than in childbearing/rearing. A longer life span further accentuates that childrearing may only represent a relatively short period in a person's life. This, in turn, encourages women to invest more in skill formation. Investing in better education then provides women with more choice as to whether to form relationships, the type of family they live in, and 
whether to actually have children. Having fewer children, or no children, not only reduces the amount of unpaid work carried out in a household, but also means that a women's labour market potential may now be far more highly valued than her childbearing/rearing potential. However, reliable contraception could also mean that childbearing may be delayed or avoided entirely because of the pressures to perform in paid work and women (and men) are having fewer children than they want. Declining fertility can also have some indirect impact on paid work patterns and general social support. For instance, Jencks suggests with declining fertility, prime age men (and it has to be assumed women as well) have fewer family members to ask for help in finding jobs or providing financial and emotional support.

Technological change in the area of health, including simple innovations such as improved sanitation or better quality food, have dramatically increased average lifespan in industrialised countries. For example, historically, disease, accidents, starvation, as well as war, meant that many children grew up without a father, or a mother. It also meant a high proportion of children did not reach adulthood. Few people survived long enough to be grandparents. Although discussing a period well into the industrial revolution, Uhlenberg (1980) notes that in the U.S., even as recently as in 1900, 1 out of four white children under the age of fifteen had lost a parent, and 1 out of 62 had lost both. The corresponding figures for 1976 were 1 out of 20 and 1 out of 1800 . Therefore issues such as sole parenthood and fatherless families are not new developments but are simply created in different ways in industrialised societies.

Finally, a longer lifespan also means that people may move through a variety of work and family arrangements (e.g. Davey 1998a). This may include, as a child, living for a period in an intact two-parent family with both biological parents present, in a sole parent family and in a blended family. As a young adult living arrangements may include living with parents, living in flatting situations, or living alone. As an adult a person could also live in a variety of family and household settings, some of which might be work-rich and some work-poor. In older age groups people, particularly women, are likely to live in a single person, work-poor, household for some period. 


\section{Norms}

While rational economic factors may guide decisions about family formation and structure sociologists and anthropologists have long argued that norms are also important in moulding behaviour (e.g. England and Farkas 1986). Non-governmental institutions, such as the church, have often promoted these norms. For example, Sarre (1996) suggests that marriage is a norm that has helped society link fathers to children.

In a review article on the British "underclass", Buckingham (1999) outlines a behavioural model that provides reasons why family structures have changed. In this model are the incentive effects of welfare and a change in beliefs. The change in beliefs includes a breakdown of the work ethic and a rejection of the ideal of marriage. Even Becker, who argues that the economic approach to explaining family change is a very powerful one, suggests that other "facets of human behavior" are helping influence change in family formation and function (1981:256). Social norms can be particularly important in the formation of non-traditional family types such as same-sex couples. Folbre (1994), drawing on ideas from within institutional economics, argues that in making decisions, around family formation, type and structure, information is costly and even when it can be easily acquired, it takes time to process and analyse. She suggests that habit, tradition, and cultural stereotypes provide individuals with a "short-cut" guide to behaviour.

Within contemporary industrial society specific cultural "norms" have often been referred to in discussions of family type. For example, extended families in New Zealand are more common amongst Maori and Pacific Island people (Davey 1998). As a further New Zealand example, co-habitation is more common amongst Maori than non-Maori in New Zealand. Carmichael (1996: 40) argues that amongst Maori "the contemporary popularity and tolerance of informal cohabitation legitimates a traditional cultural indifference to formality in the establishment and ending of spousal relationships..." This issue has also been discussed in the U.S. For example, Morgan et al (1993) argue that the current differences in family structure amongst various ethnic groups can be linked back to historical differences in cultural norms of marriage and childrearing. In addition, even 
within particular cultures "norms" might change over a person's lifecycle. For example, Akerlof (1998), as well as Korenman and Neumark (1991), note that men have been found to put more effort into their paid work once they marry. The idea is that marriage is a "rite of passage" and that men (and women) change their behaviour to fulfil certain societal expectations once they form this legal union. Within this notion is the idea that "nature" can be "tamed". For example, Blankenhorn (1995) sees men as being naturally violent and sexually opportunistic but this behaviour is reined in by marriage and the responsibilities it usually brings.

Lilla (1998), in a review article, argues that the moral and cultural revolution that took place in industrialised countries in the 1960s has had a major on-going impact on living arrangements in the 1990s. There was an increasing belief in individualism and more flexibility in relationships. This increased fluidity in relationships can be positive for the adults involved, however there is some evidence of negative impacts on children. For example, in Britain Hobcraft (1998) uses longitudinal data to show multiple relationships can be problematic for children.

Jencks (1993: 190) links norms and economic conditions with changes in living arrangements, but with the linkages working in a complex way. He suggests that the attitudes of an "educated elite" towards sex, marriage and parenthood started to shift in the 1960s. In part, this change was encouraged by many of these couples suddenly having the financial ability to support two households. These attitudes were then spread via the media to other groups in society. These new norms were then reflected in laws and institutions designed and run by the educational elite. He argues that this shift in norms improved the lives of the educated elite. But, Jencks suggests the change in norms also meant low income men no longer felt morally obliged to support family life. Woods (1995), in supporting the views of Jencks, suggests that it is economic factors that may make marriage less attractive for the "elite", and then this lowers the "social cost" of similar behaviour by other groups for whom the economic changes are not as relevant. The result is that sole parenthood will increase amongst the poor even if economic incentives that group face have not changed much. 
Some "norms" or belief systems about appropriate behaviour are complex and often involve contradictions. Again linking work, family, and changes in the lives of primeaged people, Hochschild (1995) suggests there are many contradictions for men. While a large proportion of middle-class men might have "new father" ideals, their paid work often limits involvement with their children. ${ }^{60}$ But Hochschild notes at the same time unemployment and poor wages may challenge the provider role of working class men, yet actually give them more time with their children.

There are also spatial aspects brought into discussion of norms. For example, Cready et al (1997) suggest that population size can affect norms promoting marriage. They argue that norms promoting marriage will tend to be stronger in smaller, and usually more conservative, communities. Whether, this is actually the situation in New Zealand will be explored in Chapter twenty-one.

\section{Government social and economic policies}

Also featuring in literature on family formation and structure is the role of government policy. Laws regarding marriage and divorce, including issues of rights to property and whether same-sex couples can legally marry, affect the "marriage market". For example, if there is the potential for assets to be required to be divided after a legal separation then, given the uncertainty of marriage tenure, some people may choose to avoid legal marriage (Birks 1998a).

The welfare and tax systems may also have an impact on family formation and structure. In particular, in the U.S. some analysts, especially those with a conservative bent, suggest that welfare payments are a major factor behind the growth in the number of young, poorly educated, sole mother families (e.g. Murray 1984). Other researchers, such as Lichter et al (1992), also note that the availability of welfare enhances women's economic independence from men. They suggest that welfare income subsidises the

\footnotetext{
${ }^{60}$ This assumes they do not have negotiating power to change these hours.
} 
marital search process, just as unemployment payments enable the unemployed to search longer for a better job. In New Zealand, Rankin (1999) demonstrates how tax and welfare policies may encourage some low-income childrearing couples to separate. However, other researchers (e.g. Hoynes 1997, Moffitt 1992) argue that U.S. empirical research provides little overall evidence that the welfare system alone can directly explain the high rate of female-headed families.

Other government policies can have an impact on family type structures. For example, justice policies, such as the use of imprisonment, as well as decisions made in the Family Court about child custody will have an impact. In particular, the concept of sole custody, often based around traditional norms for men and women, has a major impact on the structure of families (Birks 1998b). In addition, laws such as those on divorce, adoption, abortion and surrogacy will all have some affect on families. In the U.S., there is also some evidence that stringent enforcement of child support payments has some tendency to keep couples together (Garfinkel et al 1999).

Social policy can also have some impact on the amount of unpaid work carried out in a society, which in turn can impact on families. Carlson (1990) argues that one of the goals of some designers of the "Swedish experiment" was to professionalise household work and, ultimately, break down the traditional patriarchal family. Carlson goes on to argue that Sweden "leads the world" in having the smallest average household size (2.2 persons) and the highest percentage of single person households.

However, generally the government will not be leading social changes, but reacting, often quite slowly, to changing "norms" already occurring in society.

\section{Conclusion}

A wide range of literature supports the concept that changes in economic systems of production, and ultimately changes in labour demand, have some impact on the formation and structure of families and households. However, many other factors, including norms, sex-ratios, technology, life-expectancy, changing demographics and government policy 
also appear to have some influence on the formation and structure of families and households. It would appear that in industrialised countries much of the economic rationale for forming stable couples, extended families or other multi-adult households has disappeared. For some groups, part of the instability in living arrangements seems to be linked to a parallel instability of paid work, but for others it is a reflection of greater personal resources and more choice. Yet in modern economies couple formation, usually with the intention of creating a long-term relationship, is still relatively common.

Theories that the loss of stable and relatively well paid work for a significant group of men, particularly men with a low level of education, is a factor in driving changes in family formation and structure have become popular. Other theories suggest that poor economic prospects for some groups of women also influence family structure. However, the impact of the loss of jobs for men on its own is contested. At the same time, the increasing participation of women in paid work, and linked to this increasing economic independence, is also seen as having an impact on families and households formation and structure. While the loss of paid work by some groups in society and gains by others needs to be seen as part of wider social and cultural factors which influence behaviour, nevertheless the changes in patterns of paid work, either directly or indirectly, do appear to have had some impact on the formation and structure of families and households.

In turn, changes in the formation and structure of families and households then feed back into patterns of both paid work and unpaid work. This suggests that the analysis of changing work-patterns for individuals benefits from a parallel analysis of changing family and household patterns.

Finally, the reasons put forward for the changes in family formation and structure, such as decline in couples, and in childrearing situations, the increase in sole parent families, often assume that we are dealing with homogenous groups. Yet, as an example, it appears from the research literature that the reasons for a poorly educated teenage urban black woman in the U.S. having a child but not forming a couple, and becoming work poor, may differ substantially from the reasons why some mid 30s, well-educated Pakeha 
women in New Zealand might move into sole parenthood and still remain firmly attached to the labour market. The impact on family income and the well-being of children is also likely to be quite different in these two situations. Equally, the reasons why a poorly educated divorced, middle aged male sickness beneficiary might be living on his own, are likely to be very different from the reason why a young, university educated, professional male, lives in a single person household. Therefore, while some overall patterns in causes, processes and outcomes of changing work and family patterns might seem to emerge, at the same time the literature would suggest there are dangers in trying to find any one "big picture" theory, from within any one research discipline, to fully explain the changes. However, having said that, this research will test three main hypotheses. These are:

- that well educated men are more likely to be in couples than poorly educated men.

- that men who are not in paid work are less likely to be in couples than men who are in full-time paid work

- that an increase in male joblessness has been a critical factor driving changes in family type in New Zealand 


\section{Chapter 11}

\section{The "meet" market: The marriage market and concentration of education in couples}

\section{Introduction}

Love and lust play an important part in the formation of couples. However, theory and evidence suggest that while these emotions are a key ingredient in the process of couple formation, there is also a wide range of other factors involved. In particular, there is the idea that, for a variety of reasons, when heterosexual couples do form education is an important variable in the process of partner choice.

The marriage market can act as a mechanism for reinforcing inequality. Of direct relevance to the issue of the creation of work-rich and work-poor families, there is international research that shows couples often have similar characteristics, including education. With education an important factor in labour market prospects for individuals the advantage education provides can be reinforced in couples. One way for the inequality to increase is that well-educated couples may have more links into important social networks and have more resources for further investment in their own, or their children's education. The more contentious route is through genetically determined cognitive ability being concentrated in the breeding process. 
In this chapter some of the reasons why education might be concentrated amongst particular couples are examined. ${ }^{61}$

\section{Theories about assortative mating}

There are a wide variety of theoretical approaches, across many disciplines in both social science and physical science, with relevance to the processes and outcomes of assortative mating amongst heterosexual people. This brief review of literature focuses on theories about choice of partner in which education features prominently. The overview spans a number of disciplines, although there is a particular emphasis on approaches within economics, sociology and demography.

\section{Traditional versus industrialised societies}

As discussed in Chapter ten, the notion of personal choice and "romantic love" in couple formation is relatively new. It is clear from the international literature that processes and outcomes of assortative mating can be quite different in traditional societies from those in industrialised countries. For example, Smits et al (1998) used log-linear modelling techniques to examine data from 65 countries to assess the possible links between the level of economic development and educational homogamy (both partners having a similar level of education). They found an inverted $U$ relationship. That is homogamy decreases in early stages of development but increases again in highly industrialised countries. They endeavoured to find a common "families of nations" and found Catholic, Muslim, Confucian and mixed Catholic/Protestant countries showed significantly more educational homogamy than do Protestant countries. In the remainder of this review only those theories relevant to contemporary industrial nations are considered, however this study does indicate that there may even be differences between seemingly similar countries.

\footnotetext{
${ }^{61}$ Significant parts of this chapter have been published in Callister (1998a).
} 


\section{Seeking resources or compatibility?}

Some of the ideas around assortative mating developed by the economics profession within a marriage market framework have already been discussed in the previous chapter. Much of this literature supports the idea that people with similar economic and social resources will tend to form couples. For example, Becker has suggested that "inferior" people will be matched with similar people, just as "superior" people will tend to seek similar "superior" partners. However, these superior qualities that are traded are not necessarily exactly the same characteristics. The Becker model of partner selection stresses comparative advantage, with men generally seen as having a comparative advantage in paid work, and women an advantage in unpaid work (Becker 1981). Under this model women will, therefore, tend to seek partners who signal, often through their level of education, the ability to earn a good income. In a similar vein, Farkas and England (1986) have argued that industrialised culture places a premium on superior physical features (beauty) for women and superior earning power in men. Rich men have traditionally been seen as seeking beautiful women and beautiful women seeking rich men. When there are more opportunities for women to also become rich then this adds new complexity.

Sociologists have also been a key group developing theories about assortative mating. Contributors to the debates have included DiMaggio and Mohr (1985), England and Farkas (1986), Kalmijn (1991a\&b, 1994), Mare (1991) and Oppenheimer (1988). Underlying much of the sociological explorations are concepts of status, social stratification and social mobility. In addition, much of the sociological literature draws in turn on concepts developed within economics.

In reviewing sociological hypotheses about assortative mating in terms of status Kalmijn (1994) argues there are two schools of thought. The first is that of a matching hypothesis, where people prefer to marry someone of similar status, and the second is a competition hypothesis, where people prefer to marry someone of high status. The matching hypothesis is based on the idea "...that similarity in long-term relationships ensures a common basis of conversation, provides confirmation of one's norms and values, and 
reduces friction within marriage that may arise from dissimilarity in tastes"(p. 423). The competition hypothesis is based primarily on sharing of economic resources. ${ }^{62} \mathrm{He}$ notes that both competition and matching will lead to some similarity of status in marriages.

Although not highlighted in the assortative mating literature, it may be that people adopt different behaviour in response to varying economic conditions (such as being more focussed on economic resources in a time of economic insecurity but more interested in companionship during strong economic growth). As will be discussed later in the chapter, the lifecycle stage a person is in may influence behaviour. Again, although generally not directly discussed in the assortative mating literature, changes in income distribution within a society may also have some influence on behaviour. In a situation where there are only small differences in income distribution, choice of partner has less economic impact than in times of very pronounced differences in income distribution.

\section{Why information is important in seeking a partner}

England and Farkas (1986) raise the issue of contracts in assortative mating arguing that, although relationships often do dissolve, most people appear to be seeking long term partners. The marriage market is not a "spot market", and therefore people have strong incentives to not only seek information on their potential partners current characteristics but on their future behaviour and life chances. In discussing information England and Farkas draw on "search theory" (citing Stigler 1961). They suggest that decision makers will not have perfect information. In linking uncertainty in both the labour and marriage markets they argue "[b]oth household and employment contracts are arrived at when the parties possess limited information from which to predict the benefits of the relationship, or future opportunities for alternative contracts"(p. 4). In the search process people will

\footnotetext{
${ }^{62}$ In many of these discussions there is an underlying assumption of people seeking upward mobility, but people may simply be trying to preserve what they already have. Jones (1997) provides an example of assortative mating when people are trying to preserve wealth. He suggests that the "rich" try to reduce the number of alien genes that enter their lineage. They therefore often marry relatives who share their genetic and wealth based heritage. Becker (1996) also puts forward a view about preserving wealth. He argues that families that own the most wealth want to protect it. This requires co-operation with other wealthy families to put in place laws and encourage social norms (such as church attendance, which in turn discourages stealing) that help protect that wealth. The wealthy families can increase co-operation by arranging marriages among relatives and among children of similar families.
} 
use the information that is currently available to make choices, whereas ideally they would have information on such things as long term earning capacity, loyalty or perhaps parenting ability. According to England and Farkas, the characteristics that can be observed are ascribed characteristics such as race, gender, social class of parents, and achieved characteristics, such as human capital (p. 33). Kalmijn (1994: 422) argues that, social class, occupational prestige, and level of education are important variables in terms of signalling status in assortative mating. Yet social class and occupational prestige themselves can often be linked to education.

England and Farkas also suggest that in a liberal society information about potential longterm partners can be gathered by experimentation:

Today age at marriage is significantly later, premarital sexual and nonsexual experience is more extensive, the number of serious relationships before marriage has increased, and cohabitation as a "trial" stage on the way to marriage is very common. Thus, search has been extended in duration, in the number of partners considered, and in the extent to which the information gathered is directly relevant to the later experience of marriage (p. 41).

\section{Cohabitation versus legal marriage in marriage market literature}

Much of the theorising about and the actual study of assortative mating have focussed on the institution of legal marriage. However, there has been a major decline in marriage rates since the $1970 \mathrm{~s}$ in industrialised countries, including New Zealand. While this change might not affect many of the theories regarding mate selection, some researchers suggest there could be differences between mate selection in marriage and cohabitation.

Schoen and Weinick (1993) suggest if cohabitations are "informal marriages" then choices in partner should be similar to choices of formal marriage partners. However, alternatively, if cohabitation is a special type of relationship, specifically a "looser bond", this might affect assortative mating. If it is a "looser bond", Schoen and Weinick hypothesise that partner choice in cohabitation would put more weight on "short-term" and achieved characteristics, such as education, and less to "long-term" and ascribed 
characteristics, such as age, religion and race. They come to this view by applying "exchange theory" to the "looser bond" scenario:

As a presumably permanent arrangement, marriage embeds a couple, and their children, in a kinship network where ascribed characteristics (e.g., ethnicity and religion) are important. Because cohabitation lacks the permanence of marriage, we expect less concern with kinship issues and ascribed characteristics. For example, matters relating to having and raising children are likely to be much less salient in cohabitations than in marriages. While less emphasis is placed on potential partners' ascribed characteristics, cohabitations are more likely to involve economic contributions from both partners. Consequently, both partners are likely to emphasize achieved statuses, such as education and labor force participation. Greater educational homogamy and less of a tendency for women to "marry up" with regard to education are therefore expected (p. 409).

However, there are also many types of defacto relationships. As discussed in the previous section, some are "trial marriages", some long-term relationships that never become legal unions, while others may be the type of couple arrangement chosen following the breakdown of an earlier legal marriage.

\section{Education and the marriage market}

A number of writers have argued that educational attainment is an especially important variable in assortative mating as it often signals family background and is a key determinant of success in paid work and other aspects of life (e.g. Kalmijn 1991a). Mare (1991) places much emphasis on the impact of the length of schooling and age at marriage on sorting patterns. He notes, however, that these factors change over time. Mare observes that, since the 1970s, the age at first marriage and the length of formal education has increased for both men and women in the U.S. He suggests that many processes may be in operation regarding schooling and assortative mating. For example, people are more likely to enter an educationally homogenous union when they marry at an advanced stage of education rather than at lower levels of schooling. However, on a more practical level, Mare also notes that educational institutions provide a meeting place for assortative mating to take place. 
Herrnstein and Murray (1996) argue that education has increasingly provided a very efficient way of sorting people by cognitive ability. They then go onto speculate that mating of people with similar levels of education, and they argue IQ, has increased and will continue to increase. Epstein and Guttman (1984: 273), in a review of studies of assortative mating by IQ, already suggest that "interspouse correlations for intelligence are higher than those for personality and physical traits, but lower than correlations for background characteristics such as age."

Herrnstein and Murray go on to argue that the feminist revolution has brought women with high cognitive ability into higher education and, in particular, elite colleges. Noting how all the "elite" men's colleges, as well as many women's colleges, in the U.S. have now became co-educational, this made it easier "for the brightest to pair up" (p. 112). Overall, they argue that "[i]ntermarriage among people in the top few percentiles of intelligence may be increasing far more rapidly than suspected". They note:

When access to higher education is restricted by class, race, or religion, these divisions cut across cognitive levels. But school is in itself, more immediately and directly than any other institution, the place where people of high cognitive ability excel and people of low cognitive ability fail. As America opened access to higher education, it opened up as well a revolution in the way that the American population sorted itself and divided itself. Three successively more efficient sorting processes were at work: the college population grew, it was recruited by cognitive ability more efficiently, and then it was further sorted among the colleges (p. 31).

Continuing with the cognitive ability theme, Herrnstein and Murray argue that in the past various mechanisms ensured that the best genes were not passed on. For example, in medieval Europe they suggest that the brightest men were picked to be priests and monks. In theory, and possibly in practice, many did not pass on their "bright" genes because of celibacy. They suggest that arranged marriages within the aristocracy also often did not increase inherited IQ, but decreased it. The brightest of progeny tended not to inherit title or land, but instead this was passed to the first-born son. This means that matches were based on lineage not ability. 
Both Herrnstein and Murray, and Kalmijn (1991a), make the point that there is often a lag between attending an institution of higher learning and marrying someone of similar educational level. Kalmijn goes on to say that while higher education generally results in delayed marriage the friends made while at the institutions may form the main potential pool of marriage partners. In addition, he argues that people may become used to mixing with people who have higher education and this will narrow their choices in the future.

In relation to "arranged marriages", parents can still have an influence on the choices by their children. For example, they can send their children to private fee paying single sex schools (to minimise meeting the opposite sex in school years and to screen out potential low socio-economic partners), and then to elite co-educational institutions to increase the chances of their children finding a well-educated mate.

There remains a question as to how a radical shift to "life-long learning" could affect the marriage market and educational concentration. If education is generally completed early in a person's life then the final level of education a person has will be clearly signalled in the period that most people are making their initial partner choices. Under a scenario of lifelong learning there will be more uncertainty about final educational levels attained. In this scenario the "adaptive socialization" which can modify characteristics of both partners after marriage to "improve the quality of the match" could be particularly important (Oppenheimer 1988:564).

\section{The workplace and marriage markets}

Workplaces are often seen as a key place for forming relationships. Changes therefore in the labour market can have an affect on the marriage market. For example, the increase in women in the workplace, along with reducing occupational segregation, means that it may now be easier to find a partner within a similar occupation and within a particular firm. While in the past a male lawyer might have married his secretary he might now 
marry another female lawyer. ${ }^{63}$ Firms are also continuing the screening process that educational institutions started. For example, Herrnstein and Murray note "the young man newly graduated from his elite law school joins his elite New York firm, thereupon encountering women, just as highly selected for cognitive ability as he was, in the adjacent offices at his own firm, at business lunches, across the table in negotiations, on a daily basis" (p. 112).

The loss of jobs by people with few qualifications also means that this reduces the chance of workplace romances between well-educated and poorly educated people. A low level of labour market participation by sole mothers (and to a lesser degree sole fathers) also reduces their opportunities to re-enter the marriage market.

\section{Geography and marriage markets}

Geography is often seen as an important factor in the search process. When people are young they usually live with their parents, so if the housing market is very segregated the residential marriage market may also be segregated. In this situation there is a high chance of meeting someone with a similar social background. The implication is if people marry at a young age, or if they continue living with parents before marriage, then there will be more chance of homogamy of ascribed characteristics. Once they leave home they may face a different market for partners. It may be that on leaving home young people initially live in low cost housing areas that may expose them to a new part of the marriage market. Lichter et al (1992: 786) also bring in a spatial dimension to their view of marriage markets defining "local marriage markets on the basis of residential propinquity." They go onto to argue that "[p]otential mates meet within geographically delimited areas that circumscribe their daily activities at work, in neighborhoods, and in various organizations." This may be correct for low-income people, including sole parents, who are unable to travel widely. However, this may be a narrow view of potential meeting places for some groups, particularly for well-educated people with high levels of

\footnotetext{
${ }^{63}$ It may be that due to better educational and paid work prospects that some women who once became secretaries are now becoming lawyers so in terms of genetics the matching patterns may not have changed all that much.
} 
geographic mobility. Well educated people will often have jobs in organisations with international connections, will often travel and will usually have a high level of access to national and international communications systems. As will be discussed in following chapters, geography may not be as important for the well off in society.

England and Farkas, in discussing the U.S., suggest over the last 40 years that specific institutions have evolved which not only assist in searching and reduce search costs but also extend the geographic marriage market. These include advertisements in newspapers and other media and computer dating services. In more recent times the internet has extended the marriage market internationally. In addition, there are now "bridal markets" where men from Western countries can arrange marriage to women from countries such as Russia or the Philippines. The marriages may often result in "mixed work" couples given the traditional gender roles generally sought from these women.

\section{Gender roles and changing levels of competition in the marriage market}

Both Kalmijn and Mare discuss the "changing competitiveness" of the marriage market. Noting the work of England and Farkas (1986) and Oppenheimer (1988), Mare argues that increases in women's participation in paid work and their increased career orientations have altered the expectations of both sexes for marriage. He suggests this might cause people to increase their attention on finding someone from a similar socioeconomic status. He goes on to notes that:

If men increasingly see women as breadwinners as well as mothers and homemakers, and women's preferences for men are unchanged, then men with the best prospects in the labor market will seek women who also have the best earnings potential (p. 17).

A number of other researchers have also suggested that women's resources are becoming more attractive to men when considering a marriage partner (Davis 1984, Schoen and Wooldredge 1989) This could attract men with few economic resources, but could equally attract those with a high level of resources. Mare suggests that increasing competition for marriage partners may increase educational homogamy. 
This idea that educational homogamy and competition may be increasing, has been put forward by Kalmijn (1994: 426) who, drawing on the work of Becker, and bringing in issues of sex-roles, argues:

In sum, the economic perspective on the family implies that in a society with traditional sex roles, women are competing among themselves for men with attractive economic resources, whereas men are competing for women with attractive resources in other domains. After the sex-role revolution, men are believed to compete for economically attractive women just as women have always competed for economically attractive men. Because economic competition in the marriage market has become more symmetrical, it has become more intense as well.

This view appears to be based primarily on a sex-role revolution within paid work along with a "professionalisation" of unpaid work. If men specialise in paid work and women in unpaid work, and there is a significant amount of unpaid work needed to maintain the family/household, then there is logic in seeking an exchange between male income earning resources and female resources such as housework/childcare. But if much of the unpaid work can be professionalised, then the theory of increased competition amongst both men and women for partners with good economic resources appears to be more defendable. These are the people who could become both work-rich and income-rich.

But even under the "matching" theory of people with similar characteristics and interests seeking to form relationships, competition could increase if there was a "sex-role revolution" in both paid and unpaid work. Women who had good prospects in paid work may seek a partner who has a high commitment to both paid and unpaid work. With most research on unpaid work indicating that there has been a smaller shift, on average, in men's patterns of unpaid work than in women's patterns of paid work, the men who can contribute in both areas of work may be in short supply. As will be discussed in later sections "egalitarian" attitudes and actions towards paid and unpaid work by men is often linked to age and education. That is well-educated young men are often seen as being more "egalitarian" behaviours. So for some women an attraction to a well-educated man may not primarily indicate an attraction to economic resources. 
In a "sex-role revolution" there is also the possibility of some men and women seeking partners with similarly relatively low levels of commitment to paid work, but with egalitarian views about unpaid work. If these couples were well educated they could potentially both work part time and be seen as being relatively "work poor".

In addition, effective contraception has also allowed longer first birth intervals after couples are formed, and more choice over whether to actually have children. Therefore, the need for additional unpaid work associated with childbearing has not only been reduced, but may seem very remote when assortative mating decisions are being made. Thoughts about who might be best suited to undertake unpaid work are less likely to feature prominently in mate-seeking behaviour now than previously.

Oppenheimer (1988) has also discussed the impact of changing sex roles on the marriage market. In a theoretical paper, primarily analysing timing of marriage and adapting ideas from "job-search theory", she argues that in the past it was the man's market work which would primarily determine the standard of living for a couple. This required adaptation, or bargaining, by both partners to the needs of the husband's career. With changing roles for women a shift to two potential, or actual, careers this could cause conflict and adaptations would be required. Oppenheimer suggests this would provide more incentive for making a good initial match. In turn, this would lead to a rise in the age of marriage and greater marriage instability as there would be more uncertainty about the future characteristics of women whereas the uncertainty used to be just about the men. Linking to her theories of marriage timing, she argues that searching for a partner would only begin in earnest when each person's characteristics, particularly economic potential, were more clear.

Changing gender roles also has an impact on theories of "marrying up". When men dominated tertiary education there was a strong potential for women to marry up, at least educationally. Lichter et al (1992) suggest competition in the marriage market may be becoming more intense if "educational hypergamy", that is women marrying "up", 
remains a model for most women. This implies that the pool of marriageable men will decline as women's education increases. Under this theory the pool of marriageable men also declines if male unemployment increases or the relative earnings of a significant group of men decline substantially.

\section{Further ideas about separate marriage markets}

As already discussed in Chapter two, there is debate as to whether labour markets are actually segmented. However, if dual or segmented labour markets do exist this may impact on the marriage market. As discussed, workplaces and geographic communities are one important place for searching out potential partners. If these are segmented markets this would tend to cluster well-educated workers together in one group, and poorly educated workers (and non-workers) in a separate grouping.

Drawing on many of the theories already discussed, Birrell and Rapson suggest that there may in fact be two, somewhat separate, marriage markets now operating for women. Women with a high level of financial resources (and generally a high level of education) are seen as seeking primarily companionship within a gender equity model of a relationship, ${ }^{64}$ while women with few financial resources are seen as primarily seeking a partner who can provide financial support (p. v-vi):

While these two markets are, in practice, more part of a continuum than two separate markets, they can be conceptualised as an old style 'breadwinner' market and a new style 'collaborative' market. Women with their own resources through paid work are more likely to be in the collaborative end of the market whereas women on the fringe of, or not in, the labour market are more likely to be in the breadwinner end. However, even for women looking for 'providers', their increased access to the labour market means they are under less pressure to accept a male who cannot provide a secure income.

Within this continuum it is likely some/many women with a high level of financial resources will still be seeking to further enhance these resources by primarily seeking a

\footnotetext{
${ }^{64}$ This gender-equity model would generally involve equal sharing of only a small residual of unpaid work which is not / cannot be professionalised.
} 
high earning partner. ${ }^{65}$ In this scenario it be some / many poor women will also be seeking primarily companionship. This model would suggest that educational homogamy might decline, with women with a high level of resources increasingly willingly to "marry down" if this provides a better companion. However, it may also be that a high level of social (soft) skills, which would assist companionship, are more common amongst men with good labour market prospects (with such skills enhancing labour market prospects) than amongst those men with poor labour market prospects. However, as yet there is little research to test these ideas.

\section{Relationship breakdown}

While the process of couple formation is the main focus of this part of the research, couples separating could also affect possible concentration of education within families. For example, if divorce or relationship break-up is more common amongst people with high levels of education this may, depending on their future marriage market behaviour, reduce the concentration of education in families and households. For example, highly educated women moving out of an initial relationship may be more inclined to seek a similarly qualified person or alternatively, given their own success, may not be so concerned about a partner being well qualified. McPherson (1995) puts forward the idea that education might be linked to divorce for two reasons, citing research showing some correlation between lower social and economic status and higher rates of divorce (Carmichael 1988, Patterson 1976). With social and economic status linked to education, she then suggests it could be expected that low education could be linked to an increased probability of divorce. But equally McPherson notes that higher education amongst women also provides the potential for a greater degree of economic independence, and thus higher divorce rates. Using data from the U.S., Goldscheider and Waite (1991) have found that women married to men with a postgraduate education are less than half as likely to divorce as those whose husbands never reached high school (2 percent per year

\footnotetext{
${ }^{65}$ In high-income households there is probably more opportunity to live separate lives so companionship or the ability to "get on" may actually not be as crucial as in low-income households.

${ }^{66}$ In addition, as discussed in Chapter eleven people with a high level of economic resources have potentially more to lose by making a bad match so may reduce this risk by seeking people with similar resources.
} 
versus 4.5 percent per year). They argue that one reason for this is that these men have more modern attitudes and help more around the house. However, it could also be that these particular women have more to lose from a divorce. More recent research in the U.S. (Ono 1998) suggests that dual career families have longer relationships than traditional families. This would again imply that there is more stability amongst welleducated couples.

\section{Outcomes of Assortative Mating}

A variety of data sources have been used in overseas studies to analyse the workings of the marriage market. Early studies in the U.S. include Burgess and Wallin (1943), Hollingshead (1950), Rockwell (1976) and Spanier et al (1980). While there are many weaknesses in their methodologies (for a review see Kalmijn 1994) overall they show that on a variety of measures people tend to marry (or cohabite with) people with similar characteristics. More recent studies have been carried out in Australia and the U.S. using a range of data sources (e.g. Jones 1987, Kalmijn 1991a\&b, Mare 1991, Schoen and Weinick 1993, Rimmer and Rimmer 1994). While some of these researchers were not specifically analysing assortative mating they comment on this issue.

In comparison, the operation and outcomes of the New Zealand marriage market has received little attention amongst New Zealand researchers. Exceptions include Pearson (1980) and Jones and Davis (1986). Both show a tendency for couples to have some similar characteristics.

\section{Conclusion}

There are many theories regarding the processes and outcomes of assortative mating. Some, usually based on the concept of differing, and relatively fixed, roles in paid work and family life for men and women, stress the concept of women wishing to "marry up" for resource reasons, while men seek qualities such as beauty or ability in unpaid work. Other theories focus more on people seeking partners with similar characteristics, especially similar levels of education. Within these theories there are those that see 
education as primarily a signal for economic status, some see education as a marker of social status, while others see education as signalling a set of attitudes or beliefs. Based on an idea of changing gender roles, there are also theories emerging that competition in the marriage market is increasing.

While often providing little guidance on the actual processes of assortative mating, the international literature does suggest that education has a major impact on mating outcomes.

Finally, the processes and outcomes of assortative mating may be having a significant influence on whether couples are work-rich or work-poor. If there is a high level of matching by educational characteristics in New Zealand, then it is likely that couples where both partners are well educated will be over-represented amongst work-rich couples. The situation of poorly educated people could be more complex. Based on some of the theories discussed in the previous chapter, poorly educated people may be underrepresented in couples. However, if poorly educated people do still form couples, then they are likely to form a significant proportion of work-poor couples. Some of these ideas are discussed in the following chapter. The following research ideas are then explored in Chapters nineteen and twenty.

- that there is a strong tendency for people in couples to have a similar levels of education

- that this concentration of education in couples increased between 1986 and 1996

- that concentration of education in couples is associated with a concentration of paid work in particular couples 


\section{Changes in work within families and households and some reasons for the growth of work-rich and work-poor couples}

\section{Introduction}

This chapter begins with a brief overview of some recent literature on work-poor and work-rich families and households. It then narrows its focus to changes in the paid work patterns of couples. In particular, there is an examination of the reasons why prime-aged work-rich couples and work-poor might be emerging as family types.

\section{Some overseas trends}

In Britain, the concept work-poor households and work-rich households emerged in the mid 1990s (Gregg and Wadsworth 1994). Gregg and Wadsworth show that in 1990, twice as many working-age households had no one in paid work than in 1975. Of significance, the authors note that some of the growth in work-poor households occurred during a period of overall job growth.

Intergenerational implications emerge in further British research. Dex and Taylor (1994) found that, in 1991, among households with an adult child, the adult child was in employment in 69 percent of dual-earner couple households, but was employed in only 4 percent of no-earner couple households. 
Gregg and Wadsworth (1996c) went on to show that work-poor households had been an increasing characteristic of most OECD countries between 1983 and 1994. The paper describes changes in the distribution of employment across prime aged (20-59) households for 13 OECD countries. They do, however, note that this was a period of persistently high unemployment and the results reflect this.

Also of interest was their finding that in seven countries there was a simultaneous rise in both workless and fully employed households. They also found that in all the European countries studied there has been a shift in family composition toward single adult households who had a high incidence of worklessness.

Gregg and Wadsworth show that a significant exception to the growth in work-poor households in the period studied was the U.S. However, a trend towards work-rich and, potentially, income-rich, families does show up clearly in the U.S. (Juhn and Murphy 1995). This later point is important as Juhn and Murphy found that, in 1940, the highest labour market participation by wives was in families where the male was in the bottom quintile of income but, by 1990, the highest rates were amongst wives with men in the middle quintile of income.

Juhn and Murphy went on to show that in the period 1970 to 1990 for couples in bottom deciles of income men's real incomes declined. However, increases in women's income kept real family income stable. But in the top income quintiles both men's and women's incomes increased in real terms so total family income rose considerably over this period.

OECD research also suggests a growth in work-poor households. Based on unemployment, the OECD (1995) notes that in the mid 1990s one third to one half of all unemployed across its member countries lived in households where no other person had a job. This proportion had increased almost universally across OECD countries from the mid 1980s. Moreover, a substantial and growing proportion of the unemployed living in these "jobless" households were long-term unemployed, a factor which, the OECD suggest, may exacerbate their lack of contact with the world of work. 


\section{New Zealand}

In New Zealand there was already evidence of growth in work-poor families in the period of economic growth in the early 1980s. Matching data of Johnstone and Pool (1996) with employment data indicates that while between 1981 and 1986 total employment grew by 8.1 percent the proportion of families with no one in paid work also increased from 21.1 percent to 24.7 percent. This was not just a growth in sole parent families. While sole parents not in paid work, as a percent of all families, grew from 6.9 percent to 8.7 percent, "no job" couples with dependent children grew from 3.7 percent to 4 percent, and "no job" couples without children increased from 10.4 percent to 12 percent. Using these data there was, not unexpectedly, a further increase in such work-poor families in the period of job loss between 1986 and 1991.

While changes in work and household patterns might be leading to the growth of workrich and work-poor households, in New Zealand and overseas many other factors will be influencing these trends. For example, an aging of the population will tend to create a higher proportion of work-poor households (as couples reach retirement age), while deinstitutionalisation will tend to create work-poor households rather than work-poor people living in non-private dwellings. Such a wide analysis is generally beyond the scope of this research. Instead, I focus mainly on why prime-aged couples might be moving to being either work-rich or work-poor.

\section{Why might couples be work-rich?}

Historically, aside from major periods of recession, many couples would have been workrich. Small businesses and family farms required all family members to be producing goods for either sale or consumption by the family. However, in New Zealand and in most industrialised countries, there emerged a period where many women in couples withdrew from paid work, either on getting married or having children. 
In recent decades there are many possible reasons for couples again becoming workrich. ${ }^{67}$ Firstly, there is much international evidence to suggest that many couples need two incomes to maintain their target standard of living (e.g. Harkness et al 1996). ${ }^{68}$ When women or other family members move into paid work to maintain family income this is often described as the "added worker" effect. Rankin (1993) notes that this is where workforce participation is determined more by total disposable household incomes than by wage rates. In times of falling real incomes, family members not in the workforce seek employment as a means of preserving their families' living standards. The need for an additional income to meet existing commitments can mean that additional workers' show a low sensitivity to wages offered. Added workers will tend to take the low paid, parttime jobs that primary income earners will try and avoid.

But, just like many men, a significant number of women, especially well-educated women, also want to be in paid work. There can be many reasons for women wanting to be in paid work. It can be for the money, and the economic independence it provides, it may be for status or it may be primarily for social reasons. For instance, Hochschild (1997) suggests that for some groups of women, paid work provides a less stressful and happier environment than home life.

The mixed-work model has often been seen as advantageous for advancing the careers of men. For some high earning men, there may be still be some advantages in having a wife at home looking after the children, organising dinner parties or, if they are an academic, having someone editing their work, but for middle income men there can be advantages in having a partner in paid work. For example, Kalmijn (1994) suggests that a wife's participation in paid work may assist the husband's access to networks that might help his career, her income might enable him to invest in additional human capital, and may also reduce his need to look at short term, initially higher paying, jobs but instead focus on long term career objectives.

\footnotetext{
${ }^{67}$ This is using the definition of having both partners in paid work.

${ }^{68}$ This is presumably a moving target that rises over time relative to some "average" standard of living. However, if their target is relative to some upper income group and there is an increase in income inequality then this further increases the perceived need for additional income.
} 
It may also be that increasingly the marriage market is bringing together people with a similar attitude to work. In a time use study in Sweden, Sandqvist (1997) found that in two-parent families where the mothers worked full time, the fathers were working longer hours than if the mother was working part time. She speculated that spouses tend to have similar orientations towards paid work rather than complementing each other. However, she could not tell from the data whether it was through "choice" or economic necessity.

A growth in work-rich couples might reflect a growth in self-employment. Some selfemployment, such as running a horticultural unit or perhaps a plumbing firm relies heavily on family labour. In the official statistics one partner may be classified as an unpaid family worker (but still be classified as employed).

The mixed-work couple model has primarily been based around childrearing, but in most industrialised nations there is both an aging of the population and declining fertility rates. For couples without dependent children there are fewer impediments for both partners to be in paid work. However, for couples with children in most industrialised countries a number of factors have had an impact on the amount of time parents spend with children as opposed to time in paid work. These include:

- $\quad$ smaller families

- changing attitudes with regards to parental versus non-parental care

- an increase in both public and private investment in pre-school as well as afterschool care

- an introduction of job protection through parental leave schemes

- growth of part-time work

- growth of shiftwork

There has been much research interest in work-rich couples, particularly those who are seen as having dual careers. While some of this interest simply comes from researchers wishing to find out more about their own lifestyles, there have been some concerns raised 
about the rise of two-job couples. One of the prime interests in the growth of childrearing couples where both are in paid work has been around the possible impact on children of "working" mothers. This is an issue that has already been explored briefly in Chapter four. However, generally the research and social policy focus has switched away from determining any impact of mother "absence" to examining the best ways of providing alternative high quality, but affordable, out-of-home childcare. In fact, in very recent times there has been more of a focus on the impact of a particular type of "absent" fathers, that is the group of fathers in two parent families who work long hours in paid work (Burgess 1997). Another research question is around the job mobility of such couples. When one partner finds a suitable job in another location it may be that the other partner cannot find an equally suitable job. At times, this may lead to couples living in separate households during the working week.

A further concern expressed about the growth of two-job, and particularly full-time dual career couples, is a possible decline in social capital (Crosby 1991). Historically, married women with young children have undertaken much unpaid work in the community. This includes helping as teacher's aides, delivering meals on wheels, and running community support groups. Some of these voluntary institutions and jobs have now been "marketised". An example in New Zealand is the growth of private childcare centres and the decline of parent co-operative Playcentres. However, it may be that people in dual career jobs tend instead to be working in symbolic-analytical type voluntary jobs in the community. Such jobs include being on Boards of Trustees in schools. It is possible that people who are work-poor have taken over many of the in-person service voluntary jobs in communities.

Finally, when discussing work-rich couples, Zedeck and Mosier (1990) point out that a distinction needs to be made between dual-career and dual-worker couples. They define dual-career families as those in which both partners have jobs that are personally satisfying with opportunities for promotion, and the jobs need a high level of commitment. This implies they generally also have higher levels of education. Of equal importance, many of these couples are likely to have sufficient resources to hire domestic 
substitutes to reduce the double burden of paid and unpaid work. In dual-worker families, both partners work mainly out of economic necessity and cannot afford domestic substitutes.

While these concepts are laid out, actually determining appropriate measures for each is more difficult. In Chapter twenty, I explore some possible definitions using census data.

\section{Why might couples be work-poor?}

Of more direct interest to governments and other social policy makers is a growth in work-poor couples. Some of the theories about couple formation discussed in Chapter eleven indicate that couples will tend not to form or, alternatively, will tend to separate when men are no longer in paid work. At an extreme, under these theories work-poor couples should not exist. However, as discussed, there is evidence that work-poor couples not only exist but also have been growing as a group in many industrialised countries. Therefore, further theory and evidence is needed as to why particular couples might be becoming work-poor.

A variety of theories have been put forward as to why couples might become work-poor. In part, the various individual theories reflect the particular route of individuals into work-poor status. Couples can involuntarily become work-poor through sickness or unemployment of both partners. Some couples can also become work-poor through choice, such as through early retirement, both partners studying full time or they may both be in a period of transition between jobs such as recently having returned from overseas travel. The shift to being work-poor can occur when in a mixed work, traditional family, the man exits the paid workforce and his partner does not move into paid work to compensate. Alternatively, it could occur in a couple where man was not in paid work and his partner has been. Some work-poor couples may also move from a work-rich status if both partners simultaneously exit paid work. An example of this would be where a family business, such as a farming enterprise, fails. 
In their 1994 paper Gregg and Wadsworth, put forward three main hypotheses for the growth of work-poor couples in Britain. These are "within family considerations", "common characteristics" and the welfare system. Also in Britain, Cooke (1987) has put forward a number of ideas as to why work-poor couples might exist. In general, these theories focus on the loss of jobs by men and the flow-on employment consequences within the couples. This includes an interest in the research literature as to why many women in couples do not compensate by increasing their labour market participation, or at least maintain their existing level of participation, as men exit from paid work. Combining the thoughts of a number of researchers provides a range of theories.

1. Employment opportunities, including the pay gap, along with the combined effects of welfare payments with marginal tax rates, may mean that a couple or family cannot survive on only the female partners income. So if the male exits paid work, the female partner will also exit. In Britain, Gregg and Wadsworth refer to this as the "deducted worker effect". In New Zealand, both Else (1997) and Rankin (1993) have put forward this type of argument.

2. The male partner may not be in paid work because of illness and his partner may have withdrawn from paid work to care for him. However, this could also operate in reverse if the female partner becomes ill. This idea also connects into the view that health might be an important factor in the exiting of individual men from the workforce (Dixon 1996b).

3. Loss of primary earnings may make the employment of the second earner more difficult to sustain. Cooke argues that having a primary earner may provide access to equipment, transport or contacts with potential employers that help maintain a second source of income.

4. Common characteristics. This is an idea put forward by both Gregg and Wadsworth and Cooke. Cooke suggests that the female partners of men not in paid work may have fewer labour market skills or other characteristics which disadvantage them when compared with the partners of employed men. The common characteristics could be level of formal education or cognitive ability. 
Alternatively, both partners may have other similar interests that might affect their workstatus.

5. Local labour market effects. A further theory put forward by both Cooke and Gregg and Wadsworth is that recessions are highly localised so labour demand for both women and men in an area decline.

In this research, I am primarily interested in testing theories four and five. However, while the concept of "fixed gender roles" cannot be tested using census data, they are of direct relevance to my thesis. It is therefore worth briefly exploring some of the ideas emerging from the research literature. ${ }^{69}$ There are a number of attitudes, and resulting behaviours, which might be important in relation to fixed gender roles.

1. Employers discriminate against women in the workplace, so indirectly work against women becoming primary income earners in couples.

2. Cooke argues that some women may believe that withdrawing from work will help employment prospects for their husbands. This is based on the idea that there are a finite number of jobs in the economy.

3. Morris (1990) and Cooke have suggested unemployed men may be reluctant to undertake household and childcare work, limiting paid work opportunities for their partners.

4. Allen and Hawkins (1999) have suggested there may be some instances of maternal "gatekeeping" where men with dependent children are not encouraged by their partners to become primary caregivers.

There is also a body of literature that emerged in the late 1980s and early 1990s showing that men have also faced external barriers when trying to move into non-traditional family roles (e.g. Callister 1994, 1999b). These have included some seemingly simple barriers, such as having baby-changing areas within women's toilets. Other barriers have been parent support groups, such as Plunket, Playcentre or Mother's Support being primarily aimed at women. Much of this research is either anecdotal or based on small samples, so

\footnotetext{
${ }^{69}$ Some of these ideas have been canvassed in earlier chapters.
} 
it is difficult to assess the level and extent of this type of barrier. Opinion polls can give some guide but have the drawback that they reflect stated attitudes and not how people actually behave. In a 1994 opinion poll, only a minority of New Zealanders (23 percent) said that it was a man's responsibility to earn money and a woman's responsibility to look after the home and family (Gendall and Russell 1995). The survey also indicated that only 16 percent believed that it is undesirable if a man stays at home and cares for the children while his partner went out to paid work. Podmore (1994) found a variety of views when she interviewed New Zealand parents with young children. In her study of sixty families she found that almost 20 percent were emphatic that fathers should be in paid work, 27 percent mentioned the obligation for fathers to be in paid work, 35 percent recommended more flexible arrangements including some suggesting that it was appropriate for fathers to stay home and look after children, and 13 percent pointed out a range of inadequacies in the traditional role of fathers.

\section{Do work-poor couples stay work-poor long term?}

This is an extremely important issue, but one that cannot be easily assessed in New Zealand as there are no suitable data available. ${ }^{70}$ However, the British research of Gregg and Wadsworth (1994) provide some guide to what might be taking place in New Zealand.

Gregg and Wadsworth examined transitions using British LFS data that records the employment status for an individual a year before the survey date. Gregg and Wadsworth argue between the late 1970s and 1990 the probability of gaining employment fell dramatically for members of households with no one in paid work.

\footnotetext{
${ }^{70}$ There are two reasons for this. First, until recently the New Zealand HLFS collected data on family and household type but this data could not be analysed. The change occurred shortly after I worked with Statistics New Zealand in the early stages of this research. However, second the HLFS does not ask a question about workstatus in the previous year. This in contrast to a number of other similar surveys carried out overseas (Callister 1997). However, further complicating this assessment, as discussed in Chapter ten, work-poor individuals may tend not to stay long term in couples.
} 
Gregg and Wadsworth note that transitions out into employment are as important as inflows into unemployment for the development of a group of long-term unemployed. Their data shows that in 197960 percent of non-employed households had at least one earner a year later. But by 1993 this had declined to 25 percent. In contrast they argue that the stock of two earner families was highly stable in all periods they studied.

Gregg and Wadsworth show that between 1979 and 1993 a collapse in the outflow rate of non-employed accounted for two thirds of the rise in the stock of jobless two person households and three quarters of the stock of no job single adult households. This resulted in major increases in the jobless durations of no-job households. Gregg and Wadsworth estimated that in 1979 a two adult household, on average, had no work for 18 months. But by 1985 and 1993 this had risen to about 54 months. Gregg and Wadsworth speculate that these extended durations must have led to major financial problems.

Forthcoming work by Gregg et al confirms that for a significant number of work-poor households this status is long term.

In this research, until counter evidence is available, I am assuming that these findings will be generally applicable to New Zealand.

\section{Conclusion}

Changes in both work and family patterns have led to an increase in both work-rich and work-poor couples and households in most industrialised countries. This has naturally led to a decrease in the proportion of couples with a mixed work pattern where the male was in paid work and the female not in paid work. Whether these trends also occurred in New Zealand through into the mid 1990s is explored in part three of this research. In particular, I focus on five ideas. These are:

- work-poor couples tend to have a low level of formal qualifications and work-rich couples tend to be well qualified

- changes in local labour markets impact on whole households 
- the main type of job being created in the economy has been low paid part-time work. This means that the only people who can take these jobs are those people in couples or larger households with partners or other family members in relatively well paid full-time jobs

- there has been increasing professionalisation of household work, in particular childcare, which has assisted in women moving into paid work without the need for men to decrease their level of paid work

- the majority of work-rich couples are dual-job rather than dual career couples 


\section{Chapter 13}

\section{A spatial dimension to changes in work, education and living arrangements}

\section{Introduction}

Many of the issues discussed in previous chapters have a spatial dimension. For example, discussions about globalisation have, at their heart, ideas of change in economic activity across international borders. Terms such as industrialised countries, developing nations, and the "third world" have also emerged from debates about the distribution of income and resources across the globe. The traditional regional analysis or the "north" versus the "south" development debates are part of this type of discussion, but the units of analysis are now often much smaller. They may be suburbs, or even streets (Grannis 1998). At times, these debates connect into discussions as to whether local labour markets exist and, if they do, their importance (Morrison 1990). Many of these discussions have as a key theme that people in particular geographic areas are being excluded from gains in employment and economic activity (Soldera 1999).

There is also an interest in other areas of research literature as to whether there is a geographic dimension to various family and household living arrangements. For example, do local marriage markets exist?

As in other chapters, this review can only touch on many of the important spatial aspects of changing work, families and households. It focuses primarily on why work-poor and work-rich and, connected to this, education-poor and education-rich geographic areas might be developing in industrialised countries, including New Zealand. 


\section{Theories about the clustering of people with similar characteristics}

People with certain similar characteristics have always tended to cluster together in particular geographic areas within countries, as well as within particular urban and rural areas. Historically, this clustering has often been along religious, ethnic, tribal or other kinships lines.

In industrialised countries, clustering behaviour can be affected by many factors. These include the level of religious and racial tolerance, housing policies, mobility of workers, level of income inequality, the amount of clustering of particular industries and the degree of urbanisation in the society. Part of the clustering is due to people with similar levels of work or qualifications living together in houses, normally a marriage market effect. However, where those households locate becomes primarily a housing market issue. In relation to urbanisation, the size of settlement can have an impact on the level of clustering that can occur. For instance, in small rural towns in New Zealand there has often been a relatively wide diversity of individual and household income, types of workers and types of families. ${ }^{71}$ Although perhaps living on a prime site, and in better quality accommodation, a relatively well-paid local doctor in a small town often lives in relatively close proximity to unemployed families or to manual workers. It is also likely that children from a wide range of socio-economic backgrounds attend the local school so ensuring some socio-economic diversity of children. In large urban areas, some people can more easily choose to live with those who have similar incomes or types of occupations or be forced to do so through economic circumstances.

However, in large urban areas research has shown that the clustering of people by characteristics such as religion or ethnicity can result in a relatively wide mix of employment and income-earning ability (Wilson 1987). A clustering by religion, for example, even if there is a relatively wide income distribution in society, may mean that poor Catholics live near rich Catholics and attend the same churches and same schools.

\footnotetext{
${ }^{71}$ However, in the past in New Zealand there have also been more specialist rural settlements, such as forest camps or mining settlements, where there was far less diversity of people.
} 
But many writers suggest that in both rural and urban areas sorting of people into specific geographic locations is taking place along socio-economic lines. For example in the U.S., Wilson has suggested that in black, inner-city ghettos the well educated have tended to move out. Yet, often when blacks then move into white neighbourhoods this tends to reduce the price of houses in those neighbourhoods (Harris 1999). ${ }^{72}$ In New Zealand, Morrison's research in the Wellington region has also shown that as individual Maori increase their level of education they tend to move to areas where people have similar educational qualifications, rather than staying in areas with a high proportion of Maori (Morrison 1993). Also in New Zealand, Soldera (1999) has shown that, between 1986 and 1996, in some already high unemployment areas within Auckland and Wellington, there was an increased clustering of people with characteristics that placed them at a disadvantage in the labour market. In addition, in many poor rural areas in New Zealand, due to restructuring there are no longer the higher earning bank managers or stock and station agents living in small towns and it is difficult to attract professionals, such as doctors, which further reduces the diversity of residents.

In both the research and popular media it is suggested that clustering by a variable such as income, and linked to this education, can result in "polarised" communities. In the U.S., analysts from both the political left (e.g. Reich 1993) and the political right (Herrnstein and Murray 1996) have expressed a concern about the increasing polarisation of areas in cities. Also in the U.S., Jargowsky (1997) studied the growth of what he defined as extremely poor neighbourhoods (census areas in which 40 percent or more of residents were poor) and found that the number of poor people living in these neighbourhoods almost doubled between 1970 and 1990. However, somewhat challenging the polarisation hypothesis, he also makes the point that although the number of high poverty neighbourhoods grew rapidly in the 1970s and 1980s, the majority of the poor did not live in high poverty neighbourhoods. In 1990, only 12 percent of poor people, and 25 percent of poor African-Americans, lived in high poverty neighbourhoods. In relation to

\footnotetext{
${ }^{72}$ However, Harris argues that decline in property prices is not because of discrimination per se, but a "racial proxy", that is that people prefer neighbourhoods with affluent, well-educated people and being black does not signal such characteristics.
} 
Australia, a theory of polarisation has also been put forward (Hunter and Gregory 1996: 180). Hunter and Gregory argue that between 1976 and 1991 there was:

...an increased social stratification of areas with poor people being increasingly likely to live with other poor people and the rich people increasingly isolated from exposure to their plight.

Clearly, if there is some tendency for clustering by income, and there is also an increasing "gap" between affluent and poor individuals, families and households, then any national polarisation in education, work and income distribution will be reinforced geographically. How this comes about can be part of a complex process. For example, Costa and Kahn (1999) argue that American couples with a similar level of qualifications have a colocational problem. They found that college educated couples are increasingly concentrated in larger metropolitan areas and they attribute half of this to a growing problem of colocation. The couples are not only both more likely to find suitable jobs in such locations but that relative returns of college educated couples in large cities have increased relative to small cities. This is seen as leading to a concentration of human capital in large cities.

Also linked into these processes are other complex ethnic and gender issues. For example, the Economist (1996: 27) notes:

Consider for a moment a neighbourhood in which most working-age women are not in paid jobs. This may conjure up a picture of tidy homes, children at play and gossip. Now think of a neighbourhood in which most men are jobless. The picture is more sinister. Areas of male idleness are considered, and often are, places of deterioration, disorder and danger. Non-working women are mothers; non-working men, a blight.

\section{Clustering of the economically and socially disadvantaged}

Race, gender, changing employment patterns and place are key elements of the Wilson "social isolation" hypothesis in relation to large urban areas in the U.S. Wilson, although referring to a time before the current economic boom, argues that the loss of relatively well-paying manufacturing jobs, which employed low skilled blacks from inner city 
areas, along with the out-migration of middle class blacks, created areas of significant poverty. ${ }^{73}$ As already discussed, the loss of jobs for men is then linked to a breakdown of traditional families and particularly the growth in sole mother families. However, just as important, the outward migration of the middle class is seen to weaken important socialising institutions such as churches and other community organisations which were previously supported and often run by these people. ${ }^{74}$ The outward migration of the middle class reduces job-finding networks for those left in these neighbourhoods. These theories link into the job finding ideas of "weak ties" and "strong ties" expressed by Granovetter (1973). It is theorised that people are more likely to find a job through "weak" ties, that is connections with an acquaintance who links into different worlds, than strong ties such as a work-poor close friend or a partner who has few links into outside networks.

Wilson's model is applied primarily to minority groups in the U.S. and, in particular, Blacks. Poor white Americans may face less discrimination in areas such as housing, which is one reason they are less likely to be concentrated in poor neighbourhoods.

These pockets of disadvantaged people are often seen as increasingly having little connection to the mainstream economy so even if there is strong overall economic growth, these communities will not benefit directly (e.g. Gregory and Hunter 1995). But there can be some complexities to this lack of connection. It may be that it is a supply side issue, rather than a physical location issue, which at times disconnects people from the mainstream economy. For example, an area with a large urban centre may be the site of high technology industrial plants. The infrastructure supporting these plants will tend to be motorways, overhead power pylons and large, and often, non-aesthetically pleasing buildings. However the area may also still have housing in it. Such areas can be found in South Auckland. Due to industrial characteristics of the neighbourhoods these will tend to be low cost houses, so will tend to house work-poor people. Yet, in terms of actual work

\footnotetext{
${ }^{73}$ In a later paper, Wilson (1998) recognises that the current boom has attracted many, but far from all, low skill men back into paid work.

${ }^{74}$ As already discussed, this trend occurred at the same time as many women who ran these organisations moved into paid work.
} 
available these may be work-rich areas. In the South Auckland example, it is possible as manufacturing "upskills" that labour comes increasingly from outside suburbs while poorly skilled local people remain work-poor.

Many researchers recognise that in areas where a high proportion of people, and particularly prime-aged men, are not in paid work this may impact negatively on a range of economic, social and health indicators for the residents in these communities. Van Kempen (1997) suggests there could be five inter-related problems with the development of "pockets of poverty" First, within them there is likely to be limited access to jobs. Second, there is an issue of negative neighbourhood "norms" developing. Third, there may be some stigmatisation. For example, she suggests the stigma of living in certain neighbourhoods may have an impact on attitudes towards these people by potential employers. Fourth, she suggests that within such pockets there may be limited access to "social citizenship rights". This relates to the social services offered to people in area. Finally, she suggests that the general provision of goods and services in such areas may be lower. The types of services that are likely to impact on work patterns include public transport and childcare.

An important social service in a community is schooling. Van Kempen suggests that teachers and other people involved in schooling in poor areas may have low expectations for students so "failure" becomes a self-fulfilling prophecy. Such attitudes may also reflect differences in ownership or control of schools. For instance, Reich (1993) argues that in the U.S. in the 1990s most large cities had two separate school systems, a public one for children of in-person service workers, routine production people, and the unemployed, and a private one for the children of symbolic analysts.

The concept of "neighbourhood" effects, or local "norms", usually in terms of negative role models, has recently emerged (e.g. Case and Katz 1991). In America, this is often linked to issues of race. For example, Sucoff and Upchurch (1998) provide some evidence in support of the idea that neighbourhood racial composition directly influences adolescent childbearing by "sealing off participation in mainstream social and economic 
arenas." Another writer to suggest neighbourhood effects is Mead $(1986,1992)$ with his welfare culture model. Both the Wilson and the Mead models are "contagion" or "epidemic" models. As such, they predict that neighbourhood effects will be small until some characteristics of the neighbourhood move past a trigger point. Recent American research also lends some support to the idea that there is a "tipping point" where the characteristics of a neighbourhood become so bad they start to negatively influence the behaviour of people living in it (South and Crowder 1999). Boggess and Corcoran (1999) argue that a social policy implication of epidemic models is that stopping and even reversing the epidemic may require targeting very poor communities and providing these people with a range of supports including better policing and improved schooling.

There are many difficulties with such research. There is also much debate about what characteristic of a "bad" neighbourhood might be important in influencing behaviour. It may be the poverty rate, the proportion of sole parent families, lack of middle class role models or the level of male unemployment. For instance, having many men unemployed can lower the "psychic" cost of being unemployed. However, Corcoran and Boggess suggest that if neighbourhood effects do exist it is likely to be through some combination of various factors.

As already discussed in Chapter five, like many theories in this area it is difficult to separate out the various effects of family norms, norms reinforced by schools and the wider neighbourhood effects.

In addition, Van Kempen and Marcuse (1997: 294) suggest that a concentration of similar people in a poor area can have both good and bad impacts. The bad impacts include:

- lack of information on jobs when people are surrounded by unemployed

- language of a minority might be reinforced preventing them from integrating into wider society

- access to finance and insurance may be limited 
- concentrations of poverty might erode the economic base for commercial services (banks, photocopiers etc)

The potential positive impacts include:

- like minded people might improve social networks and sometimes financial networks (e.g. credit unions)

- particular attitudes or behaviour might support specialist shops (such as ethnic food)

- ethnic entrepreneurs may find more local support for their businesses

In New Zealand, Coleman (1997) has developed a basic model that tries to explain the clustering of disadvantaged people. He suggests that inequality, through negative externality effects, such as increased crime or poor schooling, is self-reinforcing. Specifically, he argues that once benefit receipt or unemployment rates reach a certain level, there is a rapid clustering of people without jobs into an area. Thus is reinforced then by people with paid work moving out of the area. In addition he argues that "hysteresis" will occur, with disadvantaged clusters remaining or even becoming more disadvantaged during an economic upturn. This model has been partially tested in New Zealand by Soldera (1999) who found evidence of spatial hysteresis occurring in major urban areas between 1986 and 1996.

Finally, many of these models of neighbourhood effects have been developed in relation to areas within very large cities. Some researchers have raised questions as to how applicable neighbourhood effects are to New Zealand communities (e.g. Boggess and Corcoran 1999).

\section{Segmentation theories}

While much of the spatial disadvantage literature focuses on themes such as polarisation, ghettos and "dual cities", more complex theories about the spatial distribution of work and income are being developed (e.g. Marcuse 1996). Much of this literature is based on 
U.S. metropolitan cities and still has a prime concern about predominantly Black, inner city ghettos that emerged in the 1970s.

In many of these segmentation hypotheses, wider global changes in paid work are linked to changing local patterns of residence. Within the Marcuse view are embedded many of the ideas, such as the globalisation of capital, information and labour and a shift in labour demand towards those with a high level of cognitive ability, that have been explored in earlier chapters. Marcuse suggests that groups of people generally live in separate geographic areas within a residential city (p. 196-197). There are luxury housing spots, a gentrified city, a suburban city, a tenement city and an abandoned city. In parallel, there is the economic city where places of paid work are located. In this economic city, there are places of major decision making, an area of advanced services, and area of direct production, an area of unskilled work and the informal economy and, overlapping the abandoned city, a residual city. While managerial and professional groups will live in both the gentrified and the suburban city, those in the suburban areas will tend to be childrearing families. Marcuse notes that the places of "big decisions" is not entirely a geographic place with, through advances in telecommunications, decisions now being able to be made on yachts, in cars, on airplanes as well as remote locations throughout the world.

Van Kempen and Marcuse (1997) also emphasise that there is a major differences between higher order service industries (Reich's symbolic analysts) and lower order service jobs (in-person services). Jobs in the fields of management, finance, law and politics are still generally focussed on the centre of cities. This is despite better communication systems and transport. Many of the lower level jobs, for example those in cafes or office cleaning, are directly and spatially linked to the upper level jobs, but many can be found anywhere that people congregate, such as the suburbs.

There are further overlays to this type of analysis. First, there is the view that as one progresses further down the "segments" of the city race, household and family mix change. For instance, sole parenthood is more common in the "abandoned city". Second, 
there is a both a further national and global hierarchy. For instance, some cities within a particular country are where "places of big decisions" are located. In addition, the big decisions made in a major city in a small country usually have less impact than such decisions made in such a city located within a superpower. Issues of core and periphery urban areas have both a national and international perspective.

\section{Clustering of the affluent}

Van Kempen and Marcuse (1997) suggest that the world of the wealthy is much larger than any spatially defined neighbourhood. For many of these people, their lives have become global in terms of jobs, the marriage market, schooling and recreation. Yet, there are still emerging concerns related to the geography of the affluent. One concern is about the development of what might be considered the "luxury housing spots" or "gentrified" cities. For instance, the Brookings Institution (1997) describes how "gated" residential communities with private security guards, private gardeners, private schools and other private facilities are becoming more common in the U.S. for those in the upper-income brackets.

The Brookings Institution goes on to suggest that that these "gated" communities can become partly politically autonomous. ${ }^{75}$ This includes withdrawing the support for wider community facilities such as libraries or low-income rental housing. Linked to this, the internal workings of "gated" communities are based on legal contracts not social contracts. While the Brookings Institution acknowledge such communities might represent a good rational choice for individuals and families, "gated" communities might not be so good for a city, region or nation. They go on to argue (p. 176):

\footnotetext{
Democracy is based in part on mutuality and collective citizenship, with the structure of communities tying individuals together across their dissimilarities to form a city, a region, and a nation. We now ask, can a nation survive and flourish without inclusive communities to undergird the practice of citizenship? Can the nation have any wholeness when communities are fragmented and pitted against each other socially, politically, and economically?
}

\footnotetext{
${ }^{75}$ This is primarily in terms of local government politics.
} 
Reich argues that the main thing that lies at the heart of American geographic communities is level of income. This is household or family income, rather than individual income. In fact, there may still be some diversity of income within households. Alongside the core symbolic analytical high-income workers, and within the same households, can be the low paid part-time workers and temporary workers often in inperson services jobs. These are potentially the households identified by Gregg and Wadsworth (1996a) where some family members, usually women and dependent children, can take on relatively low paid and insecure jobs, due to there being a stable core household income. This view has also been put forward in Australia, where Gregory and Hunter (1995) suggest that part-time jobs are going to young people and women in the high SES neighbourhoods.

Reich is nervous about the clustering of the affluent. In relation to income, Reich (p. 268) discusses the manner in which the symbolic-analysts group "share" their earnings. Citing the work of Odendahl (1990) he notes:

\footnotetext{
In allocating personal income, the symbolic analyst has shown no lack of willingness to engage in collective investment. But increasingly, the public goods that result are shared only with other symbolic analysts. Symbolic analysts take on the responsibilities of citizenship, but the communities they create are composed only of citizens with incomes close to their own. In this way, symbolic analysts are quietly seceding from the large and diverse publics of America into homogeneous enclaves, within which their earnings need not be redistributed to people less fortunate than themselves.
}

Reich goes on to suggest that as the highly-educated, high-income groups seek tax cuts they effectively "...withdraw their dollars from the support of public spaces shared by all and dedicate the savings to private spaces they share with other symbolic analysts." Reich suggests that the renewed emphasis on "community" in America has been associated with the growth of economic enclaves. But, he says, the devolution to smaller areas of 
government can lead to a lowering of the level of cross subsidisation of amenities for the poor. $^{76}$

This U.S. literature reflects both a larger scale society, and one in which income distribution is even more extreme than New Zealand (Statistics New Zealand 1999). However, some of the themes raised may be having some impact in New Zealand.

\section{Does social policy play a role in clustering?}

Governments have a major role in determining migration flows into a country. The type of migration encouraged, or simply not able to be stopped, can have an impact on clustering behaviour. For example, new immigrants often cluster together particularly if those immigrants are poor, or from ethnic groups and/or belief systems which are unusual in the host country.

In some of the spatial clustering literature there is debate about whether people have a free choice as to where they live with a country or a city, or whether this choice is constrained. Within this discussion there is also attention placed on the role of both local and central government. Marcuse (1996: 188) notes:

Conventional economics would have it that people sort out where they wish to live by their personal preferences, and that the spatial pattern of a city results from the complex interaction of individual preferences, mediated through a housing market where, if supply and demand are in equilibrium, demand will determine residential locations. State action plays at most a secondary role in this scenario, perhaps reflecting cumulative preferences in zoning ordinances and building codes.

However, he goes on to suggest that this is not a correct view:

\footnotetext{
76 There are other researchers who have linked issues of democracy and economic exclusion, but in the opposite direction as to that suggested by Reich. For instance, Putnam (1993) suggests that communities, which are cohesive through a high rate of participation in community and "civil" based activities, tend also to be those that are economically prosperous.
} 
The state's activity flows through every artery of the housing market. Indeed, the state's actions are needed for the most minimal market even to exist: the enforcement of laws, the establishment of a currency, the judicial oversight over contracts, the forbidding of trespass, the regulation of nuisances, are all required before a private market in the commodity housing can function effectively. Not to speak of the provision of roads, sewers, utilities, water, policing, fire protection, transportation, zoning and building codes, parks, schools, and on and on. State action is sometimes spoken of as 'intervention in the housing market'; it would be more accurate to speak of the state as 'constituting the housing market'.

Within urban areas the provision of low-cost public housing has been seen as a prime factor in bringing together poor people (Mills and Lubuele 1997). In New Zealand, Morrison (1995) notes that much of the original state housing stock was built to service manufacturing centres. So initially the tenants included many people who were not work or even income poor. However, when labour demand for manufacturing declined dramatically in the 1980s, people living in these houses were isolated from areas where jobs were increasing. Low cost private rental housing can also draw work-poor people together. Some low cost rental housing may be clustered together for various reasons. For instance, it may grouped together in a geographically undesirable area, such as in a damp site, or in large cities, be part of a decaying urban landscape. In New Zealand, there have also been some small rural clusters of government owned housing, usually associated with some public works scheme such as dam building (e.g. Mangakino) or a state owned business such as railways or coal mines (e.g. Ohura) which have become available for sale or rental. In addition, in New Zealand declining farming returns, as well as centralisation of service centres, has made available a low cost rural housing stock. This may have attracted low-income beneficiaries and further disconnected them from the labour market.

Policies such a school zoning may also have an influence on clustering behaviour. If a school has a good reputation and pupils can only be drawn from a geographically defined area, then there may be increased competition for housing in the area resulting in an increase in house prices. This effectively screens out the children of work-poor families from attending the school. 
Other forms of zoning may also have an impact on the clustering of people. For example, allowing the conversion of inner city buildings in Wellington has allowed a group of work-rich people (usually without children) to concentrate in the inner city.

\section{Some challenges to the polarisation hypothesis}

There are some challenges to the idea that polarised communities are forming. First, as discussed in the introduction, Forrest and Kennett (1997) argue that there is much variation of people's characteristics within neighbourhoods, especially middle class ones.

While people in middle-class suburbs might not always stay middle-class, perhaps of greater importance is whether large groups of people remain for long periods in workpoor areas. Some U.S. research suggests that there is considerable movement in and out of poor urban areas, even amongst those people who are persistently poor (Gramlich et al 1992). ${ }^{77}$ In New Zealand, it may be that a high proportion of people spend only a short time in poor areas and move out when their employment prospects, education or income improve. Or, it may be that many people are mobile but simply move from one poor area to another poor area. Such mobility may be due to insecure housing arrangements rather than for more positive reasons.

A further potential weakness to the polarisation argument is that, as already discussed, low-income individuals can often be found in high-income areas, although these people are generally living in high-income families or households.

There is an additional challenge to one aspect of a polarisation hypothesis. This is the idea that people in the affluent areas do not have any contract with those in poor areas. Some researchers suggest that the affluent are becoming less dependent on the services of lower status groups in neighbourhoods as these groups no longer produce the cars, clothes, shoes or other goods and services for the wealthy, they do not work in the same workplaces, and they do not live in the same neighbourhoods. Yet, in a U.S. context,

\footnotetext{
${ }^{77}$ However, this particular American longitudinal study also indicated that, between 1979 and 1985, despite some "churning" the poor urban areas were becoming poorer.
} 
when affluent and poor areas are in close proximity they may have a high level of interdependency. Some groups of affluent people have the money, and the need, to purchase domestic support services, while people in the poor area can potentially provide these services (Van Kempen and Marcuse 1997). However, this type of work is generally intermittent, low income and often part of an "informal" economy. And, of relevance to this research, as part of the informal economy it may not been recorded in official statistics such as the census.

\section{Some constraints on geographic mobility}

While one set of literature stresses mobility that reduces worries about polarisation, another focuses on barriers to mobility. The housing market is sometimes seen as preventing mobility. As an example, The Economist (1997) suggests that house ownership in a depressed area can make moving to areas of job growth more difficult. In the U.K. Henley (1998) further develops this view. He argues that if the housing market weakens, as may happen locally when an industry closes, then the often-resulting negative equity in housing can have a significant effect on mobility. This will be particularly problematic if there are significant price differences between poor areas and growth areas. However, even if there is positive equity, high transaction costs tend to prevent movement. He also found that migration flows are largely unresponsive to labour market changes and, in fact, there may even be movement into high unemployment areas. There is some evidence of such immobility in New Zealand. In a study of the long-term unemployed in New Zealand, Parker (1997) notes that around 40 percent of the respondents stated that they could not move to areas with more jobs. Also in New Zealand, and in specific relation to work-poor Maori, Maré (1995) suggests that some geographic immobility may be due to attachment to established iwi.

It seems that both a high level of mobility and a lack of mobility in different situations may lead to an area becoming or remaining work-poor. For instance, a small rural areas may be work-poor long term because people cannot sell or rent their houses and move to a work-rich area, but an urban area may be long term work-poor simply because there is 
much mobility with the upwardly mobile moving out constantly and being replaced by the downwardly mobile.

Finally, while the mobility of work-poor adults may be important in terms of their finding paid work, mobility can affect learning opportunities for their children. As discussed in Chapter five, "stress theory" suggests that moving schools can have a negative impact on children. This seems to be supported by actual research (Pribesh and Downey 1999).

\section{Conclusion}

From the available theory and evidence it does appear that there are some important spatial dimensions to changes in work, and in families and households. This suggests that labour markets, marriage markets and housing markets do not operate in isolation from each other. However, despite some recent New Zealand research which supports the idea that there is an increasing geographic polarisation of the employed and unemployed there still remain questions of how relevant many of the theories of geographic polarisation, ghetto living, "gated cities" and pockets of poverty are to New Zealand. In addition, specific spatial theories, such as "neighbourhood effects", are still highly contested internationally.

Where the census data is able to provide suitable information, some of the issues discussed in this brief review are tested in Chapter twenty-one. In particular there is an exploration of clustering by education and paid work. In this investigation the following ideas will be tested:

- between 1986 and 1996 there was increasing polarisation between geographic areas in terms of average hours of work per prime-aged person

- work-poor communities stay work-poor for significant periods of time

- in 1996 work-poor areas were generally also deprived communities

- there was outward migration from work-poor areas between 1986 and 1996

- work-poor communities also tend to be education-poor 


\section{Part three}

\section{Changes in work, education, families, households and geographic communities in New Zealand 1986 to 1996}




\section{Chapter 14}

\section{Changes in the economy, population and government transfer payments}

\section{Introduction}

Identifying broad changes in the economy and underlying changes in structure of the population helps contextualise the analysis of employment and family change in subsequent chapters. A brief analysis of transfer payments is included as this also helps set the scene for the subsequent analysis of changing work and family patterns. ${ }^{78}$ In particular, it provides a guide to the numbers of prime-aged people who were work-poor and / or were not fully supported financially by another family or household member.

\section{Economic Growth and Employment Growth}

Figure 1 shows changes in real GDP and employment from a base of 1986. Despite its many problems as a measure, GDP still provides a guide to changes in output in an economy. The year 1986 is the starting point of most of the analysis in subsequent chapters. The graph shows a very slow rate of growth in real GDP through to 1989 then a decline through to 1992. GDP then grew rapidly through to the March 1995 year, with slower growth through to March 1998. For employment, there was a slight rise in total employment from 1986 to 1987 then a major decline through to 1989. There was little change in employment through to 1992, when total employment growth picked up. Employment growth then slowed post 1996 despite an increase in output in the economy.

\footnotetext{
${ }^{78}$ Many of the transfer payments I discuss could also be called welfare benefits. These include the domestic purposes benefit (DPB) and unemployment benefits. Other transfer payments, such as superannuation are generally not seen as welfare benefits. There are also transfer payments available that can be paid while a person is in paid work. For example, a certain amount of earnings from the market is allowed while receiving the DPB. Finally, there are many other support payments available such as emergency benefits, childcare subsidies and housing subsidies that are not included in this analysis.
} 


\section{Figure 1}

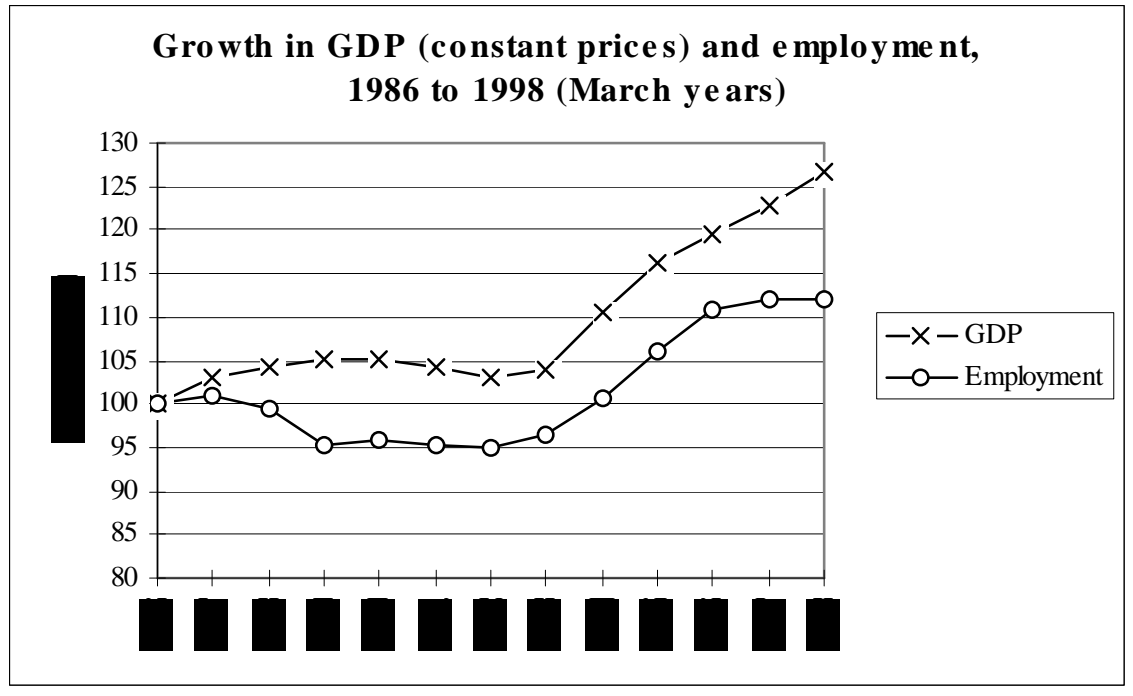

Source: Statistics New Zealand

With the censuses being taken in March 1986, 1991 and 1996, the period studied can be broadly be broken into two distinct phases. The first time period covers that of static economic activity and declining employment, the second of strong output and employment growth.

\section{Change in population}

The population of prime-aged people who were New Zealand residents was not static over the period studied. The number of people entering and exiting this age group is affected not only by the natural aging of the population (including deaths) but also by long term migration. Migration is itself influenced by a wide range of factors including the demand for labour both in New Zealand and overseas. But migration will also potentially have an impact on economic growth and changes in the supply of labour. In addition, the composition of a population, such as age structure, ethnicity, geographic and even gender balance, can change over time. Figure 2 shows a generally steady long-term growth in the population aged 15 or more, except during the height of job loss in the late 1980s. 
The location of the population also changes over time due to internal migration. Again a number of factors will affect such migration, but historically people have tended to move away from work-poor areas and move to areas where there are job opportunities. One aspect of this was the migration of many Maori from rural areas to urban areas in the 1950s, while in more recent times there has been a "drift" towards the north, and particularly Auckland.

Figure 2

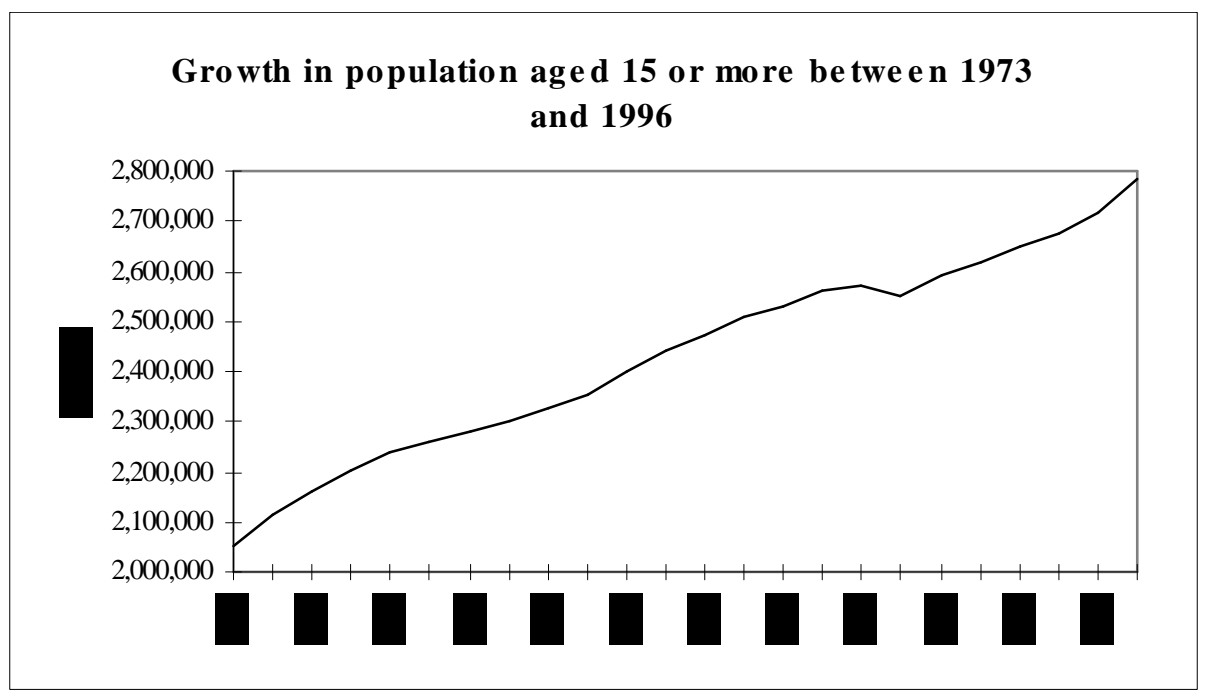

Source: Derived from the Census of Population and Dwellings, Statistics New Zealand.

As a subset of the above population, at the 1986 census there were 1.4 million prime-aged (25-59) people living as residents in New Zealand. This rose by 7.8 percent to 1.5 million in 1991, and a further 11.9 percent to reach 1.7 million in 1996. As Table 9 shows this group represented 56.9 percent of adults in 1986 and 60.8 percent in 1996. This rise was mainly due to a decline in the proportion of people aged 15-24, a group that includes many new entrants to the labour force. 
Table 9 - Number of New Zealand adults in 1986, 1991 and 1996

\begin{tabular}{|c|c|c|c|c|}
\hline 1986 & Male & Female & Total & $\%$ \\
\hline $15-24$ & 295,977 & 287,013 & 582,990 & 23.6 \\
\hline $25-59$ & 703,401 & 700,992 & $1,404,393$ & 56.9 \\
\hline $60+$ & 211,011 & 269,907 & 480,918 & 19.5 \\
\hline Total & $1,210,389$ & $1,257,912$ & $2,468,301$ & 100.0 \\
\hline 1991 & Male & Female & Total & $\%$ \\
\hline $15-24$ & 280,983 & 275,100 & 556,083 & 21.5 \\
\hline $25-59$ & 054 & 763,464 & $1,513,518$ & 58.4 \\
\hline $60+$ & 231,051 & 289,632 & 520,683 & 20.1 \\
\hline Total & $1,262,088$ & $1,328,196$ & $2,590,284$ & 100.0 \\
\hline 1996 & Male & Female & Total & $\%$ \\
\hline $15-24$ & 268,407 & 266,331 & 534,738 & 19.2 \\
\hline $25-59$ & 832,023 & 861,531 & $1,693,554$ & 60.8 \\
\hline $60+$ & 249,534 & 308,397 & 557,931 & 20.0 \\
\hline Total & $1,349,964$ & $1,436,259$ & $2,786,223$ & 100.0 \\
\hline
\end{tabular}

Source: Derived from the Census of Population and Dwellings, Statistics New Zealand.

Figures 3 and 4 show that, with exception of people aged 25-29, between 1986 and 1996 there was growth in the number of prime-aged people. This trend reflects an aging of the population in general. However, the trends shown in Figures 3 and 4 also indicate that a substantial number of new jobs had to be generated between 1986 and 1996 in order to keep unemployment figures low.

\section{Figure 3}

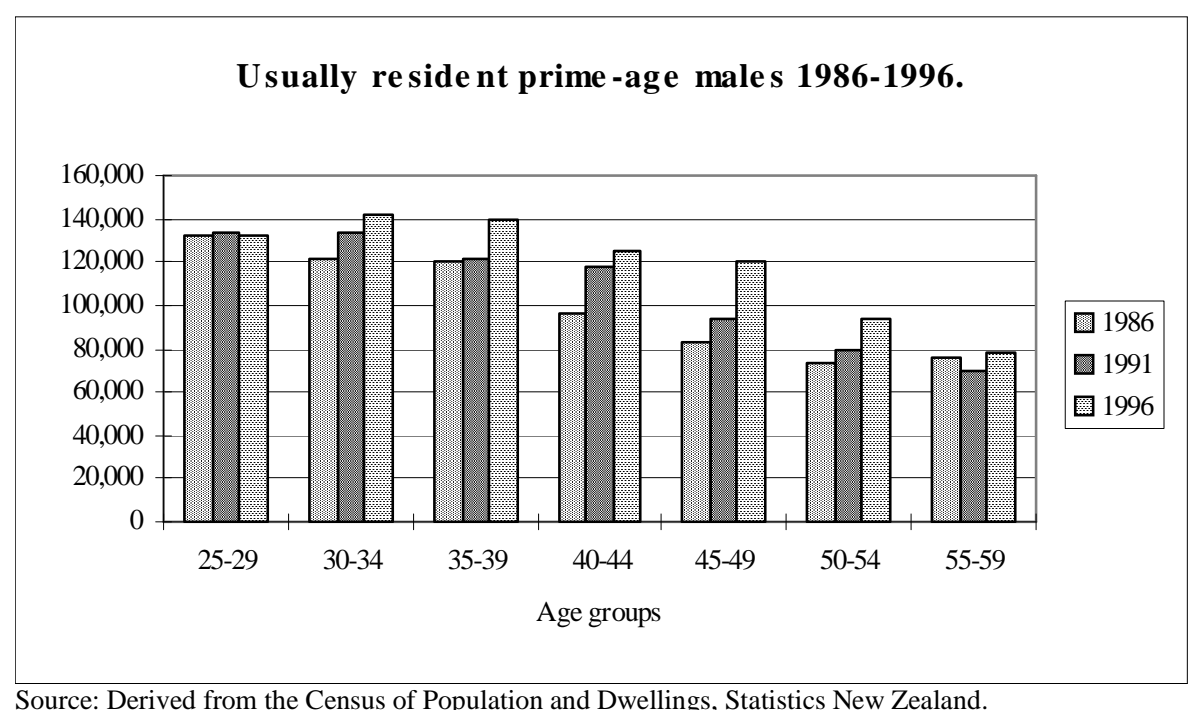




\section{Figure 4}

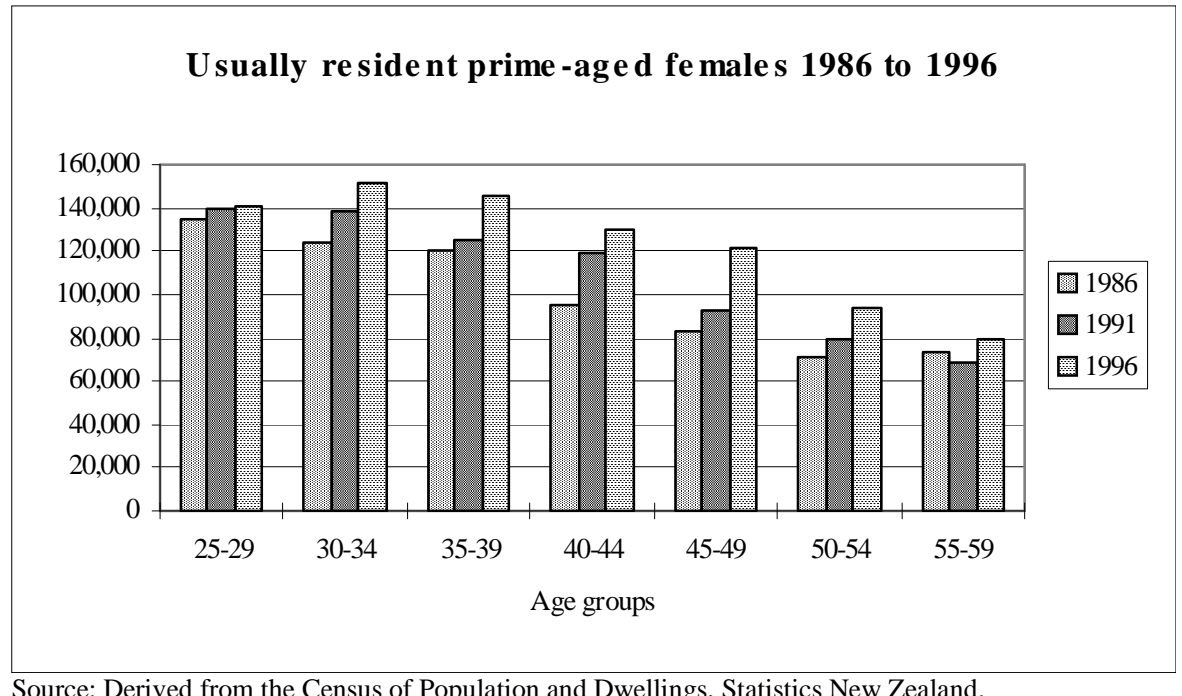

Source: Derived from the Census of Population and Dwellings, Statistics New Zealand.

While the majority of the prime-aged population in 1996 were classified as European only, people from Maori, Pacific Islands and Asian groups were an important part of the potential labour force (Table 10).

Table 10 - Number and percentage of men and women aged 25-59 by ethnicity, 1996

\begin{tabular}{lrrrr}
\hline & Women $(000 \mathrm{~s})$ & Men $(000 \mathrm{~s})$ & \% of women & \% of men \\
\hline European only & 640.2 & 622.6 & 77.3 & 78.5 \\
Maori ethnic group & 105.2 & 96.7 & 12.7 & 12.2 \\
Pacific Island ethnic group & 37.0 & 33.9 & 4.5 & 4.3 \\
Asian ethnic group & 42.3 & 36.3 & 5.1 & 4.6 \\
Other & 3.3 & 4.1 & 0.4 & 0.5 \\
\hline
\end{tabular}

Source: Derived from the Census of Population and Dwellings, Statistics New Zealand.

While the geographic based analysis of changes in working hours is carried out at an area unit level, broad geographic population data shows that most prime-aged people lived in North Island in both 1986 and 1996 (74 and 75 percent), and that Auckland was a major centre. In 1986, 25 percent of prime-aged people lived in Auckland but this had risen to 28 percent by $1996 .^{79}$

${ }^{79}$ This covers North Shore City, Waitakere City, Auckland City, Manukau City and Papakura District. 


\section{The growth in transfer payments}

Changes in overall transfer payments are not only driven by changes in employment, but also changes in the age structure of the population, altering eligibility criteria and, potentially, the level of payments available from the state versus those obtainable in the labour market. Figure 5 shows changes in the percentage of the population aged 15 or more (including the elderly) receiving a transfer payment and also the total cost of payments as a percentage of GDP. It shows a rapid growth in the proportion of people receiving a payment in the late 1980s then a rapid decline in the early part of the 1990s. Part of the high level through to the early 1990s is due to the universal family benefit and the level is also underpinned by superannuation. The graph also shows a small but steady increase in transfers as a percentage of GDP through to the early 1990s then a small subsequent decline. Changes in government policy are behind some of these shifts.

\section{Figure 5}

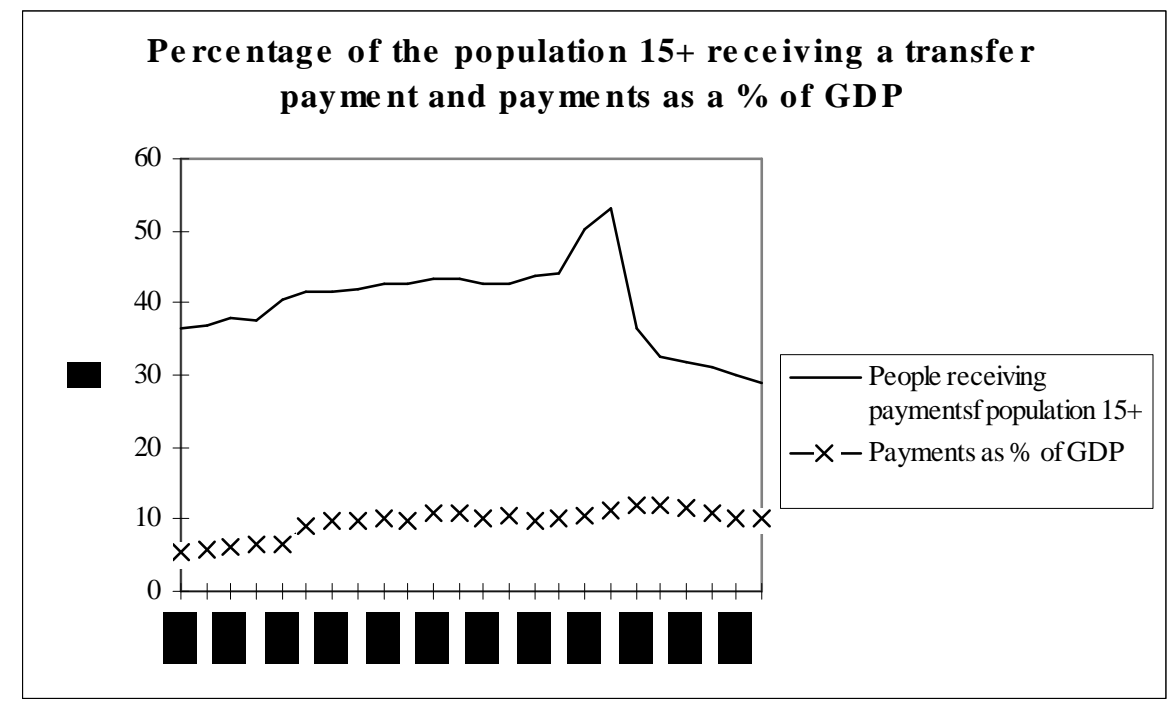

Source: Department of Social Welfare

Figure 6 indicates much of the rise in the number of people receiving a transfer payment was due to growth in unemployment (UB) and people receiving the domestic purposes benefit (DPB). As discussed in other chapters, the growth in sole parenthood may partly reflect a growth in unemployment. Much of the decline in the number of people receiving transfer payments (Figure 5) reflects the withdrawal of the universal Family Benefit in the 
early 1990s. Figure 6 also shows that payments to people who are retired dominate government transfers.

Figure 6

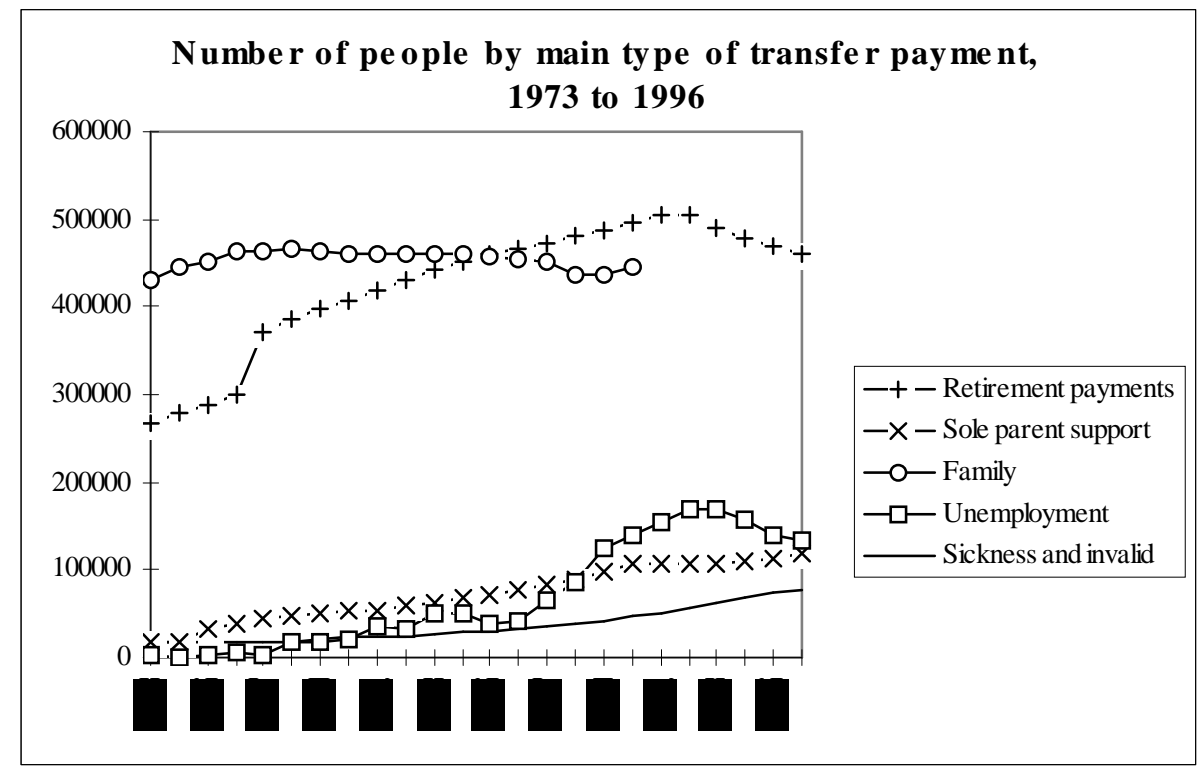

Source: Department of Social Welfare

The dominance of the retirement payments is shown again in Figure 7, but it shows the "gap" between retirement payments and other benefits was much narrower in the early 1970s. After widening considerably in the late 1970s the "gap" narrowed again in the early 1990s. There are many reasons for these changes, but they partly reflect differing approaches by "left" and "right" leaning governments. 
Figure 7

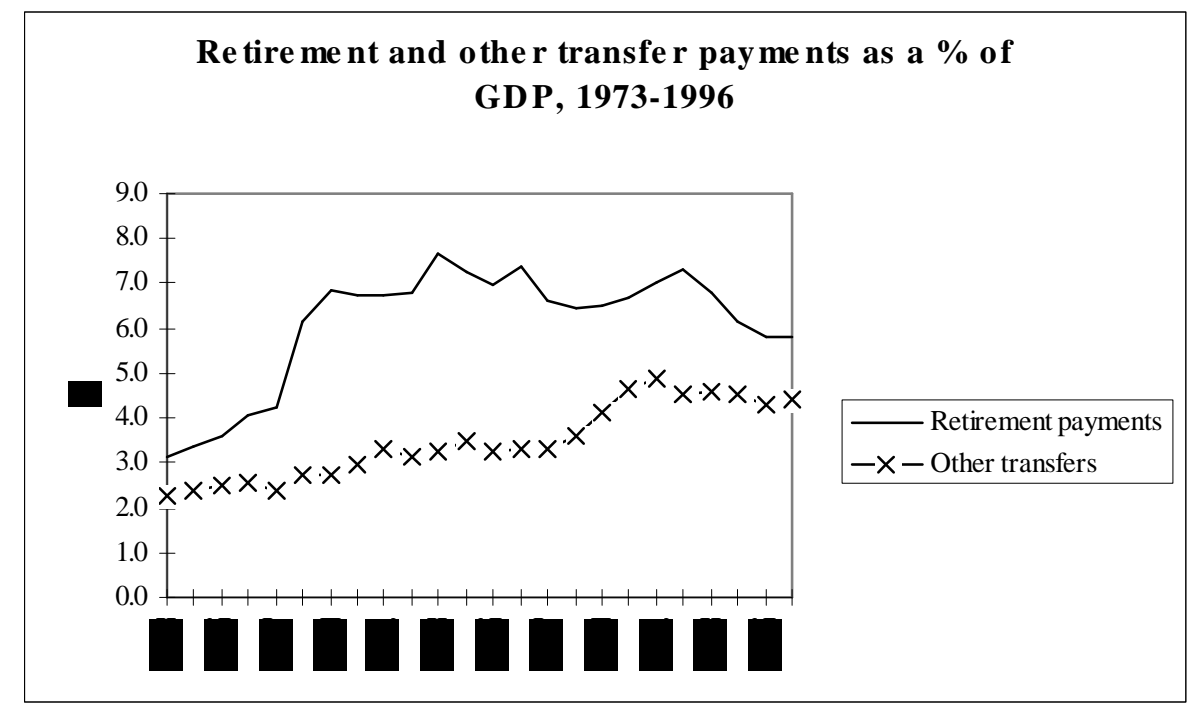

Source: Department of Social Welfare

Figure 8 further disaggregates the non-retirement payments. It shows the steady decline of the Family Benefit (and eventual cessation), as a percentage of GDP, from a position of being the most costly transfer in the early 1970s. Figure 8 shows the steady rise in DPB payments from the early 1970 s, while unemployment payments rose very rapidly in the mid 1980s. There was also a slow, but steady, rise in sickness and invalid payments since the 1970s.

The long-term growth in payments to sole parents, mostly mothers, provides a first challenge to the theory that a loss of jobs by men directly leads to a growth in sole parenthood. Goodger (1998) has made the point that the growth in sole parenthood, mostly brought about by couple separation, began ahead of the growth in male unemployment. These separations were mainly couples that had married young, often in "shot-gun" weddings, in the 1960s. However, this historical relationship does not rule out that in the 1990s male job loss could have been a factor in decisions about living arrangements. It is also possible that in the past most of the ex-partners of sole mother families were employed, but that now a high proportion of these men are not in paid work. In the past, the separation of couples may have often only created one benefitdependent household, but may now potentially create two. 


\section{Figure 8}

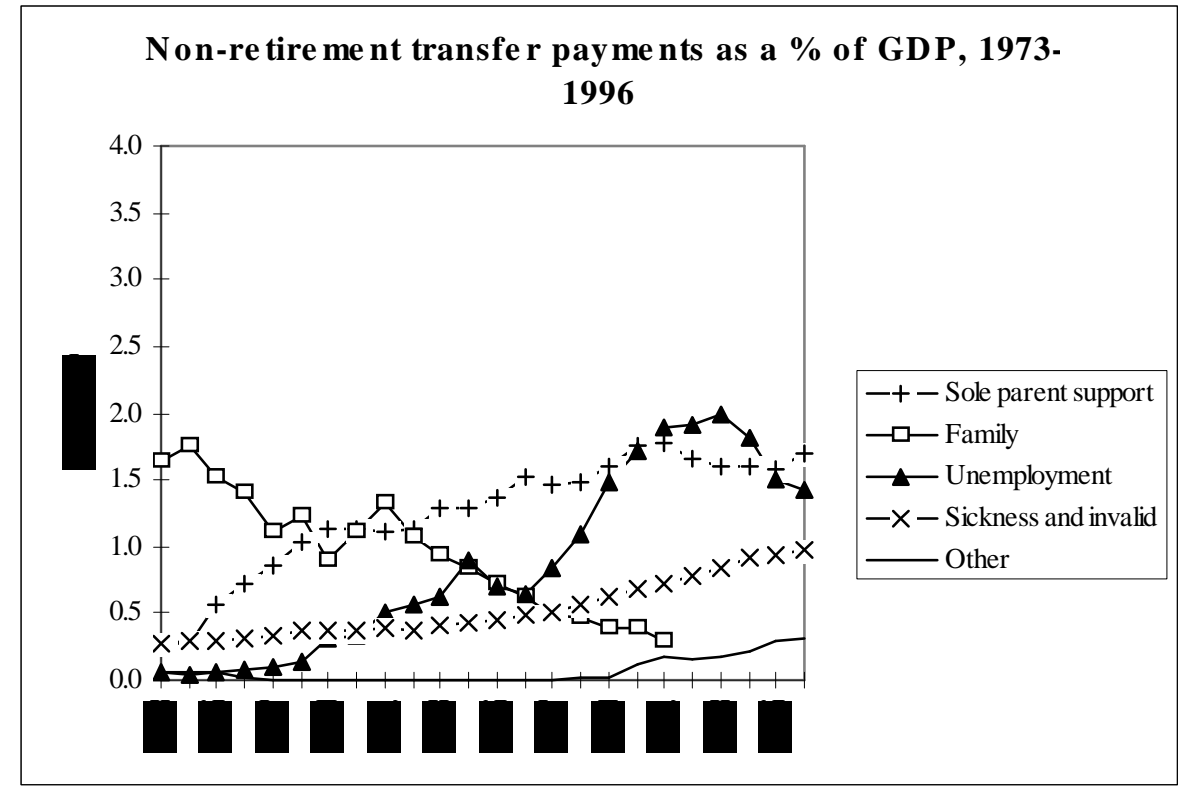

Source: Department of Social Welfare

Figure 9 combines some of the previously shown data. Using a 1986 base, it shows the growth in numbers of people in the population aged 15 or more, the growth in employment and the growth in the number of people on selected benefits usually paid to working aged people. Over the period 1986 to 1996, Figure 9 indicates that population growth was higher than employment or benefit growth. Figure 9 also shows that while governments may point to impressive employment growth in a period, population growth in the same period also needs to be considered. The growth in employment in this period would have had to be exceptionally high to catch up with population growth. However, Figure 9 also indicates there was, as would be expected, some relationship between employment growth and trends in unemployment benefit payments. This growth may be stronger in the 1990s than it was a few decades ago as in the past when some people lost a job they may have been financially supported by another family / household member. 
Figure 9

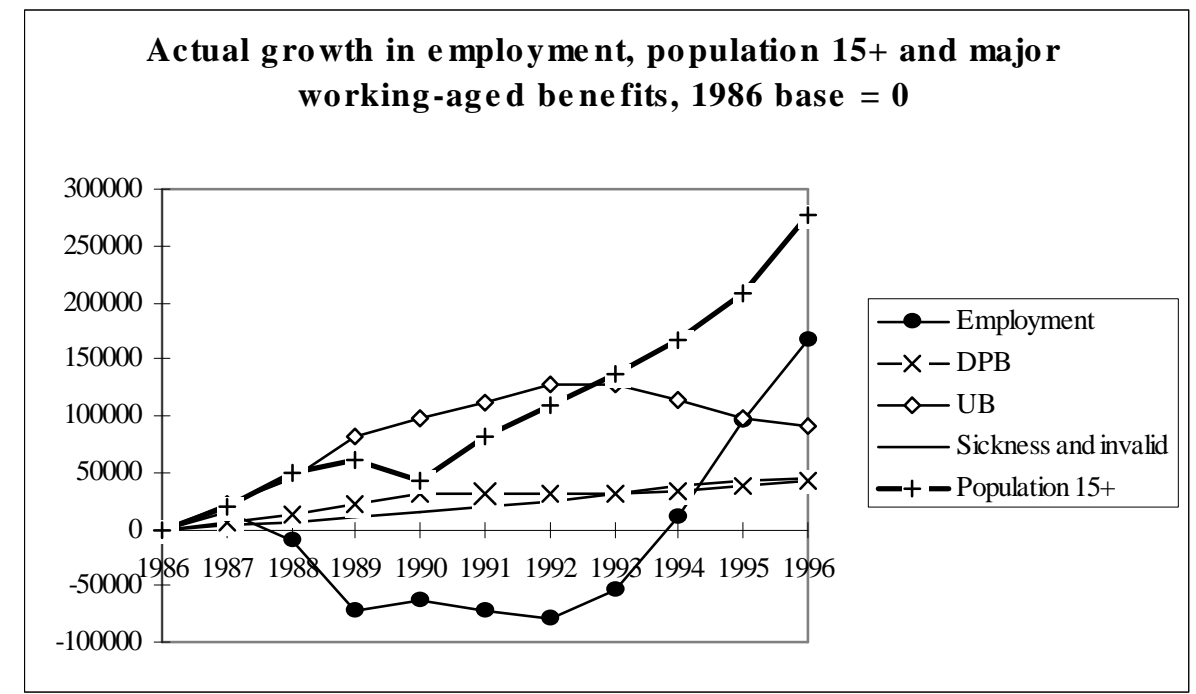

Source: Department of Social Welfare

Finally, Table 11 shows the number of people receiving one of three types of transfer payment as a percentage of the population aged 15-59. While there may be some people on sickness, unemployment or sole parent benefits who were aged 60 or more, most of the beneficiaries would have been in the 15-59 age group. Table 11 shows a doubling in the proportion of people receiving these transfers between 1986 and 1991, the period of major job loss. However, in period of major job increase between 1991 and 1996, which also included significant cuts of benefits, there was only a small decline in this percentage.

Table 11 - The number of people on benefits as a percentage of the population aged 15-59

\begin{tabular}{lcc}
\hline & Unemployment $/$ Sole parent / sickness & Unemployment / Sole parent \\
\hline 1986 & 7.5 & 6.0 \\
1991 & 15.1 & 12.6 \\
1996 & 14.7 & 11.3 \\
\hline Source: Derived from then Census and Social Welfare data
\end{tabular}

\section{Conclusion}

In combination, the GDP, employment and population data show that the period from 1986 to 1991 was a time in which there was an increase in the number of work-poor people in New Zealand. In the next five years, although there was strong employment 
growth, the increases in GDP were not enough to lift employment to a level which would absorb those already out of work as well as raise overall employment rates amongst the rapidly growing working aged population.

While retirement income is by far the main transfer payment in New Zealand, in the period 1986 to 1991 there was a strong increase in the proportion of prime-aged people receiving government transfers. A major part of this growth came from an increase in unemployment payments, but over this period there was also an increase in the number of sole parent and sickness beneficiaries. While these rises were part of much longer trends, the growth in the number of unemployed was particularly strong. It is also likely that some of the growth in sole parents and people on sickness benefits in this period was due either directly or indirectly to the rise in unemployment. In the subsequent five years, the number of people on unemployment benefits declined but the number of people receiving sole parent and sickness benefits continued to slowly increase. Overall, this meant that between 1991 and 1996 the proportion of prime-aged people receiving a government transfer only marginally declined. 


\section{Chapter 15}

\section{Changes in educational participation and attainment}

\section{Introduction}

This chapter is divided into four sections. The first section discusses recent changes in participation rates in pre-school education in New Zealand. The second section focuses both on changes in participation and attainment in the senior levels of school. While this does not impact on the current generation of prime-aged people, it will impact on future generations of prime-aged people. This is followed by a discussion of changing participation rates and attainment in tertiary education and training. While it is recognised that industry-based training is important, as there is little New Zealand data to draw on this issue is only briefly addressed. Finally, there is a brief discussion of the results of a New Zealand literacy survey. As I have already argued, a base level of literacy is important for full participation in most areas of life

\section{Pre-school education}

The provision of affordable, quality childcare has long been a central concern of the New Zealand women's movement (Coney 1993). However, while state subsidisation of childcare has often been promoted in terms of assisting women move into paid work, in recent years the educational benefits have also been seen as important. The New Zealand government increased spending on formal pre-school education in the mid to late 1980s. 
While long-term data series are not available, Table 12 shows a steady increase in participation by children in early childhood education between 1991 and 1996. The growth was particularly strong in the 1-4 year old age groups.

\section{Table 12 - Early Childhood Education - Apparent Participation Rates, Percentage of each age group}

\begin{tabular}{lrrrrrr}
\hline Age & 1991 & 1992 & 1993 & 1994 & 1995 & 1996 \\
\hline Under 1 year & 10 & 11 & 10 & 11 & 12 & 13 \\
1-2 years & 19 & 21 & 25 & 26 & 28 & 30 \\
2-3 years & 35 & 38 & 42 & 45 & 47 & 49 \\
3-4 years & 72 & 73 & 80 & 77 & 80 & 83 \\
4-5 years & 92 & 96 & 96 & 96 & 94 & 93 \\
Total & 45 & 46 & 50 & 51 & 53 & 54 \\
\hline
\end{tabular}

Source: Davey (1998a).

For a variety of reasons, successive governments had been promoting the provision of childcare by private organisations. One result had been a rapid increase in the number of these providers, many of whom offer all day care rather than the morning or afternoon sessions offered by most of the traditional institutions (see Table 13). This resulted in an increase in the proportion of children enrolled in early childhood education programs (Davey 1998a). As will be discussed in subsequent chapters, it also resulted in a strong increase in the number of people employed in this industry.

\footnotetext{
${ }^{80}$ While there has been an increase in the use of childcare over the period studied, few children under one are cared for by caregivers other than parents. In the past, this would have generally required the parents to resign from work, however parental leave allows a person to remain attached to the labour force. Waldfogel (1998) has suggested that well designed maternity leave provisions may be a key factor in reducing the pay "gap" relative to men faced by women who have children. The increasing attachment of some groups of women to the paid work labour force appears to have been assisted by the introduction of maternity leave legislation in 1981, followed five years later by the enactment of parental leave legislation. However, this leave is generally unpaid and its eligibility criteria mean that many people in "non-standard" work are excluded from coverage (Callister and Galtry 1995). The eligibility criteria mean that people in core, workrich, jobs appear to have a higher level of job protection guaranteed by legislation than work-poor people on the margins of the labour force. However, there are no reliable New Zealand data on use of parental leave to test this theory.
} 
Table 13 - Enrolments by type of early childhood education and care provider, 19911996

\begin{tabular}{lrrrrr}
\hline & Numbers & & Change & \% share of enrolments \\
\hline Service & 1991 & 1996 & $91-96$ & 1991 & 1996 \\
Kindergartens & 44,363 & 46,960 & 2,597 & 35.2 & 29.3 \\
Playcentres & 21,578 & 17,596 & $-3,982$ & 17.1 & 11.0 \\
Childcare centres & 35,127 & 57,582 & 22,455 & 27.8 & 35.9 \\
Homebased childcare & 2,364 & 6,558 & 4,194 & 1.9 & 4.1 \\
Correspondence school & 793 & 993 & 200 & 0.6 & 0.6 \\
Te Kohanga Reo & 10,451 & 14,302 & 3,851 & 8.3 & 8.9 \\
ECDU funded playgroups & 7,331 & 12,195 & 4,864 & 5.8 & 7.6 \\
Pacific Island groups & 3,274 & 3,736 & 462 & 2.6 & 2.3 \\
Unlicensed playgroups & & 369 & 369 & 0.0 & 0.2 \\
Pre-school classes in schools & 853 & 0 & -853 & 0.7 & 0.0 \\
Total & 126,134 & 160,291 & 34,157 & 100.0 & 100.0 \\
\hline Source: Adapted from Davey (1998a). & & & & &
\end{tabular}

Davey shows that there are some ethnic differences between the use of service with, for example, few non-Maori using Te Kohanga Reo services. Davey also notes that children enrolled in kindergarten and playcentres usually attended for 12 hours or less per week. In contrast, just under 60 percent of children at childcare centres were there for more than 12 hours per week. However, Davey cites research that shows that only 17 percent of children in childcare centres and home-based care were in these centres for more than 30 hours per week. This suggests that much of the care is used to facilitate part-time work rather than full-time paid work. Playcentre has been a service particularly used by the traditional mixed-work two-parent family. Data collected by the Playcentre Association shows a peak in the number of Playcentre families in 1976 (Stover 1998). When Playcentre Association data is matched with census data, this shows that in 1986 families attending Playcentre represented 9.3 percent of all families with a child under five. This declined to 8.7 percent in 1991, and reduced further to 7.0 percent in 1996.

According to the 1998 New Zealand survey of childcare, the use of childcare services by pre-school children was associated with a range of factors (Department of Labour 1999). The use was the highest for sole parents who were in paid work as well as work-rich two parent families (two full-time worker families as well as families where one partner worked full time and one part time). The lowest use of ECE was by work-poor couples. Not surprisingly the highest use of childcare was by families in the higher income groups 
and the lowest by those in the lower income groups. Again, not surprisingly, the most common arrangement for children of employed sole parents and children from two parent families where both parents worked full time was childcare centers. If, as some research would suggest, there is a significant education component to early childhood education then the children of work-rich families will have a significant cognitive start on children from work-poor families. The use of childcare by work-rich and work-poor couples is explored in detail in Callister (1999c). ${ }^{81}$

While pre-school childcare has been a primary concern with regards to supporting parents in paid work (or further education and training) increasingly out of school care is being focussed on as a barrier to paid work (Department of Labour 1999). While there are a number of reasons for this, one is that with an aging population the "baby blip" is now moving through their early school years.

\section{Senior school participation rates}

In the late 1980s there was concern expressed by the New Zealand Planning Council about New Zealand's relatively low participation rates at senior levels of high school (Callister 1990). Table 14 shows a strong growth in participation rates amongst 16, 17 and 18 year olds through to the early 1990s, but a slight decline in most age groups through to 1996. The first period was a time of high job loss, while employment grew in the latter period. These underlying employment trends are likely to have had an influence on participation rates. However, overall by the end of the period of the research participation rates were considerably higher than at the start.

\footnotetext{
${ }^{81}$ This research was undertaken while completing my doctoral research and utilised unit record data.
} 
Table 14 - Estimated proportion of all students staying on at school by age, 19861996

\begin{tabular}{|c|c|c|c|c|c|c|}
\hline & \multicolumn{3}{|c|}{ Male } & \multicolumn{3}{|c|}{ Female } \\
\hline & 16 & 17 & 18 & 16 & 17 & 18 \\
\hline 1986 & 66.6 & 34.3 & 6.9 & 69.3 & 32.8 & 5.3 \\
\hline 1987 & 66.6 & 38.4 & 7.8 & 69.4 & 36.3 & 5.7 \\
\hline 1988 & 72.5 & 41.0 & 9.0 & 76.8 & 39.4 & 7.0 \\
\hline 1989 & 77.2 & 48.0 & 10.3 & 79.0 & 48.0 & 8.7 \\
\hline 1990 & 78.6 & 48.5 & 11.1 & 80.9 & 50.3 & 9.1 \\
\hline 1991 & 84.7 & 53.9 & 12.6 & 87.8 & 55.3 & 10.4 \\
\hline 1992 & 86.9 & 60.7 & 15.6 & 87.8 & 63.8 & 12.7 \\
\hline 1993 & 83.5 & 61.0 & 16.7 & 87.2 & 62.8 & 14.0 \\
\hline 1994 & 81.9 & 58.0 & 16.7 & 86.2 & 62.6 & 14.2 \\
\hline 1995 & 80.9 & 56.0 & 14.9 & 84.7 & 60.9 & 13.9 \\
\hline 1996 & 81.7 & 57.3 & 16.1 & 85.8 & 61.4 & 13.6 \\
\hline
\end{tabular}

Underlying these overall patterns are some significant differences by ethnicity, as well as differences by gender and ethnicity in subject choices and attainment of formal qualifications (Davey 1998a). Ministry of Education data show that while Maori participation rates increased over the period the "gap" between Maori and non-Maori only marginally declined. Table 15 also show that some other "gaps", such as the gender gap, are becoming more complex when ethnicity is considered. For example, while over 90 percent of 16 year old non-Maori females were still in the education system in 1996, only 64 percent of Maori men in the same age group were still at school.

Table 15 - Retention rates of 16 year olds in 1986 and 1996 by gender and Maori / non-Maori

\begin{tabular}{lrrr}
\hline & 1986 & 1996 & Change in \% points \\
\hline Non-Maori female & 73.3 & 90.4 & 17.1 \\
Non-Maori male & 70.4 & 85.8 & 15.4 \\
Maori female & 48.4 & 67.3 & 18.9 \\
Maori male & 46.0 & 64.1 & 18.1 \\
\hline \multicolumn{2}{l}{ Source: Ministry of Education }
\end{tabular}

The level of formal certificated attainment is a critical factor in whether people then proceed to further education and training and ethnic differences again show up in these data (Table 16). 
Table 16- School leavers by highest level of attainment by ethnicity, 1996

\begin{tabular}{lrrrrrr}
\hline & Maori & Pacific Island & Asian & Pakeha & Other & Total \\
\hline Seventh form awards & 15 & 25 & 63 & 44 & 40 & 39 \\
Sixth form awards & 21 & 28 & 17 & 24 & 19 & 23 \\
School certificate & 23 & 19 & 8 & 17 & 14 & 17 \\
No qualifications & 41 & 28 & 12 & 15 & 27 & 21 \\
Total (\%) & 100 & 100 & 100 & 100 & 100 & 100 \\
\hline
\end{tabular}

Source: Davey (1998a)

If future employers select their employees on the basis of formal education, then these data show that a significant proportion of Maori and Pacific Island young people are likely to become work-poor. Yet, there are still a group of Pakeha leaving school with no qualifications who are also likely to face disadvantage.

The reasons for these ethnic differences are complex and beyond the scope of this research. However, some may link back to whether children are being raised in workpoor or work-rich households, or in work-poor communities. For instance, published "league" tables show that in the greater Wellington region, the state school of Porirua College drawing on the mainly Maori and Pacific Island work-poor areas of the Porirua Basin had, in 1998, 11 percent of students gaining a B or higher in school certificate and no-one gaining a B bursary or higher (Evening Post 1999). In contrast, the inner Wellington city state school of Wellington Girls College had 47 percent of students gaining a B or higher in school certificate and 73 percent gaining a B bursary of higher. This latter school draws on many of the high income, and mainly Pakeha suburbs of Wellington, including Kelburn and Wadestown. At an absolute extreme, Marsden Collegiate, a private school in Wellington had 72 percent of students gaining a $\mathrm{B}$ or higher in school certificate and 91 percent gaining a B bursary or higher. ${ }^{82} 83$ While there is a private education system mainly targeted at high-income families, particular state schools also draw on middle and upper income areas. The apparent poor performance of Porirua College suggests that many of its pupils will have greater difficulty in achieving

\footnotetext{
${ }^{82}$ Such comparisons need to be treated with caution. For example, they also do not indicate how these schools deal with lower achieving students.

${ }^{83}$ It is also recognized that a small number of students will commute from work poor areas to these higher achieving schools.
} 
upward mobility. As will be shown in a later chapter, Porirua College draws its pupils from a cluster of work-poor areas.

Within the schooling system in recent decades there has been much attention placed on improving educational outcomes for girls. Major gains have in fact been made, although clearly there are still areas of concern. However, in more recent times, some people have expressed a concern about the performance of a particular group of boys within schools (e.g. Roger 2000). These are the boys who are having problems with basic numeracy and literacy, are likely to eventually leave school with no or low level formal qualifications, and are likely to become work-poor. There are many reasons put forward as to why this might be occurring, including "styles of teaching". For a variety of reasons, men have in recent years been highly under-represented amongst those in childcare and pre-tertiary teaching occupations. Trends in the gender balance in teaching between 1991 and 1996 are examined in subsequent chapters.

\section{Tertiary education and training}

Participation in tertiary education and training increased rapidly over the period studied. However, reliable time series are only available from the beginning of the 1990s. Table 17 shows an age specific breakdown of participation in education of those 18 or older. It shows increases in all age groups for both men and women between 1986 and 1996. However, also clear is the changing ratio of participation of men to women in tertiary education. This ratio controls for differing numbers of men and women. In all age groups shown this ratio declined substantially between 1991 and 1996. By 1996 in only two age groups was the ratio higher than 1. In the older age groups women's participation was substantially higher in both 1991 and 1996. In part, this is a "catch-up" from earlier lower participation rates of women. 
Table 17 - Percentage of men and women participating in formal tertiary education or training, 1991 and 1996

\begin{tabular}{lcrrrrr}
\hline & Male & & Female & \multicolumn{3}{c}{ Ratio male to female } \\
\hline & 1991 & 1996 & 1991 & 1996 & 1991 & 1996 \\
18 & 43.3 & 47.9 & 44.1 & 53.0 & 0.98 & 0.90 \\
19 & 38.9 & 39.8 & 38.7 & 44.7 & 1.01 & 0.89 \\
20 & 31.9 & 35.8 & 31.0 & 39.0 & 1.03 & 0.92 \\
21 & 25.7 & 30.6 & 23.3 & 32.7 & 1.10 & 0.94 \\
22 & 20.3 & 23.6 & 16.4 & 23.2 & 1.24 & 1.02 \\
23 & 15.4 & 17.4 & 12.2 & 17.2 & 1.26 & 1.01 \\
24 & 12.7 & 13.8 & 10.0 & 13.9 & 1.27 & 0.99 \\
$25-29$ & 8.6 & 9.5 & 7.4 & 10.0 & 1.16 & 0.95 \\
$30-34$ & 6.0 & 7.0 & 6.1 & 8.0 & 0.98 & 0.88 \\
$35-39$ & 4.3 & 5.4 & 5.6 & 7.6 & 0.77 & 0.71 \\
$40+$ & 1.4 & 1.8 & 1.9 & 2.7 & 0.74 & 0.67 \\
\hline Source: Ministry of Eduction & & & & & &
\end{tabular}

Source: Ministry of Education

The following is an estimate of the proportion of prime-aged people in tertiary education. ${ }^{84}$ In 1991, 4.4 percent of prime-age men, and 5.0 percent of prime-aged women were studying. In 1996, the proportions had risen to 5.2 percent for men and 6.8 percent for women. These data indicate that the educational participation "gap" between primeaged women and prime-aged men, which was already in women's favour, widened over this period.

\footnotetext{
${ }^{84}$ In this calculation the numerator is based on Ministry of Education data, and includes all people aged 25 and older. The denominator is based on census data for people aged 25-59. This means the data presented is likely to be a small overestimate.
} 
However, Table 18 shows that, despite changes in educational participation rates, in terms of actual education attainment for prime-aged people there were still a marginally higher proportion of prime-aged women than men with no formal qualifications in 1996.

\section{Table 18- Highest qualifications of women and men in the 25-59 age group, 1986- 1996}

\begin{tabular}{|c|c|c|c|}
\hline $\begin{array}{l}\text { Highest qualification gained } \\
1986\end{array}$ & $\begin{array}{r}\text { Male } \\
000 \text { s }(\%)\end{array}$ & $\begin{array}{r}\text { Female } \\
000 \text { s }(\%)\end{array}$ & Ratio of women to men \\
\hline Degree or postgraduate & $61.7 \quad(9.2)$ & $35.5(5.4)$ & 0.59 \\
\hline Other tertiary/school qualifications & $366.4(54.8)$ & $329.0(50.4)$ & 0.92 \\
\hline No formal qualifications & $240.5(36.0)$ & $288.2(44.1)$ & 1.23 \\
\hline Total & 668.7 & 652.7 & \\
\hline Highest qualification gained & Male & Female & Ratio of women to men \\
\hline 1991 & 000s $(\%)$ & $000 \mathrm{~s}(\%)$ & \\
\hline Degree or postgraduate & $73.3(10.2)$ & $50.5(7.0)$ & 0.69 \\
\hline Other tertiary/school qualifications & $420.0(58.3)$ & $415.2(57.4)$ & 0.98 \\
\hline No formal qualifications & $227.5(31.6)$ & $258.0(35.7)$ & 1.13 \\
\hline Total & 720.7 & 723.7 & \\
\hline Highest qualification gained & Male & Female & Ratio of women to men \\
\hline 1996 & 000s $(\%)$ & $000 \mathrm{~s}(\%)$ & \\
\hline Degree or postgraduate & $98.4(12.5)$ & $77.6 \quad(9.4)$ & 0.75 \\
\hline Other tertiary/school qualifications & $452.0(57.2)$ & $489.6(59.4)$ & 1.04 \\
\hline No formal qualifications & $239.6(30.3)$ & $257.1(31.2)$ & 1.03 \\
\hline Total & 790.0 & 824.3 & \\
\hline
\end{tabular}

Calculating an index of educational dissimilarity can show the differences, and changes, in educational attainment between prime-aged women and men. Based on the above three way educational grouping, the index in 1986 was 0.082 , reduced in 1991 to 0.041 and further to 0.030 in 1996. This shows patterns of education for prime-aged men and women became much more similar over this period.

Changes are more dramatic when just the 25-34 age group is considered (Table 19). 
Table 19: Highest qualifications of men and women in the 25-34 age group, 19861996

\begin{tabular}{|c|c|c|c|c|c|}
\hline \multirow{2}{*}{$\begin{array}{l}\text { Highest qualification gained } \\
1986\end{array}$} & \multicolumn{2}{|c|}{ Male } & \multicolumn{2}{|r|}{ Female } & \multirow[t]{2}{*}{ Ratio of women to men } \\
\hline & $000 \mathrm{~s}$ & $(\%)$ & $000 \mathrm{~s}$ & & \\
\hline Degree or postgraduate & 26.1 & $(10.7)$ & 18.0 & (7.4) & 0.69 \\
\hline Other tertiary/school qualifications & 146.6 & $(60.1)$ & 147.6 & $(60.4)$ & 1.00 \\
\hline No formal qualifications & 71.2 & $(29.2)$ & 78.9 & $(32.3)$ & 1.11 \\
\hline Total & 244.0 & & 244.4 & & \\
\hline
\end{tabular}

\begin{tabular}{lrrrrrr}
\hline Highest qualification gained & & Male & \multicolumn{3}{r}{ Female } & Ratio of women to men \\
1991 & $000 \mathrm{~s}$ & $(\%)$ & $000 \mathrm{~s}$ & $(\%)$ & 0.80 \\
\hline Degree or postgraduate & 28.0 & $(10.9)$ & 23.1 & $(8.7)$ & 1.05 \\
Other tertiary/school qualifications & 160.0 & $(62.4)$ & 173.1 & $(65.3)$ & 0.98 \\
No formal qualifications & 68.3 & $(26.6)$ & 69.0 & $(26.0)$ & \\
Total & 256.3 & & 265.2 & & \\
\hline
\end{tabular}

\begin{tabular}{lrrrrr}
\hline Highest qualification gained & & Male & \multicolumn{3}{c}{ Female } \\
1996 & $000 \mathrm{~s}$ & $(\%)$ & $000 \mathrm{~s}$ & $(\%)$ & Ratio of women to men \\
\hline Degree or postgraduate & 34.5 & $(13.3)$ & 33.4 & $(12.0)$ & 0.90 \\
Other tertiary/school qualifications & 156.9 & $(60.4)$ & 179.7 & $(64.4)$ & 1.07 \\
No formal qualifications & 68.4 & $(26.3)$ & 66.0 & $(23.7)$ & 0.90 \\
Total & 259.7 & 5 & 279.0 \\
\hline
\end{tabular}

The growth in the proportion of women with a degree or higher was faster than the growth for men. By 1996 there were almost as many women with degrees or higher in this age group as men. In addition, after starting the decade with a higher proportion of women than men having no formal qualifications, the decade ended with this pattern reversing. Also of importance, is that even in this relatively young age group in 1996 a quarter of men and women had no formal qualifications. This is far too high if New Zealand is to be a "knowledge economy".

Table 20 breaks down age groups further but only shows two educational categories. These are no post school qualifications (so they may have a school qualification such as university entrance or school certificate) and those with a degree or higher qualification. The ratios are also calculated on numbers of people so demographic imbalances between men and women affect the results in this table. Table 20 shows that amongst the group who will be entering the prime-aged category in the 2001 census, that is people aged 2024 in 1996, there were more lowly qualified men than women and more women with 
degrees than men. This historically unique situation is likely to have an impact in many areas of life in the future including participation in the labour market and the marriage market.

Table 20 - Numbers and ratios of men and women with no post school qualifications and with a bachelors degree or higher, 1996

\begin{tabular}{|c|c|c|c|c|c|c|}
\hline \multirow[t]{2}{*}{ Age groups } & \multicolumn{2}{|c|}{$\begin{array}{l}\text { No post school } \\
\text { qualifications }\end{array}$} & \multirow{2}{*}{$\begin{array}{c}\text { Ratio of } \\
\text { female to } \\
\text { male }\end{array}$} & \multicolumn{2}{|c|}{$\begin{array}{c}\text { Bachelors degree or } \\
\text { higher }\end{array}$} & \multirow{2}{*}{$\begin{array}{c}\text { Ratio of } \\
\text { female to } \\
\text { male }\end{array}$} \\
\hline & Male & Female & & Male & Female & \\
\hline $20-24$ & 84,369 & 80,625 & 0.96 & 11,748 & 15,045 & 1.28 \\
\hline $25-29$ & 70,767 & 83,352 & 1.18 & 16,653 & 16,893 & 1.01 \\
\hline $30-34$ & 74,076 & 90,285 & 1.22 & 17,802 & 16,467 & 0.93 \\
\hline $35-39$ & 69,591 & 84,933 & 1.22 & 17,772 & 14,544 & 0.82 \\
\hline $40-44$ & 63,429 & 76,326 & 1.20 & 16,005 & 12,150 & 0.76 \\
\hline $45-49$ & 63,168 & 75,018 & 1.19 & 14,679 & 9,156 & 0.62 \\
\hline $50-54$ & 51,771 & 61,326 & 1.18 & 9,330 & 5,181 & 0.56 \\
\hline $55-59$ & 45,501 & 54,786 & 1.20 & 6,153 & 3,252 & 0.53 \\
\hline
\end{tabular}

The increase in the number, and proportion, of both men and women obtaining a degree raises some issues of quality of credential. The group with degrees or higher may suffer from some "dumbing down" as the group expands. In contrast, the group with no or few formal qualifications may be becoming more homogeneous. Whereas in the past there were many people with a high level of cognitive ability who did not gain formal qualifications, increasingly having no formal qualification will be a stronger indicator of cognitive disadvantage at the end of the 1990s than it used to in the past.

The major historical differences in participation and attainment rates for European, Maori and Pacific Island groups show up in Table 21. The very high rate of Asians holding degrees reflects a number of factors, including immigration of well-qualified Asians. However, some of these degrees are not recognised in New Zealand. The differences in numbers in each ethnic group and attainment rates mean that there are major differences in particular areas. For example, in 1996 there were over 80,000 prime-aged European men with a degree or higher qualification but only just over 1,000 Pacific Island men with a similar qualification. In addition, there are marked differences between the sole Maori and the mixed Maori ethnic groups. For example, amongst men aged 25-29, 54 percent of 
the sole Maori group had no formal qualification but this reduced to 34 percent for the mixed Maori group.

Table 21 - Percentage of prime-aged men and women by major ethnic group and highest educational qualification, 1996

\begin{tabular}{|c|c|c|c|c|c|c|}
\hline & & Degree or higher & Other tertiary & School & ation & Total \\
\hline Male & European Only & 13.0 & 34.7 & 25.4 & 26.9 & 100.0 \\
\hline & NZ Maori & 3.6 & 24.3 & 22.0 & 50.1 & 100.0 \\
\hline & Pacific Island & 3.3 & 18.6 & 26.9 & 51.3 & 100.0 \\
\hline & Asian & 33.2 & 19.9 & 27.6 & 19.3 & 100.0 \\
\hline Female & European Only & 9.9 & 28.7 & 33.7 & 27.8 & 100.0 \\
\hline & NZ Maori & 3.0 & 20.5 & 27.0 & 49.4 & 100.0 \\
\hline & Pacific Island & 2.5 & 18.3 & 30.6 & 48.6 & 100.0 \\
\hline & Asian Ethnic & 23.5 & 19.7 & 33.2 & 23.6 & 100.0 \\
\hline
\end{tabular}

\section{Literacy}

While this research focuses on formal educational qualifications, as discussed in Chapter seven, a New Zealand study of literacy shows some important links between literacy and employment. It also showed a strong, but as would be expected not perfect, link between formal education and literacy. The Ministry of Education (1997) carried out this study of adult literacy in March 1996 as part of a series of international surveys. The survey involved a random sample of 4,223 New Zealand adults in the age range 16-65. In New Zealand, the assessment was in English.

Some of the key findings of the research were:

- approximately one in five New Zealanders were seen to be operating at a highly effective level of literacy. This allowed them to manage abstract concepts and use specialist knowledge in interpreting information.

- over half of New Zealand adults were operating at a literacy level considered as a requirement to meet the demands of "every day life" (which suggests a significant proportion have problems). 
- this distribution of literacy skills in the New Zealand population was similar to that of Australia, the U.S. and the United Kingdom. However, in Sweden nearly three quarters of their population worked at an effective level of literacy.

- labour force status and income were related to level of literacy. People on low incomes and not in paid work tended to have low levels of literacy.

- there appears to be no evidence that literacy levels in New Zealand were decreasing. Increased retention into the senior secondary school appeared to be associated with improving literacy levels.

- while a higher proportion of Maori and Pacific Island people had low levels of literary, Maori with tertiary qualifications had literacy profiles similar to those of tertiary educated European/Pakeha.

The bottom level of literacy was defined as (p. 2):

People at this level have very poor skills, and could be expected to experience considerable difficulties in using many of the printed materials that may be encountered in daily life.

About 20 percent of the sample were seen as falling into this bottom group. Although Maori were over-represented in this group, Pacific Islands' peoples and other minority ethnic groups were especially over-represented. In part, this reflected that the test was carried out in English and that English was a second language to some of these people. Given the strong relationship between formal education and literacy it is not surprising that seventy five percent of those who had not gone beyond primary school were in the lowest level of prose literacy, with similar results for document and quantitative literacy. If employers are increasingly expecting some basic literacy amongst employees, these data indicate that perhaps twenty percent of the population will be facing major problems in the labour market.

The study suggests a need for a strong focus on adult literacy in New Zealand not just on the school age population. Many of the Maori and Pacific Island prime-aged people who were over-represented amongst those with low levels of literacy are at the younger end of the prime-working age group. They will therefore be in this age group for a long period, and given the changes in the economy, are likely to face extended periods of being work 
poor. Finally, many of these people with low levels of literacy will be parents. If, as the research suggests, parents do have a major influence on their children's own literacy, then there is a potential for a cycle of disadvantage to be established. This reinforces the need to have a very effective early childhood education and schooling for these children.

\section{Conclusion}

While part of longer terms shifts, there were some major changes in educational participation and attainment over the period studied. These changes took place in preschool education, secondary school and in tertiary education. While these changes will hopefully, in the long run, lead to an overall "upskilling" of the population there are clearly some groups who are falling behind in educational participation and attainment. Maori and Pacific Island peoples are particularly over-represented amongst these groups.

The increasing availability of childcare has allowed many women (and some men such as sole fathers) to increase their participation in paid work. However, there are still problems of access to early childhood services that mean that even if paid work is available, some groups of work-poor people cannot take up the jobs. For a variety of reasons work-rich families are far more likely to use childcare than work-poor families. If there is a significant educational component in early childhood education as the literature would suggest the children of the work-poor are disadvantaged from very early on in their lives.

While the participation and attainment rates in secondary education have increased dramatically, there are still some major, and worrying, gaps between European children and those from Maori and Pacific Island groups. However, it is worth keeping in mind that even within these groups there are marked variations in participation and attainment. Not all Maori and Pacific Island peoples are disadvantaged, and not all Pakeha are performing well in the education system. While there have been concerns in the past about the performance of girls at school, there is an emerging concern about a group of low achieving boys. Clearly, there is a need to improve the performance of children, whether boys or girls, who are still not achieving acceptable levels of numeracy and literacy at school. 
The marked variation in participation and attainment is also reflected in some dramatic differences in achievement between schools drawing on very different communities. It is difficult to see how many of the children who are attending the schools with poor achievement records will be able to participate fully in an emerging knowledge based economy.

Participation in school and tertiary education had increased between 1986 and 1996. One of the more significant events that occurred in this period was that women moving into the prime-age group were, on average, better qualified than men in the same cohort. This change is likely to have an on-going impact on the workings of the labour market, the marriage market, and childbearing and childrearing decisions in the future.

Despite the improvement in participation and attainment rates, by the mid 1990s there was still a large group of prime-aged people with no formal qualifications. In addition, there continues to be a significant group of younger people who have no formal qualifications, or only a low level of education. Again, the gap between Europeans and those from Maori and Pacific Island groups is too high.

While in the past the group with no or few formal qualifications would have contained many people with a high level of cognitive ability but who did not gain formal qualifications, increasingly younger people with no formal qualification are becoming a more homogeneous group. Unless they have a particular non-credentialised talent, or have high levels of soft skills, they are likely to face exclusion from long-term participation in paid work.

Finally, even if employers do not always expect a person to hold a formal educational qualification, they appear to increasingly expecting some basic literacy. It also appears that some basic level of literacy is needed to function adequately in society. The New Zealand survey of literacy suggests that that perhaps up to twenty percent of the population could be facing major problems in the labour market and in life in general. 
The little New Zealand research carried out on adult literacy suggests a need for a strong focus on improving literacy amongst prime-working aged New Zealanders and not just lifting literacy rates amongst the school-aged population. Clearly, effectively lifting the levels of a large group of adults is an extremely difficult challenge. However, if they are not lifted there is the chance that we will potentially have a "lost generation" in terms of participation in paid work. 


\section{Chapter 16}

\section{Broad changes in employment and skill use}

\section{Introduction}

In this chapter I explore three broad questions. The first is whether paid work has been "disappearing". In this analysis of the disappearance of work, I track changes back to the 1950s. The second question is whether the distribution of paid work has been changing. In particular, I am interested in the broad mix between full-time and part-time jobs, the distribution between women and men and the distribution by age. The third issue is whether relatively skilled jobs have been growing at a faster rate than relatively unskilled jobs. This includes some brief cases studies.

The chapter begins by outlining broad changes in paid work for the population aged 15 to 64 in the period from the 1950s to the mid 1990s. This relies on an historical series developed by Chapple $(1994,1999)$ using a range of data sources. It then moves onto identifying some key trends in employment between 1986 and 1996 using data from both the Census and the HLFS.

The final section is in two parts. The first part examines broad educational, industrial and occupational data as a means of initially assessing the changing demand for skills. The chapter then focuses on some case studies of industrial and occupational change. The first is an assessment of how the "cafe society" is having an impact on employment, and in particular whether "hamburger flipping," type "McJobs" have been a prime part of recent employment growth. The second examines the impact of the growth of teaching jobs. The third case study briefly examines occupational change within the industrial group of 
manufacturing. Trends in work patterns within the target prime-aged group (25-59) are then discussed in more detail in the following chapter.

\section{Changes in employment for the working age population, 1950s to the 1990s}

There have been many detailed analyses of long-term changes in patterns of paid work in New Zealand. These include those published by organisations such as Statistics New Zealand (formally the Department of Statistics), the New Zealand Planning Council, as well as individual researchers (e.g. Easton 1991, Morrison 1991, Shirley et al 1990, Thomson 1999). In the later part of 1999 and early 2000, Thomson's work received particular attention from the media. Thomson's research has been reported as suggesting that work is rapidly disappearing for those aged 45 and over (Ansley 2000, Patterson 1999, Stirling 2000). ${ }^{85}$

As discussed in Chapter two, there are a number of ways of measuring participation rates. A common statistic is labour force participation. In the following figures, and most of the subsequent data, another measure is used. This divides the total population in a target age group into those who are in paid work and those not in paid work. This latter group includes both those seeking work and those who have completely withdrawn (for both positive and negative reasons) from labour market participation.

Figure 10 illustrates broad employment trends by showing the percentage of workingaged men and women (15-64) who were in paid work from 1956 to 1996. The top line represents men and the bottom line women. This shows that employment trends for both men and women were particularly volatile in the main period I am focussing on in this research, that is 1986 to 1996 . However, of equal importance Figure 10 shows that overall participation rates in paid work varied little in the 42 years from 1956 to 1998. This crude

\footnotetext{
${ }^{85}$ Patterson reports that over the next decade a third of New Zealand men will have permanently exited the labour force by their later 40s and half by the mid 50s. Ansley quotes Thomson as predicting that "within the next 10 years a third of men and even more women will be without substantial paid work as they reach their later 40s". Full-time work is vanishing and being replaced by casual, low paid work" (p. 18). As will be shown, these are major forecast declines in work participation relative to current data.
} 
measure would suggest that in this time period work had not been disappearing. However, the distribution of work between women and men changed dramatically. In the 1950s, about 90 percent of men and 30 percent of women were employed. In the late 1990s, men's employment rate had declined by around 20 percentage points and women's increased by about the same amount.

\section{Figure 10}

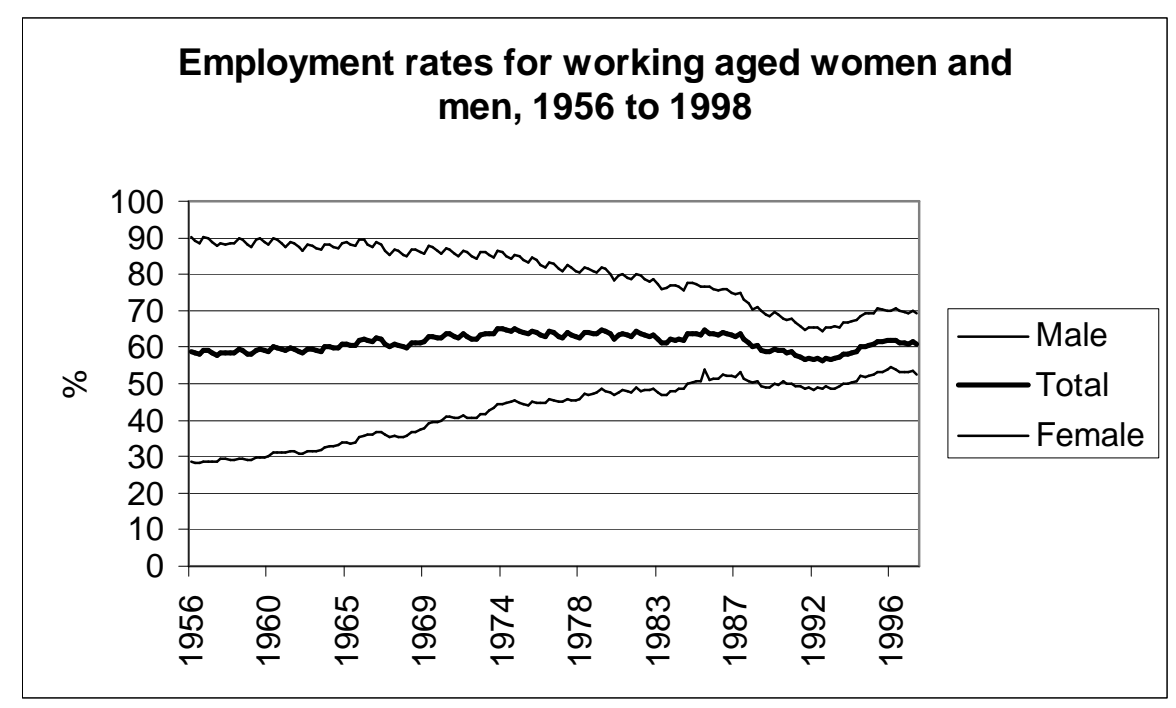

Source: Derived from Chapple (1994, 1999)

Figure 10 excludes an important aspect of employment, that is people who would like to be in paid work but cannot find a suitable job. Figure 11 shows both the percentage of working age people employed and unemployed from 1956 to 1998 (top line employment and bottom line unemployment). 
Figure 11

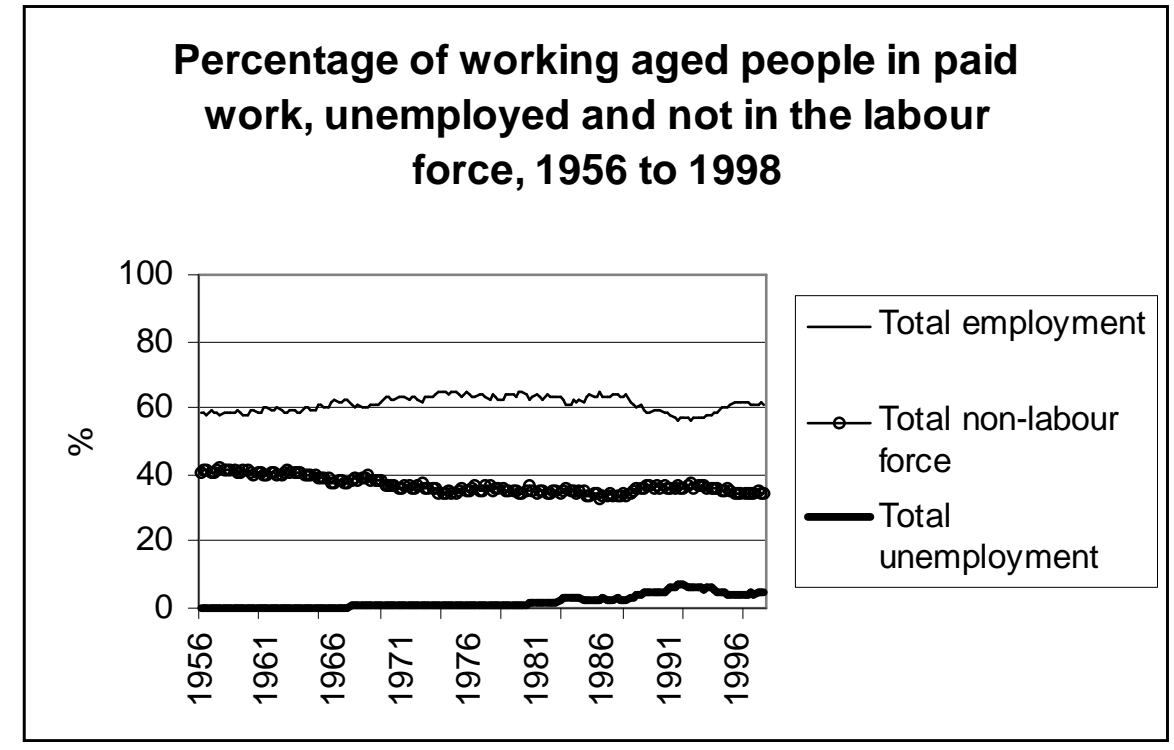

Source: Derived from Chapple (1994, 1999)

Figure 11 shows that unemployment was very low through to the mid 1970s but then started to rise. There was a second large rise in unemployment took place in the late 1980s. While the level of unemployment fell back in the mid 1990s it was still considerably higher than in the 1950s to the early 1970s. The chart also shows that the percentage of working aged people not in the labour force decreased. This suggests that a higher proportion of the population wanted paid work, or needed paid work, in the late 1990s.

\section{Was paid work disappearing between the 1950s and the late 1990s?}

Given the relatively stable overall employment rates, Figures 10 and 11 do not initially suggest that paid work disappeared between the mid 1950s and the late 1990s. Figure 12 provides some ways of further assessing whether work has been disappearing. It first shows three ways of calculating employment rates. The first, shown in the top line (total), is simply the total number of working age people in paid work divided by the population. This is the total line on Figure 10. The second line down (FTE 1) treats part-time jobs as half a full-time job, while the bottom line treats a part-time job as being worth a third of a full-time job (FTE 2). Then linear trendlines are fitted to each series. While none of the 
trendlines are of a particularly good fit, they do show that quite different interpretations could be drawn about the amount of work available in society. The total trendline suggests that work has not been disappearing on a per capita basis, whereas the other two suggest that the amount of work per capita has been decreasing over the long term. However, such a calculation of part-time work, particularly using the ratio of one third, takes no account of potential increases in hours worked within the full-time category. In addition, the truncation of the vertical axis in Figure 12 exaggerates the scale of change.

\section{Figure 12}

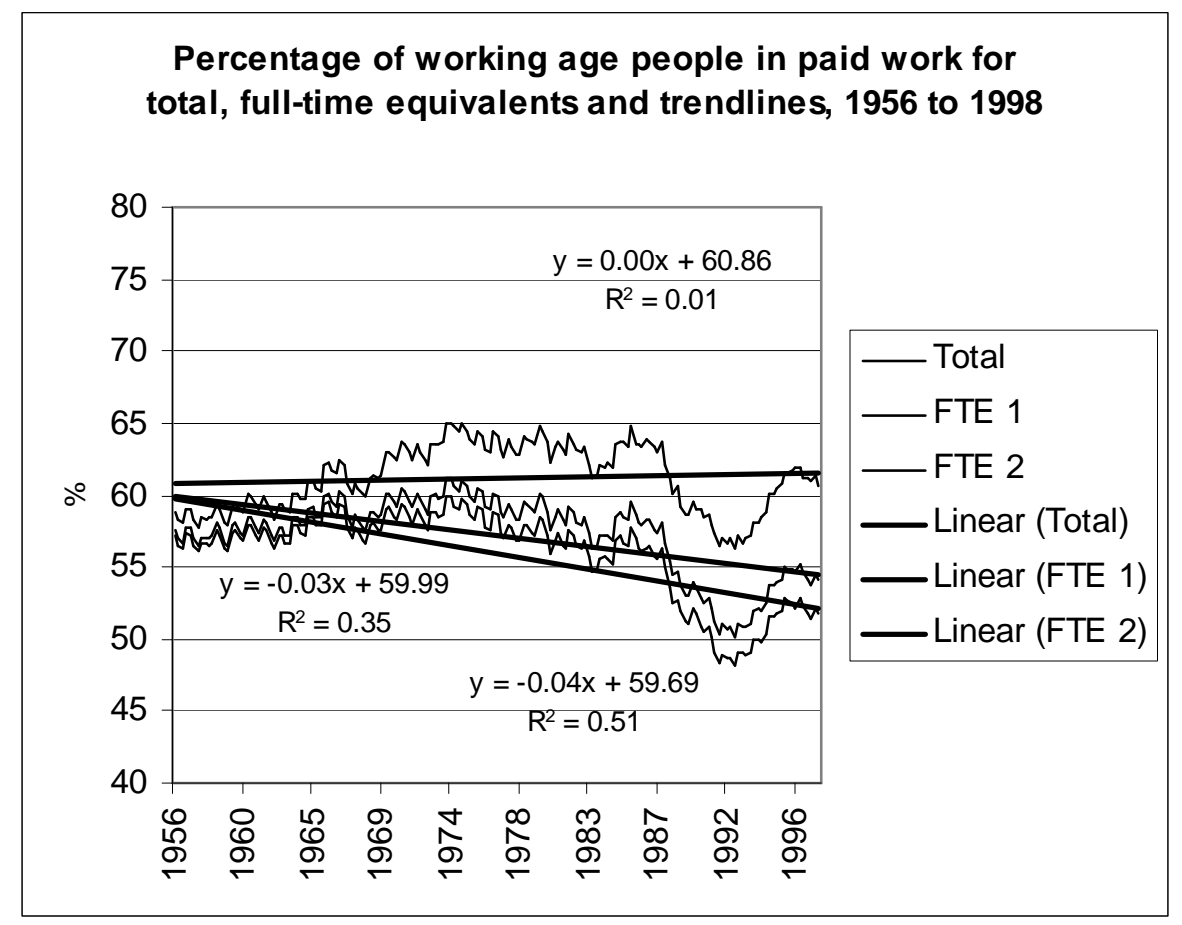

Source: Derived from Chapple (1994, 1999)

Note: In calculating the regressions time is measured in quarters.

As with many time series, quite different trends can be shown if different starting points are used. In particular, if the late 1960s/early 1970s is seen as the starting point of the analysis then the view that work has been disappearing has some more support. Certainly during the early restructuring period work was rapidly disappearing, but then this was followed by a very rapid growth in employment. The graph also shows why the period 1986 to 1996 is of considerable interest. 
Thomson (1999) argues that it is important to focus on full-time jobs. ${ }^{86}$ He suggests that from full-time jobs people are better able to save, pay taxes and support dependent family members. ${ }^{87}$ Using census data and age cohorts, he reports a steady decline in full-time employment for men from the early 1950s to the mid 1990s. Thomson also shows a steady increase in female employment over the same period, but argues that this has now come to a halt and is declining in some age groups. As discussed, Thomson's research has been reported as suggesting that work is rapidly disappearing for those aged 45 and over.

Figure 13 shows long-term trends in full-time employment (30 or more hours per week) from 1956 to 1998 . While these data do show that there had been a decline of full-time work per head of population from the 1970s to early 1990s, they do not support any idea of a strong on-going loss (or gain) of full-time jobs, for either men or women in the broad 15-64 age group in the late 1990s.

\footnotetext{
${ }^{86}$ In his study Thomson uses 20 hours per week as the cut-off point for full-time work.

${ }^{87}$ While this is generally correct, changes over time may challenge this view. If through productivity gains real incomes keep increasing then the amount of working time can theoretically decrease to less than 20 hours without reducing the tax base, the ability to support dependents and the ability to save. In addition, currently in a couple or extended family household a part-time job of one family member alongside other people working full-time (or even part-time) may allow that part-time income to support family dependents or to create a stream of savings. Such household savings may not be possible without the part-time job. There are, therefore, some dangers in only focussing on full-time work.
} 
Figure 13

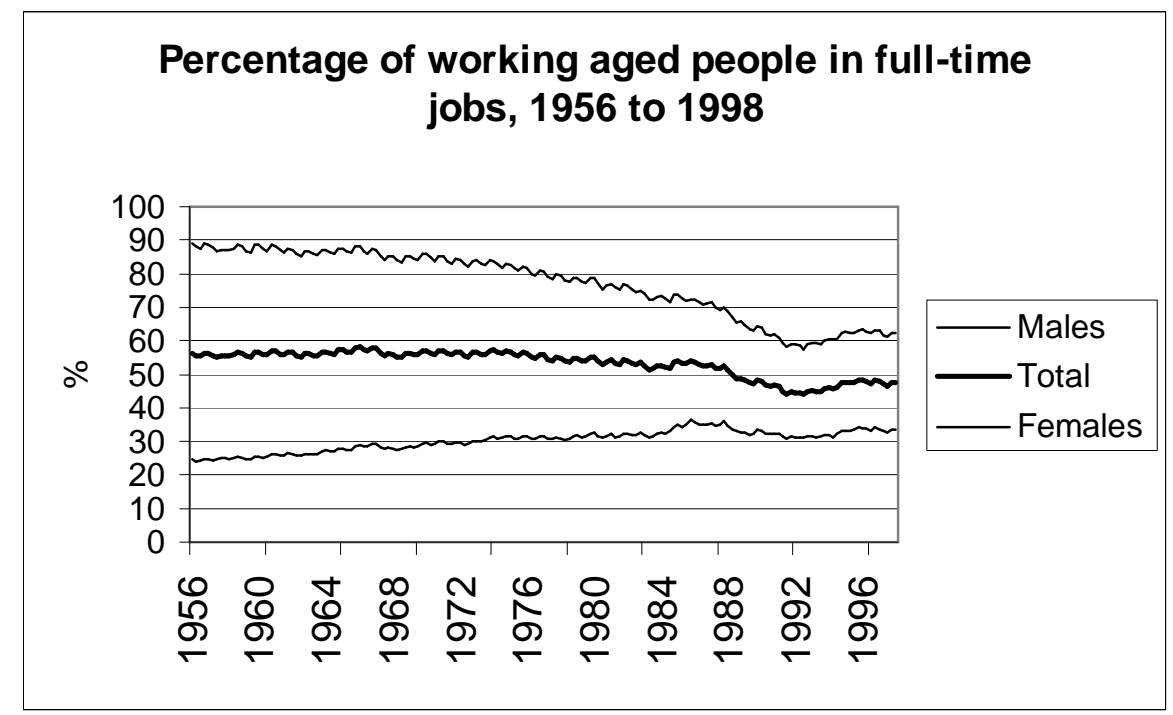

Source: Derived from Chapple $(1994,1999)$

HLFS data also does not support the idea of an on-going loss of full-time jobs for either men or women aged 45 and over (Callister and Rose forthcoming).

\section{Changes in employment 1985 to 1999}

It is clear from the previous chapters, and from the data already shown in the graphs in this chapter, that the main period studied covers a time of significant economic and social change in New Zealand. The starting point of my census-based research is not at the very beginning of the major period of restructuring, but is still very much in its early days.

While the primary data source for this research is census data, Figure 14 uses data from the HLFS to show the broad changes in both employment and unemployment over the period studied as well as two years beyond 1996. The chart shows unemployment was around 4 percent in 1986, but increased steadily over the first part of the period to peak at about 11 percent in 1992, one year after the 1991 census. Unemployment then declined with 1996, another census year, representing a low point in the second half of the period shown. The employment trend line shows some growth in employment to 1987 (the year of the sharemarket crash), then major job losses through to 1992. Employment then 
started to increase rapidly, but took to 1994 to reach the same level as 1986 . While 1996 is not the peak of employment in this period, the rate of growth did subsequently slow. In terms of subsequent discussions, the graph indicates that the 1991 census was conveniently near the bottom of an employment cycle and the 1996 census near to the top of the cycle. Due to this major cycle in most of my time comparisons using census data I compare data from 1986 and 1996.

\section{Figure 14}

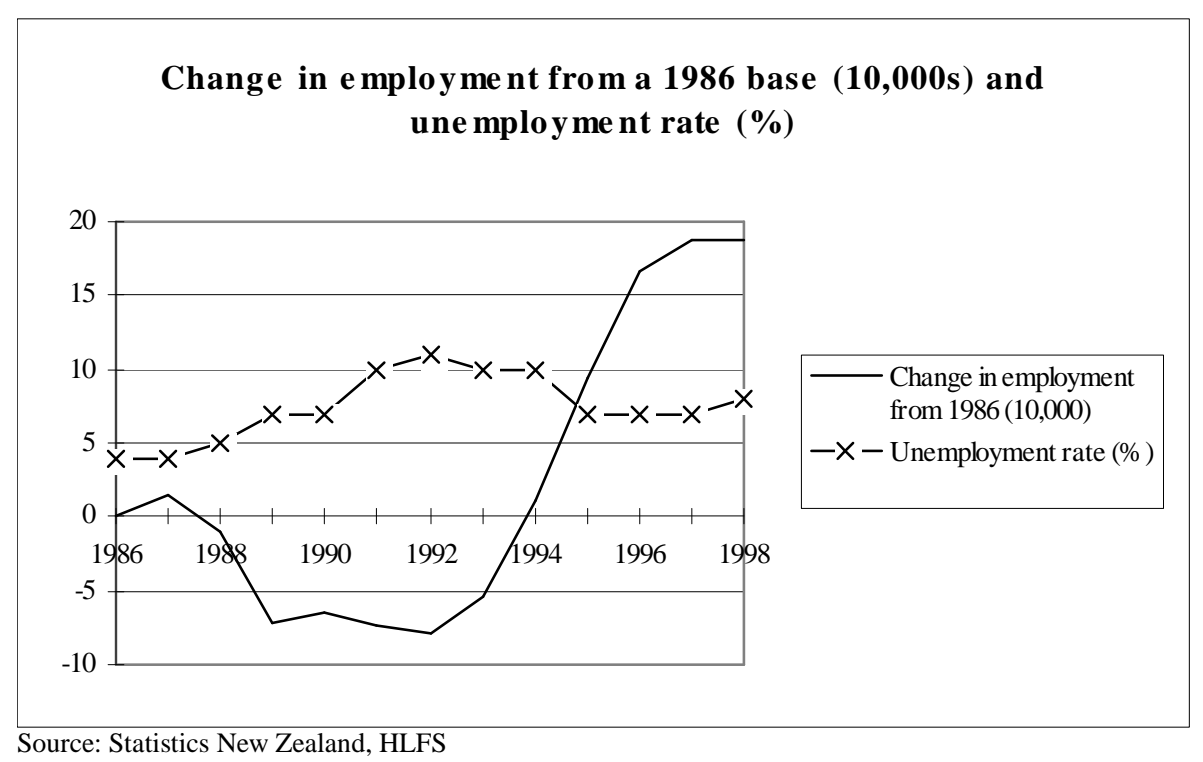

Figure 14 does not bring into the analysis changes in population or any gender dimension. Table 22 shows changes in population, employment and total hours worked and again shows major differences in trends when gender is considered.

Table 22 - Actual and percentage change in population, employment and hours of paid work for men and women aged 15+, 1986-1996

\begin{tabular}{|c|c|c|c|c|c|}
\hline & \multicolumn{3}{|c|}{ Actual (000s) } & \multicolumn{2}{|c|}{$\%$ change } \\
\hline & 1986 & 1991 & 1996 & $86-91$ & $91-96$ \\
\hline Male population & $1,210.4$ & $1,262.1$ & $1,350.0$ & 4.3 & 7.0 \\
\hline Female population & $1,257.9$ & $1,328.2$ & $1,436.3$ & 5.6 & 8.1 \\
\hline Male employment & 890.3 & 795.1 & 890.0 & -10.7 & 11.9 \\
\hline Female employment & 609.1 & $\begin{array}{r}605.3 \\
\text { (Million) }\end{array}$ & 740.8 & -0.6 & 22.4 \\
\hline Male hours of paid work * & 41.3 & 35.7 & 42.2 & -13.6 & 18.2 \\
\hline Female hours of paid work & 22.0 & 20.7 & 27.4 & -5.9 & 32.4 \\
\hline
\end{tabular}


The hours worked data provides another way of assessing whether work was disappearing in this time period. The fact that hours worked by any one group are trending up or down carries no necessary implication about what is happening to work overall and may simply reflect a re-distribution of work. Census data shows that between 1986 and 1991 total hours in paid work in New Zealand decreased from just over 63 million to just over 56 million. However, total hours then increased to just under 70 million hours in 1996. Overall, total hours worked by people 15 or over increased between 1986 and 1996. Tables 23 and 24 show total hours worked divided by the population aged 15 or more. It should be noted that, with respect to 1996 data, it is assumed that people who did not record their hours, in fact worked zero hours. An additional column shows the effect of excluding these people from the analysis. Overall, the data do not suggest a wholesale disappearance of work between 1986 and 1996, particularly when we note the rise in average hours between 1991 and 1996. In addition, of relevance to an aging population, the average hours worked per person for people aged 60 or more increased. However, Table 24 does show once again that the gender distribution of work has been changing.

Table 23 - Total hours and averaged hours of paid work per total number of people in each age group, 1986-1996

\begin{tabular}{lrrrrrrr}
\hline & \multicolumn{3}{c}{ Total hours (millions) } & \multicolumn{4}{c}{ Averaged hours per person } \\
\hline Age group & 1986 & 1991 & 1996 & 1986 & 1991 & 1996 & $1996^{*}$ \\
$15-24$ & 15.1 & 10.0 & 11.6 & 25.9 & 18.0 & 21.7 & 23.5 \\
$25-59$ & 45.9 & 44.4 & 54.3 & 32.7 & 29.3 & 32.0 & 34.3 \\
$60+$ & 2.3 & 2.0 & 3.7 & 4.8 & 3.8 & 6.5 & 6.7 \\
$15+$ & 63.3 & 56.4 & 69.5 & 25.7 & 21.8 & 25.0 & 26.5 \\
\hline Source: Derived from the Census of Population and Dwellings, Statistics New Zealand. \\
* Excludes those unidentified and not specified in calculation
\end{tabular}

Table 24 - Total hours and hours of paid work per total number of people aged 15 or more by gender, 1986-1996

\begin{tabular}{lcccccc}
\hline & \multicolumn{3}{c}{ Total hours (millions) } & \multicolumn{4}{c}{ Averaged hours per person } \\
\hline & 1986 & 1991 & 1996 & 1986 & 1991 & 1996 \\
Male & 41.3 & 35.7 & 42.2 & 34.1 & 28.3 & 31.2 \\
Female & 22.0 & 20.7 & 27.4 & 17.5 & 15.6 & 19.1 \\
\hline Source: Derived from the Census of Population and Dwellings, Statistics New Zealand.
\end{tabular}


Table 25 shows census based employment rates for the population age 15 or older. In these initial data I have included the non-respondents in the total population.

Table 25 - Employment rates and labour force participation rates for women and men aged 15 and over, 1986 to 1996

\begin{tabular}{lrrrrr}
\hline \multicolumn{5}{c}{$\%$ in paid work } \\
\hline Women & Men & Total & $\begin{array}{c}\text { Ratio women } \\
\text { to men }\end{array}$ & $\begin{array}{c}\text { Total LF } \\
\text { participation }\end{array}$ \\
1986 & 48.4 & 73.6 & 60.7 & 0.66 & 65.2 \\
1991 & 45.6 & 63.0 & 54.1 & 0.72 & 60.4 \\
1996 & 51.6 & 65.9 & 58.5 & 0.78 & 65.4 \\
Change 86-96 & 3.2 & -7.7 & -2.2 & 0.12 & 0.2 \\
\hline \multicolumn{2}{l}{ Source: Derived from the Census of Population and Dwellings, Statistics New Zealand. }
\end{tabular}

The decline in the percentage of the total population stating they were in paid work, but the very slight rise in the proportion in the labour force over this period might seem to be in conflict. However, it is possible to have falling participation in paid work and rising labour force participation if more people start to register in surveys as unemployed and seeking work.

In order to assess the changes in participation rates in various age groups it is useful to have a guide to employment changes in these age groups. The following Charts (15-19) are drawn off the HLFS database and show overall changes in employment between 1986 and 1996 by age group and when these changes took place

For men, the HLFS data to September 1999 show that in the period 1985 to the early 1990s there was a major loss in employment for all age groups. There was then a slight rise in employment in the age group 20-39 from 1992 to the mid 1990s, followed by another small decline. For men aged 45-59 after the initial period of job loss there was a plateauing of employment rates in the 1990s. In contrast, there was a small rise in the 6064 age group over the whole period considered. 
Figure 15

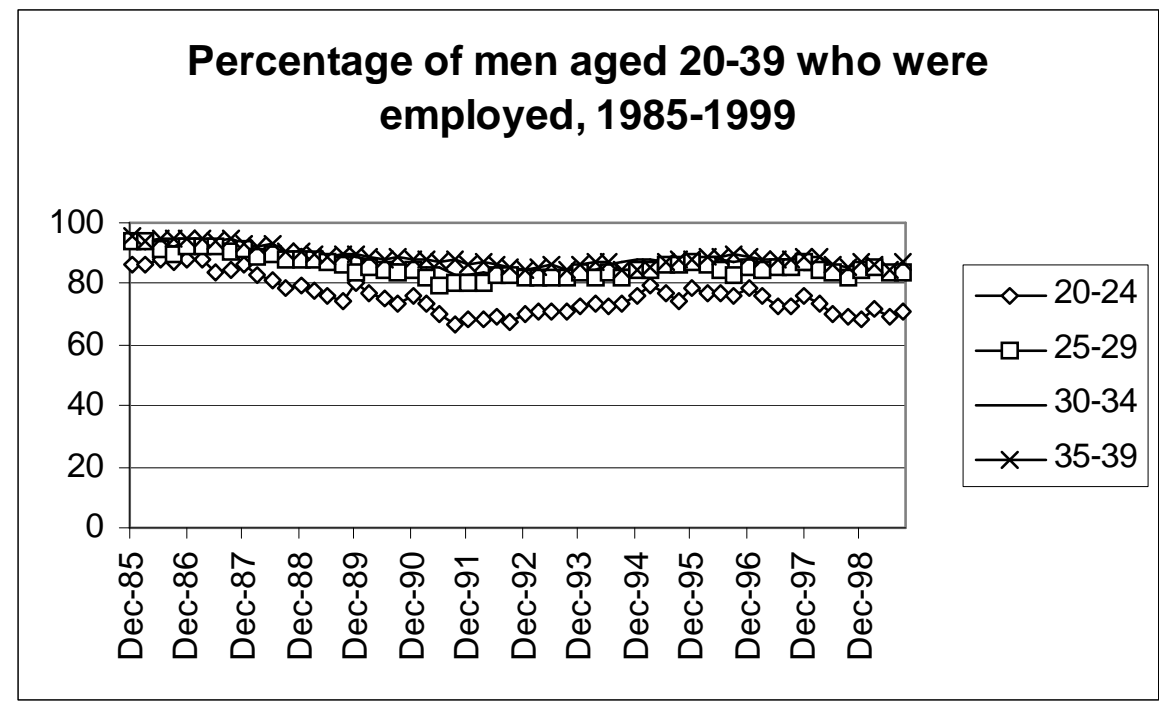

Source: Statistics New Zealand, HLFS

Figure 16

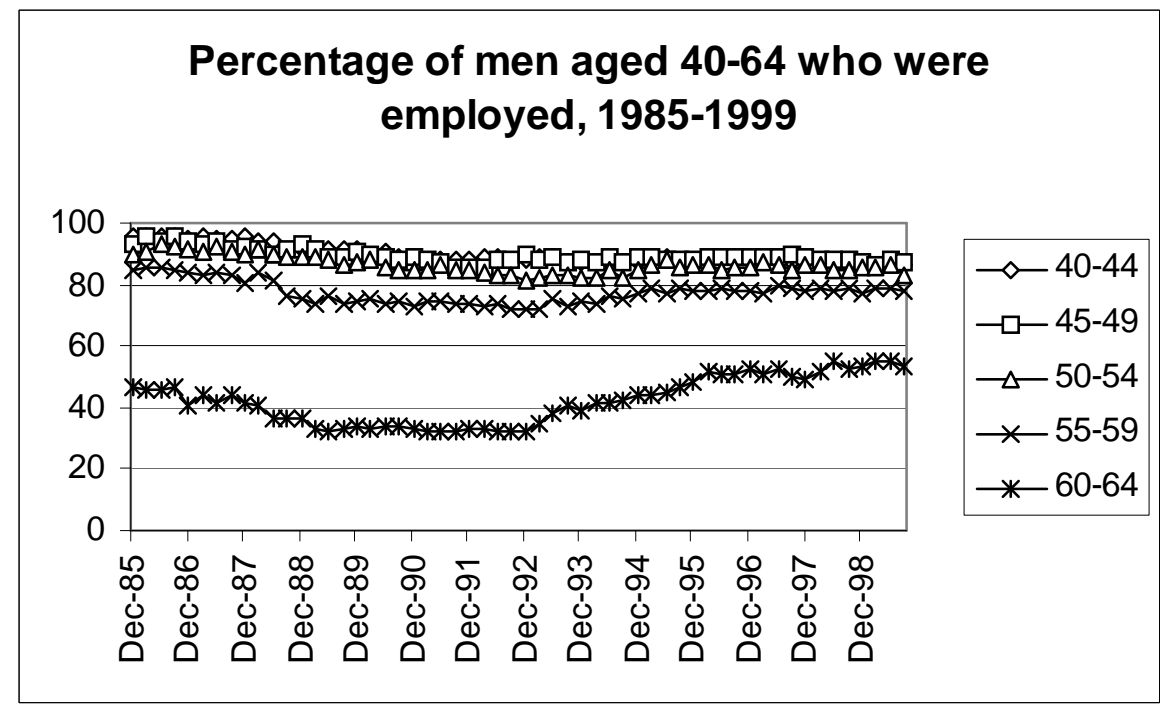

Source: Statistics New Zealand, HLFS

The charts for women suggest that that the long-term increase in participation rates slowed over this period. The data show that in the 20-24 age groups for women there were recent small declines in employment rates. In many of the other age groups participation rates tended to plateau in the 1990s. However, employment rates continued to rise in the most of the older age groups over the latter part of the 1990s. 
Figure 17

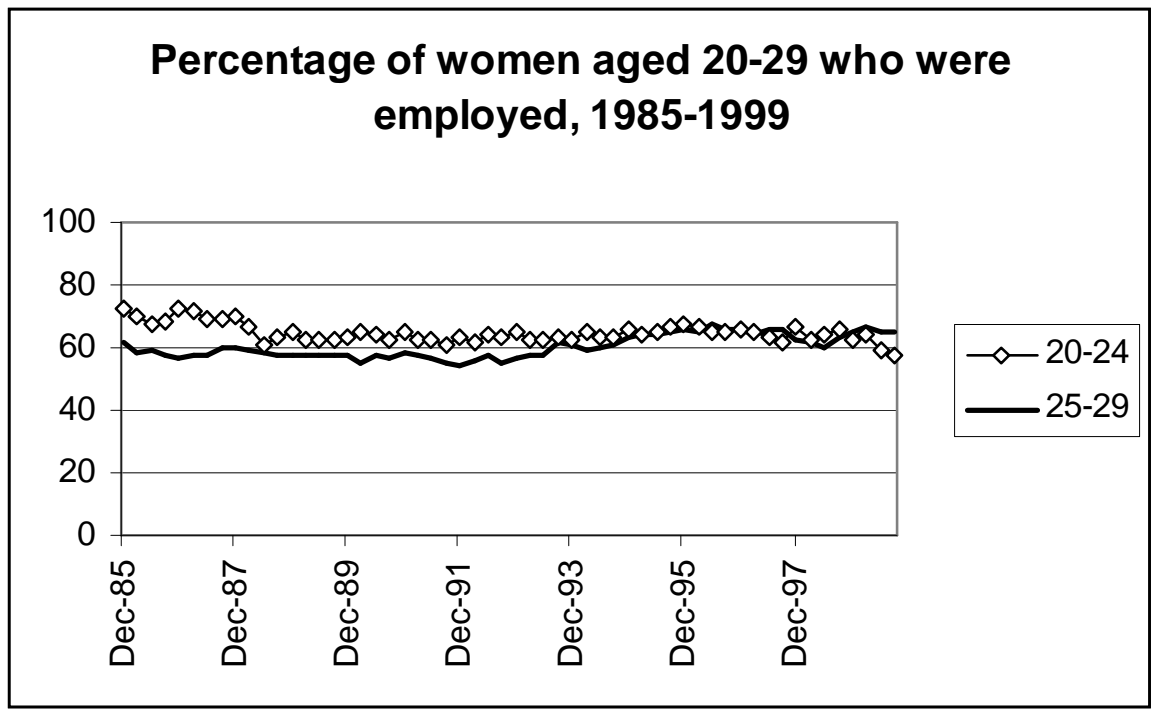

Source: Statistics New Zealand, HLFS

Figure 18

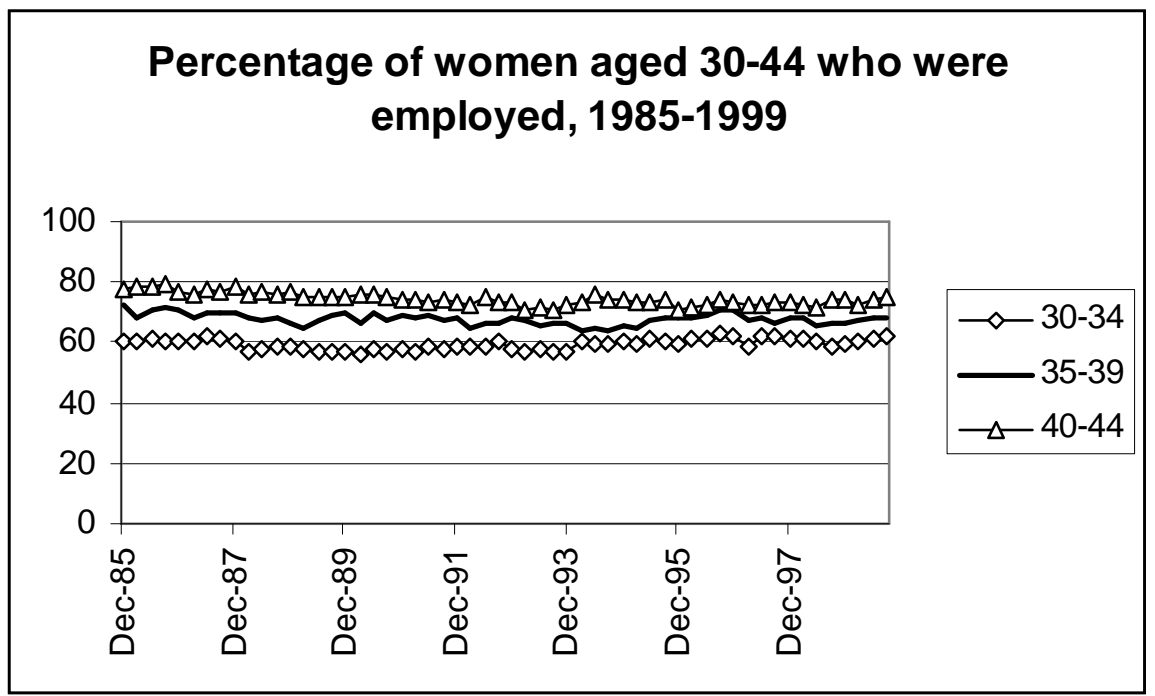

Source: Statistics New Zealand, HLFS 


\section{Figure 19}

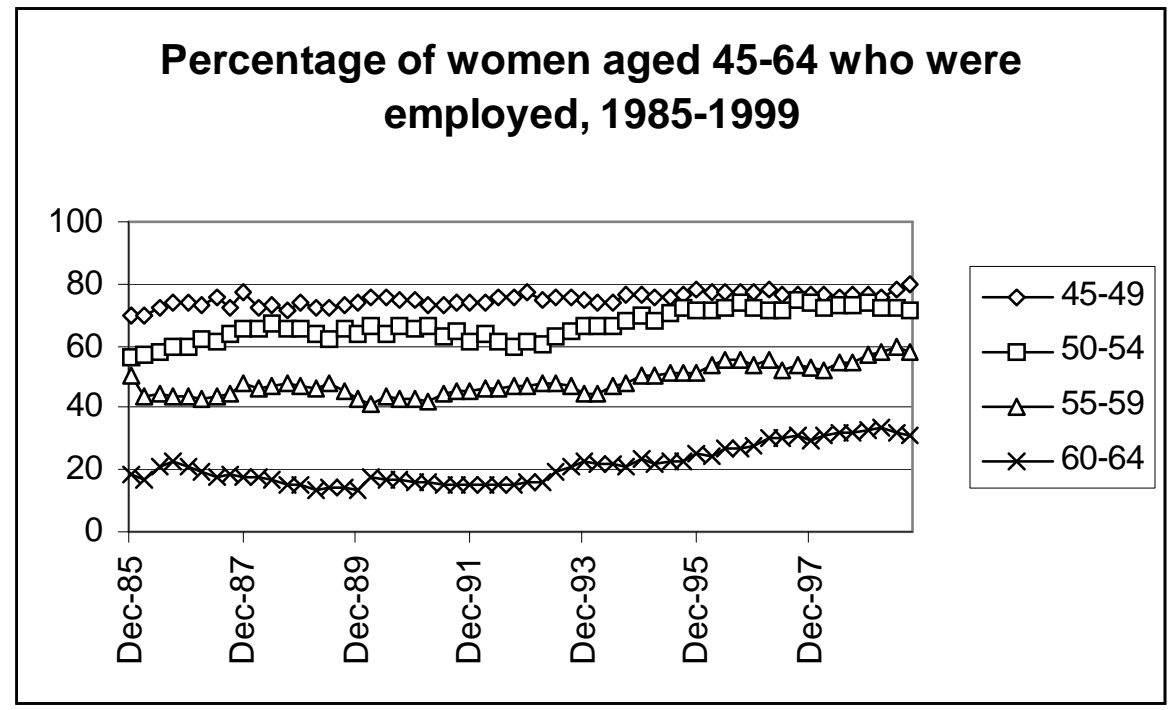

Source: Statistics New Zealand, HLFS

\section{Changing hours of paid work}

Most of the employment data shown in the chapter so far include people who might only work one hour per week as well as those who work very long hours. A more complex picture emerges when work time is divided into part-time and full-time hours. ${ }^{88}$

Much of the growth in employment since 1981 was in part-time work. In the five years 1981 to 1986 the number of full-time jobs increased by 7.2 percent, while part-time jobs increased by 13.6 percent. In the next five years to 1991, full-time jobs decreased by 9.9 percent, but part-time jobs grew by 12.7 percent. In the final five years to 1996, the number of full-time jobs rose by 8.8 percent, while the number of part-time jobs expanded by 51.7 percent.

In 1981, part-time work represented 14 percent of employment. This rose to 15 percent in 1986, 18 percent in 1991 and 23 percent in 1996. In 1981, 3.7 percent of men worked part time but this had risen to 14.6 percent in 1996. For women, 45 percent worked part time in 1981 and rose to 56 percent in 1996.

\footnotetext{
${ }^{88}$ In the next chapter, an even more detailed breakdown of hours for prime-aged people is developed.
} 
The timing of these changes in full-time and part-time work can be illustrated using data from the HLFS.

Figure 20 shows large and ongoing losses of full-time jobs held by men through to 1992 and although there was some strong growth in the number of full-time jobs held by men through to 1996 , it took to 1996 to reach the employment levels of 1986 . There was a lower level of loss of full-time jobs held by women through to 1992, but the subsequent growth was also lower. However, by 1996 there were more women working full-time than in 1986.

Figure 20 also shows that, despite some minor downturns, there was growth in part-time work over the whole period and that the number of part-time jobs held by women increased particularly strongly between 1991 and 1997.

\section{Figure 20}

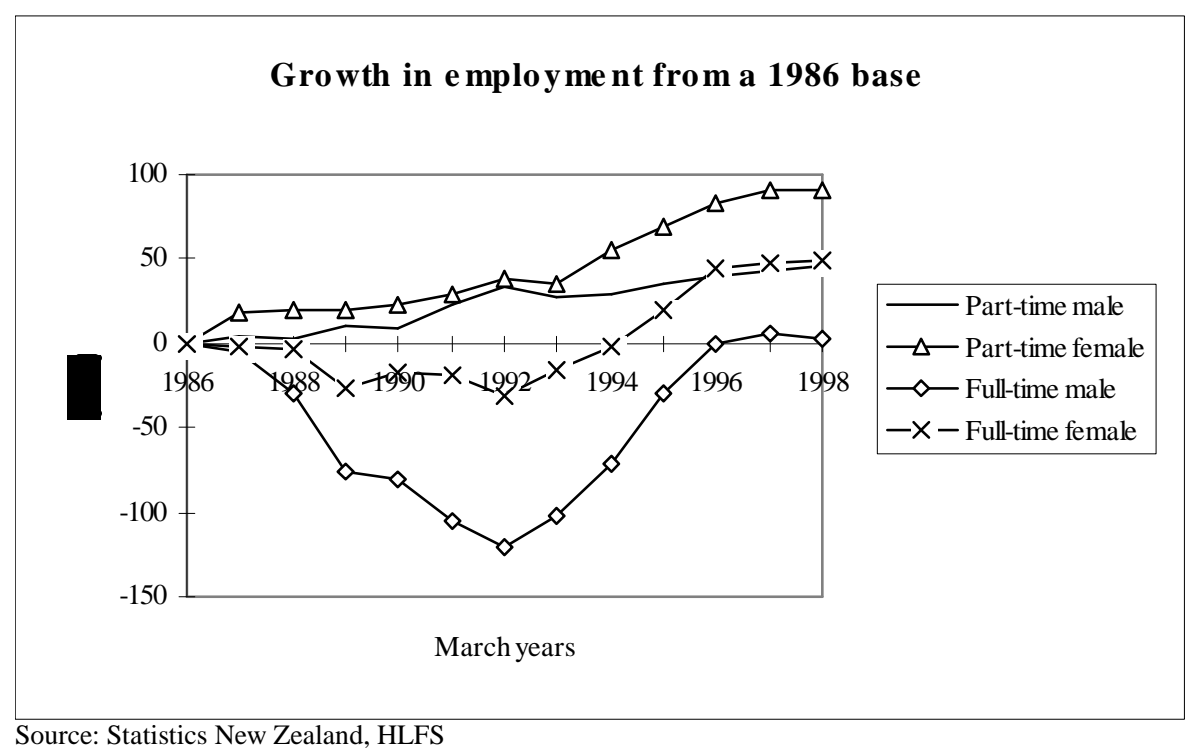

Without an analysis of the skills required, the shifts shown in Figure 20 appeared to have increased the type of job traditionally filled by young people (male and female), people (male and female) over 60, and by prime-aged women (particularly those with young children). Figure 21 shows the actual growth in numbers of people part time by age 
group. It shows that while there was growth across all age groups the growth between 1986 and 1996 was particularly strong amongst young people.

Figure 21

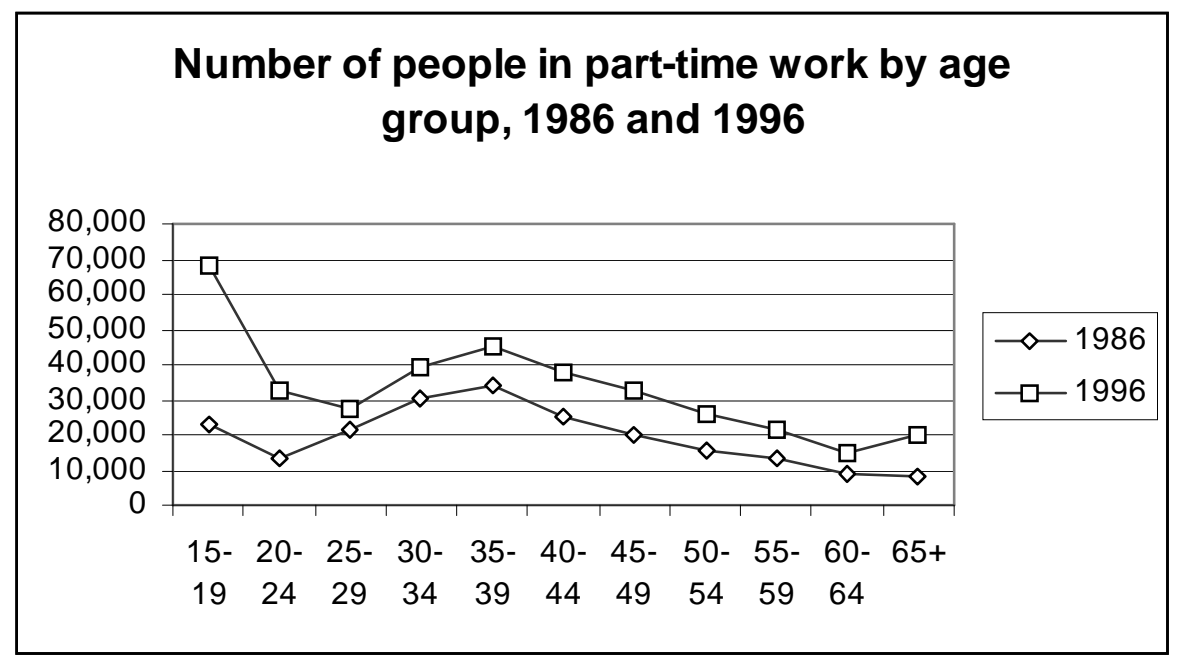

Source: Derived from the Census of Population and Dwellings, Statistics New Zealand.

Table 26 then shows the ten largest gains in part-time employment when gender, age and living arrangements are considered. It shows that the strongest growth in part-time work for young people was among dependent children. Most of these young people were likely to be either still at school or in further education and training and living with their parents. 
Table 26 - Top ten gains in part-time work by gender, age and living arrangement Growth in numbers between 1986 and 1996

\begin{tabular}{|c|c|c|c|}
\hline Gender & Age & Living arrangement & \\
\hline Female & $15-19$ Years & Dependent children & 16,404 \\
\hline Male & 15 - 19 Years & Dependent children & 15,144 \\
\hline Female & $15-19$ Years & Adult Child in Family & 5,565 \\
\hline Female & 40 - 44 Years & Parent in Couple Family & 5,139 \\
\hline Female & $20-24$ Years & Adult Child in Family & 4,719 \\
\hline Male & $60-64$ Years & Couple Only & 4,692 \\
\hline Female & $50-54$ Years & Couple Only & 4,560 \\
\hline Male & 15 - 19 Years & Adult Child in Family & 4,470 \\
\hline Female & $50-54$ Years & Couple Only & 4,047 \\
\hline Female & 35 - 39 Years & Parent in Couple Family & 4,038 \\
\hline
\end{tabular}

Source: Derived from the Census of Population and Dwellings, Statistics New Zealand.

Figure 22 shows the change in the percentage of men in each age group in part-time work in 1986 and again in 1996. Again it shows that the percentage working part time did increase across all age groups, but that part-time work was most common amongst men outside of the prime-aged group.

\section{Figure 22}

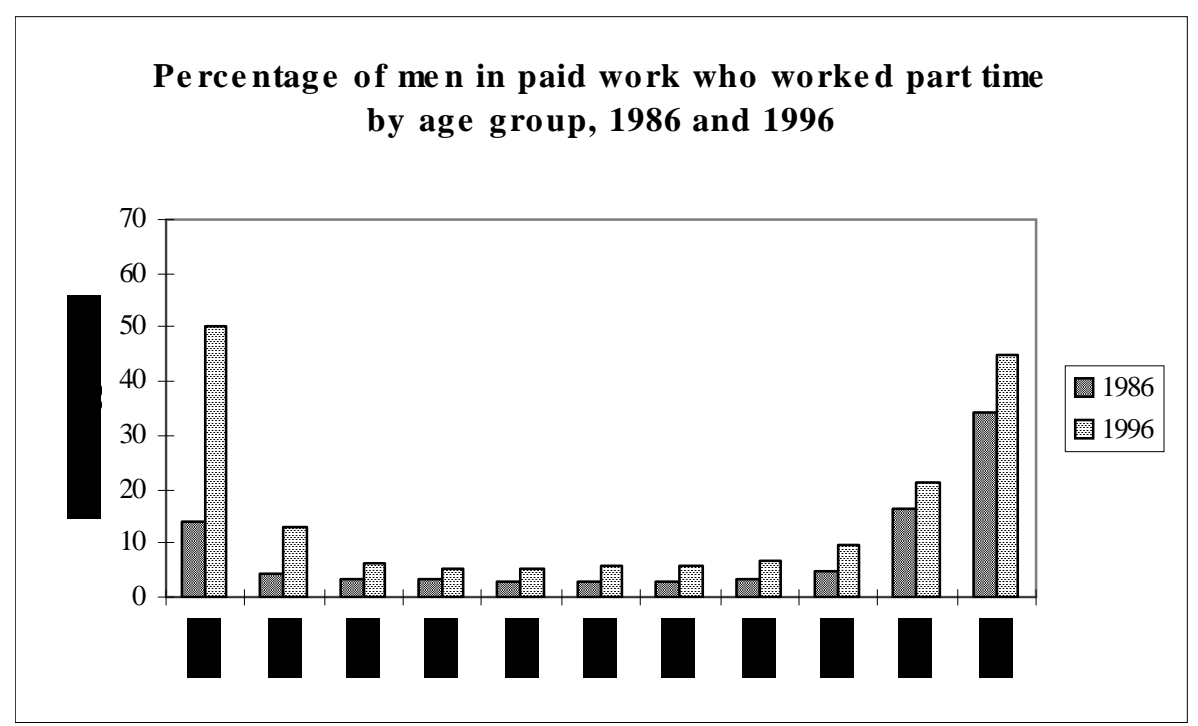

Source: Derived from the Census of Population and Dwellings, Statistics New Zealand.

Figure 23 is drawn on the same scale. For women at the start of the decade, part-time hours was the most common in the 60 or older age groups and those in the 30-39 age group. However, by the end of the decade part-time work had become very common amongst those 15-19 year olds who were in paid work. While there is much complexity when actual hours are considered, the data indicates that for men and women in the 15-19 
age groups there was particularly strong growth in the percentage of those working very short hours. For example, in 1986 seven percent of men aged 15-19 worked less than 10 hours per week, but by 1996 this had risen to 25 percent. Much of this represents students working part time while in tertiary education and many of these people are likely to move onto better-paid full-time jobs as they age.

Of those males working part time and aged 15-17, 82 percent were studying full time or part time in 1996. For men aged 18-19 the figure was 70 percent. For the women aged 1517 working part time 83 percent were studying. For women aged 18-19 this figure was also 70 percent.

However, a more negative view is that many entry-level jobs are increasingly insecure and most of these people will never make the transition into long-term full-time work. Adding further complexity, in some of the prime-aged groups a lower proportion of employed women worked part time at the end of the decade than at the start of it.

\section{Figure 23}

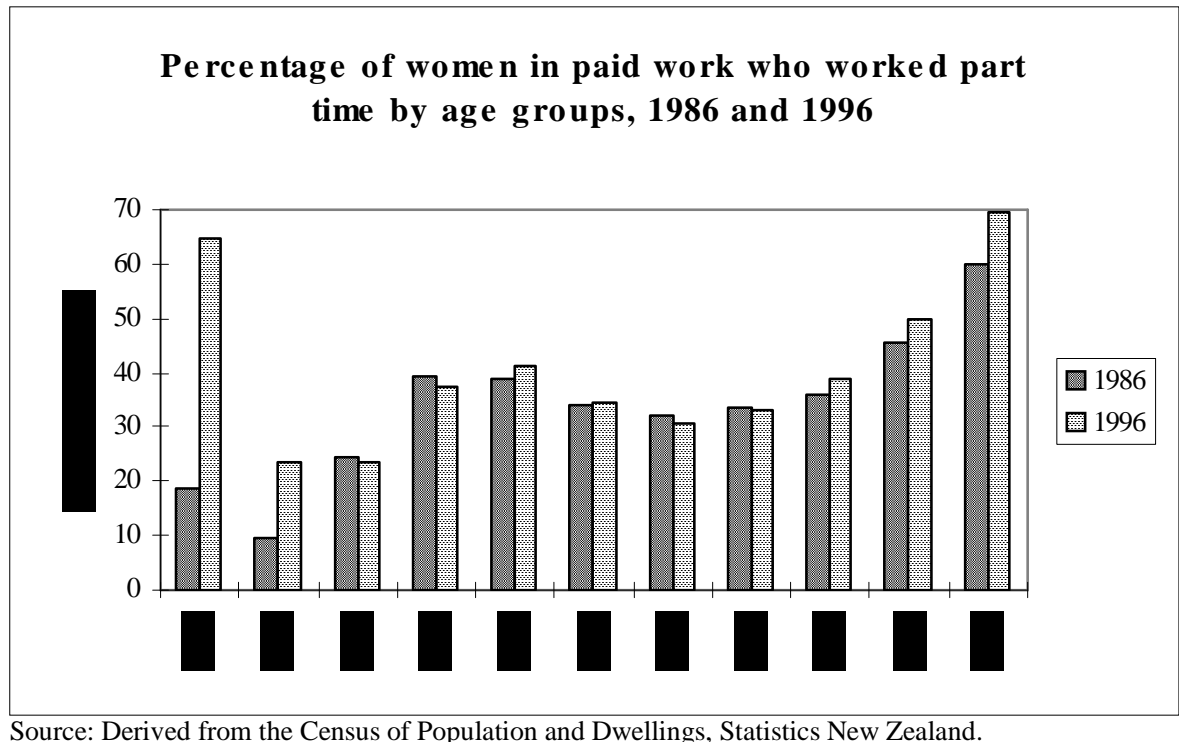

Some broad trends emerge from these data. These are that between 1986 and 1996 there was:

- a significant loss of full-time jobs held by men aged 20-59 
- a loss of jobs held by 15-19 year olds. In addition, at the same time in this age group there was a major switch from working full time to part time. This resulted in a significant rise in the number of young people working part time

- a small gain in part-time employment by men in all age groups over 20

- a gain in employment, both part time and full time, by women in their mid 40s to their early 60s

- a gain in full-time employment by women aged 25-34

As discussed in earlier chapters, I am not presenting time series using ethnicity. However, as an illustration, Figure 24 shows quite marked differences between ethnic groups in participation in full-time work by men in 1996. The lowest rates were amongst the sole Maori group and the Asian ethnic group. The Asian group includes the many new immigrants who arrived in the 1990s.

\section{Figure 24}

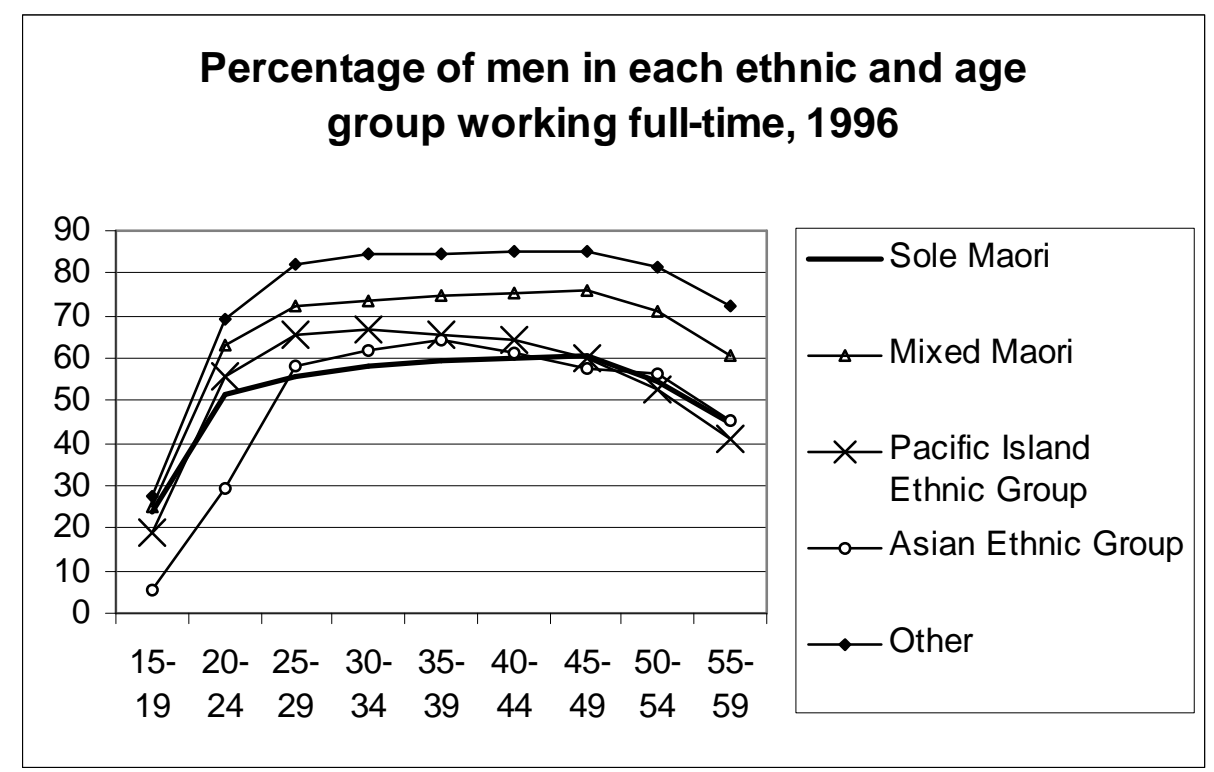

Source: Derived from the Census of Population and Dwellings, Statistics New Zealand.

Underlying this ethnic data are some educational differences. This is complicated because some Asian immigrants were well qualified but, for a variety of reasons, still found it difficult to participate in the labour market. 
These data do not directly answer the question as to whether it is low wage, part-time, work that is predominantly being created. The growth in part-time work amongst young people could be consistent with these ideas. So could the growth of full-time work by women in their forties alongside the loss of full-time work by men in their forties, if poor quality jobs obtained by women were generally replacing good quality jobs held by men.

\section{Prime-aged workers as a percentage of those in paid work}

In 1986, prime-aged men formed 43 percent of all people in paid work while prime-age women comprised 29 percent. By 1996, these percentages had declined marginally to 41 percent for men but rose strongly to 35 percent for women (Table 27).

Table 27 - Prime-aged workers as a percentage of those in paid work, 1986-1996

\begin{tabular}{lrrr}
\hline & 1986 & 1996 & Change \\
\hline Male 15-24 & 13.4 & 9.8 & -3.6 \\
Female 15-24 & 10.9 & 8.9 & -2.0 \\
& & & \\
Male 25-59 part time & 1.4 & 2.5 & 1.1 \\
Female 25-59 part time & 9.7 & 11.7 & 2.0 \\
Male 25-59 full time & 41.7 & 38.8 & -2.9 \\
Female 25-59 full time & 18.9 & 22.9 & 4.0 \\
& & & \\
Male 60+ & 2.9 & 3.5 & 0.6 \\
Female 60+ & 1.1 & 1.8 & 0.8 \\
& 100.0 & 100.0 & 100.0 \\
\hline Source: Derived from the Census of Population and Dwellings, Statistics New Zealand.
\end{tabular}

When ethnicity is considered, in 1996 prime-aged men of the European ethnic group represented only one third of those in paid work. Therefore, while prime-aged European men have often been seen as the normative group with which to make comparisons, they no longer dominate, at least numerically, the paid workforce.

\section{The changing demand for skills}

As discussed in previous chapters there are many studies both overseas and in New Zealand that show that people with little formal education have lower rates of participation in paid work. The following section focuses on employment rather than 
unemployment and the non-labour force. The first part looks at changes in employment by qualification. The second part analyses changes in occupation with the view that occupational change provides some clues about changing demand for skills.

Tables 28 and 29 show the percentage of men and women in each age and by highest qualification who were in paid work in 1986 and 1996. The first table shows those people aged 20-44, and the second 45-64.

Table 28 show some complexity in trends. Some of the most important ones are:

- for men in all the 20-44 age groups the greatest decline in employment was amongst those with no formal qualifications

- however, apart from university-qualified men in the 20-24 age group, there were also declines amongst men in all age groups and all qualifications.

- for women aged 20-44, there was growth in employment in most age groups and in most qualification categories.

- exceptions for women were those with "other tertiary" qualifications or lower in the 20-24 age group, women with no formal qualifications in all age groups, and women with "other tertiary" qualifications in the age groups 35-39 and 40-44.

- between 1986 and 1996, for both men and women aged 20-44, having no formal qualifications became a much stronger predictor of whether a person was in paid work. 
Table 28 - Percentage of men and women in each age (20-44) and qualification group in paid work, 1986 and 1996

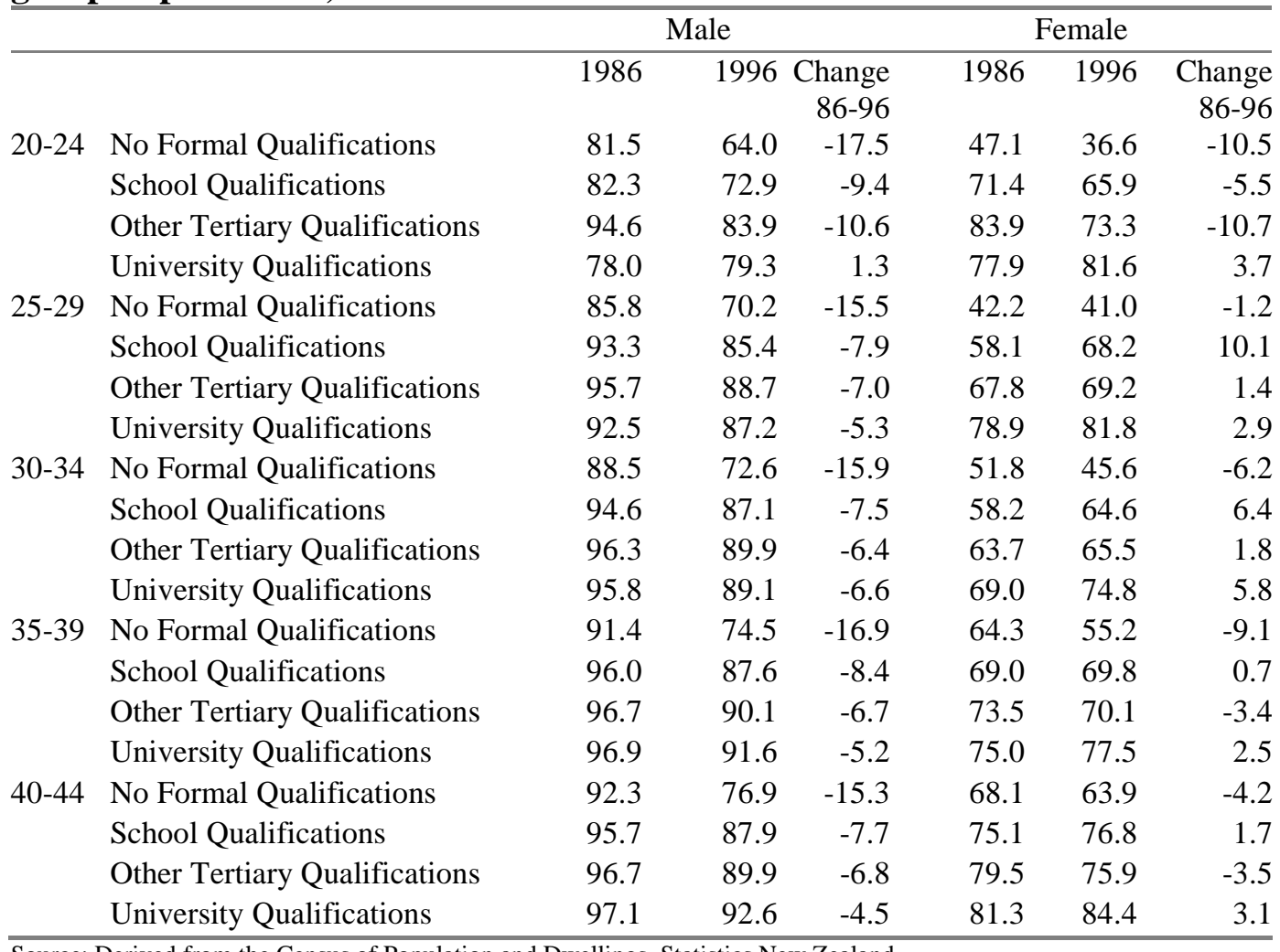

Source: Derived from the Census of Population and Dwellings, Statistics New Zealand.

The trends were slightly different for some people aged 45-64. Key trends that emerge from Table 29 are:

- for men aged 45-59 there were declines in employment in all qualification groups, but the decline was the strongest amongst men with no formal qualifications

- apart from a small decline amongst women with "other tertiary" qualifications in the 45-49 aged group, there were gains as employment in all age groups and qualification categories

- for men aged 60-64 there were gains in employment in all educational groups

- however, again in all the age groups shown, for both men and women, having no formal qualification appears to be a major barrier to participation in paid work 
Table 29 - Percentage of men and women in each age (45-59) and qualification group in paid work, 1986 and 1996

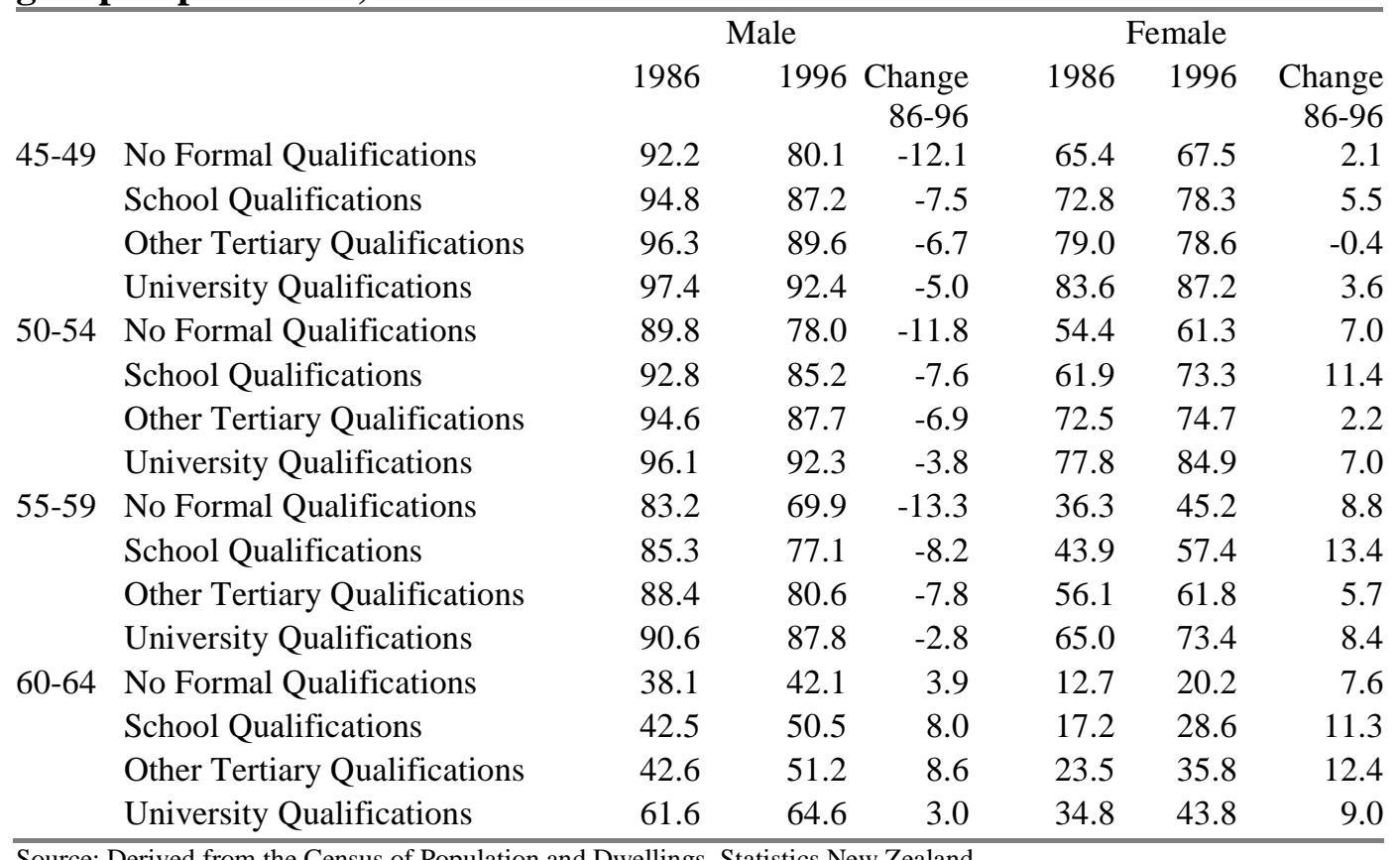

Source: Derived from the Census of Population and Dwellings, Statistics New Zealand.

Another way to examine changes in skill requirements is to look at changes in occupation (see Chapter two). Taking a longer-term historical perspective, Haines (1989) has shown a growth in managerial and professional jobs. Using census data she showed that between 1971 and 1986 the proportion of people employed in professional and technical work rose from 12.7 percent to 15.3 , while those employed in administrative and managerial jobs rose from 2.5 percent to 5.0 percent.

Jackson (1997) has updated this analysis, although using a slightly different occupational classification. Table 30 drawn from his research shows the very strong job loss for men over the 1986 to 1991 period. It also shows how a large proportion of this job loss was in production related occupations. This reflects the major job loss in manufacturing industries over this period. The reasons for this job loss are complex, but most of the key factors have already been outlined in previous chapters. Yet, over this period of job loss there were strong gains in professional and technical as well as managerial occupations. Women made particularly strong gains, in employment terms, in professional and technical occupations. 
Table 30 - Change in the number of people employed between 1986 and 1991, people aged 15 and over

\begin{tabular}{lrrr}
\hline$(000 \mathrm{~s})$ & Male & Female & Total \\
\hline Professional and technical & 7.6 & 19.6 & 27.2 \\
Administrative and managerial & 3.3 & 5.5 & 8.8 \\
Clerical & -11.4 & -7.1 & -18.4 \\
Sales & 5.2 & 3.2 & 8.4 \\
Service & 1.4 & -2.1 & -0.7 \\
Agriculture, forestry and fishery & -14.7 & -4.1 & -18.8 \\
Production and related & -87.3 & -23.5 & -110.8 \\
Total & -95.9 & -8.6 & -104.4 \\
\hline
\end{tabular}

Source: Jackson (1997)

Table 31 focuses on the employment growth period between 1991 and 1996. It also uses the 1995 occupational classification system (NZSCO95). It shows changes in the number of jobs in each occupation. However, access to unit record data has also allowed a calculation of total hours worked in each occupation.

Table 31 - Employment and hours worked by occupation, 1991 and 1996 - All people aged 15 and over

\begin{tabular}{|c|c|c|c|c|c|c|}
\hline & \multicolumn{2}{|c|}{ Employment (000s) } & \multicolumn{2}{|c|}{ Hours (millions) } & \multicolumn{2}{|c|}{$\begin{array}{l}\text { \% change 1991- } \\
1996\end{array}$} \\
\hline & 1991 & 1996 & 1991 & 1996 & Jobs & Hours \\
\hline Armed Forces & 7.7 & 5.6 & 0.4 & 0.3 & -27.0 & -28.3 \\
\hline $\begin{array}{l}\text { Legislators, } \\
\text { Administrators and } \\
\text { Managers }\end{array}$ & 162.3 & 188.9 & 7.7 & 9.2 & 16.4 & 18.5 \\
\hline Professionals & 167.6 & 191.2 & 6.7 & 8.0 & 14.1 & 19.5 \\
\hline $\begin{array}{l}\text { Technicians and } \\
\text { Associate Professionals }\end{array}$ & 150.7 & 172.4 & 6.1 & 7.0 & 14.4 & 16.0 \\
\hline Clerks & 200.8 & 221.8 & 6.9 & 7.7 & 10.5 & 11.4 \\
\hline Service and Sales & 170.7 & 220.4 & 5.7 & 7.3 & 29.1 & 28.7 \\
\hline Agriculture and Fishery & 137.4 & 153.8 & 6.5 & 7.3 & 11.9 & 12.6 \\
\hline Trades Workers & 149.4 & 149.0 & 6.4 & 6.8 & -0.3 & 4.8 \\
\hline $\begin{array}{l}\text { Plant and Machine } \\
\text { Operators and } \\
\text { Assemblers }\end{array}$ & 131.7 & 135.6 & 5.6 & 6.2 & 3.0 & 10.7 \\
\hline Elementary Occupations & 99.8 & 111.3 & 3.5 & 4.0 & 11.5 & 14.4 \\
\hline
\end{tabular}

The data in Table 31 shows the strongest growth, in percentage terms, was in service and sales occupations. However, the second fastest growing occupational group was in the managerial group. In addition, there was strong growth in the generally skilled area of professionals and technical occupations, as well as in agriculture and fishery jobs and 
elementary occupations. While the farming and fishing occupations will range from those requiring a high level of skill to a low level, the elementary jobs are generally at a low end of skill requirements. In some of these occupational groups this growth followed a major decline in employment in the previous five years.

The table also shows some differences between growth rates in the number of jobs and hours worked. A faster increase in hours than in jobs suggests that people are generally working longer hours, while a stronger increase in jobs than hours suggests a shortening of hours worked by individuals. In the former situation, a fragile economic upturn may mean that employers are offering overtime instead of employing new staff. Setting aside armed forces, in all other occupational groups except sales and services hours increased faster than jobs. In the trades worker category, total hours increased between 1991 and 1996 but the number of jobs actually declined.

Table 32 shows each occupational group as a percentage of total jobs and hours worked. It shows that there was a small increase in the relative share of the group of managerial, professional and technical occupations, with a faster increase in the proportion of hours worked in this group. Elementary jobs stayed stable as a proportion of employment, but the relative hours worked declined marginally. When clerical, sales and services jobs are combined they increased slightly as a proportion of total jobs and hours worked.

Overall, these occupational data for this short period of growth would not suggest either a widespread "deskilling" or "upskilling" of work. Instead they support the concept of a polarisation of skills, with a growth in the higher skill occupations (and in hours worked) but at the same time a continuing demand for a significant number of jobs that are not generally considered high skill. 
Table 32 - Employment and hours worked by occupation, 1991 and 1996 - All people aged 15 and over

$\%$ in each group

\begin{tabular}{lrrrr}
\hline & \multicolumn{3}{c}{ Employment } & \multicolumn{2}{c}{ Hours worked } \\
\hline & 1991 & 1996 & 1991 & 1996 \\
Armed Forces & 0.6 & 0.4 & 0.7 & 0.5 \\
Legislators, & 11.8 & 12.2 & 13.9 & 14.4 \\
Administrators and & & & & \\
Managers & 12.2 & 12.3 & 12.1 & 12.6 \\
Professionals & 10.9 & 11.1 & 10.9 & 11.0 \\
Technicians and & 14.6 & 14.3 & 12.4 & 12.0 \\
Associate Professionals & 12.4 & 14.2 & 10.2 & 11.5 \\
Clerks & 10.0 & 9.9 & 11.6 & 11.4 \\
Service and Sales & 10.8 & 9.6 & 11.6 & 10.6 \\
Agriculture and Fishery & 9.6 & 8.7 & 10.2 & 9.8 \\
Trades Workers & & & & \\
Plant and Machine & 7.2 & 7.2 & 6.3 & 6.2 \\
Operators and & 100.0 & 100.0 & 100.0 & 100.0 \\
Assemblers & & & & \\
Elementary Occupations & 34.9 & 35.6 & 36.9 & 38.0 \\
Total & & & & \\
& 27.0 & 28.5 & 22.6 & 23.5 \\
\hline Managerial, professional & & & \\
and technical & Clerks, service and sales & & &
\end{tabular}

As a further attempt to understand the changing skill mix of those employed, Table 33 shows a modified Reich (1993) reclassification (see Chapter two). For the symbolicanalytical category, managerial and professional occupations are grouped together, the inperson service group only covers sales and service workers, and the routine production group includes clerks, plant and machinery and elementary occupations. A new group is that of technical-analytical workers. This covers technicians and associate professionals as well as trades workers. Workers in agriculture and fisheries occupations are also a separate group. The one group left out of this classification are those people in the armed services. 
Table 33 - Changes in number of jobs and hours worked by occupational grouping for people aged 15 and over, 1991-1996

\begin{tabular}{lcrrr}
\hline & Jobs (\%) & \multicolumn{3}{c}{ Hours worked (\%) } \\
\hline & 1991 & 1996 & 1991 & 1996 \\
Symbolic-analytical & 24.1 & 24.9 & 26.3 & 27.5 \\
Technical-analytical & 21.9 & 20.8 & 22.7 & 21.7 \\
In-person service & 12.5 & 14.3 & 10.3 & 11.5 \\
Routine production & 31.4 & 30.4 & 28.9 & 28.2 \\
Agriculture and fisheries & 10.1 & 9.7 & 11.8 & 11.1 \\
& 100.0 & 100.0 & 100.0 & 100.0 \\
\hline Source: Derived from the Census of Population and Dwellings, Statistics New Zealand.
\end{tabular}

Table 33 shows that routine production occupations still formed the largest single group in both 1991 and 1996, although with a slight decline over the five-year period. These are the jobs primarily at risk from continuing mechanisation or transfer to low wage countries. The table also shows that when symbolic and technical analytical jobs are combined as a percentage of total jobs, they declined marginally between 1991 and 1996. In 1996 they represented 45 percent of all jobs and just under half of the hours worked.

Overall, across the whole workforce at a broad level of occupation the long-term data supports the idea that the number of jobs requiring a high level of symbolic analytical skills has increased. However, the demand for some particular technical skills has declined. In addition, in recent years there has also been growth in in-person service type jobs. Some of these are low skill occupations. The modified Reich classification therefore supports the concept that a polarisation of demand for skill is taking place. The impact of age and gender in this possible polarisation is discussed in more detail in the following chapter. However, the following case studies provide some insights into this issue.

\section{Case studies}

\section{McJobs?}

The "professionalisation" of unpaid work can create employment but much of this employment is low skilled, and often part-time, in-person services work. In the food industry, this type of employment is often characterised as "hamburger flipping". 
There are six key occupations in the production and service of meals and beverages and these are shown in Table 34. In 1991, there were a total of 39,027 jobs in this group, but by 1996 this had risen to 52,431, a 34 percent increase. The growth in these occupations represented 6 percent of total new jobs in this period. However, even by 1996 these occupations represented only 3.2 percent of total jobs. They are also jobs that tend to be held by young people. Table 34 shows that in the 10-year age span of the 15-24 age group there were almost as many people employed in these occupations as in the 35-year span of the 25-59 age group. In addition, young people dominate what would be seen as the low skill jobs, such as waiter, while prime-aged people form a higher proportion of generally more skilled cooks/chefs. Finally, it is an industry where women, and particularly young women, are over-represented. For many of the young people these will represent initial jobs, often while they study, and they will not be long-term employees.

Table 34 - Number and percentage of people employed in production and service of meals and beverages 1996

\begin{tabular}{|c|c|c|c|c|c|c|c|}
\hline & & Men & & & omen & & \\
\hline & $15-24$ & $25-59$ & $60+$ & $15-24$ & $25-59$ & $60+$ & Total \\
\hline Cook* & 1,695 & 2,988 & 39 & 1,041 & 1,347 & 21 & 7,131 \\
\hline Other Cook & 882 & 1,482 & 57 & 768 & 3,942 & 285 & 7,416 \\
\hline Bartender & 1,425 & 1,716 & 114 & 1,299 & 2,610 & 51 & 7,215 \\
\hline Waiter/Waitress & 1,212 & 432 & 6 & 5,730 & 2,826 & 24 & 10,230 \\
\hline $\begin{array}{l}\text { Catering Counter } \\
\text { Assistant }\end{array}$ & 1,866 & 729 & 48 & 4,329 & 4,158 & 252 & 11,382 \\
\hline Kitchen-hand & 2,112 & 648 & 42 & 2,841 & 3,291 & 123 & 9,057 \\
\hline Total & 9,192 & 7,995 & 306 & 16,008 & 18,174 & 756 & 52,431 \\
\hline $\begin{array}{l}\text { Total as a } \% \text { or all jobs } \\
\text { in each age group }\end{array}$ & 5.7 & 1.2 & 0.5 & 11.0 & 3.2 & 2.5 & 3.2 \\
\hline
\end{tabular}

Source: Derived from the Census of Population and Dwellings, Statistics New Zealand.

* Equivalent to chef in 1991

A further way of looking at potential "hamburger flippers" is by measuring direct employment in the industry group "restaurants, cafes, and other eating and drinking places" (Table 35). This group comprised 3.4 percent of total jobs in 1996. This compares with a 1991 figure of 4.9 percent for the U.S. Again, for prime-age people their involvement was lower. In addition, not all jobs in these areas are low skill or directly “in-person services”. However, many were part time. 
Table 35 - Number and percentage of people employed in the industry group "restaurants, cafes and other eating and drinking places", 1996

\begin{tabular}{|c|c|c|c|c|c|c|c|}
\hline & \multicolumn{3}{|c|}{ Male } & \multicolumn{2}{|c|}{ Female } & \multicolumn{2}{|c|}{ Total } \\
\hline & $15-24$ & $25-59$ & $60+$ & $15-24$ & $25-59$ & $60+$ & \\
\hline Number & 8,892 & 11,988 & 687 & 14,808 & 18,417 & 507 & 55,299 \\
\hline $\begin{array}{l}\% \text { of all jobs in } \\
\text { each age group }\end{array}$ & 5.6 & 1.8 & 1.2 & 10.2 & 3.3 & 1.7 & 3.4 \\
\hline
\end{tabular}

When the industry group of "food, beverages and tobacco products retailing" is also considered a similar pattern emerges. This is the industry containing the low skilled checkout counter operators and shelf stackers. When combined, this group and the eating industry provide a significant proportion of the employment of women aged 15-24. In 1996, one fifth of women in this age group were employed in these two broad industry groups. In comparison, these industries provided 6.2 percent of jobs prime-aged women, and a mere 3.3 percent of the jobs held by prime-aged men. These data do suggest that if these types of jobs keep expanding then they will provide mainly low skilled, and low paid, employment for young people.

\section{Teaching}

Teaching is generally seen as a skilled occupation, although the qualifications required for some types of early childhood teaching are still minimal. It is also assumed that a higher level of skill, through holding higher qualifications, is required for tertiary teaching. Reflecting a wide range of factors, including changing demographics over the period 1991 to 1996 , the number of tertiary teachers grew by 1,500 , there was a loss of just over 500 secondary school jobs, while the number of primary school teachers grew by nearly 400. In contrast, between 1991 and 1996, the total number of people employed in the early childhood sector doubled from just over 9,000 to well over 18,000. Many of the reasons for this growth are outlined in Chapter fifteen. The total rise in pre-school workers represented just over 4 percent of total jobs created in the economy in this period and, in absolute terms, was far higher than the growth in manufacturing employment. Almost all childcare jobs were filled by women and, unlike other forms of teaching, a significant number of jobs are held by young women. As already discussed, the increase in availability of childcare also assists parents, and again mainly women, move into paid work. 
The data also show a loss of jobs by men in primary teaching but a gain by women, and increasing proportion of women in tertiary teaching. Table 36 shows the various types of teaching as a percentage of jobs in each age group and indicates that for prime-aged women teaching represents an important area of employment.

Table 36- Teaching occupations as a percentage of total employment, 1996

\begin{tabular}{|c|c|c|c|c|c|c|c|}
\hline & \multicolumn{2}{|r|}{ Men } & \multicolumn{4}{|c|}{ Women } & \\
\hline & $15-24$ & $25-59$ & $60+$ & $15-24$ & $25-59$ & $60+$ & Total \\
\hline $\begin{array}{l}\text { Tertiary Lecturer } \\
\text { and/or Tutor }\end{array}$ & 0.2 & 0.9 & 0.9 & 0.2 & 1.0 & 0.7 & 0.8 \\
\hline $\begin{array}{l}\text { Secondary School } \\
\text { Teacher }\end{array}$ & 0.1 & 1.0 & 0.5 & 0.3 & 1.5 & 1.1 & 1.0 \\
\hline $\begin{array}{l}\text { Primary School } \\
\text { Teacher }\end{array}$ & 0.2 & 0.5 & 0.3 & 1.3 & 3.1 & 2.2 & 1.5 \\
\hline Pre-school teacher & 0.2 & 0.1 & 0.1 & 3.9 & 2.1 & 1.3 & 1.1 \\
\hline Total teachers & 0.8 & 2.5 & 1.8 & 5.7 & 7.7 & 5.4 & 4.5 \\
\hline
\end{tabular}

\section{Manufacturing}

As already indicated, there was a major loss of jobs in manufacturing between 1986 and 1991. However, also of interest are shifts in occupation within the industry group. Between 1991 and 1996 the manufacturing workforce increased marginally (Figure 25). However, at the same time there was also a shift from "factory floor" type jobs to service and sales, clerical, professional and managerial occupations. The reasons for this type of change have been outlined in Chapter seven. While generally this shift would have been toward higher skilled non-manual occupations, the loss of trade jobs represents a loss of an often highly skilled area of work (technical-analytical jobs). 
Figure 25

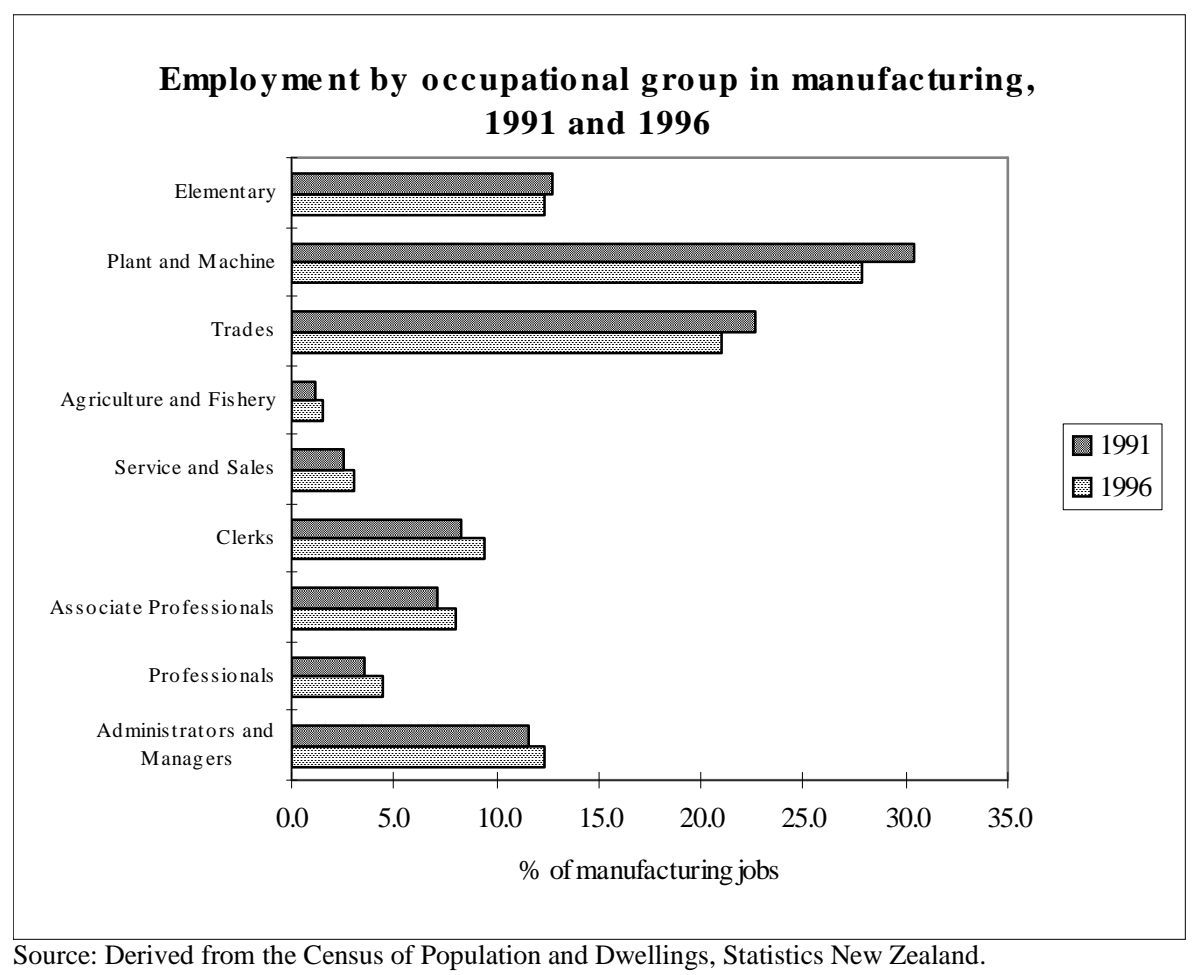

\section{Conclusion}

Employment rates for men aged 15-64 fell through the 1950s, 1960s and 1970s whilst those for females rose. Employment trends were particularly volatile between the mid 1980s and the mid 1990s. However, overall, total employment rates for those aged 15-64 did not change substantially in the 42 years from 1956 to 1998.

There was, however, a decline of full-time work per head of population from the 1970s to early 1990s but this reversed in the 1990s. The data do not support the idea that, overall, paid work has been rapidly "disappearing" from the economy. However, over this long time period there has been a dramatic change in the distribution of paid work. While in the 1950s, gender was the critical predictor of whether someone would be in paid work, the differences between men and women had reduced substantially by the late 1990s. However, even by the end of the 1990s gender still remained an important factor in employment and particularly full-time employment. 
The period 1986 to 1996 was a time of major change in the labour market. In particular, in the early part there was a major loss of jobs followed by a period of strong job growth. The data supports the idea that changes in demand patterns by employers (or lack of demand) were the key driving force in determining altering patterns of paid work. In the early years, employers were reacting to a wide range of pressures from the reductions and removal of tariffs to changes in consumer preferences. While there was some growth in the total number of jobs available in the early to mid 1990s, it was part-time work that dominated this growth. Overall, the data do not show a significant change total employment rates but significant changes in the types of jobs available and who held them.

Reflecting some of these shifts, a key finding of this chapter is that there was a significant loss of full-time jobs held by men aged 20-59 in the decade between 1986 and 1996 . Overall, employment rates of this group declined substantially between 1986 and 1991 . Despite the subsequent growth in total employment between 1991 and 1996 these lower employment rates changed little. The loss of employment in manufacturing industries, and to a lesser degree job loss for men in industries such as farming, appears to be a major factor behind this trend. While a high proportion of these jobs were low skill in terms of formal credentials required to work in them, some had high levels of industrybased skill. In addition, not all were low paid. Examples include work in freezing works and jobs on the waterfront. In the area of manufacturing, an analysis of occupations between 1991 and 1996 show a shift towards non-manual occupations. These changes support the idea that shifts in labour demand were a critical factor behind changes in the employment of prime-age men. But in some industries and occupations, for example primary teaching, there was a decline in the number of men employed but an increase in the number of women. In some situations like this, labour supply side issues appear to be of some importance.

Overall, between 1986 and 1996 prime-aged men as a group declined as a proportion of those in paid work from just over 43 percent to just over 41 percent. This decline would have been larger had it not been for an aging workforce and the reduction in the number 
of people aged 15-19. These issues, and others connected with the dramatic changes in employment patterns for prime-aged men are explored in more detail in the following chapter.

Over the period of analysis, there was also a decline in the employment rates of both men and women in the 15-19 year age group. At the same time, in this age group there was a major switch from working full time to part time. This resulted in a significant rise in the number of young people working part time. There are a number of possible reasons for this trend. One is that entry-level jobs are increasingly of a part time nature. Reinforcing this is the growth of service sector jobs and, in particular, the growth of a "cafe" society. Young people are particularly likely to be employed in low paid, and often relatively low skill jobs, such as table waiting staff. Overall, the data presented in this chapter would lend some support to this view. A second reason is that with an increase in participation in tertiary education, along with a rise in fees, more young people are combining parttime work with study. Data presented in this and previous chapters would also indicate that this was occurring. However, it is highly likely that for many young people these are temporary jobs and they will move into other occupations and industries as they reach their prime-working ages.

While there was a major loss of full-time jobs for men aged 20-59, there was a small increase in part-time employment by men in all age groups over 20. Again, this is explored in more detail in the following chapter.

In contrast to the trends for men, there was a gain in employment, both in part time and full time, by women in their mid 40s to the early 60s in the period 1986 to 1996 . In addition, there was an increase in the proportion of women aged 25-34 in full-time work.

The changes in men's and women's employment rates meant that, on the basis of this crude measure, there was a decline in the employment gap between men and women between 1986 and 1996. There was also an increased diversity of labour market outcomes 
within men as a group and women as a group. This is also further explored in the next chapter.

Although holding a formal tertiary qualification has become a more powerful predictor of participation in paid work for individuals, actual trends in skill use and demand are more difficult to determine. In part, this is due to changes in occupational classifications over the period. While certainly there were many part time, and probably temporary, "McJobs" created in this period, the proportion of people employed in symbolic-analytical occupations also increased between 1991 and 1996. Longer-term data also show a continuing growth of managerial and professional occupations. There has also been growth in sales and service type jobs. Overall, these occupational data for the short period of growth between 1991 and 1996 would not suggest either a widespread "deskilling" or "upskilling" of work amongst the population aged 15 or older. Instead, they support the concept of a polarisation of skills, with a growth in the higher skill occupations but at the same time a continuing demand for a significant number of jobs that are considered low skill. The issue of "deskilling" versus "upskilling", in relation to prime-aged people, is discussed in more depth in the next chapter. 


\section{Chapter 17}

\section{The changing distribution of paid work for prime-aged people}

\section{Introduction}

This chapter focuses on changes in employment for prime-aged people (25-59) between 1986 and 1996. The first section revisits changes in employment rates touched on in the previous chapter. In the second section, changes in hours worked are examined. In this, particular attention is given to changes in labour market outcomes for men. The final section uses New Zealand data to explore possible reasons for the growth in the proportion of prime-aged men not in the labour force.

A main aim of this chapter is to determine whether there was a trend towards a polarisation of work amongst prime-aged people, particularly men, so that some became work-rich and another group work-poor over the period 1986 to 1996. 


\section{Broad changes in employment}

Table 37 shows broad changes in population, number of jobs, and total hours of paid work for prime-aged New Zealand women and men between 1986 and 1996.

Table 37 - Actual and percentage change in population, employment and hours of paid work for men and women aged 25-59, 1986-1996

\begin{tabular}{lrrrrr}
\hline & \multicolumn{3}{c}{ Actual (000s) } & \multicolumn{2}{c}{ \% change } \\
\hline & 1986 & 1991 & 1996 & $86-91$ & $91-96$ \\
Male population & 703.4 & 750.1 & 832.0 & 6.6 & 10.9 \\
Female population & 701.0 & 763.5 & 861.5 & 8.9 & 12.8 \\
& & & & & \\
Male employment & 646.5 & 611.5 & 673.4 & -5.4 & 10.1 \\
Female employment & 429.2 & 463.7 & 564.8 & 8.0 & 21.8 \\
& & (Million) & & & \\
Male hours of paid work & 30.8 & 28.5 & 33.2 & -7.5 & 16.5 \\
Female hours of paid work & 15.1 & 15.9 & 21.1 & 5.3 & 32.7 \\
\hline \multicolumn{2}{l}{ Source: Derived from the Census of Population and Dwellings, Statistics New Zealand. }
\end{tabular}

The data show that between 1986 and 1991 employment growth for prime-aged women almost paralleled population growth, although total hours in paid work increased at a slower rate. In the next five years, employment growth and the increase in total hours worked kept well ahead of population growth. The story is very different for prime-aged men. There were very strong declines in employment between 1986 and 1991, with employment still not rising faster than population growth in the next five years.

\section{Gender, ethnicity, education and employment}

Overall, employment rates for prime-aged men and women were discussed in the previous chapter. However, these rates can then be further broadly analysed by ethnicity and education (Table 38). The international research literature already reviewed suggests that education, ethnicity and gender are all of importance in employment rates. Due to the problems in developing accurate ethnic time series set out in Chapter four, the following table only shows data from the 1996 census. 


\begin{tabular}{|c|c|c|c|c|}
\hline & Degree or higher & Other tertiary & School & $\begin{array}{l}\text { No formal } \\
\text { Qualification }\end{array}$ \\
\hline \multicolumn{5}{|l|}{ Male } \\
\hline European only & 94 & 91 & 89 & 80 \\
\hline NZ Maori & 91 & 80 & 78 & 61 \\
\hline Pacific Island group & 81 & 77 & 76 & 63 \\
\hline Asian group & 67 & 72 & 68 & 64 \\
\hline \multicolumn{5}{|l|}{ Female } \\
\hline European only & 84 & 78 & 73 & 60 \\
\hline NZ Maori & 82 & 65 & 61 & 42 \\
\hline Pacific Island group & 78 & 64 & 59 & 43 \\
\hline Asian group & 56 & 54 & 47 & 43 \\
\hline
\end{tabular}

Table 38 illustrates the complex interaction of the three variables. It shows that in 1996 well-educated European men had the highest overall rate of employment. The next highest rate of employment was among Maori men who held degrees. However, the employment rates of Asian men (and women) who held degrees were very low. This reflects the unusual nature of some of this group. An above average proportion of these people were not unemployed but undertaking further education. ${ }^{89}$ However, another group were new immigrants who, through a variety of reasons including their qualifications not being recognised in New Zealand, were not in work.

In addition, despite the decline in overall participation rates for men, European men with only school qualifications still had a relatively high level of employment in 1996. But European women with degrees also had a relatively high employment rate. Also of interest, in all the ethnic groups, except Asians, women with degrees had higher employment rates than men with no formal qualifications.

\footnotetext{
${ }^{89}$ In restricting my analysis to New Zealand residents I have excluded overseas students who were in New Zealand simply to study.
} 
Table 38 emphasises that while that formal education is a critical factor in the labour market in New Zealand, in the mid 1990s gender and ethnicity also remained very important variables amongst prime-aged people. In these data age would have had some impact on participation in paid work with Maori and Pacific Islands groups overall younger than Europeans.

Table 39 provides a further idea of how gender, ethnicity and education affected participation in paid work for the European and Maori groups. While it shows that either being female or Maori, but especially both, lowered the participation in paid work, the effects were much stronger in the group that has no formal qualifications. There could be a number of reasons for this, including the possibility that discrimination, on the basis of either ethnicity or gender (or both) occurs more frequently amongst those with few qualifications. However, there are likely to be supply factors as well, such as sole motherhood being more common amongst the low skilled Maori group.

Table 39 -“Gap” in percentage points between paid work participation rates of various selected groups, 1996

\begin{tabular}{|c|c|c|c|c|}
\hline & Degree or higher & Other tertiary & School & $\begin{array}{r}\text { No formal } \\
\text { qualification }\end{array}$ \\
\hline European male and Maori Male & 3.2 & 11.4 & 11.5 & 18.5 \\
\hline European male and European female & 10.3 & 13.1 & 16.2 & 19.7 \\
\hline European female and Maori female & 1.1 & 12.8 & 11.6 & 18.1 \\
\hline European male and Maori female & 11.3 & 26.0 & 27.8 & 37.7 \\
\hline
\end{tabular}

Table 40 just shows prime-aged men, but by five year age cohorts. A number of patterns emerge from these 1996 data. These include: 
- The proportion of men recorded as not in the labour force was higher than those unemployed and seeking work in all age groups and all educational groups. While research discussed in previous chapters suggests that these may not be totally distinct groups, nevertheless these data do indicate that a significant proportion of prime-age men were not seeking work. When 1986 data is considered there was an increase in both unemployment and the non-labour force between 1986 and 1996, but the non-labour force grew faster in most age and educational groups.

- In all age groups this imbalance between men not in the labour force and those unemployed was the highest amongst men with no formal qualifications.

- There was a slight tendency for those with lower levels of qualifications or no formal qualifications to work part time in the 25-54 age groups but this reversed in the 55-59 group. Some of these men aged 55-59 will have been working part time as a positive transition into retirement. However, for others this would have been the only work available. 
Table 40 - Percentage of men in each labour force status within each educational group, 1996

\begin{tabular}{lrrrrr}
\hline $\begin{array}{l}\text { Highest Qualifications } \\
\text { 25-29 }\end{array}$ & Full time & Part time & Unemployed & Non labour & Total \\
\hline No Formal Qualifications & 64.5 & 5.7 & 12.1 & 17.7 & 100.0 \\
School Qualifications & 79.5 & 5.9 & 5.8 & 8.9 & 100.0 \\
Other Tertiary Qualifications & 84.0 & 4.7 & 4.4 & 6.9 & 100.0 \\
University Qualifications & 81.0 & 6.2 & 5.0 & 7.8 & 100.0 \\
\hline
\end{tabular}

\begin{tabular}{lrrrrr}
\hline $30-34$ & Full time & Part time & Unemployed & Non labour & Total \\
\hline No Formal Qualifications & 66.8 & 5.8 & 10.0 & 17.5 & 100.0 \\
School Qualifications & 82.1 & 5.1 & 4.8 & 8.1 & 100.0 \\
Other Tertiary Qualifications & 85.5 & 4.4 & 3.8 & 6.2 & 100.0 \\
University Qualifications & 84.5 & 4.7 & 4.7 & 6.2 & 100.0 \\
\hline
\end{tabular}

\begin{tabular}{lrrrrr}
\hline 35-39 & Full time & \multicolumn{1}{c}{ Part time } & Unemployed & Non labour & Total \\
\hline No Formal Qualifications & 68.5 & 6.0 & 8.5 & 17.0 & 100.0 \\
School Qualifications & 82.4 & 5.2 & 4.4 & 7.9 & 100.0 \\
Other Tertiary Qualifications & 85.1 & 4.9 & 3.5 & 6.4 & 100.0 \\
University Qualifications & 87.5 & 4.2 & 3.5 & 4.8 & 100.0 \\
\hline
\end{tabular}

\begin{tabular}{lrrrrr}
\hline $40-44$ & Full time & Part time & Unemployed & Non labour & Total \\
\hline No Formal Qualifications & 71.1 & 5.8 & 7.1 & 15.9 & 100.0 \\
School Qualifications & 82.5 & 5.5 & 4.1 & 8.0 & 100.0 \\
Other Tertiary Qualifications & 84.6 & 5.4 & 3.4 & 6.6 & 100.0 \\
University Qualifications & 88.2 & 4.4 & 3.2 & 4.2 & 100.0 \\
\hline
\end{tabular}

\begin{tabular}{lrrrrr}
\hline $45-49$ & Full time & Part time & Unemployed & Non labour & Total \\
\hline No Formal Qualifications & 74.1 & 6.0 & 5.5 & 14.4 & 100.0 \\
School Qualifications & 81.8 & 5.4 & 4.1 & 8.7 & 100.0 \\
Other Tertiary Qualifications & 84.3 & 5.3 & 3.2 & 7.1 & 100.0 \\
University Qualifications & 87.9 & 4.5 & 3.0 & 4.5 & 100.0 \\
\hline
\end{tabular}

\begin{tabular}{lrrrrr}
\hline $50-54$ & Full time & Part time & Unemployed & Non labour & Total \\
\hline No Formal Qualifications & 71.5 & 6.5 & 4.8 & 17.2 & 100.0 \\
School Qualifications & 78.6 & 6.6 & 4.0 & 10.7 & 100.0 \\
Other Tertiary Qualifications & 81.6 & 6.1 & 3.2 & 9.1 & 100.0 \\
University Qualifications & 87.0 & 5.3 & 2.5 & 5.2 & 100.0 \\
\hline
\end{tabular}

\begin{tabular}{lrrrrr}
\hline 55-59 & Full time & Part time & Unemployed & Non labour & Total \\
\hline No Formal Qualifications & 62.5 & 7.3 & 4.5 & 25.6 & 100.0 \\
School Qualifications & 68.4 & 8.7 & 4.4 & 18.5 & 100.0 \\
Other Tertiary Qualifications & 72.4 & 8.1 & 3.8 & 15.6 & 100.0 \\
University Qualifications & 79.1 & 8.7 & 2.6 & 9.5 & 100.0 \\
\hline Source: Derived from the Census of Population and Dwellings, Statistics New Zealand.
\end{tabular}

Source: Derived from the Census of Population and Dwellings, Statistics New Zealand. 


\section{Hours of paid work for prime-aged people}

While there is no analysis in this section of the relationship between hours worked and income, Dixon (1998), using Household Economic Survey data, shows that this relationship for men strengthened between 1984 and 1987, with those men in the higher deciles of weekly earnings on average working the longest hours per week. Also of relevance is the finding by Statistics New Zealand that in 1996 the income gap between men and women was the greatest in the area of full-time work which may, in part, reflect hours worked. While there was very little difference in median income between men and women when they worked part time (or were unemployed or not in the labour force) women only earned 80 percent of the income men earned when in full-time paid work (Statistics New Zealand 1998).

Figure 26 shows the pattern of hours for prime-aged men who were in paid work in 1986 and 1996. Two significant patterns emerge. First, in both 1986 and 1996 there were the peaks around the five and ten hourly categories discussed in Chapter one. For example, many men stated that they worked 40 hours per week, but hardly any recorded 41 or 39 hours. It is not clear whether people generally work in five hourly blocks or whether people simply report work hours using five or ten hourly blocks. The small peak around 30 hours is particularly problematic as this is the cut-off point in determining whether someone works part time. It is not surprising that many people work 30 hours as, based on a standard five day week, this would be 6 hours a day. This is also the standard school day. As an indication of the difference it makes when part-time work is alternatively defined as 30 or less hours per week instead of less than 30 hours, the proportion of prime-aged men working part time in 1996 in the former definition was 8 percent versus 6 percent using the latter definition. For women the two figures were 32 percent versus 28 percent. These are small but significant differences.

Second, the peak around 40 hours for prime-aged men declined in the period studied with some men working longer hours but some shorter hours. However, even in 1986 a significant group of prime-aged men worked "non-standard" hours (outside the range of 30-49 hours). 
Figure 26

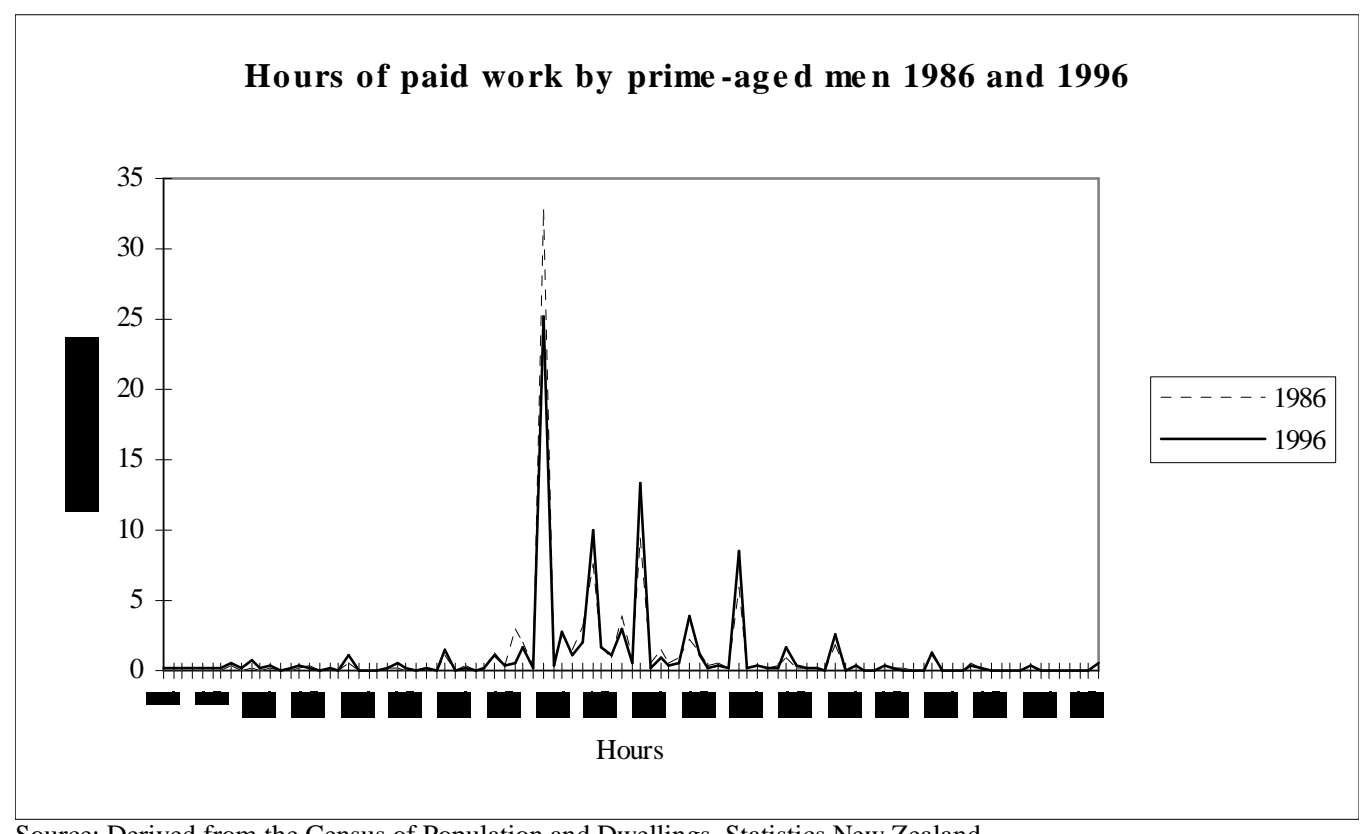

Source: Derived from the Census of Population and Dwellings, Statistics New Zealand.

Given that it is difficult to see much of the 1986 data in Figure 26, Figure 27 shows the difference between the percentages in 1996 and 1986. The large positive shifts (1 percent or over) were that the proportion working 45 hours per week lifted by 2.7 percentage points, 50 hours 3.8 points, 55 hours 1.7 points and 60 hours 2.6 points. The large negative shifts $(-1 \%$ or more) were 37 hours -2.4 points, 40 hours -7.5 points and 44 hours -1.2 points. While at the end of the period studied for a significant group of men the "40 hour" week remained the norm, there was an increase in the proportion working "non-standard" hours. 
Figure 27

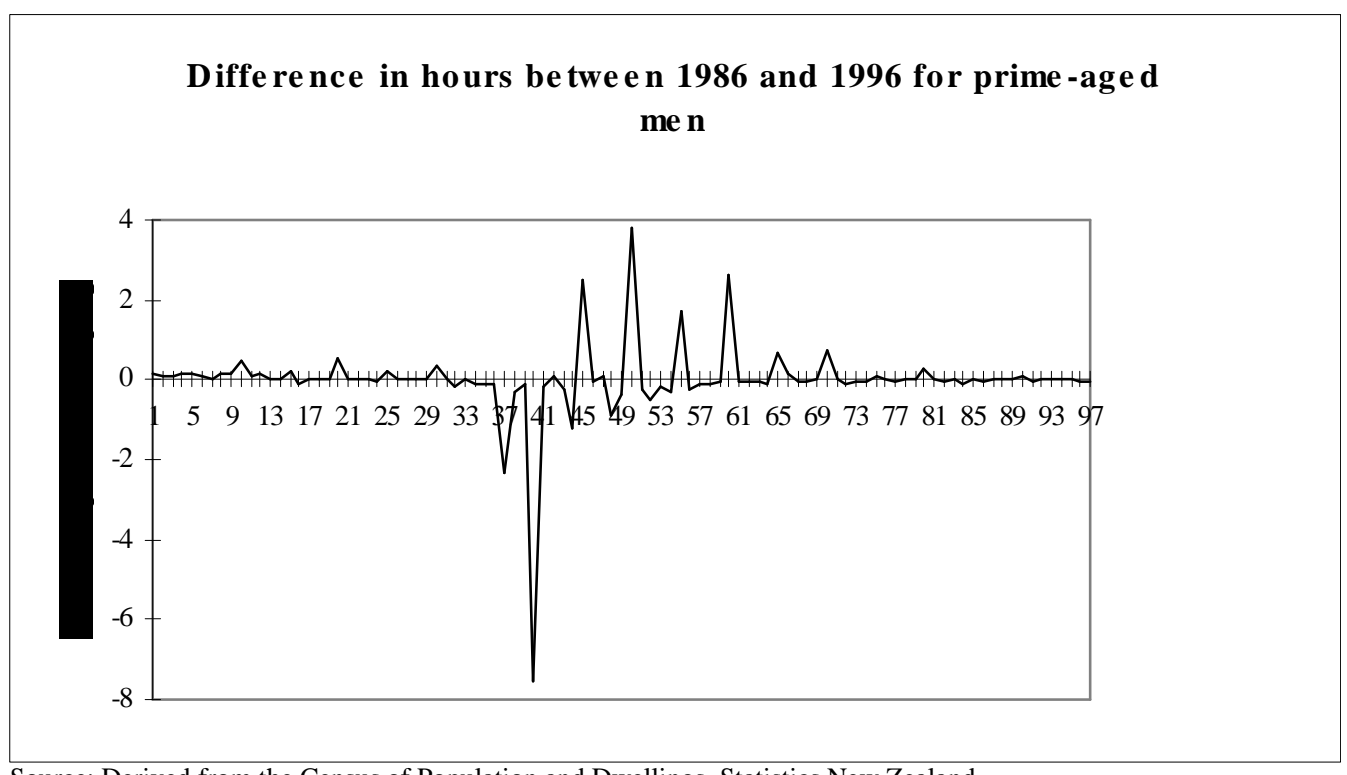

Source: Derived from the Census of Population and Dwellings, Statistics New Zealand.

Figure 28 shows the distribution of hours worked by prime-aged women in 1986 and 1996. There was the same peak around the 40-hour week, as well as the same move away from this norm as for men. However, in contrast to the prime-aged men, far more women were already working under this standard.

\section{Figure 28}

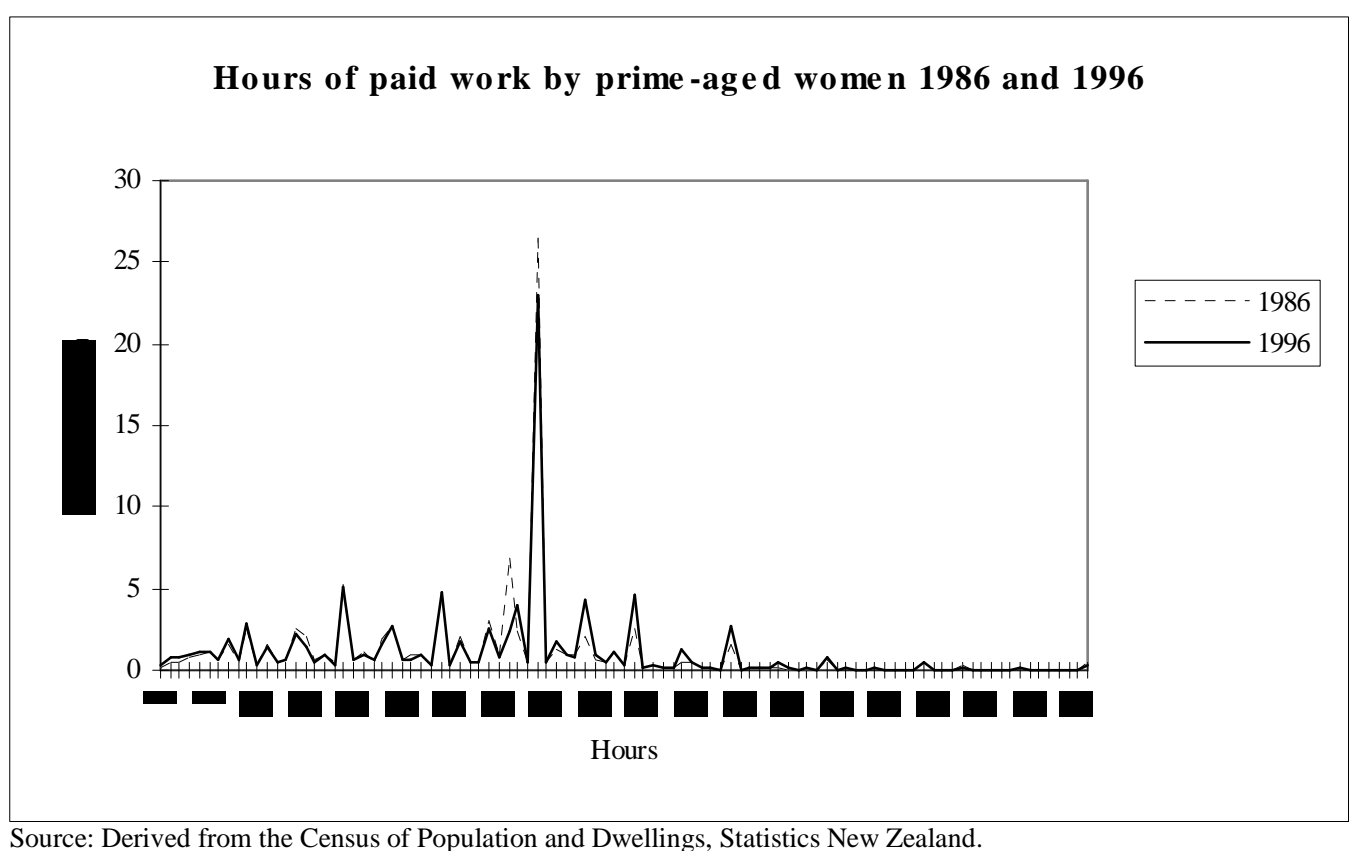

Source: Derived from the Census of Population and Dwellings, Statistics New Zealand. 
Figure 29 shows the change in hours worked between 1986 and 1996 for prime-aged women. For women large positive shifts were around 38 hours (1.7 points), 45 hours (2.2 points), 50 hours (2.2 points and 60 hours ( 1 point). While a very small rise, and from a small base, the proportion of women working only a couple of hours per week increased. Although the reason for this is not clear from the data, it may partly represent a rise in casual work. In contrast, the proportion of women working 37 hours per week declined by 4.4 percentage points and 40 hours by 3.5 points. The pattern of growth in women working longer hours is similar to that of men and is a further indication of convergence of male and female patterns of work.

Figure 29

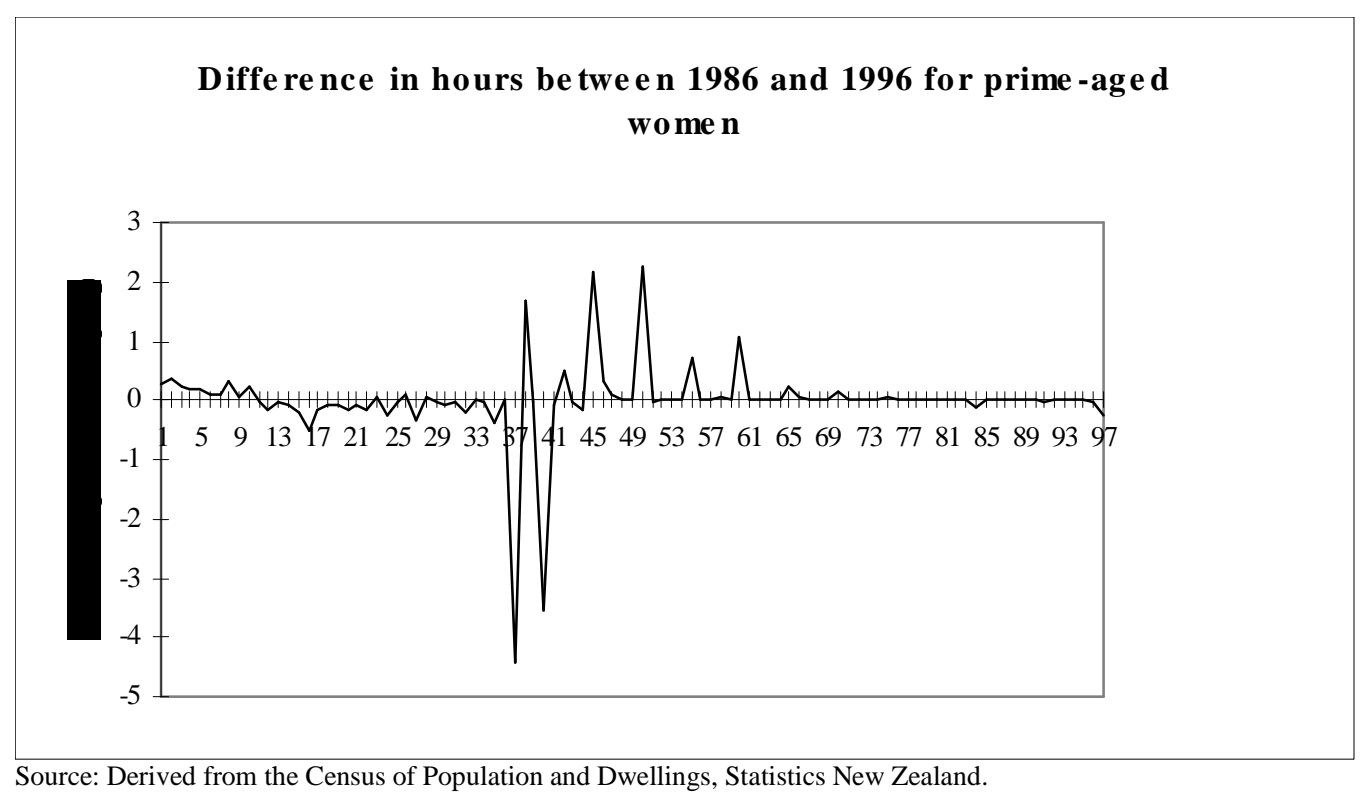

Table 41 simplifies these graphs and shows the proportion of prime-aged women and men working in various hourly categories. 
Table 41 - Distribution of hours of paid work for women and men aged 25-59 $\%$ in each group

\begin{tabular}{rccccccc}
\hline Women & $\begin{array}{c}\text { \% working } \\
\text { under 10 } \\
\text { hours* }\end{array}$ & $\begin{array}{c}\text { \% working } \\
\text { under 30 } \\
\text { hours* }\end{array}$ & $\begin{array}{c}\text { \% working } \\
\text { 40 or more } \\
\text { hours* }\end{array}$ & $\begin{array}{c}\text { \% working } \\
50 \text { or more } \\
\text { hours* }\end{array}$ & $\begin{array}{c}\text { \% working } \\
60 \text { or more } \\
\text { hours* }\end{array}$ & $\begin{array}{c}\% \text { working } \\
70 \text { or more } \\
\text { hours* }\end{array}$ & $\begin{array}{c}\% \text { working } \\
80 \text { or more } \\
\text { hours* }\end{array}$ \\
\hline 1986 & 6.6 & 34.0 & 44.4 & 9.8 & 5.2 & 2.9 & 1.8 \\
1991 & 6.7 & 32.5 & 46.9 & 11.8 & 5.9 & 3.0 & 1.8 \\
1996 & 8.4 & 33.8 & 48.0 & 14.1 & 6.4 & 2.7 & 1.4 \\
Men & & & & & & & \\
1986 & 0.8 & 3.3 & 87.9 & 32.4 & 15.0 & 6.3 & 3.1 \\
1991 & 0.9 & 4.6 & 87.3 & 35.3 & 16.8 & 6.9 & 3.2 \\
1996 & 1.9 & 6.1 & 88.0 & 40.2 & 19.0 & 7.1 & 3.3 \\
\hline
\end{tabular}

Source: Derived from the Census of Population and Dwellings, Statistics New Zealand.

* This is a percentage of those gainfully employed and who specified their hours of work

Despite the very strong growth in part-time employment across the whole economy from 1986 to 1996, the proportion of prime-aged women working part time stayed relatively stable. However, Table 41 reinforces the patterns shown in Figure 29 with a small increase in the proportion of women in the target age group working very short hours, as well as a strong increase in those working 50 or more hours per week and a smaller increase in those working 60 or more hours per week. ${ }^{90}$ At the more extreme end of the weekly hours there was a small decline in the proportion working 70 and 80 or more hours. Yet, due to an increase in participation rates and the population increase, a greater number of women were to be found in 1996 working these very long hours than in 1986.

For prime-age men in paid work, there had also been a small growth in the proportion working very short hours. For prime-aged men there was also a increase in the proportion working 50 hours or more per week, a smaller increase in the proportion working 60 or more hour weeks, and marginal increases in the proportion working very long hours. There was a move away from a standard working week in both directions, to working shorter and longer hours. It is noteworthy that this movement occurred both before and after the introduction of the 1991 Employment Contracts Act. This supports the view discussed in other chapters that in the period studied there were many forces other than employment law influencing patterns of paid work.

\footnotetext{
${ }^{90}$ While labour market commentators sometimes state that employment can mean just one hour per week, in fact very few men or women do work just one hour a week. The data show that 417 prime-aged women stated they worked one hour per week in 1986 and this had risen to 1,992 in 1996. In 1996, this represented just 0.4 percent of those who stated their hours of paid work. For prime-aged men just 66 stated they worked one hour per week in 1986 and this had risen to 957 in 1996, or 0.1 percent of those stating their hours.
} 
Table 42 further simplifies these changes. It shows the proportion of total prime-aged men and women not in paid work and the percentage employed who worked various hours. The table shows that while the overall patterns did not alter dramatically, there was still some significant change in the size of various groups.

Table 42 - Distribution (\%) of prime-aged people by workstatus, 1986 and 1996

\begin{tabular}{lrrr}
\hline Hours per week & 1986 & 1996 & $\begin{array}{r}\text { Change } \\
86-96\end{array}$ \\
\hline Male under 30 hours & 1 & 2 & 1 \\
Female under 30 hours & 10 & 11 & 1 \\
Male 30-49 hours & 31 & 22 & -9 \\
Female 30-49 hours & 17 & 17 & 0 \\
Male 50 or more hours & 15 & 16 & 1 \\
Female 50 or more hours & 3 & 5 & 2 \\
Male not in paid work & 4 & 9 & 5 \\
Female not in paid work & 19 & 18 & -1 \\
Total & 100 & 100 & \\
\hline Source: Derived from the Census of Population and Dwellings, Statistics New Zealand.
\end{tabular}

\section{Education and changing hours of paid work for prime aged people}

As discussed in previous chapters, a wide range of factors influence working hours for prime-aged people. These include whether people have dependent children and the age of children, whether they are self-employed, for agricultural workers the time of year hours are recorded, and the occupation they are in. In addition, if a person lives in a household with other adults then decisions about work hours may be arrived at by taking into account the work patterns of all members of that family / household. Complex multivariate analysis would be needed to uncover the importance of various factors but such an analysis is not of central interest to this research. In addition, it is highly likely that many of the individual factors are themselves correlated and that unobserved variables will also be of considerable importance.

At a very aggregate level, a change in hours can be influenced by a changing workforce. For example, if women tend to work, on average, shorter hours than men, and women become a larger part of the labour force, then average hours worked will decrease. Equally, if people in self-employment tend to work longer than average hours, and self- 
employment increases, then average hours worked by the population will increase. However, using average or median type measures is problematic if a polarisation is occurring with, for example, there being more part-time wage and salary type jobs bringing women into the workforce but also more self-employment lifting hours for another group. An initial analysis of the data showed very little change over the period studied in median hours when a range of variables, such as gender and education, were considered. As already shown, there was some polarisation of hours between 1986 and 1996, so the median hours worked hardly changed.

This section focuses primarily on highest level of formal education and hours of work for women and men. This focus on education continues the overall theme of this research that education is an increasingly important factor in the labour market. However, to provide some idea of the impact of age on work hours some initial data on hours by age are presented for 1986 and 1996.

Tables 43 and 44 show some small variation by age. In both years there was a greater tendency for prime-aged men to work longer than a 40 week in older age groups but then reduce their hours as they neared 60 . However, there were also some complexities in the changes between 1986 and 1996. While the rise in the proportion of men working very short hours was fairly even across all age groups, the increase in longer than standard hours was more pronounced amongst older men. As an example, in 199633 percent of men aged 25-29 worked 50 or more hours per week, but by the age 45-49 this peaked at 45 percent. The increase in the proportion of older men working longer hours may not necessarily mean that hours have increased. It may simply be that the men who lost their jobs in the period between 1986 and 1996 tended to be those who worked standard hours. Further detailed research would be needed to unpick these changes in hours worked. 
Table 43 - Distribution of hours of paid work for prime-aged men, 1986

$\%$ in each group

\begin{tabular}{lcccccccccc}
\hline & $<5$ & $<10$ & $<20$ & $30+$ & $40+$ & $50+$ & $60+$ & $70+$ & $80+$ \\
\hline $25-29$ & 0.1 & 0.9 & 2.1 & 96.5 & 87.6 & 28.5 & 12.8 & 5.5 & 2.7 \\
$30-34$ & 0.1 & 0.8 & 1.8 & 96.8 & 88.2 & 33.4 & 15.7 & 6.7 & 3.3 \\
$35-39$ & 0.1 & 0.7 & 1.7 & 97.1 & 88.7 & 36.2 & 17.2 & 7.2 & 3.6 \\
$40-44$ & 0.1 & 0.6 & 1.6 & 97.2 & 89.2 & 36.8 & 17.5 & 7.3 & 3.7 \\
$45-49$ & 0.1 & 0.8 & 1.8 & 96.9 & 88.7 & 34.5 & 16.1 & 6.7 & 3.4 \\
$50-54$ & 0.1 & 0.9 & 2.1 & 96.4 & 86.9 & 29.6 & 13.1 & 5.5 & 2.8 \\
$55-59$ & 0.2 & 1.1 & 2.6 & 95.2 & 84.6 & 24.9 & 10.6 & 4.2 & 2.1 \\
\hline Source: Derived from the Census of Population and Dwellings, Statistics New Zealand.
\end{tabular}

Table 44 - Distribution of hours of paid work for prime-aged men, 1996

$\%$ in each group

\begin{tabular}{lccccccccccc}
\hline & $<5$ & $<10$ & $<20$ & $30+$ & $40+$ & $50+$ & $60+$ & $70+$ & $80+$ \\
\hline $25-29$ & 0.6 & 2.2 & 4.2 & 93.8 & 87.5 & 32.7 & 14.1 & 5.4 & 2.4 \\
$30-34$ & 0.6 & 1.9 & 3.7 & 94.6 & 89.0 & 38.1 & 17.3 & 6.5 & 2.9 \\
$35-39$ & 0.5 & 1.7 & 3.5 & 94.6 & 89.2 & 42.0 & 19.8 & 7.5 & 3.4 \\
$40-44$ & 0.5 & 1.7 & 3.5 & 94.4 & 89.2 & 44.2 & 21.5 & 8.0 & 3.7 \\
$45-49$ & 0.5 & 1.6 & 3.5 & 94.3 & 88.7 & 44.8 & 21.8 & 8.1 & 3.7 \\
$50-54$ & 0.5 & 1.8 & 4.1 & 93.2 & 87.0 & 42.1 & 20.3 & 7.5 & 3.6 \\
$55-59$ & 0.8 & 2.7 & 5.7 & 90.2 & 82.4 & 36.9 & 17.8 & 6.7 & 3.1 \\
\hline Source: Derived from the Census of Population and Dwellings, Statistics New Zealand.
\end{tabular}

Tables 45 and 46 show there was more complexity for women both in 1986 and 1996. For example, in the 30-39 age group a significant proportion of women worked under 20 hours per week. A range of factors would be behind this pattern, including the impact of childrearing for the group of women who had children. Tables 45 and 46 also show an increase in the proportion of women working 50 or more hours per week in all age groups but like men with the largest increase amongst older women.

Table 45 - Distribution of hours of paid work for prime-aged women, 1986 $\%$ in each group

\begin{tabular}{lcccccccccc}
\hline & $<5$ & $<$ & $<$ & $<0$ & $30+$ & $40+$ & $50+$ & $60+$ & $70+$ & $80+$ \\
\hline $25-29$ & 1.9 & 6.4 & 15.8 & 75.6 & 53.9 & 9.0 & 4.2 & 2.3 & 1.4 \\
$30-34$ & 2.6 & 9.1 & 24.0 & 60.7 & 41.5 & 9.7 & 5.3 & 3.0 & 2.0 \\
$35-39$ & 1.9 & 7.0 & 21.2 & 61.1 & 40.3 & 10.1 & 5.6 & 3.2 & 2.0 \\
$40-44$ & 1.4 & 5.3 & 17.1 & 65.9 & 43.5 & 10.5 & 5.7 & 3.2 & 1.9 \\
$45-49$ & 1.3 & 4.9 & 16.1 & 67.8 & 44.6 & 10.4 & 5.6 & 3.0 & 1.8 \\
$50-54$ & 1.6 & 5.7 & 17.4 & 66.6 & 43.2 & 9.7 & 5.3 & 2.9 & 1.7 \\
$55-59$ & 2.1 & 7.3 & 19.7 & 64.2 & 41.0 & 8.2 & 4.4 & 2.3 & 1.4 \\
\hline Source: Derived from the Census of Population and Dwellings, Statistics New Zealand.
\end{tabular}


Table 46 - Distribution of hours of paid work for prime-aged women, 1996 $\%$ in each group

\begin{tabular}{lrrrrrrrrrr}
\hline \multicolumn{1}{c}{$<$} & $<$ & $<$ & $<$ & $<20$ & $30+$ & $40+$ & $50+$ & $60+$ & $70+$ & $80+$ \\
\hline $25-29$ & 2.7 & 7.7 & 15.4 & 76.7 & 59.7 & 13.2 & 4.9 & 1.9 & 0.9 \\
$30-34$ & 4.0 & 11.0 & 24.1 & 62.8 & 46.6 & 12.5 & 5.3 & 2.2 & 1.1 \\
$35-39$ & 3.5 & 10.2 & 24.4 & 58.8 & 41.4 & 12.6 & 5.9 & 2.5 & 1.4 \\
$40-44$ & 2.3 & 7.1 & 18.4 & 65.5 & 46.7 & 15.0 & 6.9 & 2.8 & 1.5 \\
$45-49$ & 2.0 & 6.0 & 15.6 & 69.5 & 49.6 & 16.1 & 7.7 & 3.2 & 1.6 \\
$50-54$ & 2.4 & 7.3 & 17.7 & 67.1 & 47.2 & 15.8 & 7.8 & 3.3 & 1.8 \\
$55-59$ & 3.6 & 10.1 & 22.5 & 61.4 & 41.8 & 13.6 & 7.1 & 3.2 & 1.7 \\
\hline Source: Derived from the Census of Population and Dwellings, Statistics New Zealand.
\end{tabular}

While the stage of a person's lifecycle does appear to have some impact on working hours, in order to simplify the analysis the following focuses on the whole age span of 2559. Tables 47 and 48 show changing hours of paid work for men and women in each main educational group.

First, Table 47 reinforces the earlier findings that there has been some shift by men away from working between 30 and 40 hours. For example, in all qualification groups, more men were working either 50 or more hours per week or less than 30 hours per week by the end of the period studied. However, by 1996, the polarisation was the greatest amongst men with no formal qualifications. This group, if they had a job in the first place, were most likely to work very long hours or very short hours. It is likely that many of these men had no choice but to work in part-time jobs or, if they did have a full-time job, it was often for low wages so they needed to work long hours. A further investigation of census data show that amongst this group of men working long hours were self employed people such as farmers, shop owners, fishermen and taxi drivers who did not have formal qualifications. Also of note was the very strong rise between 1986 and 1996 in the proportion of men with a degree or higher working 50 or more hours per week. Again, further census data show that many of these were in managerial and professional jobs. Some of these longer hours will have been through choice but some through changes in workplaces putting more pressure on their restructured workforce. 
Table 47 - Distribution of hours of paid work of prime-aged men by education

\begin{tabular}{rrrrrrrr}
\hline & $\begin{array}{c}\% \\
\text { working } \\
\text { under 10 } \\
\text { hours* }\end{array}$ & $\begin{array}{c}\% \\
\text { working } \\
\text { under 30 } \\
\text { hours* }\end{array}$ & $\begin{array}{c}\% \\
\text { working } \\
40 \text { or } \\
\text { more } \\
\text { hours* }\end{array}$ & $\begin{array}{c}\% \\
\text { working } \\
\text { 50 or } \\
\text { more } \\
\text { hours* }\end{array}$ & $\begin{array}{c}\% \\
\text { working } \\
60 \text { or } \\
\text { more } \\
\text { hours* }\end{array}$ & $\begin{array}{c}\text { working } \\
70 \text { or } \\
\text { more } \\
\text { hours* }\end{array}$ & $\begin{array}{c}\text { working } \\
80 \text { or } \\
\text { more } \\
\text { hours* }\end{array}$ \\
\hline $\begin{array}{r}\text { Degree or higher } \\
1986\end{array}$ & 0.4 & 2.5 & 81.3 & 35.7 & 15.1 & 5.3 & 2.4 \\
1991 & 0.7 & 3.7 & 84.7 & 41.0 & 16.9 & 5.5 & 2.3 \\
1996 & 1.5 & 5.4 & 86.7 & 46.5 & 18.7 & 5.4 & 2.2 \\
Other tertiary/school & & & & & & & \\
1986 & 0.5 & 2.7 & 87.8 & 32.1 & 14.3 & 5.8 & 2.8 \\
1991 & 0.8 & 4.1 & 87.7 & 35.2 & 16.4 & 6.5 & 3.1 \\
1996 & 1.7 & 5.7 & 88.4 & 40.2 & 18.8 & 7.0 & 3.3 \\
No qualifications & & & & & & & \\
1986 & 1.3 & 4.5 & 89.7 & 31.6 & 15.6 & 7.1 & 3.7 \\
1991 & 1.2 & 5.8 & 87.7 & 33.3 & 17.5 & 8.0 & 3.9 \\
1996 & 2.5 & 7.5 & 87.8 & 37.0 & 19.4 & 8.2 & 3.8 \\
\hline
\end{tabular}

Source: Derived from the Census of Population and Dwellings, Statistics New Zealand.

For prime-aged women, qualifications were more strongly associated with hours worked. Women with a degree or higher were more likely to work 40 or more hours per week. However, at the extreme of 70 hours and over education was not a critical factor. There was also a strong increase in the proportion of women with degrees working 50 and 60 or more hours per week between 1986 and 1996. In part, this reflects the increased representation of these women in managerial and professional occupations. There was also a slight decline in the proportion of women with degrees or higher working part time, but in contrast there was an increase in the proportion of women with no formal qualifications in part-time work. This growth was particularly strong in the under 10 hours per week group. It is difficult to assess whether this latter growth was by choice or a reflection of changing labour market conditions for low skilled workers. Some of this trend will reflect issues such as women with no qualifications being over-represented in sole parent families which, for a variety of reasons, tend to inhibit them working full time.

With women who held degrees or higher qualifications becoming more likely to be workrich both in terms of being in paid work and hours worked, if these women tend to form couples with work-rich men, then this concentrates paid work in these couples. This is explored in subsequent chapters. 
Table 48 - Distribution of hours of paid work of prime-aged women by education

\begin{tabular}{|c|c|c|c|c|c|c|c|}
\hline & $\begin{array}{c}\% \\
\text { working } \\
\text { under } 10 \\
\text { hours* }\end{array}$ & $\begin{array}{c}\% \\
\text { working } \\
\text { under } 30 \\
\text { hours* }\end{array}$ & $\begin{array}{c}\% \\
\text { working } \\
40 \text { or } \\
\text { more } \\
\text { hours* }\end{array}$ & $\begin{array}{c}\% \\
\text { working } \\
50 \text { or } \\
\text { more } \\
\text { hours* }\end{array}$ & $\begin{array}{c}\% \\
\text { working } \\
60 \text { or } \\
\text { more } \\
\text { hours* }\end{array}$ & $\begin{array}{c}\% \\
\text { working } \\
70 \text { or } \\
\text { more } \\
\text { hours* }\end{array}$ & $\begin{array}{c}\% \\
\text { working } \\
80 \text { or } \\
\text { more } \\
\text { hours* }\end{array}$ \\
\hline \multicolumn{8}{|l|}{$\begin{array}{l}\text { Degree or } \\
\text { higher }\end{array}$} \\
\hline 1986 & 6.0 & 25.0 & 53.7 & 15.5 & 6.7 & 2.9 & 1.6 \\
\hline 1991 & 5.8 & 23.6 & 59.0 & 20.8 & 8.2 & 3.1 & 1.6 \\
\hline 1996 & 6.0 & 24.2 & 61.8 & 26.3 & 10.1 & 2.9 & 1.2 \\
\hline \multicolumn{8}{|l|}{$\begin{array}{l}\text { Other } \\
\text { tertiary/school }\end{array}$} \\
\hline 1986 & 6.7 & 33.6 & 43.5 & 10.0 & 5.2 & 2.9 & 1.8 \\
\hline 1991 & 6.7 & 32.5 & 46.0 & 11.6 & 5.8 & 3.0 & 1.8 \\
\hline 1996 & 7.6 & 32.8 & 48.1 & 12.0 & 6.5 & 3.1 & 1.6 \\
\hline \multicolumn{8}{|l|}{$\begin{array}{l}\text { No } \\
\text { qualifications }\end{array}$} \\
\hline 1986 & 6.4 & 35.9 & 43.9 & 8.4 & 4.8 & 2.8 & 1.8 \\
\hline 1991 & 6.8 & 35.4 & 44.8 & 9.6 & 5.4 & 3.1 & 1.9 \\
\hline 1996 & 9.4 & 37.4 & 44.6 & 10.2 & 5.5 & 2.7 & 1.5 \\
\hline
\end{tabular}

Source: Derived from the Census of Population and Dwellings, Statistics New Zealand.

\section{Change in the types of jobs held by prime-aged people}

\section{Occupational change}

Table 49 shows changes in the percentage of total jobs in each occupational group over the period 1991 to 1996 . This is the period of employment growth following the major period of job loss. 
Table 49 - Percentage of prime-aged people in each occupational group, the ratio of women to men in each group, and the percentage full time and held by women

\begin{tabular}{|c|c|c|c|c|c|c|}
\hline & \multicolumn{2}{|c|}{$\%$ of jobs } & \multicolumn{2}{|c|}{$\begin{array}{l}\text { Ratio of women to } \\
\text { men }\end{array}$} & \multicolumn{2}{|c|}{$\begin{array}{l}\% \text { full time and } \\
\text { held by women }\end{array}$} \\
\hline & 1991 & 1996 & 1991 & 1996 & 1991 & 1996 \\
\hline Armed Forces & 0.4 & 0.3 & 0.08 & 0.10 & 7.2 & 8.4 \\
\hline $\begin{array}{l}\text { Legislators, Administrators and } \\
\text { Managers }\end{array}$ & 13.8 & 14.3 & 0.47 & 0.55 & 27.2 & 29.7 \\
\hline Professionals & 13.8 & 14.0 & 1.17 & 1.23 & 39.0 & 40.2 \\
\hline $\begin{array}{l}\text { Technicians and Associate } \\
\text { Professionals }\end{array}$ & 11.4 & 11.9 & 0.66 & 0.81 & 29.6 & 32.5 \\
\hline Clerks & 13.6 & 14.1 & 4.93 & 4.45 & 55.3 & 52.8 \\
\hline Service and Sales Workers & 10.5 & 11.3 & 1.89 & 2.04 & 34.1 & 34.6 \\
\hline Agriculture and Fishery Workers & 9.7 & 9.3 & 0.47 & 0.53 & 20.7 & 21.0 \\
\hline Trades Workers & 10.4 & 9.6 & 0.06 & 0.07 & 4.3 & 4.6 \\
\hline $\begin{array}{l}\text { Plant and Machine Operators and } \\
\text { Assemblers }\end{array}$ & 9.9 & 9.1 & 0.29 & 0.27 & 17.8 & 16.5 \\
\hline Elementary Occupations & $\begin{array}{r}6.5 \\
100.0\end{array}$ & $\begin{array}{r}6.2 \\
100.0\end{array}$ & $\begin{array}{l}0.63 \\
0.76\end{array}$ & $\begin{array}{l}0.75 \\
0.84\end{array}$ & $\begin{array}{l}18.6 \\
29.1\end{array}$ & $\begin{array}{l}19.9 \\
30.2\end{array}$ \\
\hline
\end{tabular}

Source: Derived from the Census of Population and Dwellings, Statistics New Zealand

Table 49 reinforces the findings in Chapter sixteen that there was some polarisation in occupations and potentially demand for skills over the period shown. These data confirm a longer-term trend toward a greater proportion of skilled managerial, professional and technical jobs, as well as a growth in clerical and service occupations. The managerial and professional jobs increasingly require an above average level of formal education and, in the situation of professional jobs, usually a qualification from a university. Most are full time. The clerical and service occupations include a mixture of some skilled and relatively low skilled work, and a high proportion were part time. ${ }^{91}$

In all occupational groupings, with the exception of clerks and plant and machinery operators, the ratio of employment of prime-aged women to prime-aged men increased. However, women remained under-represented in managerial and technical jobs, although over-represented in professional occupations (which includes nurses). On average, women also earned lower incomes in managerial and professional occupations. For example, in 1996, there were just over 44,000 prime-age men working full time in managerial jobs and earning more than $\$ 50,000$ a year. In the same year, there were only

\footnotetext{
91 Examples of what could be considered skilled workers in this broad occupational group include chef, detective, funeral director, national park ranger, and outdoor recreation guide.
} 
a little more than 8,000 prime-age women in this position. Table 49 also shows that women continued to be over-represented in clerical and service jobs.

While in 1996 there were still more men employed than women, these data suggest that, increasingly, more of both the relatively skilled and unskilled jobs held by prime-aged people in the New Zealand economy were being undertaken by women while a group of prime-aged men were experiencing some difficulties in finding or remaining in relatively unskilled work (such as elementary occupations). This suggests that the types of low skill jobs available in the economy were changing over the period studied. Disappearing were the hard physical jobs such as labouring and increasing were the jobs such as sales workers. However, even some of the manual jobs being created tended to be female dominated. For example, between 1991 and 1996 the number of people in the occupation "cleaners" increased. The majority of these, 55 percent in 1996, were prime-aged women.

Overall, while occupational segregation for prime-aged women and men remained strong the changes in employment did lead to a decrease in such segregation between 1991 and 1996. At a 3-digit level (97 occupations), the index of dissimilarity stood at 0.53 in 1991 , but had reduced to 0.50 in 1996 . This is in line with a long-term trend, with a slow but steady decline in the index since the 1970s (Haines 1989). But also of relevance, this segregation appears to be the strongest in the occupations seen as lower skilled. Dividing the 97 occupations into two groups indicates this. The first group of 39 were drawn from the higher skill managerial, professional and technical occupations. In this group, the index in 1991 was 0.38 but declined to 0.34 in 1996. In the second group, the index in 1991 was 0.62 and reduced to 0.61 in 1996. This suggests that in jobs that generally require higher levels of cognitive skills, gender is decreasing in importance, but that in jobs that require either manual skills or "soft skills" such as interpersonal skills gender remains important. In general, it would seem that women have an advantage in jobs requiring soft skills (the jobs that are increasing) while men still have an advantage in jobs requiring physical skills (the jobs that are declining). While nature provides the difference in physical skills, it is less clear-cut as to whether nature or nurture give women some advantage in "soft skills". 


\section{A Growth in Symbolic-analytical jobs?}

As shown in the previous chapter, changes in occupation can be examined using a revised Reich classification. Table 50 shows changes in these occupational groups, by male and female and full-time and part-time groupings.

Table 50 - Percentage in each grouping for prime-aged people, 1991 to 1996

\begin{tabular}{lrrrrr}
\hline 1991 & Male & Female & Male & Female & \\
\hline & Full time & Full time & Part time & Part time & Total \\
Symbolic-analytical & 15.4 & 9.2 & 0.4 & 2.7 & 27.7 \\
Technical-analytical & 15.9 & 3.8 & 0.8 & 1.3 & 21.8 \\
In-person services & 3.4 & 3.6 & 0.2 & 3.3 & 10.5 \\
Routine production & 13.2 & 10.5 & 0.8 & 5.6 & 30.1 \\
Agriculture and fisheries & 6.3 & 2.0 & 0.4 & 1.1 & 9.8 \\
Total & 54.2 & 29.1 & 2.6 & 14.0 & 100.0 \\
\hline
\end{tabular}

\begin{tabular}{lrrrrr}
\hline 1996 & Male & Female & Male & Female & \\
\hline & Full time & Full time & Part time & Part time & Total \\
Symbolic-analytical & 14.8 & 9.9 & 0.6 & 3.0 & 28.3 \\
Technical-analytical & 14.8 & 4.3 & 0.8 & 1.7 & 21.6 \\
In-person services & 3.3 & 3.9 & 0.4 & 3.7 & 11.3 \\
Routine production & 12.2 & 10.2 & 1.1 & 5.9 & 29.4 \\
Agriculture and fisheries & 5.5 & 2.0 & 0.5 & 1.3 & 9.3 \\
Total & 50.6 & 30.3 & 3.4 & 15.6 & 100.0 \\
\hline
\end{tabular}

Source: Derived from the Census of Population and Dwellings, Statistics New Zealand

Note: This excludes armed forces

Over the short period shown, there was a very slight rise in both symbolic-analytical occupations and in-person services. However, the percentage of people working in technical-analytical declined slightly. Also of interest, is that, even by 1996, a significant proportion of prime-aged people still worked in routine production occupations. Some of these will be at risk of eventually being transferred to low-income countries. However, some, such as road construction, will always be needed locally. Overall, between 1991 and 1996 there was no change in the proportion of prime-aged people working full time in symbolic / technical occupations (44 percent) but a slight increase in the proportion working part time in in-person services and routine production (from 10 to 11 percent). While the data lends some further support to the polarisation of skills, again they do not support the idea that the post restructured economy was mainly creating part-time and low skill service jobs for prime-aged people. 


\section{High IQ jobs?}

As discussed in Chapter five, Herrnstein and Murray (1996) predicted that a particular group of jobs requiring a high level of IQ were growing. Table 51 shows the number of prime-aged men and women employed in the jobs selected by Herrnstein and Murray in both 1991 and 1996. It shows that, overall, these jobs formed a relatively small proportion of all employment but that over this period of job growth they did increase in both number and proportion for prime-aged men and women.

\section{Table 51 - High IQ jobs from the Bell Curve for prime-age men and women (000s)}

\begin{tabular}{lrrrr}
\hline & Women & \multicolumn{3}{c}{ Men } \\
\hline & 1991 & 1996 & 1991 & 1996 \\
Physicists, Chemists and Related & 0.2 & 0.4 & 1.2 & 1.4 \\
Professionals & & & & \\
Mathematicians, Statisticians and Related & 0.1 & 0.1 & 0.3 & 0.3 \\
Professionals & & & & \\
Computing Professionals & 0.7 & 1.2 & 2.3 & 4.3 \\
Architects, Engineers and Related & 0.6 & 1.2 & 13.9 & 17.4 \\
Professionals & & & & \\
Life Science Professionals & 0.5 & 0.8 & 1.9 & 2.3 \\
Health Professionals (Except Nursing) & 3.2 & 3.9 & 7.0 & 6.9 \\
Tertiary Teaching Professionals & 5.0 & 5.7 & 5.9 & 6.3 \\
Business Professionals & 7.4 & 10.2 & 12.3 & 12.8 \\
Legal Professionals & 1.4 & 2.0 & 4.3 & 4.5 \\
Social and Related Science Professionals & 2.1 & 3.6 & 1.7 & 2.7 \\
Total & 21.2 & 29.2 & 50.8 & 59.0 \\
\% of all jobs by prime-aged women or men & 4.6 & 5.4 & 8.4 & 9.1 \\
\hline Source: Derived from the Census of Population and Dwellings, Statistics New Zealand & &
\end{tabular}

Table 51 also illustrates the continuing high level of occupational segregation in some occupations, with the group architects, engineers and related professional particularly standing out. Yet, in some groups, notably business professionals, there has been strong growth in the number of prime-aged women.

\section{Were female occupations growing faster than male occupations for prime-aged people?}

Finally, when job growth resumed between 1991 and 1996 were there more jobs created for prime-aged people in traditionally female dominated occupations than male dominated ones? To test this, changes in employment for prime-aged people in the 97 three digit occupations were examined. In 1991, 54 of these had a ratio of women to men 
less than 0.5. That is, less than half of employees in these occupations were women. In this group between 1991 and 1996 total jobs grew by 42,000, with both men and women gaining around 21,000 jobs each.

In contrast, in the 43 occupations where ratio was 0.5 or higher in 1991 (female dominated), prime-aged employment grew by 84,000, with women gaining 64,000 jobs, while men gained 20,000 jobs. So in the traditionally male dominated jobs, women gained as many jobs as men, while in the female dominated jobs women made further gains.

In the ten most male dominated occupations (ratios of 0 to 0.04) in 1991 the number of women employed increased by 570 and men by 4,539 . In contrast, in the ten most female dominated industries in 1991 (ratios of 6.5 to 27.8) the number of women increased by 18,783 while the number of men grew by 1,641 . So again, the most "male" jobs had not been providing many jobs for men, but the most "female" jobs continued to expand strongly for women.

Some of the growth of women in particular occupations is the result of complex social and economic change. For example, between 1991 and 1996 there was an increase in part-time work for women in the occupation "market oriented agricultural fishery workers" in the industry group "agriculture and hunting". Yet, the census shows major job losses in the same industry and occupation groupings for male full-time workers. This could indicate a downturn in the industry and decreased hours by the people who used to work full time. However, equally it might indicate a change in the type of jobs and those employed in them. For example, men working on pastoral farms appear to have been increasingly replaced, in the statistics, by women working part time on horticultural units. One of the most graphic differences can be shown in the occupation of teaching. Between 1991 and 1996 there were 2,865 extra prime-aged women working as teaching professionals in the industry group "social and related community services". In the same period 1,695 prime-aged men exited this occupation. In this example, the reasons for this change are complex. In part this reflects that older male teachers have been retiring and 
are not being replaced by younger men. But the reason why young men are not attracted to teaching and whether this has any impact on children, particularly boys, is not entirely clear and is the subject of some debate in New Zealand (Roger 2000).

Overall these data indicate that part of the reason for the static employment of men is that traditional male occupations were either declining or not growing rapidly.

\section{Men not in the labour force}

As already shown, one of the most significant shifts over the period studied was the increase in the number, and proportion, of prime-aged men classified as not being in the labour force. Whether this is a positive or negative trend depends on the reasons why this took place, the age of the men and future job prospects, what these men are doing with their time while outside of the labour force, living arrangements and how long these men spend outside of the labour force. As also previously discussed, the census is a snapshot. Therefore, not all men recorded as not in the labour force would have been out of work for long periods.

Many of the reasons why prime-aged men might have been finding it difficult to remain in paid work, and had eventually given up actively looking, have already been canvassed. The following shows some of the characteristics of prime-aged men not in the labour force.

Figure 30 uses data from the HLFS to show the increase in the number of men (aged 15 or older) not in the labour force over the period 1986 to 1998, as well as indicating the main activity they said they were involved in. In this wide age group, retirement was clearly an important reason for not being in the labour force. While most of this will simply reflect a cohort effect of the aging of the population, part of this increase will have been due to redundancy and early retirement of a group of prime-aged men who would have kept working had jobs been available. 
There was also some slow, but steady, growth in the number of men studying. In addition, although it is difficult to see on this graph, there was also growth, from a low base, in the number of men whose main activity was looking after children. These tend to be men within the prime working age group.

\section{Figure 30}

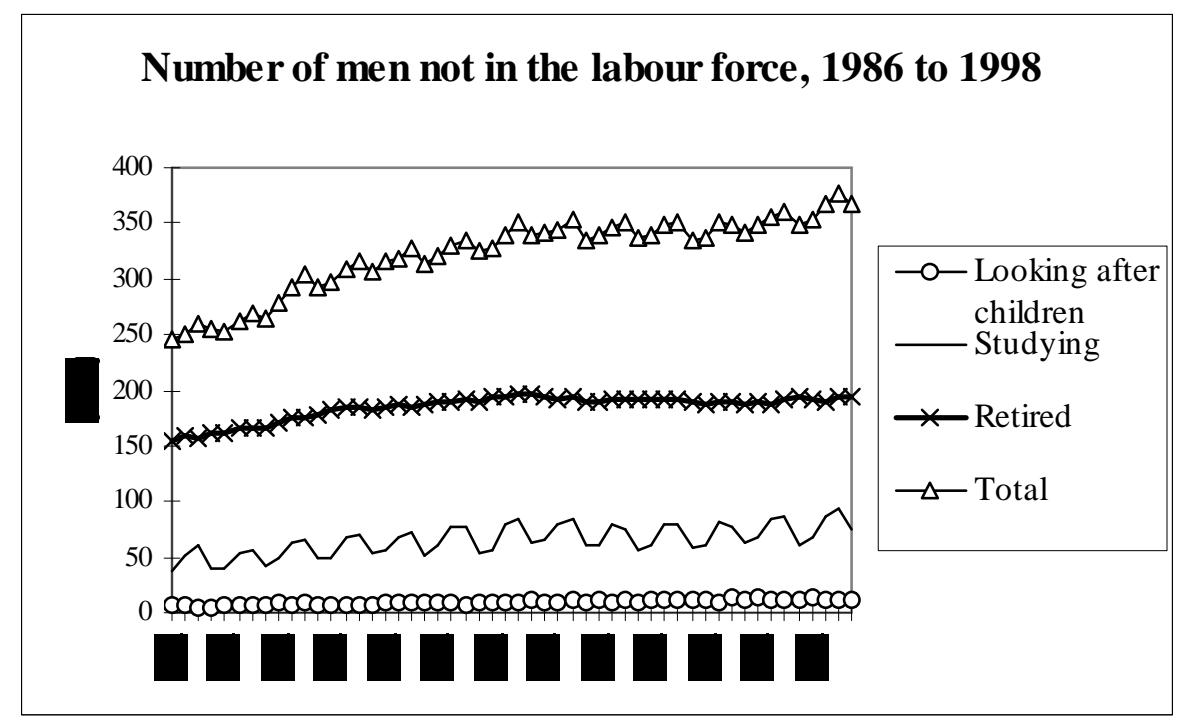

Source: Derived from the HLFS

Note: The group "other" is not shown as a separate line but is included in the total.

As already discussed, prime-aged men with no formal qualifications face major difficulties in the labour market. While this may have encouraged some prime-aged men to seek further education, an increase in educational participation provides only part of the answer as to why prime-aged men exited paid work. In the mid 1990s, more men were extending their initial time in education or returning in later life for further education and training. But Table 52 indicates that while many of the men in the younger age groups were studying (either full time or part time), the majority of men who were unemployed or not in the labour force were not studying. While in the younger age groups rates of studying were the highest amongst those not in the labour force or working part time, by age 50 the highest rates were to be found amongst men classified as unemployed. However, as shown earlier in this chapter, this unemployed group is much smaller than the non-labour force group by age 50 . 
In addition, even if they were not in the labour force and were studying full time, for one group of men this was likely to have been a temporary phase with a return to employment when the study was complete. Included in this group were men undertaking post-graduate diplomas, MBAs, or doctoral research. Some of these men when they returned to paid work were more likely to earn higher incomes. But another group of men will have been attending low-level employment training and for many of these a return to long term, well paid, employment would have been far more difficult.

Table 52 - Percentage of men in each labour force status who studied (part-time and full-time study), 1996

\begin{tabular}{lrrrrrrr}
\hline & $25-29$ & $30-34$ & $35-39$ & $40-44$ & $45-49$ & $50-54$ & $55-59$ \\
\hline Full time & 8.2 & 7.3 & 6.3 & 5.7 & 4.7 & 3.6 & 3.2 \\
Part time & 27.6 & 17.4 & 12.7 & 9.5 & 7.6 & 5.6 & 4.5 \\
Unemployed & 13.8 & 14.1 & 12.8 & 11.3 & 10.2 & 7.5 & 4.7 \\
Non labour & 28.3 & 21.4 & 16.3 & 13.5 & 9.6 & 5.6 & 3.0 \\
Total & 11.8 & 9.6 & 7.9 & 6.8 & 5.5 & 4.1 & 3.3 \\
\hline Source: Derived from the Census of Population and Dwellings, Statistics New Zealand
\end{tabular}

Dixon (1996b) raised the question as to whether poor health has been affecting the employment patterns of prime-aged men. Given increasing life expectancy, it is difficult to see why men, in general, would be less healthy than in the past. Also given shorter stays in hospitals employable men will generally have been out of the labour force for shorter periods. However, particular sub-populations may have had poorer health. Some may have been self-induced such as through drug and alcohol dependency. But such dependency may also have been encouraged by increased unemployment. It may be that non-employment and poor health is a vicious cycle with a loss of employment being the cause of some types of poor health. For example, a lower income might mean a move to poorer, overcrowded and less healthy housing. 1996 census data does provide a crude, but strong, link between self assessed health status and employment. ${ }^{92}$ The census asked people if they had a health problem lasting 6 or more months, asked if the health problem meant they had difficulty communicating, socialising or mixing and finally asked if they had a disability or handicap lasting six months or more. Of those prime-aged men who

\footnotetext{
92 A detailed analysis of specialist health surveys is needed to help assess the relationships between health status and employment (and employment and health status). In New Zealand there is an on-going research effort in this area and the relationships should slowly become clearer.
} 
worked full time in 1996, 7.7 percent said they had a specified health problem, this rose to 19.8 percent if they were unemployed and seeking work, and to 39.8 percent if they were not in the labour force (Table 53). In total, 33.4 percent of prime-aged men not in paid work classified themselves as having a health problem. Some of these people will have had accidents and will be out of work for a short period while some will have had long-term chronic health problems. It is also likely that age was an important factor in these relationships and further research could better disaggregate these data.

Table 53 - Percentage of prime-aged men in each labour force status with a health problem, 1996

\begin{tabular}{lrrr}
\hline & $\begin{array}{r}\text { Health problem or } \\
\text { condition lasting 6 } \\
\text { months or more }\end{array}$ & $\begin{array}{r}\text { Difficulty with } \\
\text { communicating, } \\
\text { socialising or mixing }\end{array}$ & $\begin{array}{r}\text { Disability or handicap } \\
\text { lasting 6 months or more }\end{array}$ \\
\hline Full time & 7.7 & 2.0 & 8.9 \\
Part time & 18.5 & 5.6 & 20.3 \\
Unemployed & 19.8 & 6.2 & 21.2 \\
Not in labour force & 39.8 & 14.1 & 41.5 \\
\hline \multicolumn{2}{l}{ Source: Derived from the Census of Population and Dwellings, Statistics New Zealand }
\end{tabular}

It is also possible that a very small group of prime-aged men had exited the labour force to look after sick friends or relatives or to undertake voluntary work. However, a stronger possibility is that men who had exited the workforce then turned to voluntary work so in a wider sense were not work poor. The census asked some broad questions about voluntary work carried out outside a person's household. Table 54 indicates that in 1996 some men not in the labour force were undertaking such work, but that the proportion was less than those in full-time work. However, in the data presented there is no time dimension. Therefore, it could be that a full-time paid worker doing half an hour per month of voluntary work is being compared with a non-labour force prime-aged male undertaking 30 hours of caring work per week. An analysis of data from the 1999 Time Use Survey may help shed some light on this. 
Table 54 - Percentage of prime-aged men in each labour force status undertaking voluntary or caring work in the past four weeks, 1996

\begin{tabular}{lrr}
\hline & $\begin{array}{r}\text { Caring for a person in a different } \\
\text { household }\end{array}$ & Volunteer training, counselling etc \\
\hline Full time & 14.3 & 13.5 \\
Part time & 17.0 & 15.1 \\
Unemployed & 18.6 & 12.3 \\
Not in labour force & 11.9 & 7.9 \\
\hline
\end{tabular}

Figure 31 focuses just on men looking after children. This is an important issue as it relates to changes occurring in both family and work. In theory, part of the loss of jobs by men, but the increasing participation of mothers in paid work, could be due to changes in gender roles in couple families who have young children.

Figure 31

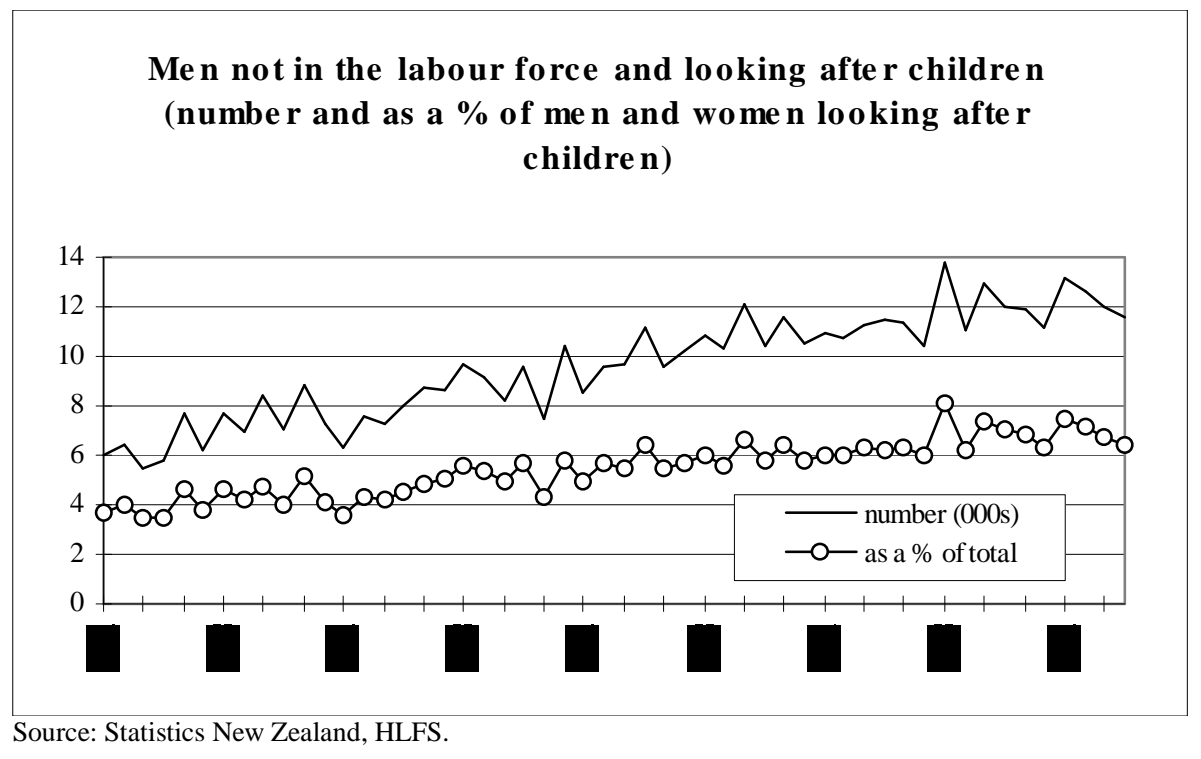

Figure 31 shows that the rise in the number of men looking after children continued over periods of overall employment loss and employment gain. When the numbers of men undertaking childcare as a main activity is divided by the total number of men and women in this group, there was also a rise in this proportion over the period shown.

In 1996 there were just over 100,000 men aged 25-59 who were not in paid work. In the same year there were just over 11 thousand men who were classified as not in the labour force and looking after children as a main activity. This is in contrast with around 260,000 prime-aged women not being in work, but 170,000 women being classified as 
looking after children. Even assuming that an additional group of unemployed men were looking after children, when compared with women relatively few men appeared to have exited paid work to become full-time caregivers. There are a number of possible reasons why this was so:

1. a high proportion of men who were not in paid work may not have been fathers

2. many fathers who were not in paid work were not living with their children

3. that fathers in two parent families who were out of work tended to be with partners who were also out of work and so gender roles in the home were not challenged

4. that many of the fathers who in recent years appeared to be spending more time with their children were unemployed and actively looking for work, working part time or were shiftworkers

5. while there are exceptions to the rule, men are generally incapable or unwilling of looking after children

Most of these reasons cannot be explored in this research. However, point 2 will be partially answered in Chapter eighteen, while point 3 will be explored in Chapter twenty. As to the last point, I have argued elsewhere that the idea that men in general are incapable of looking after children is incorrect (Callister 1999b). However, through fixed gender roles in a household they may be unwilling. As already discussed in an earlier chapter, the impact of nature and nurture on men's ability to undertake particular roles remains the subject of some debate.

Finally, there is a group of men who involuntarily have exited the labour force through being in prison. As discussed in previous chapters, in the U.S. this group is seen as part of the disguised unemployed. In New Zealand, there are complexities in measuring the number of people in prison, depending on issues such as whether they are on short-term remand. However, in 1996 according to the census data collection, around 2 percent of men not in the labour force were in prison. While those in prison at the time of being surveyed were naturally work poor, judging by their previous use of benefits they also 
have a strong potential of being on-going work poor (Bain 1998). ${ }^{93}$ A census of the New Zealand prison population carried out in 1997 also showed that three quarters of men and women in prison had no school qualifications, figures much higher than the overall population. $^{94}$

Overall, all these data suggest that the non-labour force group of prime-aged men had by the mid 1990s become more heterogeneous than in the past. While the majority of such men appeared to be in this position because of changes in labour demand, changes in labour supply were also a factor. Included in this latter group were some well-qualified men who had good labour market prospects and who, for a variety of reasons including pursuing further education or looking after children, had taken some time out of paid work.

\section{Conclusion}

One of the major changes over the period 1986 to 1996 was in the employment and nonemployment of prime-aged men. In 1986, 11 percent of prime-age men were either not in paid work or worked part time. By 1996 this had risen to 25 percent. Taking an even narrower definition of working "standard" hours or higher, in 1986, 81 percent of primeaged men were in paid work and working 40 or more hours per week, but by 1996 this had declined to 71 percent. Therefore, at the time the 1996 census was taken nearly 30 percent of prime-aged men appeared to be excluded from what has been the traditional work pattern for prime-aged men. However, it is not clear how many of these men will be work-poor long term. Some of the older men will have been in paid work for much of their adult lives. However, some younger men will have faced difficulties from early on in their working lives due to the timing of the structural reforms.

In the late 1990s, Maori and Pacific Island men were particularly likely to be either not in paid work or working part time. For example, in 1996 just under 40 percent of prime-age

\footnotetext{
93 The study showed that 69 percent of females and 52 percent of males had been on benefits before being in prison.

${ }^{94}$ A significant group of these prisoners will be younger than the target prime-aged group.
} 
Maori men were either not in paid work or worked part time. In 1996, only about 60 percent of prime-aged Maori men worked 40 or more hours per week.

There was a small increase in the proportion of well-educated men who were not in paid work over this period. However, even in 1996 the most well-qualified European men were still in full-time paid work. In contrast, the decline in employment was particularly strong amongst men with no formal qualifications. While in the late 1990s having a good formal educational qualification did not guarantee a job for prime-aged men, having no formal qualification became a much stronger predictor of non-employment. Being Maori and having no qualification increased the likelihood of not being in work. In addition, other research shows that the most disadvantaged men were those classified as sole Maori ethnicity and with no formal educational qualification.

In contrast, there was a small increase in participation of prime-aged women, in all major educational groupings, over the period studied. While the gender-based work participation "gap" remains large, it declined over this period. In 1996, the gap was the smallest amongst well-qualified women and men. The ethnic "gap" in work participation rates was also narrower as people gain higher levels of formal qualifications. The most disadvantaged women in the labour market were those with no formal educational qualifications and of Maori ethnicity. Again, other research shows that being sole Maori increases this disadvantage.

The themes of polarisation and diversity can be seen in the hours of paid work for both prime-aged men and women. It is not surprising that as the labour market became more flexible that there was some overall move away from people working a standard, full-time working week (30-49 hours).

While there has been much focus by labour market commentators on the growth in the number of part-time jobs in the economy, in fact, between 1986 and 1996 there was no increase in the proportion of prime-aged women working part time. However, the number increased due to both a rise in the actual number of women in this age group and an 
increase in their participation in paid work. The data also shows that despite change for both men and women, overall, far more women than men continued to work part time, and worked shorter hours in their part-time jobs than their male counterparts. In contrast, more men continued to work full time, working longer hours, on average, than women who worked full time. Yet at the same time, over the decade there was also a small increase in the proportion of both women and men working very short hours, and a larger increase in those working more than 50 hours per week. While commentators tend to focus on the growth in part-time work as a sign of a more flexible labour market, for many prime-aged men (and some women) working longer hours was the actual result of a greater level of flexibility. However, this tends to be disguised in the simple part time / full time split which is commonly reported on.

The data on hours worked show that despite a considerable reduction in the impact of gender as a variable over the period studied, it still remains a strong predictor of hours of paid work for prime-aged people. This seems to be primarily linked to gender being an extremely strong predictor of who has the primary responsibility for childrearing in families (one or two parent).

In terms of the impact of education on hours worked, this impact appeared not to be as strong as the impact of a lack of qualifications on whether a person had a job in the first place.

For some people, the polarisation of hours of paid work for prime-aged people will have been negative. Included in this group are those parents working long hours out of economic necessity who would have liked to spend more time with their children, and those people working short hours but wanting a full-time job. But for others the increasing diversity of hours worked will have been positive. For many employers this will have represented an increasing ability to match labour requirements to changes in output. For some employers having people working on relatively fixed salaries but increasing hours will have reduced unit labour costs. However, at extremes, this may also represent an unproductive practice with tired workers becoming inefficient or in some 
situations creating dangers. Finally, for some employees more flexible working hours enables them to better balance their work and non-work lives.

An analysis of changes in type of work over the period studied reinforces the findings of the previous chapter. Jobs that required symbolic, non-manual, analytical skills continued to increase slowly, while manual, routine production jobs continued to decline. However, adding complexity, while most of the symbolic-analytical jobs were full time, some were part time. It is difficult to define whether these part-time jobs should be considered as core or peripheral jobs. However, whether they are part-time or full-time, symbolicanalytical jobs generally require a high level of cognitive ability. Overall, prime-age women continued to increase their share of the symbolic-analytical jobs, including those that were full time. However, continuing the theme of polarisation, in the period studied there was an increase in the number of in-person service jobs held by prime-age people, particularly women. Some of these were relatively low skill, low paid jobs, with a significant number being part time. Yet, the overall data does not suggest that there has been a headlong rush into the creation of a vast number of low skill jobs for prime-aged people.

A significant number of prime-aged people were not in paid work in each of the censuses. In earlier times, most of these were women at home looking after children. However, the major change over the period studied was the proportion of prime-aged men who were not in paid work. While some men were unemployed and seeking work so were still technically in the labour force, a significant group of men completely exited the labour force. The data presented on the main activities of prime-aged men not in the labour force suggests a small group of these men moved into positive alternative activities, such as looking after children full time or studying. While many of these men may have been pushed into these new activities through changes in labour demand, for some this would have been an active choice. Overall, the non-labour force group of men became less homogeneous over the period studied. 
While many women, including those with formal educational qualifications, are still work-poor in terms of paid work for periods in their lives due primarily to choices made with respect to childrearing responsibilities, in the late 1990s, a significant group of both men and women faced either supply or demand side barriers to active long-term participation in full-time paid work. Given that in New Zealand there is a lack of data on tenure and turnover, it is difficult to estimate the size of this group. Whether older people in this group are a "lost generation" created by the restructuring process is still unclear. However, given the shift in demand away from low skill workers, prime-aged people with few cognitive and / or interpersonal skills do appear to face a difficult future in New Zealand. Younger prime-aged people without these skills face a particularly uncertain long-term future in the labour market.

In contrast, at the other extreme there has been a growing group of work-rich prime-aged people who worked long hours each week. Some of these people will be long-term workrich, while for others it represented a particular period in their lives. For example, some women may be work-rich in a career job until their mid 30s, have a period out of paid work while children are young, then work part time while the children are young and then return to full-time work. Some men may now also do this. Other people may work long hours in the start-up phase of a business then reduce their work to more standard hours. While in the 1990s there was some connection between hours of work and income, it is not at all clear that work rich prime-aged people generally had high incomes.

How some of these changes in paid work for prime-aged women and men then flow through to family, household and geographic settings is discussed in following chapters. 
Chapter 18

\section{Some associations between education, paid work and living arrangements for prime-aged people}

\section{Introduction}

In this chapter New Zealand census data is used to explore some associations between level of formal education, participation in paid work and family / household living arrangements for prime-aged people. ${ }^{95}$ In doing this, the main focus is on the living arrangements of prime-aged men. This chapter is concerned about the living arrangements of individuals and therefore there is little analysis of the characteristics of partners, if a person has one, or other household members. While most attention is given to either couple only or couple with dependent children households, some other household living arrangements are also examined. These include sole-parent households, living alone and living in non-family arrangements in a private dwelling and non-private dwelling living. Finally, in much of the analysis I use five yearly age cohorts.

The chapter begins by exploring two factors that have been identified in earlier chapters as potentially influencing couple formation or stability. These are total sex ratios, and then specifically the ratio of employed men to total women. The chapter continues by exploring overall trends in couple living arrangements, including legal marriage, in New Zealand.

\footnotetext{
95 In this chapter I draw heavily on papers I have published while undertaking my doctoral research. The three main papers are Callister (1999d, 2000a \& b). In Callister (2000a), I explore these associations in far more depth, including a deeper analysis of ethnic issues. In Callister (1999d) my primary focus was on the work and living arrangements of fathers.
} 
The next part of the chapter focuses in the living arrangements of prime-aged men, both in private and non-private dwellings. In this exploration three interrelated issues are examined. First, is education a key variable in living arrangements? Second, how is employment status associated with living arrangements for men? The third question is how these variables may be working together. A fourth issue is whether the impact of these variables has changed over the time period studied.

The final section of the chapter revisits some of the data discussed in the previous chapter showing the growth of part-time work. It examines whether prime-aged women who lived in couple households filled most of the part-time jobs held by prime-aged people. The next chapter then examines the employment status of the partners of women in part-time jobs. This is to test the idea that women living in couples with an employed partner hold a significant proportion of part-time jobs held by prime-aged people.

\section{Sex ratios}

As discussed in Chapter ten, sex ratios may have an influence on couple formation and dissolution. Table 55 shows the number, and ratio, of men and women in five yearly age groups for 1986 to 1996. The table shows between 1986 and 1996 there was a decline in the ratio of men to women within all prime-age groups. By 1996 the ratio was the lowest in the 25-34 age group. While these imbalances were not great, these data suggest that, assuming that most women and men wished to be in a heterosexual, cohabitational couple, and have a partner of a similar age then a small overall decline in couple formation would have been expected in the period studied. ${ }^{96}$ In contrast to the other age groups, in the 50-59 age group there had been a small excess of men in 1986 but this balance had evened up by 1996. Overall, in 1986 there were just over 2,400 more primeaged men than women. In 1991 this had reversed to there being over 13,000 more women than men. By 1996, this imbalance in favour of women had increased to over 29,500.

\footnotetext{
${ }^{96}$ While a significant proportion of people do have a partner in a five-year age span, the age gap is larger for older people and has also been changing over time (Callister 2000a).
} 
Table 55 - Ratio of men to women by five-yearly age group, 1986-1996

\begin{tabular}{lcccc}
\hline & 1986 & 1991 & 1996 & $\begin{array}{c}\text { Change } \\
1986-1996\end{array}$ \\
\hline $25-29$ & 0.99 & 0.96 & 0.94 & -0.05 \\
$30-34$ & 0.98 & 0.96 & 0.94 & -0.04 \\
$35-39$ & 1.00 & 0.98 & 0.95 & -0.05 \\
$40-44$ & 1.01 & 0.99 & 0.97 & -0.04 \\
$45-49$ & 1.01 & 1.01 & 0.99 & -0.02 \\
$50-54$ & 1.03 & 1.00 & 1.00 & -0.03 \\
$55-59$ & 1.04 & 1.01 & 0.99 & -0.05 \\
& & & \\
$25-59$ & 1.00 & 0.98 & 0.97 & -0.03 \\
\hline \multicolumn{5}{l}{ Source: Derived from the Census of Population and Dwellings, Statistics New Zealand. }
\end{tabular}

Such ratios can also be calculated within particular ethnic groups. In nations where there is little couple formation outside each ethnic group such ethnic based ratios are very important. However, in New Zealand there is evidence that for Maori and Pakeha, couple formation between the two ethnic groups has been common since colonisation (Pool 1991). This assumption is further tested in Chapter nineteen.

Table 56 reworks the overall sex-ratio data. It is based on the theories discussed in earlier chapters that women are generally seeking a heterosexual partner who has a paid job or will tend to exit a relationship when a man becomes unemployed.

Table 56 - Ratio of men in paid work to total women in each age group, 1986-1996

\begin{tabular}{lcccr}
\hline & 1986 & 1991 & 1996 & $\begin{array}{r}\text { Change } \\
1986-1996\end{array}$ \\
\hline $25-29$ & 0.90 & 0.74 & 0.74 & -0.16 \\
$30-34$ & 0.91 & 0.79 & 0.76 & -0.15 \\
$35-39$ & 0.94 & 0.82 & 0.78 & -0.16 \\
$40-44$ & 0.95 & 0.85 & 0.81 & -0.14 \\
$45-49$ & 0.95 & 0.86 & 0.83 & -0.12 \\
$50-54$ & 0.94 & 0.82 & 0.81 & -0.13 \\
$55-59$ & 0.88 & 0.72 & 0.73 & -0.15 \\
& & & & \\
$25-59$ & 0.92 & 0.80 & 0.78 & -0.14 \\
\hline
\end{tabular}

Source: Derived from the Census of Population and Dwellings, Statistics New Zealand.

This table indicates a shortage of employed men in all age groups even in 1986. However, between 1986 and 1996 in all age groups, but particularly those aged 25-29 and 55-59, there was a major decline in this sex ratio. These data suggest that a significant mismatch 
between women and men in their broad age group if women were seeking economic resources. However, in order to really assess this a measure of income, and preferably wealth, would also be needed.

It is also likely from the data in Table 57 that a group of women, once established in a couple, may have found that by 1991 and beyond their partner was not, in fact, able to regularly provide the main market income. This would have been reinforced by the decline in average real market income for men in most of the age groups studied over this period (Statistics New Zealand 1999). Other women may have already known of, or suspected, this possibility prior to forming a couple. It may be that some of this latter group entered de facto unions, rather than formal marriage, out of recognition of their partner's inability to provide economic security. However, other people may have liberal attitudes towards roles in paid and unpaid work and were happy to enter unions with the expectation that the woman would be the main income earner.

Some of the employment sex-ratio imbalance may also be counterbalanced by an increasing number of women choosing to remain without a heterosexual partner (or, at least, not cohabiting with them), or more women choosing to form same-sex couples. Sex-ratios, at a finer geographic level, are revisited in Chapter twenty-one.

\section{Some trends in living arrangements amongst prime-aged people}

\section{Fewer people in legal marriages}

Many commentators have analysed the decline in the proportion of people in New Zealand legally marrying (e.g. Davey 1998a). Marriage rates have historically declined in New Zealand in times of economic hardship, but the latest decline began in the mid 1970s and has been a long-term trend (Statistics New Zealand, 1998). Figures 32 and 33 show the increase in the proportion of those who had never married was led by the younger prime-aged group. ${ }^{97}$ In fact, for both men and women aged 50 or more there has been a reduction in the proportion of people never married in much of the period shown with

\footnotetext{
97 These data are calculated using marital status data and exclude those who did specify this status.
} 
stability in recent censuses. Even for the 40-44 age groups there was a decline in the proportion of people never married through to 1986.

In the early years some of the rise in the rate of younger people not marrying will have been due to people delaying marriage. But in the future, many of those who may have been simply delaying marriage may never marry. While the rise in the proportion of younger men and women not marrying could be seen to be associated with a declining level of male employment there were other predictors of marriage decline in action over this period. These include more liberal attitudes, an increasing female participation in tertiary education and the introduction of the Domestic Purposes Benefit. Given the literature discussed in Chapter ten, the decline in formal marriage rates is probably more due to changing social norms than linked to changes in the economy.

Figure 32

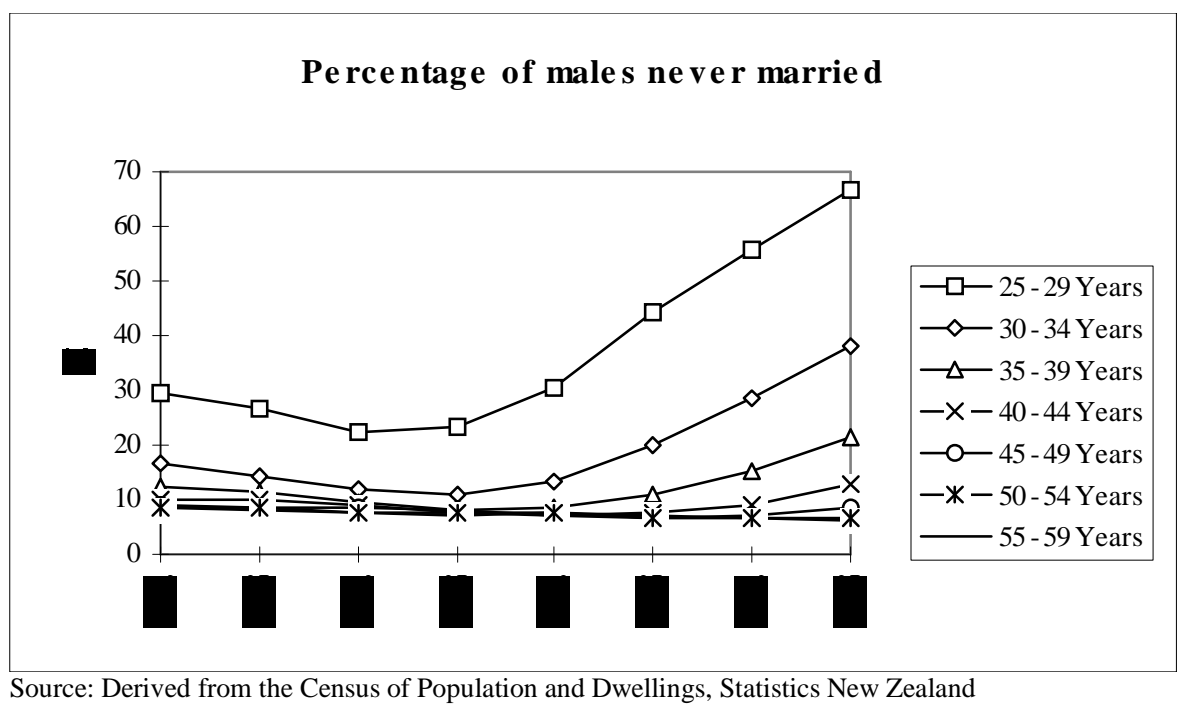


Figure 33

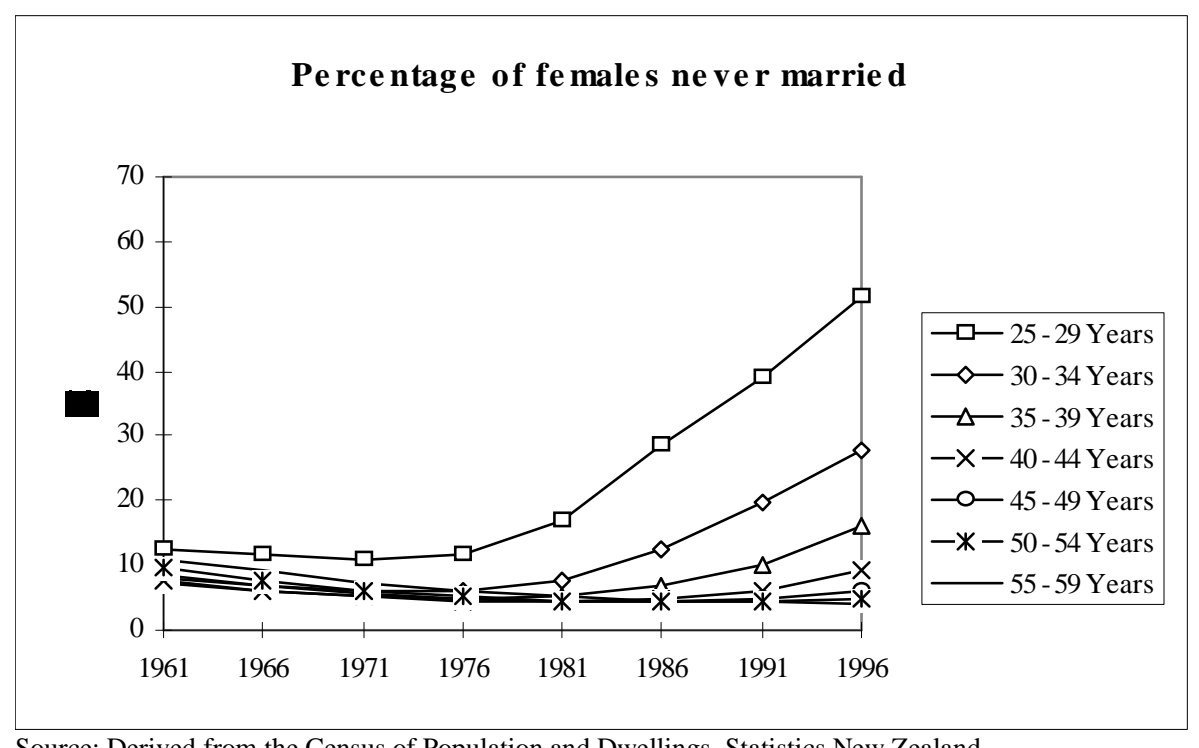

Source: Derived from the Census of Population and Dwellings, Statistics New Zealand

\section{Fewer people in couples}

Many people who have never married are, or have been, in defacto relationships. However, there are no data on those who have never been in a defacto relationship and similarly there are no data on those who have separated or have been "widowed" from a defacto union. In addition, 1986 was the first census in which a specific question on living arrangements was asked. ${ }^{98}$ However, when comparisons are made with data in the early part of the century it can be safely assumed that most people living in a couple were legally married. These long term census data show that the percentage of people aged 2024 living in a couple in 1996 was far lower than that at the 1966 census, but actually higher than in both 1936 and 1906. For those aged 25-39 the proportion in couples in 1996 was again lower than 1966, but about the same as in 1936 and 1906 (Statistics New Zealand 1998). ${ }^{99}$

\footnotetext{
${ }^{98}$ Statistics New Zealand did ask about de facto unions in the 1981 census as an adjunct to the marital status question, but the question was poorly answered and there are concerns about the quality of the data.

99 An imbalance of men to women will have had some influence on the 1906 data. Arnold (1982) shows that in the late nineteenth century and even through to 1906 there were considerably more men than women living in New Zealand. In 1906, the ratio of available females to available males in the 25-30 age group was 0.59 , for 30-35 year olds 0.59 and for the 35-40 age group 0.63. The 1936 data will have also been affected by the 1930s depression when marriage was delayed.
} 
New Zealand researchers, using census data, have already indicated that there has been a decline in the proportion of people in couples in the period I am studying. For instance, Davey (1998a), shows that between 1981 and 1996 there was a declining proportion of Maori, Pacific Island and Pakeha people aged 20-39 who lived in couple households. Yet, the proportion of people aged 40-59 (in all ethnic groups) who lived in couples appeared to have remained relatively stable over this period.

While my research generally does not focus on couples defined by the census marital status question, Figure 34 shows changes between 1986 and 1996 in the proportion of men in couples using this measure (the pattern for women is very similar).

Figure 34

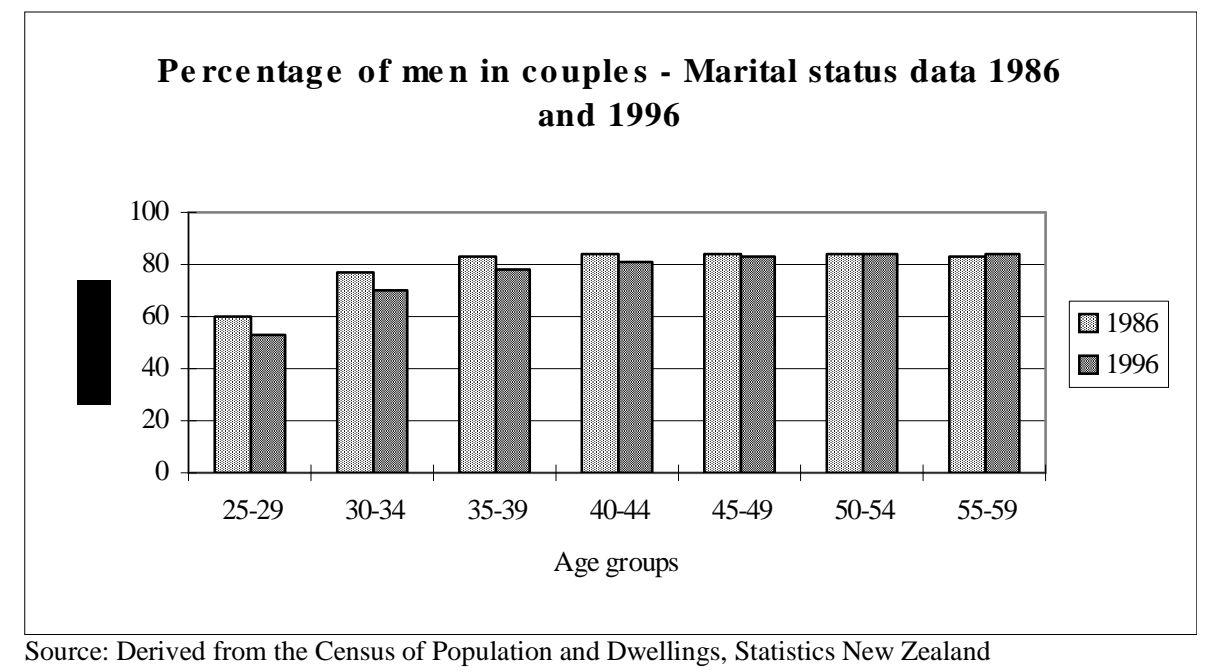

Most of the subsequent analysis is based on household type rather than family type. To gain some idea of differences between trends when using family and household data, the following table shows both martial status and derived couples for men (including absent family members). As Table 57 shows, while the two different definitions generate slightly different numbers, the overall trends are very similar. 
Table 57 - Percentage of men in couples, 1986 and 1996 - Two measures

\begin{tabular}{rrrrrrr}
\hline & \multicolumn{3}{c}{ Marital status couples } & \multicolumn{3}{c}{ Couple households* } \\
\hline & 1986 & 1996 & Change & 1986 & 1996 & Change \\
$25-29$ & 59 & 53 & -6 & 58 & 49 & -9 \\
$30-34$ & 76 & 70 & -6 & 76 & 67 & -9 \\
$35-39$ & 82 & 78 & -4 & 82 & 75 & -7 \\
$40-44$ & 83 & 81 & -2 & 83 & 78 & -5 \\
\hline
\end{tabular}

Sources: Published census data and special tabulations

* with or without children

Using 1996 data, in overall patterns of couple living there were some important ethnic differences. For example, men who described themselves as sole Maori were more likely than other ethnic groups (including "mixed" Maori) ${ }^{100}$ to be in couple households when they were young, but far less likely in older age groups. The patterns of Asian men also showed some differences. While less likely than other groups to be in a couple under the age of 30 they had the highest rates of couple living from 30-59 (Callister 2000a).

\section{No job, no partner?}

Table 58 shows only 1996 data and uses the narrow category of living in a legally married couple household. This is the target group in many overseas studies of labour market and family change. The table shows there was a relatively strong relationship between employment status and whether a male lived in such a couple. Those men working full time were most likely to legally married. Those least likely were unemployed or not in the labour force with very little difference between these two groups. Yet, the data also shows that, in 1996, a significant proportion of men not in paid work were nevertheless living in a legally married couple household.

\footnotetext{
100 This is where a person identifies as part of the Maori ethnic group but also has one or more other ethnic affiliations.
} 
Table 58 - Proportion of men in each labour force status living in a legally married couple household, 1996

\begin{tabular}{lrrrrr}
\hline Age & Full time & Part time & Unemployed & Non labour & Total* \\
\hline $25-29$ & 31.7 & 20.0 & 15.3 & 15.3 & 28.2 \\
$30-34$ & 55.5 & 40.8 & 31.2 & 30.2 & 50.8 \\
$35-39$ & 67.0 & 50.6 & 40.3 & 36.7 & 61.9 \\
$40-44$ & 68.7 & 55.6 & 45.3 & 41.2 & 64.4 \\
$45-49$ & 60.0 & 51.5 & 42.2 & 41.4 & 57.1 \\
$50-54$ & 54.5 & 50.9 & 40.2 & 39.8 & 52.0 \\
$55-59$ & 59.5 & 56.9 & 42.8 & 46.5 & 56.1 \\
\hline \multicolumn{5}{l}{ Source: Derived from the Census of Population and Dwellings, Statistics New Zealand } \\
* These totals based only on men who stated their labour force status
\end{tabular}

Some of these people may have been married for a second or subsequent time. However, based on other research using census data, there is also some small relationship between labour force status and whether a person (and their partner) is married for the first time (Callister 1999e). That is, employed men were more likely to be in couples where both partners were married for a first time than were men in other labour market statuses.

Table 59 shows the proportion of men in each labour force status who in 1996 were living in defacto relationships. The link between labour force status and couple living is considerably weakened when this group is considered. However, also of interest when Tables 58 and 59 are compared is that defacto living was a popular choice relative to marriage amongst young men in all labour force statuses but in older age groups marriage was the most common couple arrangement in all labour force statuses. This further supports the idea of delayed marriage.

Table 59 - Proportion of men in each labour force status living in a defacto couple household, 1996

\begin{tabular}{lrrrrr}
\hline Age & Full time & Part time & Unemployed & Non labour & Total* \\
\hline $25-29$ & 24.3 & 19.4 & 19.4 & 14.5 & 22.7 \\
$30-34$ & 18.0 & 18.5 & 17.4 & 14.0 & 17.6 \\
$35-39$ & 13.6 & 15.4 & 15.0 & 12.6 & 13.7 \\
$40-44$ & 14.7 & 14.8 & 14.3 & 12.7 & 14.5 \\
$45-49$ & 24.6 & 21.4 & 17.3 & 16.7 & 23.4 \\
$50-54$ & 31.0 & 25.7 & 20.6 & 20.6 & 29.1 \\
$55-59$ & 26.9 & 22.5 & 20.2 & 20.2 & 25.0 \\
\hline
\end{tabular}

Source: Derived from the Census of Population and Dwellings, Statistics New Zealand

* These totals based only on men who stated their labour force status 
Table 60 merges the two types of couples and brings in a time dimension. ${ }^{101}$ It shows two dates, 1986 and 1996. The table indicates the relationship between employment status for men aged 25-59 and the proportion living in couple households.

Table 60 shows some complexity in the associations and the changes over time. However, two main points stand out:

- in both 1986 and 1996 men who were not in the labour force were far less likely than men working full time to be in a couple household.

- between 1986 and 1996 labour market status weakened as a predictor of whether a man would live in a couple household.

Adding complexity, the data show that there was a decline between 1986 and 1996 in the proportion of employed men in the 25-49 age groups who were in couples. This decline also took place amongst men aged 25-39 defined as unemployed. This trend possibly reflects a delay in couple formation and suggests that this delay is not just limited to men in marginal labour market positions. This provides a challenge to theories that it is men who are not in paid work who mainly are exiting this type of household arrangement.

As a further challenge, the proportion of men not in the labour force but who lived in couples increased in all the age groups shown. However, more information is needed about these men. Some will have been out of the labour force by choice and be supported by a well earning partner. These couples will generally be economically independent. However, other men will have been out of the labour force because both partners in the couple had lost their jobs. This emphasises the importance of knowing the economic circumstances of all members of a household.

While there was a decline in the proportion of unemployed men in couples in the younger age group, the size of this decline decreased by age group. The decline finally changed to

\footnotetext{
${ }^{101}$ In further research the changes over time of married and defacto couples as separate groups could be usefully analysed.
} 
an increase in the proportion of unemployed men who lived in couple households in the 40-44 age group. This pattern also shows up in the 50-59 age group. This suggests that unemployment expanded into existing older couples over the period studied, whereas amongst the younger age groups unemployment either delayed couple formation or younger unemployed men exited shorter-term (and possibly often defacto) couple relationships in which they had previously been involved.

Finally, in the 55-59 age group there was a small increase in the proportion of men in couples in most labour force statuses. The reasons for this trend are not clear. 
Table 60 - The percentage of men in each age group and labour force status living in a couple household (with or without children), 1986 and 1996

\begin{tabular}{|c|c|c|c|c|}
\hline & & $\%$ & & Change in $\%$ \\
\hline & & 1986 & 1996 & 1986-1996 \\
\hline \multicolumn{5}{|l|}{$25-29$} \\
\hline & Full time & 62 & 56 & -6 \\
\hline & Part time & 50 & 39 & -11 \\
\hline & Unemployed & 37 & 34 & -3 \\
\hline & Non labour force & 20 & 29 & 9 \\
\hline \multicolumn{5}{|l|}{$30-34$} \\
\hline & Full time & 79 & 73 & -6 \\
\hline & Part time & 68 & 59 & -9 \\
\hline & Unemployed & 50 & 48 & -2 \\
\hline & Non labour force & 29 & 43 & 14 \\
\hline \multicolumn{5}{|l|}{$35-39$} \\
\hline & Full time & 84 & 80 & -4 \\
\hline & Part time & 73 & 65 & -8 \\
\hline & Unemployed & 56 & 55 & -1 \\
\hline & Non labour force & 32 & 48 & 16 \\
\hline \multicolumn{5}{|l|}{$40-44$} \\
\hline & Full time & 85 & 83 & -2 \\
\hline & Part time & 74 & 69 & -5 \\
\hline & Unemployed & 56 & 59 & 3 \\
\hline & Non labour force & 36 & 53 & 17 \\
\hline \multicolumn{5}{|l|}{$45-49$} \\
\hline & Full time & 85 & 84 & -1 \\
\hline & Part time & 76 & 72 & -4 \\
\hline & Unemployed & 59 & 59 & 0 \\
\hline & Non labour force & 43 & 57 & 14 \\
\hline \multicolumn{5}{|l|}{$50-54$} \\
\hline & Full time & 85 & 85 & 0 \\
\hline & Part time & 76 & 76 & 0 \\
\hline & Unemployed & 59 & 60 & 1 \\
\hline & Non labour force & 49 & 59 & 10 \\
\hline \multicolumn{5}{|l|}{$55-59$} \\
\hline & Full time & 85 & 86 & 1 \\
\hline & Part time & 79 & 79 & 0 \\
\hline & Unemployed & 61 & 62 & 1 \\
\hline & Non labour force & 62 & 66 & 4 \\
\hline
\end{tabular}

Source: Derived from the Census of Population and Dwellings, Statistics New Zealand

As discussed in earlier chapters, due to data problems I have not attempted to develop ethnic comparisons. However, to illustrate the possible importance of ethnicity I draw on 1996 data. To simplify the analysis, Figure 35 focuses on the 35-39 age group. This a group where the effects of delays in couple formation should have substantially weakened. It is also an age when the work histories (and future prospects) of the men would be much clearer to prospective and current partners. Figure 35 shows the percentage of men in each ethnic group and each employment state who lived in a couple household. It shows clearly, that for men in full-time work the ethnic differences were 
fairly small in 1996. However, in the other employment statuses ethnicity becomes of some importance. Two groups stand out, Asians and Pacific Island people. For Asian men employment status has little relationship to whether they lived in a couple household. For Pacific Island men the relationship becomes slightly stronger. It is likely that a range of factors influenced these patterns. For example, there are likely to be major differences between New Zealand and overseas born Asians and Pacific Island peoples, and it is likely that couple living is much higher amongst those men who state they hold religious beliefs.

The graph also shows that in each labour force status men with a sole Maori ethnicity were the least likely to live in a couple. So men with a sole Maori ethnicity are not only the least likely group to be in full-time paid work, but they were also the least likely to live in a couple household. Overall, the figure provides some further challenge to the idea that there is a simple relationship between labour force status and living arrangements for men.

Figure 35

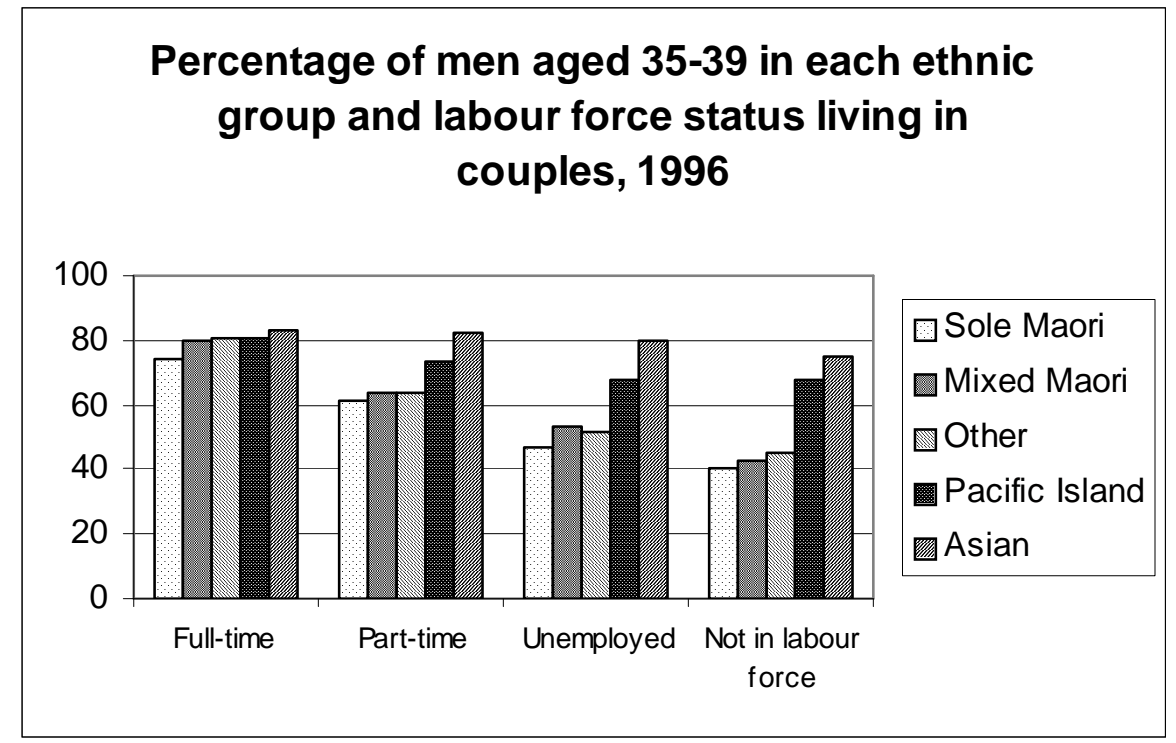

Source: Derived from the Census of Population and Dwellings, Statistics New Zealand 


\section{Men, employment and childrearing couples}

Table 61 focuses only on childrearing couple households. Like Table 60, it shows that men who were not in the labour force were far less likely than men working full time to be in a childrearing couple in both 1986 and 1996. However, again the difference between these two groups declined. Second, there was an almost universal decline in the age groups shown in the proportion of men in the labour force who were in childrearing couples between 1986 and 1996. In fact, the strongest decline was amongst men who either worked full time or part time. This trend, and the increase in the proportion of men not in the labour force who were in childrearing couples, seemingly provides a further challenge to theories about men not being in paid work exiting this type of household arrangement. However, additional information is needed on those men in paid work who were no longer in childrearing couples, such as whether they were generally in insecure low-income jobs.

The trend for more men who were not in the labour force to be in childrearing couples seems to mainly reflect the growth in proportion of men in this work status and that this group became less homogeneous. A small number of these men were well educated and in stable long-term relationships. A small number potentially had good job prospects but had decided to stay home full time and look after children. However, just as welleducated women tend no longer to spend years out of the workforce looking after children full time at home, those well-educated men who looked after children full time were also likely to spend relatively short periods out of paid work. Other men were perhaps studying part time while their partner becomes the main "breadwinner". Again, this would tend to be of a short-term nature. However, as will be shown in Chapter twenty, a high proportion of those men not in the labour force and still in couple households were living in work-poor couples.

In the older age groups, there will have been couples with adult children living with them. Many of these would have been students at tertiary institutions, but some will have been adult children who had returned to live with their parents. This issue will be discussed in more detail in a later section. 
Table 61 - The percentage of men in each age group and labour force status living in a couple household with a child (dependent and adult children), 1986 and 1996

\begin{tabular}{|c|c|c|c|c|}
\hline & & $\%$ & & Change in $\%$ \\
\hline & & 1986 & 1996 & 1986-1996 \\
\hline \multicolumn{5}{|l|}{$25-29$} \\
\hline & Full time & 36 & 24 & -12 \\
\hline & Part time & 32 & 19 & -13 \\
\hline & Unemployed & 28 & 22 & -6 \\
\hline & Non labour force & 12 & 17 & 5 \\
\hline \multicolumn{5}{|l|}{$30-34$} \\
\hline & Full time & 65 & 50 & -15 \\
\hline & Part time & 56 & 41 & -15 \\
\hline & Unemployed & 42 & 37 & -5 \\
\hline & Non labour force & 23 & 33 & 10 \\
\hline \multicolumn{5}{|l|}{$35-39$} \\
\hline & Full time & 77 & 67 & -10 \\
\hline & Part time & 66 & 54 & -12 \\
\hline & Unemployed & 49 & 48 & -1 \\
\hline & Non labour force & 27 & 41 & 14 \\
\hline \multicolumn{5}{|l|}{$40-44$} \\
\hline & Full time & 78 & 72 & -6 \\
\hline & Part time & 65 & 58 & -7 \\
\hline & Unemployed & 48 & 51 & 3 \\
\hline & Non labour force & 29 & 45 & 16 \\
\hline \multicolumn{5}{|l|}{$45-49$} \\
\hline & Full time & 71 & 63 & -8 \\
\hline & Part time & 61 & 53 & -8 \\
\hline & Unemployed & 48 & 46 & -2 \\
\hline & Non labour force & 32 & 43 & 11 \\
\hline \multicolumn{5}{|l|}{$50-54$} \\
\hline & Full time & 56 & 46 & -10 \\
\hline & Part time & 48 & 40 & -8 \\
\hline & Unemployed & 41 & 37 & -4 \\
\hline & Non labour force & 28 & 34 & 6 \\
\hline \multicolumn{5}{|l|}{$55-59$} \\
\hline & Full time & 40 & 31 & -9 \\
\hline & Part time & 34 & 27 & -7 \\
\hline & Unemployed & 31 & 26 & -5 \\
\hline & Non labour force & 24 & 26 & 2 \\
\hline
\end{tabular}

Source: Derived from the Census of Population and Dwellings, Statistics New Zealand

Figure 36 again narrows the focus down to men in the 35-39 age group in 1996. It also further narrows the focus on those men who lived in a legally married couple household and who had a dependent child. It brings in ethnicity and examines the proportion of men in each labour market status and each ethnic group who lived in a childrearing couple household. The pattern is somewhat similar to Figure 35 but the differences between ethnic groups are more pronounced. This will, in part, reflect differences in attitudes towards legal marriage. Also of interest, is that the patterns for the mixed Maori group are 
more similar to the group "other" (mainly European ethnicity) than they are to the sole Maori group.

While there are underlying educational differences between these ethnic groups, other factors were also at work. For example, in the situation of sole Maori men in full-time work versus Asian men in full-time work, Asian men without qualifications were one and a half times more likely to be in this living arrangement than Maori men with no qualifications. The next section specifically examines education as a variable in living arrangements. Figure 36 again indicates that norms appear to have some importance in living arrangements. However, ultimately the census data cannot confirm the impact of norms on behaviour. This requires other types of research.

\section{Figure 36}

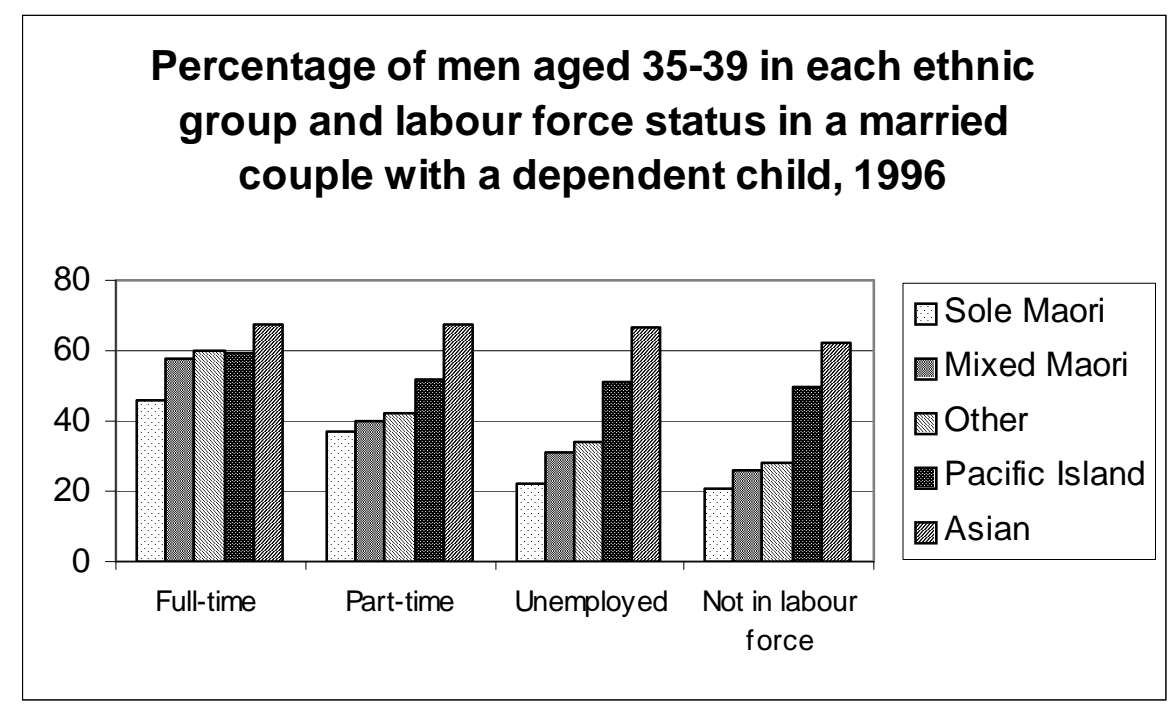

Source: Derived from the Census of Population and Dwellings, Statistics New Zealand

\section{Some associations between education and living arrangements for men}

Overall, in 1986 educational status had only a relatively weak association with whether a male lived in a couple household. However, just as education became a stronger predictor of labour force status in 1996, it also became a stronger predictor of whether men lived in couple households. Table 62 shows that between 1986 and 1996 the largest decline in men in couples was amongst those with no formal qualifications, while the least decline was amongst those men with university qualifications. In fact, in the older age groups the 
decline in the proportion of university-qualified men in a couple household was either insignificant or non-existent.

Table 62 - The percentage of men in each age group and educational group living in a couple household (with or without a child), 1986 and 1996

\begin{tabular}{|c|c|c|c|c|}
\hline & & $\%$ & & Change in $\%$ \\
\hline & & 1986 & 1996 & 1986-1996 \\
\hline \multicolumn{5}{|l|}{$25-29$} \\
\hline & No formal qualifications & 58 & 48 & -10.0 \\
\hline & School qualifications & 57 & 51 & -6.0 \\
\hline & Other tertiary & 65 & 57 & -8.0 \\
\hline & University & 52 & 47 & -5.0 \\
\hline \multicolumn{5}{|l|}{$30-34$} \\
\hline & No formal qualifications & 73 & 61 & -12.0 \\
\hline & School qualifications & 76 & 68 & -8.0 \\
\hline & Other tertiary & 81 & 73 & -8.0 \\
\hline & University & 77 & 72 & -5.0 \\
\hline \multicolumn{5}{|l|}{$35-39$} \\
\hline & No formal qualifications & 79 & 67 & -12.0 \\
\hline & School qualifications & 82 & 75 & -7.0 \\
\hline & Other tertiary & 85 & 79 & -6.0 \\
\hline & University & 84 & 82 & -2.0 \\
\hline \multicolumn{5}{|l|}{$40-44$} \\
\hline & No formal qualifications & 81 & 73 & -8.0 \\
\hline & School qualifications & 82 & 78 & -4.0 \\
\hline & Other tertiary & 86 & 81 & -5.0 \\
\hline & University & 86 & 85 & -1.0 \\
\hline \multicolumn{5}{|l|}{$45-49$} \\
\hline & No formal qualifications & 81 & 76 & -5.0 \\
\hline & School qualifications & 81 & 80 & -1.0 \\
\hline & Other tertiary & 86 & 82 & -4.0 \\
\hline & University & 87 & 85 & -2.0 \\
\hline \multicolumn{5}{|l|}{$50-54$} \\
\hline & No formal qualifications & 81 & 78 & -3.0 \\
\hline & School qualifications & 80 & 80 & 0.0 \\
\hline & Other tertiary & 86 & 83 & -3.0 \\
\hline & University & 87 & 86 & -1.0 \\
\hline \multicolumn{5}{|l|}{$55-59$} \\
\hline & No formal qualifications & 80 & 78 & -2.0 \\
\hline & School qualifications & 79 & 79 & 0.0 \\
\hline & Other tertiary & 85 & 84 & -1.0 \\
\hline & University & 86 & 86 & 0.0 \\
\hline
\end{tabular}

Studying the impact of education and employment on living arrangements separately is potentially problematic given the strong association between educational qualifications and participation in paid work for men shown in previous chapters. Table 63 therefore 
studies the effect of both these variables simultaneously. However, in order to simply the analysis, again only men in the 35-39 age group are examined.

Table 63 shows a number of patterns. First, it indicates that for men employed full time there was a decline in the proportion of men living in couple households amongst all educational groups. However, the strongest decline was amongst those men with no formal qualifications, with only a marginal decline amongst those men with university qualifications. In 1996, in this age group men who worked full time and also held a university qualification had the highest probability of being in a couple household. In contrast, amongst those men who were not in the labour force there was a rise in the proportion in couples in all educational groups. Despite this, in 1996, the men most unlikely to be in a couple were those not in the labour force and who also had no formal qualification. When combined, the variables of education and employment status are reasonably strong predictors of whether men will be living in a couple household.

Table 63 - 35-39 - Percentage of men in a couple household

\begin{tabular}{|c|c|c|c|c|}
\hline & & 1986 & 1996 & $\begin{array}{r}\text { Change } \\
86-96\end{array}$ \\
\hline \multirow[t]{4}{*}{ Full time } & No Formal Qualifications & 83 & 76 & -7 \\
\hline & School Qualifications & 83 & 79 & -4 \\
\hline & Other Tertiary & 86 & 82 & -4 \\
\hline & University & 86 & 85 & -1 \\
\hline \multirow[t]{4}{*}{ Part time } & No Formal Qualifications & 74 & 63 & -11 \\
\hline & School Qualifications & 74 & 66 & -8 \\
\hline & Other Tertiary & 76 & 68 & -9 \\
\hline & University & 66 & 69 & 4 \\
\hline \multirow[t]{4}{*}{ Unemployed } & No Formal Qualifications & 56 & 51 & -4 \\
\hline & School Qualifications & 50 & 53 & 3 \\
\hline & Other Tertiary & 62 & 56 & -5 \\
\hline & University & 52 & 69 & 17 \\
\hline \multirow[t]{4}{*}{ Non-labour force } & No Formal Qualifications & 32 & 43 & 10 \\
\hline & School Qualifications & 32 & 51 & 19 \\
\hline & Other Tertiary & 48 & 55 & 7 \\
\hline & University & 48 & 65 & 17 \\
\hline
\end{tabular}




\section{Non-couple living arrangements for men}

There is considerable diversity in living arrangements for men not in couples, but labour market status is an important variable in these patterns. Table 64 provides an overview in 1996 of the differences between men and women in living arrangements when not living in couple households. What clearly stands out is that a significant number of women lived in sole parent households, whereas for men living alone was the largest category. Living as an adult child is also more important for men than women. Also of significance is the difference in numbers of men and women living in non-private dwellings. As the table shows, a very small part of this reflects differences in the prison population.

Table 64 - Number of men and women aged 25-59 in each living arrangement, 1996

\begin{tabular}{llrr}
\hline & & Female & Male \\
\hline Private dwelling & Sole Parent with Dependent children & 87,978 & 17,175 \\
& Adult Child in Family & 22,803 & 44,229 \\
& Other Family Relationship & 10,653 & 10,527 \\
& Living with Family or Families, not Related & 23,877 & 23,667 \\
& Living Alone & 48,330 & 62,946 \\
& Living in a Non-Family Household & 35,262 & 51,681 \\
& Unable to Categorise & 18,492 & 21,363 \\
Non-private dwelling & 8,277 & 15,645 \\
& Living in Non Private Dwelling & 189 & 2,406 \\
& Subset living in prison * & 255,672 & 247,233 \\
\hline
\end{tabular}

Source: Derived from the Census of Population and Dwellings, Statistics New Zealand.

* This number needs to be treated with caution

Table 65 shows a basic ethnic breakdown of men in Table 64. It includes the not specified ethnicity group as well as the "unable to categorise" living arrangement. The not specified ethnic group is very large, and within this group a high proportion of living arrangements cannot be determined. Again, it is reminder of the problems this group pose when trying to establish trends. Table 65 provides an indication that in non-couple living arrangements ethnicity appears to be of some importance. 
Table 65 - Percentage of men aged 25-59 in each ethnic group living in particular non-couple households, 1996

\begin{tabular}{lrrrrrr}
\hline & Sole Maori & \multicolumn{2}{c}{$\begin{array}{c}\text { Mixed Maori Pacific } \\
\text { Peoples }\end{array}$} & Asian & \multicolumn{2}{c}{$\begin{array}{l}\text { Not } \\
\text { specified }\end{array}$} \\
& \multicolumn{7}{c}{7.8} & 13.1 & 5.9 & 1.5 & Other \\
\hline Sole parent & 16.8 & 27.2 & 24.5 & 19.0 & 2.5 & 19.2 \\
Adult child & 16.7 & 7.4 & 18.8 & 7.6 & 1.2 & 2.4 \\
$\begin{array}{l}\text { Other family } \\
\text { relationship }\end{array}$ & 11.4 & & & & & \\
Living with family not & 11.1 & 13.4 & 9.4 & 17.4 & 2.3 & 9.8 \\
related & & & & & & \\
Living Alone & 18.3 & 12.4 & 11.7 & 14.0 & 9.9 & 32.6 \\
Non-family household & 15.0 & 26.7 & 13.5 & 24.2 & 4.2 & 24.3 \\
Unable to Categorise & 1.4 & 1.5 & 1.7 & 1.0 & 67.5 & 0.4 \\
Non private dwelling & 9.3 & 3.5 & 7.4 & 10.9 & 10.8 & 5.1 \\
Total & 100.0 & 100.0 & 100.0 & 100.0 & 100.0 & 100.0 \\
N= & 21,840 & 21,138 & 9,348 & 8,745 & 29,379 & 156,783 \\
\hline
\end{tabular}

Source: Derived from the Census of Population and Dwellings, Statistics New Zealand.

There are a number of areas where there were important differences between ethnic groups. For example 17 percent of sole Maori men lived as adult children in a family versus 27 percent for the mixed Maori group. There could be many reasons for this. One might be more of the younger adult children of mixed Maori may have been in tertiary study than sole Maori. Also of note, was that men from the "other" group were far more likely to live alone. This may be that with higher incomes more of these men can choose to live alone. However, within this broad 25-59 age group there are also differences in the age structures of the various ethnic groups.

Table 66 shows some selected non-couple living arrangements by labour force status for prime-aged men in 1996. It shows that, apart from non-private dwellings, in all the living arrangements indicated most men worked full time. This needs to be kept in mind when viewing Table 67. In the non-private dwelling group there will have been students living in halls of residence, men in prison, those living in boarding houses and those in longterm hospital stays. 
Table 66 - Total number of men aged 25-59 living in selected living arrangements, 1996

\begin{tabular}{lrrrr}
\hline & Full time & Part time & Unemployed Not in labour \\
& & & & force \\
\hline Sole parent & 8,022 & 1,245 & 1,965 & 4,986 \\
Adult child & 25,443 & 2,961 & 4,143 & 7,344 \\
Living alone & 42,351 & 4,065 & 4,272 & 9,204 \\
Non-family & 32,997 & 3,426 & 3,696 & 7,197 \\
Non-private dwelling & 4,686 & 930 & 900 & 4,983 \\
\hline Source: Derived from the Census of Population and Dwellings, Statistics New Zealand.
\end{tabular}

Table 67 provides a more detailed breakdown of living arrangement by labour force status and age in both 1986 and 1996. It shows the percentage of men in each labour force status living in selected household arrangements. It shows that men in the younger ages who were not in the labour force in both 1986 and 1996 primarily lived with their parents, in non-family households or in non-private dwellings. Further illustrating the strong relationship between labour market status and living arrangement, only three percent of men aged 35-39 who were in full-time work were living as an adult child in a family in 1996, but this rose to ten percent for men not in the labour force. In addition, one percent of men in this age group in full-time work lived in non-private dwellings, but this rose to nine percent of those not in the labour force. Yet, also of interest was the decline between 1986 and 1996 in the proportion of unemployed and non-labour force men living in most of these non-couple arrangements. This reflects the earlier finding that more men not in paid work now live in couples. 
Table 67 - Percentage of men in each labour force status living in selected household arrangements, 1986 and 1996

\begin{tabular}{|c|c|c|c|c|c|c|c|c|c|c|}
\hline \multirow[b]{2}{*}{$25-29$} & \multicolumn{2}{|c|}{$\begin{array}{l}\text { Sole parent } \\
\text { household }\end{array}$} & \multicolumn{2}{|c|}{$\begin{array}{l}\text { Adult child } \\
\text { in family }\end{array}$} & \multicolumn{2}{|c|}{$\begin{array}{r}\text { Living } \\
\text { alone }\end{array}$} & \multicolumn{2}{|c|}{$\begin{array}{l}\text { Non- } \\
\text { family } \\
\text { private }\end{array}$} & \multicolumn{2}{|c|}{$\begin{array}{c}\text { Non- } \\
\text { private } \\
\text { dwelling }\end{array}$} \\
\hline & 86 & 96 & 86 & 96 & 86 & 96 & 86 & 96 & 86 & 96 \\
\hline Full time & 0 & 1 & 13 & 13 & 6 & 7 & 13 & 15 & 2 & 2 \\
\hline Part time & 1 & 2 & 17 & 20 & 8 & 6 & 16 & 19 & 2 & 4 \\
\hline Unemployed & 2 & 4 & 23 & 23 & 6 & 6 & 18 & 16 & 3 & 3 \\
\hline Non labour & 6 & 5 & 22 & 21 & 6 & 6 & 21 & 17 & 20 & 11 \\
\hline Total* & 1 & 2 & 14 & 16 & 6 & 6 & 14 & 16 & 3 & 3 \\
\hline \multicolumn{11}{|l|}{$30-34$} \\
\hline Full time & 1 & 1 & 5 & 6 & 6 & 7 & 6 & 8 & 1 & 1 \\
\hline Part time & 2 & 3 & 8 & 9 & 8 & 8 & 9 & 12 & 2 & 3 \\
\hline Unemployed & 5 & 6 & 15 & 13 & 8 & 8 & 12 & 11 & 3 & 3 \\
\hline Non labour & 11 & 8 & 14 & 12 & 7 & 8 & 16 & 11 & 18 & 10 \\
\hline Total* & 1 & 2 & 6 & 7 & 6 & 7 & 7 & 9 & 2 & 2 \\
\hline \multicolumn{11}{|l|}{$35-39$} \\
\hline Full time & 2 & 2 & 3 & 3 & 5 & 7 & 3 & 4 & 1 & 1 \\
\hline Part tim & 3 & 4 & 5 & 6 & 7 & 9 & 6 & 7 & 1 & 3 \\
\hline Unemployed & 7 & 7 & 10 & 9 & 9 & 11 & 8 & 8 & 2 & 3 \\
\hline Non labour & 13 & 10 & 12 & 9 & 8 & 10 & 14 & 9 & 17 & 9 \\
\hline Total* & 2 & 3 & 3 & 4 & 6 & 8 & 4 & 5 & 2 & 2 \\
\hline \multicolumn{11}{|l|}{$40-44$} \\
\hline Full time & 2 & 2 & 2 & 2 & 4 & 7 & 2 & 3 & 1 & 1 \\
\hline Part tim & 4 & 5 & 4 & 4 & 6 & 10 & 5 & 5 & 2 & 3 \\
\hline Unemployed & 6 & 7 & 8 & 6 & 9 & 12 & 7 & 7 & 4 & 3 \\
\hline Non labour & 10 & 9 & 11 & 7 & 10 & 11 & 14 & 7 & 15 & 7 \\
\hline Total* & 2 & 3 & 3 & 3 & 6 & 7 & 3 & 3 & 1 & 2 \\
\hline \multicolumn{11}{|l|}{$45-49$} \\
\hline Full time & 2 & 2 & 2 & 1 & 6 & 7 & 2 & 2 & 1 & 1 \\
\hline Part time & 3 & 3 & 3 & 3 & 12 & 11 & 4 & 4 & 2 & 3 \\
\hline Unemployed & 6 & 4 & 6 & 5 & 6 & 14 & 6 & 7 & 4 & 2 \\
\hline Non labour & 7 & 6 & 7 & 5 & 10 & 13 & 12 & 6 & 15 & 7 \\
\hline Total* & 2 & 2 & 2 & 2 & 6 & 8 & 3 & 3 & 2 & 2 \\
\hline \multicolumn{11}{|l|}{$50-54$} \\
\hline Full tim & 1 & 1 & 1 & 1 & 7 & 7 & 2 & 2 & 1 & 1 \\
\hline Part time & 2 & 2 & 2 & 2 & 10 & 11 & 4 & 3 & 2 & 2 \\
\hline Unemployed & 3 & 3 & 3 & 3 & 15 & 17 & 7 & 7 & 4 & 2 \\
\hline Non labour & 5 & 3 & 5 & 4 & 13 & 15 & 12 & 6 & 11 & 6 \\
\hline Total* & 1 & 1 & 2 & 2 & 7 & 9 & 3 & 3 & 2 & 2 \\
\hline \multicolumn{11}{|l|}{$55-59$} \\
\hline Full tim & 1 & 0 & 1 & 1 & 8 & 8 & 2 & 2 & 1 & 1 \\
\hline Part time & 1 & 1 & 1 & 1 & 10 & 11 & 4 & 3 & 2 & 2 \\
\hline Unemployed & 2 & 2 & 2 & 2 & 19 & 19 & 6 & 5 & 4 & 2 \\
\hline Non labour & 2 & 2 & 2 & 2 & 14 & 15 & 8 & 4 & 7 & 4 \\
\hline Total* & 1 & 1 & 1 & 1 & 9 & 10 & 3 & 3 & 2 & 2 \\
\hline
\end{tabular}

Source: Derived from the Census of Population and Dwellings, Statistics New Zealand.

* This includes men who did not specify their labour market status.

While living alone can be a positive choice for many people, it appears from the data shown that for a group of men this living arrangement is associated with being excluded from both work and family life. An unknown proportion of the men living alone or in 
other households without children will, in fact, be fathers who are not living with their biological children. While more information is needed, these data also potentially suggest that many men who have children, yet are not living with them, are not moving on to reform new long-term cohabiting relationships, but are living in non-family situations. They may still, however, be involved in less formal relationships with another partner (or their original partner), and some of them may be highly involved with their children despite not living with them. However, the census data cannot shed light on these types of relationships.

\section{Some associations between employment, education and living arrangements for women}

Traditionally associations between employment and living arrangement are more complex for women. Instead of employment status determining living arrangement often living arrangement, including the presence of dependent children and the ages of those children, influences employment patterns. Nevertheless, Table 68 shows changes in the association between employment status and whether women lived in couples between 1986 and 1996.

In most of the age groups the largest declines in couple living were amongst women not in the labour force and those unemployed. In contrast, in some of the age groups the proportion of women who were employed full time and lived in couples increased. When changes in the actual numbers of women in each employment status are taken into account, these two trends partly reflect that women in couples were increasingly likely to be in paid work. As will be subsequently discussed in Chapter twenty, the women moving into paid work were highly likely to have a partner also in paid work and so form workrich couples. However, the data also reflect the growth in sole parenthood and the number of women living along over this time period. 
Table 68 - The percentage of women in each age group and labour force status living in a couple household (with or without a child), 1986 and 1996

\begin{tabular}{|c|c|c|c|c|}
\hline & & $\%$ & & Change in $\%$ \\
\hline & & 1986 & 1996 & 1986-1996 \\
\hline \multicolumn{5}{|l|}{$25-29$} \\
\hline & Full time & 61.2 & 62.1 & 0.9 \\
\hline & Part time & 86.9 & 71.0 & -15.9 \\
\hline & Unemployed & 58.6 & 42.3 & -16.3 \\
\hline & Non labour force & 75.0 & 56.9 & -18.1 \\
\hline \multicolumn{5}{|l|}{$30-34$} \\
\hline & Full time & 71.9 & 69.9 & -2.0 \\
\hline & Part time & 92.0 & 84.0 & -8.0 \\
\hline & Unemployed & 67.9 & 51.9 & -16.0 \\
\hline & Non labour force & 78.5 & 67.5 & -11.0 \\
\hline \multicolumn{5}{|l|}{$35-39$} \\
\hline & Full time & 77.7 & 74.8 & -2.9 \\
\hline & Part time & 91.9 & 85.6 & -6.3 \\
\hline & Unemployed & 70.0 & 55.0 & -15.0 \\
\hline & Non labour force & 76.7 & 67.4 & -9.3 \\
\hline \multicolumn{5}{|l|}{$40-44$} \\
\hline & Full time & 78.6 & 77.4 & -1.2 \\
\hline & Part time & 91.3 & 85.5 & -5.8 \\
\hline & Unemployed & 67.8 & 56.2 & -11.6 \\
\hline & Non labour force & 75.6 & 66.0 & -9.6 \\
\hline \multicolumn{5}{|l|}{$45-49$} \\
\hline & Full time & 77.4 & 77.3 & -0.1 \\
\hline & Part time & 90.9 & 85.3 & -5.6 \\
\hline & Unemployed & 66.0 & 55.0 & -11.0 \\
\hline & Non labour force & 77.7 & 69.2 & -8.5 \\
\hline \multicolumn{5}{|l|}{$50-54$} \\
\hline & Full time & 74.9 & 75.5 & 0.6 \\
\hline & Part time & 88.5 & 84.4 & -4.1 \\
\hline & Unemployed & 63.1 & 53.4 & -9.7 \\
\hline & Non labour force & 77.7 & 71.3 & -6.4 \\
\hline \multicolumn{5}{|c|}{ 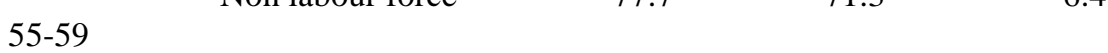 } \\
\hline & Full time & 67.7 & 72.1 & 4.4 \\
\hline & Part time & 82.6 & 80.5 & -2.1 \\
\hline & Unemployed & 51.9 & 48.6 & -3.3 \\
\hline & Non labour force & 75.4 & 72.3 & -3.1 \\
\hline
\end{tabular}

Source: Derived from the Census of Population and Dwellings, Statistics New Zealand

Some of the major non-couple living arrangements for women have already been touched on in an earlier table, however Table 69 shows more detail. In particular, in 1996 soleparenthood was the main non-couple living arrangement for younger women, while living alone became more important in older age groups. 
Table 69 - Percentage of all prime-aged women in main household living arrangements, 1996

\begin{tabular}{lrrrrrrr}
\hline & $25-29$ & $30-34$ & $35-39$ & $40-44$ & $45-49$ & $50-54$ & $55-59$ \\
\hline Couple only & 27 & 15 & 9 & 12 & 26 & 43 & 53 \\
Parents in Couple Family & 31 & 54 & 64 & 62 & 48 & 31 & 19 \\
Sole Parent with Dependent children & 14 & 14 & 14 & 12 & 7 & 3 & 2 \\
Adult Child in Family & 8 & 3 & 2 & 1 & 1 & 1 & 1 \\
Living with Family or Families, not Related & 3 & 1 & 1 & 2 & 4 & 5 & 5 \\
Living Alone & 3 & 4 & 4 & 5 & 7 & 10 & 13 \\
Living in a Non-Family Household & 10 & 5 & 3 & 2 & 2 & 3 & 3 \\
Living in Non Private Dwelling & 1 & 1 & 1 & 1 & 1 & 1 & 1 \\
\hline Source: Derived from the Census of Population and Dwellings, Statistics New Zealand. & & & &
\end{tabular}

Table 70 focuses on the living arrangements of women not in the labour force in 1996. This simply exaggerates the trends shown in Table 69. Amongst women aged 25-44 who were not in couples and also not in the labour force, the largest single group were in soleparent households. Comparing Tables 69 and 70 shows that the major differences in living arrangements are in the under 40 year olds. The differences in the two tables also reflect that women living in couple only households are highly likely to be in paid work.

Table 70 - Percentage of prime-aged women not in the labour force in main household living arrangements, 1996

\begin{tabular}{|c|c|c|c|c|c|c|c|}
\hline & $25-29$ & $30-34$ & $35-39$ & $40-44$ & $45-49$ & $50-54$ & $55-59$ \\
\hline Couple only & 7 & 4 & 4 & 8 & 22 & 40 & 54 \\
\hline Parents in Couple Family & 49 & 63 & 63 & 58 & 47 & 31 & 19 \\
\hline Sole Parent with Dependent children & 30 & 25 & 25 & 22 & 12 & 6 & 3 \\
\hline Adult Child in Family & 4 & 2 & 2 & 2 & 2 & 1 & 1 \\
\hline Living with Family or Families, not Related & 2 & 1 & 1 & 2 & 4 & 5 & 5 \\
\hline Living Alone & 1 & 1 & 2 & 3 & 6 & 9 & 12 \\
\hline Living in a Non-Family Household & 4 & 2 & 2 & 2 & 3 & 3 & 3 \\
\hline Living in Non Private Dwelling & 2 & 1 & 1 & 2 & 2 & 2 & 1 \\
\hline
\end{tabular}

As data in the next chapter will show, people with similar levels of formal qualification tend to form couples. It is then likely that the former partners of sole-mothers generally had a similar level of formal education to that of the mother. In 1996, women with no, or a low level, of formal qualifications were more likely to live in sole-mother households. This suggests that a higher proportion of poorly educated men are likely to be the father of children in sole mother families than well-educated men. However, again census data cannot prove this. 


\section{Were part-time jobs held by prime-aged people mainly filled by women in couples?}

The final association between work and living arrangement that I explore in this chapter is that of part-time work and living arrangement. Were most of the part-time jobs held by prime-aged people filled by women living in childrearing couples? Table 71 shows the percentage of prime-aged workers who worked part time by their living arrangement in both 1986 and 1996. It indicates that women in couples, and particularly mothers, were highly over-represented amongst prime-aged part-time workers. In 1986, 79 percent of part-time prime-aged workers were women in couples. However, while still very high, by 1996 this has declined to 67 percent. Table 71 shows that in the period 1986 to 1996 parttime work spread across to men in a range of living arrangements and also into a wider range of living arrangements for women. These data suggest that part-time work is no longer just an "optional" extra for partnered women with young children. For some prime-aged people it will be their hours of choice but for many others it will be the only job available.

Table 71 - Distribution (\%) of prime-aged part-time workers by living arrangement, 1986 and 1996

19861996

\begin{tabular}{lrrrr}
\hline & Males & \multicolumn{2}{r}{ Females Males } & Females \\
Couple in Couple Only & 2 & 12 & 4 & 15 \\
Parent in Couple Family* & 6 & 67 & 8 & 52 \\
Sole Parent & 0 & 4 & 1 & 8 \\
Adult Child in Family & 1 & 1 & 1 & 1 \\
Living with Family or Families, not Related & 1 & 2 & 1 & 0 \\
Living Alone & 1 & 1 & 2 & 3 \\
Living in a Non-Family Household & 0 & 0 & 2 & 2 \\
Living in a Non-Private dwelling & 1 & 1 & 1 & 0 \\
Total & 13 & 87 & 19 & 81 \\
\hline Source: Derived from the Census of Population and Dwellings, Statistics New Zealand. & \multicolumn{4}{c}{} \\
* includes non-dependent children & \multicolumn{4}{c}{. }
\end{tabular}

Figure 37 brings in a finer age analysis and narrows the group to prime-aged mothers with dependent children. Again, it shows while this group were over-represented amongst part-time workers in many age groups their dominance declined over the decade. The 
question of the labour force status of these women's partners is discussed in Chapter twenty.

Figure 37

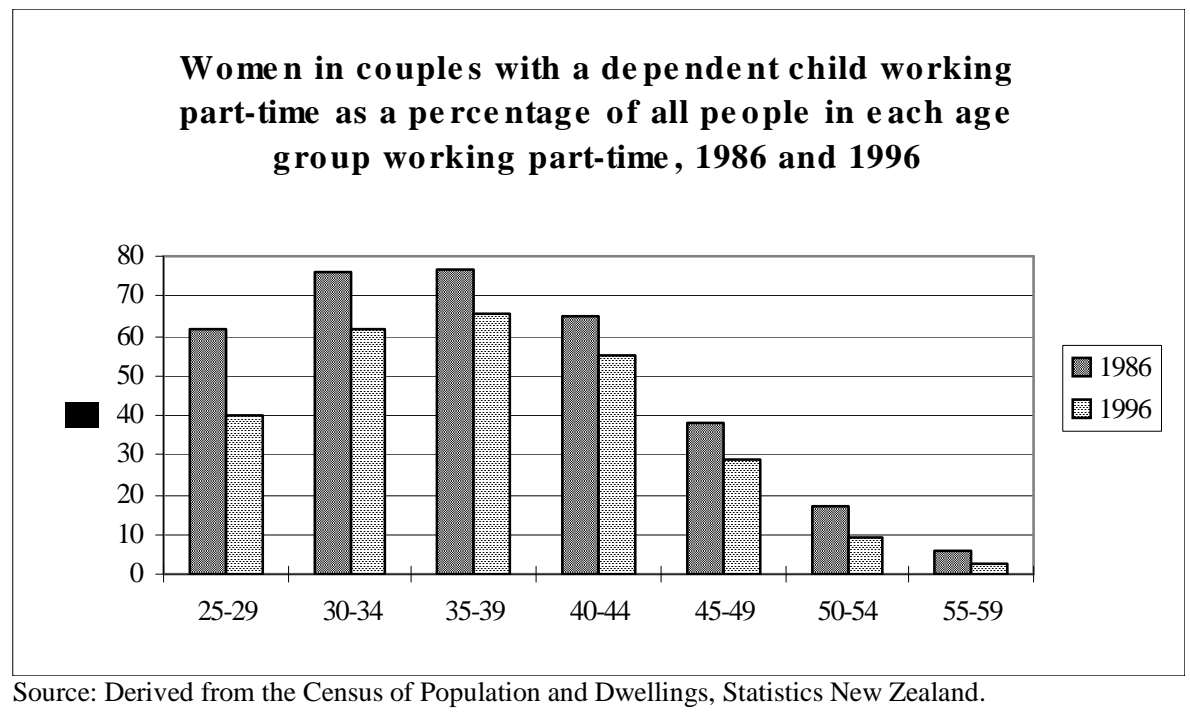

These data do not support the idea that much of the growth in part-time work for primeaged people was due to women in couples moving into this work. While women in couples were by 1996 still highly over-represented amongst part-time workers, part-time work spread to both men and women in a wide range of living arrangements in the period studied. In addition, the data supplied in earlier chapters show that much of the growth in part-time work had been amongst young men and women and men and women aged 60 or older. What still remains untested in this research is whether these older or younger parttime workers tended to live in work-rich households allowing them to take on this type of work.

\section{Conclusion}

There was a small but increasing "excess" of women to men between 1986 and 1996. However, given the small size of the "mismatch", the changing ratios of total prime-aged men to women were unlikely to have a significant effect on the living arrangements of men and women. The changing employment ratios may have had a greater impact. Between 1986 and 1996 in all age groups, but particularly those aged 25-29 and 55-59, 
there was a major decline in this sex-ratio. Yet, even in 1986 there was a "shortage" of employed men. These data suggest that many single women, should they have been seeking a heterosexual partnership and if they were also seeking economic resources, would have faced difficulties in finding a New Zealand partner with good employment prospects from within their broad age group in 1996. In addition, a significant number of women already in couples potentially faced having a partner move out of paid work. Based on these traditional provider / economic dependency theories, then the proportion of men in couples would have been predicted to decline over the period studied.

While this prediction was correct, the census data shows a complex pattern of change in the living arrangements of prime-aged people. Between 1986 and 1996, there was a decline in the proportion of legally married prime-aged people. However, this decline was part of a much longer-term trend. In addition, the decline primarily took place amongst people under 45, which suggest delayed marriage rather than a wholesale rejection of marriage.

When defacto couples were also considered, there was an overall decline between 1986 and 1996 in the proportion of men and women aged 25-44 who lived in a couple household. This is an important group as it is in these age groups that decisions to have children are generally made and it is also generally the time that the very intense part of childrearing takes place. In contrast, there was little change in the proportion in couples in the age group 45-59. Some of the latter group will be "reconstituted" or "blended" families.

The long term data also show that the percentage of people aged 20-24 living in a couple in 1996 was far lower than that at the 1966 census, but higher than in both 1936 and 1906. For those aged 25-39 the proportion in couples in 1996 was again lower than 1966, but about the same as in 1936 and 1906. This reinforces the idea that short-term trends can be misleading, particularly if the starting point of the analysis represents a non-typical period in history. 
In trying to develop some relationship between changes in patterns of paid work and living arrangements there is a very complex mix of variables at work. These include gender, education, whether a person had dependent children as well as a range of further measurable and unmeasurable variables. It is extremely difficult to isolate which variable might be impacting on other variables and, if there are any causal relationships, which way they operate.

Despite these problems, the census data showed that employment status in New Zealand was strongly associated with the proportion of men living in couple households. In both 1986 and 1996, the higher degree of attachment to the labour force the greater the probability of living in a couple household. This is despite a decline in the range of variation between the labour market statuses and the proportion of men living in couples over the period studied.

In 1986, educational status had only a very a weak association with the proportion of men in couples, but this relationship strengthened slightly in 1996. Education and employment themselves have a strong association and when combined became a relatively good predictor of whether a man lived in a couple household in 1996. However, a weakness of the New Zealand census is the employment status variable provides only information on employment at the time of the census. Information on workstatus over the previous year would help explore the relationship between labour market participation and living arrangement.

New Zealand data indicate that some of the changes in the association between labour market status and whether men were living in couple households were due to men not in paid work becoming a less homogeneous group than in the past. As unemployment and non-labour force participation amongst prime-aged men increased in New Zealand it spread into all living arrangements, including affecting men in existing couples. Many of the couples in the older age groups would have formed when the employment prospects for prime-aged men looked much brighter. As discussed in the previous chapter, while most of the change in employment appears to reflect a shift in labour demand, some of 
the decline in participation in paid work of men aged 25-44 reflects labour supply side changes. These include a group of men choosing to look after children full time and / or to return to study. Some of this change, in turn, reflects changes in women's employment, with, as shown in the previous chapter, increasing potential for a small, but growing, group of women in areas such as managerial and professional occupations to financially support their partners should they choose to do so. However, the data shown in this chapter does not indicate the labour force status of partners.

Overall, while in New Zealand the data suggest that some of the recent changes in the proportion of men living in couples may reflect altering social norms or other nonemployment related factors, there is still strong support for the theory that men who have poor prospects in the labour market also have poor prospects in the marriage market. However, while this relationship exists, it is also worth noting that in both 1986 and 1996, for prime-age men both in paid work and not in paid work living in a couple household was still the most common single living arrangement.

While census data show some diversity in living arrangements for men not in couples, age and labour market status were important variables in these patterns. In 1996, approximately a third of all men in the 25-29 age group were either still living with their parents or were in flatting type households. However, by their late $30 \mathrm{~s}$ and early $40 \mathrm{~s}$, the largest group of men outside of couples lived alone. The living alone arrangement for older men was particularly common for men not in paid work. While living alone can be a positive choice for many people, it appears that for a group of men in this living arrangement is associated with being excluded from work and / or family life.

In contrast, in 1996 amongst women aged 25-44 who were not in couples, the largest single group were in sole-parent households. A significant proportion of these households were work-poor. In the age groups 50-59, the largest single living arrangement for women was living alone. Many of the women in both groups were highly likely to be the ex-partners of the men living alone or living at home with their parent /s or in other nonfamily households. 
There was little evidence to support the idea that much of the growth in part-time work was due to prime-aged women in couples moving into this work. While women in couples were still over-represented amongst part-time workers, over the time period studied part-time work spread to both men and women in a wide range of living arrangements. In addition, as shown in previous chapters, much of the growth in part-time work was amongst people outside of the 25-59 age group.

Finally, the ethnic data included in this chapter suggest that while there are strong associations between labour market status, education and living arrangements, cultural and social norms also are important. In particular, there appear to be a group of Asian and Pacific Island people for whom changes in the labour market are not associated with major changes in living arrangements. The data also emphasise that there are some small, but important, differences in behaviour of those defined as sole Maori and those Maori who also have other ethnic affiliations. 


\section{Chapter 19}

\section{A polarisation into education-rich and education-poor households and couples?}

\section{Introduction}

At the start of this chapter I briefly analyse the distribution of education across households with prime-aged people living in them. I then move on to analyse the outcomes of assortative mating of prime-age heterosexual couples. In these couples both partners had to be within this 25-59 age group. The main aim of this analysis is to see if education is concentrated within couple families by people tending to have a partner with a similar broad level of education. ${ }^{102}$

In recognition that the $25-59$ is a wide age group, I repeat much of this analysis for a narrower group of 25-34 year olds. This narrower age group was chosen for five main reasons. First, the 34 upper age limit provides a ten-year age cohort for analysis. This means all those who were in the target age group in 1986 would have moved out of it by 1996. Second, using a relatively young upper age group means that while some early relationships or marriages will have dissolved through partners splitting up few will have been dissolved through the death of one partner. Third, it is within this younger age grouping that the recent advances in educational attainment by women will show up more clearly. Therefore changing patterns of women's and men's educational qualifications are analysed in more detail than in the first section. A further reason for studying this narrower group is that this would generally cover a high proportion of couples starting

\footnotetext{
${ }^{102}$ Some of the findings of this chapter have been published in Callister (1998a).
} 
families. Finally, having a smaller age sub-group allows some basic comments to be made about the changes in the concentration of education amongst younger people versus the older age group.

In the section studying couples aged 25-34, some comparisons are then made between the assortative mating outcomes of those legally married for the first time and those in defacto relationships. It should be noted that in all the other analyses legally married couples, whether married for a first or subsequent times, as well as de facto couples are included. Finally, the chapter examines the impact of bringing ethnicity into the analysis of sorting outcomes. Due to problems with time series this analysis only uses 1996 data, and a simple Maori and non-Maori split.

\section{The concentration of education in particular households}

Chapter eighteen indicated that if prime-aged men and women had no formal educational qualification they were slightly less likely to be in a couple than if they had a university degree or high qualification. The chapter also showed that the variable of education as a predictor of living arrangement strengthened slightly over the period studied. In addition, it showed that that if prime-aged men were both education poor and without paid work they were much less likely to be in a couple than those in paid work and education rich.

Table 72 shows households rather than families. It shows the proportion of people with a degree or higher and then the proportion of total prime-aged people by the number of prime-aged people in each household. It shows that most prime-aged people lived in two prime-aged person households. There could, of course, have been other people living in these households outside of this age range. Overall, Table 73 shows that prime-aged people with a degree or higher were marginally more likely to be in a household where there were two prime-aged people living. However, these two people did not need to be living as a couple. 
Table 72 - The proportion of total prime-aged and with a degree or higher by the number of prime-aged people in each household, 1996

\begin{tabular}{|c|c|c|}
\hline $\begin{array}{l}\text { No of prime-aged peopl } \\
\text { each household }\end{array}$ & $\begin{array}{l}\text { in } \% \text { of prime-aged people with a } \\
\text { degree or higher }\end{array}$ & $\%$ of total prime-aged people \\
\hline 1 & 18.1 & 21.5 \\
\hline 2 & 71.2 & 67.3 \\
\hline 3 & 7.6 & 8.1 \\
\hline 4 & 2.3 & 2.3 \\
\hline 5 & 0.5 & 0.6 \\
\hline $6+$ & 0.2 & 0.3 \\
\hline Total & 100 & 100 \\
\hline $\mathrm{n}$ & 167,404 & $1,605,936$ \\
\hline
\end{tabular}

\section{Assortative mating outcomes for couples aged 25-59}

In this analysis I only focus on couples where both partners were aged 25-59. The proportion of couples where both partners were in this prime-age band increased slightly from 85 percent in 1986 to 87 percent in 1996. While there is some possibility that couples with one partner outside of the target age range have vastly different assortative mating patterns this is highly unlikely.

In the analysis of assortative mating three broad groups of highest qualification obtained are used. These are degree or higher, other tertiary/school qualification combined, and no formal qualification. In all the tables, the "no qualifications" category includes those still at school, although this was an insignificant group in the 25 and over age group. Although the numbers who did not specify their educational qualification was collected, in the actual analysis this group is excluded. The number of educational categories used has an influence on the degree of educational matching which might be found. For example, while a significant number of couples might both have "vocational qualifications", given the gendered nature of occupations which utilise such qualifications, such as nursing or plumbing work, at a fine level of analysis matching may not be common.

Table 73 shows how prime-aged people were "sorted" at census time in 1986, 1991, and 1996. ${ }^{103}$ The table shows the percentage of couples in each qualification mix. In brackets

${ }^{103}$ The census provides only a snapshot and gives no idea about the stability of these relationships. 
there is the ratio of the actual percentage relative to the expected value given random sorting. Due to data coding conventions in Statistics New Zealand in 1986 and 1991 the tables are likely to include some same-sex couples but where the sex of one partner had been recoded in order to form a "heterosexual" couple. In 1996 couples could identify themselves as same-sex, and these were excluded. ${ }^{104}$ Finally this, and the other tables showing couples, include only those living in private dwellings and exclude those absent on census night. ${ }^{105}$

\section{Table 73 - Highest qualifications of women and men in couples in the 25-59 age group}

$\%$ in each group

\begin{tabular}{llrrrr}
\hline 1986 & & \multicolumn{2}{c}{ Female } \\
\hline \multirow{4}{*}{ Male } & $\mathrm{n}=425,265$ & $\begin{array}{r}\text { Degree or } \\
\text { postgraduate }\end{array}$ & $\begin{array}{c}\text { Other } \\
\text { tertiary/school }\end{array}$ & $\begin{array}{c}\text { No formal } \\
\text { qualification }\end{array}$ & Total \\
& Degree or postgraduate & $2.9(6.2)$ & $5.7(1.2)$ & $0.8(0.2)$ & 9.5 \\
& Other tertiary/school & $1.8(0.7)$ & $33.6(1.2)$ & $19.3(0.8)$ & 54.8 \\
& No Qualification & $0.3(0.2)$ & $12.4(0.7)$ & $23.1(1.5)$ & 35.8 \\
& Total & 5.0 & 51.8 & 43.1 & 100.0 \\
\hline
\end{tabular}

\begin{tabular}{llrrrr}
\hline 1991 & & \multicolumn{4}{c}{ Female } \\
\hline \multirow{4}{*}{ Male } & $\mathrm{n}=449,022$ & $\begin{array}{r}\text { Degree or } \\
\text { postgraduate }\end{array}$ & $\begin{array}{c}\text { Other } \\
\text { tertiary/school }\end{array}$ & $\begin{array}{c}\text { No formal } \\
\text { qualification }\end{array}$ & Total \\
& Degree or postgraduate & $3.9(5.3)$ & $6.3(1.0)$ & $0.5(0.1)$ & 10.7 \\
& Other tertiary/school & $2.6(0.6)$ & $40.9(1.2)$ & $15.9(0.8)$ & 59.4 \\
& No Qualification & $0.3(0.2)$ & $12.6(0.7)$ & $17.0(1.7)$ & 29.9 \\
& Total & 6.8 & 59.8 & 33.4 & 100.0 \\
\hline
\end{tabular}

\begin{tabular}{llrrrr}
\hline 1996 & & \multicolumn{2}{c}{ Female } \\
\hline \multirow{2}{*}{ Male 507,840} & $\begin{array}{r}\text { Degree or } \\
\text { postgraduate }\end{array}$ & $\begin{array}{c}\text { Other } \\
\text { tertiary/school }\end{array}$ & $\begin{array}{c}\text { No formal } \\
\text { qualification }\end{array}$ & Total \\
& Degree or postgraduate & $5.3(4.3)$ & $7.2(0.9)$ & $0.7(0.2)$ & 13.1 \\
& Other tertiary/school & $3.6(0.7)$ & $41.2(1.1)$ & $13.4(0.8)$ & 58.2 \\
& No Qualification & $0.5(0.2)$ & $13.4(0.8)$ & $14.8(1.8)$ & 28.7 \\
& Total & 9.4 & 61.8 & 28.8 & 100.0 \\
\hline
\end{tabular}

Source: Derived from the Census of Population and Dwellings, Statistics New Zealand.

\footnotetext{
104 This comment also applies to the analysis of couples aged 25-34. The ability to separate out same-sex couples also means that 1996 census provides an opportunity to assess assortative mating in same-sex couples.

105 Absentees cannot be included as only age, sex, marital status, and parental information is collected regarding people absent on census night.
} 
Table 73 shows a number of trends. These include that:

- people with degrees or postgraduate qualifications were, in each census, highly unlikely to be with people with no formal qualifications.

- the proportion of couples where both had degrees or higher increased between 1986 and 1996 while the proportion who both had no formal qualifications declined.

- people with degrees or higher are far more likely to be with a similarly qualified partner than random sorting would predict. However, this concentration of high level qualifications decreased slightly between 1986 and 1996

- people with no formal qualification were also more likely to be together in a relationship than random sorting would predict. This over-representation of couples with no qualifications increased slightly between 1986 and 1996

- in 198659.6 percent couples had a similar level of qualifications. This rose to 61.8 percent in 1991, but declined slightly to 61.3 percent in 1996.

While education was concentrated amongst particular couples, the number and proportion of well educated couples also increased over the period studied. Using this type of measure, education became less concentrated in couples.

The finding that people with similar levels of qualifications have a tendency to form relationships is very much in line with the international literature. The overseas researchers primarily used log-linear models to analyse the existence and significance of associations within complex tables of categorical data. Table 74 provides key results of fitting four log-linear models to the data contained in the previous table. 
Table 74 -Log linear results for 25-59 year olds - Type III (LR) Tests ${ }^{106}$

\begin{tabular}{lrrr}
\hline Source & Degrees of freedom & Chi-square & Pr > Chi-square \\
\hline & & & \\
Time & 2 & $4,049.1276$ & 0.0001 \\
Male education & 2 & $132,256.574$ & 0.0001 \\
Female education & 2 & $394,017.299$ & 0.0001 \\
Time*male education & 4 & 325.6313 & 0.0001 \\
Time*female education & 4 & $4,151.2480$ & 0.0001 \\
Male education*female education & 4 & $272,799.023$ & 0.0001 \\
Time*male education* female education & 8 & 242.9074 & 0.0001 \\
\hline
\end{tabular}

The results indicate that time, and women's and men's changing education rates were all important factors in the changes taking place. The association between women's and men's education was particularly important. An inspection of the estimated parameters in the model showed that within this interaction there was a particularly important association between partners with degrees or higher in each census.

This analysis of prime-age couples indicates that education is more concentrated in couples than would be expected given random mating. In particular, people with a university qualification were likely to be with a similarly qualified partner. With education being a key variable in determining labour market outcomes for individuals, this concentration of education in couples potentially reinforces the advantage or disadvantage an individual faces in the labour market. However, while there was some minor change between 1986 and 1996 the analysis does not support the idea that in the time period studied education in couples became more concentrated.

\section{Assortative mating outcomes in couples aged 25-34}

In line with international trends, New Zealand data indicate that in couples women are generally younger than men. While this has some effect when studying the 25-59 age group, the effect becomes strong the narrower the cohort studied. However, change is also occurring. For example, in 1986, 83 percent of partnered 30-year-old men had younger partners. ${ }^{107}$ However, by 1996 this had decreased to 75 percent. This may indicate some

\footnotetext{
106 These tests were used on the advice of ISOR at Victoria University.

${ }^{107}$ Partners in the age group 15-50 were considered in this calculation.
} 
change occurring in the selection of partners and the characteristics sought. This change is illustrated in Figure 38.

Figure 38

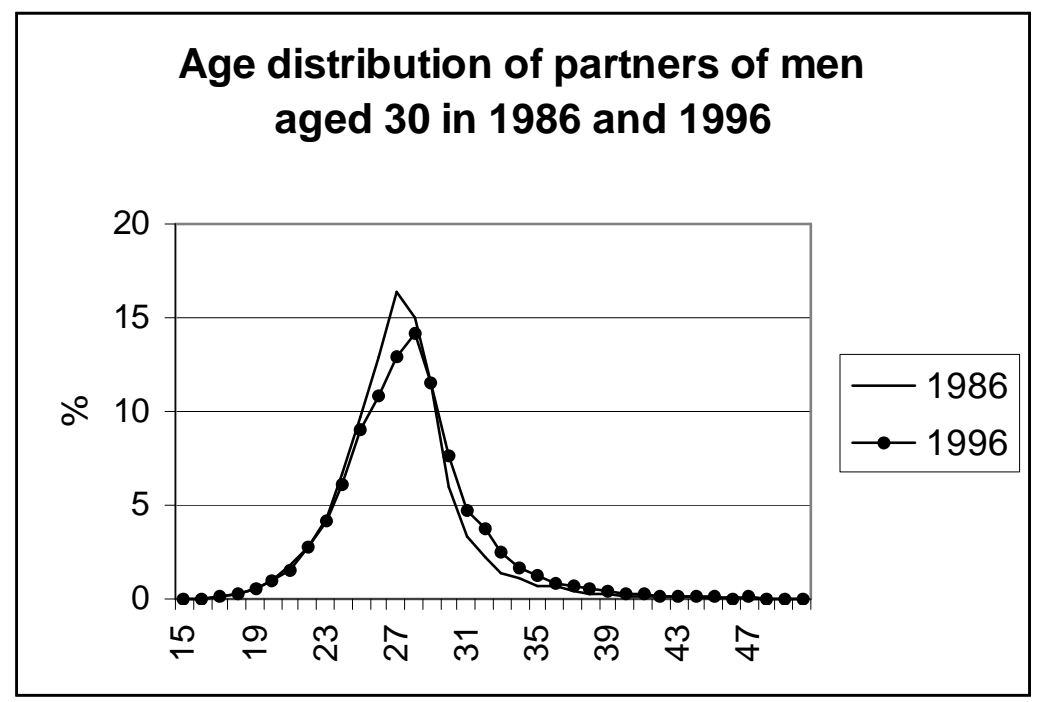

Source: Derived from the Census of Population and Dwellings, Statistics New Zealand.

A significant proportion of men and women aged 25-34 who were in couples had a partner who was outside of this age group. For example, in 1996 of the women aged 2534, 2.4 percent had a male partner aged under 25 while 28 percent had a partner aged 35 or older. For men, 10.9 percent had a partner under 25 and 6.4 percent a partner aged 35 prime-aged older. However, again it is difficult to see why the people excluded would have had significantly different characteristics from those included. ${ }^{108}$

Table 75 shows how the target 25-34 age group were "sorted" at census time.

\footnotetext{
108 One potential way of reducing the number of couples with one partner outside the target-age group would be to use offset age groups, such as analysing all couples where the women were in the 25-34 age group, and all men in a 27-36 age group. However, even with this offset, many couples would have been excluded. In 1986, and 1991, 39 percent of couples had one partner outside the target age group, and this increased to 43 percent in 1996.
} 
Table 75 - Highest qualifications of women and men in couples in the 25-34 age group $\%$ in each group

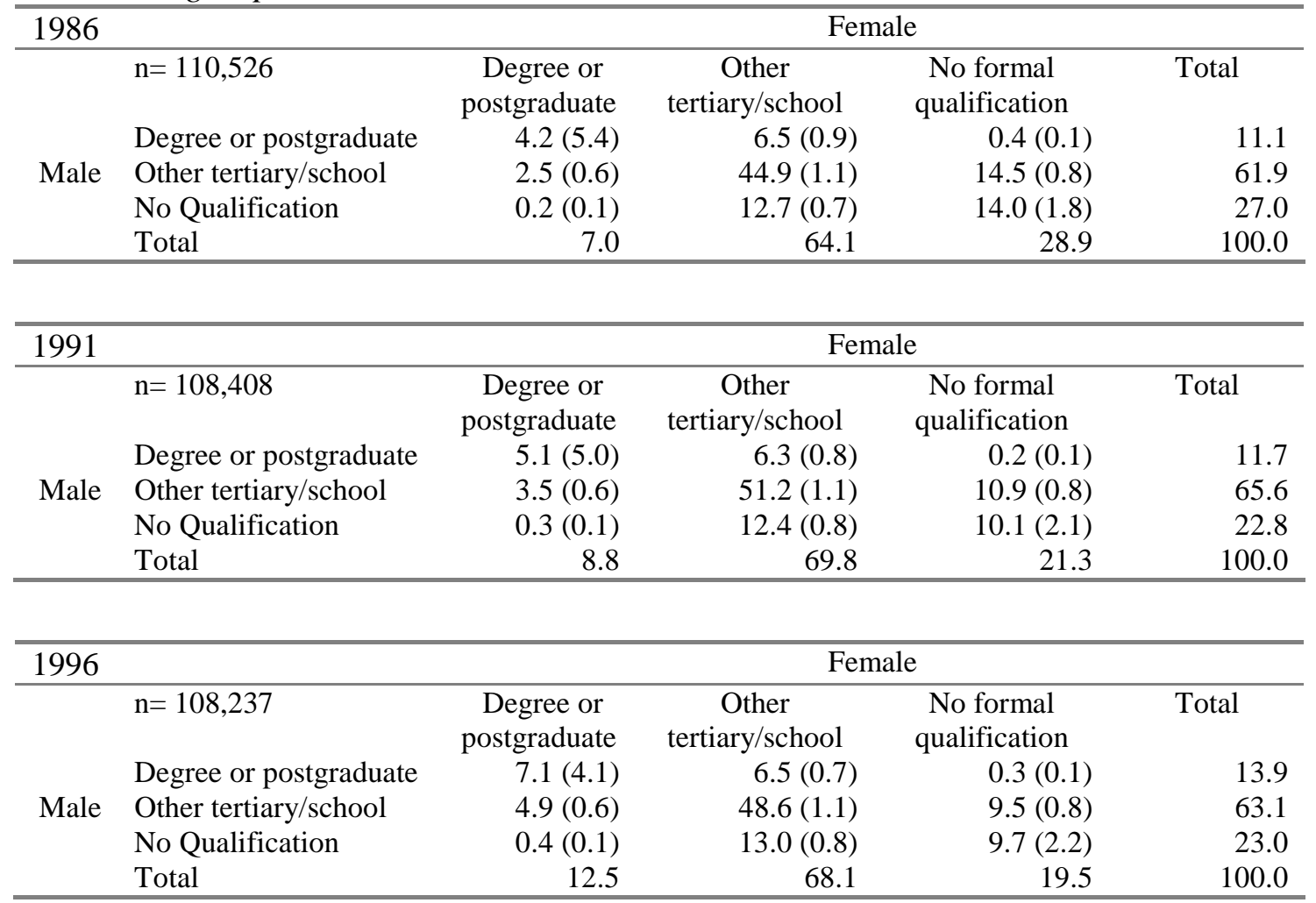

Source: Derived from the Census of Population and Dwellings, Statistics New Zealand.

These data exclude those who did not specify their qualification

Table 75 shows that the broad trends identified in regards to the 25-59 year old couples also hold for this younger subset. However, there are some minor differences. These are examined in the following table. Table 76 compares the proportion of couples in the 2559 age group with a similar level of qualifications (or no formal qualifications) with the sub-group of 25-34 year olds.

Table 76 - Proportion of couples with both partners having the same broad level of qualifications

\begin{tabular}{lcc}
\hline \multicolumn{3}{c}{ Couple age group } \\
\hline & $25-59$ & $25-34$ \\
1986 & 60 & 63 \\
1991 & 62 & 66 \\
1996 & 61 & 65 \\
\hline \multicolumn{2}{l}{ Source: Derived from the Census of Population and Dwellings, Statistics New Zealand }
\end{tabular}

This table shows that amongst the younger subset there is a slightly higher level of couples with similar qualifications. This does provide some support for the idea that 
education has become more concentrated over time. However, it may be simply that an older age cohort includes more people who have "re-sorted" with education not being quite as important in this re-sort. While an analysis of marital status by age group may partly explain this difference this was not carried out in my research. In addition, in the older age groups there were more marked differences in educational attainment between men and women. However, with an increasing proportion of older people undertaking further study qualifications will also be changing within existing couples.

A further analysis of the data for both age groups shows that one result of the increasing supply of women with degrees between 1986 and 1996 was that men with degrees became more likely to be with similarly qualified women (Table 77). Men with degrees were also less likely to be with a woman with no formal qualifications. The assortative mating patterns for women did not change as much, although women with degrees were marginally less likely to be with a man who had a degree. These trends show up much more strongly in the younger subset.

Table 77 - Partners of men and women with degrees - Percentage with degrees and percentage with no qualifications

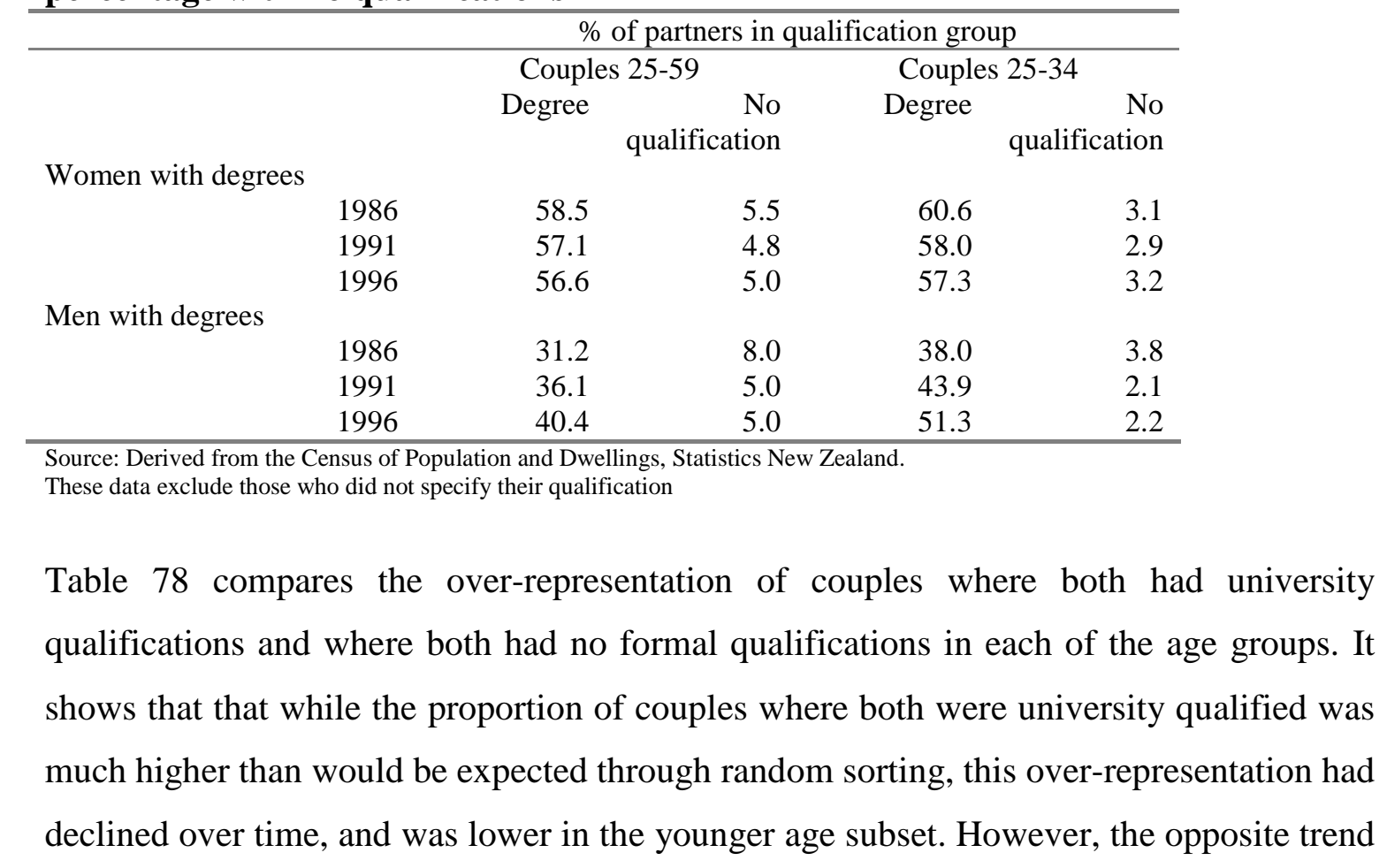


was apparent amongst couples with no formal qualifications. This latter trend suggests that it is becoming more difficult for people with no formal qualifications to form relationships with those who have some formal education. This supports the idea that young people with few qualifications face a disadvantage in both the labour and the marriage markets.

Table 78 - Ratio of actual sorting to random sorting for couples who both have university qualifications and both have no formal qualifications

\begin{tabular}{lrrrr}
\hline \multicolumn{4}{c}{ Couples 25-59 } & \multicolumn{2}{c}{ Couples 25-34 } \\
\hline & Both university & Both no qualification & Both university & Both no qualification \\
1986 & 6.2 & 1.5 & 5.4 & 1.8 \\
1991 & 5.3 & 1.7 & 5.0 & 2.1 \\
1996 & 4.3 & 1.8 & 4.1 & 2.2 \\
\hline \multicolumn{2}{l}{ Source: Derived from the Census of Population and Dwellings, Statistics New Zealand. }
\end{tabular}

Finally, the main data contained in Table 75 was tested using log-linear modelling. Table 79 provides the key results of fitting various log-linear models to the data for 25-35 year old couples.

Table 79 - Type III (LR) Tests

\begin{tabular}{lrrr}
\hline Source & Degrees of freedom & Chi-square & Pr > Chi-square \\
\hline & & & \\
Time & 2 & 98.9062 & 0.0001 \\
Male education & 2 & $45,498.2886$ & 0.0001 \\
Female education & 2 & $100,236.377$ & 0.0001 \\
Time*male education & 4 & 55.5014 & 0.0001 \\
Time*female education & 4 & 743.5501 & 0.0001 \\
Male education*female education & 4 & $72,227.1327$ & 0.0001 \\
Time*male education* female education & 8 & 61.1665 & 0.0001 \\
\hline
\end{tabular}

Again, the results are very similar to those found for the 25-59 year old couples. All associations are significant, but the association between the education levels of men and women is of the greatest significance.

\section{Other associations in the marriage market outcomes for couples aged 25-34}

In this final part of this chapter some aspects of ethnicity and martial status are considered relative to assortative mating. While education is clearly important, as already discussed a wide range of factors will be at work in the marriage market. Some of these data are 
collected by the census. Such variables include religious affiliation and country of birth. But there are many important factors about which the census has no direct information, such as physical attributes, beliefs systems or whether the person had been an unmarried sole parent before forming a new relationship. In the following tables two variables are briefly, and separately, explored. The first is the issue of legal marriage versus de facto relationships. Most overseas studies on assortative mating only analyse those in legal marriages, and usually first marriages. While marital status is an outcome of sorting it could, at times, be potentially a factor in the sorting process. For example, those who have been divorced may not be considered suitable partners for those who hold strong fundamentalist religious beliefs.

Table 80 shows couples legally married for the first time, and those both in a defacto relationship. This excludes other possible arrangements such as where one partner was married for the first time and for the other it was a second marriage. However, in total, the two groups analysed represented 90 percent of couples in the target age group in 1996.

Table 80 - Highest qualifications of women and men in couples aged 25-34, 1996 $\%$ in each group

\begin{tabular}{|c|c|c|c|c|c|}
\hline \multicolumn{2}{|c|}{ Both legally married for first time } & \multicolumn{4}{|c|}{ Female } \\
\hline \multirow{5}{*}{ Male } & $\mathrm{n}=70,872$ & $\begin{array}{c}\text { Degree or } \\
\text { postgraduate }\end{array}$ & $\begin{array}{c}\text { Other } \\
\text { tertiary/school }\end{array}$ & $\begin{array}{l}\text { No formal } \\
\text { qualification }\end{array}$ & Total \\
\hline & Degree or postgraduate & 7.9 & 7.0 & 0.3 & 15.1 \\
\hline & Other tertiary/school & 4.8 & 50.9 & 8.7 & 64.4 \\
\hline & No Qualification & 0.3 & 12.0 & 8.2 & 20.5 \\
\hline & Total & 12.9 & 69.9 & 17.1 & 100.0 \\
\hline \multicolumn{2}{|c|}{ Both defacto } & \multicolumn{4}{|c|}{ Female } \\
\hline \multirow{5}{*}{ Male } & $\mathrm{n}=27,201$ & $\begin{array}{c}\text { Degree or } \\
\text { postgraduate }\end{array}$ & $\begin{array}{c}\text { Other } \\
\text { tertiary/school }\end{array}$ & $\begin{array}{l}\text { No formal } \\
\text { qualification }\end{array}$ & Total \\
\hline & Degree or postgraduate & 6.7 & 5.7 & 0.3 & 12.7 \\
\hline & Other tertiary/school & 5.8 & 43.2 & 10.5 & 59.6 \\
\hline & No Qualification & 0.6 & 14.8 & 12.3 & 27.7 \\
\hline & Total & 13.1 & 63.7 & 23.2 & 100.0 \\
\hline
\end{tabular}

Source: Derived from the Census of Population and Dwellings, Statistics New Zealand.

These data exclude those who did not specify their qualification

The data show that marriage was far more popular than defacto living arrangements. It also supports other research which has found that when age was controlled for married couples were slightly more likely to have formal qualifications (Statistics New Zealand 
1994). Of relevance to the following table, Statistics New Zealand also found that Maori were more likely than non-Maori to live in defacto relationships.

As shown in other chapters, ethnicity is an important variable when considering labour market participation. As also discussed in earlier chapters, in much of the marriage market literature in the U.S., African Americans and white Americans are treated as two separate groups. However, in New Zealand inter-marriage between Maori and non-Maori has been common since colonisation.

In Table 81 the definition for Maori includes those who have multiple ethnic affiliations. The table includes both legally married and defacto relationships. Finally, while changes over time would be of interest, as already discussed time comparisons are difficult. 
Table 81 - Highest qualifications of women and men in couples aged 25-34, 1996 $\%$ in each group

\begin{tabular}{|c|c|c|c|c|c|}
\hline \multicolumn{2}{|c|}{ Both Maori } & \multicolumn{4}{|c|}{ Female } \\
\hline \multirow{5}{*}{ Male } & $\mathrm{n}=6,756$ & $\begin{array}{c}\text { Degree or } \\
\text { postgraduate }\end{array}$ & $\begin{array}{c}\text { Other } \\
\text { tertiary/school }\end{array}$ & $\begin{array}{l}\text { No formal } \\
\text { qualification }\end{array}$ & Total \\
\hline & Degree or postgraduate & 0.8 & 1.1 & 0.1 & 2.0 \\
\hline & Other tertiary/school & 1.4 & 28.5 & 15.3 & 45.2 \\
\hline & No Qualification & 0.4 & 21.8 & 30.6 & 52.8 \\
\hline & Total & 2.7 & 51.3 & 46.0 & 100.0 \\
\hline
\end{tabular}

\begin{tabular}{|c|c|c|c|c|c|}
\hline \multicolumn{3}{|c|}{ Man Maori, woman non-Maori } & \multicolumn{2}{|c|}{ Female } & \multirow[b]{2}{*}{ Total } \\
\hline \multirow{5}{*}{ Male } & $\mathrm{n}=7,110$ & $\begin{array}{l}\text { Degree or } \\
\text { postgraduate }\end{array}$ & $\begin{array}{l}\text { Other } \\
\text { tertiary/school }\end{array}$ & $\begin{array}{c}\text { No formal } \\
\text { qualification }\end{array}$ & \\
\hline & Degree or postgraduate & 3.1 & 3.5 & 0.2 & 6.8 \\
\hline & Other tertiary/school & 3.4 & 45.5 & 10.7 & 59.6 \\
\hline & No Qualification & 0.8 & 19.8 & 13.1 & 33.6 \\
\hline & Total & 7.2 & 68.8 & 24.0 & 100.0 \\
\hline
\end{tabular}

\begin{tabular}{|c|c|c|c|c|c|}
\hline \multicolumn{2}{|c|}{ Man non-Maori, woman Maori } & \multicolumn{4}{|c|}{ Female } \\
\hline \multirow{5}{*}{ Male } & $\mathrm{n}=6,177$ & $\begin{array}{c}\text { Degree or } \\
\text { postgraduate }\end{array}$ & $\begin{array}{c}\text { Other } \\
\text { tertiary/school }\end{array}$ & $\begin{array}{l}\text { No formal } \\
\text { qualification }\end{array}$ & Total \\
\hline & Degree or postgraduate & 2.9 & 4.0 & 0.6 & 7.5 \\
\hline & Other tertiary/school & 2.6 & 44.3 & 14.7 & 61.6 \\
\hline & No Qualification & 0.1 & 16.3 & 14.5 & 30.9 \\
\hline & Total & 5.6 & 64.6 & 29.7 & 100.0 \\
\hline
\end{tabular}

\begin{tabular}{|c|c|c|c|c|c|}
\hline \multicolumn{2}{|c|}{ Both non-Maori } & \multicolumn{4}{|c|}{ Female } \\
\hline \multirow{5}{*}{ Male } & $n=86,667$ & $\begin{array}{c}\text { Degree or } \\
\text { postgraduate }\end{array}$ & $\begin{array}{c}\text { Other } \\
\text { tertiary/school }\end{array}$ & $\begin{array}{l}\text { No formal } \\
\text { qualification }\end{array}$ & Total \\
\hline & Degree or postgraduate & 8.3 & 7.3 & 0.3 & 15.9 \\
\hline & Other tertiary/school & 5.5 & 50.8 & 8.6 & 64.9 \\
\hline & No Qualification & 0.4 & 11.4 & 7.4 & 19.2 \\
\hline & Total & 14.2 & 69.6 & 16.2 & 100.0 \\
\hline
\end{tabular}

Source: Derived from the Census of Population and Dwellings, Statistics New Zealand.

These data exclude those who did not specify their qualification

There were quite significant differences in the qualification patterns between these couples. For example, where both partners were Maori just over 30 percent were in a situation where both had no formal educational qualification. This proportion halved when only one partner was Maori, and halved again when neither partner was Maori. This reflects the overall lower levels of qualifications of both men and women in families where both partners were Maori. While the data indicates that within each couple type people with similar levels of qualifications tend to form relationships, there was also some tendency for Maori to have Maori partners. The proportion of couples where both were Maori was four times greater than would be expected through random mating. 
Again these data were tested using log-linear modelling (Table 82).

Table 82 - Type III (LR) Tests

\begin{tabular}{|c|c|c|c|}
\hline Source & $\begin{array}{r}\text { Degrees of } \\
\text { freedom }\end{array}$ & Chi-square & $\begin{array}{r}\mathrm{Pr}>\text { Chi- } \\
\text { square }\end{array}$ \\
\hline Ethnicity & 3 & $10,810.6752$ & 0.0001 \\
\hline Male education & 2 & $3,502.2431$ & 0.0001 \\
\hline Female education & 2 & $3,040.6443$ & 0.0001 \\
\hline Ethnicity *male education & 6 & 491.7116 & 0.0001 \\
\hline Ethnicity $*$ female education & 6 & 244.8253 & 0.0001 \\
\hline Male education $*$ female education & 4 & $3,748.3997$ & 0.0001 \\
\hline Ethnicity $*$ male education $*$ female education & 12 & 121.4493 & 0.0001 \\
\hline
\end{tabular}

Table 82 indicates that there was a strong association between women's and men's education, but that ethnicity was also having some impact on sorting patterns. There will be many factors behind these sorting patterns, many of which would be difficult to identify in empirical research. However, one factor that could be explored is a spatial influence. As indicated by much U.S. research, local marriage markets may need to be considered..$^{109}$

Tables 81 and 82 provides some indication of why childrearing couples where both partners were Maori were in 1991 found to be significantly more likely to be work-poor than couples where only one partner was Maori (Callister 1996b). It also reinforces the problem of defining couples as "Maori" by only one partner.

Finally, Table 81 only shows those Maori who had formed couples. Some of these would have been childrearing, however, other data shows that in childrearing situations Maori were significantly over-represented amongst sole parents. This may be because long-term relationships had not been formed or had dissolved.

\footnotetext{
${ }^{109}$ For example, there are some rural areas where Maori with few formal qualifications are concentrated such as in Northland. In the table shown, in couples where both were Maori 18.6 percent lived in rural areas, where only the woman was Maori this dropped to 15.7 percent rural, and where the man was Maori this declined further to 13.9 percent. However, it is not know whether these people actually found their partners from within these areas or that one, or both, had subsequently moved there.
} 


\section{Conclusion}

While love and lust may be fundamental driving forces in finding a suitable partner for marriage or cohabitation, the level of education also seems to be a very important factor in assortative mating. In line with overseas patterns, there is a strong tendency for partners in New Zealand couples to both have the same broad level of formal qualification. In particular, those people with a high level of formal qualifications tend to form relationships with people with similar qualifications. In addition, it is very unlikely for couples to form where partners have very markedly different levels of qualification. One result of this behaviour is that the advantage or disadvantage an education qualification gives an individual in the labour market tends to be reinforced rather than reduced in households via the marriage market.

While there was a very small increase in the overall proportion of couples who had similar education levels between 1986 and 1996 the data does not appear to support the hypothesis that education has become significantly more concentrated within couples over the time period studied. However, a finer level of analysis shows some important trends. Although primarily due to fewer people overall having no formal qualifications, the actual proportion of couples where both have no formal qualifications has been falling, at the same time there has been a small increase in the probability that poorly qualified people, if they do form couple households, they will be with poorly qualified partners.

Although there are links between ethnicity and education, ethnicity in itself also appears to an important factor in mating decisions. However, unlike some other inter-ethnic mating patterns in industrialised countries, in New Zealand there is a high rate of mating between Maori and non-Maori.

People with low levels of formal qualifications are less likely than well educated individuals to form couples and, if they do, are more likely to be in defacto relationships than be legally married for a first time. Therefore, education is concentrated in 
households in two ways. Once a household contains one person with a high level of formal qualifications, then these people are more likely to have partners, and these partners are also likely to have a high level of formal education.

Overall, the theory and data suggest that the "marriage market" is an important factor in influencing whether families become "education-rich" or "education-poor". Whether education-rich couples are work-rich and education-poor couples work-poor is explored in the following chapter. 


\section{A polarisation into work-rich and work-poor couples and households?}

\section{Introduction}

This chapter begins with a brief examination of how paid work has been distributed across New Zealand households. It then moves onto a more detailed analysis of changes in work patterns amongst prime-aged heterosexual couples. ${ }^{110}{ }^{111}$ This includes examining some of the characteristics of work-rich and work-poor couples. Finally, those couples with a child under five years of age are analysed. These have, in the past, often been mixed work couples with the male in full-time work and the female at home looking after the children. In this chapter most of the focus is on workstatus, including the categories of parttime and full-time work, rather than a detailed analysis of changing hours of work within households or couples.

It is recognised that the analysis presented in this chapter is very much of an exploratory nature and is primarily descriptive. This is mainly because I do not consider that census data can provide a clear idea of the driving forces behind the changes that have been occurring in families and households. As discussed in earlier chapters, a wide range of other data sources and theories, from the effects of nature and nurture on gender roles through to the impact of welfare systems, are needed to fully understand the factors driving any change in work patterns within couples.

\footnotetext{
${ }^{110}$ This part of the analysis draws on Callister (1998b).

${ }^{111}$ Due to lack of suitable data, issues such as how multi-earning couples schedule their work across the day and across the week are not considered. Even the New Zealand Time Use survey does not provide suitable data for such research.
} 


\section{Households}

In this analysis of households only private dwellings are considered and family members absent on census night are excluded. Table 83 shows all households with people aged 15 or older. In this, and the following table, only those people in the target age group are counted. For example, in Table 83 a two-person household may actually have four people living in it if there were two children under 15 years of age present. In Table 83 about a quarter of households had one person in the target age group, and about a half had two people in the target age group living in them. ${ }^{112}$

\section{Table 83 - Percentage of work-rich and work-poor households with people aged 15 or more living in them, 1986-1996}

\begin{tabular}{|c|c|c|c|c|}
\hline & \multicolumn{4}{|c|}{ Number of people in household 15 and over } \\
\hline $\begin{array}{l}\% \text { of households with no-one } 15 \text { and } \\
\text { older in paid work (work-poor) }\end{array}$ & 1 person & 2 persons & 3 persons & 4 persons \\
\hline 1986 & 59.4 & 20.7 & 5.5 & 3.0 \\
\hline 1991 & 63.9 & 26.9 & 11.6 & 8.3 \\
\hline 1996 & 60.0 & 24.2 & 11.5 & 10.3 \\
\hline \multicolumn{5}{|l|}{$\begin{array}{l}\% \text { of households with all } 15 \text { and older } \\
\text { in paid work (work-rich) }\end{array}$} \\
\hline 1 & 40.6 & 45.9 & 35.0 & 28.0 \\
\hline 1991 & 36.1 & 43.0 & 28.2 & 19.9 \\
\hline 1996 & 40.0 & 49.4 & 38.2 & 29.4 \\
\hline \multicolumn{5}{|l|}{$\begin{array}{l}\% \text { of households with a mixture of } \\
\text { people } 15 \text { and older in and not in paid } \\
\text { work }\end{array}$} \\
\hline 1986 & & 33.4 & 59.5 & 69.0 \\
\hline 1991 & & 30.1 & 60.2 & 71.8 \\
\hline 1996 & & 26.3 & 50.3 & 60.3 \\
\hline
\end{tabular}

Source: Derived from the Census of Population and Dwellings, Statistics New Zealand.

Table 83 shows a number of trends. In all one, two, three and four person households there was an increase in the proportion of work-poor households, and a decline in workrich households between 1986 and 1991. This trend was reversed in most household sizes in the next five years. However, with the exception of one-person households, in all other

\footnotetext{
112 In the period from 1986 to 1991 there was a small increase in the proportion of households with one person over 15 , from 24.7 percent to 27.3 percent, then staying virtually stable through to 1996 (27.9 percent). The proportion of two person households declined marginally from 52 percent in 1986 to 50.1 percent in 1996, while 3 person households declined slightly from 14.6 percent in 1986 to 14 percent in 1996. In 1986, there were 8.7 percent of households with five or more occupants in the target age group, and this also dropped slightly to 8 percent in 1996. The work patterns of these larger households are not analysed in this table.
} 
households the proportion of both no-job and all-job households was higher in 1996 than 1986. This resulted in a decline in mixed-job households. The table also shows a high proportion of no-job one-person households. In part this reflects that the table will include many elderly living on their own and will also include sole parent families with children under 15 years of age.

Table 84 counts only households containing at least one person aged 25-59. Again, there could be other people in these households outside the age range, such as young children, teenagers or people over 60. The workforce status of these people is not considered. Attention is focussed on households with one, two, or three people in the target age group. In this table over a third of households comprised one prime-aged person, and nearly 60 percent two prime-aged person households. ${ }^{113}$

Table 84 - Percentage of work-rich and work-poor households with people aged 2559 living in them, 1986-1996

\begin{tabular}{|c|c|c|c|}
\hline & \multicolumn{3}{|c|}{ Number of people in household 25-59 } \\
\hline $\begin{array}{l}\% \text { of households with no one aged } 25-59 \text { in } \\
\text { paid work (work-poor) }\end{array}$ & 1 person & 2 persons & 3 persons \\
\hline 1986 & 30.8 & 3.2 & 4.4 \\
\hline 1991 & 39.2 & 8.6 & 10.8 \\
\hline 1996 & 36.8 & 8.7 & 13.2 \\
\hline \multicolumn{4}{|l|}{$\begin{array}{l}\% \text { of households with all people aged } 25-59 \\
\text { in paid work (work-rich) }\end{array}$} \\
\hline 1986 & 69.2 & 63.0 & 44.9 \\
\hline 1991 & 60.8 & 61.0 & 36.8 \\
\hline 1996 & 63.2 & 66.1 & 42.3 \\
\hline \multicolumn{4}{|l|}{$\begin{array}{l}\% \text { of household with a mixture of people } \\
\text { aged } 25-59 \text { in and not in paid work }\end{array}$} \\
\hline 1986 & & 33.8 & 50.8 \\
\hline 1991 & & 30.4 & 52.4 \\
\hline 1996 & & 25.2 & 44.5 \\
\hline
\end{tabular}

Source: Derived from the Census of Population and Dwellings, Statistics New Zealand.

Table 84 shows a marked increase in the proportion of work-poor prime-aged households in each household size and a decline in work-rich households between 1986 and 1991. In

\footnotetext{
113 The proportion of households with one person in the target age group rose very slightly from just over 35 percent in 1986 to just under 37 percent in 1991, then stabilised. For households with two persons, the figures were 61 percent in 1986, 59 percent in 1991, and 57 percent in 1996. For households with three people in the target age group, there was a rise from 3.1 percent in 1986 to 4.6 percent in 1996. This later rise could reflect a number of factors, including older children (aged 25-59) staying in the family home longer.
} 
the next five years, there was a decline in one prime-age person work-poor households, stability in the two-person households, but an increase in work-poor three prime-aged person households. For all households, there was an increase in the proportion that could be considered work rich between 1991 and 1996. However, in only two person primeaged households was the proportion who were work-rich higher in 1996 than in 1986.

When overall trends in Table 84 are analysed they show that, in 1986, 13 percent of prime-aged households were work-poor, this rose to 20 percent in 1991 and declined marginally to 19.4 percent in 1996. In 1996, out of the OECD countries Belgium was the highest at 24.8 percent, while the lowest was the U.S at 15.4 percent (Gregg et al forthcoming). The rates of other OECD countries in 1996 were Australia 16.3 percent, Canada 19.9 percent, France 21.9 percent, Germany 20.7 percent, Greece 20.1 percent, Ireland 20.4 percent, Italy 20.7 percent, Luxembourg 16.4 percent, Netherlands 19.7 percent, Portugal 13.3 percent, Spain 20 percent and the U.K. 21.6 percent.

At the other extreme, in 198664.4 percent of households were work-rich, this declined to 59.8 percent in 1991, then rose again to 63.4 in 1996. That the work-poor households declined only marginally, but work-rich households increased in the time of strong job growth between 1991 and 1996 suggests that prime-aged people living in households with someone already in paid work took many of the new jobs.

Also of importance, Table 84 shows that households were far more likely to be work-poor when there was only one prime-aged person living in them. ${ }^{114}$ This group includes workpoor sole parent families.

There are a number of important factors missing from this type of household analysis. First, there is no information on the relationships between household members, there is no gender analysis, and the presence of children is not considered. For instance a household

\footnotetext{
${ }^{114}$ Again, it needs to be noted that there could be other people outside the 25-59 age group living in these households.
} 
with two prime-aged people could be a flat with unrelated people, it could be two sole fathers living in the same household, or it could be a parent and adult child.

Tables 85 and 86 use data from the HLFS to provide another view of changes in the proportion of households that could be classified as being work-rich or work-poor. The data are only available from September 1996 and the tables show trends through to December 1998. These data are based on a survey and given the small size of some of the cells the results need to be treated with caution. In addition, in couples and one-parent families the households include adult children so these are incorporated in the calculation as to whether a household was work-rich or work-poor. This means it is possible to have a mixed work sole parent family. Finally, the data cannot be directly compared with Tables 83 and 84 as slightly different age groups are used. Despite some changes within particular household types, overall, the tables show little change in the proportion of work-rich and work-poor households over the relatively short period shown. However, this new data source will be important in the longer term as it will allow researchers to examine how economic and employment cycles affect the changes in work within particular household types. Some transitions in and out of work in these household types will also be able to be calculated. 
Table 85 - Percentage of each household type in which all adults aged 15-64 were in paid work, 1996-1998

\begin{tabular}{|c|c|c|c|c|c|c|c|c|c|c|}
\hline Household & $\begin{array}{r}\text { Sep } \\
96\end{array}$ & $\begin{array}{r}\text { Dec } \\
96\end{array}$ & $\begin{array}{r}\text { Mar } \\
97\end{array}$ & $\begin{array}{r}\text { Jun } \\
97\end{array}$ & $\begin{array}{r}\text { Sep } \\
97\end{array}$ & $\begin{array}{r}\text { Dec } \\
97\end{array}$ & $\begin{array}{r}\text { Mar } \\
98\end{array}$ & $\begin{array}{r}\text { Jun } \\
98\end{array}$ & $\begin{array}{r}\text { Sep } \\
98\end{array}$ & $\begin{array}{r}\text { Dec } \\
98\end{array}$ \\
\hline $\begin{array}{l}\text { Couple with no } \\
\text { children }\end{array}$ & 71 & 71 & 69 & 70 & 70 & 69 & 69 & 70 & 70 & 71 \\
\hline $\begin{array}{l}\text { Couple with one } \\
\text { child }\end{array}$ & 70 & 68 & 68 & 69 & 70 & 68 & 67 & 67 & 64 & 67 \\
\hline $\begin{array}{l}\text { Couple with two } \\
\text { children }\end{array}$ & 69 & 69 & 68 & 68 & 67 & 68 & 68 & 65 & 67 & 65 \\
\hline $\begin{array}{l}\text { Couple with three or } \\
\text { more children }\end{array}$ & 67 & 64 & 64 & 64 & 65 & 63 & 64 & 63 & 60 & 63 \\
\hline One-parent family & 39 & 38 & 37 & 37 & 37 & 40 & 37 & 35 & 37 & 38 \\
\hline $\begin{array}{l}\text { Other family } \\
\text { households with or } \\
\text { without others }\end{array}$ & 64 & 62 & 63 & 58 & 60 & 62 & 61 & 60 & 61 & 60 \\
\hline $\begin{array}{l}\text { Non-family } \\
\text { household }\end{array}$ & 74 & 77 & 71 & 72 & 73 & 75 & 71 & 68 & 69 & 69 \\
\hline $\begin{array}{l}\text { One person } \\
\text { household }\end{array}$ & 71 & 72 & 71 & 71 & 72 & 72 & 70 & 69 & 68 & 69 \\
\hline Total & 66 & 66 & 65 & 65 & 65 & 65 & 64 & 63 & 63 & 64 \\
\hline
\end{tabular}

Table 86 - Percentage of each household type in which no adults aged 15-64 were in paid work, 1996-1998

\begin{tabular}{|c|c|c|c|c|c|c|c|c|c|c|}
\hline Household & $\begin{array}{r}\text { Sep } \\
96\end{array}$ & $\begin{array}{r}\text { Dec } \\
96\end{array}$ & $\begin{array}{r}\text { Mar } \\
97\end{array}$ & $\begin{array}{r}\text { Jun } \\
97\end{array}$ & $\begin{array}{r}\text { Sep } \\
97\end{array}$ & $\begin{array}{r}\text { Dec } \\
97\end{array}$ & $\begin{array}{r}\text { Mar } \\
98\end{array}$ & $\begin{array}{r}\text { Jun } \\
98\end{array}$ & $\begin{array}{r}\text { Sep } \\
98\end{array}$ & $\begin{array}{r}\text { Dec } \\
98\end{array}$ \\
\hline $\begin{array}{l}\text { Couple with no } \\
\text { children }\end{array}$ & 10 & 10 & 11 & 10 & 10 & 10 & 11 & 9 & 8 & 9 \\
\hline $\begin{array}{l}\text { Couple with one } \\
\text { child }\end{array}$ & 6 & 6 & 6 & 7 & 7 & 5 & 6 & 7 & 8 & 7 \\
\hline $\begin{array}{l}\text { Couple with two } \\
\text { children }\end{array}$ & 5 & 4 & 4 & 4 & 5 & 5 & 6 & 7 & 6 & 7 \\
\hline $\begin{array}{l}\text { Couple with three or } \\
\text { more children }\end{array}$ & 7 & 6 & 8 & 7 & 7 & 7 & 8 & 9 & 8 & 8 \\
\hline One-parent family & 47 & 48 & 49 & 46 & 45 & 44 & 46 & 49 & 48 & 44 \\
\hline $\begin{array}{l}\text { Other family } \\
\text { households with or } \\
\text { without others }\end{array}$ & 15 & 14 & 13 & 16 & 15 & 12 & 13 & 14 & 15 & 15 \\
\hline $\begin{array}{l}\text { Non-family } \\
\text { household }\end{array}$ & 11 & 9 & 11 & 12 & 10 & 7 & 10 & 11 & 12 & 13 \\
\hline $\begin{array}{l}\text { One person } \\
\text { household }\end{array}$ & 30 & 28 & 29 & 29 & 28 & 28 & 31 & 31 & 32 & 31 \\
\hline Total & 16 & 15 & 16 & 16 & 16 & 15 & 16 & 17 & 17 & 16 \\
\hline
\end{tabular}

In these tables gender or education are not considered. In the next section these variables are considered but the focus is only on couple households. 


\section{Changes in patterns of paid work within prime-age couples}

While changes in paid work within single person households are of interest, couples provide an opportunity to assess the combined impact of changes in both women's and men's paid work within one household unit. In the following analysis both partners had to be in the 25-59 age group. Table 87 shows broad changes in work-patterns for this group of couples.

Table 87 -Couples in the 25-59 age group by paid work status of both partners $\%$ in each group

\begin{tabular}{lrrr}
\hline & 1986 & 1991 & 1996 \\
\hline Both in paid work (work-rich) & 63.1 & 62.3 & 68.6 \\
Both not in paid work (work-poor) & 2.7 & 7.7 & 6.9 \\
One person in paid work (mixed-work) & 34.2 & 30.0 & 24.5 \\
Total & 100.0 & 100.0 & 100.0 \\
& & & \\
$\mathrm{n}=$ & 465,057 & 480,660 & 516,195 \\
\hline \multicolumn{4}{l}{ Source: Derived from the Census of Population and Dwellings, Statistics New Zealand }
\end{tabular}

Source: Derived from the Census of Population and Dwellings, Statistics New Zealand

Table 87 shows a strong increase in the proportion of prime-aged work-poor couples between 1986 and 1991, but a small decline over the next five years. The proportion of work-rich couples declined over the first five years, but expanded between 1991 and 1996. Not surprisingly, the strong growth in the proportion of work-poor couples took place in a time of overall job loss, while the growth in work-rich couples occurred during overall job growth. The result of all these trends was a very rapid decline in the proportion of mixed-work couples over the period studied. This reduction of mixed work couples fits with the household data and is in line with long-term trends in many other industrialised countries. Given the New Zealand patterns of male and female employment back to the 1950s shown in previous chapters, as well as the relatively high rates of couple living, the mixed-work couple arrangement must have been in long-term decline in New Zealand. However, the growth of work-poor couples was a relatively new phenomenon with such a growth last seen in the depression of the 1930s.

To provide some guide as to whether the proportion of work-rich or work-poor couples should be expected given the work patterns of individuals who lived in couples, first the proportion of work-rich, work-poor and mixed work couples was calculated. This 
proportion was then compared with what would have been expected given a random allocation of work-rich and work-poor individuals across couples. In 1986, there were as many work-rich couples as would be predicted by random sorting (a ratio of 1.0), but 1.8 times as many work-poor couples In 1996, these ratios had increased to 1.1 times as many work-rich couples as would be predicted by random sorting, and 2.3 times as many workpoor couples. ${ }^{115}$ These data add a new dimension to the data on the living arrangements of individuals shown in the previous chapter. The data show that in both 1986 and 1996 work-poor men who lived in couples tended to have work-poor partners. In addition, in 1996 in 62 percent of work-poor couples both partners were classified as not being in the labour force. This means that the majority of prime-aged work-poor couples did not appear to be actively seeking paid work.

Table 88 provides a finer breakdown of Table 87 by dividing hours of work into full time and part time.

Table 88 -Couples in the 25-59 age group by paid work status of both partners, 1986-1996

$\%$ in each group

\begin{tabular}{lrrrr}
\hline & 1986 & 1991 & 1996 & $1986-1996$ \\
\hline Male full time, female full time & 37.5 & 37.9 & 40.9 & 3.4 \\
Male full time, female part time & 23.8 & 22.1 & 24.2 & 0.4 \\
Male full time, female not in paid work & 31.7 & 24.8 & 18.9 & -12.8 \\
Male part time, female full time & 1.0 & 1.4 & 2.1 & 1.1 \\
Male part time, female part time & 0.8 & 1.0 & 1.5 & 0.7 \\
Male part-time, female not in paid work & 1.1 & 1.1 & 1.5 & 0.4 \\
Male not in paid work, female full time & 1.1 & 2.7 & 2.6 & 1.5 \\
Male not in paid work, female part time & 0.4 & 1.4 & 1.5 & 1.1 \\
Male not in paid work, female not in paid work & 2.7 & 7.7 & 6.9 & 4.2 \\
n= & 465,057 & 480,660 & 516,195 & \\
\hline
\end{tabular}

Source: Derived from the Census of Population and Dwellings, Statistics New Zealand

While Table 87 showed a decline in the proportion mixed-work couples, Table 88 shows that the decline only took place in the "traditional" situation where the male partner worked full time and the female was not in paid work. This decline between 1986 and 1996 was very strong. In contrast, while the other types of mixed-work couples were very small in 1986, they all showed some small growth over the ten years to 1996. The two

\footnotetext{
115 The ratio for mixed work couples with the male the one in work was 0.8 while for the opposite arrangement it was 0.5 .
} 
strongest growing couple types were those with both partners not in paid work, followed by those where both worked full time. These are the two extremes of being work-rich and work-poor. It is also interesting to note that there was no decline in the proportion of couples where both worked full time through the low period of employment in the 1990s.

\section{Age and the work-status of couples}

Figure 39 provides a breakdown of work patterns within couples using 1996 data. It is based on the age of the women in the couple. Figure 39 shows age is an important variable in these working arrangements, with a reduction in the proportion of work-rich couples during the main childrearing ages for women. This is also the age group when the traditional model of men working full time and women not in paid work is at its highest. Overall, despite the increase in the number of men not in paid work there were few couples where the women worked full time and the man was not in work. Also of importance was the rapid rise in the proportion of older couples where neither partner was in paid work. Due to men generally being older in couples some men would have reached an age where they were eligible for superannuation. Some will also have had sufficient personal financial assets to retire. However, some of these older couples were likely to have been supported by another state benefit. Many in this older group will have had very different social norms than younger couples and may not have considered the option of the female partner becoming the sole market income earner. 


\section{Figure 39}

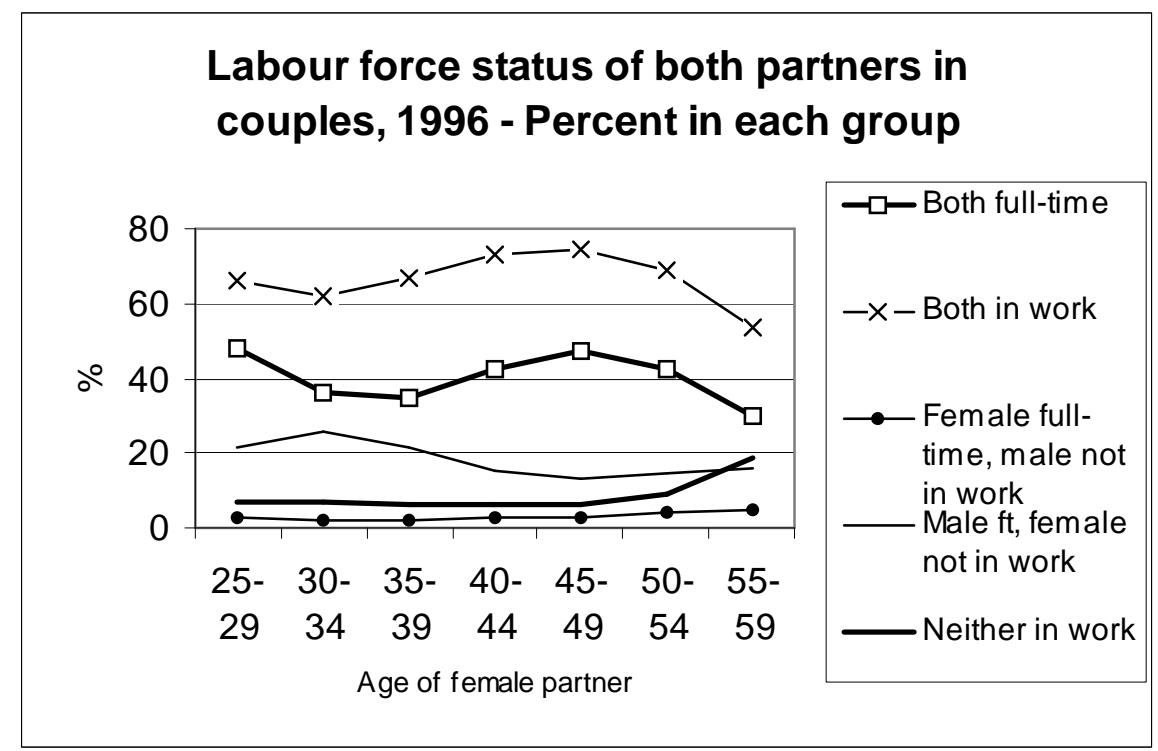

Source: Derived from the Census of Population and Dwellings, Statistics New Zealand

Figure 39, along with other family research, indicate that having young children is an important factor as to whether couples are work-rich or work-poor. However, as discussed in previous chapters, research has shown that in childrearing families the income of the primary income earner (usually the male) is important in decisions as to whether the other partner (usually the female) stays home and looks after children full time for some period or whether one partner works part time.

\section{Male income and the employment status of women}

Figure 40 explores the relationship between male income (per annum) and female employment in prime-aged couples. Figure 40 shows that in 1996 the highest rates of participation in full-time work were amongst women with a partner declaring a loss in income or no income. A significant proportion of these couples were likely to be running family businesses. Full-time work for women then peaked again when their partner was in the $\$ 20,001-\$ 30,000$ income range. Female participation in part-time work climbed steadily from $\$ 0$ male income through to reach a peak at a male income of $\$ 100,000$ or more. This supports the idea that women are most able to work part time when a primary income earner in a family financially supports them. Overall, the highest rates of 
participation in paid work amongst partnered women were for those whose partner showed a loss, followed by those with an income in the $\$ 40,001$ to $\$ 50,000$ range. While in this analysis the workstatus of the male is not known, it does suggest that selfemployment was a factor in whether couples were work-rich. However, lending some support to the view that many women in paid employment are trying to protect family income, Figure 40 shows the highest rate of women unemployed and actively seeking work was in families where the male income was in the range $\$ 1-\$ 10,000$. Yet, it also shows that the rate of women actually working in this income range for men was relatively low. In fact, the highest rate of women not in the labour force was when male income was very low. These will tend to be the work-poor couples. Overall, the graph indicates that while many women may have moved into paid work to boost low male income much of the long-term growth of work-rich couples has been for other more complex reasons.

\section{Figure 40}

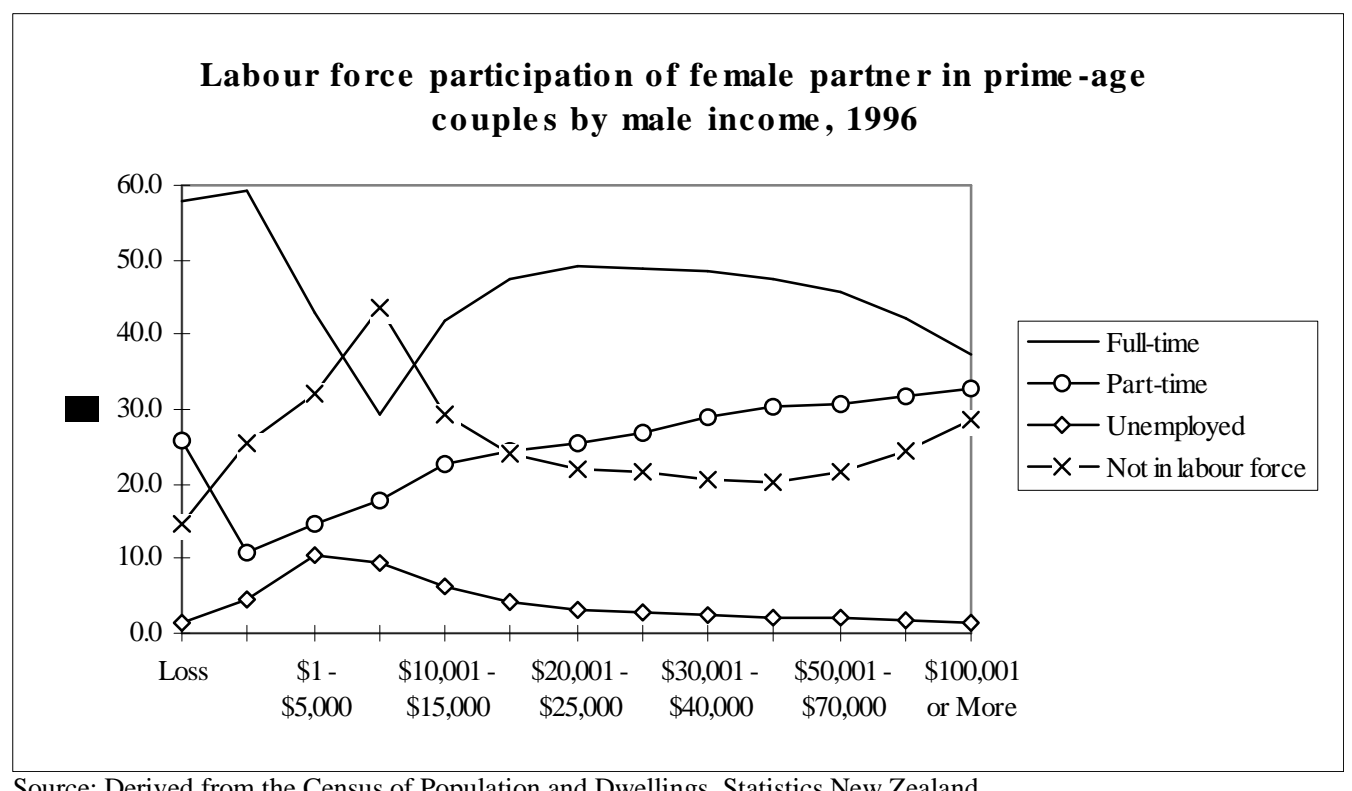




\section{Self-employment and couples}

Table 89 explores the intersection of self-employment and employee status with changes in work patterns within couples. The largest decline between 1986 and 1996 was amongst those couples where one partner was a wage and salary earner and one not in paid work. The two biggest growth areas were no-job couples and "other combinations". The growth in "other combinations" indicates that a new diversity of work arrangements is emerging. Finally, another small growth area was one full-time employee with a self-employed partner. Often self-employment is discussed in isolation, whereas it may be that many start-up businesses actually require one person in a family to be a full-time employee elsewhere to initially support the business. Also of interest, when compared with Table 88, the data in Table 89 shows that while there was a growth in the proportion of couples where both worked full time, there was actually a slight decline in the proportion where both worked as wage or salary earners.

Table 89 - Couples in the 25-59 age group by paid work status of both partners, 1986-1996

$\%$ in each group

\begin{tabular}{|c|c|c|c|c|}
\hline & 1986 & 1991 & 1996 & $\begin{array}{r}\text { Change } \\
1986-1996\end{array}$ \\
\hline Both full-time wage or salary earner & 23.7 & 22.9 & 23.6 & -0.1 \\
\hline Both part-time wage or salary earner & 0.5 & 0.4 & 0.6 & 0.1 \\
\hline Both full-time self employed or employer & 6.2 & 5.9 & 6.4 & 0.2 \\
\hline Both not in paid work & 2.7 & 7.7 & 6.9 & 4.2 \\
\hline $\begin{array}{l}\text { One full-time wage or salary earner, one full-time self } \\
\text { employed or employer }\end{array}$ & 7.3 & 8.4 & 9.4 & 2.1 \\
\hline $\begin{array}{l}\text { One full-time wage or salary earner, one part-time wage } \\
\text { and salary earner }\end{array}$ & 15.5 & 13.7 & 13.9 & -1.6 \\
\hline One full-time wage or salary earner, one not in paid work & 25.1 & 21.1 & 16.5 & -8.6 \\
\hline $\begin{array}{l}\text { One full-time self-employed or employer, one part-time } \\
\text { wage or salary earner }\end{array}$ & 4.8 & 4.6 & 4.6 & -0.2 \\
\hline $\begin{array}{l}\text { One full-time self-employed or employer, one part-time } \\
\text { self-employed or employer }\end{array}$ & 3.0 & 3.2 & 4.6 & 1.6 \\
\hline $\begin{array}{l}\text { One full-time self employed or employer, one non- } \\
\text { employed }\end{array}$ & 7.5 & 6.0 & 4.4 & -3.1 \\
\hline \multirow[t]{2}{*}{ Other combinations } & 3.8 & 5.9 & 9.3 & 5.5 \\
\hline & 100.0 & 100.0 & 100.0 & \\
\hline
\end{tabular}

Source: Derived from the Census of Population and Dwellings, Statistics New Zealand

Note: Self-employed category includes unpaid family workers

As shown in Chapter eighteen, prime-aged women living in couples with a male partner were over-represented amongst prime-aged people working part time. However, as also 
shown part-time work had been spreading to both men and women in a wide range of household arrangements in the period studied. Table 90 provides a basic way of further analysing part-time work in couples. It shows the number, and percentage, of prime-aged women working part time and living in a couple by the labour force status of their male partner.

\section{Table 90 - Number and percentage of women in prime-aged couples who worked} part time by male labour force status, 1986 and 1996

\begin{tabular}{|c|c|c|c|c|}
\hline & \multicolumn{2}{|c|}{ Total } & \multicolumn{2}{|c|}{$\%$} \\
\hline Male employment status & 1986 & 1996 & 1986 & 1996 \\
\hline Full-time employer of others & 19,119 & 22,452 & 16 & 16 \\
\hline Full-time self employed and not employing others & 16,536 & 22,626 & 14 & 16 \\
\hline Full-time wage or salary earner & 74,166 & 76,485 & 64 & 55 \\
\hline Full-time unpaid worker in family business & 213 & 1,443 & 0 & 1 \\
\hline Part-time employer of others in own business & 306 & 2,367 & 0 & 2 \\
\hline Part-time self employed and not employing others & 972 & 792 & 1 & 1 \\
\hline Part-time wage or salary earner & 2,286 & 3,594 & 2 & 3 \\
\hline Part-time unpaid worker in family business & 48 & 606 & 0 & 0 \\
\hline Unemployed and seeking work & 705 & 2,346 & 1 & 2 \\
\hline Non-labour force & 1,200 & 5,238 & 1 & 4 \\
\hline Not specified & 564 & 2,262 & 0 & 2 \\
\hline Total & 116,133 & 140,214 & 100 & 100 \\
\hline
\end{tabular}

First, Table 90 does show that the number of women in couples and employed part time grew in almost all the categories of male employment. The table also confirms that by far the highest proportion of female part-time workers who were in a couple did have a male partner in full-time work. However, as a proportion of part-time workers, women with a male partner who was in full-time work declined over the period 1986 to 1996 . This was brought about solely by a decline within couples where the male was a full-time employee.

The data in Table 90 provides some layers of complexity to the added female part-time worker theory. The growth in part-time work amongst women was, in fact, spread across a wide range of family working arrangements. For instance, there was growth in partnered women working part time where their male partner was self-employed and small, but significant, growth in those where their partner was not employed. It is highly 
likely in these quite different family situations, the women's motivation for being in parttime work varied enormously.

Was male employment seeking behaviour associated with the labour force status of their partner?

Given concepts of traditional roles, it might be expected that if a couple were work-poor then the male would be actively trying to find a job. Table 91 focuses on the association of a female partner's labour force position in 1996 with whether men in prime-aged couples were actively seeking work. It shows the ratio of men actively seeking work to those who had exited the workforce. The men most likely to be seeking work were those with a partner also seeking work. Some of these could be new immigrants or New Zealanders having returned from living overseas. Many may not be long-term work-poor. In all the other female labour market statuses, most men did not seem to be actively seeking work. It is surprising that the proportion seeking work varied little as to whether their partner was employed full time, part time or not in the labour force. However, the reasons why they were not seeking work may have varied considerably. A male with a partner in full-time work may have been skilled and living in a work-rich area but not be under financial pressure to seek paid work, whereas a male with a partner not in the labour force may have been unskilled and living in a work-poor area and had given up hope of finding a job. It is also likely that there were some regional variations in this behaviour.

Table 91 - Ratio of men unemployed and seeking work to those not in the labour force by employment status of their female partner in prime-age couples, 1996

\begin{tabular}{|c|c|c|c|}
\hline \multicolumn{2}{|c|}{ Female employment status } & Ratio & Total \\
\hline \multirow[t]{4}{*}{ Full time } & Wage and salary & 0.4 & 11,547 \\
\hline & Self employed & 0.3 & 705 \\
\hline & Employer & 0.2 & 402 \\
\hline & Unpaid family worker & 0.3 & 291 \\
\hline \multirow[t]{4}{*}{ Part time } & Wage and salary & 0.5 & 6,222 \\
\hline & Self employed & 0.3 & 546 \\
\hline & Employer & 0.3 & 99 \\
\hline & Unpaid family worker & 0.3 & 357 \\
\hline \multicolumn{2}{|c|}{ Unemployed and seeking work } & 2.1 & 6,174 \\
\hline \multicolumn{2}{|c|}{ Not in labour force } & 0.3 & 29,586 \\
\hline
\end{tabular}




\section{Some characteristics of prime-aged work-rich and work-poor couples}

In this section some of the observed characteristics of work-rich and work-poor couples are examined. This analysis focuses on hours worked, level of formal education, ethnicity, occupational status, income and health status. While one aim of this analysis is to better determine why particular groups of couples might be work-poor rather than work-rich, another is to explore whether there was some diversity within each of these seemingly polarised couple types.

\section{Hours of work}

While in most of this analysis I classify work-rich couples as being those where both partners were in paid work, it is useful have a clearer idea of the range of hours worked. Table 92 shows a breakdown in hours worked by couples with both partners in paid work in 1986 and then in 1996. Table 93 shows the changes between these two censuses. In both 1986 and 1996 the largest single group of work-rich couples were those who both worked 40-49 hours per week. When changes in each cell between 1986 and 1996 were calculated, the results reinforce the findings of previous chapters that over the time studied fewer prime-aged men were working in the range of 30-49 hour weeks. It also shows the largest increases were for couples where the male worked 50 or more hours per week. This reinforces the idea that a key element of labour market flexibility for men has been that of working longer hours. Table 92 also shows that in work-rich couples men tended to work 40 or more hours per week, whereas there was more variety of hours amongst their partners.

While in 1986 and 1996 in relatively few work-rich couples both partners worked short hours, this proportion increased slightly over the period studied. For example, in 1986 in 0.5 percent of couples both worked less than 20 hours per week but this had increased slightly to 0.9 percent in 1996 . At the other extreme, in a significant proportion of workrich couples both worked 40 or more hours in 1986 and 1996. In 198636.1 percent worked these hours, while this rose to 40.1 percent. These hours' data show that within work-rich couples there was some polarisation of hours worked over the decade. It is 
possible that there were major differences in characteristics between couple at both ends of this spectrum but unfortunately when the data was collected this potential was not considered. However, given that the couples with very low combined hours of work are relatively small their characteristics will not have a major impact on the subsequent analysis.

Table 92 - Hours of paid work by both partners in prime-aged couples, 1986 and 1996 - \% in each group

\begin{tabular}{|c|c|c|c|c|c|c|c|}
\hline \multirow[t]{2}{*}{1986} & & \multicolumn{5}{|c|}{ Female hours } & \multirow[b]{2}{*}{$50+$} \\
\hline & & $1-9$ & $10-19$ & $20-29$ & $30-39$ & $40-49$ & \\
\hline \multirow{6}{*}{$\begin{array}{l}\text { Male } \\
\text { hours }\end{array}$} & $1-9$ & 0.1 & 0.1 & 0.1 & 0.1 & 0.2 & 0.0 \\
\hline & $10-19$ & 0.1 & 0.2 & 0.1 & 0.2 & 0.3 & 0.1 \\
\hline & $20-29$ & 0.1 & 0.2 & 0.3 & 0.3 & 0.3 & 0.1 \\
\hline & $30-39$ & 0.7 & 1.2 & 1.5 & 2.7 & 1.9 & 0.3 \\
\hline & $40-49$ & 3.9 & 8.0 & 9.6 & 11.4 & 18.1 & 2.2 \\
\hline & $50+$ & 2.6 & 5.0 & 6.1 & 6.4 & 8.7 & 7.1 \\
\hline \multirow{2}{*}{\multicolumn{2}{|c|}{1996}} & \multicolumn{5}{|c|}{ Female hours } & \\
\hline & & $1-9$ & $10-19$ & $20-29$ & $30-39$ & $40-49$ & $50+$ \\
\hline \multirow{6}{*}{$\begin{array}{l}\text { Male } \\
\text { hours }\end{array}$} & $1-9$ & 0.3 & 0.1 & 0.1 & 0.2 & 0.4 & 0.1 \\
\hline & $10-19$ & 0.2 & 0.3 & 0.2 & 0.3 & 0.4 & 0.2 \\
\hline & $20-29$ & 0.1 & 0.2 & 0.4 & 0.3 & 0.6 & 0.2 \\
\hline & $30-39$ & 0.4 & 0.6 & 0.9 & 1.4 & 1.5 & 0.5 \\
\hline & $40-49$ & 3.5 & 5.6 & 7.6 & 8.9 & 16.4 & 3.5 \\
\hline & $50+$ & 3.8 & 5.8 & 7.4 & 7.3 & 11.4 & 8.8 \\
\hline
\end{tabular}

Table 93 - Change in hours of paid work by both partners in prime-aged couples, 1986 to 1996

\begin{tabular}{llrrrrrr}
\hline \multicolumn{7}{c}{ Female hours } \\
\hline & & $1-9$ & $10-19$ & $20-29$ & $30-39$ & $40-49$ & $50+$ \\
& $1-9$ & 0.2 & 0.1 & 0.1 & 0.1 & 0.2 & 0.1 \\
Male & $10-19$ & 0.1 & 0.1 & 0.1 & 0.1 & 0.2 & 0.2 \\
hours & $20-29$ & 0.1 & 0.0 & 0.1 & 0.1 & 0.2 & 0.2 \\
& $30-39$ & -0.2 & -0.6 & -0.7 & -1.3 & -0.4 & 0.1 \\
& $40-49$ & -0.4 & -2.4 & -2.0 & -2.5 & -1.7 & 1.3 \\
& $50+$ & 1.2 & 0.8 & 1.2 & 0.9 & 2.7 & 1.7 \\
\hline \multicolumn{7}{l}{ Source: Derived from the Census of Population and Dwellings, Statistics New Zealand }
\end{tabular}

\section{Single jobs or multiple jobs?}

The hours shown in Table 92 and 93 (and subsequent tables) are for total hours worked. However, these total hours could be worked in only one job, or in more then one job. The 
data in Table 94 shows that in about a fifth of work-rich couples, one or both partners had more than one job in the week previous to when the census was taken. Although this issue is not explored further, it is possible that many of the people working in more than one job would have been in low paid, and often insecure, work.

Table 94 - Number of jobs held simultaneously for prime-aged people in work-rich couples, 1996

\begin{tabular}{llrrr}
\hline & & \multicolumn{3}{c}{ Male number of jobs } \\
\hline & & 1 Job & More than 1 Job & Total \\
& 1 Job & 79.9 & 7.1 & 87.1 \\
Female number of jobs & 10.0 & 3.0 & 12.9 \\
& More than 1 Job & 89.9 & 10.1 & 100.0 \\
\cline { 2 - 4 } & Total & &
\end{tabular}

\section{Educational qualifications}

Education is clearly a key variable in this research. One of the original research questions was whether formal education would be a key factor whether couples were work-rich or work-poor. Tables 95 and 96 show the highest educational qualifications of both partners in work-rich and work-poor couples. First, it is of interest that there were a similar proportion of couples with degrees or higher qualifications in both groups. This may be partly due to older students being in the work-poor group as well as qualified new immigrants (whose qualifications may not be recognised in New Zealand) who had not been able to find work. ${ }^{116}$ This is partly tested in the next set of tables. However, more clear-cut is the difference between the two categories when both partners had no formal qualifications. A third of work-poor couples were also education poor, whereas only 12 percent of work-rich couples were education-poor. Yet, these tables also show that in 1996 many unqualified couples were still work-rich.

These tables indicate that while education was an important factor in whether couples were work-rich or work-poor there were clearly other factors that influenced behaviour.

\footnotetext{
${ }^{116}$ My own household would have been in the group of couples with degrees classified as work-poor in the late 1990 s.
} 
Table 95 - Highest educational qualifications of both partners in prime-aged couples where both were employed, 1996

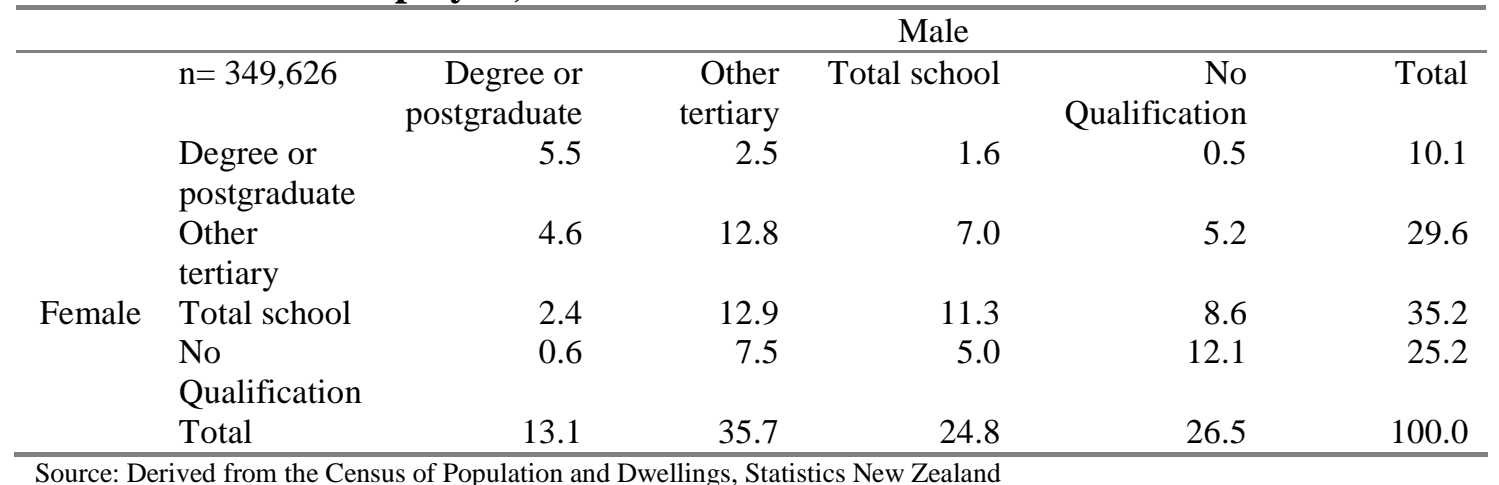

Source: Derived from the Census of Population and Dwellings, Statistics New Zealand

Table 96 - Highest educational qualifications of both partners in prime-aged couples where neither were employed, 1996

\begin{tabular}{|c|c|c|c|c|c|c|}
\hline & \multirow[b]{2}{*}{$\mathrm{n}=34,782$} & \multicolumn{5}{|c|}{ Male } \\
\hline & & $\begin{array}{r}\text { Degree or } \\
\text { postgraduate }\end{array}$ & $\begin{array}{l}\text { Other } \\
\text { tertiary }\end{array}$ & Total school & $\begin{array}{r}\text { No } \\
\text { Qualification }\end{array}$ & Total \\
\hline & $\begin{array}{l}\text { Degree or } \\
\text { postgraduate }\end{array}$ & 5.3 & 1.2 & 0.7 & 0.3 & 7.5 \\
\hline & $\begin{array}{l}\text { Other } \\
\text { tertiary }\end{array}$ & 2.5 & 6.1 & 2.7 & 4.2 & 15.5 \\
\hline \multirow[t]{4}{*}{ Female } & Total school & 2.3 & 6.0 & 10.0 & 8.9 & 27.1 \\
\hline & No & 0.6 & 7.7 & 7.1 & 34.6 & 49.9 \\
\hline & Qualification & & & & & \\
\hline & Total & 10.6 & 21.0 & 20.5 & 47.9 & 100.0 \\
\hline
\end{tabular}

\section{Ethnicity}

As indicated in previous chapters, ethnicity is an important factor in employment for individuals. However, as much of the research has also shown there are strong associations between education and ethnicity. Although in Tables 97 and 98 these connections are not unpicked, the tables still show some important characteristics. In 1996, by far the highest proportion of work-rich couples were those where both partners were of European ethnicity. This is not surprising given the relative sizes of the population groups. This was also the situation for work-poor couples, although this proportion was considerably lower and no longer a majority. 
Table 97 - Ethnicity of both partners in prime-aged couples where both were employed, 1996

\begin{tabular}{llrrrrrr}
\hline \multicolumn{7}{c}{} & \multicolumn{7}{c}{ Male ethnicity } \\
\hline $\mathrm{n}=349,608$ & European & NZ Maori & $\begin{array}{r}\text { Pacific } \\
\text { Island }\end{array}$ & Asian & Other & Total \\
& European & 78.6 & 4.6 & 0.7 & 0.3 & 0.2 & 84.4 \\
& NZ Maori & 4.3 & 3.8 & 0.4 & 0.1 & 0.0 & 8.5 \\
Female & Pacific Island & 0.7 & 0.2 & 2.0 & 0.0 & 0.0 & 3.0 \\
ethnicity & Asian & 0.9 & 0.1 & 0.0 & 2.8 & 0.0 & 3.9 \\
& Other & 0.1 & 0.0 & 0.0 & 0.0 & 0.1 & 0.2 \\
& Total & 84.7 & 8.7 & 3.0 & 3.3 & 0.3 & 100.0 \\
\hline Source: Derived from the Census of Population and Dwellings, Statistics New Zealand
\end{tabular}

Table 98 - Ethnicity of both partners in prime-aged couples where neither were employed, 1996

\begin{tabular}{llrrrrrr}
\hline & \multicolumn{7}{c}{ Male ethnicity } \\
\hline $\mathrm{n}=35,067$ & European & NZ Maori & $\begin{array}{r}\text { Pacific } \\
\text { Island }\end{array}$ & Asian & Other & Total \\
& European & 42.4 & 4.8 & 0.6 & 0.3 & 0.2 & 48.3 \\
& NZ Maori & 5.0 & 13.7 & 1.0 & 0.1 & 0.0 & 19.9 \\
Female & Pacific Island & 0.7 & 0.5 & 9.5 & 0.1 & 0.0 & 10.9 \\
ethnicity & Asian & 1.0 & 0.1 & 0.1 & 17.7 & 0.0 & 19.0 \\
& Other & 0.1 & 0.0 & 0.0 & 0.0 & 1.8 & 2.0 \\
& Total & 49.3 & 19.2 & 11.2 & 18.3 & 2.0 & 100.0 \\
\hline \multicolumn{2}{l}{ Source: Derived from the Census of Population and Dwellings, Statistics New Zealand }
\end{tabular}

Table 99 shows the ratio of the data in Table 97 to Table 98 . That is the ratio of the number of couples who were work-poor relative to the number who were work-rich in each ethnic group in 1996. In the previous chapter, I have shown that that when individual Maori have formed couples, those couples where both partners were Maori tended to have a lower level of qualifications than if only one partner was Maori. Therefore, it would be expected that there would be a higher proportion of work-poor Maori families where both partners were Maori. This does show up clearly in Table 99. 
Table 99 - Ratio of numbers of prime-aged work-poor couples to work-rich couples in each ethnic group, 1996

\begin{tabular}{llrrrrrr}
\hline \multicolumn{7}{c}{ Male ethnicity } \\
\hline & European & NZ Maori & $\begin{array}{r}\text { Pacific } \\
\text { Island }\end{array}$ & Asian & Other & Total \\
& European & 0.05 & 0.10 & 0.09 & 0.07 & 0.09 & 0.06 \\
Female & NZ Maori & 0.12 & 0.37 & 0.28 & 0.25 & 0.14 & 0.24 \\
ethnicity & Pacific Island & 0.10 & 0.23 & 0.48 & 0.26 & 0.20 & 0.37 \\
& Asian & 0.11 & 0.14 & 0.24 & 0.63 & 0.33 & 0.49 \\
& Other & 0.10 & 0.08 & 0.33 & 0.20 & 2.05 & 0.80 \\
& Total & 0.06 & 0.22 & 0.37 & 0.56 & 0.73 & 0.10 \\
\hline Source: Derived from the Census of Population and Dwellings, Statistics New Zealand & & &
\end{tabular}

If the male partner was Maori and their partner was a female European, then the ratio of work-poor to work-rich couples was 0.1. Similarly, for a female Maori and a male European the ratio was 0.12 . But when both were identified as being Maori, the ratio jumped to 0.37. However, by far the highest ratio was amongst couples where both were from Asian backgrounds. The lowest ratio was where both partners were of European ethnicity. It is not entirely clear the reasons for the high ratio amongst Asian couples. However, Chapter eighteen did show that even when an Asian man was not in work he was still highly likely to live in a couple household. So instead of being a work-poor individual male living in a non-couple household they were often living in a work-poor couple.

\section{Income}

It would be expected given the patterns of work, education and ethnicity that work-rich couples would earn much higher household incomes than work-poor couples. Table 100 draws on an unpublished data produced by Statistics New Zealand on couple households to show real incomes from the early 1980s through to the mid 1990s. The data source is the Household Economic Survey. The data shows market income and there is no age restriction on the couples. The table shows a major gap between the average incomes of work-poor and work-rich couples and that this gap increased between 1982 and 1996. However, averages do disguise some significant variation. Census data (total income not just market income) shows that there were low-income work-rich couples and, assuming the data is correct, a small number of relatively high income work-poor couples. For 
example, in 1996 in 11 percent of prime-aged work-rich couples both partners earned less than $\$ 20,000$ per year and in 1.1 percent of work-poor couples both partners earned $\$ 40,000$ or more. The diversity of incomes was particularly evident amongst the workrich couples. Some of these will include the "working-poor" whose incomes will be very near to, or even possibly in some situations below, what could be obtained on benefits. The table also shows that, on average, mixed work couples where it was the male in work had higher incomes than if it was the female who was employed. In addition, this gap increased substantially between the early 1980s and the mid 1990s. The reasons for this are not clear. However, the average income gap between those couples with just the female in work and work-poor couples was high throughout the whole period. At this very crude level of analysis, there appears to be a strong incentive for the female partner in work-poor couples to search for work.

Table 100 - Trends in average real household market income of couple households by employment status of both partners, March $\$ 1996$

\begin{tabular}{lrrrr}
\hline & $1981 / 82$ & $1985 / 86$ & $1990 / 91$ & $1995 / 96$ \\
\hline Work-poor & 11,898 & 13,396 & 10,075 & 10,522 \\
Female in work & 40,174 & 35,532 & 41,408 & 32,352 \\
Male in work & 45,413 & 44,774 & 47,900 & 51,356 \\
Work-rich & 62,300 & 55,249 & 62,062 & 65,249 \\
Total & 47,399 & 44,046 & 44,625 & 48,816 \\
Ratio work-poor to work-rich & 0.25 & 0.30 & 0.23 & 0.22 \\
\hline Source: Statistics New Zealand, HES & & & &
\end{tabular}

A more detailed study of income distribution in New Zealand does suggest there is some link between changes in work in couple households with changes in household income distribution (O’Dea 2000).

Table 101 then shows a selection of sources of income in the previous year for people in work-poor couples. The fact that only a fifth of men and fifteen percent of women had income from salaries and wages in the previous year suggests that work-poor status for a significant number of couples may have been relatively long term. However, as indicated in previous chapters, work-poor couples are more likely to separate (due to financial stresses and a range of other reasons) so this may work against a pattern of there being a significant number of long-term work-poor couples. 
Table 101 - Sources of income in the previous year for prime-age work-poor couples, 1996

$\%$ who received income from stated source*

\begin{tabular}{lrrr}
\hline & Male income & Female income & Both partners income \\
\hline Salary or wages & 21.4 & 14.7 & 8.4 \\
Sickness benefit & 13.1 & 11.8 & 9.6 \\
Domestic purposes benefit & 1.1 & 5.1 & 0.5 \\
Unemployment benefit & 40.3 & 37.1 & 33.2 \\
ACC regular payments & 7.1 & 1.7 & 1.2
\end{tabular}

Source: Derived from the Census of Population and Dwellings, Statistics New Zealand.

* These sources of income are not exclusive with a person potentially having a range of income sources over a year.

A number of other important patterns can also be observed. For example, the higher rate of men than women being on ACC payments reflects men being in more accident-prone occupations. In Table 101, the domestic purposes benefit data for women, and to a lesser degree for men, indicates that there were some work-poor sole parents who had formed work-poor couples in the previous year. If this is the case, the data also suggests that, with many prime-aged men not in paid work, the re-partnering of sole mothers often does not reduce children's dependency on government transfer payments. Unfortunately, at the time of gathering the data I did not consider examining income sources for work-rich people. This would have provided some idea of the number who had also received benefit payments.

Finally, while income is not a major issue in this research, there was in 1996 a strong tendency in work-rich couples for people with similar income levels to be in partnership. In particular, there was a very strong tendency for women and men who declared a loss to be in the same couple. This reflects self-employment amongst couples.

\section{Occupations}

In the census, only the occupations of those currently employed are collected. Therefore, only work-rich couples could be analysed. Table 102 shows the ten most common occupational mixes for work-rich prime-aged couples in 1996. The first set of data is for all hours of employment and the second where they both worked full time. 
Table 102 - Ten largest occupational mixes in prime-aged couples, 1996

\begin{tabular}{|c|c|c|c|c|c|c|c|}
\hline \multicolumn{4}{|c|}{ Both in paid work } & \multicolumn{4}{|c|}{ Both working full time } \\
\hline Male & Female & $(000 s)$ & $\%$ & Male & Female & $(000 \mathrm{~s})$ & $\%$ \\
\hline Agriculture & Agriculture & 20.7 & 6.1 & Manager & Manager & 12.6 & 6.3 \\
\hline Manager & Clerical & 18.7 & 5.6 & Agriculture & Agriculture & 12.3 & 6.1 \\
\hline Trades & Clerical & 18.0 & 5.4 & Manager & Clerical & 10.3 & 5.2 \\
\hline Manager & Manager & 16.4 & 4.9 & Trades & Clerical & 10.2 & 5.1 \\
\hline Professional & Professional & 15.4 & 4.6 & Professional & Professional & 9.8 & 4.9 \\
\hline Technical & Service & 11.6 & 3.3 & Technical & Clerical & 6.7 & 3.3 \\
\hline Trades & Service & 10.6 & 3.2 & Manager & Professional & 6.4 & 3.2 \\
\hline Manager & Professional & 10.2 & 3.0 & Plant \& mach & Clerical & 6.0 & 3.0 \\
\hline Plant \& mach & Clerical & 9.9 & 2.9 & Technical & Professional & 5.0 & 2.5 \\
\hline Professional & Clerical & 9.2 & 2.7 & Technical & Technical & 5.0 & 2.5 \\
\hline
\end{tabular}

Source: Derived from the Census of Population and Dwellings, Statistics New Zealand.

In both this table, and when the full list of combinations was examined, no particular occupational grouping dominated. Nevertheless, there were some important patterns even in these top ten combinations. Some of the combinations confirm that an important group of work-rich couples were those self-employed in a family type business. In this category, the agriculture combination was an important one. Also, in many of the combinations another aspect of assortative mating showed up. In many couples where both were employed (for any hours) occupational matching was higher than randomly expected. It was the highest in the armed forces, but this was a very small group. Having both partners working in agriculture was 6.1 times higher than would be expected through random sorting, both managers 4.9 times, and both professional 4.6 times. In contrast, some occupational mixtures were very unlikely. For example, professional women were far less likely than random sorting would suggest to be partnered by men in plant and machinery or elementary occupations.

The data shown in Table 102 provides a further indication that the lives of some workrich couples will be very different from others. For example, the five percent of couples where both worked full time in professional occupations were likely to have relatively high incomes and will have therefore been able to purchase human support services such as cleaners and technological support such as automatic dishwashers. If they had young children, many were likely to work Monday to Friday in daylight hours when most childcare (including schooling) services tend to be available. A contrasting group was the three percent where the male was in a full-time plant and machinery occupation and his 
partner worked in a clerical job. Both partners were likely to have relatively low incomes, may have been working non-standard hours and, once finished their paid work, will have generally faced the full extra burden of household work. These two positions reinforce the idea of some significant polarisation of experience within the overall work-rich group.

These examples raise the question of just how many work-rich couples might be considered dual-career couples versus dual-job couples. The following data allows an exploration of a hypothesis stated in Chapter twelve that the majority of work-rich couples were dual-job rather than dual career couples. Table 103 provides a range of estimates.

\section{Table 103 - "Dual-career" couples as a percentage of all employed prime-aged} couples, 1996

\begin{tabular}{lrr}
\hline & Number & $\%$ \\
\hline Both managerial, professional or technical - All hours & 78,048 & 23.2 \\
Both managerial, professional or technical - Both full time & 52,602 & 15.6 \\
Both managerial or professional - All hours & 45,750 & 13.6 \\
Both managerial or professional - Both full time & 31,575 & 9.4 \\
Both earning more than $\$ 40,000$ - All hours & 27,165 & 8.1 \\
Both earning more than $\$ 40,000$ - Both full time & 22,023 & 6.6 \\
Both earning more than $\$ 70,000$ - Both full time & 3,738 & 1.1 \\
\hline Source: Derived from the Census of Population and Dwellings, Statistics New Zealand.
\end{tabular}

Source: Derived from the Census of Population and Dwellings, Statistics New Zealand.

Note: In first $4 \mathrm{n}=336,228$, last three $n=335,979$

Based on these estimates, dual-career couples could represent anything from one to 23 percent of work-rich couples. However, whatever classification system is chosen it is clear that in 1996 dual career-couples did not represent a majority of work-rich couples. This is important as many popular books and academic research on working couples focus on the dual-career couples and how they can best balance work and outside responsibilities such as looking after children or elderly parents. In contrast, the problems and challenges facing dual-job couples will often be quite different and may require different solutions. For example, couples with high incomes can purchase private individual solutions while low and middle income couples often need more "familyfriendly" support from wider society.

Another group of work-rich couples identified in previous chapters were the one-career, one-job couple. As a crude measure, the number of men (all hours) in managerial, 
professional or technical jobs, with a female (again all hours) in any other occupation represented 20.2 percent of all work-rich prime-age couples. When the reverse situation was calculated this represented a further 15.4 percent. So, in total, 36 percent of work-rich couples could be seen as one-career and one-job couples. This is clearly a bigger group than the dual-career couples and may represent a more practical, or perhaps the only, way for many couples to balance work and family responsibilities. The drawback, in terms of gender equity, is that it is still more common for men to be in the career job.

Finally, Table 104 uses the modified Reich classification system used in previous chapters to further explore the occupational characteristics of work-rich couples. This time the analysis is restricted to couples where both worked full time in 1996. Again, it emphasises that work-rich couples span a wide range of occupations supporting the concept of diversity of experiences of being work-rich.

Table 104 - Modified Reich classification system for prime-aged couples with both partners in full-time work, 1996

$\%$ in each group

\begin{tabular}{lrrrrrr}
\hline $\mathrm{n}=199,362$ & \multicolumn{5}{c}{ Male occupation } \\
\hline Symbolic & Symbolic & Technical & In-person Ag and fish & Routine & Total \\
Technical & 15.8 & 8.1 & 3.0 & 2.1 & 3.2 & 32.2 \\
In-person & 4.1 & 5.1 & 1.4 & 0.8 & 1.9 & 13.3 \\
Female & 10.2 & 12.1 & 5.6 & 2.4 & 7.3 & 37.5 \\
Ag and fish & 0.5 & 0.6 & 0.2 & 6.2 & 0.7 & 8.2 \\
Routine & 1.0 & 2.3 & 0.9 & 0.6 & 4.1 & 8.8 \\
Total & 31.7 & 28.1 & 11.0 & 11.9 & 17.3 & 100.0 \\
\hline Source: Derived from the Census of Population and Dwellings, Statistics New Zealand.
\end{tabular}

\section{Health}

As discussed in previous chapters, health problems of individuals have been seen as a barrier to participation in paid work for individuals. Patterns of census health data for individuals then clearly show through in work-rich and work-poor couples. Table 105 shows the proportion of men and women in prime-age couples that stated they had a health problem. The data also indicates the close links between health status, paid work status and education. These data supports the idea that some, and possibly a significant proportion, of work-poor couples were created through one partner leaving paid work to care for the other. However, these data do not indicate the extent of the health problem. 
Table 105 - Percentage of women and men in prime-age couples with health problems, 1996

\begin{tabular}{lccc}
\hline & $\begin{array}{c}\text { Male health } \\
\text { problems } \\
\%\end{array}$ & $\begin{array}{c}\text { Female health } \\
\text { problems } \\
\%\end{array}$ & $\begin{array}{c}\text { Both with health } \\
\text { problems } \%\end{array}$ \\
\hline Wo0s) & 7.7 & 5.8 & 1.1 \\
Work poor (31.8) & 28.4 & 17.3 & 10.0 \\
$\begin{array}{l}\text { Work poor and neither partner with formal } \\
\text { qualifications (10.5) }\end{array}$ & 33.2 & 20.1 & 12.3 \\
Source: Derived from the Census of Population and Dwellings, Statistics New Zealand &
\end{tabular}

\section{Families with a child under five years of age}

This final section of the analysis focuses primarily on families with child under five. Traditionally, the presence of young children in families has been a major barrier to couples being work-rich. Table 106 provides a snapshot of the main work and parenting arrangements for families raising pre-school children in 1986, 1991 and 1996.

Table 106 - All families with a child under five - \% of families in each group, 19861996

\begin{tabular}{lrrrr}
\hline & 1986 & 1991 & 1996 & $\begin{array}{r}\text { Change } \\
86-96\end{array}$ \\
\hline Father in paid work, mother not in paid work & 49.2 & 35.6 & 28.5 & -20.7 \\
Mother in paid work, father not in paid work & 0.8 & 2.1 & 2.4 & 1.6 \\
Both Parents in paid work & 30.2 & 28.4 & 35.8 & 5.6 \\
Neither Parent in paid work & 3.2 & 9.8 & 7.6 & 4.4 \\
Sole parent - Mother in paid work & 2.1 & 2.8 & 5.3 & 3.2 \\
Sole parent - Mother not in paid work & 13.3 & 18.8 & 18.4 & 5.1 \\
Sole parent - Father in paid work & 0.6 & 1.0 & 0.9 & 0.3 \\
Sole parent - Father not in paid work & 0.6 & 1.5 & 1.1 & 0.5 \\
Total & 100.0 & 100.0 & 100.0 & \\
& & & & \\
\% of families without a parent in paid work & 17.1 & 30.1 & 27.1 & \\
n= & & & & \\
$\%$ 2-parent families & 173,202 & 192,546 & 197,718 & \\
\hline Source: Derived from the Census of Population and Dwellings, Statistics New Zealand. & &
\end{tabular}

A significant feature of the table is that, although the proportion of two-parent families appeared to stabilise between 1991 and 1996, the paid work patterns within family types continued to change from 1986 to 1996. In particular, there was a dramatic decline in the mixed work, separate sphere model of work and parenting in two-parent families 
throughout the whole period. In families where both partners were in paid work, the main growth was amongst those where the father worked full time and the mother part time. ${ }^{117}$ Further census data show that women are returning to paid work earlier after the birth of a child. In 1986, 21 percent of mothers with a child under one were in paid work. By 1996, this had risen to 31 percent. ${ }^{118}$

Of particular interest to policy makers was the proportion, and number, of families with a child under five with no parent in paid work (work-poor). The number of these families increased dramatically from just over 29,600 in 1986 to around 58,000 in 1991. While this number declined to approximately 54,000 in 1996 , it was still significantly higher than the 1986 position. What is also clear is that, as is well known, the highest proportion of work-poor childrearing families were sole parent families. For example, in 198681 percent of work-poor families with a child under five were sole parent families, this declined to 68 percent in 1991 but grew slightly again to 72 percent in 1996 . The poverty often faced by sole parent families is well documented in New Zealand (e.g. Stephens et al 1995). As already indicated, over time it is likely that some work-poor sole parents will be repartnering to form work-poor couples, just as some work-poor couples will separate to form work-poor sole parent families (plus potentially one other work-poor household). While longitudinal data is needed to test this in New Zealand, there could be a relatively high level of fluidity between these two family types.

There is also an interest nationally and internationally on the growth of "fatherless" families. This usually focuses on the growth of sole-mother families. ${ }^{119}$ However, the 1996 census also shows that many partnered fathers with pre-school children work long

\footnotetext{
${ }^{117}$ Removing those situations where men worked part time indicates that by 1996 only 26.7 percent of families were in the "traditional" model of the father in full-time paid work and the mother at home. This is, of course, a snapshot. Paid work arrangements for particular families, as well as family arrangements, potentially change from the time a child is born.

${ }^{118}$ This is a proportion of families where the mother is present, excluding sole-father families. In these situations, with a child under one, the biggest increase had been amongst mothers with a partner already in paid work. However, there was also a rise in the proportion of sole mothers returning to paid work and couples where the father did not have a paid job.

${ }^{119}$ Whether children living in sole mother families are really "fatherless" and what level of contact they have, or should have, with non-custodial fathers is the subject of on-going debate (e.g. Birks and Callister $1999 \mathrm{a} \& b)$.
} 
hours. This generally limits their time with their families. ${ }^{120}$ In 42 percent of two-parent families with a child under five, fathers worked 50 or more hours per week and, in 20 percent of families, they worked 60 or more hours. These are slightly higher percentages than in 1991. This growth is not surprising given the generally higher percentage of prime-aged men working longer hours.

Also of interest is the labour force status of the partners of fathers working long hours of paid work. There is one view that the men who devote much of their lives to paid work tend to be those with partners at home looking after the children and doing all the housework. But, in fact, data (Table 107) for couples with a child under five show that very long hours of paid work (70 or more per week) were more common amongst men with partners working full time than amongst those with partners not in paid work. Again, self-employment, including farming, is likely to be an important factor in this pattern. Fathers were most likely to work standard 30-49 hour weeks if they had a partner not in paid work.

Table 107 - Percentage of partnered fathers in prime-aged couples with a child under five by hours of paid work by labour force status of their partners, 1996

\begin{tabular}{|c|c|c|c|c|c|c|c|}
\hline & & \multicolumn{6}{|c|}{ Fathers hours of paid work } \\
\hline & & Under 10 & $10-29$ & $30-49$ & $50-69$ & 70 or more & Total \\
\hline Mothers & Full time & 1.5 & 4.1 & 50.0 & 32.9 & 11.4 & 100.0 \\
\hline hours of & Part time & 1.3 & 2.8 & 48.5 & 39.3 & 8.2 & 100.0 \\
\hline paid work & $\begin{array}{l}\text { Not in paid } \\
\text { work }\end{array}$ & 2.0 & 3.2 & 55.5 & 34.0 & 5.2 & 100.0 \\
\hline
\end{tabular}

Source: Derived from the Census of Population and Dwellings, Statistics New Zealand.

Of equal significance, however, there were in the 1990s a considerable number of families with a pre-school child where the father was not in paid employment. This could have been a non-employed father in a two-parent family or a non-employed sole father. In 1986, there were just under 8,000 fathers in these two groups. But, by 1991, this had risen to nearly 26,000 fathers and, while declining in the next five years, there were still just under 22,000 in 1996. As discussed in previous chapters, some of these men will have chosen this work-status, but many will have been forced into it through changes in labour

\footnotetext{
${ }^{120}$ Exceptions include farmers who may be able to combine their work and family life.
} 
demand. The combined changes in the labour market and in family type between 1986 and 1996 are complex, but for men they include:

- there was a dramatic decline in the "traditional" two-parent family, where the father was the sole income provider and the mother stayed home and looked after the children

- one group of men were potentially seeing far less of their children due to the growth of sole motherhood or, if the were in a couple household, because they were working long hours in paid work

- another small group had actively chosen to spend more time with their children by voluntarily moving into part-time work or exiting the workforce

- a further group of men in couples had the opportunity to spend more time with their children thrust upon them through the growth in male unemployment

Some of these changes appear to be potentially positive, but the impact of shifts such as more unemployed men spending more time at home are less clear. However, in general the increase in the proportion of children without a parent in paid work seems to be a very negative one.

The final part of the analysis briefly focuses on prime-aged couples with a child under five. These are a subset of the prime-age couples already analysed. In each of the years studied, this subset represented about a quarter of all prime-age couples. To indicate some of the potential impact of ethnicity, Table 108 includes a column of 1996 data for couples where both partners were Maori and in the target age group. 
Table 108 - Couples both in the 25-59 age group who have a child under five - \% in each group

\begin{tabular}{lrrrr}
\hline & & \multicolumn{1}{c}{ All } & Maori* \\
\hline & 1986 & 1991 & 1996 & 1996 \\
Both parents in full-time paid work & 14.7 & 15.3 & 18.6 & 20.3 \\
Father full-time paid work, mother part-time paid work & 22.5 & 23.0 & 28.9 & 14.5 \\
Father full-time paid work, mother not in paid work & 56.3 & 45.2 & 35.8 & 27.4 \\
Father part-time paid work, mother full-time paid work & 0.6 & 0.7 & 1.2 & 1.8 \\
Father part-time paid work, mother part-time paid & 0.6 & 0.8 & 1.3 & 1.8 \\
work & & & & \\
Father part-time paid work, mother not in paid work & 1.5 & 1.5 & 2.2 & 4.5 \\
Father not in paid work, mother full-time paid work & 0.6 & 1.5 & 1.8 & 3.8 \\
Father not in paid work, mother part-time paid work & 0.3 & 1.1 & 1.3 & 2.8 \\
Both parents not in paid work & 2.8 & 10.8 & 8.9 & 23.1 \\
n= & 118,680 & 127,371 & 131,106 & 8,466 \\
\hline
\end{tabular}

Source: Derived from the Census of Population and Dwellings, Statistics New Zealand.

* Both partners were Maori

By simply looking at the top and the bottom of the table, it is evident, for the combined ethnic group that there were increases in narrowly defined work-rich and work-poor couples between 1986 and 1991. The last column of Table 108 shows that in Maori families, those couples where both worked full time or neither was in paid work were highly over-represented in 1996. In this table, as in many others, there is evidence of both a polarisation in work-rich and work-poor couples, as well as an increase in diversity of work arrangements.

\section{Conclusion}

A number of research questions have been explored in this chapter. The first was one of the four main research questions outlined in the introduction. This was whether there was an increasing concentration of paid work within particular families and households between 1986 and 1996. The small amount of household data presented supports the idea that there was a small increase in the concentration of work (or lack of it) in particular households. There was certainly a decline in the proportion of mixed work households.

The data presented on couples also lends support to the idea that work-rich and work poor couples increased between 1986 and 1996, while mixed work couples declined. As with other industrialised countries strong employment growth amongst individuals in the mid 1990s did not significantly reduce the proportion of work-poor couples. Despite the 
presence of young children continuing to depress the employment levels of many women over the period studied, the trend towards work-rich and work-poor families also took place amongst families with pre-school children. Age also seems to be a factor in the shift to work-poor couples with this arrangement more common amongst older couples.

While there was some support found for the idea that work-poor couples tended to be those where both partners had a low level of formal qualifications, there were wellqualified work-poor couples and poorly qualified work-rich couples. However, despite this diversity, by the mid 1990s when both partners had no formal qualifications there was a significant chance that such couples would be work-poor. This is not surprising given the relationship between education and participation in work for individuals and the way the marriage market tends to bring together similarly qualified people. Ethnicity, while associated itself with education, also appeared to be important factor in whether couples were work-poor in the mid 1990s. However, more detailed analysis would be needed to determine the actual and independent impact of ethnicity.

While the growth in part-time work amongst prime-aged women with an already employed partner has, in the long term, been an important factor in the creation of workrich couples, by 1996 part-time work was no longer solely dominated by prime-aged women in couples who had a male partner in full-time work. Part-time work had spread to some prime-aged men, across a variety of household and family types, and had also spread to younger and older people. In some families and households it appears that parttime work may be the only type of work available, but for others working part time will be a positive choice.

The mixed work model of men in full-time work, usually as an employee, and women not in paid work for raising children rapidly declined over the period studied. Again there was a trend towards both work-rich and work-poor childrearing families. This includes a growth in work-poor sole mother families between 1986 and 1996 
Overall, this chapter has demonstrated that while there was considerable diversity in work arrangements in prime-aged households and families in the period studied there was nevertheless a shift towards a polarisation of work in households and families. As in other industrialised countries, increasingly the differences in work patterns between prime-aged families and households in New Zealand are becoming more important than the differences in work patterns between the individual prime-aged adults living in them. 


\section{Chapter 21}

\section{A polarisation into work-rich and work-poor geographic areas?}

\section{Introduction}

I begin this chapter with an exploration of whether there was a spatial polarisation into work-rich and work-poor areas over the period 1986 to $1996 .{ }^{121}$ This includes an attempt to assess whether particular area units were long-term work-poor. I then explore some broad characteristics of area units when ranked by their workstatus. The primary focus in this exploration is the educational qualifications of the residents and whether work-poor areas were also education poor. However, ethnicity is also brought into this particular analysis. I then explore whether there has been a separation into education-rich and education-poor areas in New Zealand. As discussed in Chapter three, my chosen unit of analysis is the area unit. In analysing the workstatus of an area, I focus mainly on a calculated "average" hours of paid work across the whole population (whether in work or not) in each area rather than on employment rates. ${ }^{122}$ In addition, as in most other chapters, I limit my analysis to people aged 25-59. Finally, I conclude the analysis by examining whether long-term work-poor areas were also "deprived" in 1996.

In this chapter I am analysing the paid work patterns of the residents living in a particular area, not the amount of work undertaken within it. Many of the residents may work outside of the area unit and people may commute into the residential area to undertake paid work.

\footnotetext{
${ }^{121}$ A major part of this chapter has been published in Callister (1998c).

${ }^{122}$ How I calculate the average work hours in an area unit is laid out in Chapter three. However, it is worth repeating that in my calculations I include the not specified category when working out average hours. This means that average hours are likely be slightly understated, particularly in 1996.
} 


\section{The growth of work-rich and work-poor area units}

Table 109 shows the proportion of area units in 1986, 1991 and 1996 that might be considered work-rich or work-poor using five cut-off points. It firstly shows that, like poverty lines, there can be great sensitivity around the choice of cut-off point for workpoor area units. However, the table does show a rise in the proportion of areas that were work-poor, in each of the chosen measures, between 1986 and 1996. In contrast, there was no rise in the proportion of areas that could be considered work rich. The table also shows that the loss of paid work between 1986 and 1991 was not just concentrated in a few disadvantaged locations but had an impact on a significant number of areas within New Zealand. This provides a major challenge to the more extreme ideas of polarisation. In addition, if under 20 hours is considered to be a good measure of the really work-poor areas in New Zealand there were still relatively few such areas even at the height of the loss of jobs in $1991 .^{123}$

\section{Table 109 - Percentage of area units by average hours of paid work: Prime age} people

\begin{tabular}{lrrr}
\hline Average hours per person & 1986 & 1991 & 1996 \\
\hline Under 20 hours ("work poor"1) & 0.4 & 4.1 & 1.4 \\
Under 25 hours ("work poor" 2) & 1.7 & 15.2 & 7.4 \\
Under 30 hours ("work poor" 3) & 15.3 & 52.0 & 27.4 \\
35 or more hours ("work rich" 1) & 24.6 & 11.9 & 25.4 \\
40 or more hours ("work rich" 2) & 6.2 & 2.8 & 6.2 \\
\hline Source: Derived from the Census of Population and Dwellings, Statistics New Zealand.
\end{tabular}

Table 110 shows the numbers of prime-aged people, and Table 111 the percentage, living in these particular areas from 1986 through to 1996. Again, they show that relatively few people lived in the areas defined as very work-poor.

\footnotetext{
${ }^{123}$ As an hypothetical example, if there were equal numbers of men and women, 80 precent of the men were employed and all working 40 hours per week and 50 percent of the women were employed and all working 30 hours per week, then the "average" hours per person would be 24.
} 
Table 110 - Number of prime-aged people in each group of area units

\begin{tabular}{lrrr}
\hline Average hours per person & 1986 & 1991 & 1996 \\
\hline Under 20 hours ("work poor"1) & 2,898 & 44,463 & 10,623 \\
Under 25 hours ("work poor" 2) & 11,952 & 207,471 & 92,058 \\
Under 30 hours ("work poor" 3) & 197,400 & 838,734 & 453,603 \\
35 or more hours ("work rich" 1) & 235,371 & 119,769 & 324,897 \\
40 or more hours ("work rich" 2) & 61,005 & 25,077 & 66,429 \\
\hline Source: Derived from the Census of Population and Dwellings, Statistics New Zealand.
\end{tabular}

Table 111 - Percentage of prime-aged people in each group of area units

\begin{tabular}{lrrr}
\hline Average hours per person & 1986 & 1991 & 1996 \\
\hline Under 20 hours ("work poor"1) & 0.2 & 2.9 & 0.6 \\
Under 25 hours ("work poor" 2) & 0.9 & 13.7 & 5.4 \\
Under 30 hours ("work poor" 3) & 14.1 & 55.4 & 26.8 \\
35 or more hours ("work rich" 1) & 16.8 & 7.9 & 19.2 \\
40 or more hours ("work rich" 2) & 4.3 & 1.7 & 3.9 \\
\hline \multicolumn{4}{l}{ Source: Derived from the Census of Population and Dwellings, Statistics New Zealand. }
\end{tabular}

However, these tables provide no idea of whether it was the same areas that were workrich or work-poor in each census period. As a first test, the areas that had an average of under 20 hours of work per person per week in each census were identified. In fact, there were only four. These were Balgownie, Mangere Station, Porirua Central and Rangipo. Table 112 provides a further attempt to assess how many area units were long-term workpoor. Because the under 20 hours cut-off point was so restrictive an under 25 hours cutoff was then tested. In total there were still only 21 area units that fitted this criterion. However, a major problem with this type of measure is that the relatively high employment at the starting point of the analysis sets a limit on numbers that cannot be exceeded even if the areas were then work-poor in both 1991 and 1996.

Table 112 - Area units where prime-aged people worked, on average, less than 25 hours per week in 1986, 1991 and 1996

\begin{tabular}{|l|l|l|l|l|}
\hline Balgownie & Hampden & Ohura & Rangipo & Waiopehu \\
\hline Blackball & Himatangi Beach & Oponae & Ratana & \\
\hline Fordlands & Mangakino & Otangarei & Tangimoana & \\
\hline Foxton Beach & Mangere Station & Paremoremo East & Te Teko & \\
\hline Granity & Middleton & Porirua Central & Templeton & \\
\hline
\end{tabular}

Source: Derived from the Census of Population and Dwellings, Statistics New Zealand.

Of these 21 area units, three were the site of major prisons, Paremoremo East, Templeton and Rangipo, in Waiopehu there was a major institution for disabled people, while 
Porirua was the site of a major psychiatric institution. Mangere Station was also the site of a major hospital. Rangipo has since closed, while the Porirua and the Waiopehu institutions have has been substantially reduced in size. These examples show the effect of including people living in non-private dwellings.

Figure 41 shows changes over time in a different way. It shows the distribution of area units by average hours for prime-age people in 1986 as well as the average hours for the same areas ten years later. In this graph the white line in the middle of the black line is the 1986 data.

\section{Figure 41}

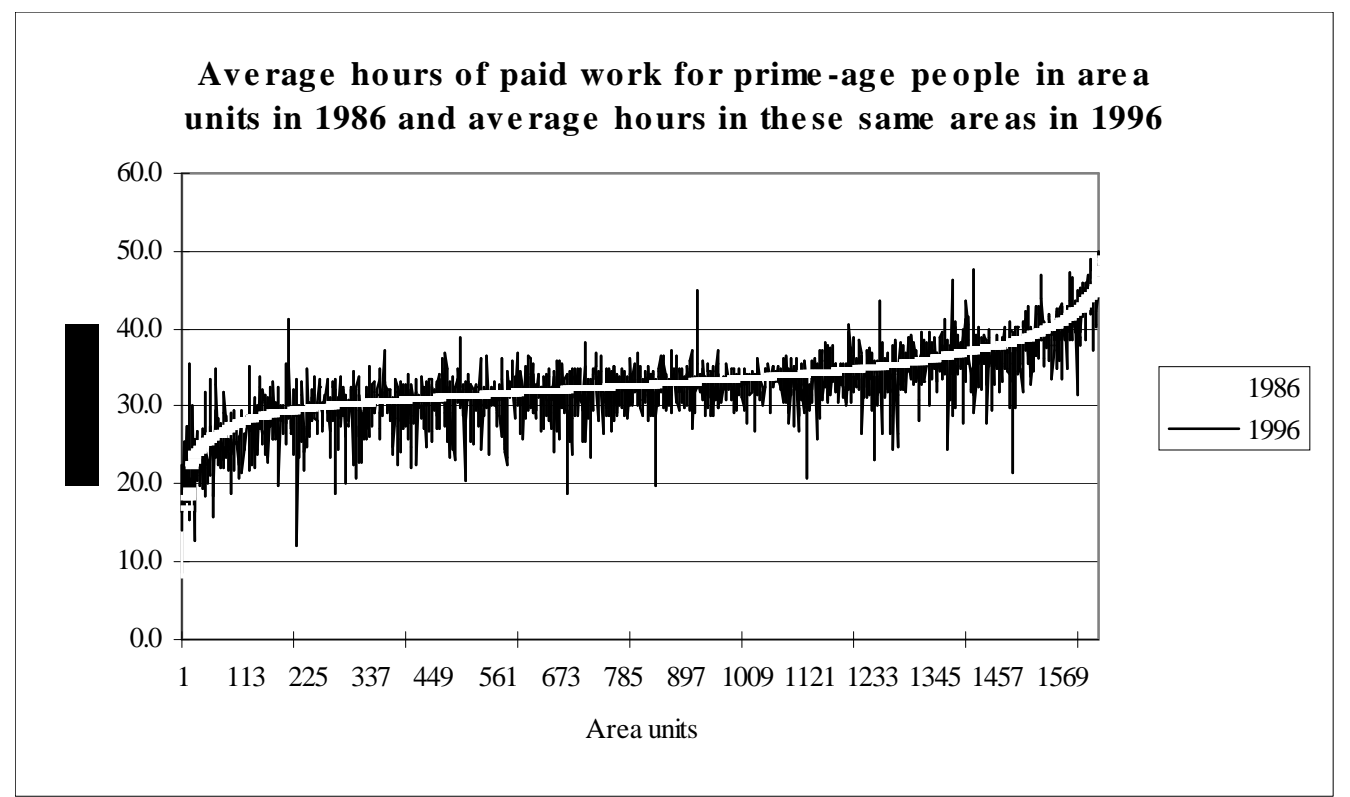

Source: Derived from the Census of Population and Dwellings, Statistics New Zealand.

The graph shows that there were considerable changes in the average hours per person in many individual area units. However, the extremely large shifts tended to be in very small area units. ${ }^{124}$ Overall, in this period of initial major job loss followed by strong employment growth the average hours worked per person per week declined in 57 percent of area units. The graph also shows that at both ends of the curve there were some communities with particularly high and particularly low average hours of paid work. It is

\footnotetext{
${ }^{124}$ For example, in Balfour Community in the South Island, there were 69 prime-age people in 1986 and 63 in 1996, and average hours increased from just under 30 in 1986 to just over 40 in 1996.
} 
possible that the sudden downward curve at the bottom end may be associated with the concept of "tipping" discussed in Chapter thirteen when neighbourhood effects are considered. While this cannot be tested in the current research, these particular neighbourhoods may be the ones where negative neighbourhood effects are operating.

There are many dimensions to the changes over time, including some differences between urban and rural areas. To illustrate this, Figure 42 restricts the analysis to changes within the Auckland urban area between 1986 and 1996. When compared with Figure 41 the graph shows that there were far fewer areas that had very high average hours of paid work in 1986. In addition, there was a decline through to 1996 in average hours per person in the ten areas with the highest hours in 1986. In some of these areas, this simply reflects a process of urbanisation in which farmland, where people tend to work long hours, was subdivided. However, of more interest to policy makers was the decline in average hours of paid work between 1986 and 1996 in many of those areas which were already work poor in 1986. These areas include communities well known to researchers and social service agencies including Otara East, Otara West and Glen Innes East. ${ }^{125}$ The one community in those ten with the lowest average hours of paid work in 1986 that did show a marked increase in average hours was Point Chevalier South. This partly reflects "gentrification" which, in turn, was linked to changes in government housing policy. Former state houses, which were in a prime location close to the harbour and city centre, were sold. This gentrification process can be seen in the proportion of the prime-age population in this area who had a degree or higher qualification. In 1986, five percent of the prime-age population in Point Chevalier South had a degree or higher, which was below the national average. However, by 1996, in this area unit the proportion of the prime-age population with a degree or higher had risen to over 16 percent, over the national average. However, another reason for this area to increase its average hours was

\footnotetext{
${ }^{125}$ In Auckland, as in some other larger urban areas, there tends to be a clustering of work-poor areas. For example Glen Innes East, Point England and Tamaki are neighbours. However, Glen Innes East is also a close neighbour to the high-income neighbourhoods of St Heliers, Glendowie and Kohimarama. In fact, buses running to a part of Glen Innes first pass through Kohimarama and St Heliers so, at one level, there will be some mixing of people.
} 
the closure of a major psychiatric institution. This, and the rural subdivision example, illustrates some ways in which the work-status of an area unit can change over time.

Figure 42

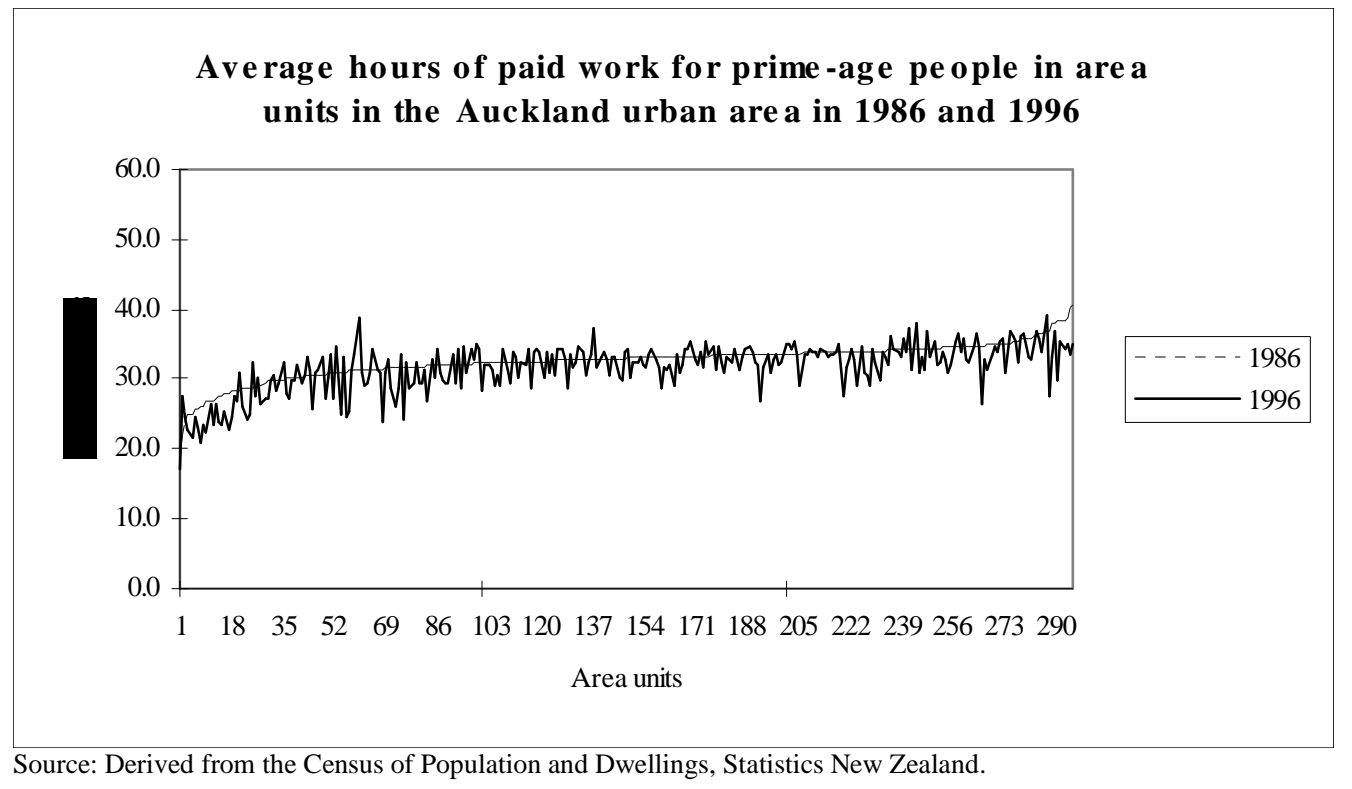

In order to provide further New Zealand-wide analysis, area units were grouped into deciles by their average hours of paid work per person in each census. This is a relative measure within each census rather than an absolute one across time. Given the concern about the lack of paid work in many area units, there is a particular focus on the status and characteristics of a group that might be considered to be work poor. These are the area units in the bottom decile. ${ }^{126}$ In contrast, work-rich area units are seen as those in the top decile of hours of paid work.

Of those area units that were in the bottom decile of hours in 1986, 60 percent were still in the bottom decile in 1991. The movement out of the bottom decile was not as strong in the next five years, despite this being a period of significant overall employment growth. Of those area units that were in the bottom decile of hours in 1991, 78 percent were again in the bottom decile in 1996.

\footnotetext{
${ }^{126}$ As it is not possible to divide 1,636 area units equally into deciles, the bottom three contained 164 units, the next four 163, and the top three 164 units.
} 
Overall, 52 percent of area units in the bottom decile in 1986 were still in the bottom decile in both 1991 and 1996. In addition, of those in the bottom decile in 1986, 82 percent were in the bottom two deciles in 1996, a further 7 percent in the third to bottom decile, and 4 percent had moved into the fourth to bottom decile. Only two very small rural areas rose from the bottom decile in 1986 to reach the third to top decile by 1996. Also noteworthy, the average hours of paid work per person increased between 1986 and 1996 in only 32 percent of the area units in the bottom decile in 1986, and 43 percent of the next decile. ${ }^{127}$

These data lend support to some of the international research discussed in Chapter thirteen that has identified that in particular areas labour market disadvantage continues over a long period. But the data also suggest that there is some, albeit limited, mobility of area units in terms of average hours of paid work undertaken.

As also discussed in Chapter thirteen, of critical importance is whether a high proportion of people remain for long periods in work-poor areas. These New Zealand data do not directly shed light on these issues. However, ethnicity can provide some idea of movement. In some area units, such as Otara East, North and South, which were workpoor in each census, there was a high concentration of people from Pacific Island ethnic groups in each time period. If there had been a considerable level of mobility this concentration might be expected to reduce significantly. These data would suggest that there might be only limited mobility for at least some groups of people.

Finally, while the mobility of work-poor adults may be important in terms of their finding paid work, it could have a negative impact on learning opportunities for their children. For instance, there are already concerns about the high roll turnover in many South Auckland schools. This impacts, in turn, on the educational outcomes, and ultimately job prospects, of the next generation.

\footnotetext{
${ }^{127}$ However, the gains and losses in average hours were not strongly concentrated in any particular decile. The percentage of area units in each decile that increased their total average hours between 1986 and 1996 were (from work-poor to work-rich deciles): 32, 43, 51, 49, 48, 45, 38, 45, 44 and 40 percent.
} 


\section{The location of work-rich and work-poor areas}

The data indicate that while many work-poor areas were to be found in large urban areas such as South Auckland or the Porirua Basin near Wellington, they were also to be found throughout rural and urban New Zealand. However, in the rural areas it was the small rural service centres rather than the farming areas that were particularly prone to being work poor. In 1996, rural centres represented 8.2 percent of the area units studied, but made up 14.1 percent of work-poor area units. ${ }^{128}$ Some small towns, such as Patea and Shannon, were also work-poor in each census. Most urban areas had at least one area unit that was work-poor over a long period. Examples include Otangarei in Whangarei, Fordlands in Rotorua, Orini in Whakatane, Lower Aramoho in Wanganui, Taita North in Lower Hutt, Addington in Christchurch and South Dunedin.

In rural New Zealand, while some work-poor areas exist, a significant proportion of work-rich area units were also to be found. In each of the censuses, around 70 percent of the work-rich area units were rural, with rural centres representing a further 5-6 percent in each census. ${ }^{129} \mathrm{~A}$ small number of the work-rich rural areas, as well as those within small towns or urban areas, were primarily tourist destinations rather than being service centres for farmers. Examples were Fox Glacier, Mt Cook, and Queenstown. However, the majority of the rural work-rich areas were farming area units. This included dairy farming areas, where long hours of paid (and unpaid) work are common, especially at the time of the year the census was taken. These work-rich rural areas are not necessarily incomerich, with long hours often worked in family businesses, regardless of the economic cycle. ${ }^{130}$ However, there were some area units in major urban areas that were work rich. Unlike the work-rich rural area units, these urban area units tended to contain people with above-average levels of education. For example, in 1996, in the Wellington area, there

\footnotetext{
${ }^{128}$ In all censuses 285 of the areas studied were classified as rural (17.4 percent of area units) and 134 as rural centres (8.2 percent of area units). In 198613.1 percent of prime-aged people lived in the rural areas, but this had risen to 13.2 percent in 1996 (some of this rise was due to the increasing popularity of rural "lifestyle" blocks). In 1986, 2.3 percent of prime-aged people lived in rural centres but by 1996 this had declined marginally to 2.2 percent.

${ }_{129}$ Rural centres have a total population between 300 and 999. These are not termed as urban and identifying these settlements distinguishes them from true rural areas and larger townships.

${ }^{130}$ The hours of paid work measure includes unpaid work in a family business.
} 
were five area units that were in the top decile of work hours nationally. These were Karaka Bay-Worser Bay, Wadestown, Roseneath, Churton Park, and Grenada. In the first three, there were particularly high levels of education amongst the population. Overall, of those area units which were work-rich in 1986, just under two-thirds were again in this top decile in both 1991 and 1996. These long-term work-rich areas tended to be the farming communities.

There are also some other important aspects of work-poor areas. For example, Table 113 shows that in 1996 there were some pockets within New Zealand where a very high proportion of prime-aged men were not in paid work.

Table 113 - Percentage of area units where 30, 40 and 50 percent of prime-age men were not in paid work, 1996

\begin{tabular}{lrrr}
\hline & $30 \%$ or more & $40 \%$ or more & $50 \%$ or more \\
\hline 1986 & 1.7 & 0.6 & 0.3 \\
1991 & 13.5 & 4.9 & 2.1 \\
1996 & 14.0 & 5.9 & 2.1 \\
\hline
\end{tabular}

In 1996, 96 area units had 40 percent or more of prime-aged men not in paid work. However, in about half (47) of these areas the average hours of those actually in work were above New Zealand's average hours for employed prime-aged men. Of these area units, 19 percent were rural areas, and a significant 36 percent were rural centres. The rural centres were particularly over-represented in this group. So these were polarised areas, with part of the community in paid work and working relatively long hours, while another significant part were not in paid work. This suggests that in some area units a finer analysis, for example at mesh-block level, would be useful.

In addition, while there was found to be some clustering of work-poor (for example in South Auckland) and clustering of work-rich areas, some work-poor areas may be very close to work-rich areas. ${ }^{131}$ A good example can be found in the Wellington region. Again just focussing on employment rates for prime-aged men in the Porirua Zone, the areas of

${ }^{131}$ In order to assess this, I examined maps showing area units. 
Endeavour had only 2.8 percent and Resolution 3.0 percent of prime-aged men not in paid work in 1996. Just over the hill, in a state housing area with no view of the harbour, the area unit of Cannons Creek North had a rate of 58.3 percent, Cannons Creek South 45.4 percent, Cannons Creek East 47.5 percent, and Waitangirua 51.6 percent.

\section{Gender issues}

As suggested by the Economist (1996), it is possible that the "problem" communities are only those where there is little paid work amongst prime-age men. The analysis of average hours in area units disguises some major changes in women's and men's paid work hours over the period 1986 to 1996. As previous chapters have shown, over the period studied participation in paid work increased for prime-age women, as did the hours worked for some of these women. For prime-age men participation declined, as did the hours worked for many men still in paid work. These patterns show up strongly when trends within area units are examined. However, Table 114 also reaffirms that women, overall, had a lower participation in paid work, and when they were in it, tended to work shorter hours than men.

Table 114 - Percentage of area units where the average hours of paid work for all prime-aged women or men was less than 30 hours per week

\begin{tabular}{lrrr}
\hline & 1986 & 1991 & 1996 \\
\hline Women & 97.7 & 98.2 & 91.0 \\
Men & 0.8 & 9.5 & 6.7 \\
\hline \multicolumn{4}{l}{ Source: Derived from the Census of Population and Dwellings, Statistics New Zealand. }
\end{tabular}

While job losses for men were widespread between 1986 and 1991, there were some very major declines in men's average hours in some area units. ${ }^{132}$ For example, in six area units, Tokomaru Bay, Kawau, Whangarei Central, Kaingaroa Forest, West Invercargill, and Moerewa, men's average hours across the area unit declined by 20 hours or more. These very large declines can usually be traced to a particular event, such as the closing of a freezing works in the situation of Moerewa and the restructuring of state forestry operations in the Kaingaroa Forest area.

\footnotetext{
${ }^{132}$ Again, this is an average across the total prime-aged male population.
} 
In order to gain a further insight into the possible links between men's and women's patterns of paid work, Tables 115, 116 and 117 provide a breakdown of the growth or loss of average hours of paid work in area units by gender between 1986 and 1996.

Table 115 - Number and percentage of area units by change in average hours for prime age men and women, 1986-1991

\begin{tabular}{lrr}
\hline & Male hours declined & Male hours steady or increased \\
\hline Female hours steady or increased & $601(36.7 \%)$ & $28(1.7 \%)$ \\
Female hours declined & $987(60.3 \%)$ & $20(1.2 \%)$ \\
\hline Source: Derived from the Consus of Population and Dwellins, Statistics New Zealand
\end{tabular}

Source: Derived from the Census of Population and Dwellings, Statistics New Zealand.

In the period 1986 to 1991 , in 38.4 percent of area units female hours remained steady or increased. In contrast, in this period, in only 2.9 percent of area units male hours remained steady or increased.

Table 116 - Number and percentage of area units by change in average hours for prime age men and women, 1991-1996

\begin{tabular}{lrr}
\hline & Male hours declined & Male hours steady or increased \\
\hline Female hours steady or increased & $268(16.4 \%)$ & $1,285(78.5 \%)$ \\
Female hours declined & $47(2.9 \%)$ & $36(2.2 \%)$ \\
\hline Source: Derived from the Census of Population and Dwellings, Statistics New Zealand.
\end{tabular}

Source: Derived from the Census of Population and Dwellings, Statistics New Zealand.

The increase in employment amongst prime-aged people between 1991 and 1996 shows up in Table 116. In 94.9 percent of area units female hours remained steady or increased. In this period in 80.7 percent of area unit, male hours remained steady or increased.

Table 117 summarises these changes over the whole ten-year period. In this period, in nearly 86 percent of area units average female hours remained steady or increased. In just under 11 percent of area units average male hours stayed steady or increased. One of the impacts of these changes is that by the end of the ten year period there was a closer relationship between men's average hours and women's average hours of paid work within the area units studied. Running a simple linear regression across the data in 1996 produced an $r^{2}$ of 0.41 as against 0.15 in 1986. This suggests that, increasingly, when men face major difficulties in a particular labour market, then opportunities for employment by women are also constrained. Other area units tend to have high hours of paid work for 
both men and women. In the situation of couples, these trends have already been shown in the shift from a mixed-work, male primary-income-earner model to either a work-rich, two earner model or a work-poor, no earner model.

Table 117 - Number and percentage of area units by change in average hours for prime age men and women, 1986-1996

\begin{tabular}{lrr} 
& Male hours declined & Male hours steady or increased \\
\hline Female hours steady or increased & $1,243(76.0 \%)$ & $158(9.7 \%)$ \\
Female hours declined & $218(13.3 \%)$ & $17(1.0 \%)$ \\
\hline
\end{tabular}

Source: Derived from the Census of Population and Dwellings, Statistics New Zealand.

Finally, Table 118 provides four specific examples of area units. Otara East is a South Auckland urban area that was in the bottom work-poor decile in all censuses. Hauraki Plains is a North Island farming area that was in the top decile of hours in each census. Wadestown is an education-rich, high-income, central Wellington suburb and an area that moved into the work-rich decile in 1996. Finally, Moerewa, a small rural town in Northland, is shown. Moerewa moved into the bottom decile of work in 1991 and was again in this decile in 1996. The situation of Moerewa highlights the difficulty experienced by small towns in providing new employment opportunities once a key industry has closed.

Table 118 - Average hours for prime-age men and women in examples of work-rich and work-poor area units, 1986-1996

\begin{tabular}{cccc}
\hline Otara East & 1986 & 1991 & 1996 \\
\hline Male hours & 33.9 & 19.9 & 29.0 \\
Female hours & 16.9 & 11.2 & 16.9 \\
Hauraki Plains & & & \\
Male hours & 57.4 & 50.8 & 54.7 \\
Female hours & 28.4 & 26.9 & 27.4 \\
Moerewa & & & \\
Male hours & 41.5 & 21.3 & 22.7 \\
Female hours & 18.3 & 12.6 & 15.1 \\
Wadestown & & & \\
Male hours & 44.6 & 43.7 & 46.2 \\
Female hours & 26.2 & 27.5 & 31.2 \\
\hline Source: Derived from the Census of Population and Dwellings, Statistics New Zealand.
\end{tabular}

Comparing the data for Otara East and Wadestown shows that by the mid 1990s, while within each area men, on average, were involved in more paid work than women, in some of the work-rich area units the women's labour market position was better than that of 
men in work-poor area units. This reflects both educational and ethnic differences, with well-educated Pakeha women increasingly better placed in the labour market than poorly educated Maori and Pacific Islands men.

\section{Were work-poor residential areas actually work-poor?}

This question was not considered in the original research and so relevant data was not collected. However, in the process of writing a joint paper analysing the characteristics of work-rich and work-poor areas (Callister and Morrison 1999), Morrison undertook some initial exploration of this issue using census data drawn from Supermap3. It appears that in 1996 there were some areas that were work-poor when the measure was based on the workstatus of the residents, but they were areas where many people were working. To be like this people from outside the area needed to commute in to undertake their paid work. While this issue needs more exploration on a national basis, it does suggest that in some work-poor areas the problem is a labour supply side issue rather than being a demand side one. For example, it could be that people in some work-poor areas were not qualified to undertake the work carried out in their community. An example might be where there was a high-technology industrial area associated with state housing. It may also be that local childcare was not available in some work-poor residential communities.

\section{Do work-poor couples live in work-poor areas?}

While it is useful analysing women's and men's work patterns separately many live together as couples. It would then be expected that work-poor couples would tend to live in work-poor areas. However, there are two issues, which are both of potential interest to policy makers, which need to be considered when analysing couples. First, were heterosexual couple households less common in areas where there was an excess of either women or men in the area, and/or were they less common in areas where there were a high proportion of men who were not in paid work? Second, if couples do form, there is 
then the question as to what proportion were work-rich or work-poor. ${ }^{133}$ Table 119 explores these issues.

Table 119 - Some characteristics of area units by average hours of paid work per prime-age person, 1996 data

\begin{tabular}{|c|c|c|c|c|c|c|c|}
\hline $\begin{array}{l}\text { Deciles of } \\
\text { average } \\
\text { work } \\
\text { hours } \\
\text { sorted by } \\
1996 \text { data }\end{array}$ & $\begin{array}{r}\text { No of } \\
\text { prime-aged } \\
\text { people }\end{array}$ & $\begin{array}{r}\text { Ratio of } \\
\text { total } \\
\text { prime-age } \\
\text { women to } \\
\text { total men }\end{array}$ & $\begin{array}{r}\text { Ratio of } \\
\text { total } \\
\text { women } \\
\text { to men in } \\
\text { paid } \\
\text { work }\end{array}$ & $\begin{array}{r}\text { No of } \\
\text { prime- } \\
\text { aged } \\
\text { couples* }\end{array}$ & $\begin{array}{r}\text { Couples as } \\
\% \text { of } \\
\text { prime-age } \\
\text { pop }\end{array}$ & $\begin{array}{r}\text { No of } \\
\text { prime-aged } \\
\text { work-poor } \\
\text { couples }\end{array}$ & $\begin{array}{r}\text { Work-poor } \\
\text { couples as } \\
\text { a } \% \text { of all } \\
\text { couples }\end{array}$ \\
\hline Work poor & & & & & & & \\
\hline Decile 1- & 137,442 & 1.04 & 1.75 & 33,303 & 24.2 & 6,064 & 18.2 \\
\hline Decile 2 & 183,960 & 1.08 & 1.48 & 50,522 & 27.5 & 5,745 & 11.4 \\
\hline Decile 3 & 178,698 & 1.06 & 1.37 & 50,880 & 28.5 & 4,499 & 8.8 \\
\hline Decile 4 & 202,689 & 1.06 & 1.31 & 59,546 & 29.4 & 4,260 & 7.2 \\
\hline Decile 5 & 190,272 & 1.05 & 1.27 & 59,785 & 31.4 & 3,921 & 6.6 \\
\hline Decile 6 & 206,823 & 1.04 & 1.23 & 65,831 & 31.8 & 3,489 & 5.3 \\
\hline Decile 7 & 193,932 & 1.04 & 1.20 & 62,680 & 32.3 & 2,915 & 4.7 \\
\hline Decile 8 & 150,258 & 1.02 & 1.17 & 49,883 & 33.2 & 1,888 & 3.8 \\
\hline Decile 9 & 139,599 & 1.00 & 1.14 & 46,816 & 33.5 & 1,617 & 3.5 \\
\hline $\begin{array}{l}\text { Decile } 10 \text { - } \\
\text { Work-rich }\end{array}$ & 109,842 & 0.91 & 1.03 & 39,398 & 35.9 & 1,364 & 3.5 \\
\hline Total & $1,693,515$ & 1.04 & 1.28 & 518,644 & 30.6 & 35,762 & 6.9 \\
\hline
\end{tabular}

First, there seems no obvious relationship between the overall ratio of total prime-aged women to total prime-aged men and the proportion of couples in a particular decile. However, as predicted, the table shows some tendency for an increased proportion of couples in the population as the average hours of paid work in area units increased and the ratio of total women to employed men decreased. This appears to lend support to theories that lack of paid work for both men and women affects the formation or stability of couples. Therefore, in childrearing situations, sole parenthood, albeit mainly sole motherhood, will tend to be more common in work-poor areas. The apparent lack of employment in these areas will also constrain attempts to encourage sole parents into paid work. However, some caution is needed in some of these conclusions given that some work-poor residential areas were, in fact, work-rich areas in terms of labour demand (Callister and Morrison 1999).

\footnotetext{
${ }^{133}$ In this analysis, both defacto and legally married couples are counted.
} 
It is also not surprising that, in Table 119, an increasing proportion of the couples that were formed were work rich as the amount of paid work undertaken within the area units increased. It may simply be that couples needed both partners to be in paid work in order to live in work-rich areas, or that work-poor couples (or sole parents) can only afford to live in work-poor areas. The high proportion of couples who were work poor in workpoor areas lends support to the idea that, while "fixed-gender roles" for men and women in paid and unpaid work and / or the design of welfare benefits may be having some impact on the creation of such couples, a lack of job opportunities in local (or nearby) labour markets is a critical factor in the growth of this family type. However, again some caution is needed in this conclusion given the research by Callister and Morrison. In addition, because there were still work-poor couples in work-rich areas this further suggests there were some supply-side factors that could be important. ${ }^{134}$

\section{Some reasons for residents in particular area units being work-rich or work-poor}

As discussed in Chapter thirteen, there are likely to be a wide range of reasons why the residents in an area might, on average, be work-rich or work-poor. Many, such as the number and viability of local employers, the level of crime in an area, the topography, or the quality of local services, such as schools, are either difficult to measure or the data can only be compared with census data by integrating a number of databases. Simply based on census data, the work-poor area units in each year were a somewhat mixed group. For example, included in the long-term group of work-poor area units were a small number of sites of major prisons, psychiatric institutions, or educational institutions where large groups of people were not in the labour force. These areas included Paremoremo East, Rangipo, and Tokanui, and Massey University. Some work-poor areas can be traced to a specific industry collapse such as Patea where the freezing industry closure in the early 1980s. Others, such as Foxton Beach, have been in a long-term economic decline.

\footnotetext{
${ }^{134}$ For some of these couples being work-poor may not be a problem. For example, they may have chosen to retire early, and have a high level of savings.
} 
There were some work-poor urban areas that are well known to researchers and policy makers, such as those in South Auckland, Porirua, and Lower Hutt. In these area units, the housing market and, in particular, the concentration of state housing appears to be an important factor in the concentration of work-poor people and families. Yet, policies such as providing housing assistance for private rental dwellings should be reducing this concentration. As discussed in Chapter thirteen, the housing market could also be important in some other situations because house ownership in a depressed area can make moving to areas of job growth more difficult. This will be particularly problematic if there are significant price differences between areas. It may also be that some work-poor individuals have moved to small rural towns in order to find low-cost accommodation with one result being that they are further isolated from the job market. While important issues, these have not been explored in this current research. This is mainly because the census is not an ideal data source for such research.

At the other extreme, for people to live in areas with high house prices, they may simply have to be work-rich in order to afford this choice.

As already shown, at an individual level education is an important factor in labour market participation and earnings. Linked to this, ethnicity is also an important variable in the labour market. Both these factors seem to be an important variable in clustering behaviour. Table 120 groups area units by deciles of paid work hours in 1996. The characteristics of these groups are then shown in terms of the proportion of prime-age people with degrees or higher, the percentage with school or tertiary qualifications, and the percentage who were from Maori or Pacific Islands ethnic groups. In addition, as a crude test of the link between community participation, economic activity and potentially also social cohesion, the proportion of people who said they undertook community work is shown. ${ }^{135}$

\footnotetext{
${ }^{135}$ This measures unpaid work carried out for people who did not live in the same household and includes a wide range of activities such as gardening for an elderly person or fund raising for a marae.
} 
Table 120 - Characteristics of area units by average hours of paid work per primeage person, 1996 data

\begin{tabular}{|c|c|c|c|c|}
\hline $\begin{array}{l}\text { Deciles of average } \\
\text { work hours sorted by } \\
1996 \text { data }\end{array}$ & $\begin{array}{r}\% \text { of prime-aged } \\
\text { people with } \\
\text { degree or higher }\end{array}$ & $\begin{array}{r}\% \text { of prime-aged } \\
\text { people with post } \\
\text { school } \\
\text { qualifications or } \\
\text { higher }\end{array}$ & $\begin{array}{r}\% \text { of prime-aged } \\
\text { people of Maori } \\
\text { or Pacific } \\
\text { Islands ethnic } \\
\text { groups }\end{array}$ & $\begin{array}{r}\% \text { of prime-aged } \\
\text { people who } \\
\text { undertook } \\
\text { community } \\
\text { work }\end{array}$ \\
\hline Decile 1 - Work-poor & 4.4 & 24.0 & 47.7 & 38.6 \\
\hline Decile 2 & 6.2 & 30.2 & 27.9 & 41.3 \\
\hline Decile 3 & 7.8 & 33.5 & 20.8 & 42.4 \\
\hline Decile 4 & 9.9 & 37.4 & 17.2 & 42.1 \\
\hline Decile 5 & 11.1 & 40.1 & 13.4 & 43.2 \\
\hline Decile 6 & 12.2 & 42.0 & 10.2 & 43.3 \\
\hline Decile 7 & 14.9 & 45.2 & 9.2 & 43.1 \\
\hline Decile 8 & 17.3 & 47.9 & 8.8 & 44.4 \\
\hline Decile 9 & 16.4 & 45.9 & 8.9 & 44.3 \\
\hline Decile 10 - Work-rich & 7.5 & 35.2 & 7.9 & 48.1 \\
\hline Total & 10.9 & 38.4 & 16.8 & 42.9 \\
\hline
\end{tabular}

For education, up to decile 8 of work hours, there is a clear link between the proportion of people who had formal qualifications and the hours of paid work in an area unit. ${ }^{136}$ The slightly lower education rates in decile 9 , but particularly the low rates in decile 10 , were associated with the over-representation of farming areas. A lack of formal qualifications has not historically been such a barrier to participation in paid work on family farms. However, this is likely to change as farming increasingly comes to be seen primarily as a business rather than as a way of life. It is also clear that Maori and Pacific Island peoples were significantly over-represented in work-poor areas. Just under two thirds of primeage people in the combined Maori and Pacific Islands ethnic grouping lived in the bottom four deciles. The reasons for this are complex, but include that Maori and Pacific Island peoples have, on average, lower levels of formal educational qualifications. However, there were some individual work-poor area units, particularly in the South Island, with a very low level of Maori and Pacific Island residents. In addition, while Maori and Pacific Island people were over-represented in work-poor areas the majority of people in these areas were not from these ethnic groups.

\footnotetext{
${ }^{136}$ The percentage of the prime-age population with degrees in area units that were in the bottom decile of paid work in each census was calculated and also came out to 4.4 percent.
} 
Although the differences are very minor, particularly in the middle deciles, there was an increasing proportion of people who undertook community work as the average hours of paid work in an area increased. This is consistent with the idea that area units that support each other through voluntary work are more "cohesive" and therefore more prosperous. However, this relationship was less clear when the average hours of paid work per week in each area (rather than grouped data) were related to the proportion of prime-aged people who stated they undertook community work. When a linear regression model was fitted this provided an $r^{2}$ of 0.0935 . The relationship looks even more shaky when the average hours of paid work were compared with a weighted average hours of community work per week. This produced an $\mathrm{r}^{2}$ of 0.0015 . In terms of explaining the differences in community work between the lowest and highest decile there could be many reasons for this. For example, the higher rate of community work, particularly in the rural area units, may simply reflect a lack of commercial services in some areas that then need to be provided by unpaid work. The lower rate in some work-poor areas may also reflect a shortage of physical capital for facilities such as halls or buildings suitable for playgroups that assist in developing strong community networks. This issue of community work is revisited in the section on work-poor and "deprived" communities.

As with most grouped measures, there are also some major exceptions to broad patterns shown. For example, the Waiheke Island area unit, which was in the bottom decile of paid work not only in 1996 but also in the previous two censuses, had nearly 12 percent of the prime-aged population with degrees or higher in 1996. Waiheke, an island close to central Auckland and linked by ferry services and with many well qualified residents living "alternative lifestyles", appears to be an example of a "voluntary" work-poor area.

Finally, in Figure 43 the relationship between paid work and education is explored in a different way. This chart uses employment rates instead of hours worked. In 1996, 11 percent of area units had 40 percent or more of their prime-aged people not in paid work, while for 3 percent of units, the figure was 50 percent or more. Figure 43 shows the area units in terms of both the proportion of prime-aged people with no formal qualification and the proportion not in paid work. In the areas where a high proportion of prime-aged 
people had no formal qualification, there does seem to have been some link between a community-wide lack of education and a lack of paid work. When a linear trendline was fitted this produced an $r^{2}$ of 0.27 . This improved to 0.35 when a polynomial line was fitted. However, overall, these possible trendlines suggest that the relationship between the two variables is not that strong. Instead it seems that it is in the higher range of concentration of low skills that the relationship strengthens. This supports concepts of "tipping" over a certain threshold. As also discussed earlier, farming communities can be work-rich but education poor.

\section{Figure 43}

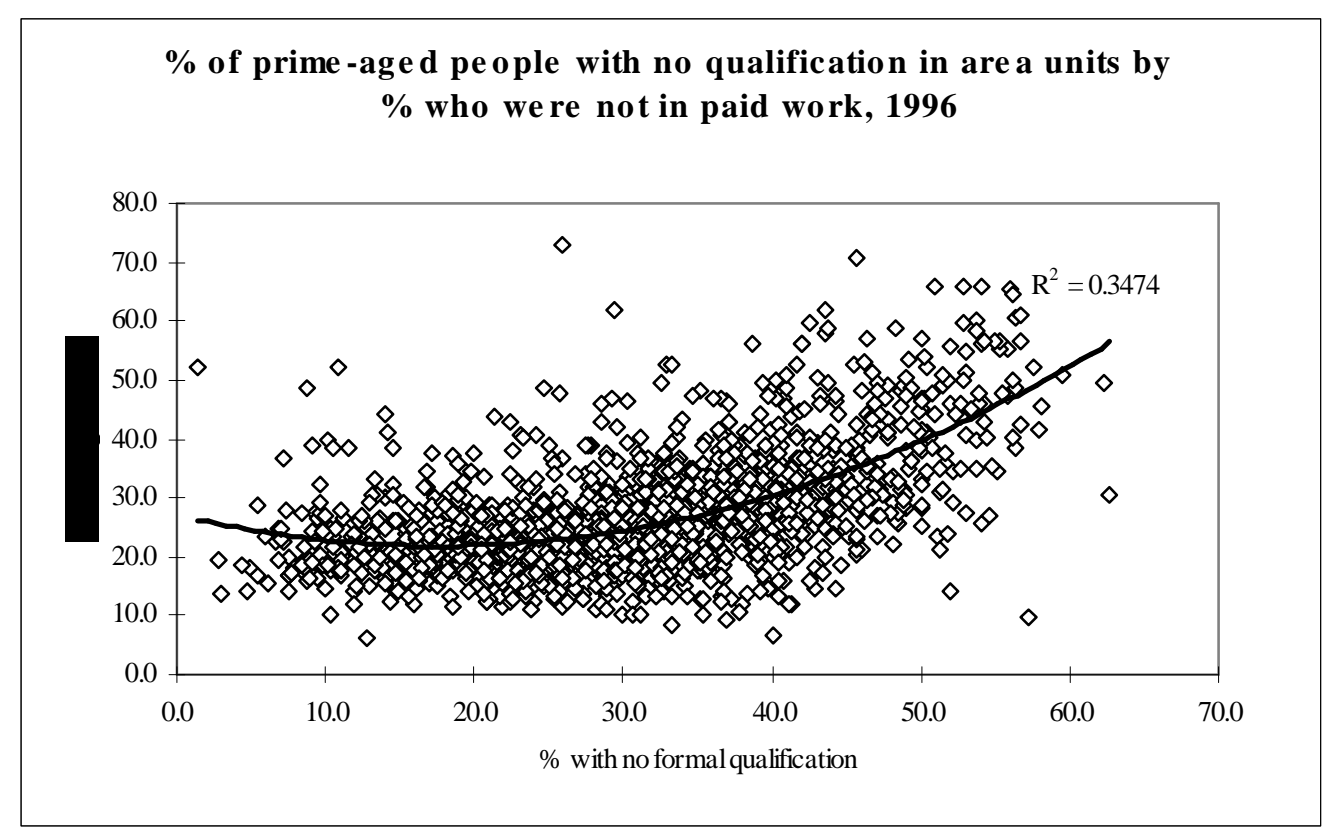

Source: Derived from the Census of Population and Dwellings, Statistics New Zealand.

\section{Were there education-rich and education-poor area units?}

The data in Table 120 has already indicated that education tends to be concentrated in particular area units. Figure 44 focuses only on education and not the amount of work carried out in the area. It also only uses 1996 data. Figure 44 shows area units ranked by the percentage of prime-aged people with post school (tertiary) qualifications and the percentage of people with degrees or a higher qualification in each area unit. This chart provides further evidence that people with tertiary qualifications, and particularly those with degrees or higher, have some tendency to cluster together in particular areas. It will 
be those people with degrees or higher who tend to be the "symbolic analysts" who increasingly are the generators of ideas, wealth and, ultimately jobs, in an economy. This clustering is not surprising given that education is a key factor in income generation and that it is well known that there are desirable high cost housing areas (often with all day sun and / or good views) and undesirable low cost areas.

\section{Figure 44}

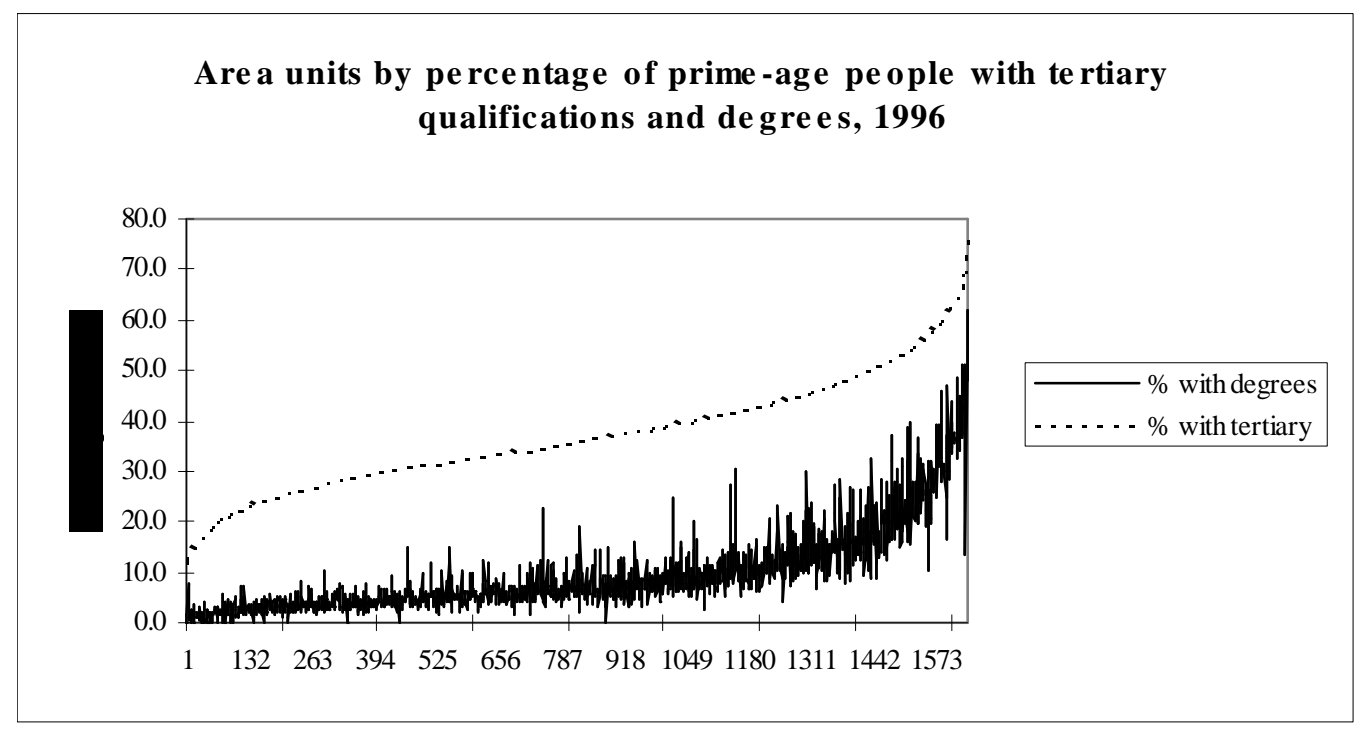

Source: Derived from the Census of Population and Dwellings, Statistics New Zealand.

As an alternative measure in 1996, ten percent of the area units studied contained 44 percent of prime-age people with degrees or higher qualifications. At the other end of the spectrum, the bottom ten percent of communities contained around one half a percent of those prime-age people with degrees or higher. When a wider range of qualifications is considered similar, but less extreme, patterns show up. Again for 1996, and for all post school qualifications, the top ten percent of communities contained 27 percent of those with such qualifications. The bottom ten percent contained only 1.1 percent of people with post-school qualifications. This type of measure could be problematic because areas units contain different numbers of people, yet, further testing of the data showed little relationship between the size of each area unit and the percentage of prime-age people with a degree. However, people with degrees were more likely to live in area units within urban areas. In 1996, in the combined grouping of rural areas and rural centres, 6.1 
percent of prime-age people had degrees, while in non-rural areas this nearly doubled to 11.8 percent.

Figure 45 views this concentration from another angle and shows for 1986 and 1996 the percentage of prime-aged people in each area unit in New Zealand that had no formal qualification.

Figure 45

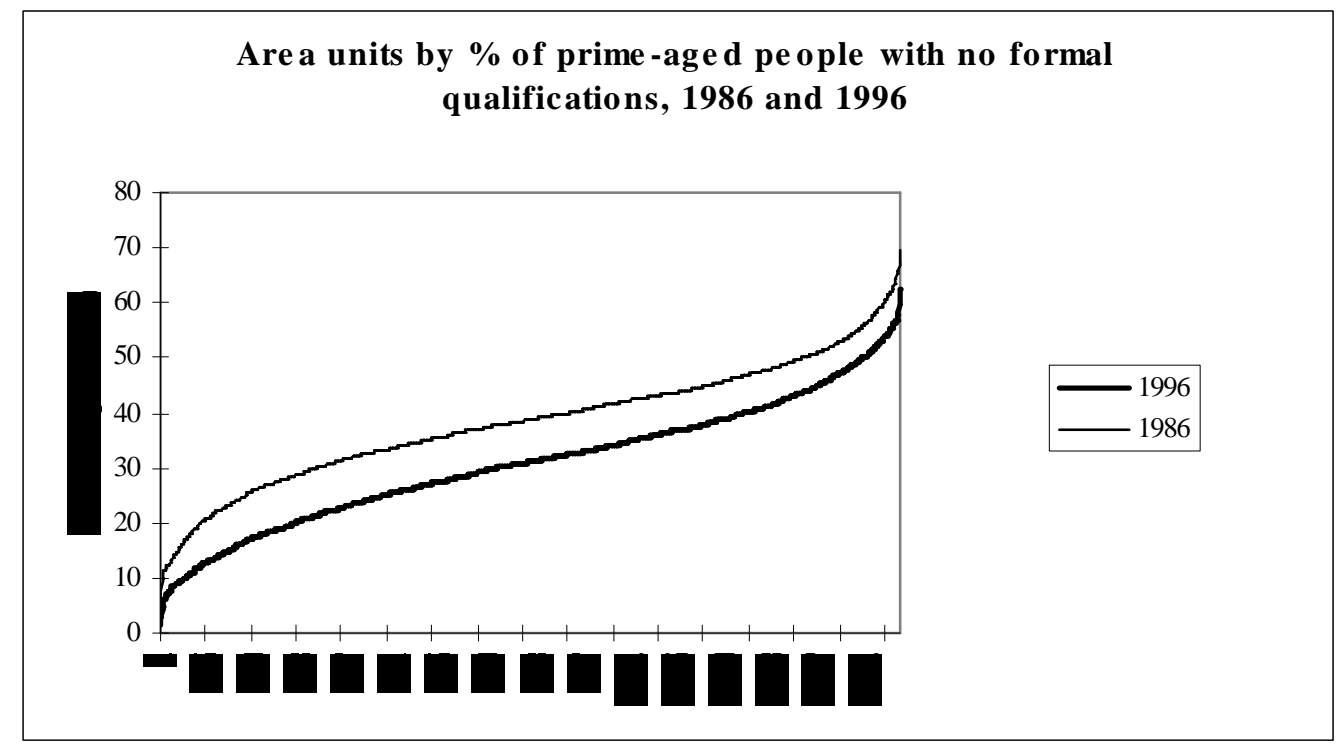

Source: Derived from the Census of Population and Dwellings, Statistics New Zealand.

Figure 45 shows that in both 1986 and 1996 while people without formal qualifications were not evenly spread throughout the community, they were also not just clustered into a very small number of area units. It also shows that the decline in the proportion of people with no formal qualifications was spread across most of New Zealand. However, this chart does not directly compare the same area units, it shows all area units sorted in 1986 and then sorted again in 1996. This is still a useful comparison as it could have been through migration some areas became more education poor over the period.

Of equal interest is whether the increasing participation in school and tertiary education is resulting in education-poor area units improving their position. Unfortunately, changes in the census education question make comparisons for all tertiary education difficult. 
Therefore, in Table 121, area units are grouped into deciles by the percentage of primeage people with a degree or higher. The change in the percentage points of people with degrees or higher in these same grouped area units between 1986 and 1996 was then calculated. This type of analysis is repeated in Table 122 but recording those prime-aged people with no formal qualification.

Table 121 - Percentage of prime-age people with a degree or higher by area units, 1986 and 1996

\begin{tabular}{lrrr}
\hline \multicolumn{4}{c}{$\begin{array}{c}\text { \% of prime-age people } \\
\text { with a degree or higher* }\end{array}$} \\
\hline Deciles sorted by 1986 data & 1986 & 1996 & $\begin{array}{r}\text { Absolute } \\
\text { change in \% }\end{array}$ \\
Decile 1 - Education poor & 1.1 & 2.4 & 1.3 \\
Decile 2 & 2.4 & 3.8 & 1.4 \\
Decile 3 & 3.2 & 4.6 & 1.5 \\
Decile 4 & 3.8 & 5.3 & 1.5 \\
Decile 5 & 4.6 & 6.7 & 2.1 \\
Decile 6 & 5.4 & 7.8 & 2.4 \\
Decile 7 & 6.5 & 8.8 & 2.4 \\
Decile 8 & 8.1 & 11.2 & 3.0 \\
Decile 9 & 11.3 & 16.5 & 5.2 \\
Decile 10 - Education rich & 21.7 & 29.6 & 7.9 \\
& & & \\
Total & 7.4 & 10.9 & 3.5 \\
\hline Source: Derived from the Census of Population and Dwellings, Statistics New Zealand. \\
* This is an average of the percentages in each area unit
\end{tabular}


Table 122 - Percentage of prime-age people with no formal qualification by area units, 1986 and 1996

\begin{tabular}{lcrr}
\hline \multicolumn{3}{c}{$\begin{array}{c}\text { \% of prime-age people with } \\
\text { no formal qualification }\end{array}$} \\
\hline Deciles sorted by 1986 data & 1986 & 1996 & $\begin{array}{r}\text { Absolute } \\
\text { change in \% }\end{array}$ \\
Decile 1 - Education poor & 56.8 & 48.5 & -8.3 \\
Decile 2 & 49.1 & 41.4 & -7.7 \\
Decile 3 & 45.3 & 37.4 & -7.9 \\
Decile 4 & 42.7 & 35.7 & -7.0 \\
Decile 5 & 40.0 & 31.9 & -8.1 \\
Decile 6 & 37.6 & 29.5 & -8.1 \\
Decile 7 & 34.8 & 26.9 & -7.9 \\
Decile 8 & 31.5 & 23.1 & -8.4 \\
Decile 9 & 27.0 & 18.8 & -8.2 \\
Decile 10 - Education rich & 18.3 & 11.9 & -6.4 \\
& & & \\
Total & 37.6 & 29.6 & -8.0 \\
\hline Source: Derived from the Census of Population and Dwellings, Statistics New Zealand. \\
$*$ This is an average of the percentages in each area unit
\end{tabular}

Table 121 shows that while all deciles gained from the increase in university educated people, the deciles which gained the most from the increase were ones which already had the highest proportion of people with degrees in 1986. This means that either people in education-poor area units are less likely to obtain degrees and / or, if they do, they then tend to move to area units that already have a higher proportion of people with this type of qualification. As discussed in earlier chapters, there is evidence that children from low employment communities have low rates of attending tertiary education institutions. And, as discussed in Chapter thirteen, there is international evidence that education is one important route out of poor areas. So via both mechanisms many of the gains from increased public and private spending on university education may not be directly spreading into the area units which could most benefit from an increase in the proportion of well qualified people. However, the picture is not so grim when Table 122 is examined. In all areas there was a similar decline in the proportion of people who had no formal education. Yet, to put a negative slant on this, if education was to be spread more evenly on a spatial basis the declines needed to be far higher in education poor areas. 


\section{Changes in the prime-aged population in area units}

As discussed in Chapter thirteen, there are reasons why the prime-aged population in work-poor areas might decline (e.g. moving to work-rich areas) and, equally, there are some theories as to why the population could increase (e.g. cheap housing that people on government benefits can move to). To test the relationship between workstatus of an area and population change, I examined the percentage change in average hours related to percentage change in prime-age population across all area units between 1986 and 1996. This produced an $\mathrm{r}^{2}$ of 0.0009 suggesting no simple linear relationship. However, ultimately, a better test would be to examine the relationship between the amount of work carried out within an area (and nearby areas where people could commute to) and the change in residential population.

\section{Were work-poor areas deprived?}

A question of critical interest to social policy makers is whether work-poor communities are actually deprived. It could be that some communities with low levels of paid work amongst prime-age people were simply areas where people were choosing a low income but a high quality lifestyle, with Waiheke Island an example. There could also be areas where a significant number of people have retired early with sufficient wealth to ensure a good quality of life. There is much debate over quality of life or well-being measures. However, one New Zealand measure that can easily be applied to area units is the Index of Deprivation. This was initially developed using 1991 census data (Crampton et al 1997) but has now been updated to 1996. This index is based on a range of variables including unemployment, quality of housing, access to a car, access to a telephone and household income levels.

A regression analysis shows a reasonably close relationship between the 1996 index of deprivation and the average paid work hours of prime-aged people in area units in 1996. For total average hours of paid work there was an $r^{2}$ of 0.55 , while for the hours of men 
only this rose to $0.57 .{ }^{137}$ However, perhaps of more importance is the matching at the low end of hours of paid work. When the work-poor decile (164 area units) was compared with the decile of area units with the highest level of deprivation, 120 area units (or 73 percent) fell within both criteria. An example of an area unit that did not meet the double criteria was, not surprisingly, Waiheke Island.

Figure 46 shows an alternative calculation. It shows that in most area units there was also a strong, but not perfect, correlation between the percentage of prime-aged men not in paid work in an area and the level of deprivation of the area (the correlation coefficient was 0.84$)$.

Figure 46

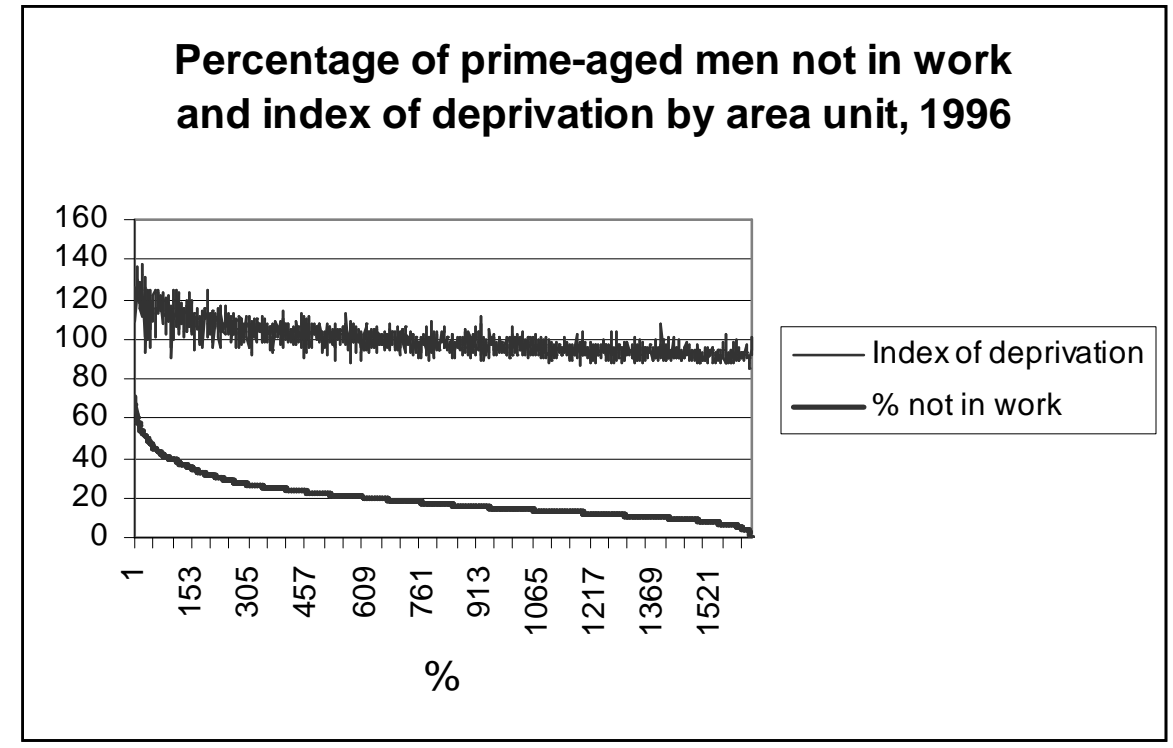

Source: Derived from the Census of Population and Dwellings, Statistics New Zealand.

Finally, those area units that were in the bottom decile of hours of work in each census as well as also in the most deprived decile when assessed using the deprivation index were identified. $^{138}$ This gave 65 units that could be considered long-term work-poor and

${ }^{137}$ For women the $\mathrm{r}^{2}$ was 0.35 . This supports the view that it is the communities with large numbers of prime-age men out of paid work that are the most deprived.

${ }^{138}$ To gain some qualitative idea of how deprived these communities were, over the time I undertook my doctoral research I visited most of the LTWPD areas in the North Island between Wellington and Auckland. While clearly containing low cost housing, purely on a visual basis none of the communities I visited would be classified as ghettos if compared with some of the poorest areas of the U.S. Certainly, in none of the areas I visited was I concerned about driving or walking through them. Yet, these areas are deprived when 
deprived areas (LTWPD). Some of their characteristics were then assessed. The actual LTWPD unit areas are listed in the Appendix.

First, Figure 47 repeats some aspects of Table 120 and shows basic measures of ethnicity, education, proportion of prime-aged men not in paid work and size of prime-aged population in these 65 areas. Education levels varied from a high of 40 percent of primeaged people with post school qualifications to a low of 13 percent. However, in most areas the level of education was relatively low (the New Zealand average was 38 percent). The variation in education levels again suggests that while education is one important factor in determining whether individuals, families or communities are workpoor there are a range of other factors, many of which are probably not collected in surveys such as the census, which impact on work opportunities and decisions.

There was some tendency for area units with small populations to be over-represented in the LTWPD group. However, as already discussed there were also many small, and generally rural, work-rich areas in New Zealand. The relative size line on the graph shows each area unit's population as a percentage of the total population in the whole group. It shows that there was no obvious relationship between size and ethnic mix or the other characteristics shown. In this group the smallest area unit was the rural area of Kohukohu, with a 1996 population of 102 prime-aged people in 1996. The largest was Ngaruawhia with 2,241 people.

Figure 47 shows that there was a wide variation in the ethnic mix of area units. Not surprisingly, at one extreme the lowest proportion of Maori or Pacific Island were to be found in South Dunedin and Blackball (under 10 percent), both South Island area units where Maori and Pacific Island people were already highly under-represented. In South Dunedin there were 861 prime-aged people in 1996, and 43 percent of prime-aged men were not in paid work. At the other extreme, just under 90 percent of Otara North's (in South Auckland) population of 636 people were classified as Maori or Pacific Islands 
groups. In this area unit the same figure of 43 percent of prime-aged men were not in paid work in 1996.

Figure 47

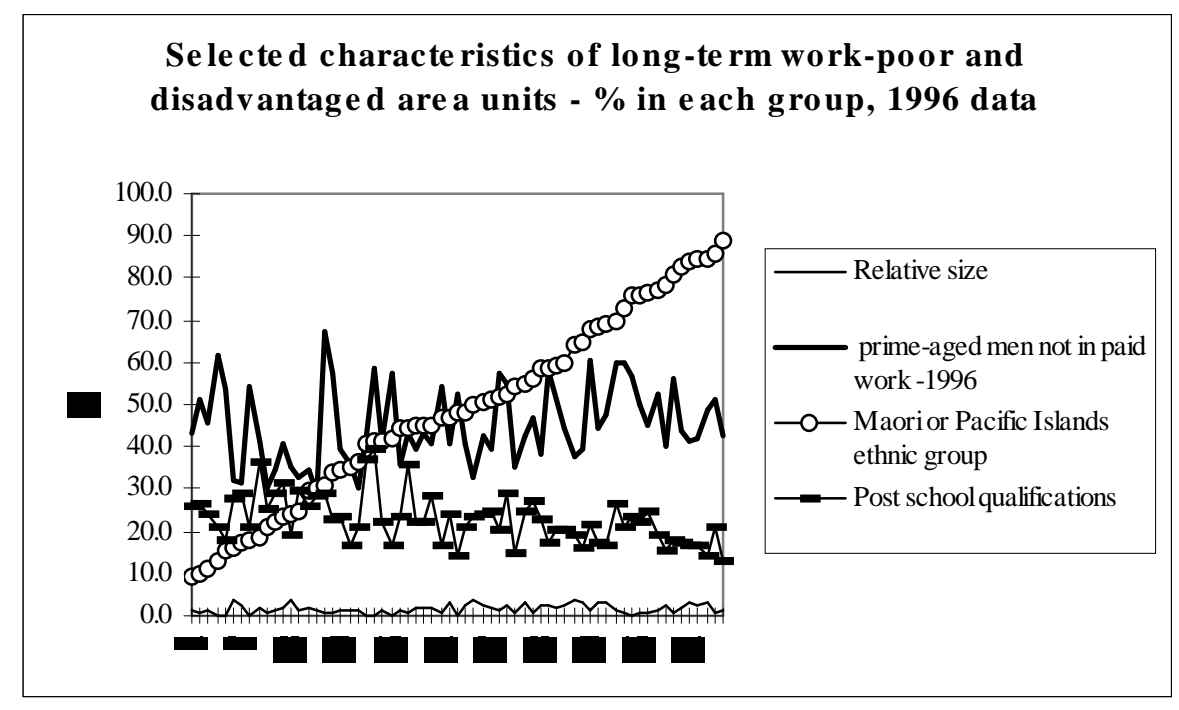

Source: Derived from the Census of Population and Dwellings, Statistics New Zealand.

A further analysis of the data showed that 12.3 percent of LTWPD areas were rural, and 13.8 percent were rural centres. This is an under-representation of rural area units (17.4 percent of total) but an over-representation of rural centres (8.2 percent).

The data also shows that there was marked variation in growth rates of the prime-aged populations in the LTWPD areas (see Appendix). Overall, the total prime-aged population grew by 21 percent over the period 1986 to 1996 while the LTWPD areas grew by 19 percent. These data again suggest that some complex migration / natural increase patterns are occurring and more in-depth analysis is needed to determine the reasons for the wide variation in growth rates.

Finally, the last column of the table in the Appendix shows the proportion of the primeaged population who stated they were involved in community work. When an average was calculated from this list it showed that the level of community work (at 39.8 percent) was only slightly below the national average of 42.9 percent. There was a marked variation with the units but an important factor in the variation was whether the area was 
a rural (or rural centre) or an urban area. The average of urban areas was 37 percent, while the average for rural areas was 47 percent. These crude data provide very little support for the idea that a lack of "cohesiveness" is a factor in an area being LTWPD.

\section{Conclusion}

While not exhibiting the extremes seen in the U.S., New Zealand does have enclaves of work-rich and work-poor groups of people and, somewhat linked to this, areas where there are high and low concentrations of formal educational qualifications. This, along with the index of deprivation data, suggests there is an important geographic dimension to the distribution of work and, ultimately, well-being in New Zealand.

On various measures, the proportion of work-poor areas increased between 1986 and 1996. This was mainly caused by the loss of paid work amongst prime-age men, particularly amongst those with few formal qualifications. Although women's hours of paid work increased in many areas, this was not sufficient to compensate for the loss of work by men in these same areas.

Work-poor area units were to be found throughout New Zealand. Key features of workpoor areas were both a low level of formal qualifications and a high proportion of residents who are from Maori or, within urban areas, from Pacific Islands groups. Within the large cities, work-poor area units were most likely to be found within traditional state housing areas, such as Otara in Auckland and Porirua in Wellington. However, in the mid 1990s, small rural centres were over-represented amongst work-poor communities. This latter trend appears to reflect the general running down of small rural service centres.

In all periods studied, a high proportion of the work-rich area units were communities in which farming or tourism were key industries. However, there were also some work-rich urban areas. Unlike work-rich rural areas, the urban areas tended to have a relatively high proportion of people with formal qualifications. In these urban areas, there was a particularly strong increase in the participation and hours of paid employment of prime- 
age women. In these work-rich areas, prime-age women were more likely to be in couples with male partners who already had high rates of participation in paid work, that is workrich couples. Historically, some of these urban work-rich, and education-rich, areas would have been the home of "traditional" mixed-work childrearing families, with the man in full-time paid work and the woman not in paid work. Increasingly, however, in these areas couples, both with and without children, were becoming dual job, and, sometimes, dual-career families. It is likely that the average hours of paid work in these educationrich urban communities will keep rising as women increase both their labour force participation and their hours of paid work. This will generally also equate with increasing incomes for these type of families and, potentially, increased financial resources for the communities in which they live.

The data also suggest that couple formation or stability is at a geographic level somewhat linked to patterns of paid work, with couple families more prevalent in areas where paid work is plentiful. This suggests that labour markets, housing markets, and "marriage markets" are not separate.

The reasons for the development of work-poor areas are complex and need further exploration. However, they include a lack of labour demand, low levels of formal qualifications in most of these areas and, primarily in large urban areas, concentrations of relatively low-cost housing that brings people with educational and other potential disadvantages together. The housing market may also have an impact in preventing the mobility of individuals from some small rural work-poor areas. However, the reasons appear to vary somewhat between work-poor areas.

While increased educational attainment for individuals is likely to improve their life chances, the rapid rise in educational participation in tertiary institutions over the last decade appeared to be unevenly spread on a geographic basis. This trend suggests that, increasingly, people with similar levels of education have been clustering together. Yet, while there are examples of education-rich and education poor areas in New Zealand at 
the same time there remain many communities where there is a wide mixture of education levels amongst the residents.

The data in this chapter shows that a significant proportion of both work-poor and education-poor areas remained in this state for relatively long periods. While there was mobility for some communities, it was generally fairly limited. However, it is not clear from this research whether the same people reside in these areas or, just as importantly, similar areas, for long periods. While some overseas studies suggest a high level of mobility for individuals, longitudinal studies as well as other types of research with a geographic dimension are needed to answer this question in New Zealand.

There was little evidence that there had been strong outward migration from work-poor residential areas and into work-rich areas over the period studied. Again, this reflects a complex picture where some people do move away from these areas but where others grow as long-term work-poor people migrate to cheaper housing.

Finally, while further research is needed in terms of linking patterns of paid work to deprivation of an area, the data presented would suggest that, currently, in New Zealand, the level of participation in paid work by prime-aged residents in a geographic area is a major factor in determining the well-being of individuals in that area. How that might then flow through into the possible neighbourhood effects discussed in Chapter thirteen remains to be explored in New Zealand. 


\section{Chapter 22}

\section{Conclusion}

\section{Introduction}

In this conclusion, I revisit the primary research questions set out in Chapter one. First, I provide a short summary of my findings relative to the eight major research questions. However, simple trends disguise much complexity and I therefore go on to discus my findings in more detail. In particular, it will be noted that ethnicity is treated within the more nuanced discussions. Despite its prominence in much of the research literature, let alone popular and journalistic treatments, ethnicity itself is not related in any simple way to the most important changes in employment and household patterns. My discussion of the main findings is arranged in three levels. First, individuals are considered. Then families and households are examined. Finally, geographic communities are discussed. I also discuss some of the wider implications of my research findings. While this includes examining some specific policy implications, the discussion does not attempt to explore particular policies in great detail. This is because the primary focus of my research centred on identifying trends in employment and living arrangements as opposed to directly exploring possible policy solutions to any specific problems that might be emerging. However, I was aware while undertaking the research that it could be of assistance in policy discussions. I therefore made a conscious effort to publish many of the findings as the research progressed. In my policy discussion, I particularly focus on those polices that affect families with children. Finally, in this conclusion, I briefly discuss ways that research and data collections in the areas of work and households might be improved. 


\section{Summary answers to the eight major research questions}

The following are the eight major questions asked in Chapter 1.

In the long term has paid work been disappearing?

No, but employment has not been growing fast enough to absorb the increased labour supply.

Did the employment loss and subsequent employment growth between 1986 and 1996 lead to an increasing polarisation in paid work participation and hours worked for prime-aged individuals?

Yes. Although employment rates converged across gender lines, there was increased variation in employment rates within women as a group and men as a group. In addition, polarisation in terms of hours worked rose for men and women.

Was there also an increasing concentration of paid work, in terms of both participation and total hours worked, within particular families and households?

Yes. There was a shift within prime-aged couples and households to either work-poor or work-rich status between 1986 and 1996.

Was there a change in the concentration of hours of paid work by prime-aged people within geographic areas?

Yes. Using various measures, the proportion of work-poor areas increased between 1986 and 1996.

Was formal education a critical factor in any polarisation taking place in the distribution of paid work? 
Yes. Educational attainment rose on average, but those with little or no education saw relative employment rates deteriorate.

Have changes in paid work had a major influence on any of the changes in living arrangements which occurred over the time period studied?

Despite many factors affecting decisions about family and household formation, the data indicates that those people with poor prospects in the labour market tend to have poor prospects in the marriage market.

Did human capital, as measured by formal education, became more concentrated within particular families between 1986 and 1996?

In the mid 1980s, education was already concentrated in couple households. However, this concentration did not increase over the period studied. Yet, over this period, education became a stronger predictor of whether couples formed.

Did formal education also become more concentrated within particular geographic areas in the period studied?

Yes. The rapid rise in educational attainment over the 1980s and early 1990s was unevenly spread on a geographic basis.

\section{Individuals}

The first over-riding question of this research asked whether paid work had been disappearing both over the long term and during the period 1986 to 1996. Certainly, during the restructuring of the economy between the mid 1980s and early 1990s, there was a rapid decline in employment. However, this was followed by a strong increase in 
employment. Despite some continuing media reportage that work is disappearing, overall, the long-term data do not support this view.

The finding that work has not been disappearing is an important one for various areas of policymaking. As an example, if paid work is rapidly disappearing, then there would be little point in ensuring a high level of geographic mobility for individuals who had lost jobs in particular areas of New Zealand. If a large and growing proportion of people were to be permanently outside the labour force, then these people may be better left living in areas where jobs had disappeared rather than being encouraged to move to other areas. As further example, if work had been rapidly disappearing due to workers being replaced by machines, then mechanisms such as a Universal Benefit Income scheme would need far more careful consideration to help spread the benefits of this new productivity to those not in work. Designing sustainable retirement support schemes would also be highly problematic if work was disappearing.

While there has been a long-run stability in employment rates, since the 1970s there was also an increase in unemployment levels. These two trends can only take place simultaneously if the non-labour force group declines. Despite recent worries about "discouraged workers" no longer looking for work, in the 1990s a smaller proportion of people aged 15-64 were not in the labour force than in the 1950s. This means the proportion of the population wanting or needing paid work has been increasing since the 1950s. This is not surprising. If most men still want to be in paid work, and an increasing number of women also want paid employment, then the proportion of people wanting work increases.

Clearly, not enough jobs have been created to cater for this expanding labour supply. So while the overall proportion of people in jobs has stayed relatively stable, the distribution of those jobs has changed dramatically. In the 1950s, most women were work-poor in terms of paid work and were not classified as actively seeking employment. Since then, for a variety of reasons, far more prime-aged women have moved into paid work. However, a major, and generally unwanted, change that took place in the mid 1980s to 
the early 1990s was the significant loss of jobs amongst prime-aged men. While this loss did not continue for the remainder of the 1990s, an historically significant proportion of prime-aged men in the late 1990s had become work-poor. While for many men the time out of paid work will have been relatively short, there was evidence that the proportion of prime-aged men who were out of the labour force for long periods increased. Further complicating the picture, there emerged a small group of men, again for a variety of reasons, who voluntarily opted out of full-time work for a period. Added to this, a group of women remained who also found it difficult to retain a firm attachment to the labour market. All this means that the picture of work for prime-aged men and women has changed dramatically from that of the 1950s. By the middle of the 1990s there was far more diversity in work arrangements in the labour market and, to a lesser degree, in the home, for men and women.

The changes in women's work patterns, particularly those of mothers, have long been of interest to policy makers for a variety of reasons. In the 1970s, there was some initial concern about the impact of "working mothers" on children. Policy makers had to grapple with problems relating to the expansion of high quality and affordable childcare. They continue to grapple with issues such as paid parental leave, including whether it should apply only to women, and whether the diversity amongst women and work arrangements means that there will be a mainly "middle-class capture" of the benefits. In more recent times, the loss of jobs by prime-aged men has created a new set of concerns for policy makers. However, one of the main concerns of the changing distribution of work was due to parallel and, at times, connected changes in living arrangements and responsibilities in families. Many of those not in paid work in the 1980s and 1990s were no longer supported financially by their families. Instead, they were supported by the state.

The next main research question was:

- in New Zealand, did the employment loss and subsequent employment growth between 1986 and 1996 lead to an increasing polarisation in paid work participation and hours worked for prime-aged individuals? 
Certainly, in the mid 1990s there were people who were work-poor, sometimes for long periods. Others were work-rich, again sometimes for long periods. In addition, and connected with the changes in employment, other New Zealand research showed a polarisation in income earning amongst individuals. Yet, as already discussed, there had been a polarisation in work status (and income) in the 1950s, although this was primarily along gender lines. In the 1990s, the polarisation of work increasingly occurred within men as a group and within women as a group. For prime-aged men in particular, there was certainly a polarisation in work, with a growth in the proportion working long hours as well as an increase in the proportion working short hours or not in work at all.

While for reasons set out in Chapter 4 changes in the distribution of work on an ethnic basis were not a prime focus of this research, it is clear that there was an ethnic dimension to the polarisation of work. Employment rates of Maori and Pacific Island peoples were relatively high in the early 1980s. However, both groups suffered disproportionately in the period of job loss through to the early 1990s. In particular, those people defined as sole Maori faced major disadvantages in the labour market. In addition, many of the new Asian immigrants who arrived in the 1990s found it difficult to find employment, thus substantially raising the number of Asians who were work poor.

However, the question about the polarisation of work for individuals cannot be answered in isolation and needs to be linked to another major research question.

- was formal education a critical factor in any polarisation which occurred in the distribution of paid work?

First, over the period studied there was a strong increase in the proportion of young people participating in some form of tertiary education. This growth was particularly strong amongst women. In fact, by the mid 1990s a greater proportion of young men than young women had no formal qualifications. While the distribution of education between women and men changed, the overall growth in educational participation meant that, by 
one measure at least, education became less concentrated in the population. Fewer primeaged people were education-poor. Yet, at the same time, there remain a worryingly high proportion of young people who have no formal qualifications and who generally have low levels of literacy and numeracy.

Second, in New Zealand as in most industrialised countries, education (or more accurately a lack of it) became a much more powerful predictor of a person's labour market status. By the mid 1990s, men and women without formal qualifications faced major disadvantages in the labour market. In other words, education-poor people tended to be work-poor. Strongly associated with an over-representation amongst those with no formal qualifications, Maori and Pacific Island people were particularly hard hit by the job losses that took place between the mid 1980s and early 1990s. Yet, within Maori and Pacific Island peoples, the overall pattern that those with a high level of formal qualifications tend to be work-rich and those with no qualifications work-poor holds. This pattern is not so clear within the Asian ethnic group. Within this group there were highly qualified new immigrants who, for a variety of reasons, found it difficult to find paid work.

The reasons why overall education has become more important in determining labour market outcomes are complex. It is clear, for example, that there has been a long-term growth in symbolic analytical type jobs. These jobs generally require a high level of formal education. Yet, there is also some evidence of a polarisation in skill requirements. Many of the new in-person service jobs that have been created do not require a high level of formal education. However, they usually require a relatively high level of "soft skills", particularly "people skills". Often a person with some form of tertiary qualification can provide a sign of these skills to employers. It is also clear that some very low skill jobs continue to exist. But, over the period studied, not enough of these jobs were created to draw back into paid work the many low-skilled men and women who were unemployed or were not in the labour force. Due to a wide range of factors, including globalisation and the advance of technology, jobs based primarily on manual skills, which tend to be of a routine production nature, have been reducing in number. It is highly likely that low- 
skill routine production jobs will continue to be relocated to low-wage countries. In addition, new technology, such as call centres, can challenge the location of some previously in-person service jobs.

Given the changes in the economy, it is likely that many of those young people who lack an initial adequate level of cognitive or interpersonal skills will continue to face problems. Based on studies such as the New Zealand literacy survey, as well as formal qualification data, this group could represent up to 20 percent of the population. Even if they have periods in paid work, it may often be in low-paid, part-time work and / or shortterm insecure work. Unless in the short to medium term there is a major period of growth in the economy that raises employment levels significantly higher than they have been in the last few decades, many of these people will be long-term work poor. This growth needs to be both strong and sustained. Based on New Zealand's recent history such sustained strong growth seems unlikely.

How the work-poor, younger, prime-aged people will fare in the longer term is a little less certain. For example, aging of the population will create demographic pressures that are likely to draw older workers into paid work. It is also possible that changes in welfare structures, along with better "second chance" education schemes, may provide both "push" and "pull" incentives for some of this group to participate more fully in the labour market.

The uncertain future for young men in this low-skill group is probably already problematic for them and is further likely to create major adjustment problems for them in the future. Many studies show that most young men want a relatively well-paid and steady job and, eventually, have the ability to support a family. Yet, for low-skill men, the prospects of achieving either of these goals appear limited. It is likely that some of them will become long-term "marginal" men, excluded from both work and family life, unless they can significantly upgrade their work and life skills and, at times, their attitudes. Having "fixed" and traditional gender roles with regard to both work and family arrangements will not be helpful to many of these men. However, working out ways to 
assist these men change their attitudes will be difficult. While there are emerging various “men's" support groups in New Zealand who endeavour to support such change they tend to mainly attract middle class men.

Currently, there are also a group of people in the older age cohorts of the prime-working ages who face disadvantages in the labour market. This older group confront many similar problems to those in younger age groups, but there are also some differences. This group need to rapidly build up retirement funds and some may be paying their children's education fees. Some might be considered part of a "lost generation" who will never return to steady work. Those living in geographic areas where work has disappeared may find shifting elsewhere a major problem. One group will also have few savings. But some, including a group of long term employees who have been made redundant and have received generous redundancy packages, will already have some savings through home ownership that may buffer them from the more extreme impacts of being work poor. While many of the older work-poor group will also be asset poor, this will not be universal. In addition, not all will have low-skill levels. However, many will have skills in areas where technology has overtaken them. Finally, in relation to living arrangements, some will have a partner or other family members who support them emotionally and / or financially. Nevertheless, there are others who will be living alone or in other non-family households, sometimes as a result of losing their jobs.

In contrast, due to better health and changes in the types of jobs available, well-educated older people are tending to work longer. For well-educated men in particular, not only will they have generally been work-rich in their prime-working ages, but they will also tend to be work-rich over their lifetimes. These types of changes in employment provide some challenge to the argument that income support for older people should be based on age rather than need.

The research showed that education had far less of an impact on hours worked per week for those people who had a job. This is not surprising. It would be expected that in an increasingly flexible labour market, and with more people having "non-standard" lives, 
there would be a general reduction in the proportion of people working "standard" hours. The changes in hours worked took place both prior to and post the passing of the 1991 Employment Contracts Act. For some people, this change in hours was by choice. For others, however, employers forced the new flexibility on them. An example was the shift to part-time work by some prime-aged men during the job loss period in the early 1990s. In a more flexible labour market, some well-educated people who can earn relatively high hourly income have greater choice to work standard, short or long hours. For example, there is a group of well-educated people who are not only well paid for the work they undertake but also enjoy many aspects of their jobs. These people will often work long hours. In contrast, poorly educated people may be forced into part-time work, sometimes with very low hours, as this is the only work available. Alternatively, if they can work much longer hours they will do so simply to earn an adequate income. The hours data are further complicated by the self-employed who often work long hours. The owners of family farms are examples of this. For some of these people, paid work and lifestyle considerations often merge.

The research also showed that while gender, and traditional childrearing responsibilities remain an important factor in hours worked, the importance of this variable had reduced throughout the period studied. Age was also found to be an important variable. Increasingly, entry-level jobs for young people and jobs for semi-retired people tend to be part time. However, in the 1990s, young people working part time tended to be involved in study, so many of these people are unlikely to continue working on a part-time basis. Working part time may also be a positive transition into retirement for some older people, while for others, it may represent an unwanted early reduction in work hours.

The analysis of working hours suggests that simple policy mechanisms for "sharing" work around the community, such as restricting by legislation the hours of those workrich people and increasing the hours of those people with little work, are unlikely to be successful. Transferring excessive hours worked by an older doctor to a young part-time waiter is problematic. Transferring income via taxation and subsequent transfers to reduce inequality is easier, but again it is not without problems. Yet, in particular areas of the 
economy a "culture" of long hours has emerged, often as a signal of "commitment" to the business. Changing norms so quality of output is valued more than quantity of input may allow some people to choose to reduce excessive working hours.

The research on changing patterns of employment for prime-aged individuals suggests that in an open free-market and technologically advanced economy a reduction in the "gender gap" is likely to be associated with a widening of the "skills gap". The data also suggest that, given the advances women have made in education, the monopoly men have had on the symbolic analytical jobs will continue to be challenged. However, the data also show that gender remains far more important in those areas of the economy that require lower levels of cognitive ability. Whether this is due to genes or social norms remains unclear. However, it is likely that the attitudes of individuals and society as a whole will continue to restrict both men and women moving into non-traditional occupations and industries.

The data on individuals also suggest that "gender" research should not just focus on crude differences, such as averages of income or life expectancy, between women as a group and men as a group. Increasingly, there are major within-group differences and simplistic "gap" measures have the potential to understate or, alternatively, overstate the position of one particular group by combining them with a larger group of disadvantaged or advantaged individuals.

The research on the employment of individuals also indicates the need for caution with regards to focusing on ethnic "gaps". Again, while Maori (and especially sole Maori), Pacific Island peoples and Asian people are over-represented amongst those who are disadvantaged in the labour market, this disguises some major variation within ethnic groups. For example, there is little "gap" in employment between well-educated Maori and well-educated Europeans. As another example, amongst the Asian group those people who are highly disadvantaged in the labour market tend to be recent immigrants. There is a danger in focusing policy interventions on simple, but sometimes highly fluid, characteristics such as ethnicity rather than developing a more complex, but ultimately 
more equitable, set of assistance measures based on real need. This focus on specific population groups is fostered by having specialist government agencies promoting the well-being of particular groups such as Maori or women. While there is some benefit in identifying disadvantage that applies particularly to one group, it can also mean that other disadvantaged people within the "mainstream" tend to be overlooked.

\section{Couples and households}

Lifting the unit of analysis by one level, there were three main research questions. These were:

- between 1986 and 1996 was there an increasing concentration of paid work within particular families and households?

- did changes in paid work have a major influence on any of the changes in living arrangements that occurred over the time period studied?

- $\quad$ did human capital, as measured by formal education, became more concentrated within particular families between 1986 and 1996 ?

A number of steps were required to answer these inter-related questions. The first was assessing whether education and labour market status had an impact on the type of household in which a person lived. The research focussed primarily on the living arrangements of prime-aged men.

The data showed a strong association between whether a prime-aged man was in full-time paid work and whether he lived in a couple. Employed men were far more likely to live in a couple than men not in work at both the beginning and end of the period studied. Yet this relationship weakened over the decade between 1986 and 1996. In addition, an analysis by ethnic group indicates that cultural norms also influence this relationship. For example, prime-aged Asian and Pacific Island men were highly likely to live in couples, regardless of their labour market status. Sole Maori men were the least likely. The overall change in the association between work and living arrangements reflects the fact that 
unemployment and non-labour force status amongst prime-aged men increased amongst men living in couple households. This partly reflects a change in the behaviour of some men and women, with a small group of women now supporting men to gain further education and some families "reversing" traditional roles in income earning and childrearing. However, unlike changes in the labour market, there is not widespread evidence of dramatic changes in men's and women's roles in the home.

The data also showed that, at the beginning of the period studied, education had little predictive power in terms of male living arrangements. By the end of the period, however, it had greater predictive power. This is not surprising, given the increasing importance of education in the labour market. In the mid 1990s, well-educated men were more likely to be in couples than poorly educated men. Education is also important in terms of the timing of couple formation, often resulting in delayed marriage. Whether the student loans increasingly required for education will further inhibit couple formation in New Zealand is the subject of on-going debate.

In the mid 1990s, combining education and employment status provides a strong predictor of whether a male lived in a couple household. However, even at this stage and despite the increasing diversity of living arrangements, couple living was still the single most common living arrangement for men in all education and work statuses.

While education on its own was not a very strong predictor of whether a person lived in a couple, the level of education of one partner in a couple was a strong indicator of the level of education of their partner. Couples in New Zealand tend to be education-rich or education-poor. The fact that people with similar characteristics, including education, are often drawn to each other should not be surprising. It is also a phenomenon that social policy makers cannot control. However, the concentration of education within particular couples changed little over the decade. Moreover, as a higher proportion of individuals have attained tertiary qualifications, this has resulted in a higher proportion of couples having at least one partner with a tertiary qualification. This means the proportion of couples who are education-poor has been declining. 
While there was a small increase in the proportion of prime-aged couple households where the female but not the male partner was in paid work, there was a much stronger shift within couples to either work-poor or work-rich status over the period studied. There was also some evidence of polarisation of work within other household types. Paid work therefore become more concentrated in particular families and households over the period studied.

The significant growth in the proportion of work-poor couples and households occurred in the period of job loss between 1986 and 1991. However, in common with trends in other industrialised countries, while the strong employment growth in the economy in the next five years increased the proportion of work-rich couples and households and reduced the overall level of official unemployment, it only marginally reduced the proportion of prime-aged couples that were work-poor. This suggests that simply focussing on official measures of unemployment, which may be reducing, disguises important changes that are taking place in both labour markets and in households.

Traditionally, couples with young children have been most likely to exhibit the mixed work pattern. However, the growth of work-rich and work-poor couples also took place amongst two-parent families with pre-school children. Along with the growth of sole parent families over the period studied, this dramatically reduced the proportion of "traditional" two parent families with a father in full-time paid work and the mother at home full time. The changes in family type and work patterns for families raising young children are likely to have been positive for some groups. For example, the increasing attachment to paid work by some women has generally been welcomed, as have the greater options for some men with regard to part-time work and greater involvement in childrearing. However, many of the changes are of concern, with important implications for social policy. For example, having a high proportion of families with no market income earner potentially places many children in a state of poverty if the welfare system does not provide an adequate safety net. The loss of jobs by men in two-parent families also suggests that, along with the interest in "fatherless" families, attention should be paid 
to the impact of increased, and often unwanted, additional time at home by a group of men. These changes in work and family roles also challenge certain key concepts, such as a "primary income earner" and "primary caregiver" that are often used in policy debates.

In the 1990s, education-poor couples were over-represented amongst work-poor couples. In addition, and connected with education, couples where both partners were Maori, both from Pacific Island groups or both from the Asian ethnic group were over-represented amongst work-poor couples. Yet, the New Zealand data, as well as the international research literature, suggest that a wide range of other factors influence the growth of work-poor couples. These include fixed gender roles within couples, local labour market effects, and health issues. It is also clear that although some characteristics were overrepresented amongst work-poor couples, there was also considerable diversity. The workpoor ranged from well-educated couples who were likely to have been temporarily unemployed through to poorly-educated couples with one or both partners with ill health and therefore likely to be among those who were long-term work-poor.

Although there are no New Zealand data to show whether many couples stay work-poor for long periods, some overseas data suggest that this state is a long-term phenomenon for a small but significant group. It is unlikely that New Zealand patterns will be significantly different. However, given that other research indicates that work-poor couples are more likely to separate, their status may change from one work-poor household to two separate work-poor households. This can then create further demand for state support, such as housing and income support for two rather than one household.

The reasons behind the growth of work-rich couples are also complex. They include push factors, such as increasingly well-educated women wanting to have a long-term attachment to the labour force, as well as pull factors, such as women needing to work to supplement family income in the face of declining male income.

The wide range of reasons behind the formation of work-rich couples is also reflected in the diversity within this group. Work-rich couples ranged from well-educated, dual-career 
couples through to couples where both partners were in low-paid occupations. When these couples are raising children, policy responses required in workplaces or by the state to ensure that parents can earn sufficient income but children are also well cared for vary enormously. For example, there is a relatively small group of work-rich, high-income families who can purchase their own support. These are the people often shown in popular magazines that seem to "juggle" work and family life effortlessly and with great success. There is now a new workforce emerging to meet the needs of the dual-career couples, including cleaners, lawn mowers, and "nannies". This trend toward using private domestic substitutes is in line with patterns in similar economies. While men may be generally undertaking the outside paid work, it appears to be mostly women undertaking the housework, and especially the childcare, in these paid work situations.

In contrast, some of the work-rich, but not high-income, families are now trying to push for workplace support programs. This includes the development of "family-friendly" polices. Some of these people want to work part time or have alternative work arrangements such as teleworking. There are well-publicised examples of companies providing such support, but how widespread these programs actually are is the subject of some debate.

At the other end of the spectrum are the work-rich but poor childrearing families. They often need state support, such as subsidised childcare or income top-ups, to keep working. They also often rely on friends and relatives for childcare support. While some of these couples may benefit from some "family-friendly" based workplace restructuring, they tend to have little negotiating power in the workplace. Therefore, they may not gain access to some of the workplace benefits available to professional and managerial staff.

Finally, in relation to the possible creation of work-rich couples, the growth in part-time work amongst prime-aged individuals occurred not only amongst people living in a couple with a partner in full-time work. Part-time work became more common across a wide range of household living arrangements. Again, for some of these people, the growth in part-time work would have been through choice, whereas for others it would 
have been the only work available. For some people without other income support in the household, being in a low paid part-time job is very problematic. However, for others being a part-time worker does not necessarily mean they live in a low-income household. In fact, much of the data suggest that in couple households, part-time work amongst women is more common where their partner has above average income. This again reinforces the idea that analysing only the labour market position of individuals is problematic. Knowing more about their living arrangements is essential in determining their level of economic and social well-being.

As already discussed, in the 1950s there was a high degree of employment (and income) inequality between men and women. However, most men and women lived together in couple households. Although there were clearly exceptions, potentially most couples shared resources within the households. Now, as discussed, there is a greater level of employment inequality within men as a group and within women as a group. Men and women also now live in a wider variety of household types. However, when men and women live together, inequalities of education, work and income of individuals are often concentrated within particular households. Therefore, while there has been a decrease in employment inequality between men and women within households (and within society as a whole) this is being replaced by an increase in inequality between households.

As a final caution, it needs to be kept in mind when thinking about the trends in household and family arrangements, that New Zealand census data only provide a snapshot. Other research shows that people make transitions not only between labour market states but also between living arrangements. As in the paid labour market, there is now a considerable level of flexibility in marriage markets and transitions in work roles, particularly paid work, within families and households.

\section{Geographic communities}

The next level of analysis of changes in work was on a geographic area basis. Two main questions were asked: 
- was there a change in the concentration of hours of paid work by prime-aged people within geographic areas?

- did formal education also become more concentrated within particular geographic areas in the period studied?

Again, there was evidence of both polarisation and diversity. The data show that in both the 1980s and the 1990s there were extremes of work-rich and work-poor residential areas. However, using various measures, the proportion of work-poor areas increased between 1986 and 1996. That is, there was some increase in the spatial concentration of non work. The increase in work-poor areas was mainly caused by the loss of paid work amongst prime-age men, particularly amongst those men with few formal qualifications. However, while there was a small, but important, group of area units that remained workpoor for the ten years studied, there was some movement in and out of work-poor status. Overseas studies also suggest some mobility of individuals in and out of such areas.

Linking the research on families and geographic areas, there was, not surprisingly, a tendency for work poor individuals and families to live in work-poor areas. In addition, couples were less common in work-poor areas. But, as always, there was some complexity to this. Work-poor couples were found in work-rich areas, while work-rich couples were found in work-poor areas. Some rural area units appear to be particularly complex, with work-rich farming couples alongside pockets of work-poor people. In addition, even in cities, although there was some clustering of work-poor areas, they were sometimes located close to work-rich areas. Often underlying these patterns are important topographical features not noted in the census, such as the work-rich areas having good views and all-day sun. In addition, although not directly analysed in the research, the cost of housing in particular areas will be having a major impact on whether an area is workrich or work-poor. For example, clusters of low cost state housing will tend to bring together groups of work-poor people. 
In policy debates much of the focus is on poor regions such as Northland, the East Coast of the North Island, and the West Coast of the South Island. However, work-poor area units were found throughout New Zealand. Within the large cities, work-poor area units were most likely to be found within traditional state housing areas. Nevertheless, in the mid 1990s, small rural centres were over-represented amongst work-poor communities. This latter trend appears to reflect the general running down of small rural service centres.

The research also suggests that, in some situations, area units may be too large to be effective units of analysis. For example, there are some area units with pockets of both work-rich and work-poor people. It seems that different size units may be appropriate for different types of analysis. For example, regional labour markets will generally be larger than area units, but "neighbourhood effects" may actually operate at a meshblock level. Regional labour markets may be important for full-time work, but part-time workers (who may also face transport problems) are likely to look for work much closer to their homes.

The reasons for the development of work-poor, and particularly long-term work-poor, areas in New Zealand between 1986 and 1996 are complex and need further exploration. However, an initial exploration suggests that they include a lack of local labour demand. In some small rural areas this can be traced to a particular shock, such as the closure of a freezing works. In large urban areas, concentrations of relatively low-cost housing appear to bring together people with educational and other potential disadvantages. The housing market may also have an impact by preventing the movement of individuals from some small rural work-poor areas. For example, if people own their houses in declining areas they may not be able to sell them and buy in higher-priced growth areas, particularly if there are major differences in regional house prices, as is the situation in New Zealand. At times, however, low cost housing in declining areas, along with income support from the state, can encourage some work-poor people to move to these areas. This further removes these people from the labour market and may also disadvantage any children they bring with them. 
Reflecting this diversity in work-poor areas, while Maori and Pacific Island peoples were highly over-represented in these areas, there were also areas with a low concentration of these groups. Again, this suggests there is a danger in targeting disadvantage based on ethnicity. In addition, while work-poor areas tended to also be education poor, there were some exceptions to this rule. This suggests that both labour supply and demand factors are important.

Although many communities with a wide mixture of education levels amongst residents remain, the rapid rise in participation in tertiary educational institutions over the last decade appeared to be unevenly spread. This suggests spatial clustering of similarly qualified (or unqualified) people is becoming more important. There are already examples of education-rich and education poor areas in New Zealand. Moreover, with education becoming a stronger predictor of labour market status, there is potential for this concentration of education to increase. Again, in a market economy, it is difficult to see how policies could be developed that could ensure a greater mixing of people with differing levels of education and income. However, policy makers, if they have the backing of the wider electorate, can endeavour to ensure income is distributed more evenly. In addition, policy makers can also try to make sure the children of those people living in education-poor areas are not educationally disadvantaged. However, as has been found in all industrialised countries, improving the quality of education in poor areas is not a simple task. For example, in New Zealand it is likely to be much harder to find wellqualified school Board of Trustees members from within work-poor areas than from with a work-rich and well-educated area. While devolution can empower local communities, assistance is also needed to make sure that there are the skills and the resources in poor communities for local people to make wise decisions. In addition, if increasingly those people with higher levels of education (and generally higher incomes) and those who are poor are geographically separated, in the longer run there is the danger that there may be a growing reluctance amongst the better off in society to share their resources. 


\section{Some further policy issues}

Overall, the research on forces driving employment changes and an analysis of actual changes in employment for individuals does not provide any simple policy answer for increasing employment, particularly secure well-paid employment. Instead, it suggests that considerable care needs to go into designing policies in a wide range of areas from macro-economic policy, which affects most people, through to childcare policies, which assist parents of young children balance work and family life. It is also clear that many of the changes required to make people more able to participate in the international economy cannot be easily influenced by government policy. For example, providing a far greater proportion of people with the vision, drive and opportunity to start their own businesses and to orient them towards the international market place requires as much of a change in social norms as it does in economic policy. However, one theme that does emerge is the need for a focus on developing human capital at all levels of society from individuals, through to families and wider society. Although it is far from clear that the upskilling of a population directly leads to job creation, it appears that the level of basic numeracy, literacy and social skills required to fully participate in society has been steadily rising. Without these basic skills, people face both economic and social exclusion.

How to upskill particular populations, especially the group at the bottom end of the literacy, numeracy and social skills distribution, is a major problem facing all industrialised countries. It is a problem that New Zealand policy-makers are well aware of, but the possible solutions are the subject of much debate. This raises questions of nurture and nature as well as issues of ethnicity. It also results in complex discussions about how best to fund, deliver and regulate education at all levels. While debate still rages on the issue of nature versus nurture, it seems that nature, in terms of genetically inherited cognitive ability, has some impact on learning potential. However, while there may be particular challenges in upgrading the skills of those disadvantaged by their genes, this only emphasises the need to ensure that conditions of nurture, in the form of family life and schooling, provide an optimal environment for learning. The issue of how much the genes that determine the sex of an individual affect educational opportunities 
and employment appear even more complex. Simple ideas that boys perform better at school than girls are now shown to be incorrect. Yet, the notion that it is now generally boys who are disadvantaged is also incorrect. There are both boys and girls who face disadvantage in schools. Similarly, assumptions that successes or failures in schooling run primarily along ethnic lines are simplistic. Yet, at times, particular policies may be needed to assist a particular group. For instance, having more male teachers in primary schools may assist some boys to achieve better through providing positive role models. Similarly, having better qualified Maori and Pacific Island teachers seems to be a useful strategy. However, many of the writings about education in New Zealand seem to be based on ideology rather than solid research and more open-minded research is needed on such things as how to assist both low achievers to improve their learning and poorly performing schools to lift their performance.

Changes in employment and family type also throw up fundamental questions about the raising of children. For example, in the globalised economy, if a particular group of lowskill men and women can no longer provide adequate financial support for raising children, should they be encouraged through the welfare and tax systems not to have children or at least to limit the number of children they have? Is this a problematic if this results in below replacement fertility levels for society? Or should a wider range of "family-friendly" benefits be introduced to support families who have low market incomes? The issue of who should support children is the subject of much debate. At one extreme is the view that choices to have children are purely personal and the costs (and benefits) of having them should be born by the parents. At the other extreme, the raising of children is seen as a wider societal issue. In New Zealand, we are currently somewhere in the middle. For example, there is much emphasis on ensuring non-custodial biological parents keep financially supporting their children if a couple family dissolves, yet free schooling supported by taxpayers is available to all that want it and healthcare is free for under six year olds.

Adding further complexity, some research suggests there may be a level of fluidity in relationships and labour markets that is no longer beneficial to individuals and 
particularly children. However, much of this fluidity, particularly in relationships, is due to personal choice in an environment of changed social norms. Yet, social norms do not develop in isolation. Changing economic circumstances also influence them. For example, while the loss of jobs for a group of men and the provision of income support for sole parents in themselves may not be the main cause for the growth in sole parent families, they appear to be part of the many reasons for the change in family type.

Linked to many of these ideas, social policy makers also need to assess the relative merits of trying to strengthen individuals, families or communities. Much of the data presented in this research would suggest that assisting individuals achieve to the highest possible level in education will, in the long term, assist them in the labour market. This will then give them more options to choose an optimal household and geographic living arrangement. This means, for example, that policies directed at areas such as early childhood education might, in the long term, help the next generation of parents in both their work and family lives. Yet, it is clear that particular individuals will have either short or long spells out of the labour market. The challenge remains for all industrialised countries to design safety nets that assist those most in need and yet still encourage most people to remain attached to the labour market. This includes designing policies that allow people to re-train.

However, there is also merit in assisting particular disadvantaged families, in their various forms, to provide the best environments to raise children. This is particularly true if those parents have multiple problems, such as violence and drug abuse. This concept of "strengthening families" is already a developing aspect of New Zealand social policy. A key element of developing such policies has been the need to think cross-sectorally. This has required agencies such as health, income support, justice and education to co-operate. It also requires co-ordination of support agencies, including non-governmental agencies, at a local level. In addition, such work needs to be backed by a solid research base. This research also needs to draw on a wide range of disciplinary approaches. 
Although the government policies for strengthening families are based on targeting at-risk groups, strengthening the economy as a whole may be a critical part of assisting families with children to retain some level of cohesion. While an adequate level of financial resources gained from labour market participation appears to be associated with a higher level of intact two-parent families, this cohesion does not necessarily require parents to remain living together. Resources such as adequate housing, money for transport or the ability to access telecommunication systems are often extremely important in allowing non-custodial parents to retain effective relationships with their children. Yet, there remains much debate about how to strengthen the economy. One model would involve further deregulation of the labour market. While it may create more jobs and higher incomes for many families, in the long run it is likely to further disadvantage a significant group of low-skill men and women. Examples of such deregulation could include removing the minimum wage or reducing job protection measures such as parental leave. Finding the right balance between policies that protect workers and those that assist employers to expand employment will continue to be difficult in industrialised economies.

In the year 2000, in New Zealand, there is also growing interest in the concept of strengthening geographic communities. As discussed in this research, there is some international evidence that geographic communities may have an impact, such as through neighbourhood effects, on the well-being of the individuals living in them. The impact of communities and the institutions within them, including schools, can be particularly important for children if families are dysfunctional. In recognition of this, some government agencies, such as the Ministry of Social Policy and the Department of Internal Affairs, have started to explore ways of strengthening communities. Amongst other agencies, this includes exploring ways of strengthening schools in disadvantaged areas. However, such policies need a strong theoretical and research base if they are to be successful. For example, in the international literature there is much debate about whether governments should support economic development at a regional level or whether it may, in fact, be better to focus on ensuring mobility of individuals and families so they do not remain living in economic and social backwaters. Even if governments support the notion 
of regional development, there is still much uncertainty as to how to best achieve this. One idea is the direct support of particular industries, while another strategy focuses more on improving local infrastructure such as roads and airports.

Overall, there seems to be much to support the idea of ensuring a high level of geographic mobility, rather than providing regional development incentives, so people can move to areas where they have better opportunities. At times, however this may require government intervention. For example, it may be more effective for the government to offer incentives for displaced forestry workers from the West Coast of the South Island to move to areas such as the central plateau in the North Island than to offer economic support to the West Coast as its milling industry declines.

\section{Research directions}

Despite the many changes in society, there is a lack of New Zealand research that can inform us as to how individuals, families and geographic communities are adapting to the new employment environment. As an example, we have little idea of how two job couples structure their work arrangements in terms of part-time, evening and weekend work, particularly if they have dependent children. Do many multi-earning couples work nonoverlapping shifts in order to cover childcare? How are such decisions related to education and income potential?

More information is needed for effective debates to occur. While this will require new datasets to be developed and new questions to be asked in existing surveys, more in-depth investigation of existing databases would be useful. In addition, qualitative research will be vital in helping us unravel these puzzles.

Much of the employment research previously carried out in New Zealand concentrates on the official measure of unemployment for individuals. Much recent research, including my own, shows the need to bring into any analysis of employment change the group no longer in the labour force. Complicating this, by the end of the 1990s this category of non labour force (as well as unemployed) is no longer so homogenous as it once was. This 
also suggests that in order to judge whether men (or women) not in paid work are disadvantaged, socially and economically isolated, or part of an underclass, a variety of information is needed other than just the labour market status of the particular individuals. The data on family and household change, including the data showing the simultaneous growth of work-rich and work-poor households, indicate that this information should include the labour market status, education and income (and preferably wealth) of other family members if they live in a family setting. It should preferably take into account the situation of extended family networks, such as whether people living on their own or with their own parents have children living in other households. Determining, for example, whether some men have become "marginal" due to both employment and family change is not a simple task.

As an example of possible new quantitative research, existing cross-sectional census data could be investigated further, including through the use of econometric techniques. This could include setting up a quasi-cohort analysis using census data to trace age cohorts to see how their status has changed over time in terms of living arrangements and labour market status. This idea has been recently promoted by Statistics New Zealand and funding has been provided in the 2000 budget for some cohort modelling. The aim is to eventually develop a database of social and population statistics that integrates data from various sources and allows the experiences of different cohorts to be studied.

Since 1995, the Household Labour Force Survey also has some new data on employment across households. As illustrated in this thesis, this can show whether households are work-rich or work-poor. As yet, this database remains unexplored. One relationship that may be able to be tested using these new data is whether there is any association between individuals working part time and wanting more hours of work and the labour force status of any other people in their household. Linked to this, we know little about job security and work tenure of individuals in New Zealand. It would be relatively easy to add an occasional question to the New Zealand Household Labour Force Survey on tenure, as is the situation in the parallel U.S. survey. This would then allow tenure data to be linked to the new household data. 
Changes to the census questionnaire may help us better understand economic and social relationships that increasingly run across households rather than within them. For instance, it may be possible to identify non-custodial parents and their living arrangements. For example, aside from Child Support data, there is little information on the economic, social and emotional support that non-custodial parents give their children. However, specific new surveys may be needed to understand wider employment, family and household change.

It is clear that new longitudinal datasets would be useful in understanding changes in work and changes in families and the linkages between the two. This has been recognised by a wide range of interest groups in New Zealand. In the year 2000 government budget round, funding was announced for a longitudinal survey of income, employment and family dynamics to be run over the next ten years.

However, as discussed in earlier chapters, longitudinal studies are not a panacea. Even with the newly announced survey, there is the problem that we will have to wait a long time before the data becomes of use. Much of the longitudinally based research emerging from the U.S. (and from the existing New Zealand longitudinal studies) on family and work change is based on studies using surveys started in 1960 and 1970s. In the meantime, we will generally be reliant on the findings of overseas studies, but with the usual caution needed when taking information from another cultural context.

Gathering the type of data researchers most want will continue to be difficult, as this tends to intrude into people's private lives. As shown in this research the "not specified" category is already problematic in surveys. This, as well as other associated non-response problems, could get worse. More recognition is needed of this non-response problem. It may be that, increasingly, researchers will need to use alternative data sources such as tax data or income support data. However, there are many problems facing private researchers in accessing such databases. 
There also needs to be more sophisticated research in the area of ethnicity. For example, there are significant differences between the group of sole Maori and those Maori with multiple ethnic affiliations. The reasons for these differences are still not clear and more research should be carried out to determine the reasons. It may also be that there are better ways of assigning ethnicity. One method would be to allow people to assign their own hierarchy to their various ethnic groups rather than allowing Statistics New Zealand to undertake this based on some fixed formula. However, given the high rate of intermarriage in New Zealand, and the subsequent high rate of people belonging to multiple ethnic groups, classification systems also need to be developed so people are no longer simply assigned to one ethnic group. Not only are more sophisticated concepts of ethnicity useful in the research process, new concepts of ethnicity have the potential to change the nature of political debates. For example, based on current classification systems, in fifty years time a far higher proportion of the population may be seen as being simply Maori or Pacific Island people. Yet, in reality, a large proportion of this group will have multiple ethnicities.

As already indicated, in addition to quantitative research, there also needs to be more qualitative research carried out on changes in work and living arrangements. While sophisticated multi-variate analysis of large-scale databases such as the census may help get a better idea of factors associated with particular choices made in work, education and family life, such research ultimately cannot tell us why such choices are made. For example, in-depth qualitative research is needed to determine why some low skill middleaged people seek to increase their ability in literacy while many other seemingly similar people do not.

In particular, there is little in-depth knowledge of how some men, especially low-skilled men, are adapting to the major changes they are facing in work and family life. In undertaking such research, there is a need for debates about the methodologies used. For example, there has been much debate about the involvement of women in research on women and for Maori to be involved in research on Maori. There needs to be similar debate as to whether there are situations where it might be appropriate to use a male-only 
research team; where a mixed team might provide the most useful results; where a women-only team might provide some useful insights, or whether, in fact, the gender of the researchers matters at all. However, in general when undertaking in-depth research into men's lives, especially with regard to issues such as health and fatherhood, an "inclusive" approach to research would seem to be the most appropriate. The argument for inclusive research is also especially strong when behavioural change amongst the group being researched is an anticipated and hoped for outcome of the research process.

Finally, there are many non-data based barriers to research on the linkages between changes in work and changes in families. In particular, in New Zealand, unlike many other industrialised countries, there is no specialised and independent Work and Family Research Institute in which this research to take place. There is also little long term funding in New Zealand to build up the expertise needed for such research.

\section{Final remarks}

In conclusion, New Zealand society is showing signs of increasing polarisation and diversity of experience in labour markets, marriage markets and housing markets for individuals. Not surprisingly, this has been occurring at the same time as income has become less evenly distributed across society. At one end of the spectrum, there is an emerging small group of prime working aged people with high levels of education, who have high income and relatively secure, full-time jobs, who generally live in couple families or actively choose to live alone generally in neighbourhoods of "choice". At the other end of the spectrum, there are a small group of people who tend to have low levels of literacy and / or social skills, who tend to involuntarily live alone or raise their children in sole parent families generally in neighbourhoods of "fate". However, as yet the "gap" between these two extremes does not appear to be as wide as in countries such as the U.S. In addition, the majority of New Zealanders continue to be somewhere in the "middle", exhibiting a wide range of employment and living arrangements. While much of this new diversity has come about through choice, some people have had the changes forced on them through economic restructuring. However, in turn, part of the restructuring was 
forced on New Zealand because of wider global economic and social change. The challenge for New Zealand policy makers is to make sure that this polarisation does not become more extreme and that people, especially children, have ways of moving out of positions of disadvantage. 


\section{References}

Adler, P. S. (1992) "Introduction", in P. S. Adler (ed.), Technology and the Future of Work, Oxford University Press, New York, pp. 3-14.

Akerlof, G. (1998) “Men without children”, Economic Journal, 108 (447): 287-309.

Allen, S. M. and Hawkins, A. J. (1999) "Maternal gatekeeping: Mothers' beliefs and behaviors that inhibit greater father involvement in family work", Journal of Marriage and the Family, 61 (1): 199-212.

Amato, P. R. and Rivera F. (1999) "Paternal involvement and children's behavior problems", Journal of Marriage and the Family, 61:375-384.

Anderson, G., Brosnan, P. and Walsh, P. (1992) "Adapting to the recession: Labour force changes and labour cost reductions", in P. S. Morrison (ed.), Labour, Employment and Work in New Zealand: Proceedings of the fifth Conference, Wellington, Victoria University, pp. 89-97.

Angrist, J. D. and Evans, W. N. (1998) "Children and their parents' labor supply: Evidence from exogenous variation in family size", American Economic Review, 88 (3): 450-477.

Ansley, B. (2000) "Just the Job: Fewer workers working longer hours sees more people asking: Do we work to live or live to work", The Listener, January 29, pp. 16-19.

Antonelli, C. (ed.) (1992) The Economics of Information Networks, North-Holland, Amsterdam.

Arnold, M. N. (1982) "Aspects of finding a wife in nineteenth-century New Zealand", V.U.W. Working Papers in Economic History 82/1, Victoria University, Wellington.

Aronowitz, S. and DiFazio, W. (1994) The Jobless Future, University of Minnesota Press, Minneapolis.

Arrow, K. J. (1997) "Invaluable goods", Journal of Economic Literature, XXXV: 757765.

Atkinson, J. (1985) "Flexibility, Uncertainty and Manpower Management", IMS Report No 89, Institute of Manpower Studies, U.K.

Attewell, P. (1987) "The de-skilling controversy", Work and Occupations, 14 (3): 323346. 
Attewell, P. (1992) "Skill and occupational changes in U.S. manufacturing", in P. S. Adler (ed.), Technology and the Future of Work New York: Oxford University Press, pp. 46-88.

Attewell, P. (1999) "The impact of family on job displacement and recovery", in, M. PittCatsouphes and B. K. Googins (eds.), The Evolving World of Work and Family: New Stakeholders, New Voices, Sage, New York.

Bain, H. (1998) "Prison population rockets", The Dominion, December 17, p. 1.

Barash, D. (1982) Sociobiology and Behavior, Elsevier, New York.

Becker, G. S. (1965) “A theory of the allocation of time”, Economic Journal, 75: 493517.

Becker, G. S. (1974) "A theory of marriage", in T. W. Schultz (ed.), Economics of the Family: Marriage, Children, and Human Capital, University of Chicago Press, Chicago, pp. 299-344.

Becker, G. S. (1981) A Treatise on the Family, Harvard University Press, Cambridge.

Becker, G. S. (1996) Accounting for Tastes, Harvard University Press, Cambridge.

Becker, G. S., Landes, E. M. and Michael, R. T. (1977) "An economic analysis of marital instability", Journal of Political Economy, 85: 1141-1187.

Bergmann, B. R. (1986) The Economic Emergence of Women, Basic Books, New York.

Bergmann, B. R. (1995) "Becker's theory of the family: Preposterous conclusions", Feminist Economics, 1 (1): 141-150.

Bergstrom, T. (1997) "A survey of theories of the family", in M. R. Rosenzweig and O. Stark (eds.), Handbook of Population and Family Economics, Vol 1A., Elsevier, Amsterdam, pp. 21-79.

Berman, E., Bound, J. and Griliches, Z. (1994) "Changes in the relative demand for skilled labour with US manufacturing industries: Evidence from the Annual Survey of Manufacturing”, Quarterly Journal of Economics, 109: 367-398.

Biddulph, S. (1995) Manhood: An Action Plan for Changing Men's Lives, Finch, Sydney.

Birks S. (1998a) "Why men shouldn't marry", paper presented at "Real Time", 8 September, Massey University. 
Birks S. (1998b) “Gender, policy and social engineering”, paper presented at the New Zealand Association of Economists 1998 Annual Conference, Wellington, 3 September.

Birks, S. and Callister. P. (eds.) (1999a) Perspectives on Fathering, Centre for Public Policy Evaluation, Palmerston North.

Birks, S. and Callister. P. (eds.) (1999b) Perspectives on Fathering II, Centre for Public Policy Evaluation, Palmerston North.

Birrell, B., and Rapson, V. (1998) "A not so perfect match: The growing male/female divide, 1986-1996", Centre for Population and Urban Research, Melbourne, Monash University.

Blankenhorn, D. (1995) Fatherless America: Confronting Our Most Urgent Social Problem, Basic Books, New York.

Blau, F. and Ferber, M. (1986) The Economics of Women, Men and Work, Prentice-Hall, New Jersey.

Block, F. (1990) Postindustrial Possibilities University of California, Berkeley.

Bluestone, B. and Harrison, B. (1988) The Great American Job Machine: The Proliferation of Low-wage Employment in the U.S. Economy, Basic Books, New York.

Boggess, S. and Corcoran, M. I. with Jenkins, S. P. (1999) Cycles of Disadvantage, Institute of Policy Studies, Wellington.

Bollard, A. (1988) Small Businesses in New Zealand, Allen and Unwin, Wellington.

Booth, A. L. and Francesconi, M. (1997) “Career mobility in Britain”, Working Paper 972, ESRC Research Centre on Micro-social Change, University of Essex, Colchester.

Bourdieu, P. and J. Passeron, J. (1977) Reproduction in Education, Society and Culture, Sage, London.

Bowie, R. D. (1983) “The Dual Labour Market” in B. H. Easton (ed.), Studies in the Labour Market, NZIER Research Paper 29, pp. 71-94.

Braverman, H. (1974) Labor and Monopoly Capital, Monthly Review Press, New York.

Bronfenbrenner, U. (1979) The Ecology of Human Development: Experiments by Nature and Design, Harvard University Press, Cambridge.

Brookings Institution (1997) Fortress America: Gated Communities in the United States, Brookings Institution, Washington D.C. 
Brooks-Gunn, J., Duncan, G. J. and Aber, L. (eds.) (date 1997?) Neighborhood Poverty: Context and Consequences for Children, Vol 1, Sage, New York.

Brosnan, P. and Walsh, P. (1996a) "Non-standard employment in Australia and New Zealand: Preliminary results from a comparative survey", in R. Fells and T. Todd (eds.), Current Research in Industrial Relations: Proceedings of the 10th AIRAANZ conference, AIRAANZ, pp. 78-87.

Brosnan, P. and Walsh, P. (1996b) "Plus ca change...: the Employment Contracts Act and non-standard employment in New Zealand, 1991-1995", in P. S. Morrison (ed.) Labour, Employment and Work in New Zealand, Proceedings of the Seventh Conference 28th and 29th November, Victoria University, Wellington, pp. 157-166.

Bryant, W. K. and Zick, C. D. (1996) "Are we investing less in the next generation? Historical trends in time spent caring for children", Journal of Family and Economic Issues, 17 (3 \&4): 365-392.

Buckingham, A. (1999) "Is there an Underclass in Britain?", British Journal of Sociology, 50 (1): 49-75.

Bullard, T. (1996) Developing competency and skills in Te Whanau O Waipareira Trust, in P. S. Morrison (ed.) Labour, Employment and Work in New Zealand, Proceedings of the Seventh Conference 28th and 29th November, Victoria University, Wellington, pp. 97-103.

Bullard, T., Capper P., Hawes K., Hill R. and Tustin C. (1995) "The Hunting of the skills", paper presented to ANZAM '95 conference, Townsville, Australia 3-6 December.

Burgess, A. (1997) Fatherhood Reclaimed, Vermilion, United Kingdom.

Burgess, E. W. and Wallin, P. (1943) "Homogamy in social characteristics", American Journal of Sociology, 44: 109-124.

Burgess, J., Gleisner, J. and Rasmussen, E. (1995) "Male part-time employment in Australia and New Zealand: A comparative analysis", paper presented to the 1995 AIRAANZ conference, Melbourne.

Bururu, R., Irwin, D. and Melville, D. (1998) "Labour market trends and outlook", Labour Market Bulletin, 1\&2: 1-33.

Cain, G. G. (1976) "The challenge of segmented labour market theories to orthodox theory: A survey”, Journal of Economic Literature, 14: 1215-1257.

Cairns, T. (1991) "Whaangi: Caring for a child", in G. M. Maxwell, I. B. Hassall, and J. P. Robertson (eds.), Towards a Child and Family Policy in New Zealand, Office of the Commissioner for Children Wellington, pp. 100-102. 
Callister, P. (1990) Tomorrow's Skills, New Zealand Planning Council, Wellington.

Callister, P. (1993) "Growth in male part-time work: Recession spinoff or social change, paper presented to the New Zealand Geographers Conference", Victoria University.

Callister, P. (1994) "Fathers as primary caregivers in two parent families", paper presented to the 1994 New Zealand Association for Research in Education, December 14, Christchurch.

Callister, P. (1995) "Families and patterns of work: Paid and unpaid parental leave in two parent families" in P. S. Morrison (ed.), Labour, Employment and Work in New Zealand: Proceedings of the Sixth Conference, Victoria University, Wellington, pp. 128-135.

Callister, P. (1996a) "Family-friendly" workplaces: Why do we need them and who potentially benefits?, New Zealand Sociology, 11(2): 183-222.

Callister, P. (1996b) "Ethnic and labour force classifications in couple families: Some methodological issues in the use of census data", New Zealand Population Review, 22 (1\&2): 83-87.

Callister, P. (1997) "Trends in employee tenure, turnover and work scheduling patterns: a review of the empirical research evidence", Occasional Paper Series 1997/1, Department of Labour, Wellington.

Callister, P. (1998a) "The "meet" market: Education and assortative mating patterns in New Zealand", New Zealand Population Review, 24: 43-69.

Callister, P. (1998b) "“"Work-rich" and "work-poor" individuals and families: Changes in the distribution of paid work from 1986 to 1996", Social Policy Journal of New Zealand, 10: 101-121.

Callister, P. (1998c) "Some geographic dimensions of being "work-rich" and "workpoor": Changes between 1986 and 1996", Social Policy Journal of New Zealand, 11: 161182.

Callister, P. (1999a) The Fathers Who Care: Partners in Parenting Project: Does it matter that there was not a partnership in the research process?, http://www.fatherandchild.org.nz/research/fwc-review.html

Callister, P. (1999b) "Iron John or Ironing John? - The changing lives of New Zealand fathers", in S. Birks and P. Callister (eds.), Perspectives on Fathering, Centre for Public Policy Evaluation, Palmerston North, pp. 23-40. 
Callister, P. (1999c) "The early childhood education and care arrangements of pre-school children of work-rich and work-poor couples", paper presented to the NACEW seminar Childcare, Families and Work, 8 December, http://www.nacew.govt.nz

Callister, P. (1999d) "No job, no wife? Fathers, paid work and changes in living arrangements in New Zealand", in S. Birks and P. Callister (eds.), Perspectives on Fathering II, Centre for Public Policy Evaluation, Palmerston North, pp. 116-132.

Callister, P. (1999e) "Education: A key factor in economic and social exclusion?", in P. S. Morrison (ed.), Labour, employment and work in New Zealand: Proceedings of the eighth conference, Victoria University, Wellington, pp. 231-238.

Callister, P. (2000a) Living and Working in New Zealand, Wellington: Institute of Policy Studies.

Callister, P. (2000b) "A not so perfect match: The New Zealand experience", New Zealand Population Review, 26(1):1-21.

Callister, P. and Davey, J. (1995) "Unpaid work in New Zealand: What can the official statistics tell us?”, New Zealand Sociology, 10 (2): 155-181.

Callister, P. and Galtry, J. (1996) "Parental leave in New Zealand: Is it meeting the needs of employees, employers and children?", paper presented at Striking a Balance: Families, Work, and Early Childhood Education seminar, NZCER, June 18.

Callister, P., Podmore, V. N. with Galtry, J. and Sawicka, T. (1995) Striking a Balance: Families, Work and Early Childhood Education. NZCER, Wellington.

Callister, P. and Morrison, P. (1999) "Work poor and deprived: The location and characteristics of some of New Zealand's most disadvantaged area units", paper presented to the New Zealand Geographers Conference, Palmerston North, July 3 \& 4.

Callister, P. and Rose, D. (1996) "Changing skill requirements in New Zealand" in R. Le Heron and E. Pawson (eds.), Changing Places: New Zealand in the Nineties, Longman Paul, Auckland, pp. 105-108.

Callister, P. and Rose, D. (forthcoming) Implications of Labour Market Change for Retirement Income Policy, Ministry of Social Policy, Wellington.

Carlson, A. (1990) The Swedish Experiment in Family Politics: The Myrdals and the Interwar Population Crisis, Transaction Publishers, London.

Carmichael, G. A. (1988) "Socio-Demographic correlates of divorce in New Zealand", Journal of the Australian Population Association, 51 (1) 58-81. 
Carmichael, G. A. (1995) "Consensual partnering in the more developed countries: An overview", Working Papers in Demography No. 56, Research School of Social Sciences, The Australian National University.

Carmichael, G. A. (1996). "Consensual partnering in New Zealand: Evidence from three censuses", New Zealand Population Review, 22 (1\&2): 1-44.

Case, A. C. and Katz, L. F. (1991) "The Company you keep: The effects of family and neighborhood on disadvantaged youths", Working paper No 3705, National Bureau of Economic Research, Cambridge, M.A.

Casey, B. (1991) "Survey evidence on trends in "non-standard' employment", in A. Pollert (ed.), Farewell to flexibility?, Blackwell, Oxford, pp. 179-199.

Caspi, A., Enter Wright, B. R., Moffitt T. E and Silva P. A. (1998) "Early failure in the labor market: Childhood and adolescent predictors of unemployment in the transition to adulthood", American Sociological Review, 63: 424-451.

Castells, M. (1996) The Information Age: Economy, Society and Culture - Volume 1: The Rise of the Network Society, Blackwell, Cambridge, M.A.

Chabris, C. F. (1998) "IQ since "The Bell Curve"”, Commentary, 106 (2): 33-40.

Chapple, S. (1994) "HLFS - Consistent labour market data", Working Paper 94/16, NZIER. Wellington.

Chapple, S. (1999) Personal communication.

Chapple, S. (2000) "Maori socio-economic disparity", paper presented at the New Zealand Association of Economists annual conference, Wellington.

Chapple, S. and Rea, D. (1998) "Time series analysis of disparity between Maori and non-Maori labour market outcomes in the Household Labour Force Survey", Labour Market Bulletin, 1\&2: 127-144.

Chodorow, N. (1978) The Reproduction of Mothering: Psychoanalysis and the Sociology of Gender, University of California Press, Berkeley.

Coleman, A. (1997) "Urban joblessness, location, and hysteresis - A theoretical approach", in P. S. Morrison (ed.), Labour, Employment and Work in New Zealand 1996, Proceedings of the Seventh Conference November $28 \& 29$, 1996, Victoria University, Wellington, pp. 61-66.

Collins, R. (1998) "The Sociological eye and its blinders", Contemporary Sociology, 27 (1): 2-6. 
Coney, S. (1993) Standing in the Sunshine: A History of New Zealand Women Since They Won the Vote, Penguin, Auckland.

Cooke, K. (1987) "The withdrawal from paid work of the wives of unemployed men: A review of the research, Journal of Social Policy, 16 (3): 370-382.

Corcoran, M., and Boggess, S. (1995) "The intergenerational transmission of poverty and inequality: A review of the literature", paper prepared for the New Zealand Treasury, Wellington.

Costa, D. L. (2000) "The wage and the length of the work day: From the 1980s to 1991", Journal of Labor Economics, 18(1): 156-181.

Costa, D. L. and Kahn, M. E. (1999) "Power couples: Changes in the locational choice of college educated, 1940-1990”, NBER Working Paper W7109, Cambridge, Mass.

Couchman, P., Fitzgerald, G. and Warren, J. (1988) Technological Change and Social Policy, Royal Commission on Social Policy, Wellington.

Crampton, P., Salmond, C. and Sutton, F. (1997) "NZDEP91: A new index of deprivation", Social Policy Journal of New Zealand, 9, 186-193.

Crane, J. (1991) "The epidemic theory of ghettos and neighborhood effects on dropping out and teenage childbearing", American Journal of Sociology, 96: 1226-59.

Cready, C. M., Fossett, M. A. and Kiecolt, K. J. (1997) "Mate availability and African American Family Structure in the U.S. Nonmetropolitan South, 1960-1990", Journal of Marriage and the Family, 59 (1):192-203.

Crosby, F. J. (1991) Juggling - The Unexpected Advantages of Balancing Career and Home for Women and their Families, The Free Press, New York.

Currie, J. and Thomas, D. (1999) "The intergenerational transmission of "intelligence": Down the slippery slopes of The Bell Curve", Industrial Relations, 38 (3): 297-330.

Dalziel, P. C. and Lattimore, R. G. (1996) The New Zealand Macroeconomy: A Briefing On the Reforms, Oxford University, Press Auckland.

Davey, J. (1998a) Tracking Social Change: From Birth to Death IV, Institute of Policy Studies, Wellington.

Davey, J. (1998b) "New Zealand children in households and families: An update", New Zealand Population Review, 24: 103-118.

Davis, K. (1984) "Wives and work: Consequences of the sex-role revolution", Population and Development Review, 10: 397-417. 
Dawkins, P. and Norris, K. (1990) "Casual Employment in Australia”, Australian Bulletin of Labour, 16: 156-173.

Denison, E. (1985) Trends in United States Economic Growth, Brookings Institution, Washington.

Dennard, H. L. (1996) "Governmental Impediments to the Employment of Contingent Workers”, Journal of Labor Research, XVII (4): 595-612.

Department of Internal Affairs (1997) Building Strong Communities: A "Thinkpiece”, Department of Internal Affairs, Wellington.

Department of Labour (1999) Childcare, Families and Work: The New Zealand Childcare Survey, Department of Labour and NACEW, Wellington.

Department of Statistics (1992) New Zealand Standard Areas Classification 1992, Department of Statistics, Wellington.

Department of Statistics (1993) New Zealand Social Trends: Work, Department of Statistics, Wellington.

Dex, S. and Taylor, M. (1994) "Household employment in 1991", Employment Gazette, 102 (10): 353-357.

Diebold, F. X., Neumark, D. and Polsky, D. (1994) "Job stability in the United States", Working Paper No 4859, National Bureau of Economic Research Cambridge, M.A.

Diebold, F. X., Neumark, D. and Polsky, D. (1996) "Comment on Kenneth A. Swinnerton and Howard Wial”, Industrial and Labor Relations Review, 49 (2): 348-352.

DiMaggio, P. and Mohr, J. (1985) "Cultural capital, educational attainment, and marital selection”, American Journal of Sociology, 90: 1231-61.

Dixon, C. (1995) "Segmentation theory and the New Zealand labour market" in P. S. Morrison (ed.), Labour, Employment and Work in New Zealand: Proceedings of the Sixth Conference, Victoria University, Wellington, pp. 376-371.

Dixon, S. (1996a) "The distribution of earnings in New Zealand 1984-94", Labour Market Bulletin, 1: 45-100.

Dixon, S. (1996b) "Labour force participation over the last ten years", Labour Market Bulletin, 2: 71-88.

Dixon, S. (1998) "Growth in the dispersion of earnings: 1984-97", Labour Market Bulletin, 1\&2: 71-107. 
Dixon, S. (1999) "Prime-aged males who are not in the labour force", Labour Market Policy Group Working Paper, Department of Labour, Wellington.

Doeringer, P. B. and Piore M. J. (1971) Internal Labor Markets and Manpower Analysis, Heath Lexington, Massachusetts.

Duncan, G. J., Yeung, W. J., Brooks-Gunn, J. and Smith, J. R. (1998) "How much does childhood poverty affect the life chances of children?", American Sociological Review, 63: 406-423.

Duncan, S. and Edwards, R. (1997) "Lone mothers and paid work - Rational economic man or gendered moral rationalities?", Feminist Economics 3 (2): 29-61.

Easton, B. (1991) "Structural change and economic growth in postwar New Zealand", Massey Economic Papers, Vol 9 No. B9103, Massey University, Palmerston North.

Easton, B. (1995) "Poverty in New Zealand: 1981-1993”, New Zealand Sociology, 10 (2): 182-213.

Easton, B. (1997) In Stormy Seas: The Post-war NZ Economy, University of Otago Press, Dunedin.

Economic Monitoring Group (1989) The Economy in Transition: Restructuring to 1989, New Zealand Planning Council, Wellington.

Elias, P. (1997) "Restructuring, reskilling and redundancy: A study of the dynamics of the UK labour market 1990-95", Working Paper 97-20, ESRC Research Centre on MicroSocial Change, University of Essex, Colchester.

Else, A. (1997) "Having it both ways? Social policy and the positioning of women in relation to men", Social Policy Journal of New Zealand, 9:16-26.

Employment Policy Institute (1996) “Employment audit commentary”, 2: .2-16.

Engbersen, G., Schuyt, Timmer, J. and van Waarden, F. (1993) Cultures of Unemployment: A Comparative Look at Long-term Unemployment and Urban Poverty, Westview Press, Boulder Colorado.

England, P. and Farkas, G. (1986) Households, Employment, and Gender: A Social, Economic and Demographic View, Aldine, New York.

Epstein, E. and Guttman, R. (1984) "Mate selection in man: Evidence, theory, and outcome", Social Biology, 31(3-4): 243-278. 
Esping-Andersen, G. (1996) "After the Golden Age? Welfare State Dilemmas in a Global Economy, in G. Esping-Andersen (ed.), Welfare States in Transition: National Adaptations in Global Economies, Sage, London, pp. 1-31.

Esping-Andersen, G. (ed) (1996) Welfare States in Transition, Sage, London.

Evening Post (1999) “Today's Schools”, June 16, pp. 24-28.

Farber, H. S. (1995) "Are lifetime jobs disappearing? Job duration in the United States: 1973-1993", Working Paper No 5014, National Bureau of Economic Research Cambridge, M.A.

Farber, H. S. (1996) "The changing face of job loss in the United States, 1981-1993", Working Paper No 5596, National Bureau of Economic Research Cambridge, M.A.

Fergusson, D. M. (1998) "The Christchurch health and development study: An overview and some key findings", Social Policy Journal of New Zealand, 10: 154-176.

Finegold, D and Soskice, D. (1988) "The failure of training in Britain: An analysis and prescription", Oxford Review of Economic Policy, 4: 21-53.

Fischer, C. S., Hout, M., Jankowski, M. S., Lucas, S. R., Swidler, A., and Voss, K. (1996) Inequality By Design: Cracking the Bell Curve Myth, Princeton University Press, Princeton, New Jersey.

Fleisher, B. M. and T. J. Kniesner (1984) Labor Economics: Theory, Evidence, and Policy, Prentice-Hall, Englewood Cliffs, New Jersey.

Fletcher, M. (1995) "Pacific Islands peoples in the labour market", Labour Market Bulletin, 1: 124-135.

Floro, M. (1995) "Women's well-being, Poverty, and work intensity", Feminist Economics, 1 (3): 1-25.

Folbre, N. (1994) Who Pays for the Kids: Gender and the Structures of Constraint, Routledge, New York.

Forrest, R. and P. Kennett, P. (1997) "Risk, residence, and the post-fordist city", American Behavioral Scientist, 41 (3): 342-359.

Fossett, M. A. and Kiecolt, K. J. (1991) "A methodological review of the sex ratio: Alternatives for comparative research", Journal of Marriage and the Family, 53: 941957.

Franklin, H. (1969) “The self-employed society”, Pacific Viewpoint, 10 (1): 29-56. 
Franklin, H. (1997) "Imitating the rich: The imperatives of consumption", in R. F. Watters and T. G. McGee (eds.), New Geographers of the Pacific Rim: Asia Pacific, C. Hurst, London, pp. 78-92.

Frater, P., Stuart, G., Rose, D. and Andrews, G. (1995) The New Zealand Innovation Environment, The BERL Foundation, Wellington.

Freeman, C. (1991) "Networks of innovators: A synthesis of research issues", Research Policy, 20: 499-514.

Freeman, R. B. (1995) “Are your wages set in Beijing?", Journal of Economic Perspecitves, 9 (3): 15-32.

Friedan, B. (1982) The Second Stage, Michael Joseph, London.

Fukuyama, F. (1997) The End of Order, Social Market Foundation, London.

Gallie, D. (1994) “Patterns of skill change: Upskilling, deskilling, or polarization?", in R. Penn, M. Rose and J. Rubery (eds.), Skill and Occupational Change, Oxford University Press, Oxford, pp 41-76.

Galtry, J. and Callister, P. (1995) "Birth and the early months: Parental leave and paid work", in P. Callister et al (eds.), Striking a Balance: Families, Work and Early Childhood Education. NZCER, Wellington, pp. 13-75.

Garfinkel, I., McLanahan, S. and Harknett, K. (1999) "Fragile families and welfare reform", Working Paper 99-11, Bendheim-Thoman Centre for Research on Child Wellbeing, Princeton.

Garrison, R. J., Anderson, V. E. and Reed, S. C. (1968) “Assortative mating”, Eugenics Quarterly, 15: 113-127.

Gendall, P. J., and Russell, D. F. (1995) The roles of men and women in society: International social survey programme Department of Marketing, Massey University.

Gershuny, J. and Robinson, J. P. (1988) "Historical changes in the household division of labour", Demography, 25 :537-52.

Gershuny, J., Bittman, M., and Brice, J. (1997) "Exit, voice and suffering: Do couples adapt to changing employment patterns", Working Paper 97-8, ESRC Research Centre on Micro-social Change, Colchester: University of Essex.

Gershuny, J., M. Godwin, and S. Jones (1994) "The domestic labour revolution: A process of lagged adaptation?" in M. Anderson, F. Bechhofer, and J. Gershuny (eds.), The Social and Political Economy of the Household Oxford University Press, Oxford, pp. 151-197. 
Gibson, J. (1998) Ethnicity and Schooling in New Zealand: An Economic Analysis Using a Survey of Twins, Institute of Policy Studies, Wellington.

Gill, I. (1988) Technological Change, Education and Obsolescence of Human Capital, University of Chicago, Chicago.

Gilligan, C. (1983) In a Different Voice, Harvard University Press, Cambridge, M.A.

Glamuzina, J. (1992) "A lesbian-feminist approach to the histories of Aotearoa: A pakeha perspective" in R. Du Plessis et al (eds.), Feminist Voices: Women's Studies Texts for Aotearoa / New Zealand, Oxford University Press, Auckland, pp. 39-44.

Gliksman, M. (1998) “Whose deficit?”, Certified Male, pp. 22-23.

Gobbi, M. (1998) "Participation in post-compulsory and training in New Zealand", Labour Market Bulletin, 1\&2: 108-126.

Goldman, N., Westoff, C. and Hammerslough, C. (1984) "Demography of the marriage market in the United States", Population Index, 50: 5-25.

Goldscheider, F. and Waite, L. (1991) New Families, No Families? - The transformation of the American Home, University of California Press, Berkeley.

Goldthorpe, J. H. (1998) "Rational action theory for sociology", British Journal of Sociology, 49 (2): 167-192.

Goodger, K. (1998) "Maintaining sole parent families in New Zealand: An historical review", Social Policy Journal, 10: 122-153.

Gordon, D. (1996) Fat and Mean: The Corporate Squeeze of Working Americans and the Myth of Managerial “Downsizing”, Free Press, New York.

Gosling, A., Machin, S. and Meghir, C. (1996) "What has happened to the wages of men since 1966?", in J. Hills (ed.), New Inequalities: The Changing Distribution of Income and Wealth in the United Kingdom, Cambridge University Press, Cambridge, pp. 135157.

Gottschalk, P. and Smeeding T. M. (1997) "Cross-national comparisons of earnings and income inequality", Journal of Economic Literature, XXXV, 633-687.

Gough, K. (1971) "The origin of the family", Journal of Marriage and the Family, November, 760-771.

Gramlich, E., Laren, D. and Sealand, N. (1992) "Moving into and out of poor urban areas", Journal of Policy Analysis and Management, 11(2), 273-287. 
Granovetter, M. S. (1973) "The strength of weak ties", American Journal of Sociology, 78: $1360-80$.

Grannis, R. (1998) "The importance of trivial streets: Residential streets and residential segregation", American Journal of Sociology, 103 (6): 1530-64.

Gray, J. (1992) Men are from Mars, Women are from Venus, Hapercollins, New York.

Gregg, P., Hansen, K. and Wadsworth J. (forthcoming) "Measuring the polarisation of work across households".

Gregg, P. and Machin, S. (1994) "Is the UK rise in inequality different?", in R. Barrell (ed.), The UK Labour Market: Comparative Aspects and Institutional Developments, Cambridge University Press, New York, pp. 93-125.

Gregg, P. and J. Wadsworth (1994) "More work in fewer households?", Discussion Paper No.72, National Institute of Economic and Social Research, United Kingdom,.

Gregg, P. and Wadsworth, J. (1996a) "Mind the gap, please? The changing nature of entry jobs in Britain", Discussion Paper No 303, Centre for Economic Performance, London.

Gregg, P. and Wadsworth, J. (1996b) "Feeling insecure?", Employment Policy Institute, London, pp.17-25.

Gregg, P. and Wadsworth, J. (1996c) "It takes two: Employment polarisation in the OECD”, Discussion Paper No. 304, Centre for Economic Performance, London School of Economics.

Gregory, R. G. and Hunter, B. (1995) "The macro economy and the growth of ghettos and urban poverty in Australia", Discussion paper No. 325, Research School of Social Sciences, Australian National University.

Grossbard-Shechtman, S. (1993) On the Economics of Marriage: A Theory of Marriage, Labor, and Divorce, Westview Press, Boulder, Colorado.

Guttentag, M., and Secord, P. F. (1983) Too Many Women? The Sex Ratio Question, Sage, Beverly Hills, CA.

Hahn, F. H. (1991) “The next hundred years”, Economic Journal, 101: 47-50.

Haines, L. (1989) Work Today: Employment Trends to 1989, New Zealand Planning Council, Wellington.

Haines, L. and Callister, P. (1989) Tomorrow's Skills, New Zealand Planning Council, Wellington. 
Hall, R. E. (1982) "The importance of lifetime jobs in the US economy", American Economic Review, 72: 716-724.

Harbridge, R., Hince, K. and Honeybone, A. (1995) "Unions and union membership in New Zealand: Annual review for 1994", New Zealand Journal of Industrial Relations, 20 (2): 163-170.

Harkness, S., Machin, S. and Waldfogel, J. (1996) "Women's pay and family incomes in Britain, 1979-91, in J. Hills (ed.) New Inequalities: The Changing Distribution of Income and Wealth in the United Kingdom, Cambridge University Press, Cambridge, pp 158-180.

Harris, D. R. (1999) ““"Property values drop when blacks move in because...”: Racial and socio-economic determinants of neighborhood desirability", American Sociological Review, 64: 461-479.

Harris, J. R. (1998) The Nurture Assumption: Why Children Turn Out the Way They Do, Free Press, New York.

Harris, K. M. (1996) "Life after welfare: Women, work, and repeat dependency", American Sociological Review, 61: 407-426.

Harris, P. (1995) Dual and Segmented Labour Markets: An Annotated Bibliography and Critical Analysis, Centre for Labour and Trade Union Studies, University of Waikato.

Haskel, J. (1996) The Decline in Unskilled Employment in UK Manufacturing, Centre for Economic Policy Research, London.

Haveman, R. and B. Wolfe (1995) "The determinants of children's attainments: A review of methods and findings", Journal of Economic Literature, 33: 1829-1878.

Hawrylyshyn, O. (1977) "Towards a definition of non-market activities", Review of Income and Wealth, 23 (1): 79-96.

Head, S. (1996) "The new, ruthless economy", The New York Review, February 29, pp.47-52.

Henley, A. (1998) "Residential mobility, housing equity and the labour market", Economic Journal, 108 (447): 414-427.

Herlihy, D. (1997) The Black Death and the Transformation of the West, Harvard University, Cambridge, M.A.

Herrnstein, R. J. and Murray, C. (1996) The Bell Curve: Intelligence and Class Structure in American life, Free Press, New York. 
Hertz, R. (1986) More Equal Than Others: Women and Men in Dual Career Marriages University of California Press, Berkeley, CA.

Herzog, H. W. Jr. (1996) "Job loss and labour market outcomes under rapid structural adjustment: The case for New Zealand", Labour Market Bulletin, 1: 19-44.

Hewitt, P. (1993) About Time: The Revolution in Work and Family, Rivers Oram, London.

Higgins, J. (1993) Beyond the Ideology of Upskilling: The Theory and Practice of Skill Trend Analysis, Unpublished $\mathrm{PhD}$ thesis, Otago University.

Himmelweit, S. (1995) "The discovery of "unpaid work": The social consequences of the expansion of "work", Feminist Economics, 1(2): 1-19.

Hobcraft, J. (1998) "Intergenerational and life-course transmission of social exclusion: Influences of childhood poverty, family disruption, and contact with the police", CASE Paper 15, Centre for Analysis of Social Exclusion, London School of Economics.

Hochschild, A. R. (1983) The Managed Heart: The Commercialisation of Human Feeling, University of California Press, Berkeley, California.

Hochschild, A. R. (1995) "Understanding the future of fatherhood. The 'daddy hierarchy' and beyond", in M. C. P. van Dongen, G. A. B. Frinkling and M. J. G. Jacobs (eds.), Changing Fatherhood: An Interdisciplinary Perspective, Thesis Publishers, Amsterdam, pp. 219-230.

Hochschild, A. R. (1997) The Time Bind: When Work becomes Home \& Home becomes Work, Metropolitan Books, New York.

Hodgson, G. M. (1994) "The Return of Institutional Economics" in N. J. Smelser and R. Swedberg (eds.) The Handbook of Economic Sociology, Princeton University Press, Princeton, N.J., pp. 58-76.

Hollingshead, A. B. (1950) "Cultural factors in mate selection", American Sociological Review, 15: 619-627.

Hoynes, H. W. (1997) “Work, welfare, and family structure: What have we learned?", in A. J. Auerbach (ed), Fiscal policy: Lessons from Economic Research, MIT Press, Cambridge, M.A., pp. 101-146.

Hunter, B. and Gregory, R. G. (1996) "An exploration of the relationship between changing inequality of individual, household and regional inequality in Australian cities", Urban Policy and Research, 14 (3): 171-182. 
Hyman, P. (1994) Women and Economics: A New Zealand Feminist Perspective, Bridget Williams, Wellington.

Hyman, P. (1995) Participation in paid and unpaid work: Rhetoric, policy, and realities for women in the "year of the family", in P. S. Morrison (ed.), Labour, Employment and work in New Zealand: Proceedings of the Sixth conference, Victoria University, Wellington, pp. 120-127.

International Labour Organisation (1999) Working longer, Working better?, ILO, Geneva.

Ironmonger, D. (1996) "Counting outputs, capital inputs and caring labor: Estimating gross household product”, Feminist Economics, 2 (3): 37-64.

Jackson, N. and Pool, I. (1996) "Will the real New Zealand family please stand up? Substantive and methodological factors affecting research and policy on families and households", Social Policy Journal of New Zealand, 6: 148-176.

Jacoby, S. M., and Sharma, S. (1992) "Employment duration and industrial labor mobility in the United States, 1880-1980", The Journal of Economic History, 52 (1): 161-179.

Jaggar, A. M. (1988) Feminist Politics and Human Nature, Rowman and Littlefield, New Jersey.

Jargowsky, P. (1997) Poverty and Place, Russell Sage Foundation, New York.

Jencks, C. (1993) Rethinking Social Policy: Race, Poverty, and the Underclass, HarperPerenial, New York.

Jensen, A. R. (1978) "Genetic and behavorial effect of non-random mating", in C. E. Noble, R. T. Osborne and N. Weyle (eds.), Human Variation: Biogenetics of Age, Race, and Sex, Academic Press, New York, pp. 51-105.

Johnstone, K. and Pool, I. (1995) "New Zealand families: Size, income and labour force participation", Population Studies Centre Discussion Paper No 10, University of Waikato, Hamilton.

Johnstone, K. and Pool, I. (1996) "New Zealand families: Size, income and labour force participation”, Social Policy Journal of New Zealand, 7: 143-173.

Jones, F. L and Davis, P. (1986) Models of Society: Class, Stratification and Gender in Australia and New Zealand, Croom Helm, Sydney.

Jones, F. L. (1987) "Marriage patterns and the stratification system: Trends in educational homogamy since the 1930s", Australian and New Zealand Journal of Sociology, 23 (2): 185-198. 
Jones, S. (1997) “Is sex really necessary?”, Dominion, May 9, p. 9.

Juhn, C. (1992) "Decline of male labor market participation: The role of declining market opportunities”, Quarterly Journal of Economics, 107 (1): 79-121.

Juhn, C. and Kim, D. I. (1995) "The effects of rising female labor supply on male wages", Working paper 5236, National Bureau of Economic Research.

Juhn, C. and Murphy K. M. (1995) "Inequality in labor market outcomes: contrasting the 1980s and earlier decades", Federal Reserve Bank New York Economic Policy Review 1(1): 26-32.

Kalmijn, M. (1991a) "Status homogomy in the United States", American Journal of Sociology, 97 (2): 496-523.

Kalmijn, M. (1991b) "Shifting boundaries: Trends in religious and educational homogamy", American Sociological Review, 56: 786-800.

Kalmijn, M. (1994) "Assortative mating by cultural and economic occupational status", American Journal of Sociology, 100 (2): 422-452.

Kalmijn, M. (1999) "Father involvement in childrearing and the perceived stability of marriage", Journal of Marriage and the Family, 61: 409-421.

Kasper, W. (1996) Free to Work: The Liberalisation of New Zealand's Labour Market, Centre for Independent Studies, Australia.

Katz, E. (1997) "The intra-household economics of voice and exit", Feminist Economics, 3 (3): $25-46$

Katz, L. F. and Murphy, K. M. (1992) "Changes in relative wages, 1963-1987: Supply and demand factors", Quarterly Journal of Economics, 107 (1): 35-78.

Kierman, K. (1992) “The roles of men and women in tomorrow's Europe", Employment Gazette, Britain, 491-499.

Klerman, J. A. (1993) "Characterizing leave for maternity: Modeling the NLS-Y data", Working paper series 93-94 Labor and Population Program Rand Corporation, California.

Klerman, J. A. and Leibowitz, A. (1993) "Employment continuity among new mothers", Working paper series 93-94 Labor and Population Program, Rand Corporation, California.

Korenman, S. and Neumark D. (1991) "Does marriage really make men more productive?", Journal of Human Resources, 26 (2): 282-307. 
Krugman, P. and A. J. Venables (1995) "The seamless world: a spatial model of international specialization", Working paper No 5220, National Bureau of Economic Research, Cambridge Massachusetts.

Lancaster, K. J. (1966) "A new approach to consumer theory", Journal of Political Economy, 74: 132-157.

Leibowitz, L. (1978) Females, Males, Families: A Biosocial Approach, Belmont: Wadsworth.

Lemonick, M. D. (1999) “Smart genes”, Time Magazine, 27 September, pp. 48-52.

Levett, A. (1995) "Work and unemployment in post-industrial times", in P. S. Morrison (ed.), Labour, Employment and Work in New Zealand: Proceedings of the Sixth Conference, Victoria University, Wellington, pp. 378-384.

Levine, D. I. and Painter, G. (1999) "The NELS curve: Replicating The Bell Curve analysis with the national education longitudinal study, Industrial Relations, 38 (3): 364401.

Levy, F. and Murnane, R. J. (1992) "U.S. earnings levels and earnings inequality: A review of recent and proposed explanations", Journal of Economics Literature, 30 (3): 1333-81.

Lichter, D. T., LeClere, F. B. and McLaughlin, D. K. (1991) "Local marriage markets and the marital behavior of Black and White women", American Journal of Sociology, 96: 843-867.

Lichter, D. T., McLaughlin, D. K., Kephart, G. and Landry, D. J. (1992) "Race and the retreat from marriage: A shortage of marriageable men?", American Sociological Review, 57: 781-799.

Lilla, M. (1998) “A tale of two reactions", The New York Review of Books, XLV (8): 4, 67.

Livingstone, I. D. (1994) Literacies, Numeracies and Scientific Understandings: A New Zealand Literature Survey with Implications for Lifelong Learning, Chartwell Consultants, Wellington.

Lloyd, T. (1999) Young Men, The Job Market and Gendered Work, Joseph Rowntree Foundation website, http://www.jrf.org.uk.

Loveman, G. W. (1994) "The case of the part-time partner" in N. A. Nichols (ed.), Reach for the Top: Women and the Changing Facts of Work Life, Harvard Business Review, Boston, pp 113-128. 
Lundberg, F. (1937) America's Sixty Families, Vanguard, New York.

Maani, S. A. (1995) Rates of return to higher education in New Zealand: A study of the census years 1981-1991, paper presented at the joint conference of the New Zealand Association of Economists, and the Law and Economics Association of New Zealand, Lincoln University, 28-30 August.

Maloney, T. (1998) Five Years After: The New Zealand Labour Market in the Employment Contracts Act, Institute of Policy Studies, Wellington.

Maori Statistics Forum (1997) Concepts of Maori Ethnicity and the Monitoring of Trends in Maori Health, unpublished draft, Statistics New Zealand.

Marcuse, P. (1996) "Space and Race in the Post-Fordest City: The Outcast Ghetto and Advanced Homelessness in the United States Today" in E. Mingione (ed.), Urban Poverty and the Underclass, Blackwell.

Marcuse, P. (1997) "The ghetto of exclusion and the fortified enclave", American Behavioral Scientist, 41 (3): 311-326.

Maré, D. (1995) "Examining labour market outcomes for Maori” Labour Market Bulletin, $1,116-123$

Mare, R. D. (1991) "Five decades of educational assortative mating", American Sociological Review, 56: 15-32.

Maxwell, G. M. (1989) "Changing family structures: 1971-1986", New Zealand Population Review, 15 (1): 17-46.

Mayer, S. E. (1997) What Money Can't Buy, Harvard University Press, Cambridge, M.A.

McDonald, P. (1997) "Gender equity, social institutions and the future of fertility", Working Papers in Demography No. 69, Research School of Social Sciences, Australian National University, Canberra.

McPherson, M. J. (1995) Divorce in New Zealand: Recent Trends, Future Directions, Policy Implications and Research Needs, Social Policy Research Centre, Massey University, Palmerston North.

Mead, L. M. (1986) Beyond Entitlement: The Social Obligations of Citizenship, Free Press, New York.

Mead, L. M. (1992) The New Politics of Poverty: The Non Working Poor in America, Basic Books, New York. 
Mead, L. M. (1997) "Raising work levels among the poor", Social Policy Journal of New Zealand, 8: 1-28.

Michielutte, R. (1972) “Trends in educational homogamy”, Sociology of Education, 45: 288-302.

Milkman, R. (1991) "Labor and management in uncertain times", in A. Wolfe (ed.), America at Century's End, University of California Press, Berkeley.

Mills, E. S. and Lubuele, L. S. (1997) "Inner cities", Journal of Economic Literature, XXXV: 727-756.

Mincer, J. (1962) "Labor force participation of married women: A study of labor supply", in H.G. Lewis (ed.), Aspects of Labor Economics, Princeton University Press, Princeton, N.J.

Ministry of Education (1997) Adult Literacy in New Zealand: Results from the International Adult Literacy Survey, Wellington: Ministry of Education.

Moffitt, R. A. (1992) "Incentive effects of the U.S. welfare system: A review", Journal of Economic Literature, 30: 1-61.

Morgan, P. (1999) Farewell to the Family? Public Policy and Family Breakdown in Britain and the USA, IEA Health and Welfare Unit, London.

Morgan, P. S., McDaniel, A., Miller, A. T. and Preston, S. T. (1993) "Racial differences in household and family structure”, American Journal of Sociology, 98 (4): 799-828.

Morris, L. (1990) The Workings of the Household, Polity Press, Cambridge.

Morris, L. (1987) "Local social polarization: A case study of Hartlepool”, International Journal of Urban and Regional Research, 11 (3): 331-350.

Morrison, P. S. (1989) Labour Adjustment in Metropolitan Regions, Institute of Policy Studies, Wellington.

Morrison, P. S. (1990) "Segmentation theory applied to local, regional and spatial labour markets", Progress in Human Geography, 14 (4): 488-528.

Morrison, P. S. (1991) "Job loss and unemployment in New Zealand during the 1980s", Working Paper No. 8, Victoria University, Wellington.

Morrison, P. S. (1993) "Exploring contemporary gender and ethnicity issues: Making (much better) use of Supermap2" Working paper No 22, Victoria University, Wellington. 
Morrison, P. S. (1995) "Work and residence in urban labour markets", in P.S. Morrison (ed.) Labour, Employment and Work in New Zealand: Proceedings of the Sixth Conference, 1994, Victoria University, Wellington, pp. 249-264.

Morrison, P. S. (1997a) "Unemployment and non-employment: urban inequalities in New Zealand, 1981-1991", paper presented to the Second Institute of Australian Geographers/New Zealand Geographical Society Joint Conference, Hobart, Australia, University of Tasmania.

Morrison, P. S. (1997b) "Research into labour, employment and work in New Zealand: An overview", in P. S. Morrison (ed.), Labour, employment and work in New Zealand: Proceedings of the seventh conference. Wellington: Victoria University, pp. 1-8.

Murray, C. (1984) Losing Ground: American Social Policy 1950-1980, Basic Books, New York.

Murstein, B. I. (1974) Love, Sex and Marriage through the Ages, Springer, New York.

Naisbitt, J. and Aburdene, P. (1990) Megatrends 2000: Ten New Directions for the 1990s, William Morrow and Company, New York.

Nakamura, A. and Shaw, K. (1994) "Overview for special issue on women's work, wages, and well-being”, The Journal of Human Resources, XXIX (2): 203-222.

Nash, R. (1986) "Educational and social inequality: The theories of Bourdieu and Boudon with reference to class and ethnic differences in New Zealand", New Zealand Sociology, 1 (2): 121-137.

Nash, R. and R. Harker (1992) "Working with class: The educational expectations and practices of class-resourced families", New Zealand Journal of Educational Studies, 27 (1): 3-20.

Nickell, S. (1997) "Unemployment and labor market rigidities: Europe versus North America", Journal of Economic Perspectives, 11 (3): 55-74.

Nussbaum, J. (1985) Fathers as primary caretakers of infant, unpublished doctoral thesis, University of California.

O'Dea, D. (2000) “The changes in New Zealand's income distribution", Treasury Working Paper 00/13, The Treasury, Wellington.

Odendahl, T. (1990) Charity Begins at Home: Generosity and Self-interest Among the Philanthropic Elite, Basic Books, New York.

OECD (1991) Employment Outlook, OECD, Paris. 
OECD (1992) Technology and the Economy - The Key Relationships, OECD, Paris.

OECD (1993) Employment Outlook, OECD, Paris.

OECD (1994) The OECD Job Study: Facts, Analysis, Strategies, OECD, Paris.

OECD (1995) Employment Outlook, OECD, Paris.

OECD (1996) Employment Outlook, OECD, Paris.

OECD (1998) "Making the most of the minimum: statutory minimum wages, employment and poverty", Employment Outlook, OECD, Paris.

Ogburn, W. F. (1938) “The changing family”, The Family, 19: 139-143.

Ogburn, W. F. (1964) On Culture and Social Change, Chicago, University of Chicago Press, Chicago.

Ohlander, A. (1994) Women, Children and Work in Sweden 1850-1993, Swedish Government Official Reports 1994:38, Ministry of Foreign Affairs, Stockholm.

Olsen, R. and Farkas, G. (1990) "The effect of economic opportunity and family background on adolescent cohabitation and childbearing among low-income Blacks", Journal of Labor Economics, 8 (3): 341-362.

Ono, H. (1998) "Husbands' and wives' resources and marital dissolution", Journal of Marriage and the Family, 60: 674-689.

Oppenheimer, V. K. (1988) "A theory of marriage timing", American Journal of Sociology, 94: 563-591.

Osterman, P. (1992) "Internal labor markets in a changing environment: Models and evidence", in D. Lewin, O. Mitchell and P. Sherer (eds.), Research frontiers in industrial relations and human resources, Industrial Relations Research Association, Madison, Wis, pp. 273-308.

Parker, B. (1997) "Very long-term job seekers' barriers to employment: A nationwide survey", Labour Market Bulletin, 1: 63-69.

Parry, O., P. Atkinson, P. and S. Delamont (1997) "Research role: The structure of Ph.D. research", Sociology, 31(1): 121-129.

Parsons, C. A. (1987) Flexible production technology and industrial restructuring: Case studies of the metalworking, semiconductor, and apparel industries, $\mathrm{PhD}$ dissertation, Berkeley, University of California. 
Patterson, J. (1999) "The third age - The age of reason: A gift and not a burden", Social Policy Journal, 13: 1-13.

Patterson, S. M. (1976) Divorce in New Zealand: A Statistical Study, Department of Justice, Wellington.

Paull, G. (1996) "The biases introduced by recall and panel attrition on labour market behaviour reported in the British household panel survey", Centre for Economic Performance Working Paper No. 827, London School of Economics.

Pearson, D. (1980) Johnsonville: Continuity and Change in a New Zealand Township, Allen and Unwin, Sydney.

Peck, J. (1996) Work-place: The Social Regulation of Labor Markets, Guilford Press, London.

Plotnick, R. D., and Hoffman, S. D. (1999) "The effect of neighborhood characteristics on young adult outcomes: Alternative estimates”, Social Science Quarterly, 80 (1): 1-18.

Podder, N. and S. Chatterjee (1998) "Sharing the national cake in post reform New Zealand: income inequality trends in terms of income sources", paper presented at the 1998 Conference of the New Zealand Association of Economists.

Podmore, V. N. (1994) Employment and Childcare Arrangements among Families, NZCER, Wellington.

Pribesh, S. and Downey, D. B. (1999) "Why are residential and school moves associated with poor school performance?”, Demography, 36 (4) : 521-534.

Putnam, R. D., with R. Leonardi and R. Y. Nanetti (1993) Making Democracy Work: Civic Traditions in Modern Italy, Princeton University Press, Princeton, New Jersey.

Radin, M. J. (1996) Contested Commodities, Harvard University Press, Cambridge, M.A.

Rae, D. (1999) Employing Contracts: An Assessment of the New Institutional Economics Theory of Employment Contracting, unpublished doctoral thesis, Economics and Politics, Cambridge.

Rankin, K. (1993) “The New Zealand workforce: 1950-2000”, New Zealand Journal of Industrial Relations, 18 (2): 214-235.

Rankin, K. (1999) "Fiscal and welfare barriers to effective fatherhood", in S. Birks and P. Callister (eds.) Perspectives on fathering, Palmerston North: Centre for Public Policy Evaluation, pp. 81-92. 
Reich, M., D. M Gordon and R. C. Edwards (1973) "Dual labor markets: A theory of labor market segmentation, The American Economic Review, LXIII (2): 359-365.

Reich, R. B. (1993) The Work of Nations: Preparing Ourselves for 21st-century Capitalism, Simon \& Schuster, London.

Rimmer, R. J. and Rimmer, S. (1994) More Brilliant Careers: The Effect of Career Breaks on Women's Employment, Canberra: Australian Government Publishing.

Robinson, J. P. (1996) "Time, housework, and the rest of life", Journal of Family and Economic Issues, 17 (3/4): 213-229.

Robinson, J. P. and A. Bostrom, (1994) "The over-estimated workweek? What time diary measures suggest”, Monthly Labor Review, 117 (8): 11-23.

Rockwell, R. R. (1976) "Historical trends and variations in educational homogamy", Journal of Marriage and the Family, 38: 83-95.

Rodgers, J. L., Rowe, D. C., and Buster, M. (1999) "Nature, nurture and first sexual intercourse in the USA: Fitting behavioural genetic models to NLSY kinship data", Journal of Biosocial Science, 31 (1): 29-41.

Roger, W. (2000) "Man Alone”, North \& South, June, pp. 32-40.

Romer, P. (1989) "Human capital and growth", NBER Working Paper No. 3173, Cambridge, Mass.

Rose, D. (1990) The Fully Employed High Income Society, New Zealand Planning Council, Wellington.

Rose, D. (1992) A Review of Labour Market Statistics, Statistics New Zealand, Wellington.

Rose, M., Penn R. and Rubery J. (1994) "Introduction: The SCELI Findings" in R. Penn, M. Rose and J. Rubery (eds.), Skill and Occupational Change (pp. 1-37), Oxford University Press, Oxford.

Rossi, A. (1977) “A biosocial perspective on parenting”, Daedalus, 106 (2): 1-31.

Sandqvist, K. (1987) Fathers and family work in two cultures: Antecedents and concomitants of fathers' participation in childcare and household work, Almqvist and Wiksell International: Stockholm.

Sarre, S. (1996) "A place for fathers: Fathers and social policy in the post-war period", Discussion Paper WSP 125, London School of Economics, London. 
Sayer, A. and Walker, R. (1992) The New Social Economy: Reworking the Division of Labor, Blackwell, Oxford.

Schoen, R. (1983) "Measuring the tightness of a marriage squeeze", Demography, 20:6178.

Schoen, R. and Weinick, R. M (1993) "Partner choice in marriages and cohabitations", Journal of Marriage and the Family, 55: 408-414.

Schoen, R. and Wooldredge, J. (1989) "Marriage choices in North Carolina and Virginia, 1969-71 and 1979-81", Journal of Marriage and the Family, 51: 465-481.

Schor, J. (1991) The Overworked American, Basic Books, New York

Schultz, T. W (1975) "The value of the ability to deal with disequilibria - Human capital and disequilibria”, Journal of Economic Literature, 13: 827-846.

Scientific America (1999) “Flynn's Effect”, Winter, pp. 20-21

Sen, A. (1999) Development as Freedom, Oxford University Press, New York.

Senker, P. J. (1992) Automation and work in Britain, in P. S. Adler, P. S. (ed.), Technology and the future of work. Oxford University Press, New York, pp. 89-110.

Sequino, S., Stevens, T. and Lutz, M. A. (1996) "Gender and cooperative behavior: Economic man rides alone", Feminist Economics 2(1): 1-21.

Sherman, B. (1995) “The end of work as we know it?", New Statesman and Society, 27 October, p. 27.

Shirley, I. (1998) "Work, families and government policy: A comparative perspective" in C. Briar and G. Gill (eds.), Work, Families and the State: Problems and Possibilities for the 21st Century Proceedings of a conference held at Massey University, November, pp. 4-9.

Shirley, I. (1999) “"In the name of the father": Men, fatherhood and public policy" in S. Birks and P. Callister (eds.) Perspectives on Fathering II, Centre for Public Policy Evaluation, Palmerston North, pp. 1-13.

Shirley, I., Easton, B., Briar, C. and Chatterjee, S. (1990) Unemployment in New Zealand, Palmerston North, Dunmore Press.

Shirley, R. M. (1996) "Changes in New Zealand work patterns: Casualisation of the labour force, 1976-91, Population Studies Centre discussion paper No 11, University of Waikato. 
Siebert, H. (1997) "Labor market rigidities: At the root of unemployment in Europe", Journal of Economic Perspectives 11 (3): 37-54.

Singelmann, J. (1978) The Transformation of Industry from Agriculture to Service Employment, Sage, Beverly Hills, CA.

Singelmann, J. and Tienda, M. (1985) "The process of occupational change in a service society: The case of the United States, 1960-80", in B. Roberts, R. Finnegan and D. Gallie (eds.), New Approaches to Economic Life, Manchester University Press, Manchester, pp. 48-67.

Skinner, B. F. (1953) Science and Human Behavior, The Free Press, New York.

Smelser, N. J. and R. Swedberg (1994) "The sociological perspective on the economy", in N. J. Smelser and R. Swedberg (eds.), The Handbook of Economic Sociology, Princeton University Press, Princeton, N.J, pp. 3-26.

Smith, D. F. (1981) “Assessing the growth of New Zealand's white-collar workforce", Australian and New Zealand Journal of Sociology, 17 (2): 77-84.

Smits, J., Ultee, W., and Lammers, J. (1998) "Educational homogamy in 65 countries: An explanation of differences in openness using country-level explanatory variables", American Sociological Review, 63: 264-285.

Snook, I. (1989) Inflated Expectations - Qualifications and Job Prospects, SET Publication, No. 1, NZCER, Wellington.

Snooks, G. D. (1994) Portrait of the Family Within the Total Economy: A Study in Longrun Dynamics, Australia 1788-1990, Cambridge University Press, Melbourne.

Soldera, P. (1999) Spatial hysteresis and the clustering of urban unemployment, unpublished Masters thesis, Institute of Geography, Victoria University.

Solow, R. (1998) “Guess who pays for workfare?”, www.jobsletter.org.nz/art/artsolow.htm

South, S. J. and Lloyd, K. M. (1992) "Marriage opportunities and family formation: Further implications of imbalanced sex ratios", Journal of Marriage and the Family, 54: 440-451.

South, S. J., and Crowder, K. D. (1999) "Neighborhood effects on family formation: Concentrated poverty and beyond", American Sociological Review, 64: 113-132.

Spanier, G. B. and Glick, P. C. (1980) "Mate selection differentials between whites and blacks in the United States", Social Forces, 58: 707-725. 
Spenner, K. (1993) Deciphering Prometheus: Temporal change in the skill level of work, American Sociological Review, 48: 824-837.

Statistics New Zealand (1993a) A Picture of Health, Statistics New Zealand/Ministry of Health, Wellington.

Statistics New Zealand (1993b) 1996 Census of Population and Dwellings: Preliminary views on content, Statistics New Zealand,Wellington.

Statistics New Zealand (1994) New Zealand Now: Families, Statistics New Zealand, Wellington.

Statistics New Zealand (1995a) New Zealand Standard Classification of Occupations 1995, Statistics New Zealand, Wellington.

Statistics New Zealand (1995b) New Zealand Standard Classification of Households and Families, Statistics New Zealand, Wellington.

Statistics New Zealand (1998) New Zealand Now: Women, Statistics New Zealand, Wellington.

Statistics New Zealand (1999) New Zealand Now: Incomes, Statistics New Zealand, Wellington.

Steinberg, R. (1990) "Social construction of skill: Gender, power and comparable Worth”, Work and Occupations, 17 (4): 449-483.

Stephens, R., Waldegrave, C. and Frater, P. (1995) "Measuring poverty in New Zealand", Social Policy Journal of New Zealand, 5: 88-112.

Stirling, P. (2000) "Working it out", The Listener, April 1, p. 33.

Stewart, J., M., McQuaid, R. W., Charlesworth-May, A. C. and Adams, J. (1998) “A summary of the results of a survey of unemployed workers in the Auckland Eastern Suburbs TTWA", Labour Market Bulletin, 1 \& 2: 145-161.

Stigler, G. (1961) “The economics of information”, Journal of Political Economy, 69: 213-225.

Stover, S. (1998) Good Clean Fun: New Zealand's Playcentre Movement, Playcentre Publications, Auckland.

Sucoff, C. A., and Upchurch, D. M. (1998) "Neighborhood context and the risk of childbearing among metropolitan-area black adolescents", American Sociological Review, 63: 571-585. 
Swinnerton, K. A. and Wial, H. (1995) "Is job stability declining in the U.S. Economy?", Industrial and Labor Relations Review, 48 (2): 293-304.

Swinnerton, K. A. and Wial, H. (1996) "Is job stability declining in the U.S. Economy? Reply to Diebold, Neumark, and Polsky”, Industrial and Labor Relations Review, 49 (2): 352-355.

Sydney Morning Herald (1998) Marginal men, Saturday, October 10.

Taubman, P. and M. L. Wachter (1986) "Segmented labor markets" in O. C. Ashenfelter and R. Layard (eds.), Handbook of Labor Economics, Vol 2), Elsevier Science, Amsterdam, pp. 1183-1217.

Taylor, L. (1992) Flexible Work Patterns, Quest Rapuara: The Career Development and Transition Service, Wellington.

The Economist (1996) 28 September, p.27

The Economist (1997) "When home is a prison”, 14 June, p. 92.

The Jobs Letter (1999) Interview, Jobs Letter No. 114, p. 3.

Thomson, D. (1999) “Our ageing workforce - benefit or burden?", paper presented at the University of Auckland Winter Lecture Series 1999, Auckland.

Tiger, L and Shepher, J. (1975) Women in the Kibbutz, Harcourt Brace Jovanovich, New York.

Tilly, C. and C. Tilly (1998) Work Under Capitalism, WestviewPress, Boulder, Colorado.

Time Magazine (1998) “Corporate welfare, a system exposed”, November 9, pp. 18-36.

Toffler, A. (1990) Powershift: Knowledge, Wealth, and Violence at the Edge of the 21st Century, Bantam Books, New York.

Topel, R. (1993) "What have we learned from empirical studies of unemployment and turnover?", American Economic Review, 83 (2): 110-115.

Uhlenberg, P. (1980) "Death and the family", Journal of Family History, 5 (3): 313-320.

Ureta, M. (1992) "The importance of lifetime jobs in the U.S. economy, revisited", American Economic Review, 82 (1): 322-335.

Van Kempen, E. T. (1997) "Poverty pockets and life chances", American Behavioral Scientist, 41 (3): 430-449. 
Van Kempen, R. and Marcuse, P. (1997) "A new spatial order in cities", American Behavioral Scientist, 41 (3): 285-298.

Vietorisz, T. and Harrison B. (1973) "Labor market segmentation: Positive feedback and divergent development", American Economic Review, LXIII (2): 366-376.

Waldfogel, J. (1998) "Understanding the "family gap" in pay for women with children", Journal of Economic Perspectives, 12 (1): 137-156.

Warme, B. D., Lundy, K. L. P. and Lundy, L. A. (1992) "Introduction", in B. D. Warme, K. L. P Lundy and L. A. Lundy (eds.), Working Part-time: Risks and Opportunities, Praeger, New York, pp. 1-17.

Weiss, Y. (1997) "The formation and dissolution of families: Why marry? Who marries whom? And what happens upon divorce" in M. R. Rosenzweig and O. Stark (eds.), Handbook of Population and Family Economics, Vol 1A, Amsterdam, Elsevier, pp. 81123.

Whatman, R. (1995) ““"Non-standard” work in New Zealand - What we know” in P. S. Morrison (ed.), Labour, Employment and Work in New Zealand: Proceedings of the Sixth Conference, Wellington, Victoria University, pp. 356-366.

Wilson, E. O. (1978) On Human Nature, Harvard University Press, Cambridge.

Wilson, W. J. (1987) The Truly Disadvantaged, University of Chicago Press, Chicago.

Wilson, W. J. (1998) "When work disappears: New implications for race and urban poverty in the global economy", CASE Paper 17, Centre for Analysis of Social Exclusion, London School of Economics.

Winkelmann, L. and Winkelmann, R. (1997) "Determining the relative labour force status of Maori and non-Maori using a multinomial logit model", Labour Market Bulletin, 1: 24-62.

Wood, A. (1994) North-South Trade, Employment and Inequality, Clarendon Press, Oxford.

Wood, R. G. (1995) "Marriage rates and marriageable men: A test of the Wilson hypothesis", Journal of Human Resources, 30: 163-193.

Workaholics anonymous: Why Americans work so hard (1994) The Economist, October 22, pg 18 .

Working Party on Industrial Relations (1989) Internal Labour Market Flexibility, OECD, Paris. 
Wright, E. O. and Singelmann, J. (1982) "Proletarianization in the American class structure", in M. Burawoy and T. Skocpol (eds.), Marxist Enquiries: Studies of Labor, Class, and States, Supplement to American Journal of Sociology, 88: 176-209.

Zedeck, S. and K. L Mosier (1990) "Work in the family and employing organization", American Psychologist, 45 (1), 240-251.

Zuboff, S. (1988) In the Age of the Smart Machine, Basic Books, New York. 


\section{Appendix}

Table A- Long term work poor and deprived area units - Ahipara to Orini

\begin{tabular}{|c|c|c|c|c|}
\hline Unit area & $\begin{array}{l}\text { Urban Area } \\
\text { Description }\end{array}$ & $\begin{array}{l}\text { Total prime-aged } \\
\text { population in } \\
1996\end{array}$ & $\begin{array}{l}\% \text { change in } \\
\text { prime-age } \\
\text { population } 86- \\
96\end{array}$ & $\begin{array}{l}\% \text { of prime-aged } \\
\text { people who } \\
\text { undertook } \\
\text { community work }\end{array}$ \\
\hline Ahipara & Rural centre & 405 & 28.6 & 48 \\
\hline Aranui & Christchurch & 2,034 & -0.1 & 35 \\
\hline Balgownie & Wanganui & 144 & 4.3 & 38 \\
\hline Blackball & Rural centre & 183 & 24.5 & 44 \\
\hline Camberley & Hastings zone & 891 & 4.2 & 34 \\
\hline Cannons Creek East & Porirua & 1,650 & 6.8 & 37 \\
\hline Cannons Creek North & Porirua & 1,248 & -8.8 & 31 \\
\hline Cape Runaway & Rural & 684 & 78.1 & 50 \\
\hline Castlecliff North & Wanganui & 1,053 & 6.7 & 40 \\
\hline Corstorphine West & Dunedin & 255 & -3.4 & 41 \\
\hline Favona & South Auckland zone & 2,013 & 28.3 & 30 \\
\hline Ferguson & South Auckland zone & 1,629 & 4.8 & 31 \\
\hline Fordlands & Rotorua & 762 & -1.9 & 38 \\
\hline Foxton Beach & Foxton community & 759 & 47.1 & 41 \\
\hline Glen Innes East & Central Auckland zone & 1,107 & 7.3 & 33 \\
\hline Gonville West & Wanganui & 690 & 7.5 & 40 \\
\hline Granity & Rural & 159 & 15.2 & 51 \\
\hline Harania East & South Auckland zone & 1,926 & 36.9 & 28 \\
\hline Harania North & South Auckland zone & 1,443 & 11.3 & 31 \\
\hline Harania West & South Auckland zone & 1,647 & 19.6 & 31 \\
\hline Hector-Ngakawau & Rural centre & 156 & 20.9 & 42 \\
\hline Hokianga South & Rural & 1,287 & 34.9 & 46 \\
\hline Huntly West & Huntly & 1,179 & -3.9 & 37 \\
\hline Insoll & Hamilton zone & 1,002 & 4.7 & 41 \\
\hline Kairua & Tauranga & 162 & 74.2 & 48 \\
\hline Kohukohu & Rural & 102 & 30.8 & 65 \\
\hline Laird Park & Wanganui & 918 & 5.5 & 42 \\
\hline Lower Aramoho & Wanganui & 843 & 9.8 & 43 \\
\hline Mahia & Rural & 405 & 36.4 & 45 \\
\hline Mangakino & Mangakino & 576 & -2.5 & 44 \\
\hline Mangere Station & South Auckland zone & 150 & 2.0 & 20 \\
\hline Maraenui & Napier & 1,419 & -3.7 & 39 \\
\hline Mosston & Wanganui & 549 & 10.2 & 42 \\
\hline Ngaruawahia & Hamilton zone & 2,241 & 21.1 & 46 \\
\hline North Cape & Rural & 282 & 40.3 & 54 \\
\hline Ohura & Rural centre & 195 & -1.5 & 49 \\
\hline Oponae & Rural & 180 & 33.3 & 47 \\
\hline Opotiki & Opotiki & 1,617 & 9.6 & 49 \\
\hline Orini & Whakatane & 252 & 35.5 & 48 \\
\hline
\end{tabular}


Table B- Long term work poor and deprived area units - Otangarei to Yatton Park

\begin{tabular}{|c|c|c|c|c|}
\hline Unit area & $\begin{array}{l}\text { Urban Area } \\
\text { Description }\end{array}$ & $\begin{array}{l}\text { Total population } \\
\text { in } 1996\end{array}$ & $\begin{array}{l}\% \text { change in } \\
\text { prime-age } \\
\text { population } 86- \\
96\end{array}$ & $\begin{array}{l}\% \text { of prime-aged } \\
\text { people who } \\
\text { undertook } \\
\text { community work }\end{array}$ \\
\hline Otangarei & Whangarei & 792 & 3.1 & 44 \\
\hline Otara East & South Auckland zone & 1,770 & 9.1 & 35 \\
\hline Otara North & South Auckland zone & 636 & 13.4 & 35 \\
\hline Otara South & South Auckland zone & 1,311 & 14.7 & 35 \\
\hline Otara West & South Auckland zone & 1,215 & 3.6 & 28 \\
\hline Papakura South & South Auckland zone & 642 & 16.3 & 34 \\
\hline Patea & Patea & 567 & -10.0 & 44 \\
\hline Phillipstown & Christchurch & 1,587 & 26.9 & 37 \\
\hline Point England & Central Auckland zone & 1,536 & 14.8 & 32 \\
\hline Porirua Central & Porirua zone & 204 & -56.1 & 19 \\
\hline Raglan & Raglan & 1,059 & 60.5 & 43 \\
\hline Ratana Community & Rural centre & 201 & 15.5 & 43 \\
\hline Shannon & Shannon & 597 & -4.8 & 46 \\
\hline South Dunedin & Dunedin & 861 & 1.4 & 37 \\
\hline Taita North & Lower Hutt zone & 1,119 & 14.8 & 35 \\
\hline Tamaki & Central Auckland zone & 1,653 & 27.8 & 31 \\
\hline Taneatua & Rural centre & 342 & 0.0 & \\
\hline Community & & & & $\begin{array}{l}46 \\
43\end{array}$ \\
\hline $\begin{array}{l}\text { Tangimoana } \\
\text { Te Kaha }\end{array}$ & $\begin{array}{l}\text { Rural } \\
\text { Rural centre }\end{array}$ & $\begin{array}{l}132 \\
150\end{array}$ & $\begin{array}{l}41.9 \\
250\end{array}$ & $\begin{array}{l}43 \\
48\end{array}$ \\
\hline $\begin{array}{l}\text { Te Kaha } \\
\text { Te Teko }\end{array}$ & $\begin{array}{l}\text { Rural centre } \\
\text { Rural centre }\end{array}$ & $\begin{array}{l}150 \\
255\end{array}$ & $\begin{array}{l}25.0 \\
26.9\end{array}$ & $\begin{array}{l}48 \\
44\end{array}$ \\
\hline Waharoa & Rural centre & 231 & -7.2 & $\begin{array}{l}44 \\
39\end{array}$ \\
\hline Waihi & Waihi & 1,998 & 29.3 & 44 \\
\hline Walmsley & Central Auckland zone & 1,425 & 43.5 & 34 \\
\hline Wembley Park & Wanganui & 783 & 5.2 & 43 \\
\hline Wiri & South Auckland zone & 1,395 & 116.3 & 27 \\
\hline Yatton Park & Tauranga & 879 & 23.1 & 43 \\
\hline
\end{tabular}

Source: Census of Population and Dwellings, Statistics New Zealand. 
